\title{
China: A New Model for Growth and Development
}


Other titles in the China Update Book Series include:

1999 China: Twenty Years of Economic Reform

2002 China: WTO Entry and World Recession

2003 China: New Engine of World Growth

2004 China: Is Rapid Growth Sustainable?

2005 The China Boom and its Discontents

2006 China: The Turning Point in China's Economic Development

2007 China: Linking Markets for Growth

2008 China's Dilemma: Economic Growth, the Environment and Climate Change

2009 China's New Place in a World of Crisis

2010 China: The Next Twenty Years of Reform and Development

2011 Rising China: Global Challenges and Opportunities

2012 Rebalancing and Sustaining Growth in China 


\section{China: A New Model for Growth and Development}

Ross Garnaut, Cai Fang and Ligang Song (eds)

Australian

National

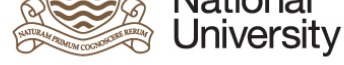

E PRESS

TSAS 社会科学文献出版社
SOCIAL SCIENCES ACADEMIC PRESS(CHINA) 
Published by ANU E Press

The Australian National University

Canberra ACT 0200, Australia

Email: anuepress@anu.edu.au

This title is also available online at: http://epress.anu.edu.au

National Library of Australia Cataloguing-in-Publication entry

Title: China : a new model for growth and development / edited by Ross Garnaut, Cai Fang and Ligang Song.

ISBN: 9781921666483 (paperback) 9781921666490 (ebook)

Notes: $\quad$ Includes index.

Subjects: $\quad$ Economic development--China.

China--Economic conditions.

China--Economic policy.

China--Commerce.

Other Authors/Contributors:

Garnaut, Ross, editor.

Fang, Cai, editor.

Song, Ligang, editor.

Dewey Number:338.951

All rights reserved. No part of this publication may be reproduced, stored in a retrieval system or transmitted in any form or by any means, electronic, mechanical, photocopying or otherwise, without the prior permission of the publisher.

Book design and layout by Teresa Prowse, http://www.madebyfruitcup.com

This edition (C) 2013 ANU E Press 


\section{Contents}

Tables vii

Figures

xi

Contributors

$\mathrm{xV}$

Acknowledgments

xvii

1 China's New Strategy for Long-term Growth and Development

Ross Garnaut, Cai Fang and Ligang Song

2 New Institutions for a New Development Model

Dwight H. Perkins

3 The New Normal of Chinese Development

Yiping Huang, Cai Fang, Peng Xu and Gou Qin

4 The End of China's Demographic Dividend

Cai Fang and Lu Yang

5 Chinese Industrialisation

75

Huw McKay and Ligang Song

6 China's Saving and Global Economic Performance

Rod Tyers, Ying Zhang and Tsun Se Cheong

7 Growing into an Innovative Economy

Yixiao Zhou

8 China's Agricultural Development

Li Zhou

9 Rural-Urban Migration

Xin Meng

10 Reforming China's Public Finances for Long-term Growth

Christine Wong 
China: A New Model for Growth and Development

11 Changing Business Environment in China

Xiaolu Wang, Jingwen Yu and Fan Gang

12 Will Chinese Industry Ever Be 'Green'?

Shiyi Chen and Jane Golley

13 Can China Achieve Green Growth?

Yongsheng Zhang

14 China's Climate Change Mitigation in International Context

Ross Garnaut

15 China's Energy Demand Growth and the Energy Policy Trilemma

Simon Wensley, Stephen Wilson and Jane Kuang

16 Financial Constraints on Chinese Outward Direct Investment by the Private Sector

Bijun Wang, Miaojie Yu and Yiping Huang

17 Determinants of Chinese Exports in Information and

Communication Technology (ICT) Products

Kunwang Li and Bingzhan Shi 


\section{Tables}

Table 4.1 Increases in demand for and supply of labour force (million, \%)

Table 4.2 Estimated results for potential inputs and outputs in China, 1978-2020

Table 4.3 Labour force participation rates in China by age group and gender (\%) 65

Table 5.1 Quadrupling living standards from a base of \$2,000 PPP GDP per capita

Table 5.2 Producer subsidy equivalents of factor market distortions in China, 2000-2009 (\% of GDP)

Table 6.1 China's outward FDI and its regional distribution

Table 7.1 Number of all firms and number of firms that engaged in R\&D expenditure

Table 7.2 Descriptive statistics of the sample for regression

Table 7.3 Regression results

Table 7.4 Regression results

Table 8.1 Outputs and growth rates of major agricultural products since 1978 (1,000 ton)

Table 8.2 Key agricultural output per capita since 1978 (kg) 150

Table 8.3 Changes in the level of integrated mechanisation (\%)

Table 8.4 Effective irrigation areas since 1978 (1,000 ha)

Table 8.5 Amount and composition of chemical fertilisers used in China, 1980-2011 (1,000 tons and \%)

Table 8.6 Share of grains produced in the 13 major provinces in the total amount of the country (\%)

Table 8.7 China's agricultural TFP growth rate and its composition (1985-2010) 156

Table 8.8 Efficiency in China's grain production by regions

Table 8.9 Farmers employed in urban areas (1,000 person) 
China: A New Model for Growth and Development

Table 8.10 Farmers employed outside agriculture during 2008-2011

$(1,000$ person, \%)

Table 8.11 Changes in the shares of GDP created by the farmers employed outside agriculture in the country's total GDP

Table 8.12 Comparison of the incomes of farmers and urban residents since 1978

Table 8.13 The central government's subsidies to agriculture (billion yuan)

Table 8.14 The central government's special funds for rewarding the governments of counties where a certain amount of grains are produced

Table 8.15 Area and carbon sequestration of the six major forest projects during 2000-2010

Table 8.16 Improvement in the minimum living security: 2001-2011 (1,000 persons, billions yuan)

Table 8.17 Labour and labour costs in the production of rice, wheat and corn per ha

Table 9.1 Summary statistics of different samples

Table 9.2 Proportion of each age group among the new arrivals by year

Table 9.3 Results from earnings regressions

Table 10.1 Composition of fiscal revenues in the comprehensive budget, 2012

Table 10.2 Sources of finance for fixed investment: 1982-2010 (\%)

Table 11.1 Provincial ranking by business environment (2006-2012)

Table 11.2 Overall scores and changes in ranking by provinces (2006-2012) 228

Table 11.3 Major obstacles to businesses by the sample firms: 2008 and $2012 \quad 230$

Table 11.4 Eight areas of business environment: changes in scores

Table 11.5 Differences in business environment between SOEs and NSEs

Table 11.6 Difference in business environment between enterprise scales 
Table 11.7 Changing business environment in different sectors: area indexes and overall index

Table 11.8 Statistical significance of differences among three groups

Table 11.9 Scales and ownership types of the sample enterprises by sector groups

Table 11.10 Changes in business environment in four regions

Table 11.A1 The structure of the BEIFCP

Table 12.1 Levels and growth of key variables by sector

Table 12.2 Growth of productivity, efficiency and technical change in Chinese Industry, 1980-2010

Table 12.3 Average annual growth rates of outputs, inputs and productivity (\%)

Table 12.4 TFP, GTFP, Efficiency and technical change across sectors and time

Table 14.1 China: power generation 2011 and 2012

Table 15.1 Two gas development scenarios for China

Table 16.1 Country, institution and industry distribution (2006-2008)

Table 16.2 Variable definition and summary statistics

Table 16.3 Results for multinomial logit model: full sample

Table 16.4 Results for multinomial logit model: consider the mitigating effects of productivity

Table 16.5 Results for multinomial logit model: one-period lag

Table 16.6 Results for multinomial logit model: first-time ODI

Table 17.1 Breakdown of China's ICT exports by custom regime (\%)

Table 17.2 The ratio of different policy zones in China's ICT export (\%)

Table 17.3 The extensive margin, quantity and quality in China's ICT export ratio

Table 17.4 Variable descriptions and summary statistics 
China: A New Model for Growth and Development

Table 17.5 Basic estimation results for dependent variable Inv

Table 17.6 Robustness check for dependent variable Inv

Table 17.7 Basic estimation results for dependent variable Inq

Table 17.8 Robustness check for dependent variable Inq 355

Table 17.9 Basic estimation results for dependent variable Inp 356

Table 17.10 Robustness check for dependent variable Inp 


\section{Figures}

Figure 3.1 Estimates of growth potentials (\%) 38

Figure 3.2 Current account surplus as a share of GDP, 2006-2012 (\%) 39

Figure 3.3 Urban-rural income ratio narrowed, 1987-2012 (\%) 40

Figure 3.4 Growth in eastern, central and western China, 2012 (\%) 40

Figure 3.5 Gini coefficients estimated by the National Bureau of Statistics, 2003-2012 41

Figure 3.6 Contribution to GDP growth, 1995-2012 (\%) 42

Figure 3.7 Total consumption share of GDP (\%) 42

Figure 3.8 Household consumption share of GDP (\%) 43

Figure 3.9 Rapid rise of migrant workers' wages 45

Figure 3.10 Labour income and consumption share of GDP (\%) 46

Figure 3.11 Private consumption share of GDP in Korea and Taiwan (\%) 47

Figure 4.1 The Chinese Lewis turning period 56

Figure 4.2 Trends of potential growth rate and of its factors in China: 1996-2020 60

Figure 4.3 Labour force participation rate in China, 201066

Figure 4.4 Effect of one percentage point increase in labour force participation rate on potential GDP growth rate 67

Figure 4.5 Effects of one extra percentage point of TFP growth on potential GDP growth rate

Figure 5.1 Quadrupling living standards from a base of \$2,000 PPP GDP per capita

Figure 5.2a Selected characteristics of successful future industrialisers at the $\$ 2,000$ PPP GDP per capita level

Figure 5.2b Selected characteristics of successful future industrialisers at the \$8,000 PPP GDP per capita level 
Figure 5.4 The relationship between macroeconomic stability, GDP per capita and financial reform in developing economies

Figure 6.1 China is no longer small in global trade

Figure 6.2 The demographic origins of China's slowdown

Figure 6.3 Trends in Chinese private, household and corporate saving, \% GDP 104

Figure 6.4 Chinese Government revenue and expenditure 105

Figure 6.5 Chinese Government net surpluses, US\$ billions 106

Figure 6.6 Saving, investment and the current account in China, \% GDP 107

Figure 6.7 Components of the People's Bank of China balance sheet, \% GDP 109

Figure 6.8 Net private and government saving in the four largest economies, $\%$ GDP

Figure 6.9 Excess annual saving (current account balances) by key region, US\$ billions

Figure 6.10 US Treasury bond yields over two decades

Figure 6.11 US, European and Japanese government bond yields since 2000

Figure 6.12 Central Bank assets, US\$ trillions

Figure 6.13 Nominal exchange rate indices vs the US\$

Figure 7.1 National R\&D expenditure

Figure 7.2 China's national R\&D intensity (the ratio of R\&D expenditure in GDP) from 1995-2010

Figure 7.3 Intramural R\&D expenditure of 31 provincial regions in 1999 (billion RMB)

Figure 7.4 Intramural R\&D expenditure of 31 provincial regions in 2010 (billion RMB)

Figure 7.5 Change of intramural R\&D intensity in 31 provincial regions from 1999 to 2010 
Figure 7.6 Share of large and medium-sized enterprise R\&D expenditure in regional R\&D expenditure in 1999 to 2010 and changes of this share from 1999 to 2010

Figure 7.7 Change of R\&D intensity of large and medium-sized enterprise (the share of R\&D expenditure in gross output) from 1999 to 2010

Figure 8.1 Outputs of major agricultural products during 2000-2012

Figure 8.2 Changes in the level of integrated mechanisation (\%)

Figure 8.3 Areas fertilising based on the soil tested (million ha)

Figure 8.4 Expansion of plastic-covered areas during 1993-2010 (1,000 ha)

Figure 8.5 A fitting curve of the ratio of urban to rural per capita incomes using provincial-level data during 1978-2010

Figure 8.6 Central government's expenditure on agriculture, farmers, and rural areas: 2002-2012 (billion yuan)

Figure 9.1 Population pyramid by hukou status

Figure 9.2 Age and gender distribution of labour force by hukou and migration status

Figure 9.3 Age and gender distribution of rural hukou labour force, 2010

Figure 9.4 The change in age and gender distribution of migrant labour force: 2008 vs 2012

Figure 9.5 Weekly hours worked for urban and migrant wage-salary workers, 2008

Figure 9.6 Relationship between hours worked and mental health problems

Figure 9.7 Monthly and hourly real wages, 2008-2012

Figure 9.8 Annual change in real wages for the first month of the first job

Figure 9.9 Migrant social welfare access: 2008-2012

Figure 9.10 Rate of return to city work experience

Figure 10.1 China's comprehensive budget: 2006-2012 (\%)

Figure 10.2 Local governments' share of budgetary expenditures and investment (\%) 
China: A New Model for Growth and Development

Figure 11.1 Changes in the overall BEIFCP: 2006-2012 223

Figure 11.2 Overall scores and ranking of provinces (2006-2012)

Figure 11.3 Eight areas of business environment: an improvement (2006-2012) 231

Figure 11.4 Legal Environment Index for enterprise scales

Figure 11.5 Financial Services Index for enterprise scales

Figure 12.1 The directional and Shephard distance functions

Figure 12.2 China's aggregate industrial energy and emissions, 1980-2010

Figure 12.3 Growth rates of GTFP, efficiency and technical change

Figure 15.1 Energy-economy development paths: China, the world and selected economies, 1990-2010

Figure 15.2 Electricity-economy and population cross-section of China by provinces

Figure 15.3 The Energy Policy Trilemma

Figure 15.4 China's energy resource endowment

Figure 15.5 China's energy demand by fuel mix

Figure 15.6 China's oil consumption and import (1980-2011, million tonnes)

Figure 15.7 China's gas consumption and import (1980-2011, billion cubic metres)

Figure 15.8 China's coal consumption and import (1980-2011, million tonnes, physical)

Figure 15.9 Policy choices

Figure 15.10 Hydrocarbon energy conversion and utilisation pathways

Figure 16.1 Distribution of productivity across Chinese firms

Figure 17.1 Share of world's ICT exports of the main producers

Figure 17.2 Per capita income and export structure

Figure 17.3 Breakdown of China's ICT exports by category of firms 


\section{Contributors}

Shiyi Chen

School of Economics,

Fudan University, Shanghai

Tsun Se Cheong

Economics Department,

School of Business, The University

of Western Australia, Perth

Cai Fang

Institute of Population and Labour

Economics, The Chinese Academy

of Social Sciences, Beijing

Fan Gang

National Economy Research

Institution, China Reform

Foundation, Beijing

Ross Garnaut

The University of Melbourne, Melbourne; The Australian National

University, Canberra

Jane Golley

Australian Centre on China in the World, The Australian National

University, Canberra

Gou Qin

China Centre for Economic Research,

Peking University, Beijing

Yiping Huang

China Centre for Economic Research,

Peking University, Beijing and Crawford

School of Public Policy, The Australian

National University, Canberra
Jane Kuang

Rio Tinto Energy, Rio Tinto, Brisbane

Kunwang Li

School of Economics,

Nankai University, Tianjin

Li Zhou

Rural Development Institute,

The Chinese Academy of Social

Sciences, Beijing

Lu Yang

Institute of Population and Labour Economics, The Chinese Academy of Social Sciences, Beijing

Huw McKay

Westpac Bank, Sydney;

Research School of Economics,

The Australian National University,

Canberra

Xin Meng

Research School of Economics,

College of Business and Economics,

The Australian National University,

Canberra

Dwight H. Perkins

Harvard University, Massachusetts

Bingzhan Shi

School of Economics, Nankai

University, Tianjin

Ligang Song

Crawford School of Public Policy,

The Australian National University,

Canberra 
Rod Tyers

Economics Department, School

of Business, The University

of Western Australia, Perth

Bijun Wang

China Centre for Economic Research,

Peking University, Beijing

Xiaolu Wang

National Economy Research Institute,

China Reform Foundation, Beijing

Simon Wensley

Rio Tinto Energy, Rio Tinto, Brisbane

Stephen Wilson

Rio Tinto Energy, Rio Tinto, Brisbane

Christine Wong

Director of Chinese Studies, Oxford

University, Oxford

Peng Xu

China Centre for Economic Research,

Peking University, Beijing
Jingwen $Y u$

National Economy Research Institute, China Reform Foundation, Beijing

Miaojie Yu

China Centre for Economic Research, National School of Development, Peking University, Beijing

Ying Zhang

Economics Department, School

of Business, The University

of Western Australia, Perth

Yongsheng Zhang

Development Research Centre

of the State Council, Beijing

Yixiao Zhou

Crawford School of Public Policy, The Australian National University, Canberra 


\section{Acknowledgments}

The China Economy Program gratefully acknowledges the financial support for the China Update 2013 provided by Rio Tinto through the Rio Tinto-ANU China Partnership, as well as the assistance provided by Elizabeth Buchanan and our colleagues at the East Asia Forum and the Asia and the Pacific Policy Society at The Australian National University. The China Update book 2013 is the $13^{\text {th }}$ edition in the China Update book series. We sincerely thank our contributors around the world for their valuable contributions to the book series and the Update events throughout these years. Thanks also go to ANU E Press for the expeditious publication of the book series, and to Social Sciences Academic Press (China) in Beijing for translating and publishing the Chinese versions of the update book series to make the research work available to the readers in China. 



\section{China's New Strategy for Long-term Growth and Development: \\ Imperatives and Implications}

Ross Garnaut, Cai Fang and Ligang Song

\section{The New Model of Chinese Economic Growth}

The Chinese economy is undergoing profound change in policy and structure. The change is necessary to increase the value of growth to the Chinese community, and to sustain growth into the future. The change is being driven partly by economic pressures that are emerging naturally from successful economic development, as labour scarcity and rapid increases in real wages change patterns of resource allocation, income distribution, environmental impact, and rates of economic growth, savings, investment and international capital flows. These changes that have emerged from the success of old patterns of growth are being reinforced by changes in national policy to secure more equitable income distribution, and less damaging impact on the domestic and international environment.

The changes are so comprehensive and profound that they add up to a new model of Chinese economic growth. This book describes the replacement of an old, uninhibited investment expansion model of growth, by transition to modern economic growth.

The book presents the results of recent research on various aspects of the transition to modern economic growth. The chapters that follow provide insights into recent changes and where they are likely to lead. They bring out some of the implications of change for China's interaction with the international economy.

Once an economy has stepped onto the escalator of modern economic growth it never stays still. China has been undergoing restless change at a dazzling pace since Communist Party decisions in 1978 committed the country to a path into market-oriented reform and integration into the international economy.

Change has been continuous and rapid. Every year of the reform period has thrown up new barriers to economic progress, new policy challenges, new solutions to some old problems and new patterns of economic activity. 
But while change has been continuous, if we stand back and look at the reform period as a whole, we can identify three broad periods, each requiring policy and structural transitions before it could give a new shape to development.

The first is the era of strong growth in agricultural and rural incomes, roughly from 1978 to 1984. The second is uninhibited investment expansion from 1985 to 2011. The third is the transition to a modern economy, which commenced in 2012.

Two innovations in economic institutions underpinned the era of strong growth in agricultural and rural incomes: the replacement of the rural People's Communes by the Household Responsibility System; and the rise of township and village enterprises out of the redundant structures of the People's Communes. Institutional changes were supported by adjustments to agricultural pricing arrangements that improved farmers' terms of trade. The increases in incomes and their equitable distribution throughout China during this period provided the political and economic foundations for general market-oriented reform as well as the springboard for far-reaching reform of urban economic institutions.

Many other changes were occurring during the era of strong growth in agricultural and rural incomes that supported wider economic reform and transformation in later years. The reforms to foreign trade and investment, the financial system and enterprise governance that became important from the mid 1980s had long incubations. More fundamentally, the rehabilitation of the education and research systems after the Cultural Revolution and the farreaching changes of Communist Party and state personnel were preconditions of future economic change.

That change took the form of transition from the mid 1980s into a long period of uninhibited investment expansion, which continued until about 2011. Urban and industrial investment were given priority and the investment share of output grew from high to higher levels to unprecedented rates at around 50 per cent of output late in the first decade of the new century.

This period was associated with high and rising savings as a proportion of income; the commitment of a high proportion of those savings in domestic investment; rapid expansion of industrial production through absorption of large numbers of rural migrants at wages that increased less rapidly than labour productivity; increasing focus on industrial exports - at first technologically simple and labour-intensive but with more complex and capital-intensive elements becoming an increasingly important part of the mix over time; intensive use of metals and energy; and, increasingly damaging domestic and global economic impacts. 
Uninhibited investment expansion involved rapid catching up from a low starting point with the capital intensity and technology of the advanced countries. It was built around deep and deepening integration into global markets for goods, services, capital and knowledge.

The several features of uninhibited investment expansion were mutually supporting. Rapid industrial expansion and a steady real wage rate increased profits, and the savings share of income in turn supported high and increasing levels of investment and rapid economic growth.

Uninhibited investment expansion 1985-2011 had several subplots. A major focus of the early years (1985-1992) was the search for an ideological and political basis for internationally oriented growth.

Collective enterprises - the township and village enterprises - were the locus of the most rapid industrial, output and employment growth in the early years. From 1992, that mantle passed to the private economy-some of which was formed through the privatisation of what had been collective enterprises. The rapid increase in the private share of economic activity through the 1990s was arrested by the re-emergence in central roles in economic growth of large-scale, state-owned enterprises (SOEs) in the first decade or so of the 21st centuryunderpinned by the huge Keynesian fiscal and monetary expansions that were crucial to China quickly restoring growth momentum when it was challenged by the Asian Financial Crisis (1998-1999) and then the Global Financial Crisis (2008-2009).

Uninhibited investment expansion was extraordinarily productive. Output increased by an average of slightly more than 10 per cent per annum, with no weak periods from 1992 to 2011. This was the strongest sustained growth in history, exceeding the extraordinary postwar expansion of Japan to 1973 in average strength. Uninhibited investment expansion took Chinese average incomes (once they were measured correctly) from low levels into the ranks of middle-income countries. China came to have the world's largest total savings and surplus savings for international investment and the world's largest exports. It was (and remains) on a path to be the world's largest economy within a few years (PPP) or by end of the decade (national accounts at ruling exchange rates).

Despite, and because of, its achievements, uninhibited investment expansion was approaching economic, social and political limits through the first decade of the 21 st century.

Amongst the signs of approaching economic limits, average output and income per person were nearing the levels at which other north-east Asian economies had experienced change in patterns and rates of growth. Per capita 
income in real purchasing power at the end of the first decade in the new century was similar to that in Japan a few years before its step down from high to moderate growth in the mid 1970s.

From about 2004, as China entered the turning period of economic development, the old growth model began to be challenged by increases in wages in excess of productivity. This development was reinforced when the work-age population began to decline in 2012.

The international economic environment became less benign for the old growth model. While China's huge current account surplus (over 10 per cent of GDP in 2007) had allowed other countries, especially the United States, to maintain growth while implementing other policies that would have brought it to an end, the great financial crisis of 2008 encouraged criticism of Chinese surpluses. Tepid growth in the old industrial countries after the financial crisis diminished opportunities for rapid expansion of exports, although continued growth in developing markets allowed some refocusing of China's geographic focus in trade expansion.

Uninhibited investment expansion was also approaching social and political limits towards the end of the first decade of the 21 st century. The increase in income inequality between rural and urban residents and between workers and owners of capital and privileged positions in government and economy became the focus of increasing comment and tension. The mandatory purchase of peasants' land for urban development, which was a feature of uninhibited investment expansion, was increasingly controversial. International concern about China's increasing contribution to the build-up of concentrations of greenhouse gases in the atmosphere broke out as diplomatic tension at the Copenhagen meeting of the United Nations Framework Convention on Climate Change in December 2009. Increasing community concern about health and amenity impacts of domestic pollution reached a crescendo in early 2013. Longstanding community concern over corruption within government was explicitly identified as a potential source of political instability by party and state leaders in 2012 and early 2013, and the old model of economic development was recognised as being conducive to corrupt use of public office.

For all of these reasons, the need to move to a new model of economic development - to make the transition to an advanced modern economy-began to be discussed with increasing purposefulness amongst Chinese scholars and thoughtful officials from around the middle of the first decade of this century. It was not that uninhibited investment expansion was exhausted; it could continue to add to economic output at a rapid rate for a few more years. But there would have to be transition to a modern economy at some time in the near future, and leaving it too late would increase the strains and costs of change. 
As several contributors to this book observe, economic forces and, especially, the turning period in the labour market have been driving structural change with increasing force since about 2004. Alongside this structural change, driven by rising real wages and real exchange rates, policy adjustments to reinforce change were discussed with increasing purpose within the Chinese policy community and, in due course, within high echelons of government.

So, China entered the third major transition of the reform era, the transition to an advanced or modern economy.

The transition to an advanced economy is characterised by the gradual fall in the share of GDP represented by industrial investment and urban infrastructure, heavy investment in education and upgrading of the quality of education, expansion of the consumption and the services shares of expenditure, reform and improvement of the legal and institutional bases for an advanced market economy, and rapid structural change to technologically sophisticated industry with a much larger proportionate place for services.

All of the standard sources of growth are affected by these changes. The labour contribution to growth is markedly lower, and the contribution of capital intensification moderately lower. The contribution of total productivity increases to growth can rise if the increasingly sophisticated economy is supported by the necessary institutional improvements. The outcome is likely to be average growth in output two or perhaps three percentage points below the average of the period of uninhibited investment expansion.

The necessary changes in economic institutions require restraint in the use of old-style fiscal and monetary expansion through public institutions to avoid downturns in economic growth. This implies acceptance of moderate cyclical slowdowns without large-scale Keynesian responses-although strong antirecessionary responses, at some cost to desirable structural change, could be expected in response to a major downturn.

Much higher priority is assigned to domestic and international environmental amenity in the transition to an advanced economy: energy saving and reductions in the carbon intensity of production are major objectives of the 12th five-year plan (2011-2015).

While the desirability of reduced inequality has been prominent in official statements of policy goals right through the reform period, reduced inequality is an objective that attracts strong policy action in the transition to a modern economy. Rising real wages have been making a strong contribution to reduction in inequality from about 2008. This book provides data on the increasing and 
now large central government payments to rural education, health, transport, communications and an income safety net over recent years. Quantitative measures of inequality have begun to fall.

China's adoption of a new model of economic growth is of immense importance to people in China and everywhere. This book is an early attempt to take a close look at many of the features of the new model.

\section{Structure of the Book}

The transition to a modern economy-China's New Growth Modelrequires adjustments in economic structure and policy and the strengthening of institutions for effective national and corporate governance and for effective market exchange. Dwight Perkins lays out the ground that has to be covered in Chapter 2.

Perkins argues that China needs to build on some emerging institutions in its economy and society, the substantial modification of some, and the replacement of others. Big changes are needed in the regulatory system, the political system as it relates to government economic decision-making, the legal system, land ownership, and the development of decentralised sources of government revenue.

Perkins points out that many features of current arrangements facilitate the widespread corruption that threatens political stability and economic performance. Reform in these areas is crucial to continuing prosperity and for the transition to a modern economy

Reform in a number of other areas is essential to the strong productivity growth that is required if reasonably rapid growth is to be maintained through the transition to a modern economy. Some of the most important of these involve reform in the relationship between urbanisation, the social welfare system, and the changing Chinese demographic structure. Others involve institutions that are important to modernisation of the financial system, the upgrading and expansion of research and development in engineering and the sciences, and the continued upgrading of the universities.

China has made major progress through dismantling inappropriate institutions. Perkins argues, however, that creating new and fundamentally restructuring old institutions is inherently more difficult than dismantling inappropriate institutions. It takes time, and the passing of time contributes to the slowing of GDP growth that is inevitable as per capita incomes rise and the economy and society become more complex. 
Yiping Huang, Cai Fang, Peng $\mathrm{Xu}$ and Gou Qin call the new model for economic growth during the transition to a modern economy the 'new normal'. They argue in Chapter 3 that important changes to the Chinese growth model are already underway. They assess growth potential as probably having fallen from around 10 per cent during the first decade or so of the 21 st century to sixeight per cent during the decade ahead. In the meantime, the current account surplus narrowed from by far the largest amongst substantial economies to well within the range of developed countries. Two well-established trends of the era of uninhibited investment expansion that had been thought to be undesirable and unsustainable were reversed: the consumption share of GDP started to rise, and income inequality as measured by the Gini coefficient began to fall.

Huang, Cai, Peng and Gou identify changes in factor markets, especially the labour market, as the primary drivers of the transition to the new growth model. Emerging labour shortages and associated rapid wage increases in recent years are largely responsible for the current transition to the 'new normal', with slower growth but more balanced structure. The authors propose that the next-step reforms should focus on redefining the relationship between the government and the market by liberalising factor markets, establishing macroeconomic policy frameworks that are compatible with expanding roles for markets and changing the government's role from directly supporting production and investment to facilitating innovation and industrial upgrading. They conclude that these reforms are necessary for China to complete the transition toward the new growth model and to avoid falling into the 'middle-income trap'.

In Chapter 4 Cai Fang and Lu Yang argue that, as a result of the shrinking working-age population (aged 15 to 59 years), all of the forces that have driven China's rapid economic growth over the past 30 years have diminished from about 2010. They estimate the average annual growth rate of potential output to be 7.2 per cent over the 12th five-year plan period (2011-2015) and 6.1 per cent over the 13th five-year plan period (2016-2020). Future sustainable growth requires deepening and extending the scope of economic reform, particularly the development of new and related areas to enhance potential growth. They also develop two scenarios in which an increase in labour force participation and improvement in total factor productivity (TFP) can significantly enhance the potential GDP growth rate. They use this to argue that a floor can be placed under the decline in the potential growth rate.

The transition to an advanced economy requires a fundamental transformation of China's economic growth pattern from heavy reliance on inputs of capital and labour to more rapid increases in TFP. The new growth model requires that central and local governments accept slower economic growth-and, in times of lower growth, desist from pumping up public investment through fiscal and 
monetary expansion that was so important in ending downturns in the era of uninhibited investment expansion. Policy should seek to accelerate growth by adjusting supply-side factors, rather than demand-side factors.

A competitive environment is vital for enhancing the potential growth rate in China in the era of transition to a modern economy. The government has an important role in improving China's TFP through reforms to strengthen institutions that are essential for the effective operation of the labour and financial markets, enterprise governance, and the government system.

In Chapter 5 Huw McKay and Ligang Song describe China's economic structure as both over-industrialised and under-urbanised relative to its level of income per head, while having a high degree of export orientation for such a large economy. They note that some aspects of the historical path of China's development and the economic structure that emerged from it were impediments to constraining damage to the environment and inequality of income and opportunity within acceptable bounds.

McKay and Song then outline desirable changes in policy to accommodate the new model of economic growth. These changes include the removal of factor market distortions through accelerating financial reform, wholesale reform of the hukou system that limits rights and services available to migrants from rural areas to the cities, continuing the current movement towards marketbased pricing of energy and imposing prices on negative external costs to the environment, giving higher priority to investment in infrastructure than in industrial capacity, and dealing with some long-run fiscal questions that are important in the reallocation of resources across the economy that is necessary in the transition to a modern economy.

McKay and Song conclude by saying that the superordinate goals of China's transition to a modern economy - reducing 'over-industrialisation', optimising urbanisation and emphasising domestic absorption over foreign sales-are ultimately complementary. They also caution that there is much that is of value in the policy contours that have already emerged in pursuit of those inherently complementary goals. Yet, inside those contours, a political battle must still be fought in some major areas of policy and institutional reform-competition policy being amongst the most important of them.

China's high levels of saving not only provide capital for prodigious levels of domestic investment, but the excess of saving over domestic investment is a major source of finance for the rest of the world, and particularly for the highly indebted English-speaking countries led by the United States. In Chapter 6, Rod Tyers, Ying Zhang and Tsun Se Cheong discuss the implications of lower Chinese saving for the international economy. They point to lower savings coming 
from all three sources: households, enterprises, and government. The slower and more 'inward focused' growth to which the Chinese Government is now committed will reduce the excess saving available for international investment. Rises in consumption will reduce household saving. Reduced oligopoly profits and financial development will reduce corporate saving. The recent rise in provincial debt has already eliminated government saving. This reduction in Chinese savings rates coincides with reduced Japanese saving and hence the end of the 'Asian savings glut'. It must eventually raise the global cost of debt, although this has been postponed recently by quantitative easing (QE) in the United States, Europe and Japan.

The monetary reaction to reduced Chinese saving will see the transmission throughout the world economy of higher long bond yields, causing a new headwind against investment worldwide.

Tyers, Zhang and Cheong then discuss the implications of lower Chinese saving rates for capital markets and investment in the United States. The eventual rise in the cost of financing in the United States will not be conducive to US economic recovery, which will have negative effects on the global economy. A major offsetting force is fiscal consolidation in North America and some other parts of the world, reducing the demand for financing in deficit countries as global saving falls, and softening the impact of reduced Chinese surpluses on global private investment. Without continuing fiscal consolidation, however, serious global contraction could follow as investment expansion resumes in the old industrial countries and QE is withdrawn.

While China's increasing focus is on domestic rather than international demand from the perspective of its own economic transition, and while investment from China has been sought by the United States and other developed countries, its timing could be unfortunate.

Innovation becomes more important the closer China approaches the global productivity frontiers. Yixiao Zhou in Chapter 7 discusses how institutional quality will affect China's innovation performance. She presents the results of statistical analysis of firm-level data that suggest that institutional quality is critical for China's innovative performance and hence for the economy's future growth.

Stronger intellectual property protection clearly boosts the probability of a firm investing in innovation. The analysis suggests that the goals set in the 'National Medium- and Long-Term Program for Scientific and Technological Development (2006-2020)' are more likely to be met if firms become the major agents performing R\&D activities. Zhou points out that improving the quality 
of domestic institutions is just the first step towards building a knowledgeintensive economy, becoming a global R\&D player and contributing to the world pool of knowledge and technology.

The development of the agricultural sector has played a crucial role in Chinese economic transformation during the reform period (1978-2012). Li Zhou in Chapter 8 reviews the major achievements in China's agricultural development in the past, and discusses the challenges that the sector faces now. He notes that China can confront these challenges by deepening agricultural reform, including in relation to land ownership; by enhancing technological progress in agricultural production; by providing social support and protection for farmers as part of governments' efforts to reduce China's rural and urban income inequality; and, by modifying food consumption patterns in order to improve people's health and reduce the wastes of agricultural resources.

Li points out that the issues relating to farmers, agriculture, and rural areas are the weak links in the chain of China's economic development. Rural China is undergoing rapid economic and social changes, which have affected the ways in which farmers themselves, the traditional communities and the governments operate. Li concludes by saying that it is important for government policies to complement market mechanisms in facilitating the ongoing process of urbanisation, and creating more employment opportunities for both migrant workers and farmers, while maintaining rural social stability. The transition to a modern rural economy would be helped by governments adopting measures that conform to or respect, rather than overrule, farmers' own choices. These latter developments would be assisted by more democratic local governance.

Xin Meng in Chapter 9 uses official data sets on rural migrants' income and population to describe some important features of the rural-urban migration over the past decade and discusses their policy implications for China's future development of the labour market. The key findings from the survey data show that in the next few decades, the main addition to the labour force for Chinese cities will still come from the rural hukou population, as less than 30 per cent of the rural labour force had migrated to cities to work. Whether those remaining in rural areas will migrate depends largely on government policy. Currently, the lack of social welfare provision and social service access have deterred many people from migrating to cities. Even when they go to the cities, they only stay for a short period, on average eight to nine years. If this duration can be doubled, rural migrant labour supply in cities could be doubled. Another finding of her work is that migrant productivity reaches a peak at the 24 th year. The current average duration of migration, however, is far away from the productivity peak, indicating significant opportunities for increasing productivity by increasing duration. Migrant duration is also affected to a large extent by policy. While in cities, rural migrants work extremely long hours, reflecting weak protection of 
conditions for migrant workers. Long work hours are identified as being related to migrant mental health problems. Social welfare reform for migrants in cities is therefore an important area of reform.

In Chapter 10, Christine Wong examines the current state of China's public finances and discusses the reforms necessary to improve their capacity to support the long-term growth of the economy. Amongst much else, she discusses the macroeconomic stabilisation role of the budget, and the way that local government finances make macroeconomic control more difficult. Wong focuses on two critical areas where reforms are urgent - the persistence of extrabudgetary resources and fragmented control of the budget, and the tendency toward excessive public investment. Both have remained stubbornly resistant to reform.

By focusing on the fragmentation of budget control and the decentralised and extremely problematic management of public investment, Wong has traced the roots of the government's current macroeconomic problems to weaknesses in the fiscal system. She proposes that to support sustainable, long-term growth in the Chinese economy, the government must regain control over macroeconomic management, by curbing local government borrowing and investment, establishing a framework for managing subnational borrowing, and introducing a monitoring and regulatory framework that requires local governments to report on their debt.

Wong also suggests that the government regains fiscal discipline by assigning the oversight authority and responsibility over the comprehensive budget with all of the components to a single institution. The Ministry of Finance is most suitable for this purpose. The implementation of these reform measures would require political support from the top leaders to adjust the distribution of authorities across central institutions to elevate the Ministry of Finance and put it firmly in charge of all fiscal resources. Support should also be given to enhance the capacity of the National People's Congress to play its supervisory role over the budget - and hence the Ministry of Finance - that is assigned to it by the Constitution.

Improving the business environment is an important policy objective, which can greatly enhance private firms' contributions to productivity growth. Xiaolu Wang, Jingwen Yu and Fan Gang in Chapter 11 use output from four enterprise surveys to explain changes and provincial differences in China's business environment in recent years, and to draw out some policy implications. The business environment in China generally improved over the period 2006-2012. 
Wang, Yu and Fan also identify some negative developments for the business environment in China. For example, the focus of expansionary fiscal policy in response to the global financial crisis on SOEs over the sample period had the effect of squeezing out normal business demand on credit and damaged the non-state sector. Firms covered by the survey focused complaints on 'openness, fairness, and equity' of policies and government administration. Problems include non-transparency of policies and government administration, uneven enforcement of regulations and, more generally, unequal treatment for different enterprises. The authors also find that sectors with greater market competition have better business environments than monopolised sectors.

Wang, Yu and Fan also reveal discriminatory treatment between SOEs and non-state enterprises (NSEs), which have a negative effect on the operation and performance of NSEs. They conclude by saying that it remains an important task for governments at different levels, through their policy changes, to improve the business environment which is conducive to the implementation of the new growth strategy adopted by the Chinese Government.

In Chapter 12 Shiyi Chen and Jane Golley estimate the changing patterns of 'green' TFP (GTFP) growth of 38 industrial sectors during the period 1980-2010 to assess whether or not Chinese industry was on the path towards a sustainable form of low-carbon growth during those years. China's industrial GTFP growth was significantly lower when productivity takes account of the negative impact of carbon dioxide emissions in the production process. Through the period covered by the study, both in aggregate and for the majority of sectors, GTFP growth was predominantly shaped by technical change. The rate of technical change increased steadily from the mid 1990s to the early 2000s, but declined continuously after that, in contrast with fluctuating but generally low rates of efficiency growth. GTFP growth was positive in the majority of sectors and in aggregate, both over the entire period and in each sub-period.

Chen and Golley reveal, however, that between 2003 and 2010, GTFP growth was not only low (and well below the 50 per cent level often taken to signal the transition to 'sustainable' growth), but lower than in the preceding decade. This finding suggests that Chinese industry seemed to have lost its way in going green. The final year of the period covered by this chapter is late in the period of Uninhibited Investment Expansion. The hope to which the authors make reference at the end of the chapter is presumably drawn from the changes in policy and structure than are emerging in the transition to a modern economy.

Yongsheng Zhang, from the State Council's Development Research Centre, and a participant in the major World Bank-State Council study of green growth, argues in Chapter 13 that green growth could play a significant role in China's modernisation. The barriers against green growth in China stem from 
institutional weaknesses in its distorted market system. China has advantages that are not available to old developed countries in seeking to establish a pattern of green growth. It can leapfrog over old industrial practices into practices that are appropriate in the modern economy.

Zhang describes green growth as involving the decoupling of economic output from heavy dependence on use of material resources, carbon emissions and other sources of environmental damage, through the creation of new green products markets, technologies, investments, and changes in consumption and conservation behaviour.

Zhang's conception of green growth is based on three key concepts: that economic growth may be decoupled from rising greenhouse gas emissions and environmental degradation, that the process of 'going green' can itself be a source of growth, and that 'going green' is part of a virtuous circle which is mutually reinforcing with growth. To seize the opportunities for a transition to a sustainable pattern of modern economic growth, China should seek green transformation of traditional sectors, expansion of emerging green industries and expansion of service sectors. Implementation of these approaches requires reforms in a number of areas: transformation of government functions, consolidation of market exchange, tougher policies and regulations on emission reduction, and environment protection. Zhang warns that there is a window of opportunity in the next two decades for China to take action; if missed, China will have to pay a much higher price for 'going green'.

Ross Garnaut in Chapter 14 describes recent progress in one of the central elements of China's transition to a modern economy: the breaking of the links between economic output and energy use and between energy use and carbon emissions. China's growth in the era of uninhibited investment expansion was characterised by exceptionally high energy use and greenhouse gas emissions. These features of old-style Chinese growth made the country the world's largest source of greenhouse gas emissions in the final years of uninhibited investment expansion. It was associated with increasingly severe domestic environmental problems, and increasing international pressure on China as a disproportionate source of contemporary and prospective global warming tendencies. Heavy energy use and reliance on imported fossil fuels for an increasing proportion of China's expansion raised concerns for energy and economic security within China.

The change in the trajectory of Chinese energy use and emissions growth in the transition to a modern economy is as outstanding as the earlier extremes in energy and emissions intensity of growth. So far the transition has been secured mainly through the use of instruments out of the old economy: regulatory intervention to close plants with unacceptably high energy or emissions 
intensity, mandatory provincial and local limits on energy use and emissions, imposition of discriminatory high prices of inputs on high energy use and emissions produced by particular industries and plants, discretionary subsidies and other support for investments in low-emissions plants, and tilting of investment approvals processes in favour of low-energy and low-emissions plants and against high-energy and high-emissions plants.

Increasingly the discussion policy is exploring interventions based on the introduction of market mechanisms and the pricing of carbon externalities. There is movement towards removal of transport preferences and favourable pricing for fossil fuels, experimentation with emissions trading systems in two provinces and seven cities. Resource taxes are being redesigned to modify use and carbon emissions, and the Ministry of Finance has been undertaking research on carbon taxes. Elements of each of these approaches to policy are likely to find a place in the future Chinese energy and greenhouse gas policy mix.

While strong energy and emissions intensity targets were introduced from the beginning of the 12th five-year plan (2011-2015), a marked change in energy and emissions intensity was not powerfully evident in the growth statistics until 2012. The much lower trajectories of energy use and emissions in 2012 are likely to be extended progressively through the transition to a modern economy. For this reason amongst others, when it is useful for exposition to draw clear temporal boundaries between periods, we see 2011 as the last year of uninhibited investment expansion, and 2012 as the first year of transition to a modern economy.

China's progress on changing the trajectory of greenhouse gas emissions transforms what is possible in effective international action to constrain global warming. Garnaut suggests that this could provide the basis for global tightening of emissions reduction targets at the United Nations Conference of the Parties to the Framework Convention on Climate Change, to be held in Paris in 2015.

China has recently become the world's largest energy consumer and, yet, it is still only in the middle stages of development. In Chapter 15, Simon Wensley, Stephen Wilson and Jane Kuang describe China's energy policy Trilemma. The Trilemma refers to the tension between maximising security of energy supply, minimising cost of energy and minimising environmental impacts of emissions.

Wensley, Wilson and Kuang point out that resolving the Trilemma is the key challenge for energy policy makers everywhere. They explore the Trilemma through four case studies: the 1970s oil crisis, China's cost revolution in nuclear 
power that is quietly unfolding today, the US unconventional oil and gas technoeconomic revolution, and the challenge for Japan in closing the 30 Gigawatt gap in the power system post-Fukushima.

With these case studies as background, the authors discuss the opportunities and challenges in the development and management of China's resources They highlight the increasing role of imports in balancing domestic supply in oil, gas, coal and uranium through the period of uninhibited investment expansion. They also explore emerging technologies, many of which China is actively developing, that have the potential to transform energy supply and use. These include development of unconventional gas and oil sources, and the electrification of transport including through electric automobiles. Security of supply is already a high policy priority, most acutely in oil.

The tensions between the three corners of the Energy Policy Trilemma are steadily becoming more acute in China. As China's energy import dependence deepens from oil to gas, security of supply is expected to increase rather than decrease in importance. Despite these challenges, the authors conclude that structural change in the Chinese economy towards a greater weighting of less energy-intensive secondary industries and higher value-added services are expected to moderate the strong linear relationship of the past two decades between energy requirements and GDP. Improvements in technical energy efficiency will further help to moderate the rate of energy demand growth.

In Chapter 16, Bijun Wang, Miaojie Yu and Yiping Huang discuss the financial constraints on Chinese outward direct investment (ODI) from the private sector. Using a firm-level panel dataset from Zhejiang Province between 2006 and 2008, they find that firms with access to finance that is less constrained are more likely to pursue ODI, and if they are involved in ODI to make larger investments. High productivity does not mitigate the negative impact of financial constraints on engaging in ODI. They conclude that, policy-wise, if financial constraints are not overcome, many productive and competitive Chinese private enterprises are likely to be shut out of ODI opportunities. As a result, the quality and return of Chinese ODI and the image and reputation of overseas Chinese enterprises will be compromised.

In Chapter 17, Kunwang Li and Bingzhan Shi examine the quantity and quality of China's information and communication technology (ICT) exports and their determinants. They find that China's ICT exports are characterised by high quantity and low quality. Patterns of foreign direct investment (FDI), opportunities for processing trade and government policy support are the main determinants of China's ICT export growth. Expansion of processing trade increases quantity but decreases quality. On the other hand, FDI and government policy have the opposite impact. 
Expansion of the quantity of China's ICT exports employs more labour, and increases consumption of natural resources, pollution and damage to the environment. Upgrading quality rather than simply increasing quantity needs to be the central feature of ICT exports in the transition to a modern economy.

The authors expect that China's export sector will be transformed from being driven by quantity, to being focused on quality and high value-added products. They conclude by saying that this transformation is consistent with the new growth strategy adopted by the Chinese Government in confronting the new challenges for future growth.

The book as a whole describes a great deal of progress across a wide range of issues in China's transition from uninhibited investment expansion, to the building of the foundations of a modern economy. The transition to a modern economy is in its early stages. Immense challenges lie ahead, especially in the institutional and legal developments that are discussed in the first few chapters in the book. The evidence presented in this book says, 'so far so good'. 


\title{
2 New Institutions for a New Development Model
}

\author{
Dwight H. Perkins
}

\section{Introduction}

If China's economy and per capita income is to continue to catch up to the levels of the world's high-income economies, China will require a different approach from the model that has dominated its extraordinary development over the past three plus decades. The model of the past in essence involved three basic components during these three decades, and a fourth component during the most recent decade. The first component involved the dissolution of the Soviet-style system of centrally planned command economy and collective agriculture and replacing it with an economic system governed to a large degree by market forces. The second component was the opening of the economy to foreign trade and foreign direct investment, and the rapid expansion of manufactured exports in the growing manufacturing sector. Most of the dynamism in this manufacturing sector came from the domestic and foreign private sectors, together with township and village enterprises that first were collectively owned and later mostly privatised. The third component facilitating the rise of export-oriented manufacturing was the shift of a large part of the rural labour surplus to urban industry and services, a shift that helped keep wages low and labour-intensive manufactured exports competitive.

Beginning to some degree during the world financial crisis of 1997-1998, the fourth component involved the massive expansion of infrastructure investment and the equally rapid expansion of urban housing investment, in effect removing the last major feature of a Soviet-type system that neglected both housing and transport infrastructure. This last component was made necessary, to a large extent, not only by the weaknesses of housing and transport, but also by the fact that the labour-surplus economy produced low levels of household consumption as a share of GDP. This low share in turn necessitated an unprecedented rise in the share of investment in GDP in order to maintain a high rate of GDP growth. ${ }^{1}$

These components of the post-1978 economic model produced more than three decades of high GDP and per capita income growth and created what, in many respects, is a first world infrastructure. Institutional change, however, mostly

1 For my views on how inadequate aggregate demand, represented by low household consumption as a share of GDP, necessitated the large infrastructure and housing investment program, see Perkins 2012. 
involved the dissolution of the institutions of the Soviet-style system and the partial dissolution of some controls, such as the household registration (hukou) system that had been used to restrict rural to urban migration. The incomplete dissolution of the regulations of the centrally planned command economy and of the household registration system left a large residue of regulatory controls administered by government officials who retained much of the discretionary authority of the old system. Only now, in the privatised market context, these officials had far wider latitude for discretion than under the old, tightly controlled, command system.

What is required going forward is a different system for controlling the economy, a system that can build on some of the institutions that have begun to develop, but requires replacing or substantially modifying many of the other institutions that continue to govern China's economy and society. In this chapter I focus on two areas where fundamental changes in these institutions are required, and briefly discuss a third area where the outlines of what needs to be done are well known and progress is already well underway. The first of these areas involves a variety of interrelated institutions, including the regulatory system, the nature of the political system as it relates to government economic decision-making, the legal system, the land ownership system and inadequate decentralised sources of government revenue. These systems, as they operate today, are responsible for a large share of the widespread corruption that threatens political stability and hence economic performance. The second area of interconnected institutions that will be discussed involves the relationship between urbanisation, the social welfare system, and the changing Chinese demographic structure. The third area I will label 'technical institutions' for lack of a better description. This involves continued modernisation of the financial system, the steady improvement and expansion of research and development in engineering and the sciences, the continued upgrading of the universities, and other institutional changes designed to maintain a high rate of growth in productivity.

\section{Regulation, Politics, Law and Corruption}

The dismantling of the Soviet-style system of centrally planned commands over the economy has left an extensive residual of regulations governing all aspects of economic activity both public and private. For example, access to land on which to build a factory or office tower is controlled by urban governments; large-scale investments must be approved by the National Planning and Reform Commission, and lesser projects must be approved at lower levels of the planning hierarchy; and, access to electricity is regulated as is access to any other utility that is controlled by local governments. Then, there are the regulations that 
all countries have that are designed to make sure that a building is safe for its occupants, that companies are fair to their workers, or that a factory doesn't pollute its neighbourhood. All countries, for example, have customs authorities that determine whether and with what taxes goods and services can enter the economy.

For the past decade, the World Bank has attempted to calculate a number of measures designed to estimate the ease or difficulty of doing business in each country. In 2013, the World Bank ranks China 91st out of 185 countries, which, by itself, does not seem so bad, except that countries only ten or so places below China include Zambia, Papua New Guinea, and Pakistan - countries that most would consider highly corrupt and difficult places in which to do business. China, to be sure, has been steadily improving its regulatory environmentit ranks 12th out of the 50 countries that have made the most progress in improving their regulatory environment (World Bank, 2012: 9). China ranks well, or fairly well, at enforcing contracts, registering property, and trade across borders (customs) (19th, 44th and 68th respectively), but poorly, or abysmally, with respect to getting credit (70th), resolving insolvency (82nd), protecting investors (100th), getting electricity (114th), paying taxes (122nd), starting a business (151st), and dealing with construction permits (181st). Given the vast amount of construction that has gone on in China during the first dozen years of the twenty-first century, the last number is particularly striking.

The fact that China ranks among the worst five countries in construction permits, but has by far the most construction activity of any country in the world in recent years, presents a paradox. In China it takes a long time to get the necessary permits (270 days) (in Singapore it is 26 days) and there are a large number of procedures involved (28) (Hong Kong requires six procedures). The number of procedures puts China near the bottom, with the worst performers on this measure, where only nine countries have more procedures, although the length of time required to receive a permit in China is well below that of the worst ten performers, which range from Mozambique at 377 days to Haiti at 1,129 days. The cost of obtaining a permit is also high for China, at 3.75 times the country's per capita income, but that is far below Zambia at 17 times, or Chad at 51 times per capita income.

This paradox of obstructive procedures, but large amounts of construction, is no doubt partly due to the fact that companies can make significant profits from construction (and in many other areas of business) in China, and so it is worth the wait and the expense. But it is also likely that the permitting process is predictable for those with the right connections and the willingness to do what is necessary, above or below the table, to get through that process. What is true for construction permits is also true for a wide variety of other regulatory 
barriers in China. It is profitable once one has gotten through them and the path through them is predictable at least as long as one has the right connections or is willing to develop them.

There are straightforward ways of trying to eliminate some of these regulatory obstruction issues, although they do not by themselves fully solve the problem. One key is to remove as much discretion as possible from the domain of the officials who decide whether to issue a license or permit or not. The rules for issuance should be clear and public, and the process itself should be transparent. If an applicant complies with all of the rules, the permit should be issued automatically. To prevent delaying tactics by officials as a means of extracting rents, there should be time lines that establish the point in the process at which a permitting agency must make a decision. The process of what is required and where a given application stands should be accessible online, so that an applicant (and a government monitoring agency) can readily check on the progress of an application. For straightforward procedures, such as issuance of a driver's license, this method will go a long way toward solving the problem of delays by the issuing official that are designed to extract rents. Where the procedure involves more complex problems, however, requiring official judgement as to the desirability of the project or the character of the applicant, these simple procedures are not likely to be sufficient to solve the issue of excessive delays.

When judgement and discretion on the part of the issuing office are involved, the problems of removing regulatory barriers are much more difficult. In China, the problem begins with the fact that the Chinese Communist Party and its key members, at both the local and higher levels, have discretionary power over a variety of issues, including many that determine whether a company or individual can receive permission to go ahead with a project or program. If the Party leadership strongly supports a project or program, it can cut through regulatory barriers and get the necessary authorisation to proceed. One problem, however, is that the Party can operate on both sides of a transaction. Local and higher level party officials can have a major say in the appointment of the government official in the regulatory office, and a similar say in the appointment of the enterprise manager (or party secretary) in the application for regulatory relief. Similarly, in the past, in applications for project funding, local party officials have had an influence over both the local branch of one of the national banks making the loan and the managers of the company or the local government officials applying for the loan. When there is more than one applicant for a single permit, the applicants with the best connections to local or higher level officials have an obvious advantage. 
From the viewpoint of the applicant for permits or regulatory relief, there are a variety of solutions to overcoming another applicant's political advantagethey can, for example, make illegal payments to the official or to others with influence over that official, they can hire a close relative of the official or of the Party secretary of the official and pay that person a high salary or give them a large consulting contract. China has no monopoly on these practices - they are common throughout the world, including in most high-income countries. Straightforward payment of bribes can be dangerous for both the payer and payee, and official malfeasance of this sort can sometimes be identified by requiring officials and other senior political people to fully report their financial and other assets to a higher authority; this practice has been used to a degree in China. In a country such as China, however, where success or failure of a project or enterprise can depend on making one's way through a maze of regulations, there are circumstances in which there is no need for formal bribes. Placing a person with powerful political connections on the board of directors, or in some other conspicuous position, can have a equivalent influence. The individual so employed may not have to actually contact the regulatory officials dealing with the company, or do anything whatsoever, to overtly help the company with the regulators. The mere knowledge that that individual is supporting the company will influence a lower level regulator to try to be helpful. The possibility that the powerful consultant or member of the board of directors might criticise the regulatory official and thereby damage or end that official's career is sufficient. Many officials will not be willing to take the chance that this will happen.

It is not surprising, therefore, that the family members of some high party officials have ended up making large fortunes. Many of these officials have no doubt made these incomes because they have skills that have contributed in a technical sense to the companies they work with, but there are examples where the main thing the family member brings to the table is his or her political connections. The problem does not occur, however, only at the top of the pyramid; it exists right through the system, down to the local level.

There are three ways of trying to deal with the relationship between regulatory power, political influence, and rent seeking. One way, which has dominated Chinese practice throughout the last three decades, is to have stiff punishments, including the death penalty, for financial crimes. This is problematic in a highly regulated economy, such as China's, where all officials have a significant discretionary decision-making power, it is difficult to find and convict enough law breakers to make a difference to the overall problem. China has a population of 1.3 billion, comprising 80 million party members, tens of millions of officials, and over 2000 county-level governments, plus even more numerous townships and villages. It is noteworthy that China has prosecuted high level officials, and not just low level rent seekers, but the task of discovering whether a crime 
of corruption has actually occurred, or whether it was just the excessive use of political influence, receipt of a personal gift that was a little too large, or a trip that was a little too lavishly funded. To an extent, the massive surveillance system that existed in the 1960s and early 1970s could control these forms of corruption, but at the price of far worse abuses of power in non-financial areas. Short of massive police surveillance, it is difficult to prove that a crime of corruption has been committed. Going after officials who are only suspected of malfeasance, but where firm proof is missing, leads to other kinds of abuses. Inevitably it is seen as motivated by a desire to eliminate political opponents.

The second straightforward method for controlling this kind of corruption is to reduce the number of regulatory barriers that companies and individuals must get through in order to prosper. The fewer regulations there are to deal with, the less a company needs to spend in time and money in getting through those regulations. A well-functioning market system can control many forms of behaviour that harm the economy without the need for regulation of any kind, but even in the most market-oriented economy, Hong Kong being a good example, there is a need for some regulations. But, if one reduces the number of regulations and hence the opportunities for rent seeking, it is easier for public security and prosecutors to identify and try the smaller number of violations that do occur. It is no accident that the two economies with the lowest level of corruption in Asia, Singapore and Hong Kong, are the economies that are most regulated by market forces rather than government regulations. Even in Hong Kong, a market economy did not immediately diminish corruption in some areas, notably in the police, where a high degree of discretionary authority was inherent in the job. In Hong Kong it also took a major anti-corruption drive orchestrated by the Independent Commission Against Corruption that was founded in 1974, but the task before the commission was a simpler one than that faced by any commission responsible for the People's Republic of China.

Thus, there must be a third way of combating corruption, and a critical step in that third way would be to change the role played by the Chinese Communist Party in the economy. In essence, as long as the Party plays a role of determining the rules of the economic system, follows that by appointing most of the government officials that administer that system, and then also directly appoints, monitors and replaces those leading major producing units in that economy-including all enterprises with a substantial degree of government ownership - the system will be riddled with conflicts of interest. Success in that system will depend more on one's political relationships than on anything else.

If the Party is to get control of corruption, therefore, it has to remove itself from the direct administration of the central and local government and of large parts of the economy. There is a precedent for doing this in recent Chinese history. The Party effectively removed itself from the day-to-day management 
of agricultural production when it abolished the Rural People's Communes. The privatisation of large parts of the urban economy, both industry and services, has also meant that decision relating to management personnel in this sector are mainly made by the private owners, foreign and domestic. Most large private units have party committees and, no doubt, many party members, but the Party does not determine company priorities and day-to-day management in any direct way. Even in the state-owned enterprises, including those shareholding enterprises where the majority shares are held by government, there has been some success in separating the role of the Party from the technical operation of the enterprise. What is needed is to complete the process of removing the Party as the main vehicle determining senior employment throughout the system. The Party would instead become a body that set the rules of the system, gave it its overall direction, and then monitored whether officials and economic units were following the rules and implementing the broad goals. It would play a role more like the traditional censorate in the imperial dynasties, but with a broader mandate than that of the censorate because it would also replace the policymaking role played by the emperor.

If the Party were to remove itself from the day-to-day management of the economy and society, certain other institutions would have to be strengthened from what they are today. Foremost among these institutions is the legal system. China has made progress in rebuilding the legal system after its dismantling during the Cultural Revolution, but it is far from adequate for what would be required in a system where party leaders and government officials were no longer the ultimate settlers of disputes between economic parties. In a full market economy, most economic disputes are handled through the courts, which are largely independent of the parties to those disputes, including government officials and units. By having independent, competent, and honest judges deciding disputes, political considerations are largely eliminated from the verdict, which is decided on its legal merits.

The contemporary legal system in China is neither independent of higher political authority, fully competent or consistently honest. The easiest to fix is competency. When the legal system was reconstituted after the Cultural Revolution, there were few people trained in the law and, hence, the judges often had no legal background. In 2010, China's law schools graduated 26,165 lawyers (NBS 2011: 746) and the total stock of lawyers numbers in the hundreds of thousands. Making judges independent so that they can make decisions strictly according to the law and the facts of the case is far more difficult. Higher level government and party officials often feel they can overrule or ignore court decisions; even company managers with sufficient political influence can often do so. Furthermore, the judges are appointed by the government and the Party, and can be removed if they do not fulfil the expectation of carrying out the goals 
of the Party. Truly independent justices must have a credible commitment to long tenure, as long as they themselves do not violate the law, and they cannot be removed for a verdict disapproved of by higher authorities. In the absence of that kind of commitment, judges will be influenced by the political winds blowing at any given moment and the legal system will be regarded as unfair.

It will probably be a long time before courts in China are made independent of politics, especially in areas where there are perceived threats to the state or the rule of the Chinese Communist Party, but the Party has no obvious interest in letting political considerations govern economic verdicts. Individual government and party members will retain their own interests, including those of the rent-seeking variety, but those interests can be a bigger threat to the rule of the Party than judges who are sometimes seen as too independent. If one can remove overt political biases from the legal process, it will also be easier to remove the problem of corrupt courts. Paying judges well and monitoring their personal assets would also go a long way toward eliminating judicial decisions driven by corrupt practices.

If China is ever to get full control of corruption, and to have a functioning economic system driven by market forces combined with regulations designed to compensate for real market failures, therefore, there are fundamental changes needed in the institutions governing China's economy and society today. The changes are interrelated: there needs to be a substantial reduction in the role played by government regulations as contrasted to market forces, and the discretionary authority of those government officials in implementing those regulations must be greatly reduced or eliminated. There must be a further withdrawal of the Party from the day-to-day operation of government agencies and economic units and a focus of the Party, instead, on setting the goals for the system, translating those goals into legislation, and monitoring progress in their implementation, but doing so from outside government agencies and economic units, not as day-to-day managers within them. There are other kinds of political institutions that could play this role, but most of them are part of China's future, rather than its present. Failure to make major progress in these areas will foster a continued rise in corruption that will steadily undermine the ability of the Party to govern the country.

\section{Rural Land and Local Government Revenues}

A major source of political instability in China over the past decade and longer has been the perceived corruption of the process whereby agricultural land is taken from farmers, at low prices, and sold to developers at much higher prices with the fund from difference between these two prices going to local 
governments, and sometimes to local officials for personal use. Unlike the issue of the role of the Party being overly involved in the day-to-day operation of government agencies and economic units, this problem of the distribution of rural land can be solved to a substantial degree by technical reforms that do not involve a change in the role of the Party, or anything else that would be politically sensitive.

The first step to solving this problem would be to allow land to be sold on the open market at prices set by that market, and giving the farmers tilling that land either ownership or long-term user rights, with the right to sell the land or their user rights, similar to the system that allows companies to lease urban land. Government officials would then no longer be able to take land away from the farmers without paying them a fair market price, or, if they managed to do so, it would be seen as theft and prosecuted as such. There would still occasionally be the need for what is known in many high-income countries as 'taking the land by eminent domain' to serve a public purpose, such as building a road, but there would be a reference price set by the market, not by administrative rule. Ideally there would also be independent courts to determine whether the land was taken at a fair price and for a legitimate public purpose or not.

If one pays a fair price for the land, and if one allows land to be taken by eminent demand, however, there need to be two additional changes in related institutions. The first such institutional reform would be a need to change and expand the social safety net as it affects not only the rural population, but also the population registered as rural that is in fact working in non-agricultural occupations, mostly in the cities. The issue of urbanisation and rural migrants (discussed below) is relevant here because rural land in China is an important part of the safety net for these migrants, as well as those living in rural areas. Allowing migrants to sell their land rights gives them funds that will ease their permanent transition to urban life, but it will also remove the fallback position of returning to their land, something that many have used when employment in the cities has fallen through. A new fallback position or safety net is required.

The second necessary institutional change is to provide local governments with sources of revenue commensurate with the level of expenditures that they are required to make. In recent years, notably during the large stimulus spending designed to maintain high GDP growth in the face of a world recession, the central government pressured local governments to carry out and pay for a large part of this stimulus. That, together with the fact that local government officials get promoted in part on the basis of the GDP growth in their area, led local governments to run up debts that have been officially estimated at close to RMB10 trillion, but unofficially at perhaps twice that figure. It is now widely recognised that the local governments do not have the revenue sources to pay for these expenditures or to service these large debts, even if they continue 
to earn revenue by paying low prices for local land and then selling the land to developers at a much higher price. If the land market is reformed and land prices become true market prices, this source of local revenue will disappear, thereby increasing the revenue shortfall.

One modest way of raising local revenues would be to charge a land tax on developer land other than agricultural land. One could also tax agricultural land, but the government only recently abolished the agricultural tax as part of an effort to increase the disposable income of the rural population. The other way is for the central government to take over more local expenditures or, alternatively, expand the subsidies it pays to local governments from central revenues. Whatever the ultimate solution, continuing to allow local governments to buy land cheaply and sell it at high prices must end if China wants to maintain rural stability.

\section{Urbanisation, Migration, Ageing and the Hukou System}

China, in many respects, is following the pattern of urban development that is characteristic of all countries that have achieved middle-income status and are heading toward becoming high-income nations. China, having spent the two decades prior to 1978 trying to tightly restrict the growth of the urban population, is rapidly becoming a nation where the increasing majority of the population is no longer involved in farming, and a large share of that nonagricultural population now resides in cities. Officially, the registered urban population in 2011 was 51.3 per cent of the total, up from only 17.9 per cent in 1978. The figure for 2011 includes some migrants (those who had been in a city for over six months), but excludes others. The urban figures also include some farmers who reside within the urban district, but this would be a small number in the major cities today. The population that is still involved in farming is much smaller than the population listed as residing in rural areas-employment in agriculture in 2011 was under 35 per cent of the population, down from a little under 70 per cent in $1978 .^{2}$ Most of the people doing farm work as their major occupation today are over the age of 40 .

There are three major challenges connected with the fast pace of urbanisation that China faces today and going forward over the next one or two decades. The first is keeping the growth rate of urban employment at a level sufficient to absorb the increases in the labour force, both rural and urban. That number

2 The official figure for the primary sector in 2011 is 34.8 per cent, but this includes employment in mining (NBS 2012). 
is perhaps 14 million per year, if most of the increase in the labour force is absorbed by urban employment. ${ }^{3}$ Since there will be close to ten million urban workers reaching retirement age and leaving the labour force each year, the net increase in employment needed to absorb these new entrants into the labour force is small, relative to the past, and will become a negative figure over time. When one adds the fact that the share of the service sector in this new employment is likely to rise and that of manufacturing begin to fall, the labour market will remain tight and wages will rise. The service sector will grow more rapidly because China has already reached the point where, in most countries, manufacturing output as a share of GDP and employment in manufacturing falls even more rapidly than the share of output. ${ }^{4}$ Thus, if China maintains a GDP growth rate of six or seven per cent per year for another one or two decades, wages should continue to rise, possibly and hopefully faster than GDP.

The second and third challenges are not so easily met, and they will require fundamental changes or improvements in the institutions currently in existence. The second challenge is the need to entirely get rid of the household registration system (the hukou system) as it is currently configured. The system is no longer used to restrict the entrance of workers into the cities, but key features of the system ensure that the population that is working, but not registered, in the urban areas is discriminated against in ways that are ultimately harmful to Chinese society. There is widespread acknowledgement that this is the case among a wide range of Chinese scholars and others who have thought about the problem. There are even a few urban districts that have taken steps to deal with important aspects of the issue, mainly cities that seek to attract migrants rather than repel or ignore them.

The problem with the way the current system is administered stems from the fact that there is little affordable housing of any quality that is available to migrant workers from the countryside. That in turn leads workers to live on construction sites, others are crowded into a single rented room in a distant suburb, and young women often reside in factory dormitories. The poor housing conditions also leads large numbers of migrant workers to leave their children in their home village with their grandparents, instead of having them attend generally higher quality urban schools that would better prepare them for urban life. The government now makes urban schools open to migrant children,

3 There were 222 million people aged 14 and under in 2011, or an average of 16 million for each year of age. A few of these people, when they finish schooling at whatever level, will stay in agriculture and a few will not enter the labour force. I have assumed that these two categories would amount to two million people per year, with the remainder looking for work in the urban workforce.

4 Manufacturing employment in 26 OECD countries, plus Taiwan, began declining on average when they reached a per capita Purchasing Power Parity Income of US\$13,300 (or within a range from US\$7,000 to US\$17,000 per capita) (Eichengreen et al. 2012: 87). This decline in manufacturing employment is often referred to as deindustrialisation although manufacturing output in most cases continues to grow. 
but few can afford the high fees and related expenses that are associated with most of the urban schools. The central government has a large public housing program for the registered urban poor, but, on the national level, there is still no such program for the migrant population. There is also a greatly improved program for rural and urban health insurance, but again the migrant population has to return to the villages where they are registered to take advantage of this program. Finally, the university entrance quotas are based on a national exam that is biased in favour of registered urban residents, what is in effect a reverse affirmative action program for the well off.

Few, if any, of these migrants will return to farm work. There are still far too many workers in agriculture and that keeps incomes for farm work low, although they have certainly risen substantially over the years. The children of these migrants are also not going to be farmers. The system needs to figure out ways to support rural migrants to the cities with housing, access to schooling for their children, and a social welfare and pension system that includes them. And these systems or institutions need to be created over the next one or two decades. To accomplish such an ambitious goal, the government following standard Chinese practice will have to experiment with what kinds of housing would be appropriate, what kinds of health care will be both affordable and will meet as many needs as possible, and what kinds of education would also be affordable and meet the needs of migrant families. Creating these institutions is not a simple matter. As the United States among others has demonstrated, high-rise apartment buildings may not work as well for poor migrant families as for the urban middle class. Similarly, the educational needs of children from the rural areas, where their parents had limited education, are different from the needs of urban families with well-educated parents, to mention only two areas of potential differences in the kinds of support required for migrants.

The third challenge has some things in common with the second challenge, but it is relevant to the entire urban population and not just to recent migrants from the countryside. It is the challenge of China's ageing population in the context of a society that is becoming mostly urban. There are two aspects to the impact on Chinese society of a rapidly ageing population. The one that typically gets the most attention is the fact that in China, the enforcement over a long period of the one child family policy has created a situation in which the old-age dependency ratio will rise rapidly, and fewer and fewer people of working age will be available to support those who have retired from the labour force. The second aspect is that urban life, in most countries, typically ends the practice of several generations of one family living under the same roof (or in adjacent houses in villages built by the families themselves). Rather, grandparents live separately from their adult children and the nuclear family 
is the norm. The working-age children may in fact live in a different city from their grandparents, something that is common in most high-income countries. Traditional ways of taking care of ageing grandparents thus no longer apply.

China's population's overall dependency ratio has fallen steadily over the past three decades, and has only recently begun to level off. This is as a result of the one child family policy which caused the share of children below working age to fall sharply, while the share of the elderly outside the labour force grew rapidly (by roughly 50 per cent over the past two decades), but from a very low level (from 8.3 per cent of the population in 1990 to 12.3 per cent in 2011). The share of children as of 2013, however, has levelled off, and may even rise modestly if the one child family policy is finally abandoned or modified, as many in China are advocating. The share of the ageing will definitely continue to rise, and do so rapidly as people live longer and as China's own 'baby boomers' (the population born after 1949 but before the one child policy) begin to retire. Of the 133 million people who were zero to nine years old in 1950, 94 million are still alive today, are aged 60 to 69 and are soon to be, or already, retired. The next age cohort that was zero to nine years old in 1960 totalled 192 million in that year, 161 million of those were aged 50 to 59 in 2010; many of the women in this group have already retired and the men will soon be approaching retirement. In addition to these people, in 2010 there were 71 million people aged 70 and over still living, up from only 30 million as recently as 1980. And the largest age cohorts of retirees come in the decades immediately after those who were zero to nine years in 1960. In 2010, there were 225 million people at an age (15 to 24) that will make them eligible to enter the labour force, compared to the 161 million in the 50-59, about to retire, age group. Ten years later (in 2020) there will be roughly 225 million in the 50-59, about to retire, age group and the same number in the 15-24, about to enter the labour force, group. (United Nations 2011)

The burden of this demographic change is usually expressed as the dependency ratio that has fewer and fewer people in the work force supporting more and more retirees. In a rural peasant society, however, this burden is mainly one of more mouths to feed around the dinner table, most of the food comes from the family's land and they build their own houses on that land. This is hardly an ideal existence, since the cultivated land is small and illness can make it difficult to cultivate even that small amount. Generally, there have been no institutions that intervene in this process - one either grew enough food and stayed reasonably healthy or one starved and got sick and died.

In an urban environment and in a modern economy, where families are mobile and go where their work takes them, elderly retirees from the workforce must have a steady income to pay the rent on their apartment, buy food from the market, and to pay for other activities. Those other activities are typically more extensive than in a peasant village, in part because more activities in an 
urban environment must be paid for with cash and people in urban centres are also used to a higher standard of living than those in rural villages. For people with sufficient funds, a variety of institutions can be created to meet their needs starting with independent housing but moving on to assisted living facilities and then to nursing homes, hospitals, and hospices toward the end of life. China is creating these kinds of institutions and it is being done commercially for those who can afford it.

The problem is that most urban residents in China, let alone the migrants from the countryside, do not have the retirement incomes that can support institutions of this sort. Many have meagre pensions, or none at all, because the company they depended on did not provide those benefits or it became bankrupt and could no longer honour commitments that it had made in more prosperous times. Thus, China faces the challenge of ensuring that its urban population has an adequate source of income in retirement and a wide range of institutions to support their needs as they age, and a health insurance system capable of paying for it. And all of this has to be created in the next one or two decades, when China will still be a far from rich nation. The one saving grace is that family ties in China remain strong and adult sons and daughters will take responsibility for their parents when they can, but, as countries such as Korea (or the United States before social security and medicare) demonstrate, in the absence of a strong safety net for the elderly, a large number will live out the remaining years of their life in poverty.

\section{Institutions Promoting Growth in Productivity}

The institutional changes that get the most attention from policy makers and the educated public in China are those connected with sustaining a high GDP growth rate. China's potential GDP growth rate will decline from the nine to ten per cent rates of the past three decades, even if China does everything right in the economic sphere. This decline appears to be underway now, but will almost certainly be underway within the coming decade. A major stimulus for infrastructure and housing going forward, similar to what occurred in 20092011, may keep the GDP growth rate up for a few years longer, but this kind of spending at levels similar to the recent past is already facing diminishing returns. Maintaining a high growth rate of, say, six to seven per cent a year over the next one or two decades will require steady and substantial increases in total factor productivity. ${ }^{5}$ High rates of growth of total factor productivity over the first two decades of the reform period were sustained by the steady

5 For a systematic analysis demonstrating the relationship between a continued high growth rate and total factor productivity, see Perkins \& Rawski 2008: 829-86. 
dismantling of the many barriers to efficiency and growth that had been thrown up by the Soviet-type economic system. Going forward, however, productivity growth will depend on the creation of ever more efficient, new and improved economic institutions, not the dismantling of old ones. Creating new and improved institutions is inevitably more complex and more difficult than simply getting rid of institutions that do not work.

The key economic institutions that are needed to sustain a high GDP growth rate are thus those that raise the productivity of both capital and labour. Sustained increases in the efficiency of capital are mainly dependent on steady improvements in the financial system, further reforms of state-owned enterprises in general and those with state monopolies in particular, and in the strategy of development pursued. There is a large literature on how to improve the financial system, and another chapter in this volume is devoted to the subject. It is noted here that China has already moved a substantial distance from a financial system made up almost exclusively of large, state-owned commercial banks that lent mainly to state-owned enterprises. There are many more banks, there are other important financial institutions, ranging from insurance companies to the two stock exchanges and beyond, and privately owned companies and individual citizens have an important degree of access to bank loans. There is still too much politics in lending decisions, and many of those promoting the most innovative enterprises have little or inadequate access to the capital markets. Thus, there are still major improvements possible and, if pursued vigorously, these improvements should substantially raise the efficiency of capital.

Reforming the state-owned enterprises is likely to be a more difficult challenge, in large part because the political power of these enterprises is formidable. It took considerable political courage to implement the major reforms of these enterprises that occurred in the late 1990s. Monopolies produce large profits that benefit powerful people, but they also reduce the incentive to promote efficiency in these critical sectors. The slowing of the massive infrastructure and housing investments will also create a situation where industries, such as steel, will face years of financial difficulties because of earlier decisions to build capacity beyond any plausible future domestic demand. The large state construction companies that have built much of this infrastructure will also have to be cut back. The alternative, such as that followed by Japan, of continuing large state construction projects designed to keep these companies busy will lead to results in China not dissimilar from what has contributed to Japan's anaemic economic growth rate. China's infrastructure investment of the past decade made a major contribution to economic growth and the efficient use of capital, but the number of projects of this sort that will contribute to raising growth and the efficient use of capital is declining. As China moves into an economy that is increasingly dominated by the service sector, the temptation 
to support numerous inefficient service providers at the expense of new, more efficient, service providers, a pattern pursued for years by both Japan and South Korea, also needs to be resisted.

Finally the efficient use of capital depends on getting the right balance between reliance on market forces and the need for some regulatory interventions to correct for important market failures. This chapter began with a discussion of the major issues connected with this challenge, and they are also discussed in the chapters in this volume on the environment and reforms in the financial system.

Improving the efficiency of labour is equally as important as raising the productivity of capital. At the low-skilled end of the labour force, and to a degree for the entire labour force, the need is for healthy and increasingly welleducated workers. There is also a need to remove the remaining barriers to the movement of that labour to its most productive uses. Those issues in essence were the subject of the second major part of this chapter. At the higher-skilled end of the labour force, the main issues have to do with steadily raising the quality of education at the university level in general, and at the postgraduate level in particular. Steady advances in the quality of research produced, whether in universities, companies, or research institutes, is critical for continued growth in the economy. China's progress in this latter area is considerable, but, as per capita incomes rise, sustained economic growth depends increasingly on innovation through research and development, that moves from small improvements in products and production processes to new products and services.

\section{Conclusion}

The challenge facing China over the next one or two decades, and the essence of the new model of growth that is required, therefore, is to create the institutions of a truly modern economy and society. Creating new institutions and fundamentally restructuring old ones is inherently more difficult than the dismantling of inappropriate institutions. It is also more time consuming, and thus contributes with other factors to the slowing of GDP growth that is inevitable as per capita incomes rise and the economy and society become more complex. In most of the areas described in this chapter, where institutional reform is required, China has made major progress. This chapter, however, has focused mainly on economic reforms, and economic reforms usually require accompanying political reforms; the political reforms needed to sustain China's transformation into a modern, high-income society are likely to be an even greater challenge than those in the economic area. 


\section{References}

Eichengreen, Barrt, Perkins, Dwight H. \& Shin, Kwanho, 2012, From Miracle to Maturity: The Growth of the Korean Economy, Harvard University Press, Cambridge.

National Bureau of Statistics of China (NBS), 2011, China Statistical Yearbook 2011, Beijing.

— , 2012, Zhongguo tongji zhaiyao 2012, Statistics Press, Beijing.

Perkins Dwight H. \& Rawski, Thomas G., 2008, 'Forecasting China's Growth to 2025', in Loren Brandt \& Thomas G. Rawski (eds), China's Great Economic Transformation, Cambridge University Press.

Perkins, Dwight H., 2012, 'China's Investment and GDP Growth Boom: When Will it End', in Masahiko Aoki \& Jinglian Wu (eds) The Chinese Economy: A New Transition, International Economic Association, Palgrave MacMillan.

United Nations, 2011, World Population Prospects, The 2010 Revision, online at http://esa.un.org/wpp/Excel-Data/population.htm. 



\section{The New Normal of Chinese Development}

Yiping Huang, Cai Fang, Peng Xu and Gou Qin

\section{China's New Transition}

China's economic performance during the reform period is sometimes described as a miracle (Lin et al. 1995). Its GDP per capita increased from US $\$ 220$ in 1980 to US\$6,000 in 2012. Not only is it now the world's second largest economy, but it also contributes at least one-third of global economic growth in recent years. China is already a major player in global markets for luxury goods, labour-intensive manufacturing exports, commodities and foreign exchange. Many economists are optimistic that China can continue its rapid economic growth, albeit at a somewhat slower pace, in the coming decades (Perkins and Rawski 2008; Lin 2011).

Structural risks, however, also grow over time, dimming China's economic outlook. Former premier Wen Jiabao once described the growth model as 'uncoordinated, imbalanced, inefficient and unsustainable' (see, for example, Wen 2006). The structural problems include the over-dependence of economic growth on external demand, continuous decline of the consumption share of GDP, worsening income distribution and devastating pollution. The investment rate rose steadily from around 25 per cent at the beginning of economic reform, to close to 50 per cent after the global financial crisis.

One consensus view that is shared by most economists is that this growth model needs to change in order for China's rapid economic growth to continue (Yu 2009; Huang 2010). Shortly after taking office in 2003, Wen vowed to take policy steps to improve growth quality; but general assessment is that those efforts achieved little in changing the growth model. In fact, many economists believe that the imbalance problems have become worse during the past decade (Lardy 2012). Some analysts argue that correction of such structural risks necessarily requires substantially slower growth, if not collapse, of the Chinese economy (Pettis 2013):

China will be the last major economy to emerge from the global crisis. ... I think it is pretty clear that over the next few years China will be forced to address and reverse the high saving rate, ... This may take a decade or more. ... If the transition is not mismanaged, average Chinese GDP growth rates will drop to $3 \%$ for the 2010-20 decade. 
This chapter argues that important changes to the Chinese growth model are already underway. Evidence shows that the Chinese economy is transitioning toward the 'new normal', involving slower but more sustainable economic growth, although this process is still at an early stage (Huang 2012). Growth potential probably lowered from ten per cent during the first decade of the twenty-first century, to six-eight per cent during the second decade. In the meantime, current account surplus narrowed significantly; the consumption share of GDP started to rebound; and even income distribution began to improve steadily. ${ }^{1}$

Second, we suggest that the primary drivers of the transition of the growth model are changes in factor markets, especially labour market changes. China's economic reform approach is sometimes described as 'asymmetric liberalisation', which freed up the product markets but continued with distortions in the factor markets (Huang 2010). Such cost distortions included such examples as subsidies to the corporates, but taxes on households, which contributes to the imbalance, and inequality and inefficiency problems, as well as strong economic growth (Huang and Tao 2010; Huang and Wang 2010). Emerging labour shortages and associated rapid wage increases in recent years are largely responsible for the current transition to the 'new normal', with slower growth but more balanced structure.

And, third, we make some policy recommendations for the Chinese economy to complete transformation of the growth model and to avoid the 'middleincome trap'. The next-step reforms should focus on redefining the relationship between the government and the market. The first is to complete the transition to a market economy by liberalising the factor markets. The second is to establish macroeconomic policy frameworks that are compatible with emerging market economies. And the third is to change the government's role from directly supporting production and investment to facilitating innovation and upgrading.

\section{Slowing of GDP Growth}

The Chinese economy has shown significant transformation in recent years, including the steady downward shift of trend growth and rebalancing of economic structure. Some structural changes, such as narrowing of the current account surplus, are well documented in official statistics. Some improvements, such as rising share of consumption in GDP, are not captured by the official data. Yet some other adjustments, such as improvement in income distribution,

1 'Michael Pettis makes 12 Fearless Predictions about China', 2012, Business Insider, 16 April, http://www. businessinsider.com/michael-pettis-makes-12-fearless-predictions-about-china-2012-4 
are confirmed by official estimation but strongly rejected by many economists. We think that the structural improvements are real and driven primarily by changes in factor markets.

GDP growth started to decelerate in 2011, partly due to the tightening of policies by the authorities. Toward the end of the first quarter in 2012, however, it became clear that growth might soon fall below eight per cent. From March that year, the government undertook a number of steps to stabilise economic growth, including support to on-going infrastructure projects in areas of water, power and transportation. Despite this policy effort, GDP growth decelerated continuously from 8.1 per cent in the first quarter to 7.4 per cent in the third quarter.

In retrospect, two special factors probably contributed to this continuous slowdown. One, export growth fell from close to eight per cent during the first half of the year to around two per cent during July-August period. And, two, housing purchase restriction (HPR), which was introduced in April 2011, led to slowing of residential property investment growth to below ten per cent during the third quarter of 2012, from above 30 per cent a year ago. Growth deceleration caused renewed fears among international investors for a hard landing of Chinese growth. Many financial market participants repeatedly called for aggressive policy actions to support growth.

The policymakers, however, stayed relatively calm and appeared to be willing to tolerate somewhat slower growth for three reasons (Huang 2012). First, many government officials became reluctant to adopt aggressive measures supporting growth after implementation of the four trillion yuan stimulus package during the global financial crisis. The package was beginning to successfully turn around economic growth in 2009. Many economists, however, argued that it increased fiscal risks, created nonperforming loans, contributed to overcapacity in some infrastructure areas and caused inflation and asset bubbles. When growth slowed again from late 2011 , the policymakers were cautious not to overstimulate the economy.

Second, economic studies estimate China's current growth potential at sixeight per cent. The World Bank's estimates were 8.6 per cent in 2011-2015 and seven per cent in 2016-2020 (WB \& DRC 2012). Cai Fang and Lu Yang (2012) estimate China's growth potential at 7.2 per cent during 2010-2015 and six per cent during 2016-2020 (Figure 3.1). In a recent multi-country review of growth performance, Barry Eichengreen, Donghyun Park and Kwanho Shin (2011) project China to grow by 6.1 to seven per cent in the 2011-2020 decade and by five to 6.2 per cent in the period 2021-2030. Similarly, a joint 
report by the Asian Development Bank and Peking University estimates the growth potential at eight per cent in 2011-2020 and six per cent in 2021-2030 (Zhuang, Vandenberg and Huang 2012).

Figure 3.1 Estimates of growth potentials (\%)

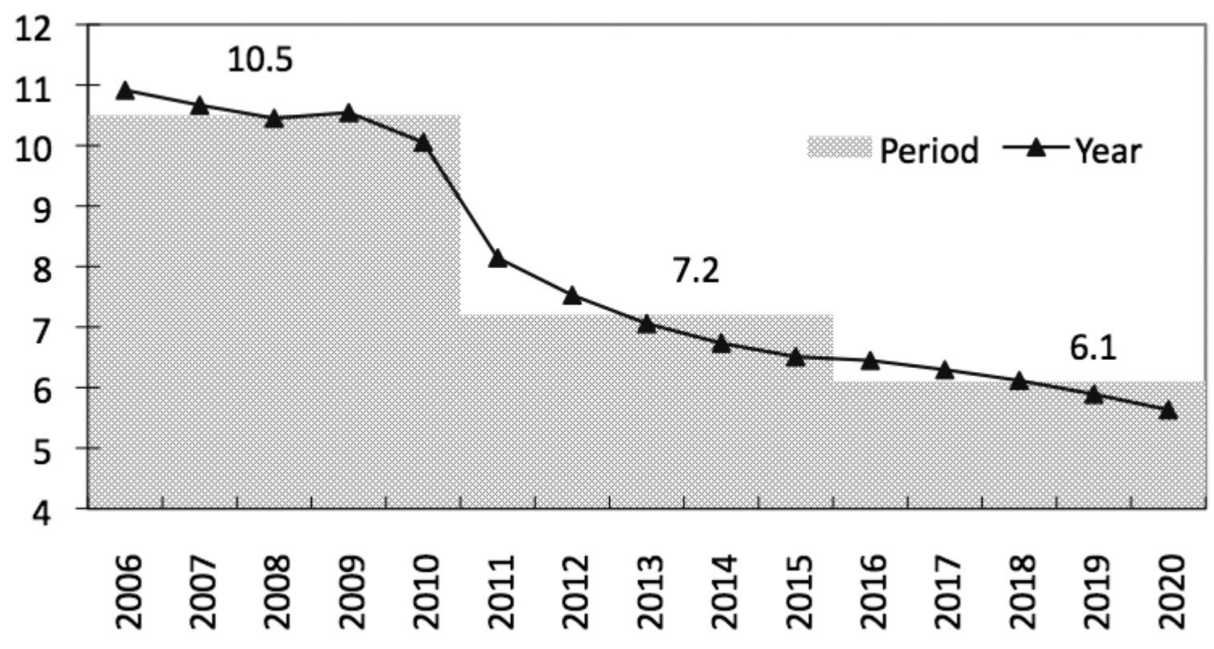

Source: Cai and Lu (2012).

And, third, economic indicators such as employment and inflation also suggested no need for aggressive policy easing, despite deceleration of GDP growth to levels below eight per cent. CPI inflation first eased, from 4.5 per cent in January, down to the trough of 1.7 per cent in October, but then picked up slowly to above two per cent in the following months. The labour market was also surprisingly resilient. In 2012, the economy created 12.7 million new jobs, despite growth slowdown. The number of migrant workers reached 163 million, up 4.7 million from a year ago and the total number of farmers employed in nonfarm jobs increased to 263 million, with an increase of 9.8 million within the year. In 25 provinces, minimum wages were adjusted, lifting the national average by 20.2 per cent; and migrant workers' monthly wages averaged 2290 yuan or US\$363, up 11.8 per cent from a year ago.

Policymakers, therefore, are no longer keen in supporting above eight per cent growth. This is mainly because growth potential is already much lower, due to the higher level of economic development and tightening condition of the labour market. For instance, in 2012, the working-age population declined by 3.5 million. The purpose of the cautious macroeconomic policy can be viewed as a strategy to allow growth to settle around its new potential. Of course, if unemployment rate rises unexpectedly, it is likely that the government will once again engage in more aggressive policies to support economic growth. 


\section{Rebalancing of the Economy}

The so-called 'new normal', however, is more than growth slowdown. Recent years have also indicated that the economy also shows clear signs of rebalancing. For instance, the current account surplus narrowed from 10.8 per cent of GDP in 2007, to 2.8 per cent in 2011 and 2.6 per cent in 2012 (Figure 3.2). Mainly because of this, the People's Bank of China (PBoC) Deputy Governor Yi Gang argued that the yuan exchange rate was near equilibrium, while US President Barak Obama's former top economic advisor, Lawrence Summers, noted in January 2013 that the yuan was not as undervalued as it was five years earlier. In recent years, two-way movement of the exchange rate and two-directional capital flows started to emerge in China.

Figure 3.2 Current account surplus as a share of GDP, 2006-2012 (\%)

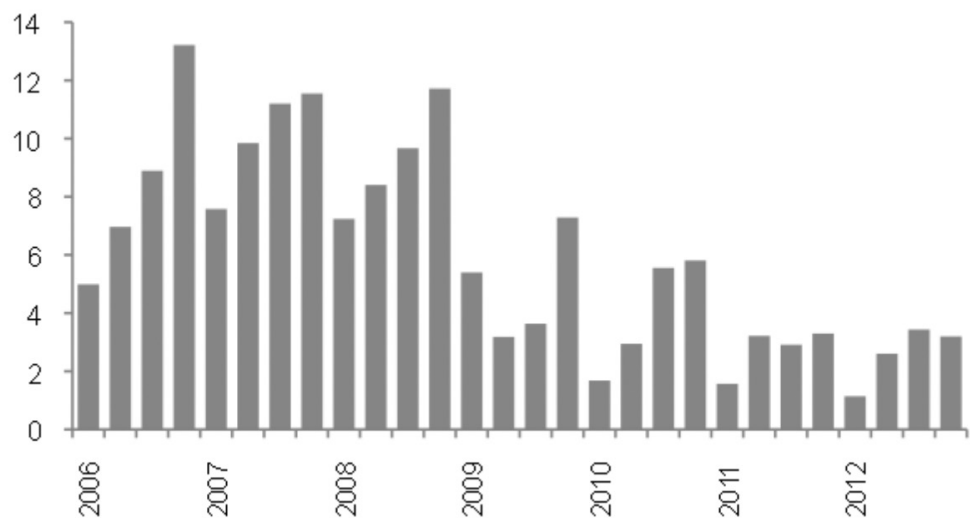

Source: National Bureau of Statistics.

Another rebalancing in recent years relates to regional disparity, with the rural-urban income gap narrowing notably (Figure 3.3). This is the result of a combination of stronger policy support to agriculture, more rapid increases in agricultural prices and steady improvement in rural productivity. In addition, China's reform success was, until recently, a story of the coastal regions. Inland economies, however, are now growing faster than the coastal economies as a result of the government's 'go west' policy, the migration of manufacturing industries, and rich resource endowments in western China (Figure 3.4). 
Figure 3.3 Urban-rural income ratio narrowed, 1987-2012 (\%)

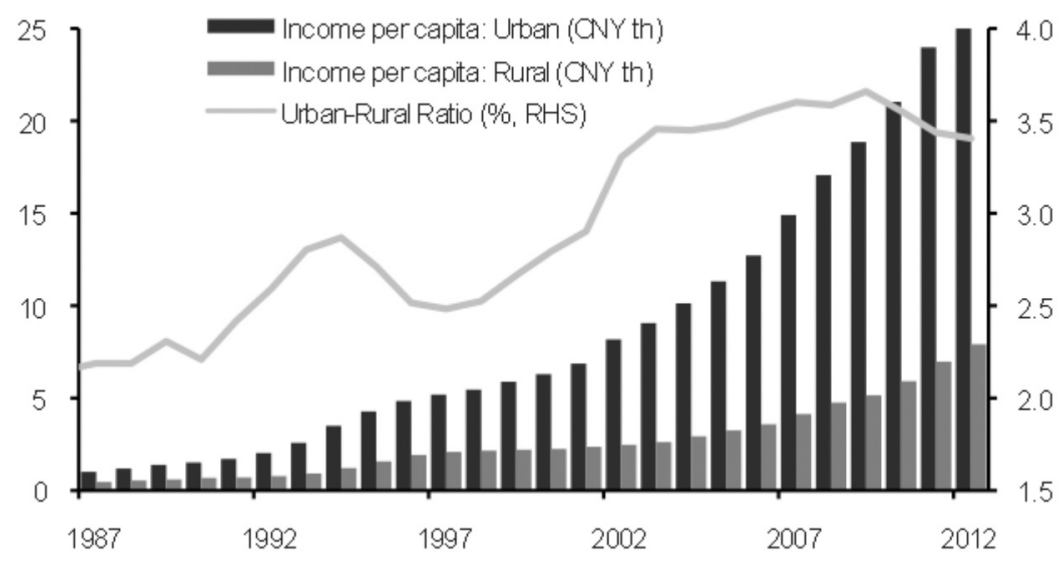

Source: CEIC Data Company.

Figure 3.4 Growth in eastern, central and western China, 2012 (\%)

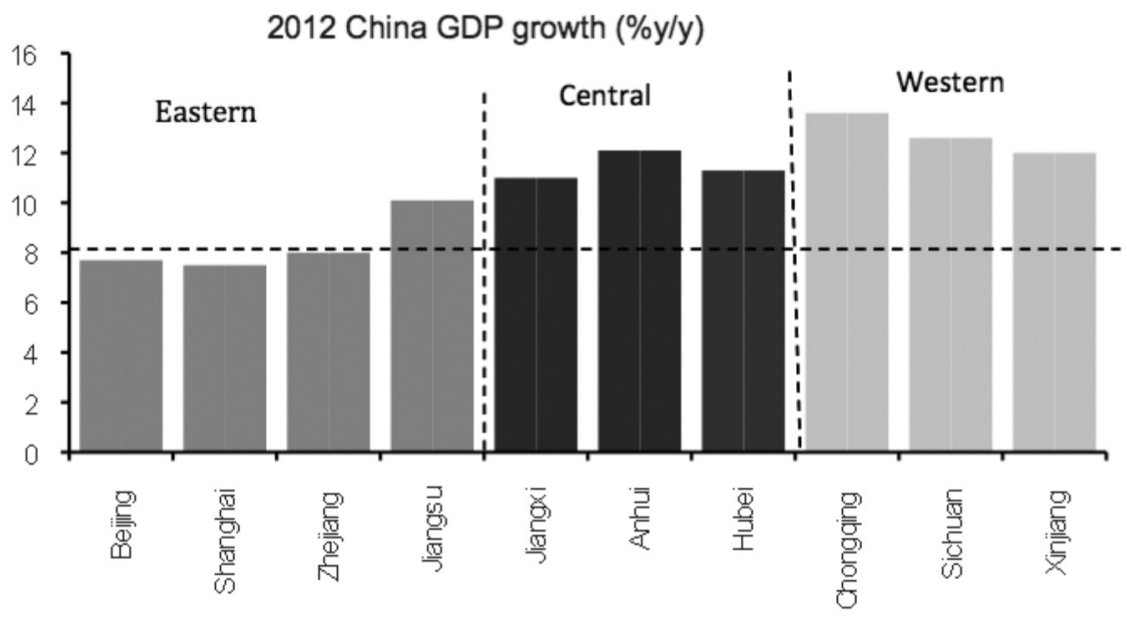

Source: CEIC Data Company.

In mid-January 2013, the Chinese National Bureau of Statistics (NBS) reported estimates of Gini coefficients for 2003-2012, which show a steady deterioration of income distribution from 0.479 in 2003 to 0.491 in 2008 and steady improvement after that, to 0.474 in 2012 (Figure 3.5). ${ }^{2}$ This, if confirmed, could mark another important turning point in China's economic development, although many Chinese economists remain sceptical about the results.

2 The Gini coefficient is a measure of income inequality - the higher the estimate, the more unequal the income distribution. 
For instance, a recent study by Southwest University of Economics and Finance reported a Gini coefficient of 0.61 in 2010. One criticism of the official NBS finding was that is did not consider income equality in household wealth, such as property. Another was under-reporting of income at the high end.

Figure 3.5 Gini coefficients estimated by the National Bureau of Statistics, 2003-2012

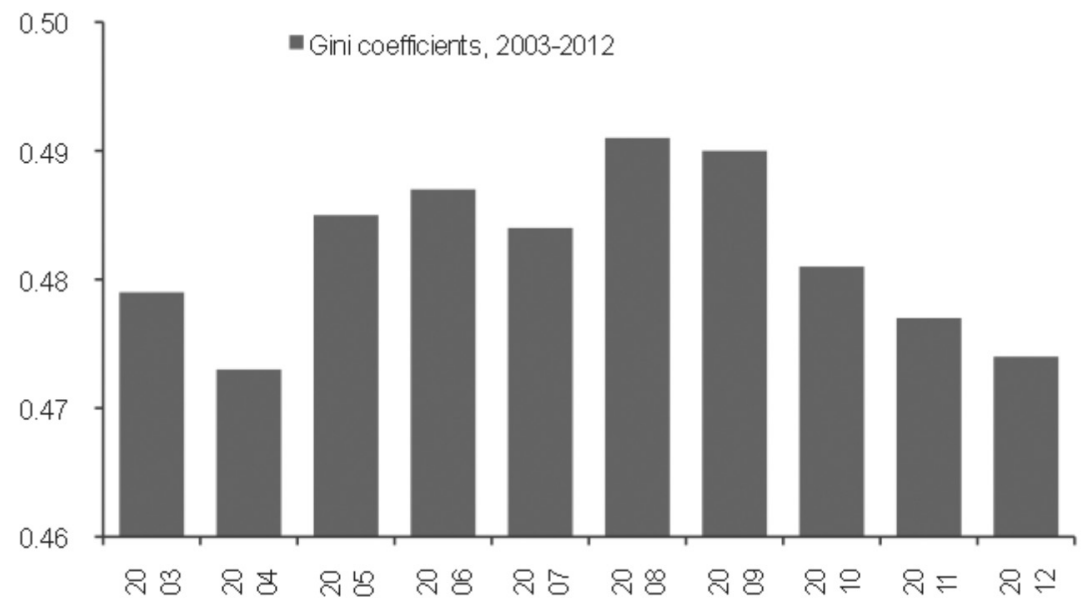

Source: National Bureau of Statistics.

Official data also suggest that the contribution of consumption to GDP growth increased from about one-third in 2007, to 52 per cent in 2012 (Figure 3.6). Two Chinese economists, Tian Zhu and Jun Zhang of Shanghai, have gone further, arguing that China's consumption share is grossly underestimated as a result of underreported residential spending, consumption covered by institutional spending and technical issues in the household survey method. They note that the consumption share estimated by the Penn World Table was 60.9 per cent in 2010, compared with the official figure of 47.4 per cent, and 58.9 per cent in the Penn World Table in 1990. 
Figure 3.6 Contribution to GDP growth, 1995-2012 (\%)

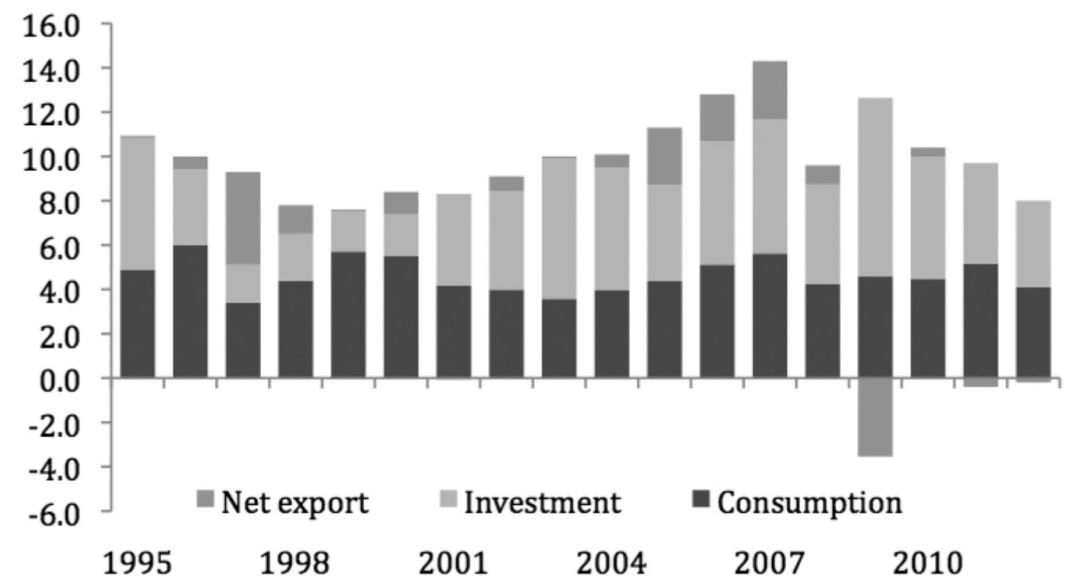

Source: CEIC Data Company.

Recent research finds that the consumption share of GDP began to rise after 2008, although this is not yet fully reflected in official statistics (Huang et al. 2012 and 2013). Huang and his collaborators find that it is difficult to reconcile accelerating retail sales and decelerating consumption in official statistics after 2008. By calculating a new growth rate for consumption, which is a weighted average of consumption-related, retail sales growth and service sales growth, they reveal that the consumption share of GDP fell during much of the past decade, as suggested by official data, but rebounded from 48 per cent in 2008 to 52 per cent in 2010, compared with the official estimate of 47 per cent in that year (Figure 3.7).

Figure 3.7 Total consumption share of GDP (\%)

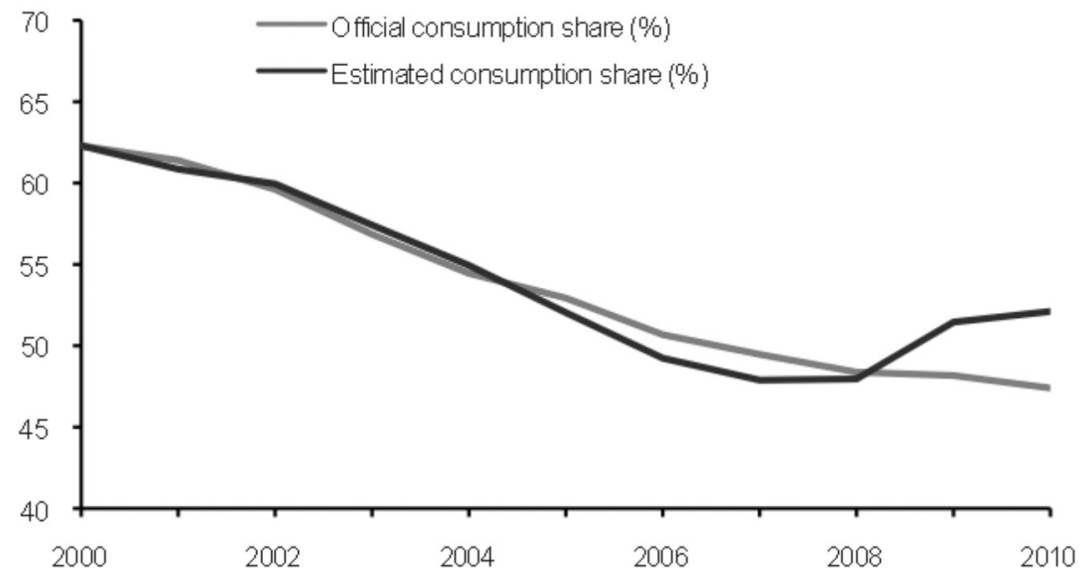


This analysis received sceptical reviews after its initial dissemination. ${ }^{3}$ Some commentators find it difficult to accept our finding, given their strong impression of increasing structural problems following the four trillion yuan stimulus package that was adopted in late 2008. Others argue that structural improvement is impossible, since the government has not undertaken more decisive reforms. The fact that Chinese consumption is probably underestimated, however, is a belief that is shared by an increasing number of Chinese economists. A 2012 study ( $\mathrm{Li}$ and $\mathrm{Xu}$ 2012), for instance, concludes that the household consumption share rebounded from 36 per cent in 2007 to 38.5 per cent in 2011 (Figure 3.8).

Figure 3.8 Household consumption share of GDP (\%)

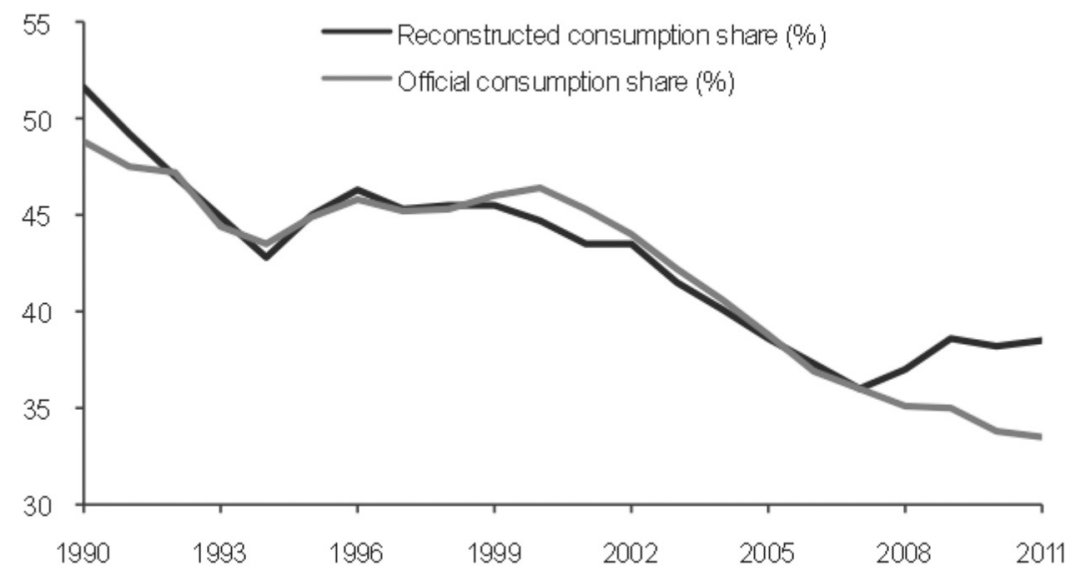

Source: Li and Xu (2012)

\section{Driving Forces Behind the New Normal}

Slower but more sustainable economic growth, and more balanced economic structure, are key features of what we call the 'new normal' of Chinese economic development. Although the government made serious efforts during the past decade, the key factors driving the transition of the Chinese economy are changes in the factor markets, especially in the labour markets. An emerging labour

3 Some articles criticising findings of this study include: 'Optimists' View on China's Economy Suffers from Fatal Flaws' (South China Morning Post, 30 January 2012), 'China is not Rebalancing a) Yet, or b) Enough' (Financial Times, http://ft.com/alphaville), 'China's Rebalancing will not be Automatic' (EastAsiaForum.com). Meanwhile, there were also articles with more sympathetic views, including 'The Incredible Shrinking Surplus: At least One of China's Economic Imbalance is Narrowing' (The Economist, 18 February 2012) and 'All Hail the Chinese Shopper' (Financial News, 27 February 2012 http://www. efinancialnews.com/story/2012-02-27/hail-the-chinese-shopper). 
shortage leads to a rapid increase in wages, which, in turn, slows economic growth, raises inflation pressure, improves income distribution, rebalances economic structure and accelerates industry upgrading (Huang et al. 2011).

Economists have developed diverse analytical frameworks to explain changes in the Chinese economy during the past decades. Justin Lin, Cai Fang and Li Zhou argue that the key to this success was the transition from the heavy industry-oriented to comparative advantage-oriented development strategy (Lin et al. 1995). Barry Naughton introduces the term 'growing out of the plan' to describe China's incremental growth of the market-oriented, private sector, while maintaining support for the old, state-owned enterprises (Naughton 1995). Jeffery Sachs and Wing Thye Woo, however, point out that Chinese economic success can be explained mainly by its convergence with the typical market system of east Asia (Sachs and Woo 2000).

Despite the differences in their perspectives, these economists all agree that the key aspect to the reform is the transition from a centrally planned system to a market system. This is certainly correct, but may only be part of the story. In a series of recent research papers, we argue that the fundamental reason behind the combination of strong economic growth and increasing structural risks is China's asymmetric market liberalisation approach (Huang 2010; Huang and Tao 2010; Huang and Wang 2010). Free markets for products ensure that production decisions are based on demand and supply conditions in the economy, and resources are allocated efficiently. Distortions in factor markets are a way of providing incentives for economic entities and, sometimes, overcoming market failures.

Factor market distortions include the household registration system that limits labour mobility between rural and urban areas; direct controls of bank deposit and lending rates; setting of energy, especially oil, prices by state agencies; and, offering discounted land-use fees to investors. In most cases, these distortions depress input costs. Labour is a special case, however, as it is unclear if labour market segmentation lowers or increases labour cost. But labour cost was low for a long time because of abundant agricultural labour or unlimited labour supply, in a typical Lewis dual-economy.

Low input costs, including low labour costs, are like subsidies to companies, but taxes on households. They boost production profits, increase returns to investment and improve the international competitiveness of Chinese exports. Low input costs also serve as a mechanism for the redistribution of income from households to the companies. Over the years, corporate profits grew much faster than household income, as household income was largely capped by stagnant wage rate. 
Over time, low input costs also contribute to structural problems. Firstly, extraordinary incentives lead to a continuous rise in the shares of exports and investment in GDP. Secondly, a rise of the share of corporate profit in the national income increases the national saving rate, as corporate saving rate is generally higher than household saving rate. Thirdly, income inequality among households deteriorates, as low-income households rely more on wage income while high-income households rely more on corporate profits and investment returns. Fourthly, the consumption share of GDP declines over time because household income grows more slowly than GDP. And, fifthly, the unusually low costs of energy, capital and other resources has also resulted in wasteful behaviour on the part of producers.

The recent transition to the 'new normal' of Chinese economic development is primarily attributable to changes in factor markets. A recent study argues that the distorted factor costs have already started to change (Huang et al. 2011). The labour market shows clear signs of supply shortage, which is evidenced by accelerating wage increases in recent years (Figure 3.9). The development of shadow banking businesses also opens the door for de facto interest rate liberalisation. The Chinese Government has also been trying to reform the price of energy, water and other resources.

The so-called Lewis turning point (LTP) - the transition of the labour market from surplus to shortage - has important implications for China's macroeconomy (Huang and Cai 2010). Rapid wage growth, especially that at the lower end of the market, cuts into profit margin. Therefore, it reverses past redistribution of income from households to corporates. As these implicit subsidies for Chinese companies are reduced, export and investment activities soften and, therefore, the economy rebalances. Applying a computable general equilibrium model of the world economy, Huang and Jiang (2010) analyse detailed economy-wide consequences of the LTP in China.

Figure 3.9 Rapid rise of migrant workers' wages

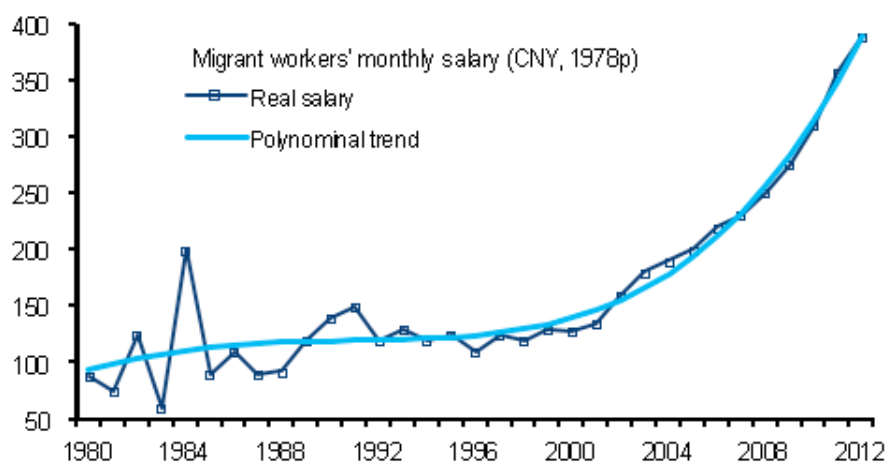


In a sense, it is relatively easy to understand why growth potential has declined in recent years. It is a universal phenomenon that growth slows as an economy develops; this is because the reduced distance from the technological frontier of the developed world means the economy can benefit less from backwardness (Lin 2012). But the growth slowdown is accelerated in China by changing demographics, including labour shortages and a diminishing working-age population. For the same reason, rapidly increasing wages also create inflation pressure, as rising costs can only be absorbed by higher output price, narrower profit margin or faster productivity growth, or a combination of the above.

So, what has contributed to the rising consumption share of GDP in recent years? The answer is household income. When an 'unlimited labour supply' exists, rapid industrialisation is accompanied by a stable wage rate and, therefore, a declining share of wage income in GDP. This is reversed when a labour shortage emerges: wages rise rapidly and the share of wage income in GDP starts to grow. In fact, labour income has also increased from 41 per cent in 2007 to 47.1 per cent in 2009 (Figure 3.10), which, in turn, has boosted consumption relative to GDP. This was also what happened in Korea and Taiwan in the mid 1980s, when their consumption shares started to recover following their respective LTP (Figure 3.11).

Figure 3.10 Labour income and consumption share of GDP (\%)

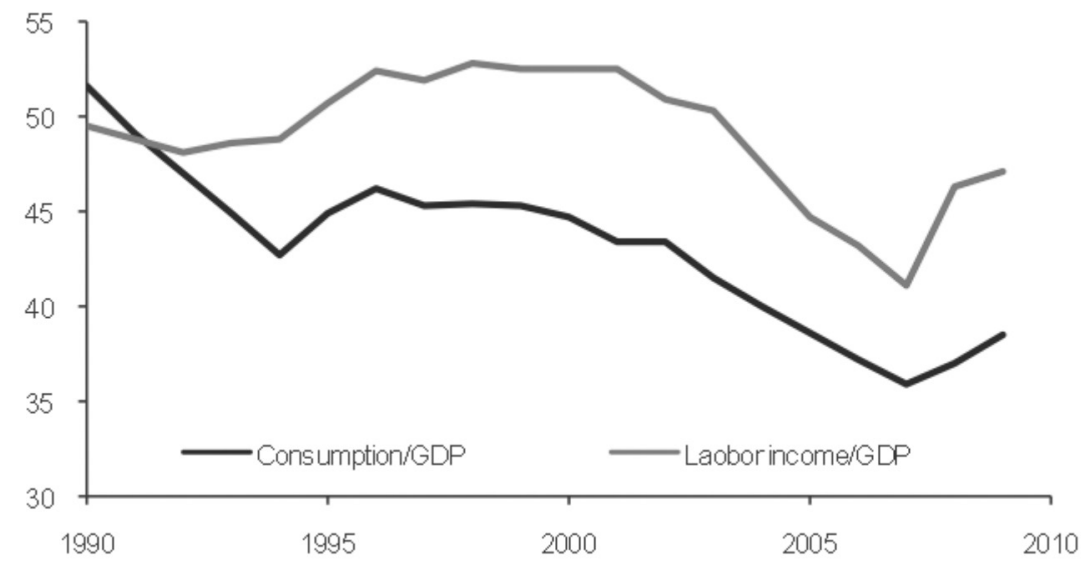

Source: Li and Xu (2012). 
Figure 3.11 Private consumption share of GDP in Korea and Taiwan (\%)

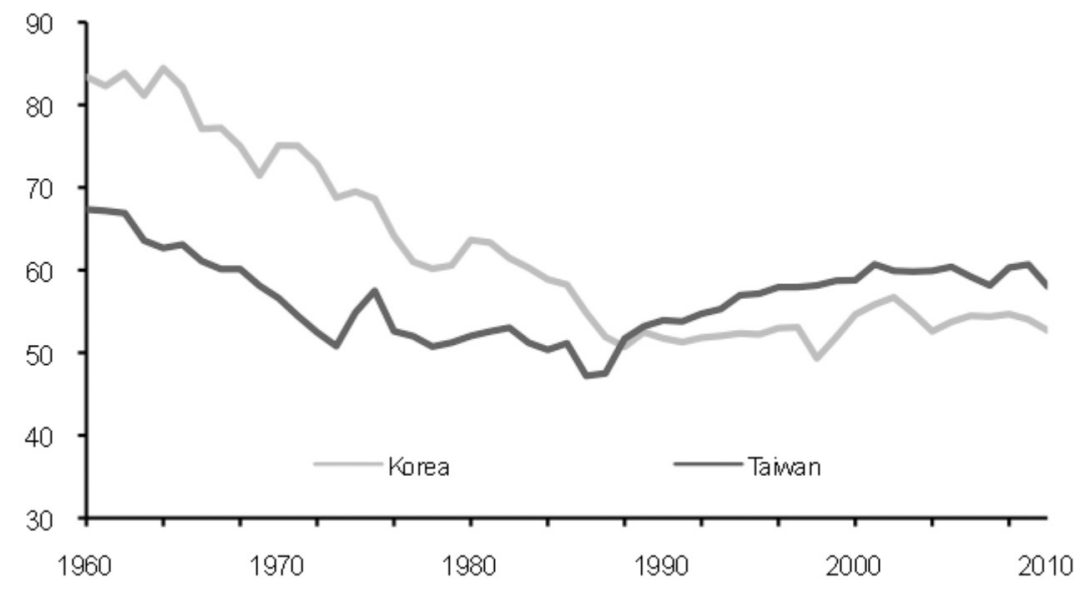

Source: CEIC Data Company.

Rapid wage growth was probably also behind the recent improvements in income distribution highlighted by the NBS, since low-income households rely more on wage income and high-income households rely on investment returns or corporate profits. If the past trend was households subsidising corporations, then the new trend is redistribution of income from corporations to households, as rising labour costs increase wage income but squeeze corporate profits. This is probably why, in rapidly developing economies, the so-called Kuznetz turning point (when income distribution shifts from deteriorating to improving) often follows the Lewis turning point (Huang and Cai 2010).

\section{What's Next?}

Clearly, rebalancing is still at an early stage. For instance, the consumption share of GDP, at 52 per cent in 2010, on our estimates, was significantly below the 70-90 per cent range in most developing and developed economies. This gap may be narrowed, in part, through continuous wage adjustment. Expected liberalisation of interest rates, which will likely lead to high deposit rates, at least, should further facilitate rebalancing. Further changes may also be required to transform the development pattern completely. This could involve measures to improve income equality beyond the primary round of income distribution, development of social welfare systems such as pension, medical insurance and education, and financial and capital account liberalisation.

The first wave of cost shocks - increases in wages - has caused significant economic restructuring. The labour-intensive manufacturing industry in the coastal region is either moving to the western provinces, or migrating to other 
low-cost countries or upgrading along the value chain. Given rapid increases in production costs in inland provinces, it is likely that China will lose its labourintensive industries, especially those export-oriented sectors, faster than many anticipate.

The second wave of cost shocks - increases in costs of capital and energy - may bring about more profound changes to the Chinese economy. Again, normalisation of these costs could reveal massively misallocated resources in the Chinese economy, especially in heavy and highly leveraged industries. Most of these companies are state-owned and were built on a distorted incentive structure. Once costs of capital and energy rise, some of these seemingly profitable companies may become financially unviable. And this would inevitably lead to major industry consolidation, which might bring the first recession to the Chinese economy since the beginning of its economic reform.

This will not, however, necessarily be the beginning of a period of growth stagnation, as some suggest (see, for instance, Pettis 2013). Taking financial repression as an example, it lowers cost of capital in the formal sector, especially for the state-owned enterprises (SOEs). But it also raises the cost of capital outside of the formal sector. Therefore, normalisation of the cost of capital could result in a temporary shrinkage of economic activities in the state sector. At the same time, it might also boost economic activities of the non-state sectors by improving their access to credit and reducing the cost of capital. Importantly, the non-state sectors now account for almost 80 per cent of total industrial output.

Successful transition to the 'new normal' of economic development is only a first step in China's long march toward becoming a high-income country. A bigger challenge facing the Chinese economy now is the so-called 'middle-income trap', as its GDP per capita reaches high middle-income level and its labour cost rises rapidly. The 'middle-income trap' may be defined as the situation that arises when an economy loses competitiveness in low value-added industries, but fails to move up to high value-added industries (Zhuang, Vandenberg and Huang 2012). Chinese industries are already under significant pressure as the three important conditions that facilitate their extraordinary growth in the past - unlimited labour supply, low-cost advantage and rapid export expansion - all diminish steadily. According to the World Bank, only 13 out of 88 middle-income economies succeeded during the past half-century in making the jump to high-income economies (World Bank 2012).

Scepticism about China's ability to continue relatively rapid economic growth is based on several concerns. One main worry is its unsustainable growth model. If the imbalance, inefficiency and inequality problems are not reversed quickly, they could seriously dampen the outlook for the Chinese economy. Unfortunately, as some analysts argue, the policy efforts to improve 
growth quality have achieved little, at least according to the official statistics (Lardy 2012). Others believe that change of the growth model is possible, but it necessarily requires substantially slower growth (Pettis 2013).

Another concern relates to the lack of progress in political reform, alongside market-oriented economic reform. This pattern of reform has led to what Wu Jinglian calls 'state capitalism' ${ }^{4}$ To a large extent, this explains the growing problems of monopoly, corruption and disparity. The SOEs, for example, are a typical example of extractive institutions - they extract monopoly profits by controlling cheap inputs and prohibiting entry into their trade or commerce by others. More importantly, China might be locked into following this path, as it will be hard to reverse, except through extreme social turmoil. Without necessary political reforms to improve political and economic institutions, Chinese growth will sooner or later collapse (Acemoglu and Robinson 2012).

A third difficulty is the potential for Chinese industry to innovate and upgrade. So far, Chinese growth has been driven mainly by low-cost advantage, increasing input and productivity gain through resource reallocation, such as rural-urban migration. But growth based on resource mobilisation is, by definition, not sustainable (Krugman 1994). But can technological innovation replace resource mobilisation to become the main driver of economic growth in China? One obvious hurdle is the low education level of hundreds of millions migrant workers. If they lose low-skill manufacturing and construction jobs, they might not be able to work in high technology and high value-added sectors. Foreign companies also complain that the Chinese legal environment is not conducive to technological innovation because of the lack of proper protection of intellectual property rights in China.

These three concerns are real issues, but they should not be overstated. Rebalancing of the Chinese economy is already underway, although it is not fully appreciated by investors and economists. Completion of rebalancing economy is subject to both further liberalisation of factor markets and additional policy reforms to improve growth quality.

Political reform will be necessary to eradicate corruption and maintain political stability. But it is unlikely that China will adopt a Western-style democracy in the near future, and the current political regime has already exhausted its growth potential. Institutions are vital to enduring growth. But optimal institutions are different for economies at different stages of development. The post-World War II experience of imposing on developing countries the institutions that are best

4 Hu Shuli, 'Fast-track China is on the Wrong Path', 2011, interview with Wu Jinglian, Wall Street Journal, Asia Edition, July 28, http://online.wsj.com/article/SB10001424053111904800304576471393143 140106.html 
suited to developed economies, such as was implemented by the Washington Consensus, was largely unsuccessful. One important reason could be that technological innovation and technological catch-up require different types of institutions - with GDP per capita at US\$6,000, China still has huge potential to gain through technological catch-up.

Even in terms of innovation, China has been doing well. It saw science and technology takeoff much earlier than most other developing countries - it's share of R\&D expenditure of GDP reached one per cent, when its GDP per capita was only US\$3,000, while, on average, other developing countries reached the same level of R\&D expenditure when GDP per capita was US\$8,000. Globally, China is already a leader in terms of total R\&D spending, patent filing and $\mathrm{R} \& \mathrm{D}$ productivity (measured by the number of patent filing divided by $\mathrm{R} \& \mathrm{D}$ expenditure). Continuous technological innovation and industry upgrading are also observed in a large number of industries, including automobile, large machinery and information technology. Protection of intellectual property rights (IPR) is a key drag on progress, but China has a nationwide IPR court system, and the number of IPR cases is increasingly rapidly. According to international experiences, IPR protection will strengthen indigenous innovation so that it becomes a dominant phenomenon.

One major difficulty is to improve labour quality or human capital. As China moves towards becoming a high-income country, industrial upgrading will continuously shift employment from labour-intensive to capital-intensive to technology-intensive sectors. The Chinese experience suggests that shifting workers from labour-intensive to capital-intensive sectors in the secondary industries requires, on average, 1.3 years of additional education. Workers shifting further to technology-intensive sectors in the tertiary industry require 4.2 years' additional education, on average. Human capital accumulation, however, can take place only gradually. For instance, the average number of years of education for the population aged at 16 years and above increased from 6.24 years in 1990 to 7.56 years in 2000, a net increase of 1.32 years. It further increased to 8.9 years in 2010, another net increase of 1.34 years.

Currently, China has a total of 260 million migrant workers, most of whom only finished junior high school. As wages rise rapidly, whether or not these migrant workers will be able to find employment in higher value-added industries will be a critical test for China's 'middle-income trap' challenge. If not, China may end up in not only growth stagnation but also facing massive unemployment problems. Therefore, improving labour quality through education and training should be a policy priority in the coming decades. 


\section{Policy Implications}

Market-oriented economic reforms have been incomplete in China. This, particularly the widespread distortions to factor costs, has contributed to success in economic growth, but has created problems, such as structural risks. Recent changes in factor markets, including emerging labour shortages and rapid wage increases, already slow economic growth and rebalance economic structures, both of which are key features of the 'new normal' of economic development.

This rebalancing trend should not be mixed with some cyclical changes. For instance, while the overall trends are for the investment share of GDP to moderate while the consumption share of GDP rises, at the beginning of 2013, this pattern reversed. The government's policy to stabilise growth inevitably boosts growth, as infrastructure spending is the only swing factor in the near term. Nevertheless, the target is much lower. At the same time, consumption, especially high-end consumer spending, is negatively affected by the government's campaign to crack down on corruption.

These temporary disturbances should not reverse the overall rebalancing trends, unless the government again pushes for investment-led growth. While this is unlikely to happen, the risk is real. The new government is keen to accelerate the urbanisation process, which may lead to further investment. In the meantime, local governments are again planning on massive investment programs. Local investment programs, however, are mainly constrained by their funding capabilities. It is critical for Beijing to keep the brakes on local and central investment programs in order for the rebalancing process to continue.

But, in itself, this is not sufficient. Further policy reforms may be necessary to complete the transition toward the new normal and to avoid the "middle-income trap'. Former president $\mathrm{Hu}$ Jintao suggested that reforms in the next stage should be organised around the central theme of redefining the relationship between the government and the market ( $\mathrm{Hu}$ 2012). In our view, this could include important policies in the following three areas. First, if China had a nomarket economy during the pre-reform period and a half-market economy during the first three decades of the reform period, it is now time to complete the transition to a market economy by removing all the remaining distortions, especially those in factor markets.

Second, China needs to establish a macroeconomic policy framework compatible with an emerging market economy, including an accountable budget system and professional monetary policymaking mechanism. China's macroeconomic policy framework remains administrative in nature. For instance, 
many of the problems associated with the four trillion yuan stimulus package was not the central government's expansionary policy, but investment programs supported or implemented by the banks, the SOEs and the local governments.

And, third, the government's role should shift from directly supporting production and investment through resource mobilisation to facilitating innovation and upgrading via supporting physical and soft infrastructure development. These could include better support to the country's education and research system and improve IPR protection. A critical test in the forseeable future is to upgrade the skills of the large number of migrant workers, most of whom have less than seven years school. It is important to devise training programs so that these workers can move to new industries when their current employers are phased out by rapidly rising costs.

\section{References}

Acemoglu, Daron \& Robsin, James A., 2012, Why Nations fail: The Origins of Power, Prosperity and Poverty, Crown Publishers, New York.

Cai, Fang (ed.), 2007, Reports on China's Population and Labor, No. 8: The Lewisian Turning Point and Policy Challenges (in Chinese), Social Sciences Literature Press, Beijing.

Cai, Fang \& Lu, Yang, 2012, 'At What Rate can Chinese Economy Grow in the Next 10 Years?', (in Chinese) in Jiagui Chen et al. (eds), Chinese Economy Blue Cover Book 2012, Social Science Literature Press.

Cai, Fang \& Wang, Dewen, 2006, 'Employment Growth, Labor Scarcity and the Nature of China's Trade Expansion', in Ross Garnaut \& Ligang Song (eds), The Turning Point in China's Economic Development, Asia Pacific Press, Canberra.

Cai, Fang \& Wang, Meiyan, 2008, 'A Counterfactual Analysis on Unlimited Surplus Labor in Rural China', China \& World Economy, vol. 16, no. 1, pp. 51-65.

Eichengreen, Barry, Park, Donghyun \& Shin, Kwanho, 2011, 'When Fast Growing Economies Slow Down: International Evidence and Implications for China', NBER Working Paper 16919.

Lu, Feng, 2011, 'Employment Expansion and Wage Growth (2001-2010)', China Macroeconomic Research Center, Peking University, Beijing, 12 June. 
Garnaut, Ross \& Huang, Yiping, 2006, 'Continued Rapid Growth and the Turning Point in China's Economic Development', in Ross Garnaut \& Ligang Song (eds), The Turning Point in China's Economic Development, Asia Pacific Press, Canberra.

$\mathrm{Hu}$, Jintao, 2012, 'Firmly March on the Path of Socialism with Chinese Characteristics and Strive to Complete the Building of a Moderately Prosperous Society in all Respects', political report delivered at the 18th national party congress, 8 November 8 , Beijing.

Huang, Yiping, 2004, 'A Labor Shortage in China', Wall Street Journal, A7, 6-8 August.

_ 2010, 'Dissecting the China Puzzle: Asymmetric Liberalization and Cost Distortion', Asia Economic Policy Review, vol. 5, no. 2, pp. 281-95.

, 2012, 'The 'New Normal' of Chinese Growth', East Asia Forum, 14 October, http://www.eastasiaforum.org/2012/10/14/the-new-normal-ofchinese-growth/

Huang, Yiping \& Cai, Fang (eds), 2010, 'Debating China's Lewis Turning Point', China Economic Journal, vol. 3, no. 2.

Huang, Yiping \& Kunyu, Tao, 2010, 'Factor Market Distortion and the Current Account Surplus in China', Asian Economic Papers, vol. 9, no. 3, pp. 1-36.

Huang, Yiping \& Jiang, Tingsong, 2010, 'What Does the Lewis Turning Point Mean for China? A Computable General Equilibrium Analysis', China Economic Journal, vol. 3, no. 2, pp. 191-208.

Huang, Yiping \& Wang, Bijun, 2010, 'Cost Distortions and Structural Imbalances in China', China and World Economy, vol. 18, no. 4, pp. 1-17.

Huang, Yiping, Chang, Jian \& Yang, Lingxiu, 2011, China: Beyond the miracleChina's Next Transition, September, Barclays, Hong Kong.

— 2012, China: Beyond the Miracle - Great Wave of Consumption Upgrading, January, Barclays, Hong Kong.

- 2013, 'Recovery of Consumption and Rebalance of the Economy in China', Asian Economic Papers, vol. 12, no. 1, pp. 47-67.

Krugman, Paul, 1994, 'The Myth of Asia's Miracle', Foreign Affairs, November/ December, vol. 73, no. 6, pp. 62-78. 
Lardy, Nicholas R., 2012, Sustaining China's Economic Growth after the Global Financial Crisis, Peterson Institute of International Economics, Washington DC.

Li, David \& Xu, Sean, 2012, 'The Rebalancing of the Chinese Economy', CCERNBER conference on the Chinese economy, Peking University, 25-26 June, Beijing.

Lin, Justin, 2011, Demystifying the Chinese economy, Cambridge University Press.

Lin, Justin, 2012, The Quest for Prosperity: How Developing Economies Can Takeoff? Princeton University Press.

Lin, Justin, Cai, Fang \& Li, Zhou, 1995, The China Miracle: Development Strategy and Economic Reform, The Chinese University of Hong Kong Press.

Naughton, Barry, 1995, Growing Out of the Plan: Chinese Economic Reform, 1978-1993, Cambridge University Press.

Perkins, Dwight \& Rawski, Thomas G., 2008, 'Predicting the Chinese Economy by 2025', in Loren Brandt \& Thomas Rawski (eds), China's Great Economic Transformation, Cambridge University Press.

Pettis, Michael, 2013, Great Rebalancing: Trade, Conflict, and Perilous Road Ahead for the World Economy, Princeton University Press.

Sachs, Jeffrey D. \& Woo, Wing Thye, 2000, 'Understanding China's Economic Performance', Journal of Policy Reform, Vol. 4, No. 1, pp. 1-50.

Tian, Zhu \& Jun, Zhang, 2012, 'Is China's consumption rate too low?', Finance Times Chinese Website(http://www.ftchinese.com/story/001048246/?print=y).

Wen, Jiabao, 2006, Government Work Report, Delivered at the National People's Congress meeting, 5 March, Beijing.

World Bank \& Development Research Center of the State Council (WB \& DRC), 2012, China: 2030-Building a Modern, Harmonious, and Creative HighIncome Society, March, Washington D.C. \& Beijing.

Yu, Yongding, 2009, 'Chinese policy responses to the global financial crisis', Richard Snape Lecture, 25 November 2009, Productivity Commission, Melbourne, Australia.

Zhuang, Juzhong, 2013, Vandenberg, Paul \& Huang, Yiping, 'Growth Beyond Low-Cost Advantages: Can the People's Republic of China Avoid the MiddleIncome Trap?', October, Asian Development Bank \& Peking University, Manila \& Beijing. 


\section{The End of China's Demographic Dividend: The Perspective of Potential GDP Growth}

\section{Cai Fang and Lu Yang}

\section{Introduction}

The unprecedented economic growth in China over the past 30 years can be attributed largely to the demographic dividend. That is, growth of the working age population guarantees an adequate supply of labour; a decline in the dependence ratio (the ratio of the dependent population to the working age population) helps to maintain a high savings rate, which is the condition for capital formation; and an unlimited supply of labour prevents return on capital from diminishing, which allows heavy investment to be the main source of GDP growth (Cai and Zhao 2012).

As is well documented (e.g. Bloom and Williamson 1998; Williamson 1998), the demographic dividend is not derived from population size or the growth rate of the population, but from a specific feature of the population age structure. Simply put, an increase in the proportion of the working age population in the total population, and a decline in the dependence ratio provide a country an opportunity to situate themselves so that a high savings rate, heavy investment and rapid economic growth can be obtained; the country thus benefits from the demographic dividend. Over the recent period of fast growth, few would consider the population age structure as a constraint of economic growth in China.

The population age structure is, however, ever-changing. As a result of population ageing, the working age population stops growing and the dependence ratio no longer decreases; eventually, the demographic dividend will cease to exist. While debating the Lewis turning point, Ross Garnaut (2010) suggests using the phrase 'Lewis turning period' instead of Lewis turning point, so that the feature of China's regional heterogeneity can be captured. Accepting this advice, we consider 2004, the year in which labour shortages first appeared and migrants' wages started to increase, as the starting time and 2010, in which working age population between 15 and 59 peaked, the ending time of the Chinese Lewis turning period (Figure 4.1). Since China has now passed such a period, all those things that are predicted by economic theories are becoming 
a reality. That is, labour shortages, diminishing returns on capital, and a decline in the savings rate will lead to a slowdown in economic growth. This is what has occurred in China in recent years, particularly since 2004.

Figure 4.1 The Chinese Lewis turning period

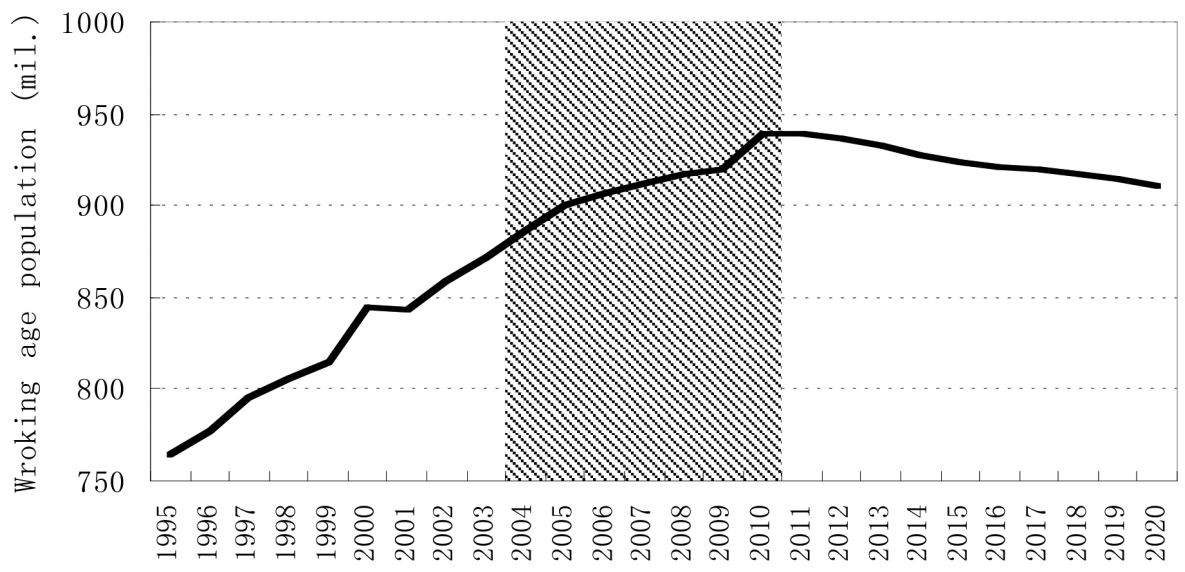

Year

Source: China Development Research Foundation (2012).

The potential GDP growth rate is determined by supply-side factors, including labour, capital and total factor productivity (TFP). In a growth accounting equation, holding the labour force participation rate (LFPR) and the natural unemployment rate (i.e. the non-accelerated inflation rate of unemployment (NAIRU)) constant, a reduction in the working age population will directly reduce the potential GDP growth rate. In addition, the reduced supply of labour, which causes diminishing returns to capital, and the increase in the dependence ratio, which causes a decline in the savings rate, do not support the fast growth of capital formation. Therefore, holding the other factors constant, a reversal of the growth trend of the working age population in China will inevitably slow its economic growth.

In fact, the process of demographic transition has taken place in China much more rapidly than anyone could have expected, and the number of people from ages 15 to 59 years has already decreased. ${ }^{1}$ Based on the data of the 6 th national

1 In this study, we assume that people aged 15 to 59 years make up the working age population, instead of people aged 15 to 64 years. The reason is twofold. First, the official retirement ages are 60 years for male workers and 55 years for female workers. Second, for China's working age population, the older the person, the lower the educational level. For example, the average years of schooling drop from nine years for people aged 20, to six years for people who are aged 60 (Wang and Niu 2010). Both reasons indicate that, at present, there is little chance for people older than 60 years to successfully remain in the labour force. 
census, the China Development Research Foundation (CDRF 2012) predicts the trend of the population age structure to change, and shows that the working age population, when assumed to be aged 15 to 59 years, started to decline in size in 2011, while the population dependence ratio, which is calculated based on the working age population (aged between 15 and 59 years), began shrinking in the same year. This trend will not be reversed, even if there is a moderate relaxation of the one-child policy. Given that the population factor has had such far-reaching impacts on the determinants of China's economic growth, including labour supply, the savings rate, the marginal return on capital and total factor productivity, such a change in the population age structure is bound to reduce the potential GDP growth rate in China.

Based on the latest population data, the chapter simulates a decline in the average potential GDP growth rate from 9.8 per cent over the period 1995-2009, to 7.2 per cent during the 12th five-year plan period (2011-2015) and 6.1 per cent over the 13th five-year plan period (2016-2020). Therefore, determining how to sustain economic growth is an important challenge facing China. In light of the properties of the potential growth rate and the experiences of China and the rest of the world, we make the following two suggestions.

First, the government should not seek an actual growth rate that exceeds the potential growth rate. Because the potential growth rate is fixed by assuming full employment of existing factors of production, artificial stimulus aimed at lifting the actual economic growth rate above the potential rate would have unhealthy consequences. For example, frequently implemented stimulus plans could cause inflation; overactive industrial policies might result in overcapacity by inappropriately protecting inefficient enterprises and backward production capacity; and, regional and industrial policies using heavy subsidies could lead to distortion of prices of production factors, and affect regional industrial structure by impacting comparative advantage.

Second, the potential growth rate can be enhanced through the application of measures to enlarge the supply of labour and capital, and to improve productivity. This requires deepening reforms in various areas, such as reform of the household registration system, and institutional reform. That is, economic reform is the key to sustaining China's economic growth. Homi Kharas (2011) points out that it would take ten years or more for China to see any obvious effects of such reforms, which implies that the Chinese Government should waste no time in initiating urgent reforms, while being ready to accept lower growth rates. There exist reform opportunities, however, that could enhance China's potential growth rate fairly swiftly, which we discuss in the present chapter. 
While suggesting the slowdown of the potential rate of China's future economic growth in accordance with the trend of population structure changes, the present chapter recommends that policy measures to stimulate economic growth so that it exceeds the potential growth rate should not be taken. Instead, two scenarios are simulated and the results suggest that an increase in the labour force participation rate and improvements in TFP can significantly expand the potential growth rate in the future.

\section{Estimation of the Potential Growth Rate in China}

We use a standard Cobb-Douglass production function to project potential GDP growth rate. This method was applied both by Louis Kuijs and Wang (2006) and Kuijs (2009).

$Y=A L^{\alpha} K^{1-\alpha}$

Where $Y$ is real GDP, $A$ is TFP, $L$ is employment, and $K$ stands for capital stock (in constant price). ${ }^{2}$ We deduce the labour productivity by dividing $L$ on both sides of the equation (1).

$$
Y / L=A(K / L)^{1-\alpha}
$$

In equation (2), labour productivity $Y / L$ (represented by $y$ ) is a function of the TFP and capital-labour ratio $K / L$ (represented by $k$ ). That is $y=A k^{1-\alpha}$. With some manipulation, labour productivity growth rate can then be rewritten and estimated from model (3):

$$
\frac{\Delta y_{t}}{y_{t-1}}=\frac{\Delta A_{t}}{A_{t-1}}+(1-\hat{\alpha}) \frac{\Delta k_{t}}{k_{t-1}}+\varepsilon_{t}
$$

Based on equation (3), we can get the estimated value of return to capital $(1-\hat{\alpha})$ and return to labour $\hat{\alpha}$ by using $\Delta y_{t} / y_{t-1}$ as the dependant variable and $\Delta k_{t} / k_{t-1}$ as the independent variable.

2 Capital stock is almost always constructed by the 'perpetual inventory method'. The well-known equation is $K_{t}=I_{t} / p_{t}+\left(1-\delta_{t}\right) K_{t-1}$, where $K_{t}$ is the measure of the real capital stock at time $t, K_{t-1}$ is the measure of the real capital stock at time $t-1$, It is the normal investment in time $t, P_{t}$ is the price index of investment in fixed assets in time $t$, and $\delta_{t}(=5 \%)$ is the rate of depreciation. The $\mathrm{K}_{1978}$ is calculated by Guo and Jia (2004). Note that $K_{t}$ is a weighted sum of all past levels of investment and depreciated value of the initial real capital stock. 
From time series of $\Delta y_{t} / y_{t-1}, 1-\hat{\alpha}, \Delta k_{t} / k_{t-1}$, the growth rate of total factor productivity $\Delta A_{t} \hat{l} A_{t-1}+\varepsilon_{t}=\Delta y_{t} / y_{t-1}-(1-\hat{\alpha}) \Delta k_{t} / k_{t-1}$ could be calculated by using equation (3). And then, $\Delta A_{t} / A_{t-1}$ can be estimated by applying the Hodrick-Prescott filter method to diminish error term $\varepsilon_{t}$.

All steps above are identical with the method which calculates the growth rate of total factor productivity. It is necessary to use potential employment $L_{t}^{*}$ to calculate the potential GDP growth rate. Where $L_{t}^{*}=$ Population $_{15-59, t} \times \operatorname{Tr}_{p t} \times\left(1-N A{ }^{2} U_{t}\right)$, Population $_{15-59, t}$ is the working age population aged 15 to 59 years, $\operatorname{Tr}_{p t}$ is the trends of labour participation rate which can be estimated by the Hodrick-Prescott filter method, and $N A I R U_{t}$ is natural rate of unemployment. In this chapter, $N A I R U_{t}=4.13 \%$ (Du and $\mathrm{Lu} 2011$ ).

Building on $\Delta A_{t} \hat{/} A_{t-1}, 1-\hat{\alpha}, L_{t}^{*}$ and capital stock $K_{t}$, the potential labour productivity growth rate $\Delta y_{t}^{*} / y_{t-1}^{*}$ could be calculated as follows:

$\Delta y_{t}^{*} / y_{t-1}^{*}=\Delta A_{t} / A_{t-1}+(1-\hat{\alpha}) \Delta k_{t}^{*} / k_{t-1}^{*}$

Where $k_{t}^{*}=K_{t} / L_{t}^{*}, y_{t}^{*}=Y_{t}^{*} / L_{t}^{*}$, and $Y_{t}^{*}$ is just the potential GDP in year $t$. Building on $\Delta y_{t}^{*} / y_{t-1}^{*}$ and $L_{t}^{*}$, the following equation can be deduced:

$\Delta Y_{t}^{*} / Y_{t-1}^{*}=\left(\Delta y_{t}^{*} / y_{t-1}^{*}+1\right) \times\left(L_{t}^{*} / L_{t-1}^{*}\right)-1$

$\Delta Y_{t}^{*} / Y_{t-1}^{*}$ is the potential GDP growth rate in year $t$. where $\Delta y_{t}^{*} / y_{t-1}^{*}$ is the growth rate of potential labour productivity, a function of the growth rate of TFP and the potential capital-labour ratio, and $L_{t}^{*} / L_{t-1}^{*}$ is potential employment growth. ${ }^{3}$ From equation (4) and (5), three factors would influence the potential GDP growth rate, that is, potential growth rate of capital-labour ratio, potential growth rate of employment and potential TFP growth rate. The working age population will affect the first two factors directly.

Before estimating the potential growth rate, it is also necessary to make some assumptions regarding the capital formation and TFP growth rates in the period to come. The predicted employment growth, the assumed growth rates of capital formation and TFP, and the estimated potential GDP growth rate are presented in Figure 4.2. In what follows, we explain the reasons for such assumptions and present detailed results from the estimation.

3 For detailed explanations on the estimation procedure, see Lu (2012). 
Figure 4.2 Trends of potential growth rate and of its factors in China: 1996-2020

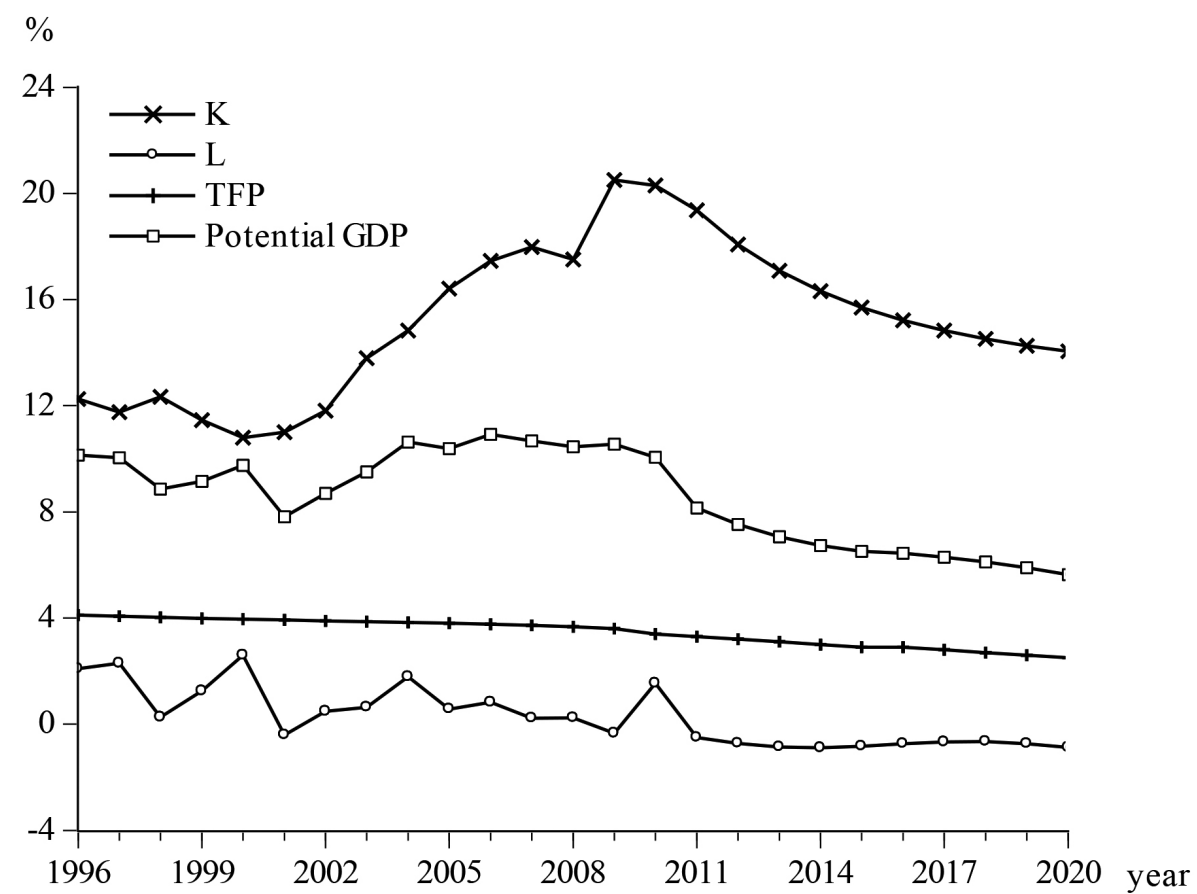

Notes: K, assumed growth rate of fixed assets investment (capital formation); L, potential growth rate of employment.

Source: Authors' own estimations.

\section{Assumption I: Capital Formation Growth will Slow Down in the Next Ten Years}

Examining the historical data, we find that the annual growth rate of fixed asset investment, deflated by the price index of fixed assets, was 13.43 per cent in 1978-1994 and 16.89 per cent in 1995-2009. In the latter period, the annual growth rate of fixed assets investment reached 20 per cent between 2003 and 2007. In tackling the global financial crisis, the growth rate of fixed assets investment rose to 33.15 per cent in 2009. Even if the outlier of 2009 is eliminated, the rate was still as high as 15.64 per cent in the period from 1995 to 2008.

Such rapid growth of fixed assets was not sustained in the years to come for three reasons. First, as a result of widespread labour shortages, marginal return to capital is declining at an accelerating pace (Cai and Zhao 2012), which will impede such a high speed of investment growth. Second, as population dependence ratios increase, the savings rate tends to fall, which results in 
a slowdown of investment growth. Last, but not least, relatively slower growth of capital formation will help China transform its growth pattern that overwhelmingly relies on domestic investment, and move to a more balanced and sustained pattern of growth.

In an equation based on least squares regression, we incorporate return to capital $(w K)$ as an independent variable to regress the dependent variable of the growth rate of total investment in fixed assets in the whole country (excluding state budgetary investment). Data used in the regression cover the years from 1982 to 2005 . The estimated results are as follows:

$I=-6.1395+0.9459^{*} w K$

(19.7312) (0.8422)

$R^{2}=0.0542$ D.W. $=0.9765$

The average return to capital of 20.22 per cent in 1996-2005 estimated by Bai et al. (2006) is put into the estimated equation, thus obtaining an annual growth rate of investment of 12.99 per cent. The annual growth rate of investment in fixed assets in China is preset as 13 per cent in the period from 2012 to 2020.

It is worth noting that the assumption is not made as a result of the above simulation, but in light of economic theory and China's economic reality. That is, a rational response to the substantial fall in marginal return on capital, with an absence of government intervention, should be slower growth of capital investment. In fact, such a predetermined annual growth rate of 13 per cent is still higher than the actual growth rate in the period from 1996 to 2005.

\section{Assumption II: Labour Force will Decrease in the Future}

The demographic and economic trends have led to a changed relationship between labour supply and demand. Take the annual increase in the number of people between the ages of 15 and 59 on the supply side, and annual increase in the number of urban workers on the demand side. When the two trends are examined together, the changing dynamics of the labour market become obvious. Since the number of agricultural workers has been falling, while that of non-agricultural workers in rural areas is not expected to expand, the increases in the number of urban workers, migrant workers included, can be treated as representative of the magnitude of the overall labour demand of the Chinese economy.

Below is a closer examination of the general employment situation in China, by comparing the demand and the supply of labour for urban sectors. There are two parts to the statistical data on urban employment in China. The first includes the total number of urban employees, which is published by 
the National Bureau of Statistics (NBS). This number does not, however, cover most migrant workers in urban areas. According to estimates made on the basis of micro data from 2009, only 12.5 per cent of the total of 310 million urban employees were migrant workers. The second part includes the total number of people classifiable as migrant workers according to NBS official definition. According to that definition, an individual qualifies as a 'migrant worker' if s/he has been away from the town or township of their household registration for six months or more. Surveys have shown that of all migrant workers, 95.6 per cent work and live in cities of varying sizes. Factoring in the overlap between these two numbers, we can calculate the actual number of urban workers, inclusive of both registered urban residents and migrant workers. We can then compare this number with the total number of people of working age in the country (Table 4.1).

Table 4.1 Increases in demand for and supply of labour force (million, \%)

\begin{tabular}{ccccccc}
\hline & \multicolumn{2}{c}{ Urban resident workers } & \multicolumn{2}{c}{ Migrant workers } & \multicolumn{2}{c}{ Working age population } \\
\hline & Numbers & $\begin{array}{c}\text { Growth } \\
\text { rate }\end{array}$ & Numbers & $\begin{array}{c}\text { Growth } \\
\text { rate }\end{array}$ & Numbers & $\begin{array}{c}\text { Growth } \\
\text { rate }\end{array}$ \\
\hline 2001 & 236 & - & 80 & - & 844 & - \\
2002 & 241 & 2.1 & 100 & 24.7 & 859 & 1.8 \\
2003 & 246 & 2.0 & 109 & 8.8 & 872 & 1.6 \\
2004 & 250 & 1.8 & 113 & 3.8 & 886 & 1.5 \\
2005 & 254 & 1.7 & 120 & 6.4 & 900 & 1.6 \\
2006 & 259 & 2.0 & 126 & 5.0 & 907 & 0.8 \\
2007 & 265 & 2.1 & 131 & 3.7 & 912 & 0.6 \\
2008 & 268 & 1.3 & 134 & 2.5 & 917 & 0.5 \\
2009 & 272 & 1.4 & 139 & 3.5 & 920 & 0.3 \\
2010 & 277 & 1.6 & 146 & 5.3 & 939 & 2.1 \\
2011 & 280 & 1.0 & 152 & 3.7 & 939 & -0.1 \\
\hline
\end{tabular}

Source: Authors' calculation based on China Statistical Yearbook (various years), China Yearbook of Rural Household Survey (various years), China Population Yearbook (various years), and Du and Hu (2011).

Between 2001 and 2011, the labour demand of urban sectors, which encompasses employment among both urban residents and migrants, grew at an annual rate of 3.2 per cent. During the same period, labour supply, measured by the number of people of working age, grew by an annual rate of only 1.1 per cent. For the purpose of this study, we have excluded people older than 60 from working age population because, given China's retirement age - 60 for men and 55 for women - they, by default, stand little chance of finding a job in the present labour market. A look at people between the ages of 15 and 59 shows that this population had begun to shrink by 2010. This suggests, among other things, that the problem of high rates of underemployment in both the rural 
and the urban labour markets was finally easing. As such, constant surplus of supply relative to demand no longer accurately describes China's labour market after the passage of the Lewis turning period.

Having observed that the working age population aged between 15 and 59 years is in decline, it can be assumed that the natural unemployment rate will remain the same as it was in 2009, namely, NAIRU $=4.132 \%$ (Du and Lu 2011), and that the labour force participation rate will follow the trend of the labour force participation rate, which was calculated using the Hodrick-Prescott filter method. As the population aged between 15 and 59 years peaked in 2010, its annual growth rate will be -0.33 per cent in $2011-2015$ and -0.31 per cent in 2016-2020. This means that the annual growth rate of employment will be -0.76 per cent during the 12 th five-year plan period and -0.74 per cent in the 13th five-year plan period. If the natural unemployment rate and the labour force participation rate remain unchanged in the following two five-year plan periods, the reduction in the size of the working age population will lead to a fall in the potential GDP growth rate.

\section{Assumption III: Total Factor Productivity Growth will be Reduced but Remain Relatively High}

Kuijs (2009) attributes the impressive increase in TFP during the period from 1994 to 2009 to restructuring of the state sector, China's entry into the World Trade Organization, and the successful integration of manufacturing into the world economy. Those forces, however, will diminish in the years to come. Hence, he expects a reduction of 0.5-2.3 percentage points in TFP per year in the period from 2010 to 2020 . Using a Hodrick-Prescott filter decomposition, we assume the trend annual TFP growth rate to be 3.10 per cent in 2011-2015 and 2.70 per cent in 2016-2020.

Based on the assumptions made above on the decline in the labour force and TFP growth and the slower growth of investment, we can estimate the potential growth rate of the Chinese economy for the period of 2011 to 2020. Our finding that the potential growth rate will decline and the trend will continue is not surprising, because many others have reached the same conclusion (e.g. Kuijs 2009; World Bank 2012). The predicted potential growth rate is much lower here, however, than that estimated by others (e.g. see Kuijs, 2009). The potential GDP growth rate we estimate is 7.2 per cent for the 12 th five-year plan period, and 6.1 per cent for the 13th five-year plan period (Table 4.2). This conclusion is not an exaggeration, given that the inevitable slowdown of mass labour migration from agricultural to non-agricultural sectors, which has been the main source of TFP growth, is not taken into account. 
China: A New Model for Growth and Development

Table 4.2 Estimated results for potential inputs and outputs in China, 1978-2020

\begin{tabular}{|c|c|c|c|c|}
\hline Growth rate (\%) & 1978-1994 & 1995-2009 & 2011-2015 & 2016-2020 \\
\hline Actual output & 10.06 & 9.90 & & \\
\hline Potential output & 10.29 & 9.83 & 7.19 & 6.08 \\
\hline Actual employment & 2.45 & 0.97 & & \\
\hline Potential employment & 3.23 & 0.90 & -0.76 & -0.74 \\
\hline Actual labour productivity & 6.55 & 8.84 & & \\
\hline Potential labour productivity & 6.85 & 8.86 & 8.02 & 6.87 \\
\hline TFP & 0.78 & 3.89 & 3.10 & 2.70 \\
\hline $\mathrm{K} / \mathrm{L}$ & 10.38 & 13.29 & 18.21 & 15.43 \\
\hline
\end{tabular}

Notes: K, assumed growth rate of fixed assets investment (capital formation); L, potential growth rate of employment.

Source: Authors' own estimations.

It is not proposed here that policy-makers pursue achieving actual GDP growth exceeding the potential rate, but rather ways are recommended to achieve enhanced potential growth rate through increasing the labour force participation rate and the TFP growth rate, which require a deepening of economic reforms.

\section{Increasing the Labour Force Participation Rate}

Data from the 6th national census show that the labour force participation rate was 70.80 per cent for population aged 16 years and above, and 77.26 per cent for population aged between 16 and 64 years in 2010. A further look at geographic distribution shows that the labour force participation rate for population aged 16 years and above was 62.20 per cent in cities, 67.32 per cent in towns and 77.62 per cent in rural areas. For population aged between 16 and 64 years, the labour force participation rate was 68.18 per cent in cities, 73.27 per cent in towns and 84.92 per cent in rural areas. The labour force participation rate at present is lower than in the 1990s, and it is likely to be even lower the following two factors are considered.

First, the exclusion of the agricultural labour force from the calculation would result in a lower labour force participation rate. Because there is no retirement age in agriculture, when the number of workers engaged in agriculture is counted, as is the common practice in statistics, the labour force participation rate tends to be overestimated. At the present stage of economic development in China, economic growth is accompanied by a constant decline in the agricultural share in terms of both output value and employment. Thus, the participation rate of the non-agricultural labour force is a better indicator of the real situation of the labour market. 
Based on data of the 6th census, here, the labour force participation rate is recalculated by excluding agricultural sectors, and it is found to be much lower than that calculated by including agriculture (Table 4.3). For example, for the 20-25-year age group, the participation rate of the non-agricultural labour force is 72.55 per cent, which is 9.79 percentage points lower than the participation rate of the total labour force. This implies that, as the agricultural share of the labour force further declines in the future, the labour force participation rate will drop much faster than what previous statistics would suggest.

Table 4.3 Labour force participation rates in China by age group and gender (\%)

\begin{tabular}{|c|c|c|c|c|c|c|}
\hline \multirow{2}{*}{ Age groups } & \multicolumn{3}{|c|}{ Total LFPR (including agriculture) } & \multicolumn{3}{|c|}{ LFPR of non-agriculture } \\
\hline & Total & Male & Female & Total & Male & Female \\
\hline $16-20$ & 32.44 & 33.06 & 30.72 & 21.78 & 22.53 & 21.31 \\
\hline $20-25$ & 72.55 & 76.66 & 69.70 & 62.76 & 68.91 & 58.95 \\
\hline $25-30$ & 88.88 & 95.73 & 82.10 & 84.33 & 94.01 & 74.61 \\
\hline $30-35$ & 90.30 & 97.01 & 83.47 & 85.98 & 95.73 & 75.79 \\
\hline $35-40$ & 90.62 & 96.92 & 84.18 & 85.53 & 95.36 & 75.02 \\
\hline $40-45$ & 90.73 & 96.63 & 84.74 & 84.43 & 94.50 & 73.41 \\
\hline $45-50$ & 87.73 & 95.06 & 79.58 & 78.49 & 91.64 & 62.87 \\
\hline $50-55$ & 76.31 & 89.90 & 62.62 & 56.99 & 81.62 & 32.19 \\
\hline $55-60$ & 67.29 & 80.41 & 53.71 & 37.57 & 60.88 & 15.04 \\
\hline $60-65$ & 49.59 & 58.14 & 40.11 & 13.80 & 22.41 & 5.89 \\
\hline
\end{tabular}

Source: Authors' calculation based on $1 \%$ sampling data of 6 th census.

Second, the extension of years of schooling would lower the labour force participation rate. As is shown in Figure 4.2, the labour force participation rate distribution by age can be characterised by a reverse U-shaped curve. That is, for lower age groups, more people are still in school, which makes labour force participation low; labour force participation substantially increases when people enter their 30s and 40s; and labour force participation declines as workers get older, because they have either a stronger desire to retire or less sought-after skills to meet the demands of the labour market. For all age groups, the labour force participation rate for men is higher than that of women, and the nonagricultural labour force participation rate is lower than the total labour force participation rate. 
Figure 4.3 Labour force participation rate in China, 2010

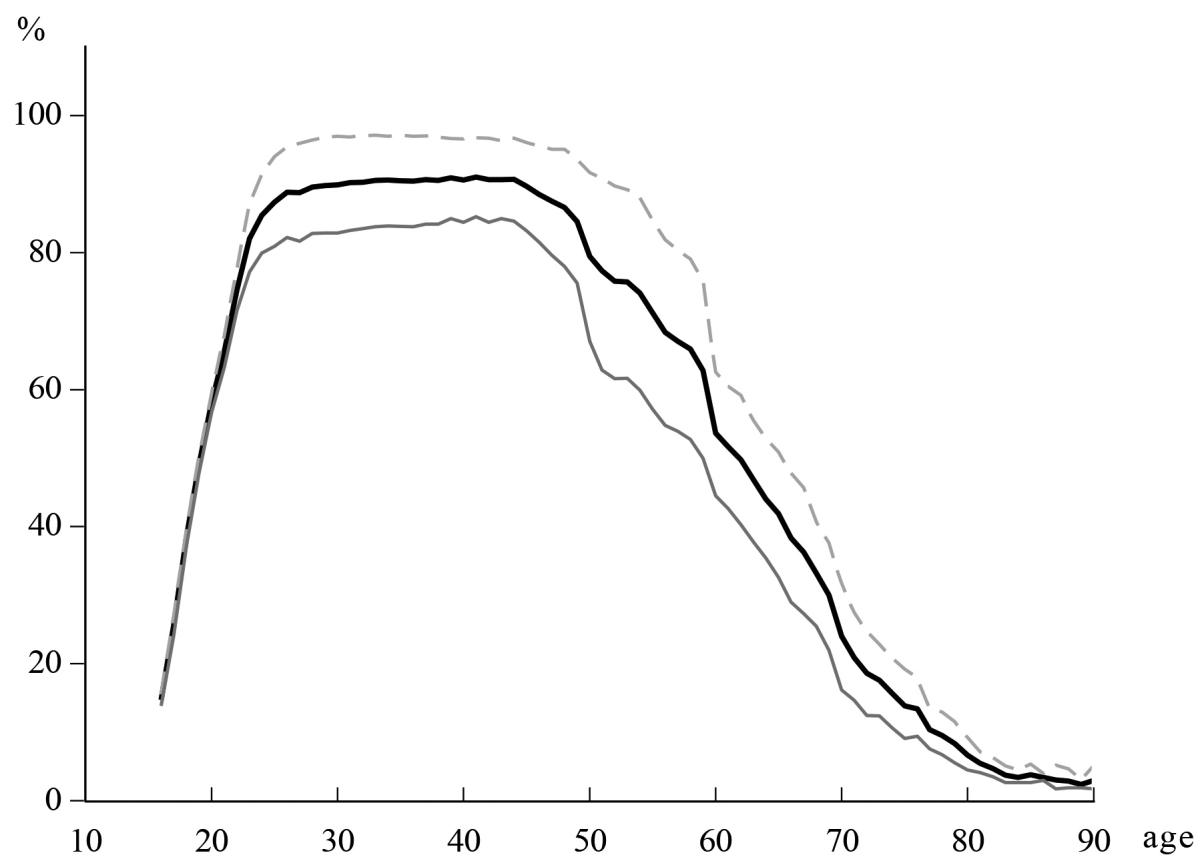

Source: Authors' calculation based on the 6th census.

It is worth noting that although the present labour force participation rate in China is still high, it will change dramatically as population aging accelerates. As the size of the working age population is no longer increasing, labour force participation determines the labour supply and, therefore, constrains the potential growth rate.

After 2011, the potential employment growth rate will become negative: -0.76 per cent in the 12 th five-year plan period and -0.74 per cent in the 13th five-year plan period. Because the root cause of this negative growth of employment, namely, the reduction of the total population aged 15 to 59 years in 2010 and the population aged 15 to 64 years in 2013, cannot be altered, the enhancement of labour force participation is the only way to increase potential labour supply and, in turn, to expand the potential output.

To test such a hypothesis, Figure 4.4 simulates the impact of an increase in the labour force participation rate on the potential GDP growth rate. Based on the above-described growth accounting equation, a scenario is assumed in which the labour force participation rate increases one percentage point every year in the period from 2011 to 2020 . This results in an average potential growth rate increase from 7.19 to 8.09 per cent during 2011-2015 and an average potential 
growth rate increase from 6.08 to 6.94 per cent during 2016-2020. As a result, the potential GDP growth rate will increase by an extra 0.88 percentage points per annum in the period from 2011 to 2022 (Figure 4.4).

Figure 4.4 Effect of one percentage point increase in labour force participation rate on potential GDP growth rate

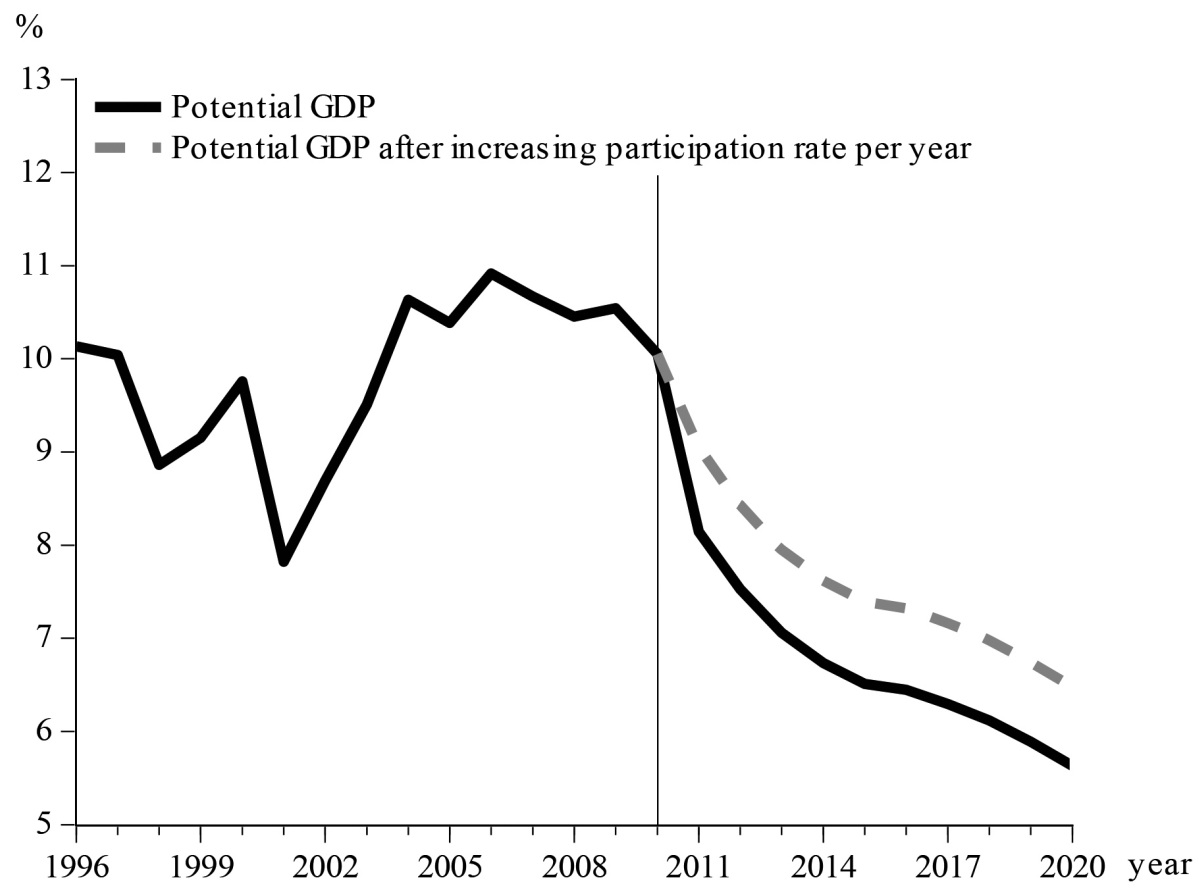

Source: Authors' simulation.

There are three potential ways for China to increase labour force participation. The first is to postpone the retirement age so that the labour force participation rate of workers at older ages can be increased. Although this measure is widely used in developed countries, it is not equally relevant for China, because older Chinese workers are often not sufficiently educated to meet the labour market demand for skills, and are likely to be in a vulnerable position if they postpone retiring. Therefore, this policy option should not be chosen in the short run.

The second method is to further promote labour migration from rural to urban areas. Compared to countries with similar per capita income, China has a relatively larger share of labour in agriculture. The possibility exists for labour migration to occur so that labour force participation can be increased in nonagricultural sectors. The existing household registration or hukou system that segregates the labour market between rural and urban areas still prevents ruralto-urban migrant workers from settling down in urban areas legitimately and 
permanently. Therefore, the hukou reform, which is aimed at legalising migrant workers' citizenship in cities, will significantly stabilise supply of labour, tap into the potential labour force, and, therefore, increase potential output.

The third approach is to raise the employment rate or to lower the unemployment rate. As China is moving away from possessing an unlimited supply of labour, and towards a neoclassical labour market framework, today's employment problems show both neoclassical and dual economy characteristics. That is, while there is still surplus labour in agriculture, the more frequent emergence of cyclical unemployment, structural unemployment and frictional unemployment raises new challenges in regards to China's macroeconomic and employment policies. The manner in which such challenges are responded to can reshape potential GDP growth in the future.

\section{Improving Total Factor Productivity}

In the face of a declining potential growth rate, the central and local governments would tend to adopt industrial policies, regional strategies and stimulus plans to pursue a growth rate exceeding the potential rate. The temptation is great because those policy measures are simple for governments to implement and they generate immediate effects. The lessons from China's economic growth per se, however, and from its forerunners in economic development (e.g. Japan) show that those policies are likely to become distortionary, and eventually impact on the sustainability of economic growth.

In contrast, deepening economic reform in various areas to expand the potential growth rate would require considerable long-term effort. As the returns to capital diminish, the old pattern of China's economic growth cannot continue, and the challenge to seek new sources of economic growth intensifies. According to the neoclassical theory of growth, such new sources must come from improvements in TFP.

The residual output that cannot be explained by inputs of production factors comes from TFP growth, which includes technological advancement, resource allocative efficiency, technical efficiency, and institutional and managerial innovation. In a neoclassical model of economic growth, TFP growth is the dominant, if not the only, driver of potential growth of output.

Based on the existing model, the scenario in which TFP grows at a rate that is one percentage point higher per year in the period from 2011 to 2020 can be assumed. That is, the annual TFP growth rate would increase to 4.01 per cent from the current 3.01 per cent. Our simulation shows that such a higher TFP growth rate would lift the annual growth rate of potential output to 8.19 per 
cent in 2011-2015 and 7.07 per cent in 2016-2020 (Figure 4.5). Overall, if China could manage to accomplish an extra percentage point of TFP growth, its potential annual growth rate would increase by 0.99 percentage points in the period from 2011 to 2020 .

Figure 4.5 Effects of one extra percentage point of TFP growth on potential GDP growth rate

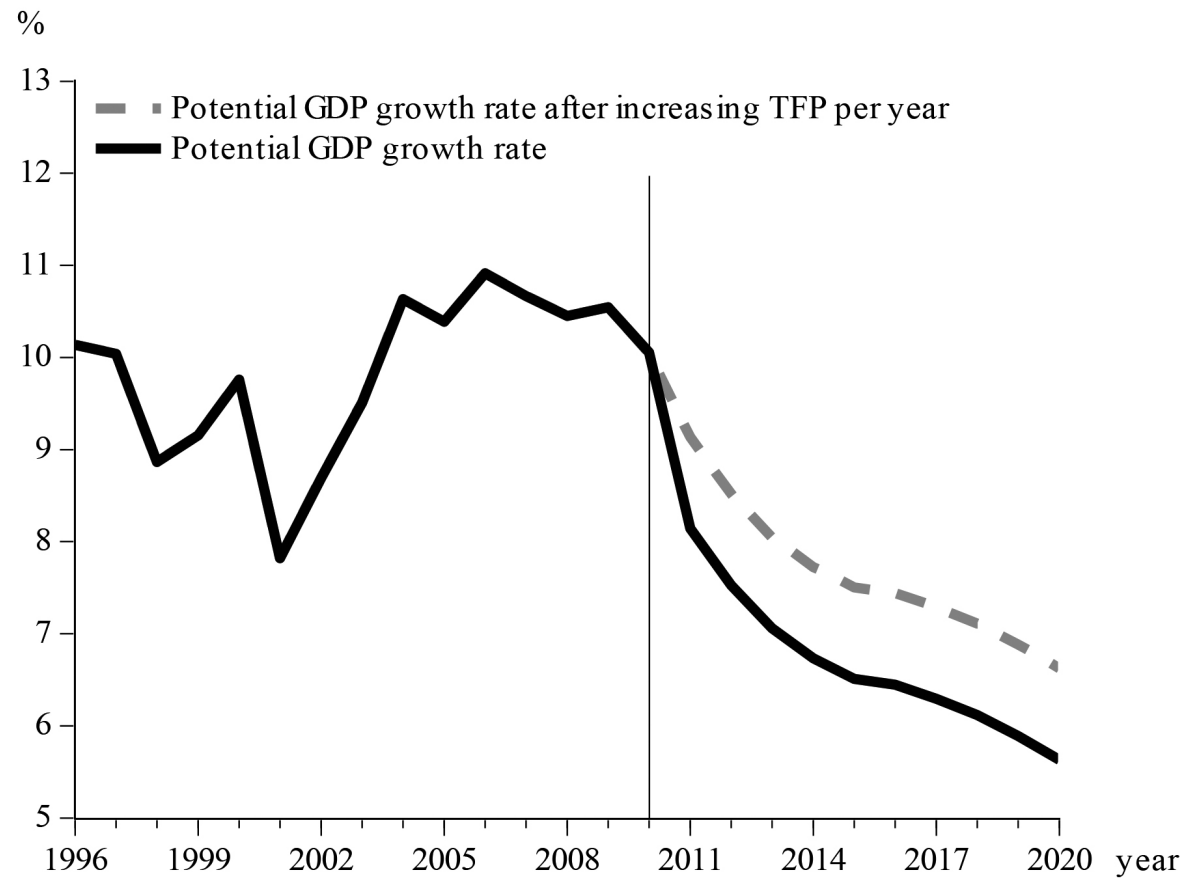

Source: Authors' simulation.

Over the past 30 years of rapid economic growth in China, the impressive performance in TFP has been largely attributed to resource allocative efficiency through labour mobility from agricultural to non-agricultural sectors. In the course of the dual economy development, with an unlimited supply of labour, such productivity gains have been like low-hanging fruit. As the surplus labour force has become gradually absorbed by the unprecedented expansion of secondary and tertiary sectors, the mass labour migration has slowed down, and the opportunity to gain resource allocative efficiency has decreased.

Furthermore, the arrival of the Chinese economy at a higher phase of development means that the gap in technology between China and developed countries has narrowed, which makes it relatively harder for China to increase TFP through technological advancement. 
Therefore, China should search for new ways to improve TFP to expand its potential growth. In fact, as China's economic growth follows more of a neoclassical framework, it will be difficult for China to add even one additional percentage point to its TFP growth rate. It is essential for the government to be determined to complete the task and is aware of where the extra productivity should come from. For China, apart from the traditional sources of TFP improvement, such as achieving technological parity with developed countries and labour migration from rural to urban sectors, there is tremendous opportunity to gain allocative efficiency in the following areas.

First, given the large disparities in productivity among subsectors within, say, the secondary sector, the mobility of factors of production from the low productivity subsector to the high productivity subsector can improve the overall productivity of the economy as a whole. Second, the flow of factors of production among enterprises can also provide allocative efficiency because there are huge disparities in productivity performance among enterprises within narrowly defined sectors. A so-called creative destruction mechanism could be created, which allows for more efficient enterprises to survive, expand and develop, and causes long-term inefficient enterprises to be eliminated. This mechanism could generate the third resources allocative efficiency.

As is well documented in the economics literature, in a mature market economy like the United States, allocative efficiency relating to entry versus exit and expansion versus contraction of firms within narrowly defined sectors contributes one-third to a half of the productivity growth (e.g. Foster et al. 2008). Based on an empirical and comparative study, Chang-Tai Hsieh and Peter Klenow (2007) find that by reallocating capital and labour to equalise marginal products among plants to the extent observed in the United States, China's manufacturing sector could gain a 30 to 50 per cent increase in its TFP.

To gain resource allocative efficiencies in the areas described above requires a policy environment within which factors of production can freely flow among regions, sectors and enterprises. There still exist institutional barriers preventing investors from freely entering certain sectors where state-owned enterprises dominate, resulting in a great loss of allocative efficiency. The Chinese Government should redefine the role and function of the state enterprises to keep them within necessary and limited arenas of economic activities, while creating equal competition opportunities for all sectors and enterprises.

\section{Conclusion and Policy Implications}

As a result of the changes in the population age structure, the working age population (aged 15 to 59 years) stopped growing in 2010. Meanwhile, economic growth continues to generate a large demand for labour, thus absorbing the 
surplus labour force in agriculture. As the surplus labour force in agriculture is substantially decreasing, the Chinese economy is entering a phase of transition shifting from a kind of dual economic development to the pattern of neoclassical growth.

According to the neoclassical theory of growth, it is unlikely that developed economies can realise growth rates comparable to their developing counterparts, which are still in the process of catching up. Accordingly, fast growth will eventually slow down as an economy moves to a certain turning point, as experiences worldwide suggest (Eichengreen et al. 2011).

There is no need to fear the slowdown of the potential growth rate. The new stage of development, however, requires China to accomplish a fundamental transformation of its economic growth pattern, from sole reliance on inputs of capital and labour to greater improvements in TFP. Therefore, the key to sustaining economic growth through expanding the potential growth rate lies in supply-side factors. If the government policies wrongly focus on stimulating demand-side factors to reach a growth rate exceeding the potential capacity of production, long-term economic growth will not be healthy and will cause a great deal of distortions. Instead, sound policies should be implemented bearing the following in mind.

First, the central and local governments should accept slower economic growth. Policy decisions should be made by adjusting supply-side factors rather than demand-side factors. Even an undesirable fall in the growth rate, caused by shocks from demand-side factors, should not be a reason for policy-makers to introduce expansionary macroeconomic policy measures. Instead, policymakers need to determine whether growth rates have been reduced to belowpotential levels. If this is not the case, a situation where export demand and investment demand are weak could be taken as a chance for the economy to accelerate its transition towards a consumption-driven pattern of growth, and to sustain growth in a more balanced manner.

Second, economic reforms should modify the traditional growth pattern. Reforms have been a major driving force of the unprecedented economic growth over the past 30 years. A competitive environment is vital for enhancing the potential growth rate in China over the next decade or so.

Third, there is an important role for the government to play in helping improve China's TFP. Paul Krugman (1994) was critical of Singapore's growth model, to which the Singaporean Government responded by introducing a national goal of two per cent annual TFP growth (Felipe, 1997). It is worth noting that improving TFP will critically depend on how China adopts further measures to deepen its reforms in many areas, including its labour market, the financial sector, the enterprise system as well as the government system. 


\section{References}

Bai, Chong-En, Hsieh, Chang-Tai, \& Qian, Yingyi, 2006, 'The Return to Capital in China,' NBER Working Paper No. w12755, National Bureau of Economic Research, Cambridge, MA.

Bloom, David E. \& Williamson, Jeffrey G., 1998, 'Demographic Transitions and Economic Miracles in Emerging Asia', World Bank Economic Review, Vol. 12, No. 3, pp. 419-55.

Cai, Fang \& Zhao, Wen, 2012, 'When Demographic Dividend Disappears: Growth Sustainability of China', in Masahiko Aoki \& Jinglian Wu (eds), The Chinese Economy: A New Transition, Palgrave Macmillan, Basingstoke.

CDRF (China Development Research Foundation), 2012, China Development Report, 2012, China Development Publishing House, Beijing.

China Population Statistics Yearbook, compiled by Department of Population, Social, Science and Technology Statistics, National Bureau of Statistics of China, Beijing, China.

China Statistical Yearbook, compiled by National Bureau of Statistics of China, Beijing, China.

China Yearbook Of Rural Household Survey, compiled by Rural Social and Economic Survey Office of the State Statistics Bureau, Beijing, China.

Du, Yang \& Ying, Hu, 2011, 'Working age population and labor force supply', Working Paper of Institute of Population and Labor Economics, http://iple.cass.cn/news/655101.htm.

Du, Yang \& Yang, Lu, 2011, 'The Natural Rate of Unemployment in China and its Implications', The Journal of World Economy, vol. 34, no. 4, pp. 3-21.

Eichengreen, Barry, Park, Donghyun, \& Shin, Kwanho, 2011, 'When Fast Growing Economies Slow Down: International Evidence and Implications for China', NBER Working Paper No. 16919, National Bureau of Economic Research, Cambridge, MA.

Felipe, Jesus, 1997, 'Total Factor Productivity Growth in East Asia: A Critical Survey', EDRC Report Series, No. 65, Asian Development Bank, Manila, Philippines.

Foster, Lucia, Haltiwanger, John \& Syverson, Chad, 2008, 'Reallocation, Firm Turnover, and Efficiency: Selection on Productivity or Profitability?' American Economic Review, vol. 98, no. 1, pp. 394-425. 
Garnaut, Ross, 2010, 'Macro-Economic Implications of the Turning Point', China Economic Journal, vol. 3, no. 2, pp. 181-90.

Guo, Qingwang \& Jia, Junxue, 2004, 'Estimating Potential Output and the Output Gap in China', Economic Research Journal, no. 5, pp. 31-9.

Hsieh, Chang-Tai \& Klenow, Peter J., 2007, 'Misallocation and Manufacturing TFP in China and India', NBER Working Paper, No. 13290, National Bureau of Economic Research, Cambridge, MA.

Kharas, Homi, 2011, 'China's Transitions to a High Income Economy: Escaping the Middle Income Trap', in Edwin Lim \& Michael Spence (eds), The Medium and Long Term Development and Transformation of the Chinese Economy: An International Perspective, CITIC Publishing House, Beijing, pp. 470-501 (in Chinese).

Krugman, Paul, 1994, 'The Myth of Asia's miracle', Foreign Affairs, vol. 73, no. 6, pp. 62-78.

Kuijs, Louis, 2009, 'China Through 2020-A Macroeconomic Scenario,' World Bank China Office Research Working Paper, No. 9, Beijing.

Kuijs, Louis \& Wang, Tao, 2006, 'China's Pattern of Growth: Moving to Sustainability and Reducing Inequality', China and World Economy, vol. 14, no. 1 , pp. 1-14.

Lu, Yang, 2012, 'China's Natural Growth Rate of Output and its Forecast,' in Cai Fang (ed.), The China Population and Labor Yearbook No.13: Demographic Transition and Economic Rebalance in China, Social Sciences Academic Press, China, pp. 98-111.

Wang, Guangzhou \& Niu, Jianlin, 2010, 'Composition and Development of the Chinese Education System,' in Cai Fang (ed.), The China Population and Labor Yearbook Volume 2: The Sustainability of Economic Growth from the Perspective of Human Resources, Brill, Leiden; Boston, pp. 43-62.

Williamson, Jeffrey G., 1998, 'Growth, Distribution, and Demography: Some Lessons from History,' Explorations in Economic History, vol. 35, no. 3, pp. $241-71$.

World Bank, 2012, ‘China 2030 Building a Modern, Harmonious, and Creative High-Income Society', http://www.worldbank.org. 



\title{
5 Chinese Industrialisation:
}

\author{
Path Dependence and the Transition \\ to a New Model
}

Huw McKay and Ligang Song

\section{Introduction}

China's economic structure can be characterised as both over-industrialised and under-urbanised relative to its level of income per head. Further, for such a large economy, it is highly export oriented. The design of any new growth model will need to respect these major structural legacies. The 'overindustrialised' assessment reflects a high proportion of secondary activity in gross value added relative to its peers; and the under-urbanised assessment reflects the fact that the policy framework has prevented internal rural-urban migration from progressing at the rate at which push and pull motivations alone would have predicted. Furthermore, the absorptive capabilities of the urban population are diminished by the underprivileged position of the migrant worker cohort. China thus has both a considerable overhang of industrial capacity and considerable latent demand for further urbanisation, alongside huge potential for generating greater benefits from the degree of urbanisation already achieved.

The fundamental inheritance of the current leadership is certainly mixed. Some aspects of this inheritance are an impediment to sustaining growth in aggregate living standards in an environmentally conscious way, while simultaneously promoting equality of income and opportunity. Others are advantageous for the pursuit of these basic national goals. Transitioning the economy in a direction that reduces 'over-industrialisation', optimises urbanisation and increases domestic absorption at the expense of foreign sales will emphasise the positive aspects of the inheritance and de-emphasise the negative. We argue that the overall policy response to these major questions - both the threats and opportunities - can be inherently complementary. Furthermore, we argue that the policy decisions and guidelines issued over the last year or so indicate that the administration understands the need for a new model and has a good idea of what should be done to achieve it. Yet the leadership is not over-confident. Indeed, the State Council memorandum on income distribution reform, which cuts across all relevant aspects of macroeconomic decision-making, released on 5 February 2013, stated that 'deepening the income distribution reform 
is a systematic project that is arduous and complicated and concerns the reallocation of various interests. There is no way to accomplish it overnight' (Quoted in Xinhua News 2013a).

The first section of this chapter presents evidence that supports our characterisation of China's current and historical economic structure as both over-industrialised and under-urbanised relative to its level of income per head. This discussion sketches China's path to the present and its structural starting point as it attempts to transition towards a new model. The second section outlines desirable changes in policy structure to accommodate a new model, alongside a discussion of initiatives that have already been put in place to that end by the administration. Following this section we indulge in a political economic aside: noting that the many facets of path dependence present a material prima facie political-economic constraint on the Chinese leadership's absolute freedom of choice and action. Even so, we conclude, optimistically, that these constraints should not be considered an insurmountable hurdle. Given the ultimate complementarity of the superordinate goals of China's next transitionreducing 'over-industrialisation' and optimising urbanisation - there is very good reason for the leadership to embark upon the process of deepening reforms with a high degree of resolve.

\section{China's Historical Industrialisation Path in Comparative Perspective}

In 1995 China achieved the US $\$ 2,000$ per capita level for purchasing power parity GDP. In 2011 it reached the US $\$ 8,000$ per capita threshold, quadrupling the size of its economy per head in just 16 years. ${ }^{1}$ Leaving aside for a moment the speed at which this increase in living standards has been achieved, which was indeed remarkable, the attainment of a four-fold increase in living standards from a base of $\$ 2,000$ per head is a notable feat for any late-industrialising economy in the post-Second World War period, and rarer than one might expect. Some of the notable nations in the Asian region that do not yet meet this criterion (although they may do so in the foreseeable future), despite some periods of impressive economic growth, are Indonesia, India, the Philippines and Vietnam. Given the relative exclusivity of the 'club' to which China earned

1 All information on post-Second World War GDP and GDP per capita levels reported in this chapter are based on the Conference Board's Total Economy Database ${ }^{\mathrm{TM}}$ as issued in January 2012, which is available from http://www.conference-board.org/data/economydatabase/ Data for before 1950 and the world economy as a whole comes from Maddison, Angus, 2009, Historical Statistics of the World Economy: 1-2006AD, March update, available from http://www.ggdc.net/maddison/ All underlying data are 1990 Geary Khamis dollars. 
membership in 2011, it provides a neat guide for a comparative analysis of industrialisation and development patterns around the Asian region and around the world. Accordingly, we have selected a sample of economies that share this distinction with China to conduct a peer review of the broadest contours of its development drive.

Before we enter into that discussion, let us turn for a moment to the relative speed at which China executed a quadrupling of living standards. Consider Figure 5.1. The columns represent the number of years each economy took to achieve the feat. The line represents the compound annual growth rate during the relevant period. China is the latest country in the sample to reach the baseline income level, and it achieved the fastest growth rate; and, accordingly, required the least amount of time to increase living standards four fold. Japan comes next, followed by the group of four precocious late industrialisers now known as the 'Newly Industrialised Economies', with Thailand and Malaysia also featuring. Two economies from outside the East Asian region - one from the Old World (Turkey) and one from the New (Mexico)-bookend an estimate of the experience of the world economy in total, before the figure moves into the first and second generation of European industrialisers and their colonial offshoots.

Figure 5.1 Quadrupling living standards from a base of \$2,000 PPP GDP per capita

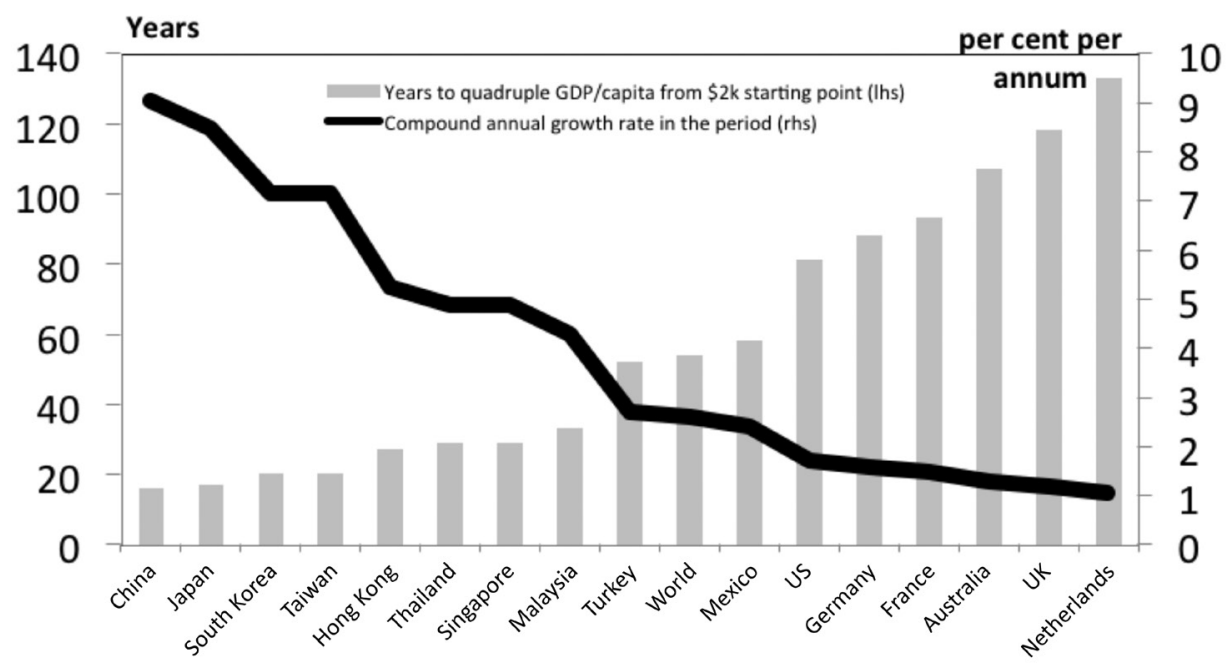

Source: See footnote 1.

Table 5.1 indicates the year in which the countries in Figure 5.1 first reached the baseline level of $\$ 2,000$ GDP per capita, going back to the Netherlands in 1827. It also shows when the quadrupling of living standards was completed. 
China: A New Model for Growth and Development

Table 5.1 Quadrupling living standards from a base of \$2,000 PPP GDP per capita

\begin{tabular}{|c|c|c|c|c|}
\hline Modern country & $\begin{array}{c}\text { Year achieved } \\
\$ 2,000 \mathrm{GDP} \\
\text { per head }\end{array}$ & $\begin{array}{c}\text { Year achieved } \\
\$ 8,000 \text { GDP } \\
\text { per head }\end{array}$ & $\begin{array}{c}\text { Number of years } \\
\text { to quadruple } \\
\text { GDP per head }\end{array}$ & $\begin{array}{l}\text { Compound } \\
\text { annual growth } \\
\text { rate in period }\end{array}$ \\
\hline Netherlands & 1827 & 1960 & 133 & 1.0 \\
\hline United Kingdom & 1839 & 1957 & 118 & 1.2 \\
\hline Australia & 1848 & 1955 & 107 & 1.3 \\
\hline United States & 1860 & 1941 & 81 & 1.7 \\
\hline France & 1869 & 1962 & 93 & 1.5 \\
\hline Germany & 1874 & 1962 & 88 & 1.6 \\
\hline Mexico & 1950 & 2008 & 58 & 2.4 \\
\hline Hong Kong & 1950 & 1977 & 27 & 5.3 \\
\hline Singapore & 1950 & 1979 & 29 & 4.9 \\
\hline Japan & 1951 & 1968 & 17 & 8.5 \\
\hline Turkey & 1955 & 2007 & 52 & 2.7 \\
\hline Taiwan & 1965 & 1985 & 20 & 7.2 \\
\hline South Korea & 1969 & 1989 & 20 & 7.2 \\
\hline Malaysia & 1969 & 2002 & 33 & 4.3 \\
\hline Thailand & 1976 & 2005 & 29 & 4.9 \\
\hline China & 1995 & 2011 & 16 & 9.1 \\
\hline \multicolumn{5}{|l|}{ memo item } \\
\hline World & 1950 & 2004 & 54 & 2.6 \\
\hline
\end{tabular}

Source: See footnote 1 .

The first generation of industrialisers took well over a century to quadruple GDP, expanding at a compound rate around one to $1 \frac{1}{4}$ per cent per annum, while the second generation (here represented by France, Germany and the United States) achieved growth rates around $1 \frac{1}{2}$ to $1 \frac{3}{4}$ per cent per annum; this enabled them to complete the task in an average of 87 years.

The availability of national accounts data grew significantly after the Second World War. So too did modern economic growth, underpinned by the dissemination of the industrialisation meme. ${ }^{2}$ Five of the 16 economies listed in Table 5.1 were on the \$2,000 GDP per head 'starter's blocks' in the early 1950s: Japan, Turkey, Mexico and the entrepot-city states of Singapore and Hong Kong. The world economy as a whole was also in that category. Maddison estimates that global GDP per capita had reached \$2,113 in 1950 .

2 Bénétrix et al. (2012: 6-7) make a practical observation on the availability of historical time series of industrial output. They argue that the availability of data is itself an indicator of industrialisation, as a poor country without an industrial sector of note would not go to the trouble of computing such statistics. That is certainly a 'reasonable surmise', as they put it. 
Moving forward to the 1960s, Taiwan (1965) and then South Korea and Malaysia (1969) reached the jumping off point, just as Japan was completing its drive to $\$ 8,000$ (1968). Thailand reached the jumping off point in 1976 . This group (excluding the special cases of Hong Kong and Singapore) of successful post-Second World War industrialisers are the peer group we have selected for China. As Japan was the first nation among the group to quadruple per capita income, it serves as the anchor for the comparative analysis. Thus in Figures 5.2a and $5.2 \mathrm{~b}$, Japan is set at 100 for every indicator, and the other countries are reported as a percentage of the Japanese level. For example, when Japanese GDP per head was at $\$ 2,000$ in 1951, its urban population share was 53 per cent. When China's GDP per head was at $\$ 2,000$ in 1995, its urban population share was 31 per cent. China's urban share is accordingly represented as 58 per cent of the Japanese level in Figure 5.2a.

In addition to the two major areas of interest to this chapter-industrial production as a share of total output and the urban population as a share of the total - we have selected proxies of human capital (average years of schooling for adults) and infrastructure (rail network length scaled by land area), in addition to life expectancy and the investment share of GDP. Export orientation is also considered, but relative scale factors make it difficult to represent in the same graphical framework as the variables considered above. As a consequence trade orientation is illustrated separately in Figure 5.3.

The most striking finding from Figure 5.2a is China's very high industrial production and investment shares at the starting point of the analysis. Its investment share far exceeded all other economies in the sample and its industrial production share likewise. High industrial production and investment shares are closely associated with China's high energy and resource as well as emissions intensities. It was close to its peers in terms of schooling and life expectancy, but it was weak in terms of infrastructure, and well behind its north Asian neighbours in terms of urbanisation. China's export orientation was much higher than that of Japan, Mexico or Turkey at the \$2,000 per head level, somewhat higher than that of South Korea, similar to Thailand, but much lower than Malaysia. 
China: A New Model for Growth and Development

Figure 5.2a Selected characteristics of successful future industrialisers at the $\$ 2,000$ PPP GDP per capita level

\section{All measures reported as a percentage of the Japanese level}

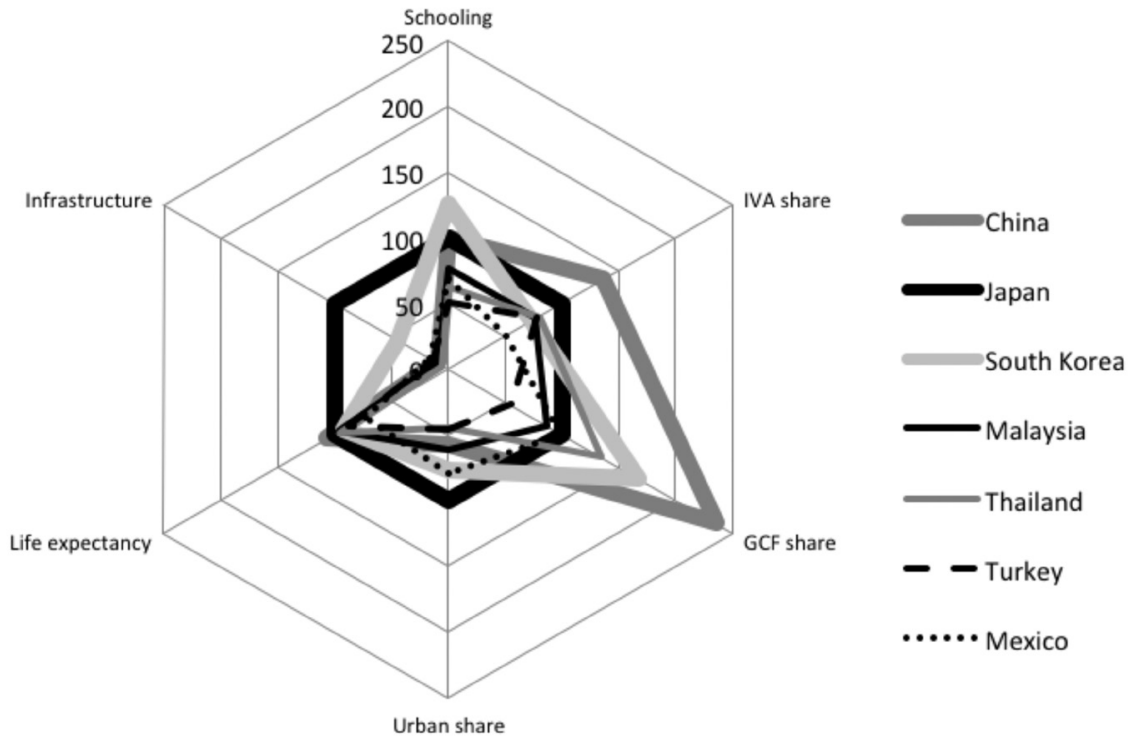

Figure 5.2b Selected characteristics of successful future industrialisers at the $\$ 8,000$ PPP GDP per capita level

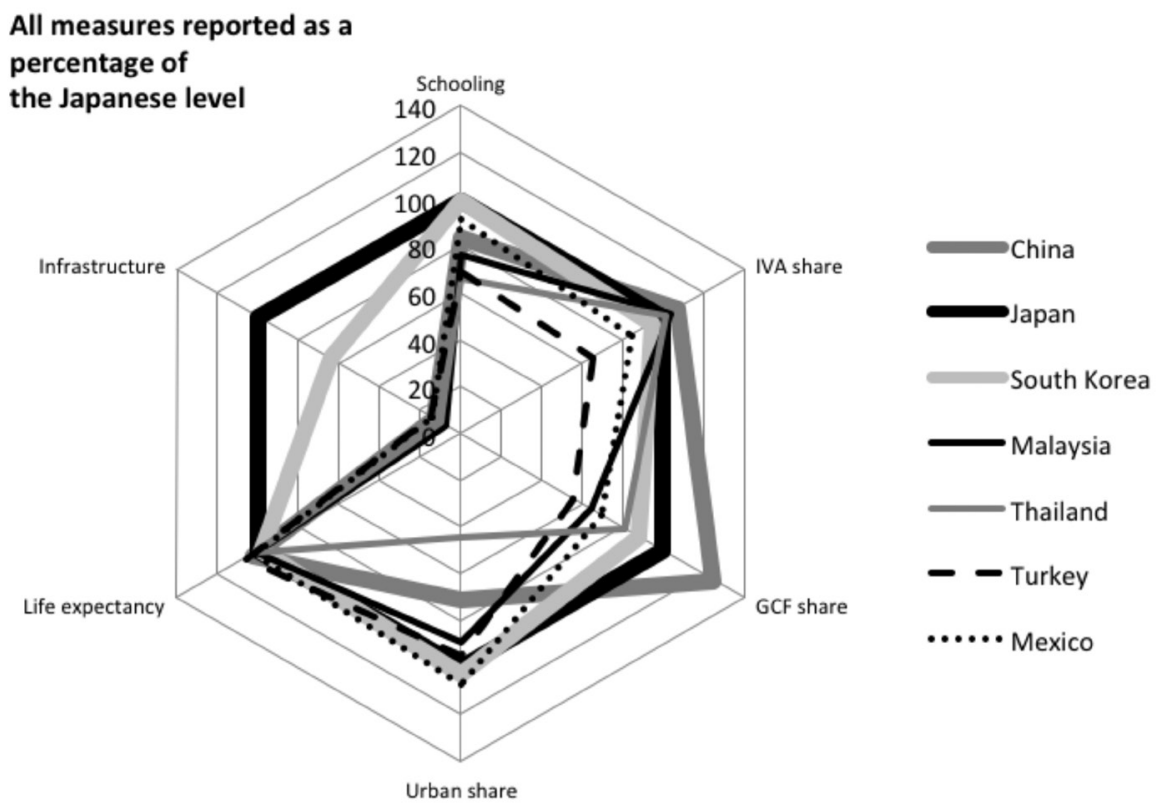


Notes to Figures:

'Schooling' refers to average years of schooling per adult.

Source: United Nations Development Program, available at http://hdrstats.undp.org/en/indicators/103006.html 'IVA share' and 'GCF share' refers to the percentage of GDP accounted for by industrial production and gross investment respectively.

Source: World Bank Databank, available at http://databank.worldbank.org/data/views/variableselection/ selectvariables.aspx ?source $=$ world-development-indicators

'Life expectancy' is at birth.

Source: ibid.

'Infrastructure' is open rail network length scaled by 2010 land area. Land area comes from the CIA World Factbook, available at https://www.cia.gov/library/publications/the-world-factbook/index.html. Rail network length is from Mitchell (1982, 1975, 1993), Union of International Railways (1991, 2000), the CEIC database and the CIA World Factbook, with interpolations by the authors.

'Urban share' is the percentage of the population classed as urban by the United Nations in their 2011 revision.

Source: http://esa.un.org/unup/

Figure 5.3 Export orientation at $\$ 2,000$ and $\$ 8,000$ PPP GDP per capita

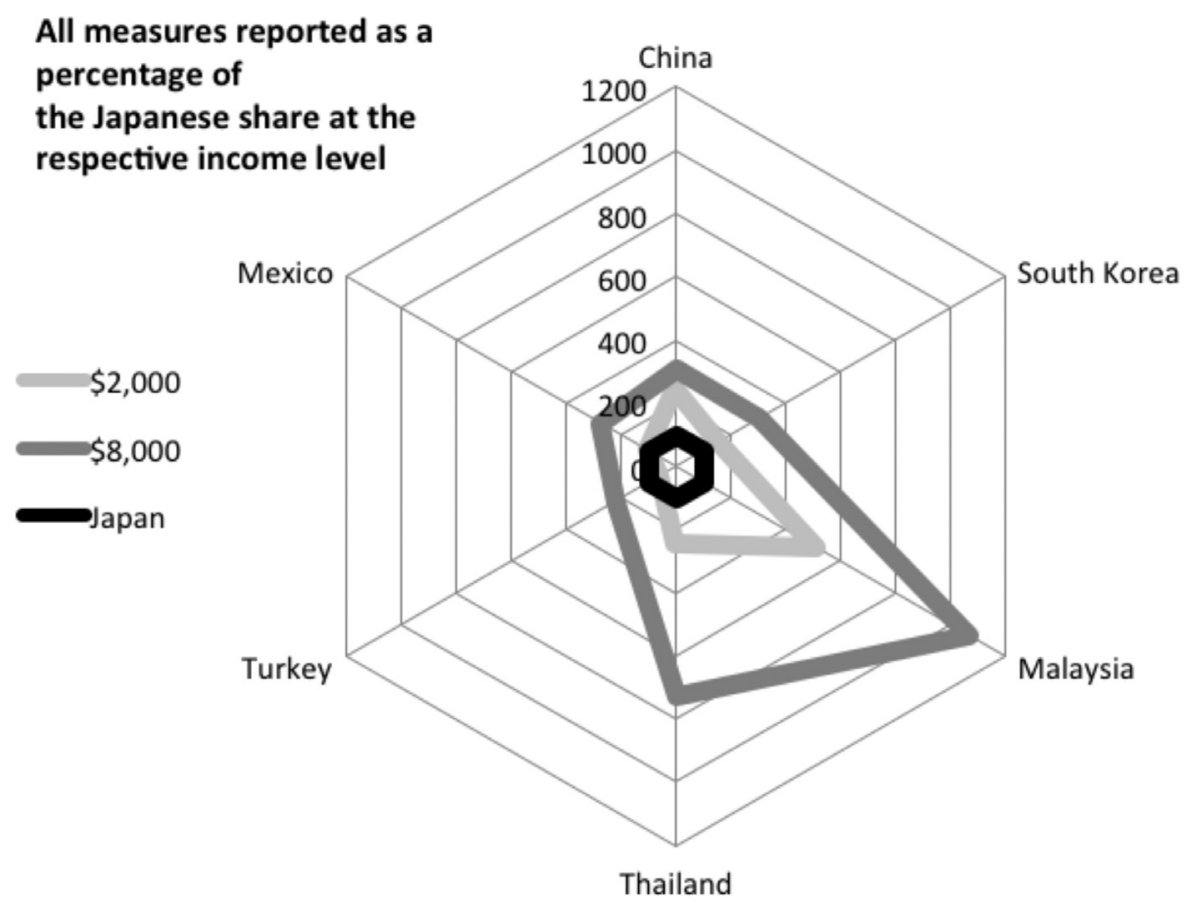

Note: Exports of goods and services as a share of GDP.

Source: World Bank Databank, available at http://databank.worldbank.org/data/views/variableselection/ selectvariables.aspx ?source $=$ world-development-indicators 
Moving forward to the $\$ 8,000$ per head snapshot, and the initial impression is that there is a much greater degree of similarity between the economies in the sample at this stage of development than at the jumping off point. The main exception is in infrastructure, where Japan remained far ahead of the rest of the group. As for China itself, its raw relative rankings on most indicators remained similar to those seen at the $\$ 2,000$ per head level, but it looked less extreme in terms of investment share and industrial production as a share of total output, and the degree to which it was lagging in terms of urbanisation declined. The decline in its lead was a result of rising shares in the other countries, while China maintained a high level. The improvement in China's relative standing in terms of urbanisation was a function of rapid increases in China and less rapid gains elsewhere. As for export orientation, China retained substantially greater exposure to foreign demand than the larger economies in the sample (noting that Mexico's participation in the North American Free Trade Agreement (NAFTA) saw it narrow it the gap to a degree); South Korea caught China up; while the two Association of Southeast Asian Nations (ASEAN) economies moved far ahead.

This investigation clearly shows that the characterisation of China's economy as simultaneously over-industrialised, under-urbanised and more export oriented than is usual for large economies - all relative to development level is valid today, just as it was in the 1990s. That is, despite rapid urbanisation in China during the last two decades and despite rapid increases in the industrial production and investment shares of output, and export orientation of sales, in other successful industrialisers in the post-Second World War period. As of 2011, at a GDP per capital level of around $\$ 8,000$, China is less atypical than it was in 1995 as a $\$ 2,000$ per head economy, but it retains a highly distinctive structure.

\section{Policy Parameters of the Current and Historical Systems}

The previous section offered a simple description of the changes in the Chinese economy between the GDP per capita levels of $\$ 2,000$ and $\$ 8,000$ within a comparative setting. This section established the 'what': the outcomes generated by the historical models of development adopted by successive eras of Chinese policymakers up to the recently installed fifth generation of leadership. We must now consider the 'how' and the 'why': the historical policy framework itself and the outcomes it attempted to facilitate.

To stylise heavily, China's over-industrialised present state is a result of a complex array of price and incentive distortions that have worked to prioritise industrial development, both heavy and light, both domestically consumed and export oriented, over other potential uses of resources. These distortions 
pervade both the real and financial spheres of the economy and create an unbalanced underlying structure. Key factor input costs-labour, land, energy and capital, plus the pricing of external diseconomies - have historically been suppressed (Huang and Tao 2010), which raises the return on investment, encourages capital accumulation over consumption and boosts international competitiveness. The result is an unusually high share of industrial value added in total output; an unusually high share of capital formation in total expenditure; unusually high gross savings across the three key institutional sectors (Ma and Wang 2007); and, unusually high export orientation for a large economy.

China's under-urbanised present state is the direct result of an overall policy framework that has prevented internal rural-urban migration from progressing at the rate at which push and pull motivations alone would have predicted (Song and Sheng 2005). The discrimination still exists as practised against migrant workers under the hukou system (Watson 2009, Song, et al. 2010), uncertainty over land tenure, and a range of socio-economic factors, such as a social security system that is inaccessible to migrant workers, serve as effective barriers to unfettered rural to urban migration and systematic participation in off-farm work (Démurger 2012). Even so, the stock of migrant workers is large, numbering 253 million people in 2011 according to Andrew Watson (2012: Table12.1: 282), although the precise number remains contested. Migrant workers and their families are not yet full participants in the lifestyle enjoyed by non-migrant urban residents. The policy objective of optimising urbanisation is at its core a desire to converge the living standards of this large but underprivileged group with those of the rest of urban society, which are hardly standing still.

In the introduction to the previous volume in this series (McKay and Song 2012: 2) we wrote the following:

the pursuit of 'balanced' economic growth is best thought of as a broad policy objective that aims to limit risks to growth and to mitigate the negative impact on welfare. It should therefore not be expressed as a particular target, such as a reduction in the current account surplus or a rise in the labour share of income. The role of policy should be to design and implement a framework that reduces distortions, encourages and rewards innovation, equalises access to education, employment, a social safety net and capital for investment, while minimising rent-seeking opportunities. The desire to achieve such an environment will create demand for institutional reforms that can facilitate these processes of structural change in the least disruptive fashion.' The proposals we advance below are put forward in that spirit. 
The recent remarks of the new premier, Li Keqiang, reported by official news agency Xinhua (2013b) are clearly in sympathy with this construct. Speaking at a macroeconomic seminar on 12 April 2013, which brought together policymakers, scholars and industry representatives, Li stressed that the deepening of reform was vital to the sustainability of growth and that any counter cyclical efforts would be considered in the context of their longer term structural implications and their impact on the reform path. The exact reporting was as follows:

'While effectively coping with short-term problems and maintaining reasonable growth, more efforts should be made to improve the quality and benefits of development, with a focus on promoting economic restructuring and upgrading, expanding employment and increasing people's incomes', he said.

He said the impetus for sustained development lies in deepening reform, urging targeted policies to cure not only 'symptoms' but deeply-rooted problems in the Chinese economy.

'If interim measures have to be carried out, they should not set up barriers for promoting market-oriented reform and development in the future', he said. (Italics by the authors)

To take those principles and make them more practically actionable, a little taxonomy is desirable. Measures and recommendations can be usefully divided into those that a) directly tackle specific distortions that create rents and skew resource allocation (for instance energy pricing), b) those associated with addressing asymmetric opportunities that lead to and inflame imbalances (for instance the pension system), and c) those that seek to minimise macroeconomic risks, or enhance macroeconomic benefits, in a more general way (for instance financial system reform).

Huang and Tao (2010) put forward the proposition that China's unbalanced economic structure (and the consequent rapid widening of the current account surplus in the 2000s) can be ascribed to what they term 'asymmetric market liberalisation'. They argue that while the goods market is predominately liberalised in China, factor market liberalisation has lagged behind. They produce estimates of producer subsidy equivalents emanating from a range of factor market distortions at an annual frequency between 2000 and 2009. A summary of their results is reported in Table 5.2. This is a good place to move from the general to the specific.

The estimates of Huang and Tao show that material distortions exist in the 'markets' for labour, land, capital, energy and the environment. Each of these distortions serves to lower input costs to business, allowing the estimation of an (admittedly crude) 'producer subsidy equivalent' in each area. These advantages 
lead to greater international competitiveness and profitability in many sectors. These excess profits come at the expense of the providers of the good or service whose output price is suppressed, in essence an inter-sectoral transfer. It is principally migrant workers who are disadvantaged by suppressed labour costs; it is the indigenous private sectors who are disadvantaged by barring them from access to finance from the formal banking sector; it is upstream energy suppliers who are disadvantaged by suppressed costs to final users; it is the community of domestic savers who are disadvantaged by the suppressed cost of capital and financial repression more generally; it is the Chinese and global commons, today and into the future, that suffer from the lack of effective pricing of negative externalities such as the environmental degradation; and, it is foreign competitors of Chinese firms who are disadvantaged by the competitive edge bestowed by a suppressed cost base in China. Further, intra-sectoral distortions, such as preferential treatment for state-run or certain foreign invested firms, also serve to skew economic structures, as not all Chinese businesses are equal in terms of their access to cheap factors (especially land and capital), and barriers to entry in many key sectors create further rents for powerful incumbents.

Table 5.2 Producer subsidy equivalents of factor market distortions in China, 2000-2009 (\% of GDP)

\begin{tabular}{l|c|c|c|c|c|c}
\hline & Land & Labour & Capital & Energy & Environ & Total \\
\hline 2000 & 0.5 & 0.1 & 4.1 & 0.0 & 3.8 & 8.5 \\
\hline 2005 & 1.3 & 2.4 & 3.0 & 1.7 & 3.0 & 11.4 \\
\hline 2007 & 1.2 & 3.2 & 3.6 & 1.6 & 2.4 & 12.0 \\
\hline 2009 & 0.9 & 2.7 & 3.5 & 0.7 & 1.8 & 9.6 \\
\hline
\end{tabular}

Source: Huang and Tao (2010: Table 5.1).

Approaching the most transparent distortions first, a move towards market-based energy pricing for end users of electricity and petroleum products should be an immediate priority. Moving towards a system that prices negative externalities, thus endogenising a portion of the cost of environmental degradation into the bottom line of business, is a further obvious area for reform. Huang and Tao argue that the combined 'prize' of reform in these areas - the reversal of 2009 levels of producer subsidy equivalents - is around 2.5 per cent of GDP annually. There have already been a number of announcements in both areas, and China is by no means new to the taxing of pollutants (OECD 2013: 136), implying both awareness of the problems and a willingness to act on behalf of policymakers. Experimental programs that would price emissions have been initiated in selected administrative regions, while energy efficiency targets have been enshrined in the five-year planning process (OECD 2013: Box 2.1: 125), both nationally and at the large-firm and industry 
level. Vehicle emission standards are monitored and enormous investments in renewable energy have been undertaken (Australian Government Department of Climate Change and Energy Efficiency, 2013).

In late March of 2013, some key announcements on energy pricing were made (Taplin and Yao 2013). The liberalisation of coal pricing arrangements inside China, and the administrative willingness to pass on changes in the market prices of energy inputs to end users more frequently and more completely than is currently the case, is an important step towards the use of price signals to guide more efficient energy use. Developments across these areas will help to address the 'over-industrialised' aspect of China's present economic structure, but there is a great deal still to do. Even so, the taxation share of Chinese retail diesel and gasoline prices is low by international standards (OECD 2013: Figure 2.9.: 131) and household and industrial electricity costs are also low (ibid.: 133).

Addressing the distortions associated with capital-where the direct 'prize' is close to $3 \frac{1}{2}$ per cent of GDP annually and the total prize in terms of macroeconomic stability is arguably considerably larger in the long runrequires a broader approach. Indeed, when Li urged 'targeted policies to cure not only "symptoms" but deeply-rooted problems', it is an acknowledgement that a redesign of the major parameters that describe the current capital allocation system ought to be on the agenda. Disentangling the complex web of the many tiers of the banking system, shadow finance, exchange arrangements and the exchange rate - monetary policy regime is no simple matter. It is not just that capital is too cheap for certain large firms. Household savers are poorly remunerated as a consequence of historically regulated deposit rates. A lack of financial market development and exchange arrangements that disallow personal outward portfolio flows provides a limited menu of alternative investment options. Small, private firms often pay too much for their capital. Chinese exporters are advantaged by the competitive exchange rate, thereby raising export orientation, while importers are disadvantaged by it, which lowers domestic absorption.

As in the areas of energy and externality price reform, there has already been much activity in the field of financial liberalisation. Greater flexibility in setting deposit and lending rates has been introduced, although they are not yet fully free. The domestic bond market has been encouraged as an alternative source of both private and public financing. Loan securitisation has been encouraged. Exchange rate flexibility has been increased progressively after the peg to the US dollar was abandoned in 2005; reserve accumulation has levelled out; the supply of RMB now available outside the Mainland has increased rapidly as part of the trade settlement program, the centrepiece of the internationalisation initiative; the Qualified Foreign Institutional Investor (QFII) program, the Qualified Domestic Institutional Investor (QDII) program and a new Renminbi 
QFII program have been revamped or instituted; and, outward flows of direct investment have continued to enjoy policy sponsorship. Furthermore, since the middle of 2012, the People's Bank of China (PBoC) has increasingly relied upon its open market operations to manage domestic liquidity and credit conditions, rather than the traditional administrative tools of required reserve ratios, window guidance and lending quotas. And, in a further move towards sophistication, rather than issuing or purchasing bills, reverse repurchase agreements dominated open market operations in 2012, when liquidity was being increased, while repurchase agreements have been used in 2013 so far to keep liquidity from expanding too quickly.

All of this activity points in the right direction. Yet, moving more swiftly on interest rate liberalisation, particularly with regard to deposit rates, would be a welcome move. An unintended consequence of the slow movement towards deregulation of interest rates has been the rapid growth of off balance sheet activity by the banks and a rise in the market share of non-banks in total credit supply. While such developments are desirable as part of an effort to deepen domestic financial markets, extraordinary growth in lightly regulated areas of the financial system unavoidably comes with heightened systemic risks.

Moving on to the monetary policy - foreign exchange nexus, in concert with the moves to increase the power of market forces in setting the domestic cost of capital, exchange rate flexibility has increased in material fashion since 2005, to the extent that the currency is an accepted element of the counter cyclical toolkit. While the daily volatility of the currency within the present band of plus-minus one per cent remains low, there have been official statements that a further widening of the band is just a matter of time. To quote People's Bank of China deputy governor Yi Gang directly, who spoke at an International Monetary Fund meeting in Washington DC on April 18, 2013:

Last year we increased the band for the exchange rate from 0.5 per cent to one per cent. I think in the near future we'll increase the floating band even further. ...

In China, we all do this kind of reform in a gradual manner. The direction is clear (quoted in People's Daily online 2013).

The desire to maintain a gradual approach to exchange rate flexibility emanates from China's structural legacies, the most obvious of which in this context is its high degree of export orientation, and the psychological difficulty of changing a winning formula. The success of China's gradual approach to financial reform through its transition era has been rightly celebrated. Yet when a new model is required, rather than a marginal evolution of business as usual, a bolder strategy is perhaps more appropriate. 
It is possible to infer a relationship between macroeconomic stability, GDP per capita and financial reform in developing economies. Our abstract conception of this relationship is depicted in Figure 5.4. We have refrained from using actual values on the GDP per capita axis, as the precise point at which these hypothesised curves cross is unknowable, and may vary considerably based on the strategy individual economies take towards its financial system in the context of its industrialisation. That said, recalling the initial discussion and peer review of China's industrialisation path and mode, in this framework it seems reasonable to pursue a gradual approach to financial reforms at a GDP per capita level of $\$ 2,000$. At $\$ 8,000$, however, the implicit cost-benefit analysis of that strategy, where macroeconomic stability is the ultimate objective, will be less clear cut. Cognisant as we are of the wisdom of the State Council, that 'deepening ... reform is a systematic project that is arduous and complicated ... There is no way to accomplish it overnight' (Xinhua News 2013a), which are especially relevant sentiments regarding financial matters, we respectfully submit that the China of today, in search of a new model, cannot be far from the crossover point in Figure 5.4, if it is not already there.

Deepening financial deregulation cuts across the three reform categories that we put forward above. It would tackle specific distortions that create rents and skew resource allocation (the low cost of capital for certain firms and industries), it would address asymmetric opportunities that lead to and inflame imbalances (improve entry conditions to boost competition, improve access to finance for private firms and households), and work to minimise macroeconomic risks, and enhance macroeconomic benefits, in a more general way (reducing systemic risk through increasing the market based allocation of capital).

Turning now to labour, the basic wages of migrant workers have been increasing rapidly in recent years, which is a joint consequence of the demographic tightening of the labour market and a policy focus on raising incomes. Historically, wage rises for this group may have been as little as half the rate of increase of the wages of other workers (Huang and Tao: appendix: 27). They remain, however, an underprivileged group in a number of key ways:

1. access to public services in their place of residence for themselves and their families, rather than in their place of registration

2. access to social security in their place of residence, rather than in their place of registration

3. access to equivalent non-wage working conditions as urban residents. 
Figure 5.4 The relationship between macroeconomic stability, GDP per capita and financial reform in developing economies

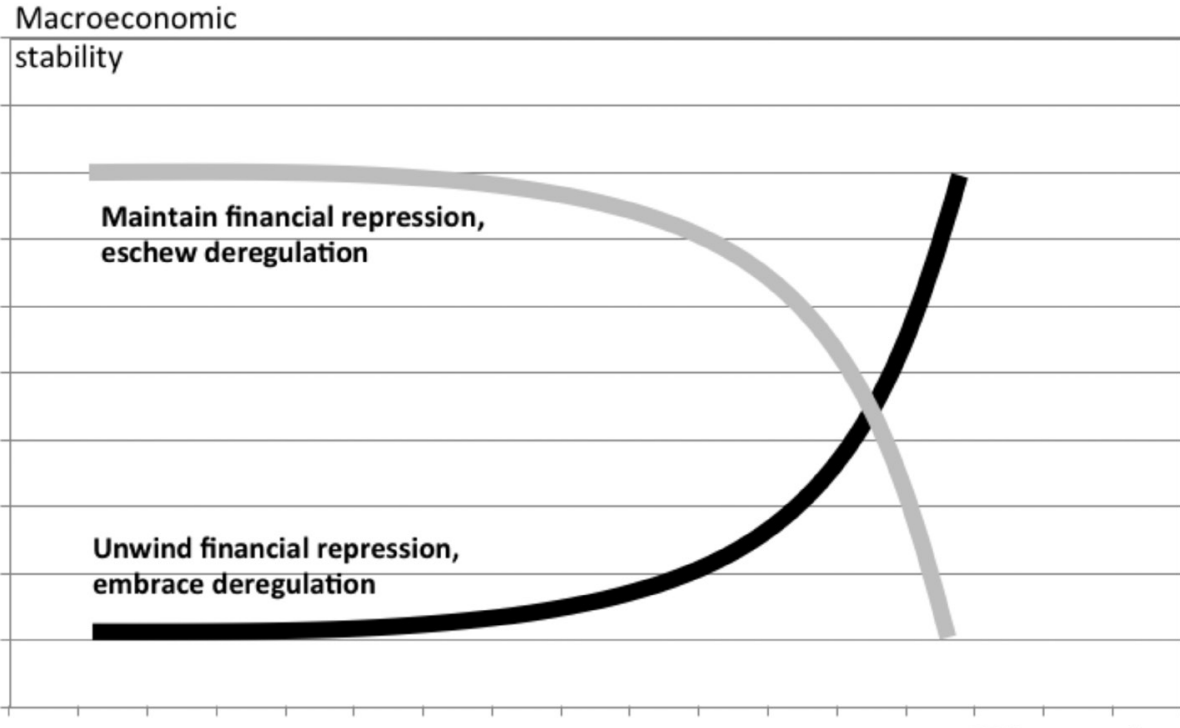

GDP per capita

Source: Authors' own conception.

Bringing about such access will do much to optimise the opportunities presented by current and future urbanisation. The increase in consumption that such optimisation implies, with an equivalent decline in savings rates, will raise domestic absorption, cushion the impact of excess capacity in industry and accommodate a re-orientation towards domestic demand rather than foreign sales. Like the financial reform question, the migrant labour question cuts across many fundamental policy areas. And also like the financial reform question, bringing about the access regime depicted above will feature initiatives that fit into each of three categories above - tackle specific distortions (the low nonwage costs borne by firms employing migrants), it would address asymmetric opportunities that lead to and inflame imbalances (improve quality and quantity of education and health care), and work to minimise macroeconomic risks, and enhance macroeconomic benefits, in a more general way (providing the demand cushion for a re-orientation towards domestic sales, while helping to absorb excess industrial capacity). It is here that the ultimate complementarity of the twin goals of reducing the characteristic 'over-industrialisation' and optimising the benefits of urbanisation becomes extremely clear.

Employers are able to avoid considerable non-wage costs when they employ migrant workers rather than registered urban residents. These costs include social security contributions; unemployment, injury and health insurance; and, 
housing and maternity benefits. This is essentially a transfer towards employers and away from the household sector, which sponsors capital accumulation over consumption. It is also a competitiveness issue, suppressing costs for Chinese labour-intensive manufacturing firms in the traded sector. Universal labour laws that do not recognise the hukou taxonomy will bring about an immediate and permanent increase in the labour share of income at the expense of excess profits.

Furthermore, it is difficult for most rural migrants to achieve urban resident status, with all the advantages (or lack of disadvantages) that this bestows in terms of access to quality and quantity of education and health services. The qualifying points systems that prevail in key destination provinces, such as Guangdong, are weighted against rural migrants. These systems are biased against poorly educated, low skill workers, who comprise the majority of the migrant labour force (OECD 2013: 97). China's average years of schooling at the $\$ 2,000$ GDP per head levels was similar to both Japan and South Korea, but it has slipped behind them at the $\$ 8,000$ per head threshold (Figures 5.2a and $5.2 \mathrm{~b})$. And, as the quality of that education is regionally variable, and affected by hukou status (OECD 2013: 91), then perhaps China is further behind than the raw figure suggests. This raises a further question about the adaptability of the current work force to a new model that is focused less on heavy industry and more on the consumption of services.

Watson's (2012) call for an integrated, centrally administered and funded and portable pension system available to all Chinese citizens is an appropriate template for social security reform. It is an obvious inefficiency in China's fiscal system that the national government has effectively centralised taxation revenues, but that expenditure responsibilities have not been transferred in lockstep.

The transition to a new model that de-emphasises manufacturing, investment and export sales and re-emphasises domestic household consumption cannot be brought about without fiscal reform. Indeed, fiscal policy is the key weapon at any government's disposal for altering the relative prices of productive factors and the ultimate distribution of national income among key sectors. One example is the preferential treatment of state-owned enterprises (SOEs) in terms of their dividend payments. The government can and should demand a higher rate of dividend payments from SOEs and redeploy the funds to accommodate the migrant welfare reforms considered above. The recently issued State Council guidelines for income redistribution set out such a policy. In a period when factor distortions that disproportionately benefit large, centrally controlled SOEs remain in place, it makes sense to redistribute their excess profits in a structurally beneficial way, rather than allowing further inefficient capital accumulation in the commanding heights. Competition policy can also 
be brought to bear in this regard. Policies that boost competition in services sectors through foreign investment and those that constrain oligopoly pricing could have considerable benefits in rebalancing the growth model (Tyers 2012).

Another relevant aspect of China's historical path is the infrastructureurbanisation nexus. In the peer review we noted that our infrastructure proxy - the length of rail line open scaled by land area-implied that China may by over-industrialised, but it is not without infrastructure deficits. Looking more broadly at the infrastructure space, annual logistics costs were equivalent to 18.1 per cent of GDP in 2012, compared to approximately ten per cent in the United States. ${ }^{3}$ Regarding mass urban transit systems, the OECD argues that 'A considerable deficit in provision needs to be overcome. In the ten largest cities, the average rail density per square kilometre is only one quarter that in the major urban areas outside of mainland China and the density per one million people is only one fifth' (2013: 74). In terms of end-to-end international trade logistics, China ranks 26th worldwide in the World Bank's Logistics Performance Index (World Bank 2012), ranking around 20 per cent less efficient than the frontier economies in the sample. Only 74 per cent of urban Chinese presently have access to sanitation, according to World Bank data (World Bank 2013). Against this evidence, it is not difficult to envisage the share of capital accumulation going into infrastructure rising, as China seeks to optimise its urbanisation opportunity, with the share going towards manufacturing capacity-particularly of the energy intensive and/or export oriented varieties - declining. Allocating investment to areas where the country continues to have a capital stock deficit, and reducing the emphasis on areas where capacity is already ample or excessive, will increase the efficiency of capital across the economy.

\section{A Political Economic Comment}

All of the above policy proposals, both specific and general, have been normative in nature. Our recommendations do not take account of the likely resistance of vested interests within the Chinese system. Entrenched rent seekers - or distributional coalitions as Olson (1982) termed them — do not have a history of stepping gracefully aside when their privileges are attacked. It would be naive to ignore this possibility in China. Indeed, the current administration has not just inherited an expenditure and income structure, it has inherited a structure of interests that have benefited from the historical model that will

3 The Chinese figure is calculated using data sourced from the CEIC data company. The figure for the United States is a personal communication from Access Asia, a Shanghai-based consultant to multinational retailers. 
seek to defend their accumulated gains and to retain their privileges. The new leadership recognises this challenge is a considerable one over and above the need to install a new growth model. Returning again to the State Council's own words: 'deepening the income distribution reform is a systematic project that is arduous and complicated and concerns the reallocation of various interests' (Xinhua News 2013a, authors' italics).

Here again, a number of initiatives have been instituted to address certain issues in the rent seeking field. Symbolic moves - 'austerity begins at home'style policies, which have already been announced, include the capping of executive remuneration for state-appointed positions in SOEs, and income growth for executives must be slower than for rank-and-file employees; existing requirements for officials to report their income and assets will be implemented more strictly; the use of public funds for entertainment, automobile purchases and international travel will now be strictly monitored (anecdotal evidence indicates that the austerity required of officials over the Spring Festival in February 2013 reportedly led to substantially reduced turnover in high end restaurants); grassroots civil servants and those in underprivileged and remote locations will have their remuneration increased at higher rates than senior and better located state employees; and, cross-referencing of SOE average salaries across different sectors, with an aim of narrowing existing wage gaps; and a freezing of government staffing levels and a progressive reduction in the number of senior positions (Xinhua News 2013c).

Recently announced policy parameters with the potential to cut deep into current sources of imbalance and inequity are as follows:

1. Demanding that the proceeds from the use and sale of state resources - for example land, seas, water, minerals, forests - must be used for the provision of public services.

2. Reforms to the taxation of property, notably the extension of the current experimental holdings taxes nationwide.

3. Dividend reforms for SOEs (increasing their payout ratio to the state by five percentage points by 2015) and listed companies (Xinhua News 2013c).

These three areas are vital for the deepening of reform and shifting the economy towards a new model that is more sustainable and equitable. Our comment is, however, that there is a large gap here: competition policy. While redistribution of rents is a useful transitional position, a long-term solution must look to minimise the rents themselves. The discussion of the previous section considered the policy options for tackling the factor market distortions that generate rents. Undue market power is another distortion that redistributes 
income to domestic firms in oligopoly sectors, and away from households, the government, and firms paying inflated prices for inputs; and, foreign firms that lose market share to such firms at home and in third markets.

The fact that the leadership is clearly not complacent on this front gives us confidence that the promising policy framework that is presently emerging will be progressively carried to its logical conclusion with resolve. The initial challenge in this regard will come with the next cyclical downturn, when the new model of growth is not yet firmly established and the temptation to mobilise demand in well-established, structurally negative ways will be strong (McKay 2011). While Li's sentiment on this future dilemma has already been quoted above, it is worth reviewing again:

'While effectively coping with short-term problems and maintaining reasonable growth, more efforts should be made to improve the quality and benefits of development, with a focus on promoting economic restructuring and upgrading, expanding employment and increasing people's incomes', he said.

'If interim measures have to be carried out, they should not set up barriers for promoting market-oriented reform and development in the future', he said. (Xinhua 2013b, authors' italics)

\section{Conclusions}

This chapter began by illustrating that China's economic structure can be characterised as both over-industrialised and under-urbanised relative to its level of income per head, while maintaining a high degree of export orientation for such a large economy. This discussion was framed by the experience of a peer group of economies that have also succeeded in quadrupling their living standards from $\$ 2,000$ GDP per head to $\$ 8,000$ GDP per head in the post-Second World War period.

Some aspects of China's historical path and the resultant contemporary structure were positioned as an impediment to sustaining growth in aggregate living standards in an environmentally conscious way, while simultaneously promoting equality of income and opportunity. Others were seen as advantageous for the pursuit of these basic national goals.

We then proceeded to outline desirable changes in policy to accommodate a new model, alongside a discussion of initiatives already put in place by the administration to that end. This discussion was initially conducted within the context of a direct effort to address specific factor market distortions, but was later broadened to macroeconomic policy writ large. Our recommendations 
were to deepen and accelerate financial reform - domestic and international - in a holistic way; move swiftly on wholesale hukou reform; continue with the current momentum towards market-based pricing of energy and negative externalities; prioritise infrastructure investment over industrial capacity; and, address fundamental long-run fiscal questions to accommodate the desired reallocation of resources across the economy. We concluded this discussion optimistically, given our view that the superordinate goals of China's next transition - reducing 'over-industrialisation', optimising urbanisation and emphasising domestic absorption over foreign sales - are ultimately complementary.

At this point we introduced a caveat: that the many facets of path dependence present a material prima facie political-economic constraint on the Chinese leadership's absolute freedom of choice and action. We applaud the present direction of the policy regime and the objectives of the administration are sound. Yet, we believe that the absence of a well-defined approach to competition policy is a clear shortfall in the existing framework put forward by the new leadership. Further, we noted that the next cyclical downturn will be a strong test of the stoicism of the reformers.

Finally, the fact that the leadership is clearly not complacent gives us confidence that the required reforms will be carried to their conclusion with resolve, if not necessarily with alacrity. There is much to recommend in the policy contours that have already emerged in pursuit of those inherently complementary goals. Yet inside those contours, a political economic battle must still be fought. Reducing 'over-industrialisation', optimising urbanisation and emphasising domestic absorption over foreign sales are necessary conditions for a successful transition of China's growth model.

The board is set. The pieces are moving. ${ }^{4}$

\section{References}

Australian Government Department of Climate Change and Energy Efficiency, 2013, Climate Change: Countries Acting Now, available at http://www. climatechange.gov.au/en/government/international/global-action-facts-andfiction/ /media/government/international/factsheets/IntAction-FacsheetCountriesActingNow-20121113.pdf

Batson, Andrew, 2013, 'China's Lending Landmark', GK Dragonomics Ideas, 10 April, subscription research service available from http://gavekal.com/ dragonomics/

4 With apologies to the scriptwriters of The Lord of the Rings for borrowing Gandalf's immortal phrase. 
Bénétrix, Agustín S., O’Rourke Kevin H. and Williamson Jeffrey G., 2012, 'The Spread of Manufacturing to the Periphery 1870-2007: Eight Stylized Facts', NBER Working Paper 18221, July.

Central Intelligence Agency, 2012, The World Factbook Online, available at https://www.cia.gov/library/publications/the-world-factbook/index.html

Démurger, Sylvie, 2012, 'Mapping Modes of Rural Labour Migration in China', in Huw McKay and Ligang Song (eds), Rebalancing and Sustaining Growth in China, ANU E Press, Canberra, pp. 207-24.

Huang, Yiping and Tao, Kunyu, 2010, 'Causes and Remedies of China's External Imbalances', China Center for Economic Research Working Paper Series, Peking University, No. E2010002, 25 February.

Ma, Guonan and Wang, Y., 2010, 'China's High Saving Rate: Myth and Reality', International Economics, no. 122 (December), pp. 5-40.

McKay, Huw, 2011, 'China's Turbulent Half Decade', in Jane Golley and Ligang Song (eds), Rising China: Global Challenges and Opportunities, ANU E Press, Canberra, pp. 9-28.

McKay, Huw and Ligang Song, 2012, 'Rebalancing the Chinese Economy to Sustain Long-Term Growth', Huw McKay and Ligang Song (eds), Rebalancing and Sustaining Growth in China, ANU E Press, Canberra, pp. 1-18.

Mitchell, Brian, 1975, European Historical Statistics: 1750-1970, Columbia University Press, New York.

—, 1982, International Historical Statistics: Africa and Asia, New York University Press, New York.

- 1993, International Historical Statistics: The Americas 1750-1988, Macmillan Stockton Press, New York.

OECD, 2013, OECD Economic Surveys: China, March 2013.

Olson, Mancur, 1982, The Rise and Decline of Nations: Economic Growth, Stagflation and Structural Rigidities, Yale University Press, New Haven.

People's Daily online 2013, 'No Winner in Competitive Currency Devaluation', available at http://english.people.com.cn/90778/8212859.html

Song, Ligang and Yu, Sheng, 2005, 'Rapid Urbanisation and Implications for Growth in China', in Ross Garnaut and Ligang Song (eds), The China Boom and Its Discontents, Asia Pacific Press, Canberra, pp. 105-27. 
Song, Ligang, Wu, Jiang, and Zhang, Yongsheng 2010, 'Urbanisation of Migrant Workers and Expansion of Domestic Demand', Social Sciences in China, vol. 31, no. 3, pp. 194-216.

Taplin, Nate and Yao, Rosealea, 2013, 'Powering Up Price Reform', GK Dragonomics Tools, 18 April, subscription research service available at http://gavekal.com/dragonomics/

Tyers, Rod, 2012, 'Looking Inwards for Growth', Huw McKay and Ligang Song (eds), Rebalancing and Sustaining Growth in China, ANU E Press, Canberra, pp. 19-44.

United Nations Development Program, 2013, International Human Development Indicators, available from http://hdrstats.undp.org/en/indicators/

United Nations, 2011, World Urbanization Prospects, the 2011 Revision, available from http://esa.un.org/unup/

Union of International Railways, 1991, UIC Member Railway StatisticsSynopsis, available at https://www.uic.org/spip.php?article1350

—_ 2001, UIC Member Railway Statistics - Synopsis, available at https:// www.uic.org/spip.php?article1350

Watson, Andrew, 2009, 'Social Security for China's Migrant Workers - Providing for Old Age', Journal of Current Chinese Affairs, vol. 38, no. 4, pp. 85-115.

_ - 2012, 'Building Social Welfare in China' in Huw McKay and Ligang Song (eds), Rebalancing and Sustaining Growth in China, ANU E Press, Canberra, pp. 265-88.

World Bank, 2012, Connecting to Compete: Trade Logistics in the Global Economy, available at www.worldbank.org/lpi

—, 2013, World Development Indicators Online, available from http://data. worldbank.org/topic/

Xinhua News, 2013a, 'China to Reform Income Distribution', online at http:// english.people.com.cn/90778/8122934.html

Xinhua News, 2013b, 'Premier Stresses Foresight in Economic Policymaking', online at http://news.xinhuanet.com/english/china/201304/14/c_132308046.htm

Xinhua News, 2013c, 'Factbox: Highlights of China's Income Distribution Reform Plan', online at http://news.xinhuanet.com/english/china/201302/07/c_132155961.htm 


\section{China's Saving and Global Economic Performance ${ }^{1}$}

Rod Tyers, Ying Zhang and Tsun Se Cheong

\section{Introduction}

During the past decade, China's excess saving became a major source of finance for the high levels of net debt in the industrialised world. Indeed, after 2005 and, particularly, in the immediate aftermath of the GFC it became the dominant single source. Yet China's net saving abroad has been slowing as domestic debt rises and both its current account surplus and its rate of foreign reserve accumulation contract. The slower and more 'inward focused' growth prospects for China (Tyers 2012) will further reduce its excess saving over time. Combined with a similar trend in Japan, this brings an end to the era of the Asian 'savings glut', ${ }^{2}$ which, other things being equal, must raise the global cost of debt. Although the signs of an associated tightening in global financial markets seem beyond the horizon at present, this is because of the 'quantitative easing' (QE) being carried out by the central banks of the largest three economic blocs, the European Union (EU), the United States and Japan. Governments in these economies continue to issue new debt but this debt is increasingly acquired by their central banks rather than foreign institutions. Since the GFC, notwithstanding their liquidity traps, the central banks of these regions have expanded their balance sheets at least two-fold and these expansions continue. ${ }^{3}$

This increase in the global supply of the key currencies has only been possible because sustained uncertainties surrounding government finance in all the regions, combined with underlying deflation, have induced global portfolio holders to maintain unprecedented shares of 'safe assets', namely money and related short financial instruments. Yet this will change and, when it does, the major central banks will have a lot of liquidity to mop up. Because of their recent adoption of $\mathrm{QE}$, their balance sheets are heavy with long-maturity financial instruments that must eventually come back to the market and, when they do, yields will rise quickly. This is significant since it is the long instruments that are both extensively traded internationally and close substitutes for equities in

1 Funding for the research described in this chapter is from Australian Research Council Discovery Grant No. DP0557885.

2 See Bernanke (2005), Chinn and Ito (2007), Choi et al. (2008) and Ito (2009).

3 Until 2013, Japan's expansion since 2000 was proportionally smaller. 
all three economic blocs. Once returned to markets these will likely create a glut of long instruments, curtailing investment financing more directly than would occur under a more conventional monetary contraction.

Given that newly cheap energy in the United States suggests it could lead the northern recovery, much then depends on the implications of slower Chinese saving growth for US capital markets and investment. It certainly means that the demand for long-maturity bonds will fall, exacerbating the glut in their markets and restricting investment credit. Moreover, China's swapping of US\$ reserve assets for central government bonds, and the ceding of the US\$ assets to the China Investment Corporation (CIC), which began in 2007, changes the criteria driving outward financial flows, including and particularly FDI, shifting the distribution of China's foreign asset portfolio away from the United States. In the end, this will mean the brunt of any continuation in the decline in Chinese savings will fall disproportionally on the United States, possibly stifling its recovery. Of course, the effects of this pessimistic scenario could be offset by effective fiscal consolidation in the United States and the other large economic blocs so that global debt falls as global saving falls, leading to a soft landing for private investment.

In this chapter these issues are quantified and analysed using elemental macroeconomics. The next section reviews the trends in domestic economic structure and growth policy in China and their consequences for excess saving there. Section 3 then examines the pattern of China's excess saving through time and the underlying trends behind our expectation that it will decline over time. The focus turns to the global economy and its recent performance in Section 4. The rise in China's international significance in relation to the corresponding scale and performance of the United States, the European Union and Japan is discussed. It also offers a macroeconomic analysis of the effects of further declines in Chinese excess saving and their likely interaction with the unwinding of QE policies in those economic blocs. Conclusions are summarised in Section 5.

\section{China's Economic 'Rebalancing' and its Excess Saving}

There is wide agreement outside China, and more recent concurrence inside, that China's growth will, and should, be increasingly underpinned by rising home consumption rather than exports. ${ }^{4}$ The foreign viewpoint is mercantilist

4 For the foreign, and particularly the US, perspective see Bergsten et al. (2008) and Lardy (2006, 2012). For the Chinese official line on the 'rebalancing' of its economy, including its external accounts, see Wen $(2007,2011)$ and Yi (2011). 
and is taken notwithstanding the considerable contributions of China's exportled growth to improvements in the foreign terms of trade and to cheaper financing of investment and government spending. In China's large trading partners, the dominant political force behind this view seems to be concern over declining overall economic performance, at least compared with China, high unemployment and the visible nature of 'offshoring'. ${ }^{5}$ Moreover, the mutual benefits from China's heretofore export-led growth strategy (Dooley et al. 2004) do appear now to be short-lived because of its sheer size. As Figure 6.1 shows, China's exports have grown rapidly since the turn of the century and now dominate world trade in light manufactures.

Figure 6.1 China is no longer small in global trade

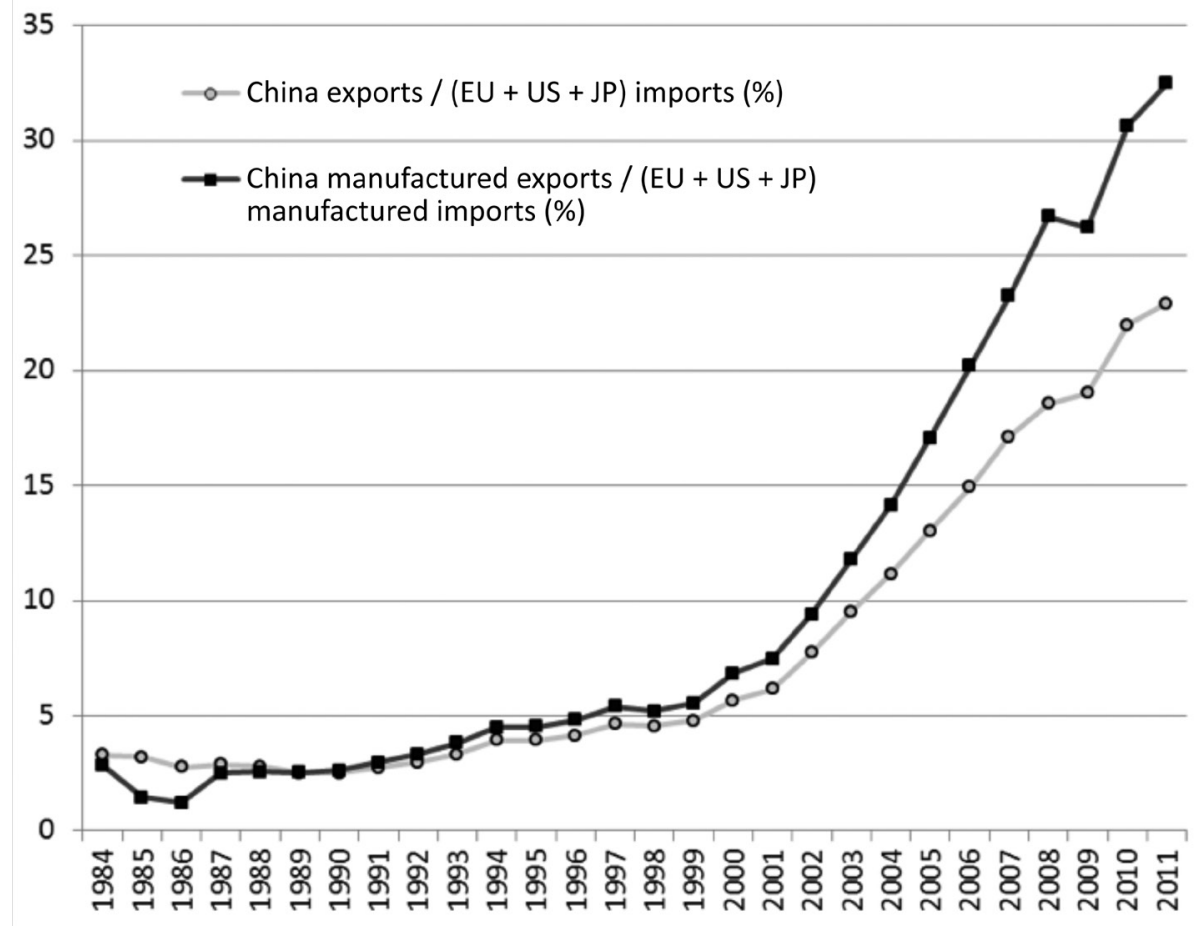

Source: World Bank http//:data.worldbank.org

5 Foreign animus toward China's economic policy regime has been further inflamed by the large current account surpluses of the last decade and the perspective of some in the West that China's political system denies basic human rights or, of others, that its large government and defence forces represent a strategic threat. See Tyers (2012). 


\section{'Looking Inward' for Further Growth}

Superficially, it would seem that a switch to domestically driven growth should be possible, just by consuming more and exporting less. But this simple idea is problematic for two reasons. First, the export-led growth strategy focuses production on light manufacturing, while China's growing middle class demands motor vehicles and high quality services that include transport, telecommunications, health and education. Its existing industries cannot suddenly diversify their output toward these products. Second, rising consumption implies reduced saving and this could tighten the global financial capital market at a time when it would be least opportune to do so.

Beyond this, there are further risks associated with a 'looking inward' strategy. Too rapid change in structure and ethos could be destabilising within China, where it is argued there looms the threat of the 'middle-income trap', which is widely ascribed to other developing regions. ${ }^{6}$ Contractionary forces include the tightening of labour markets - foreshadowing a Lewis 'turning point ${ }^{\prime}{ }^{7}$ associated with the depletion of mobile labour in rural areas and the demographic contraction stemming from China's 'one child policy', shown in Figure 6.2. In addition, there are the high environmental costs associated with China's manufacturing expansion, which are not yet fully covered, and the increased income inequality that is associated with rents in the state-owned sector. ${ }^{8}$ This inequality coincides with socioeconomic stratification in China's periphery, which has precipitated increased class, ethnic and regional conflicts.

6 Key elements of a growing literature include Easterly (2001), World Bank (2010), Eichengreen et al. (2011), Riedel (2011) and Robertson and Ye (2013).

7 The timing of China's Lewis turning point is a subject of controversy, as suggested by the contrasts between the views expressed by: Cai (2010), Garnaut (2010) and Golley and Meng (2011), and these are only a sample of a substantial literature. There is, however, little doubt that the turning point is on its way, even if there is little agreement as to whether recent real wage rises suggest its presence.

8 For a discussion of the institutional and industrial reform agenda and its difficulty, see for example Tyers and Lu (2008), Riedel (2011) and Deer and Song (2012). 
Figure 6.2 The demographic origins of China's slowdown ${ }^{a}$

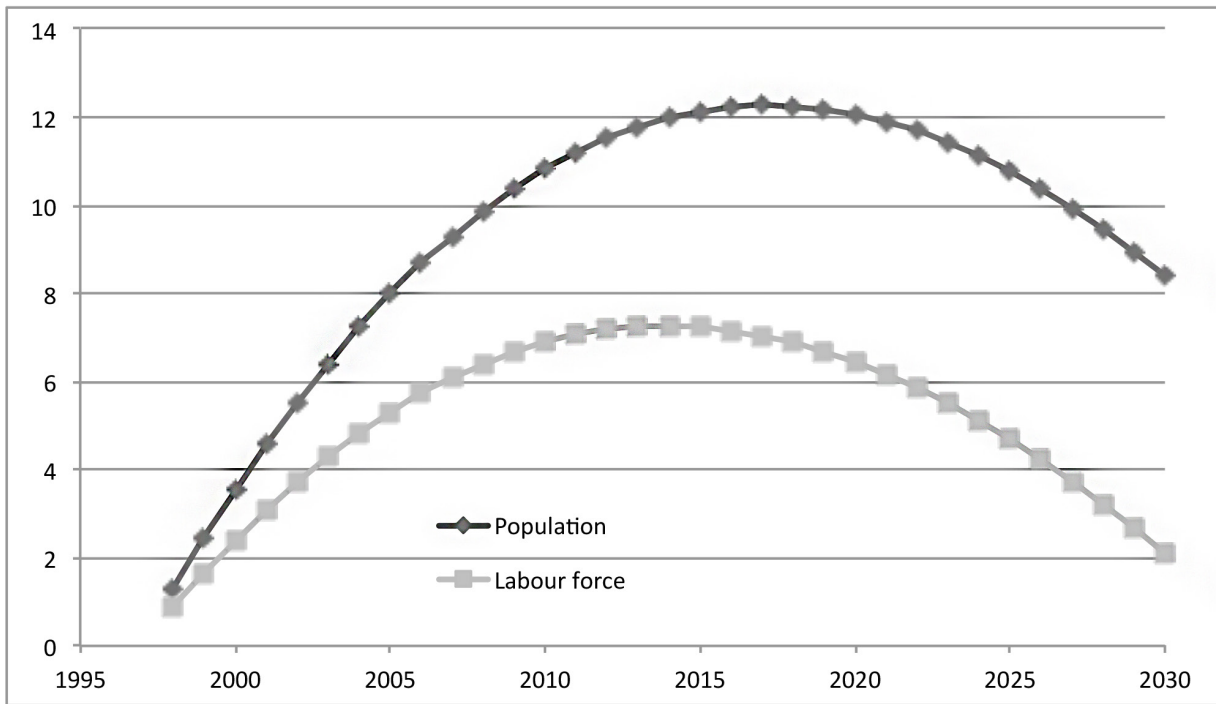

a Indices of mainland China's labour force and its population, model projections.

Source: Golley and Tyers (2012).

There are, nonetheless, substantial potential gains from further industrial reform, stemming mainly from reductions in rents in protected sections of the economy and the associated reductions in costs and prices. These extend across the comparatively protected services and heavy-manufacturing industries that continue to be dominated by state-owned enterprises (SOEs). Alternative inwardfocused policy approaches include expanded government service provision (which could imply less government saving), accelerated human capital growth to reduce costs in services and heavy manufacturing and the revitalisation of stalled industrial reforms in these same sectors. Included are further pure privatisation, the fragmentation of SOEs to induce more competitive pricing, price cap regulation and greater access to services and heavy manufacturing by foreign investors. Because the oligopoly rents earned in these sectors are linked to corporate saving (Kuijs 2006, Song et al. 2011), the latter is comparatively large in China, last measured at about one-fifth of GDP. Industry policy reforms that foster further privatisation, or that otherwise reduce oligopoly rents, are readily shown to reduce the aggregate level of Chinese saving by amounts sufficient to eliminate its current account surplus and hence its provision of excess saving to the global economy (Tyers 2012). 


\section{The Components of Saving and China's External Accounts}

National saving includes that by households, corporations and government. Savings that exceed the value of domestic private and public investment result in a current account surplus and the net acquisition of foreign assets. The excess saving is therefore the value of the net foreign acquisitions as is clear from the identity:

(1) $C A=S_{H H}+S_{C}+(T-G)-I=S_{D}-I=\Delta R-F I_{\text {Inward }}+F I_{\text {Outward }}=X-M+N$

Where $S_{H H}$ is household saving, $S_{C}$ is corporate saving, (T-G) is government saving or the fiscal surplus, $S_{D}$ is total domestic saving, $I$ is investment (including public investment), $C A$ is the current account balance and $N$ is net foreign factor income. ${ }^{9}$ FI signifies foreign investment, inflows or outflows. In China's case these terms are dominated by FDI since cross-border portfolio investments are restricted (though not eliminated) by its capital controls (Ma and McCauley 2007).

Thus, to explore the implications for external accounts we must consider changes to household, corporate and government saving and compare these with changes in investment. Numerous measurement issues arise. The first is that there are inconsistencies between China's GDP estimates based on expenditure accounts on the one hand and production accounts on the other. We use expenditure accounts to estimate overall saving, but draw on flow of funds data, which come from the production side, to separate household from corporate saving. Second, there are at least three additional measurement issues that could inflate the overall saving rate (Ma \& Yi 2010). These include a) a consistent pattern of positive inventory accumulation, which arises because consumption expenditure is survey based with inventories calculated as residual, suggests final consumption is underestimated; b) an apparent underestimation of imputed housing rent reduces both income and saving levels, possibly inflating the saving rate by a per cent or so; and, c) understatement of the retained earnings of foreign firms operating in China, causing some foreign corporate saving to be counted as domestic corporate saving. Recent evidence that Chinese household consumption is understated in official statistics is further explored by Jonathan Garner and Helen Qiao (2013) who conclude that household incomes are underestimated (mostly because consumption surveys don't capture the very wealthy, who further understate their incomes) and that consumption expenditure may be larger than official estimates by as much as a tenth of official GDP.

9 This identity is readily obtained by combining the expenditure identity, $Y=C+I+G+X-M$ with the disposal identity for GNP, $Y+N=C+T+S$, where $S=S_{H H}+S_{C}$. 
Beyond the assessment of the trend in the surplus of total domestic saving over investment, there is the matter of the international destinations of China's excess saving. It is important to note the recent pattern of substituting reserve accumulation for outward FDI and the associated changes in regional distribution of China's excess saving. We consider each of these components in turn.

\section{Household Saving}

The pattern and time trend of household saving in other Asian economies is analysed by Charles Horioka and Terada-Hagiwara (2012). They point out that the three main determinants of rates of measurable household saving are the age structure of the population and the levels of income and financial sector development. Saving rates follow a concave path, rising in the early stages of development and subsequently declining with ageing and financial development, which lowers credit constraints. They suggest that private saving in China could remain stable, affected by offsetting, opposing forces - ageing and financial development tend to reduce it and higher incomes tend to raise it. Changes in this projected pattern might be expected, however, in the aftermath of the GFC and with the commencement of China's inward-focused strategy. Moreover, the projections of Horioka and Terada-Hagiwara neither include corporate nor government saving, and changes to these are yet more likely. Official estimates of household saving through 2010 are shown in Figure 6.3. For the reasons discussed above, these are subject to question, with household saving very likely having followed a lower path, at least more recently. 
China: A New Model for Growth and Development

Figure 6.3 Trends in Chinese private, household and corporate saving, \% GDP

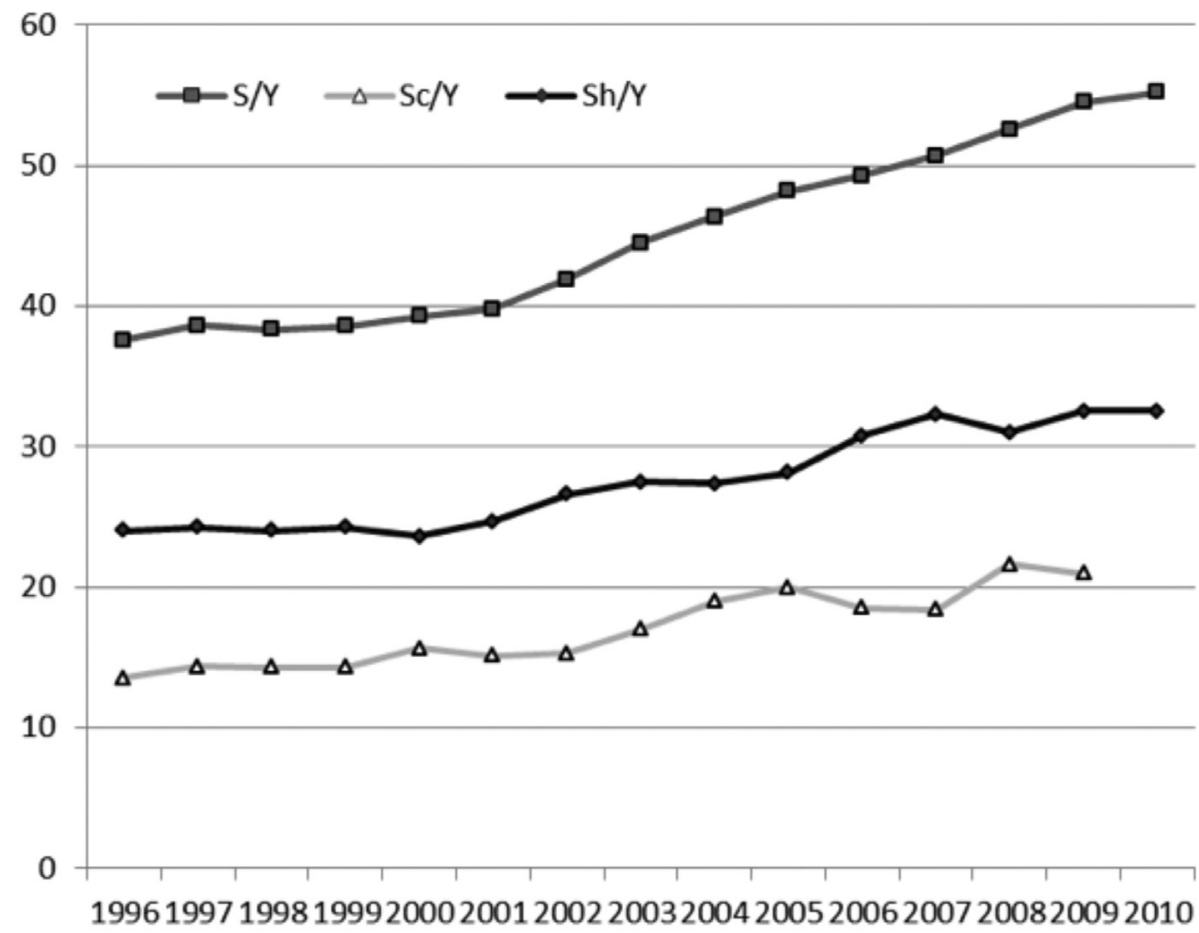

Sources: From national accounts statistics private saving is $S=Y_{N}-C-T$ and $S_{H}=S-S_{C^{\prime}}$ where corporate saving, $S_{C^{\prime}}$ is from 'flow of funds' data. These data are inconsistent (Ma and Yi 2010), though the latter is the only source for corporate saving. Flow of funds data on household saving suggests its value in 2009 was about $25 \%$ GDP.

\section{Corporate Saving}

The trend to 2010 in corporate saving is also illustrated in Figure 6.3. The estimates are from national accounts 'flow of funds' data that are not yet updated beyond this point. Looking forward, changes in total corporate saving might be anticipated for three reasons. First, to the extent that slower global growth since the GFC has affected profitability in the state sector, corporate savings might be expected to have also declined in recent years. Second, ongoing industrial policy reforms, which include the subdivision of some SOEs, are likely to have further reduced profitability and hence corporate saving. Finally, financial development and the integration of formal and informal financial markets across the country have been proceeding apace. With more options and more security in the management of funds, it might be expected that the trend of corporate saving would be downward from its extraordinary heights of three years ago. 
Figure 6.4 Chinese Government revenue and expenditure ${ }^{a}$

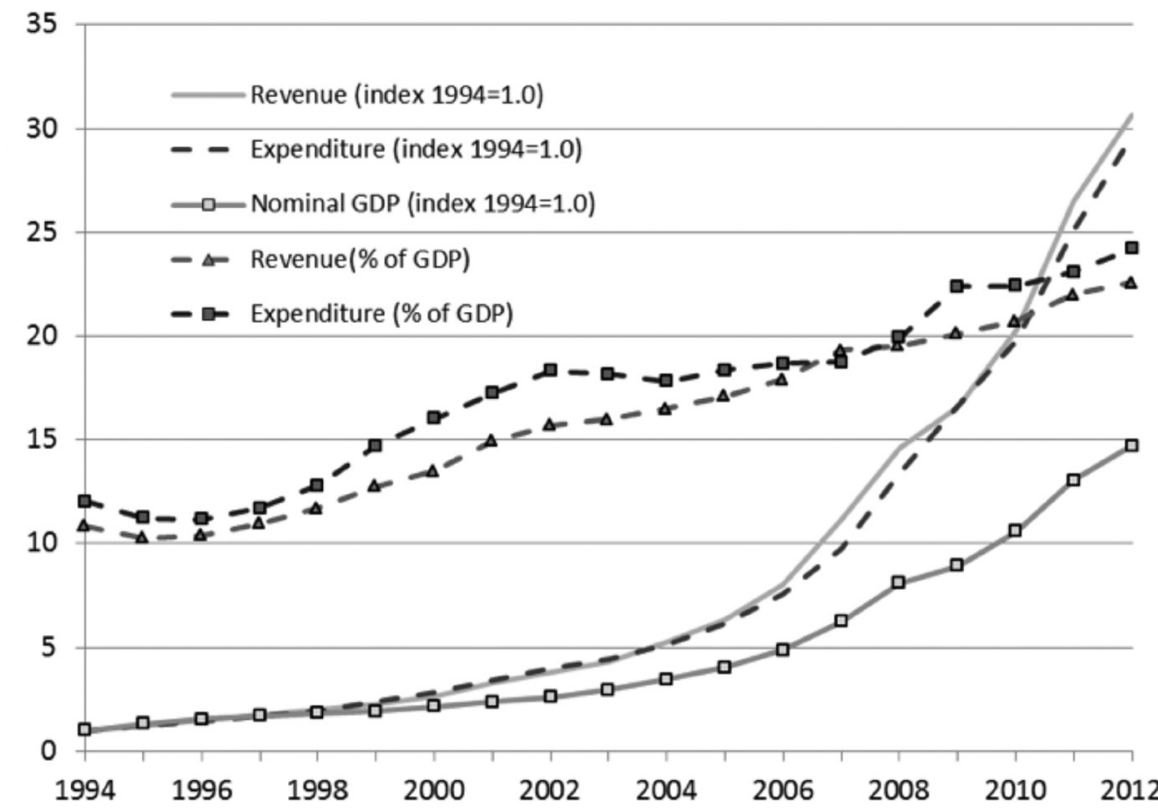

a Revenue, expenditure and nominal GDP are indices, 1994=1.0.

Sources: China NBS, Statistical Yearbook 2012.

\section{Government Saving}

Since the implementation of China's tax law in 1994, the domestic economy has gradually integrated, with an increasing share of economic activity taking place in the 'formal sector'. This has meant that central government tax revenue has grown steeply, as shown in Figure 6.4, at a rate that is notably faster than GDP. Along with this, central government financial surpluses have expanded continuously. At the same time, however, with the maintenance of capital controls, financial integration has caused China's high-saving households and firms to deposit their savings in domestic commercial banks. These banks have a long tradition of lending to SOEs and provincial governments, where debt has been effectively underwritten centrally. The comparatively recent development in this lending is an expansion in the share directed to provincial governments to finance local public investment. ${ }^{10}$ As shown in Figure 6.5, this has grown significantly since 2002 and it accelerated with the onset of the GFC and the government's plan to increase public works expenditure when export demand temporarily fell away. After 2007, the sum of the provincial deficits exceeded

10 This is notwithstanding central government sharing of national revenue with the provinces at a 50-50 rate in 2011. 
the central surplus, leading to a return to overall deficits with magnitudes expanding to unprecedented levels. Thus, government saving is also shifting in the negative direction in the post-GFC years. ${ }^{11}$

Figure 6.5 Chinese Government net surpluses, US\$ billions

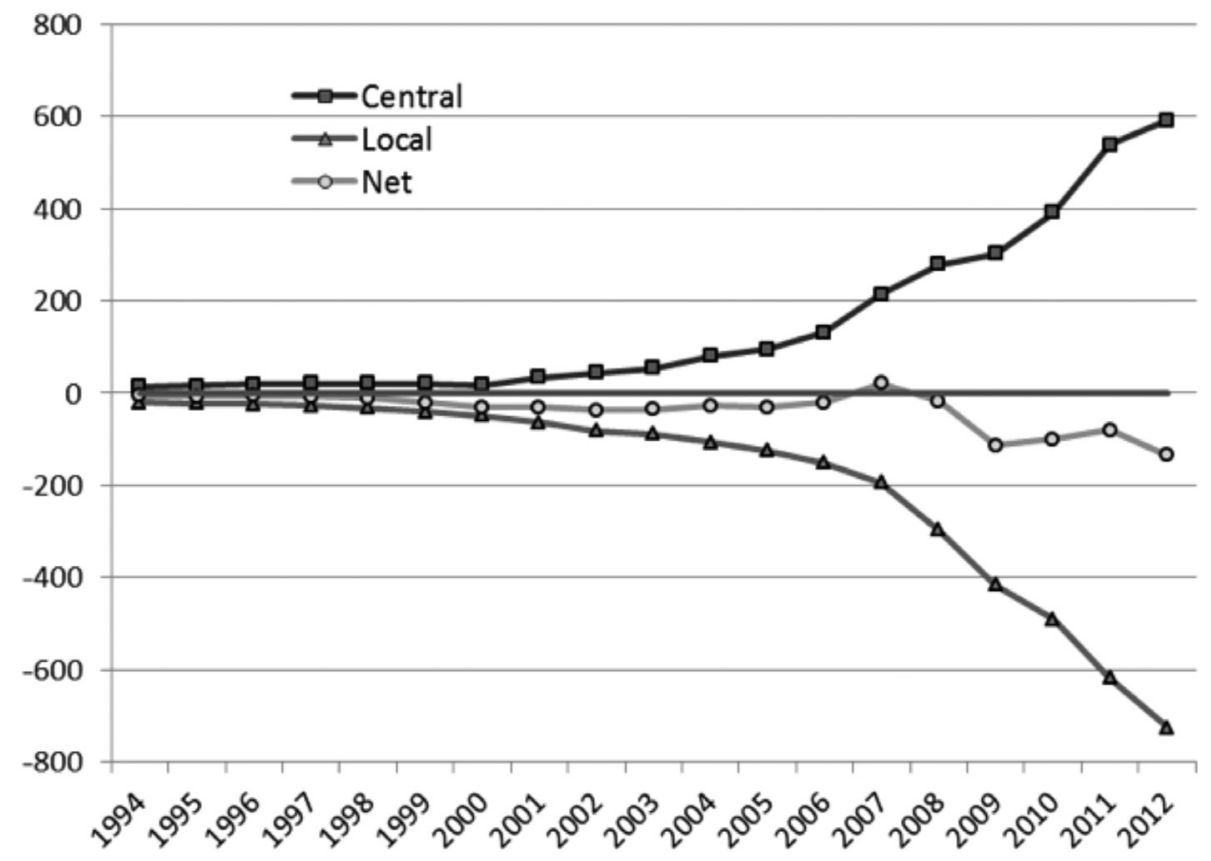

Sources: Government debt and general government gross debt position, IMF Fiscal monitor; External debt outstanding, Chinese Statistical Yearbook 2012.

\section{Implications for Overall Chinese Excess Saving Relative to Investment}

The above discussions suggest that there has been a diminution of China's total domestic saving since 2010, though this may not be fully represented in the official statistics, which only show a slight decline in 2011. At the same time, total (private and public) investment rose to nearly half of GDP. Indeed, the growth rate of completed investment in fixed assets was 24 and 20 per cent in 2011 and 2012, still much faster than recorded GDP growth. This underlies the continuously rising investment share of GDP shown in Figure 6.6 and it confirms that investment has made the greatest single contribution to China's 
'rebalancing' in recent years. ${ }^{12}$ The result has been a contracting current account surplus in the post-GFC period, particularly since 2010. A full current account figure for 2012 is not yet available, though an estimate is offered in the figure. Although China's surplus sank below the aggregate of the rest of the world in 2012 , it remained the single largest surplus across individual countries. ${ }^{13}$

Figure 6.6 Saving, investment and the current account in China, \% GDP

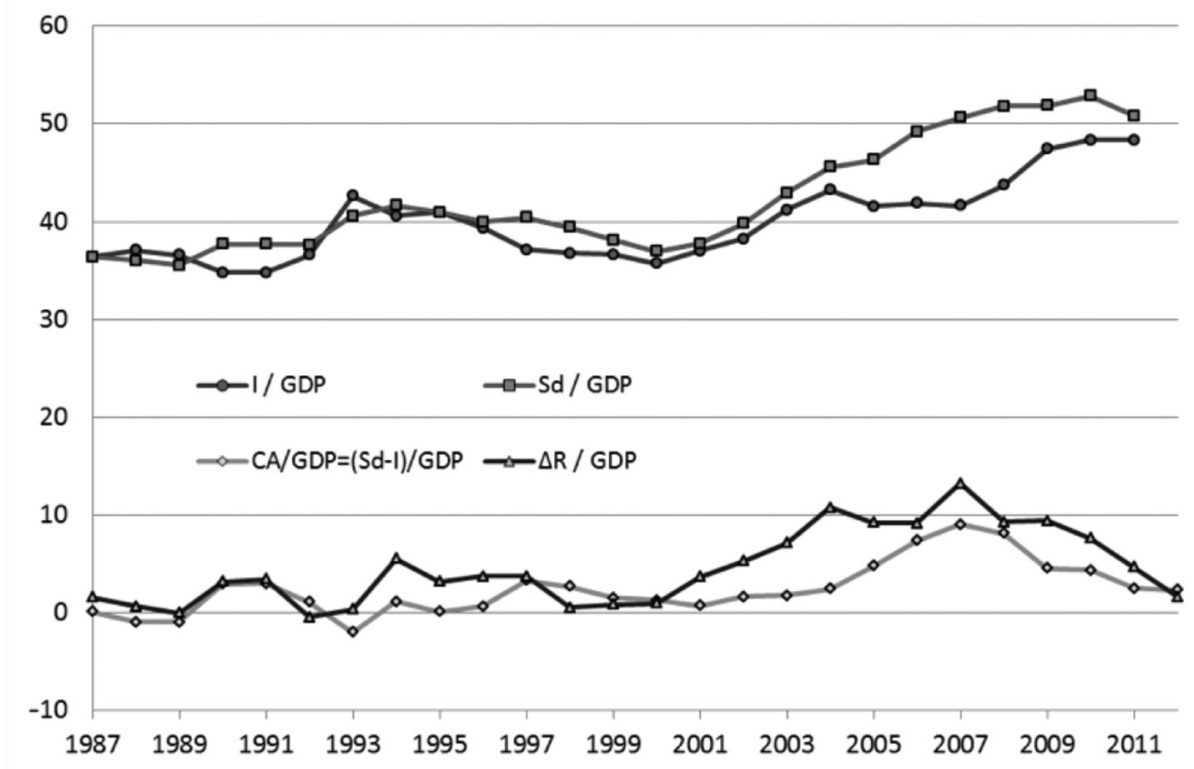

Sources: National Bureau of Statistics yearbook 2009-2012; IMF IFS data base. The value for the current account in 2012 is based on the trade balance and the authors' estimate of net factor income from abroad in that year.

Looking ahead, it is difficult to imagine a higher rate of investment without the prospect of increasingly wasteful projects. Moreover, the recent boost in public investment has stemmed from, first, national, post-GFC stimulus policy; second, the preference on the part of commercial banks to lend to protected provincial government and SOEs; and, third, the substantial excess supply of saving, bottled up in the home market by capital controls. We expect all three conditions to fade through time, so that the implications for future excess saving then depend on the differences between the rates of decline of total domestic saving on the one hand and investment on the other. In our view, a continued decline in excess saving appears the most likely future course, not just because

12 This pattern was foreshadowed by Lee and McKibbin (2007).

13 IMF, IFS Database. 
this is the apparent path since 2010, but also considering the trend toward financial deepening and the mounting evidence that consumption expenditure is growing faster than officially estimated.

\section{Reserves and Outward FDI}

A key element of China's excess saving is its rate of official foreign reserve accumulation. Effective capital controls have been retained notwithstanding progress toward the 'internationalisation' of the RMB. These restrict, though they do not eliminate, all private financial flows other than officially sanctioned inward and outward FDI. The persistent excess of home saving over investment engenders a correspondingly persistent excess of foreign exchange revenues from net exports. This surplus foreign exchange is deposited with China's commercial banks yet the capital controls prevent it from being used in international asset transactions by bank deposit holders and so the common practice has been for it to be acquired by the People's Bank of China (PBC) in exchange for newly printed Yuan. In the absence of full convertibility, these funds have then had to be deposited abroad, mainly via purchases of government bonds in the United States and Europe. ${ }^{14}$ In 2007, the US\$ domination of the PBC's assets began to be addressed by swaps with central government debt that deposited the US\$ assets with the China Investment Corporation (CIC), via which the early part of China's outward FDI was financed. Since then it has been possible for the CIC to directly acquire foreign exchange from the commercial banks. Combined with slower growth in private saving and an associated contraction in the trade surplus, this has seen slower accumulation of official foreign reserves and their reduced role on the PBC's balance sheet, as indicated in Figure 6.7.

Thus, while China's reserve accumulation has been large by international and historical standards, its scale has primarily been a consequence of outward capital controls. In effect, while the law prevents ordinary citizens from holding substantial assets abroad, the $\mathrm{PBC}$, and more recently the CIC and the mainly state-owned foreign direct investors, have been holding foreign assets on their behalf. What is of importance with regard to reserve accumulation and other outflows is their international distribution and the extent to which it is changing through time. The substitution between reserve accumulation, which takes the form of low-yielding foreign government bonds and likely better yielding portfolios of the CIC and the outward-investing SOEs may be causing a redirection of China's excess saving abroad.

14 The resulting monetary expansion was originally sterilised via the sale by the PBC of 'sterilisation bonds' (Tyers and Zhang 2011). More recently, the approach has been to reduce money creation by the commercial banks via measures such as high reserve to deposit ratios. 
Figure 6.7 Components of the People's Bank of China balance sheet, \% GDPa

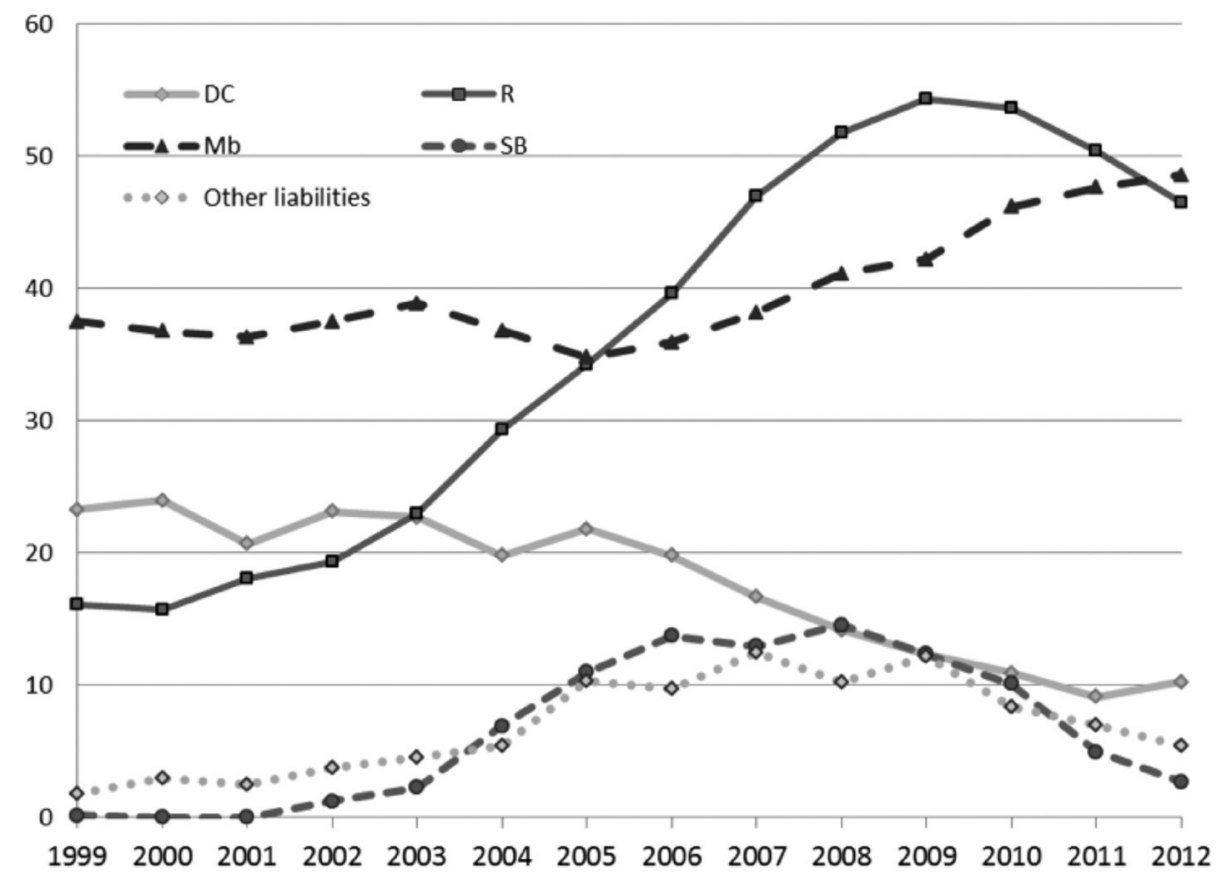

a $D C$ is domestic credit, $R$ is official foreign reserves, $M b$ is monetary base, $S B$ is sterilisation bonds issued by the PBC.

Source: People's Bank of China, Balance Sheet of Monetary Authority 1999-2012.

The CIC maintains a portfolio worth a half US\$ trillion which is spread widely, with the largest shares in US, Australian and other Asian assets. ${ }^{15}$ Change through time is led by new FDI, however, as shown in Table 6.1. The annual outflow of FDI amounted to US\$75 billion in 2011, destined primarily for other Asian investments. By contrast, the addition to official foreign reserves in that year was US\$128 billion destined, it is widely presumed, for bond acquisitions in the United States. The outward FDI was therefore a considerable offset. This compares with 2006, in which new outward FDI amounted only to US\$18 billion and reserves grew by US $\$ 247$ billion. This suggests a strong redistribution of China's outward financial flows away from the United States toward other Asian destinations.

15 Some detail on outward FDI is available from the NBS Statistical Yearbook of 2012. A summary, slightly at variance with the official statistics, is offered by the Economist (2013). 
China: A New Model for Growth and Development

Table 6.1 China's outward FDI and its regional distribution

\begin{tabular}{l|c|c|c|c|c|c|c}
\hline & $\begin{array}{c}\text { Annual } \\
\text { increment, } \\
\text { US\$ billion }\end{array}$ & Asia & Africa & Europe & $\begin{array}{c}\text { Latin } \\
\text { America }\end{array}$ & $\begin{array}{c}\text { North } \\
\text { America }\end{array}$ & Oceania \\
\hline 2006 & 17.6 & 43.5 & 2.9 & 3.4 & 48.0 & 1.5 & 0.7 \\
\hline 2007 & 26.5 & 62.6 & 5.9 & 5.8 & 18.5 & 4.2 & 2.9 \\
\hline 2008 & 55.9 & 77.9 & 9.8 & 1.6 & 6.6 & 0.7 & 3.5 \\
\hline 2009 & 56.5 & 71.5 & 2.5 & 5.9 & 13.0 & 2.7 & 4.4 \\
\hline 2010 & 68.8 & 65.2 & 3.1 & 9.8 & 15.3 & 3.8 & 2.7 \\
\hline 2011 & 74.7 & 60.9 & 4.3 & 11.1 & 16.0 & 3.3 & 4.4 \\
\hline $\begin{array}{l}\text { FDI stock at the } \\
\text { end of 2011 }\end{array}$ & & 71.4 & 3.8 & 5.8 & 13.0 & 3.2 & 2.8 \\
\hline $\begin{array}{l}\text { Value of 2011 } \\
\text { stock, US\$ billion }\end{array}$ & 425 & 425 & 303 & 16 & 24 & 55 & 13 \\
\hline
\end{tabular}

Source: China National Bureau of Statistics, Statistical Yearbook, 2012.

\section{Global Financial Interdependence and Macroeconomic Policy}

Global financial markets continue to be dominated by the United States, which has sustained a structural current account deficit since the 1990s. Though much that has been unpalatable since 2007 has been blamed on the GFC, the broad pattern of international finances did not appear to be permanently changed by it. Critically, it brought about a reversion by the private sectors in the United States, the European Union and Japan to net saving positions, while all three governments assumed net borrowing positions, as shown in Figure 6.8. It therefore replaced private debt, some of which had been unsustainable, with sovereign debt, some of which is also unsustainable, leaving heightened global uncertainty as to sovereign financing.

A key change took place around 2005, before which the large US deficit had been financed by surpluses in Japan and the oil-producing countries. Thereafter, however, the burden of this financing rested increasingly with China, as shown in Figure 6.9. By 2010 China had joined the club of major economies (Eickmeier and Kuehnlenz 2013) and was the dominant supplier of finance to the rest of the world, while the regions other than China and the United States were in approximate current account balance. The international financing game had become one between China and the United States. After 2010, though, China's relative role as surplus financer began to diminish with the shifts in its domestic saving-investment balance already discussed. It remains a substantial buyer of US debt and equities, however, highlighting the potential for disruption in US financial markets should China's excess saving continue to decline. 


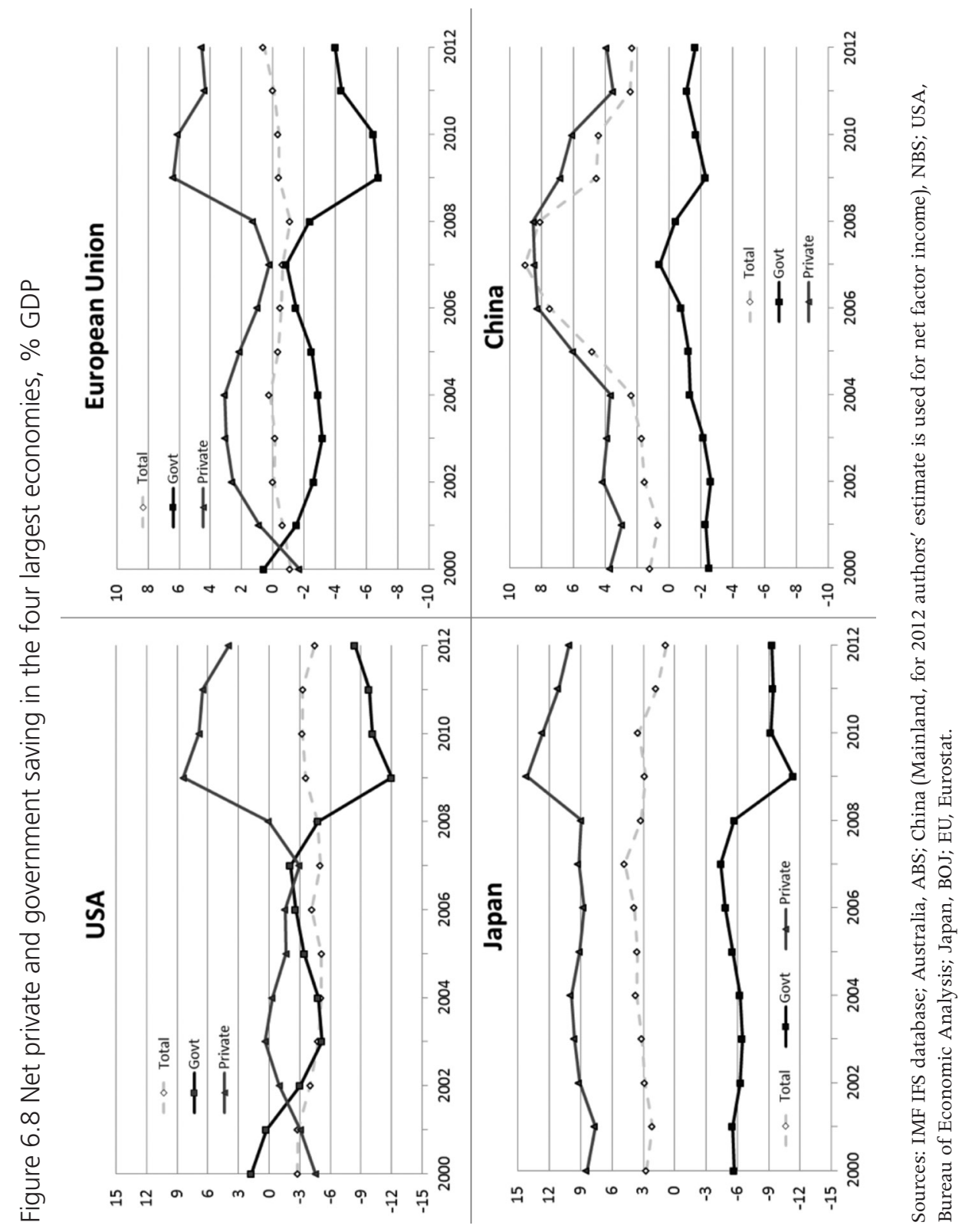


Figure 6.9 Excess annual saving (current account balances) by key region, US\$ billions

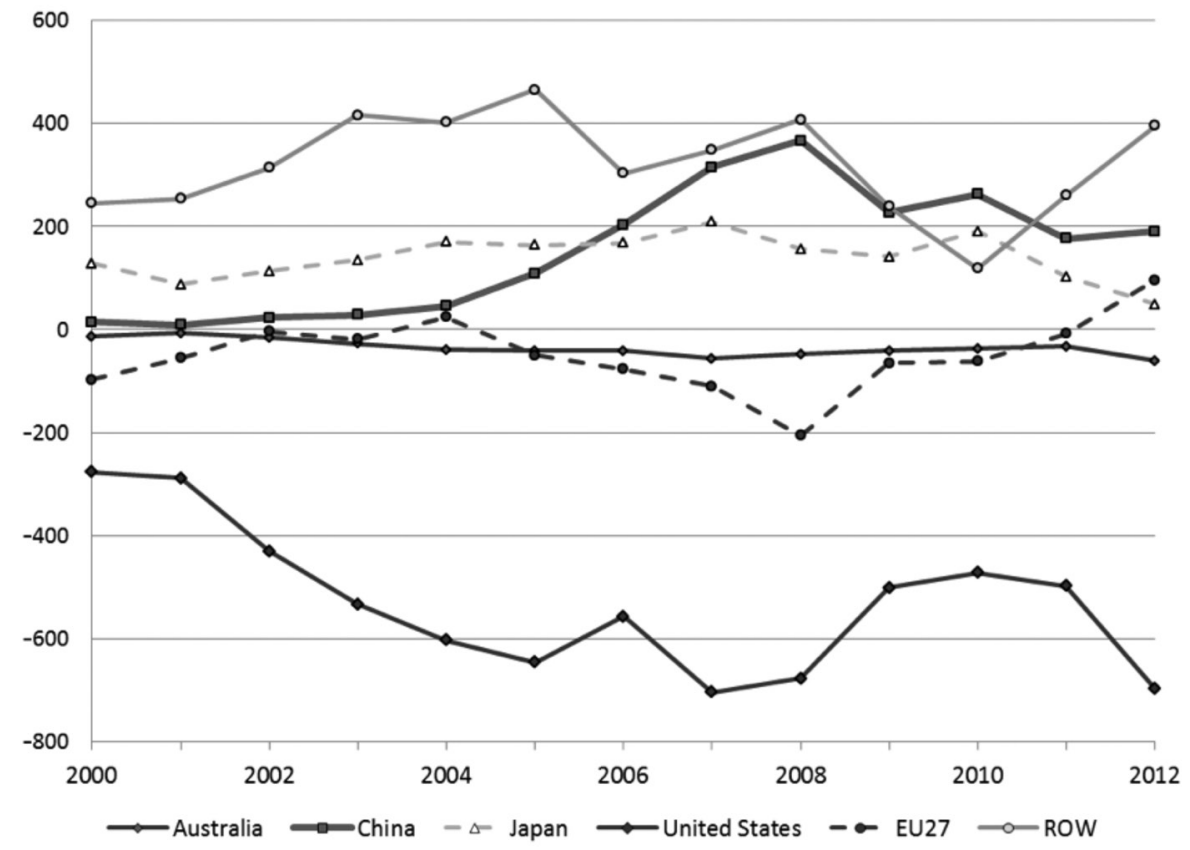

Source: IMF IFS database; China NBS; Japan, BOP and Ministry of Finance; EU27, Eurostat; US Bureau of Economic Analysis.

\section{Global Finance Over Two Decades}

Some insight into the macroeconomic events leading up to the GFC is offered by Figure 6.10, which shows the yields on short and long term US Treasury bonds since the beginning of the 1990s. Consistent with the market segmentation theory of the yield curve, we imagine that the transaction cost of financing long via a succession of short contracts to be prohibitive, allowing short- and longmaturity instruments to trade at substantially different prices. Moreover, short bonds are instruments of conventional domestic monetary policy and they are traded little between countries, or at least between the major economic blocs we are considering. Long bonds, by contrast, are instruments of private saving and investment. ${ }^{16}$ They are substitutes for equity holdings and are extensively traded internationally. Long-bond yields are therefore more stable through time than short yields and reflect movements in the equilibrium between global saving

16 While this is true as a rule of thumb, housing investment can be sensitive to short rates in economies where most mortgage contracts have variable rates. The assumption that investment financing depends on the long maturity market is accurate in a comparative sense and it is a useful simplification in modeling international financial behaviour. 
and investment. Short yields, on the other hand, reflect monetary easing and tightening through business cycles that have often been specific to particular economies. Considering this, Figure 6.10 clearly shows the two large US cycles that preceded the GFC and the tightening that led up to it in 2004-2005, when petroleum prices rose. It was this tightening that exposed those investors who expected short rates to remain low, precipitating the GFC. ${ }^{17}$ Beyond 2008, of course, the United States entered a liquidity trap, as did Europe, and Japan had been in one for at least a decade.

Figure 6.10 US Treasury bond yields over two decades

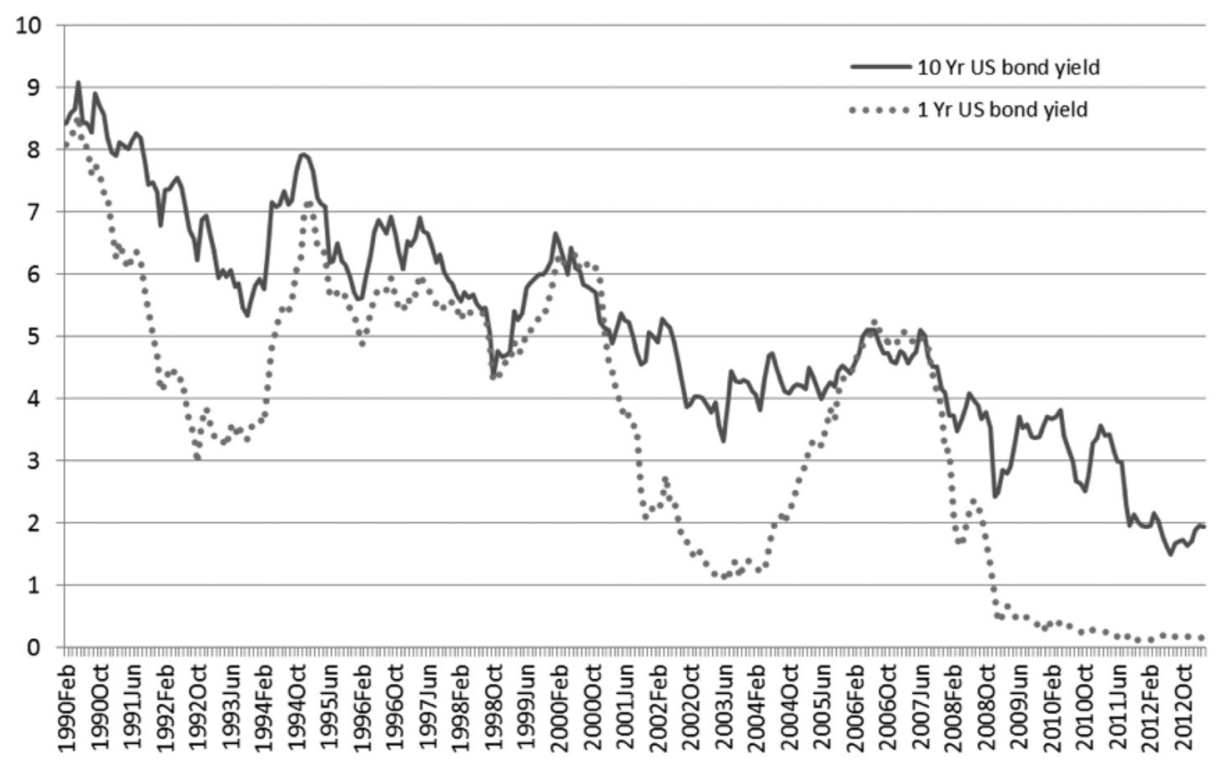

Source: US Treasury.

What is also notable from Figure 6.10 is the continuous and smooth downward trend in long-bond yields. This is as clear an index as any of the Asian savings glut. After the 1980s the great majority of the world's incremental growth took place in Asia, where saving rates were, and continue to be, substantially higher than in the rest of the world. Long yields, which had risen prior to the mid 1980s, have fallen continuously since. Though it is not shown in the figure, this long-run pattern is also observable in European, Canadian and Australian longbond yields. Importantly, and this is clear from the more recent data on yields represented in Figure 6.11, the downward trend in long yields persists beyond the GFC in all three economic regions. Yet the evidence is building that the Asian savings glut is over, led by declining net saving in both Japan and China. What, then, explains the continuing decline in long yields? 


\section{Quantitative Easing (QE)}

The most likely explanation is unconventional monetary policy, or QE, whereby money expansions are achieved via the large-scale purchase of long bonds, and related instruments, by central banks. For economies that have been stagnant in real terms since 2007, this has led to substantial expansions in central bank asset holdings, as indicated in Figure 6.11. These raise the prices of long bonds and related instruments and suppress their yields. Unlike more conventional monetary policy, the QE focus on widely traded instruments projects the domestic monetary cycle beyond national borders with immediacy. In part for this reason, the policy is being matched in the United States, Europe and Japan, causing financial outflows as investors seek out better yields abroad. ${ }^{18}$ Recent expansions in central bank balance sheets are shown in Figure 6.12. ${ }^{19}$ So what purpose does such unconventional monetary policy serve?

Figure 6.11 US, European and Japanese government bond yields since 2000

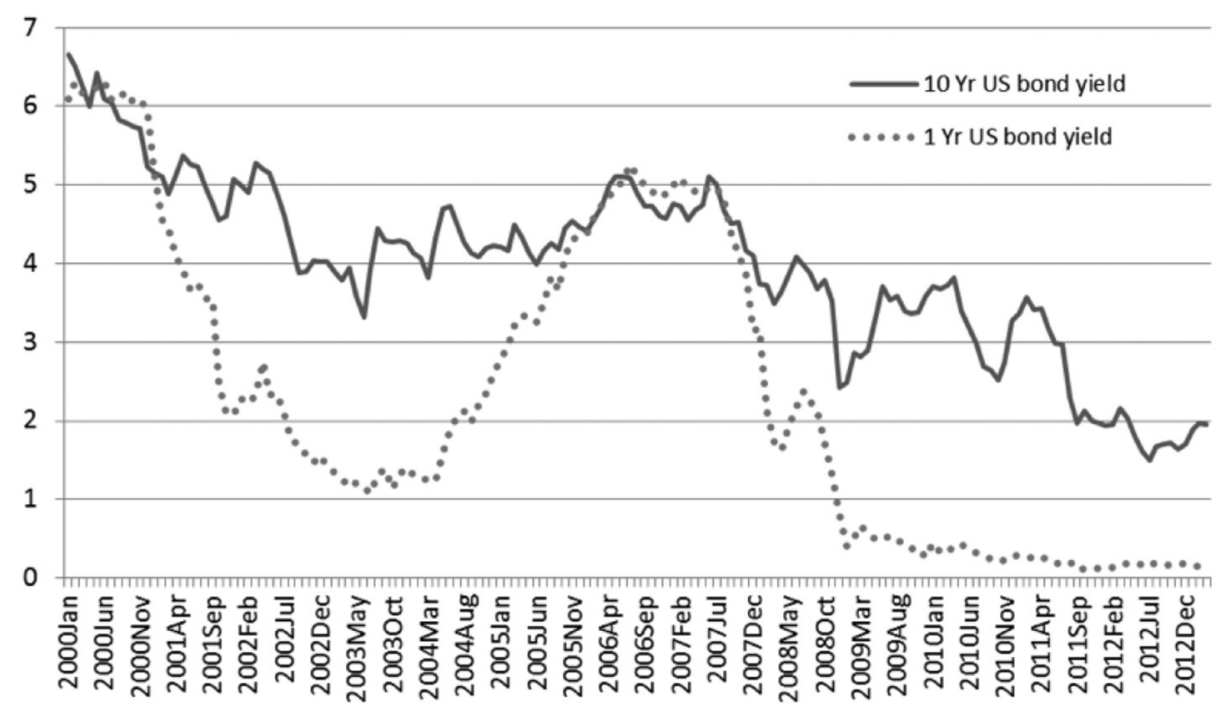

Source: US Treasury.

18 Of course, one clear rationale for QE on the part of the US Federal Reserve is that the substitution will be away from US bonds to US equities. And this has happened too. Much less is said by the Federal Reserve about the international effects.

19 It is notable that China's monetary base is large compared with the others, which is likely due to reduced money creation by China's commercial banks in response to such restrictions as high reserve to deposit ratios. 


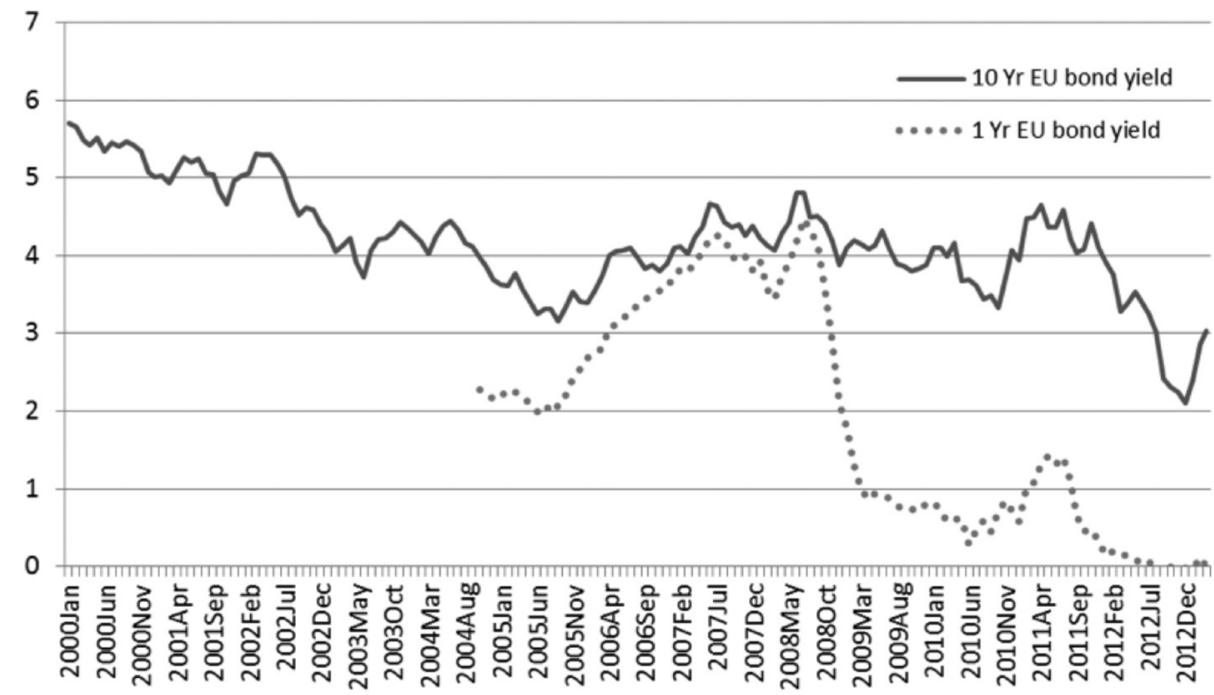

Source: European Central Bank.

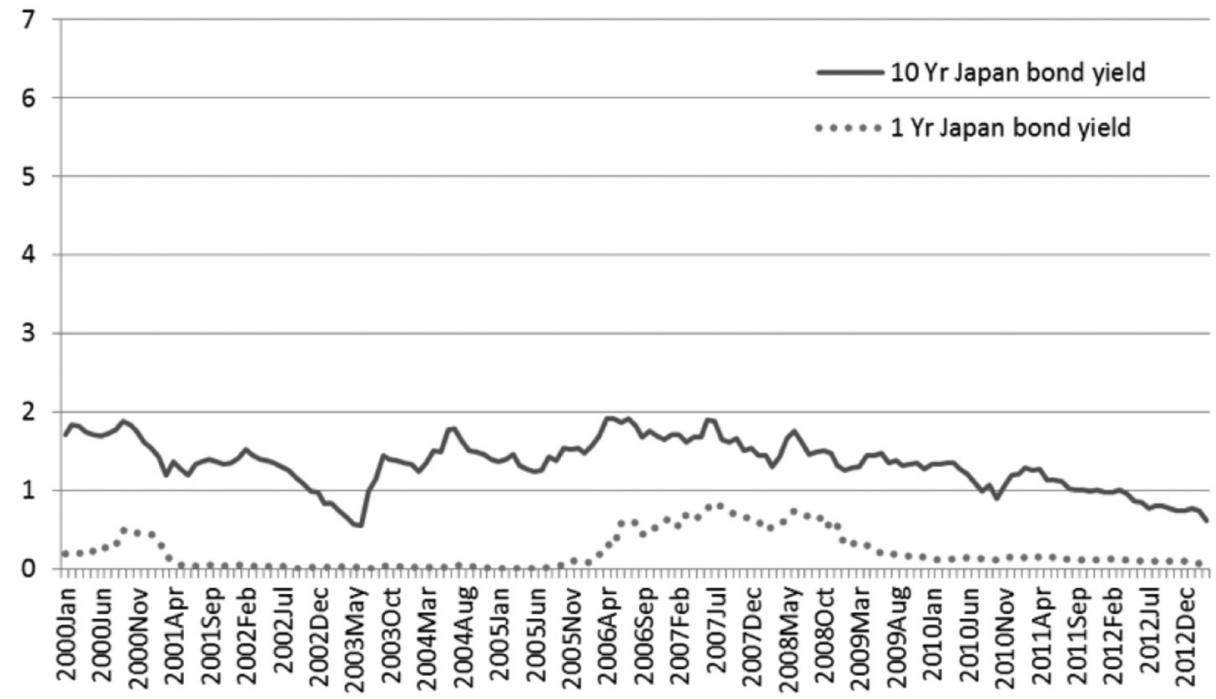

Source: European Central Bank, Reuters. 
China: A New Model for Growth and Development

Figure 6.12 Central Bank assets, US\$ trillions

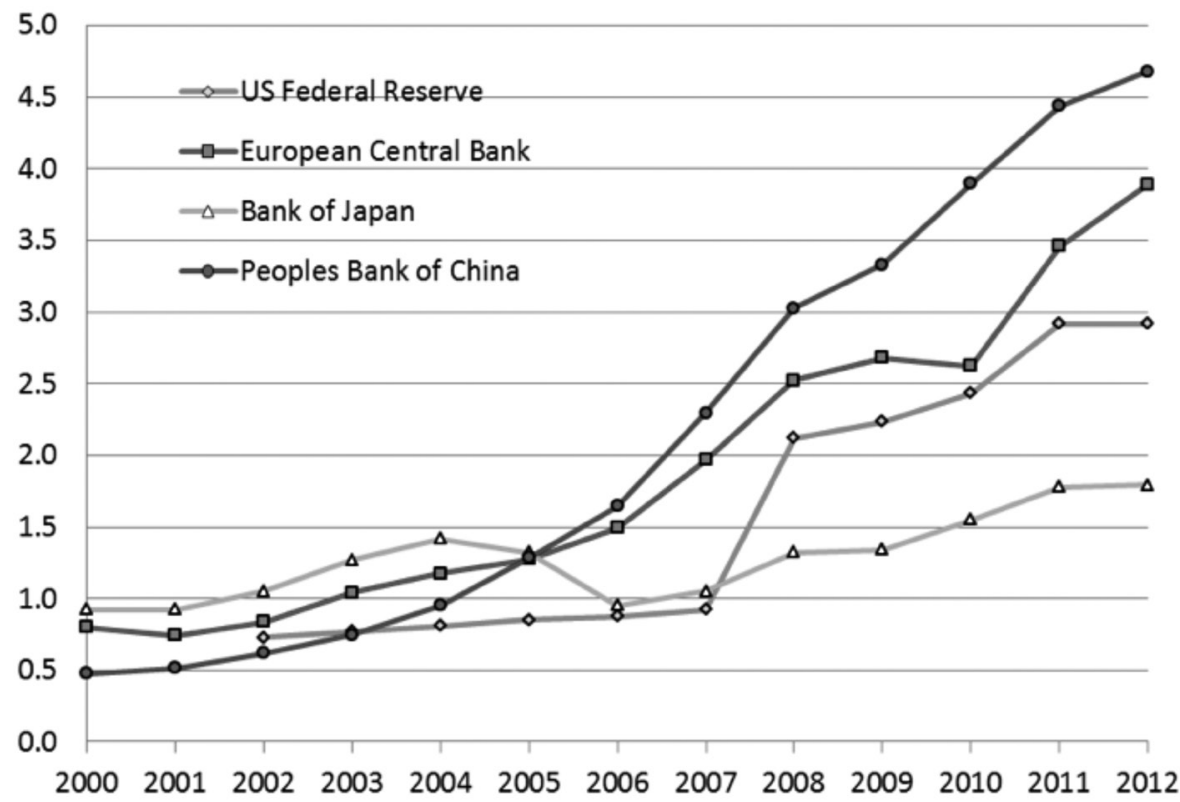

Source: EU, ECB; United States, Japan: St. Louis Federal Reserve Database; China, National Bureau of Statistics.

The three large economic blocs have, each by their own historical standards, high unemployment and governments with extraordinary sovereign debt overhangs. Further fiscal expansion seems unwise yet their liquidity traps prevent conventional monetary expansions. QE offers an alternative stimulatory course. Acquisitions by central banks offer the convenience of additional leeway for further government deficit spending. Governments continue to spend beyond their revenues and, even if there is less buying of their debt by Asian surplus economies, their own central banks acquire it. Importantly, the new abundance of regional currency depreciates the exchange rate against non-QE implementing economies and, at least in theory, this stimulates traded sectors.

\section{The Global Game}

In an important sense, QE policies are part of a strategic game within the small club comprising the major economic regions, of which China is now a member. A substantial monetary expansion by one region requires a matching response from the others to avoid appreciations that would reduce competitiveness. In the other transitional economies and the resource exporting economies like Australia, outside the club, the result has been accelerating inflation, or more 
substantial nominal appreciations relative to the United States. ${ }^{20}$ The notable thing about movements in the major currencies since 2000, shown in Figure 6.13 , is that the US\$ has gradually depreciated against all. Beyond that, the Yen, the Euro and the Yuan have tended to move together, particularly in the aftermath of the GFC, when they appeared to stabilise around their 2000 relativities, albeit all appreciating by one-third against the US\$. Very recently, there has been a break from this pattern with Japan's more aggressive QE causing a substantial depreciation relative to the others. Since the Japanese economy is now the smallest of the economic regions, it is possible that its departure from equilibrium could be sustained at minimum cost to the others.

Figure 6.13 Nominal exchange rate indices vs the US\$

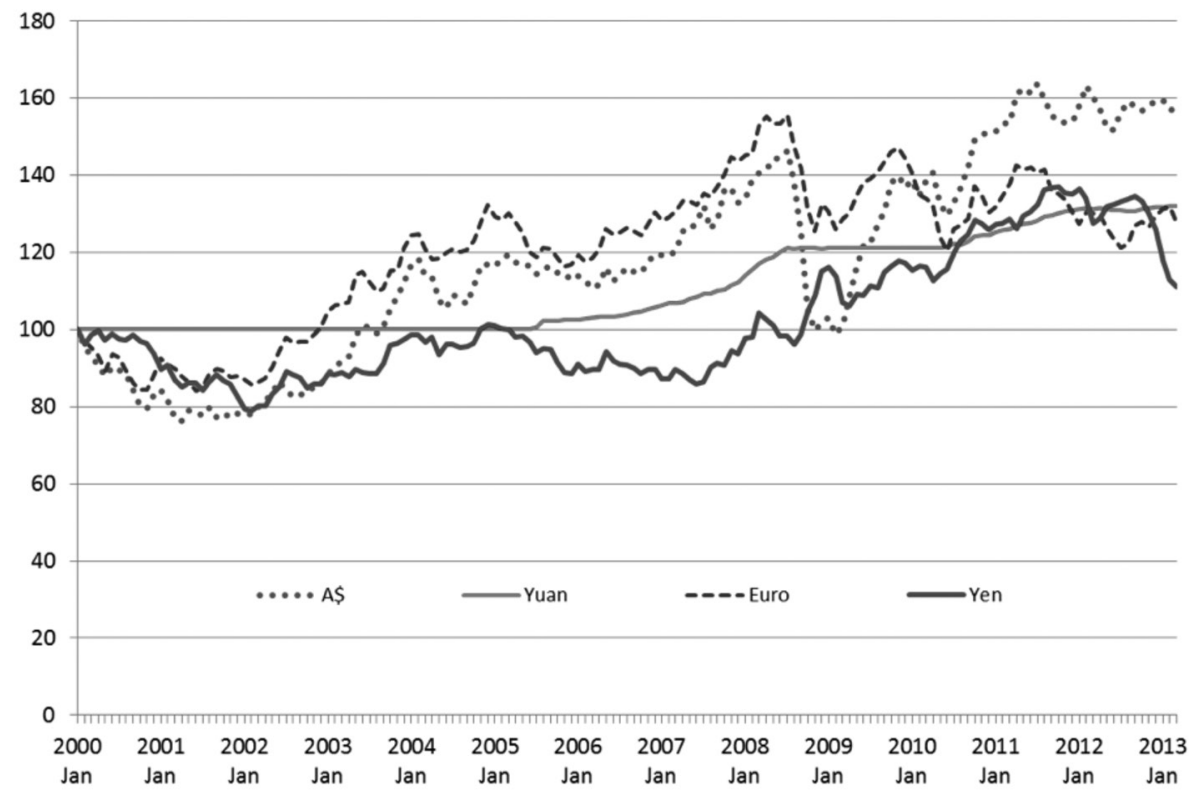

Source: IMF IFS and Eurostat.

20 The $\mathrm{A} \$$ is the resource currency of an outsider economy that is not a default risk and that has not engaged in aggressive monetary expansion. Return-seeking financial flows from the QE economies have therefore boosted its value. 


\section{The Global Economy in Prospect: The Effects of Still Less Chinese Saving}

Private portfolio holders around the world see extraordinary risk in apparently unsustainable sovereign debt and, so, are holding the additional money that is created by $\mathrm{QE}$, rather than investing in new plant and equipment. Investor confidence will not return until the sovereign debt issues are resolved, or unless there is an unexpected shock that suggests higher future productivity. Failing the latter, much depends on political struggles to reassign debt or selectively default.

Yet, there is just such a positive shock in the United States in the new availability of large quantities of energy from natural gas at comparatively low cost. This could draw portfolio holders into new private investment and lead them to shed liquidity. As they do this they will issue new debt and equity, pushing down bond prices and raising yields. Central banks will seek to prevent inflation by soaking up the shed liquidity. Much will depend on their approach to this. If they unload their holdings of long bonds first this will further raise long yields. In the past, the Japanese and Chinese governments, the oil exporting countries, or their central banks, would have been there to acquire the shed bonds. This time, if China's excess saving does decline and if the new abundance of energy holds down petroleum prices, this rescue will not occur and, unless some inflation is allowed, a credit squeeze could develop that strangles the recovery.

\section{Elemental Analysis of a Short-run Chinese Saving Shock}

To see how important China's excess saving is, we apply the standard intuitive model of macroeconomic behaviour ${ }^{21}$ to the short-run effects of a unilateral fall in China's saving on its own economy and on its partner economies. To begin with, reduced Chinese private saving would shrink the demand for home assets and this drives up home yields. If capital controls were perfect, this would have no effect on private flows abroad ${ }^{22}$ but it would reduce the current account surplus as home consumption would absorb goods that were once exported. The foreign exchange available to purchase international goods would fall, switching Chinese demand toward home goods and raising their relative prices, thus appreciating the real exchange rate. In the financial sector, higher home yields

21 This is a flex-price version of the standard Mundell (1963) - Fleming (1962) approach, that still underlies modern macroeconomic intuition. In a forthcoming more extensive quantitative analysis we use the model of Tyers and Cheong (2013) to address the issues of this chapter.

22 Imperfect capital controls mean that a greater proportion of what internationally mobile, yield-chasing investors there are in China would choose to hold home rather than foreign assets, reducing private outflows on the capital account. 
would raise the opportunity cost of holding money and contract the demand for real balances. The real appreciation requires either an inflation, a nominal appreciation or a combination of both and it is a matter of monetary policy to decide which. Let us assume the Chinese Government opts, as they have in the recent past, for the combination of both.

Now consider China's economic partners in aggregate. They face three shocks. First, there is a contraction in the external demand for their assets that places upward pressure on domestic long-bond yields. Second, there is inflation abroad, so the price level there is higher and with this comes a deterioration in their terms of trade. Third, related to this but more advantageous, there is a real depreciation. In the home financial market, reduced foreign demand raises yields on home assets, reducing home investment. The curtailed financial inflow contracts the capital account surplus and hence also the current account deficit, by providing less foreign currency to spend on foreign goods over and above export earnings. In effect, there is a contraction in aggregate demand and since the supply of goods from abroad is more elastic than from home the relative prices of home goods fall, causing the real depreciation.

Higher home yields reduce home demand for real money balances and a monetary contraction is required to prevent inflation. ${ }^{23}$ This is where the history of QE makes a difference. Central banks are loaded with long maturity assets and their inflation-targeting policy directives would dictate contractions in their balance sheets. If they first dump long assets on internationally open markets for long instruments, say with a view to returning to conventional monetary policy, this would exacerbate the home asset glut and further raise both home and foreign yields, contracting home investment even more substantially.

In the end, the partner economies face inferior terms of trade and substantially higher investment financing costs, though their real exchange rates are reduced relative to China and they export more. Some of the negative aspects of these circumstances can be offset by the controlled release of long assets by central banks and a departure from their practice of the past two decades to allow some inflation. Indeed, a period of inflation might seem politically attractive, both as a buffer against exacerbating the rise in long yields in the short run and as a means of diminishing sovereign debt burdens. Yet, if this inflation is anticipated it will precipitate a private sell-off in bond markets in any case, driving up long yields consistent with the expectations theory of the yield curve. Very steady hands will be required at central banks during this period.

23 Given our faith in the market segmentation theory of the yield curve, and the likelihood that the PBC holds long maturity US bonds, it would the long bond yield that would rise in the United States. But, because the collective portfolio comprises mainly long-maturing assets or their equivalents, it is the long rate that is the opportunity cost of holding money. 
On net, the circumstances of the economic regions other than China are inferior to an extent that depends on the scale of the rise in financing costs and of the real depreciations relative to China. It is the coincidence of timing that is important - Chinese and Japanese excess saving reductions, coming after years of QE in the other economic blocs. For the United States in particular, this could be made much worse by the combination of reduced Chinese saving with its redistribution away from investments in US assets. Since, as Figure 6.8 confirms, even quite standardised ten-year government debt contracts are differentiated across the major economic blocs. This means that redistribution away from US assets will exacerbate the associated financial contraction in the United States in particular.

\section{Conclusion}

The slower and more 'inward focused' growth to which the Chinese Government is now committed will contract its excess saving. Rises in consumption will reduce household saving, reduced oligopoly profits and further financial development will reduce corporate saving and the recent rise in provincial debt has already eliminated government saving. This coincides with reduced Japanese saving and, hence, the end of the 'Asian savings glut', and it must eventually raise the global cost of debt, which has recently been suppressed by QE in the United States, Europe and Japan. In the major economic regions, the monetary reaction to reduced Chinese saving, will see higher longbond yields that are readily transmissible globally, raising debt-service costs everywhere and causing a new headwind against investment worldwide.

Given that the United States appears to be leading the northern recovery, aided by reduced energy costs, much then depends on the implications of slower Chinese saving growth for US capital markets and investment. It is likely that the effect on the US economy will be disproportionate, not only because the two economies are already highly interdependent but also because China's financial outflows are shifting away from reserve accumulation, which is intensive in US bonds, and toward FDI that goes primarily into other Asian economies. A comparatively large rise in the cost of financing in the United States could stifle the recovery there and hence globally. The effects of this pessimistic scenario could be offset by fiscal consolidation in the large regions, so that global debt falls as global saving falls, leading to a soft landing for private investment. Without fiscal consolidation, however, the consequences could be serious global contraction. 
The critical need is to induce real investment from global portfolio holders who are currently soaking up money and avoiding what they see as systemic risks associated with ever higher sovereign debt. Achieving this will build new industries, create new employment and demand new exports from China and other Asian exporters. China's turn inward is sensible given its export environment but, contrary to the popular view, its timing could be unfortunate. Those excess savings will come in especially handy when the inevitable return to conventional monetary policy occurs. Their disappearance is a key negative global shock that is only temporarily disguised by QE in the larger economic regions.

\section{References}

Arora, V. \& Tyers, R., 2011, 'Asset Arbitrage and the Price of Oil', Economic Modelling, vol. 29, no. 2, pp. 142-50, March.

Bergsten, C.F., Freeman, C., Lardy, N.R. \& Mitchell, D.J., 2008, China's Rise: Challenges and Opportunities, Peterson Institute for International Economics, Washington DC.

Bernanke, B.S., 2005, 'Remarks by the Governor', Sandridge Lecture, Virginia Association of Economists, Richmond Virginia, March, Federal Reserve Board.

Cai, F., 2010, 'Demographic Transition, Demographic Dividend and Lewis Turning Point in China', China Economic Journal, vol. 3, no. 2, pp. 107-19.

Chinn, M.D. \& Ito, H., 2007, 'Current Account Balances, Financial Development and Institutions: Assaying the World 'Saving Glut", Journal of International Money and Finance, vol. 26, pp. 546-69.

Choi, H., Mark N.C. \& Sul, D., 2008, ‘Endogenous Discounting, the World Saving Glut and the US Current Account', Journal of International Economics, vol. 75 , pp. $30-53$.

Deer, L. \& Song, L., 2012, 'China's Approach to Rebalancing: A Conceptual and Policy Framework', China \& World Economy, vol. 20, no. 1, pp. 1-26.

Dooley, M.P., Folkerts-Landau D. \& Garber, P., 2004, 'Direct Investment, Rising Real Wages and the Absorption of Excess Labor in the Periphery', NBER Working Paper 10626 (July), National Bureau of Economic Research, Cambridge MA.

Easterly, W., 2001, 'The Lost Decades: Developing Countries' Stagnation in Spite of Policy Reform 1980-1998', World Bank, Washington DC, February. 
Economist, 2013, 'ODI-lay Hee-Ho: The Expanding Scale and Scope of China's Outward Direct Investment', 19 January: http://www.economist.com/ news/china/21569775-expanding-scale-and-scope-chinas-outward-directinvestment-odi-lay-hee-ho.

Eichengreen, B., Park, D. \& Shin, K., 2011, 'When Fast Growing Economies Slow Down: International Evidence and Implications for China', NBER Working Paper, 16919, Cambridge MA.

Eickmeier, S. \& Kuehnlenz, M., 2013, 'China's Role in Global Inflation Dynamics', Discussion Paper 7-2013, Deutsche Bundesbank.

Fleming, J.M., 1962, 'Domestic Financial Policies Under Fixed and Under Flexible Exchange Rates', International Monetary Fund Staff Papers, vol. 9, pp. 369-79.

Garnaut, R., 2010, 'Macroeconomic Implications of the Turning Point', China Economic Journal, vol. 3, no. 2, pp. 181-90.

Garner, J. \& Qiao, H., 2013, ‘China-Household Consumption most likely US1.6 trillion Larger than Officially Stated', Asian Insight, Morgan Stanley Research, 28 February, http://www.morganstanleychina.com/views/121217. html.

Golley, J. \& Meng, X., 2011, 'Has China Run out of Surplus Labour?', Chinese Economic Review, vol. 22, no. 4, pp. 555-72.

Golley, J. \& Tyers, R., 2012, 'Population Pessimism and Economic Optimism in China and India', The World Economy, vol. 35, no. 11, pp. 1387-416.

Horioka, C.Y. \& Terada-Hagiwara, A., 2012, 'The Determinants and Longterm Projections of Saving Rates in Developing Asia', Japan and the World Economy, vol. 24, pp. 128-37.

Huang, Y., 2013, 'China's New Growth Model', East Asia Forum, 14 April, http://www.eastasiaforum.org

IMF, 2013, Fiscal Monitor: Fiscal Adjustment in an Uncertain World, World Economic and Financial Surveys, April, The International Monetary Fund, Washington DC.

Ito, H., 2009, 'US Current Account Debate with Japan then, and China Now', Journal of Asian Economics, vol. 20, pp. 294-313.

Kuijs, L., 2006, 'How will China's Saving-Investment Balance Evolve?' World Bank Policy Research Working Paper 3958, Beijing, July. 
Lardy, N.R., 2006, 'Toward a Consumption-Driven Growth Path', Policy Brief 06-6, Peterson Institute for International Economics, Washington DC.

— 2012, Sustaining China's Growth after the Global Financial Crisis, Peterson Institute for International Economics, Washington DC, January.

Lee, J.W. \& McKibbin, W.J., 2007, 'Domestic Investment and External Imbalances in East Asia', CAMA Working Paper 4-2007, Australian National University, Canberra.

Lewis, W.A., 1955, The Theory of Economic Growth, Taylor and Francis, London.

Lu, F., Song, G., Tang, J., Zhao, H. \& Liu, L., 2008, 'Profitability of Chinese Firms, 1978-2006', China Economic Journal, vol. 1, no. 1.

Ma, G. \& McCauley, R.N., 2007, 'How Effective are China's Capital Controls?', in R. Garnaut and L. Song (eds), China: Linking Markets for Growth, AsiaPacific Press, pp. 267-89.

Ma, G. \& Yi, W., 2010, 'China's High Saving Rate: Myth and Reality', International Economics, vol. 122, pp. 5-40.

Mundell, R.A., 1963, 'Capital Mobility and Stabilisation Policy under Fixed and Flexible Exchange Rates', Canadian Journal of Economics and Political Science, vol. 29 , pp. $475-85$.

Riedel, J., 2011, 'The Slowing Down of Long-term Growth in Asia: Natural Causes, the Middle Income Trap and Politics', School of Advanced International Studies, Johns Hopkins University.

Robertson, P.E. \& Ye, L., 2013, 'On the Existence of a Middle Income Trap', University of Western Australia Economics Discussion Paper 13-12, Perth, February.

Song, L., Wu, J. \& Zhang, Y., 2010, 'Urbanization of Migrant Workers and Expansion of Domestic Demand', Social Sciences in China, vol. XXXI, no. 3, pp. 194-216.

Song, L., Yang, J. \& Zhang, Y., 2011, State-owned Enterprises' Outward Investment and the Structural Reform in China', China and the World Economy, vol. 19, no. 4, pp. 38-53.

Tyers, R., 2012, 'Japan's Economic Stagnation: Causes and Global Implications', The Economic Record, vol. 88, no. 283, pp. 459-607. 
Tyers, R. \& Cheong, T.C., 2013, ‘A Dynamic Global Model for Macroeconomic Analysis: Government Debt, Reserves, Bilateral Asset Holdings and Sector Specificity', presentation at the 16th Conference on Global Economic Analysis, Shanghai 12-14 June 2013, and CAMA Working Paper, February.

Tyers, R. \& Lu, F., 2008, 'Competition Policy, Corporate Saving and China's Current Account Surplus', Working Papers in Economics and Econometrics No. 496, College of Business and Economics, Australian National University, July.

Tyers, R. \& Zhang, Y., 2011, 'Appreciating the enminbi', The World Economy, vol. 34, no. 2, pp. 265-97.

Wen, Jiabao, 2007, The Conditions for China to be able to Continue to Guarantee Stable and Rapid Economic Development, 16 March, viewed 28 October 2011, www.npc.gov.cn.

2011, Report on Work of the Government, 5 March, viewed 24 March 2011, www.npc.gov.cn.

World Bank, 2010, 'Escaping the Middle-Income Trap', East Asia and Pacific Economic Update 2010 Volume 2: Robust Recovery, Rising Risks.

Yi, Gang, 2011, 'How China plans to strike an economic balance', 4 February, CaiXin Online English. 


\title{
7 Growing into an Innovative Economy:
}

\author{
Evidence from Chinese Firm-Level Data Analysis
}

Yixiao Zhou

\section{Introduction}

Since initiating market reforms in 1978, China has undergone a significant economic transformation (Lin 2011). A more recent development is that China now aims to become a knowledge-intensive economy. This goal may constitute a part of the force that drives the redistribution of knowledge in the international market (Serger and Breidne 2007). The following question, proposed by Jones and Romer (2010: 231), may become increasingly relevant:

China's population is roughly equal to that of the United States, Europe, and Japan combined. Over the next several decades, the continued economic development of China might plausibly double the number of researchers throughout the world pushing forward the technological frontier. What effect will this have on incomes in countries that share ideas with China in the long run?

On 9 February 2006, the State Council published the 'The National Mediumand Long-Term Program for Science and Technology Development (20062020)', which reflects China's ambition to be transformed into one of the world's most important knowledge sources. ${ }^{1}$ In this program, the Chinese Government emphasises the role of indigenous innovation and also the importance of R\&D activities performed by business enterprises. The guiding principles for science and technology work over the next 15 years are, 'Innovate independently, achieve development in selected areas by leaps and bounds, support development and guide the future' (Sun and Du 2010).

While there are intricate relationships between education, institutional quality, science and technology performance and economic growth, this chapter is focused on one question: how will institutional quality affect China's innovation performance?

1 Plans related to science and technologies are not new to China. For an introduction to China's innovation policy, Hutschenreiter and Zhang (2007), Serger and Breidne (2007) and Sun and Du (2010) provide good references. 
This question is fundamentally important. There has long been debate about how China has grown fast, despite its relatively low institutional quality (Huang 2008). While much of the economic growth literature views institutional quality as a fundamental determinant of economic growth and development (Acemoglu \& Johnson 2005; Hall and Jones 1999), and views factors such as physical capital accumulation, human capital accumulation and technological progress as growth itself, China's growth performance in the past three decades seems to be an outlier of what the theory predicts. In fact, some analysts regard China as a counter-example to the existing literature on law, institutions, and growth (Allen et al. 2005). The reason why China has been able to be an outlier in the past 30 years could be, however, that the development stage of this period is one that relies less on institutional quality, compared with an economy that is nearer to the world technology frontier, and strives to innovate by itself.

The spectacular growth of China up till now has been driven by the reallocation of labour and capital across manufacturing firms (Song, Storesletten and Zilibotti 2011) and mainly by export-oriented, labour-intensive manufacturing activities (Wu 2010). The success of such an economy could rely much less on institutional quality, compared with an economy that relies on R\&D investment from firms as the major source of technological progress and productivity growth. This is because R\&D investment is a long-term investment process, the returns of which take time to realise. And, compared with physical capital investment and technology imitation or technology imports, R\&D investment is also intrinsically more risky and costly. If, for example, the protection of property rights, and especially the protection of intellectual property rights, is weak, firms may be too short-sighted to invest in R\&D due to the high risk of losing the fruit of their costly R\&D efforts. Therefore, if China is to continue to converge towards the world technology frontier, and become increasingly knowledge intensive, it may not in the long run be possible to be an outlier in terms of the importance of institutional quality for economic growth.

This chapter adds to the understanding of China's innovation prospects by examining how variations of institutional quality within China impact on the $\mathrm{R} \& \mathrm{D}$ efforts of firms located in provincial regions. While there exist studies that regard China as a whole and look at how its institutional quality is related to its economic growth in a cross-country context, this study explores the issue inside China. The identification strategy exploits regional variation in the quality of institutions to answer the question: how will institutional quality impact on China's innovation performance? More concretely, will firms invest more in R\&D where the institutional quality is higher? This is the main research question of this study. If the answer is positive, institutional quality will certainly be a key to the realisation of China's science and technology take off. 
To identify the effect of institutional quality, it is necessary to control other factors that could influence firm-level R\&D efforts in the analysis. Therefore, in addition to its focus on institutional quality, this study will provide a thorough analysis of the determinants of R\&D activities by Chinese firms.

\section{R\&D Investment: Provincial Variation}

As shown in Figure 7.1, China's national R\&D expenditure (current prices) has experienced a continuous and accelerating growth in the last two decades. While China's annual GDP growth rate during the period 1990-2010 was 10.4 per cent (Lin, 2011), the growth of national R\&D expenditure has been faster and, therefore, the national R\&D intensity of China has been increasing as well (Figure 7.2). The 'National Medium- and Long-Term Program for Scientific and Technological Development (2006-2020)' sets an R\&D intensity goal of 2.5 per cent by 2020, a level similar to that of the higher-income countries such as the United States, Japan and South Korea (Fisher-Vanden and Ho 2007).

One interesting angle for examining the 'science and technology take-off' (Gao and Jefferson 2007) of China is to look more closely at performance at the provincial level. Through the analysis of variation in regional R\&D performance, it is possible to better understand the forces behind changing R\&D intensity, and thus help design policies that regions, with weaker R\&D performance, could adopt to boost that performance.

Figure 7.1 National R\&D expenditure

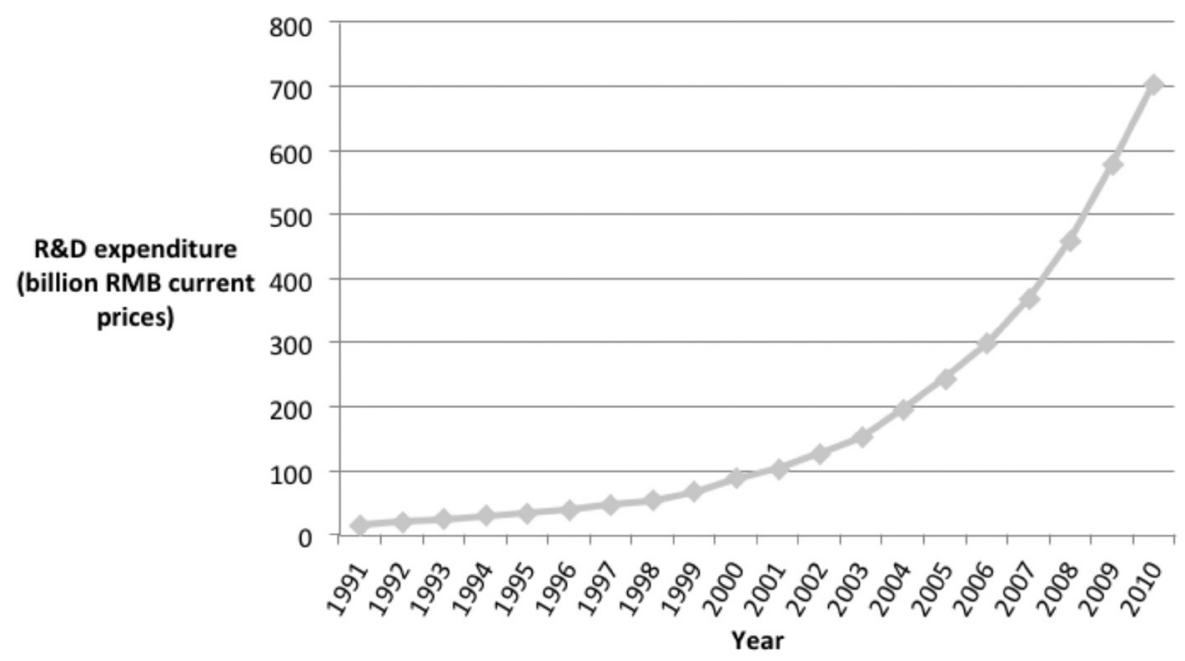

Source: China Statistical Yearbook on Science and Technology (various issues). 
Figure 7.2 China's national R\&D intensity (the ratio of R\&D expenditure in GDP) from 1995-2010

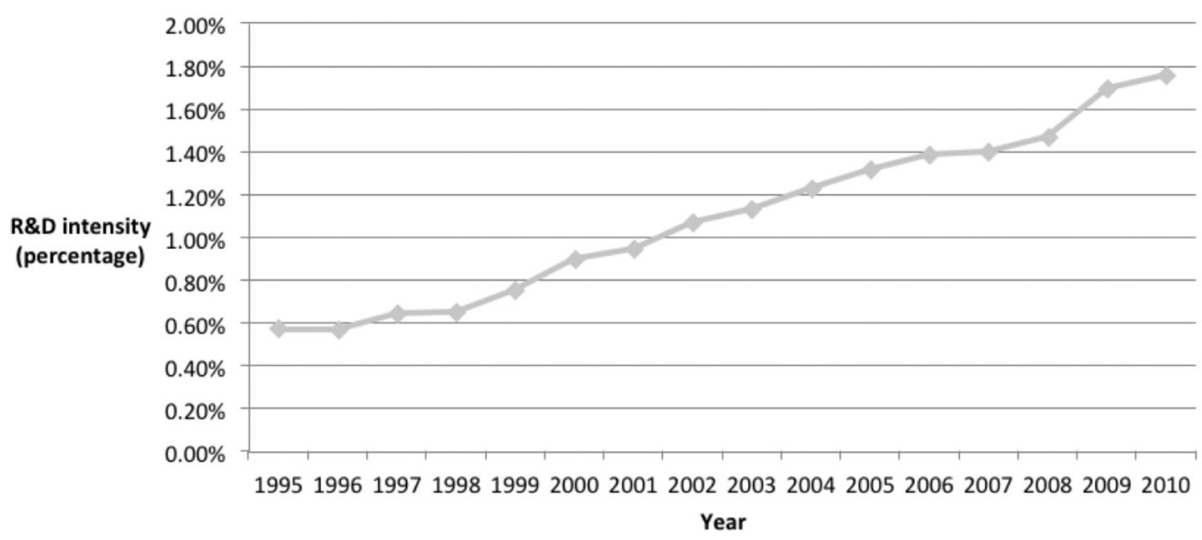

Source: China Statistical Yearbook on Science and Technology (various issues).

Figure 7.3 and Figure 7.4 show the intramural R\&D expenditure in 31 provincial regions in China in 1999 and 2010 respectively. While there are considerable variations among the Chinese regions in their R\&D expenditure in both years, one interesting observation is that, compared with 1999 in which Beijing is the single pole of $R \& D$ expenditure, several provinces such as Jiangsu, Guangdong, Shandong and Zhejiang have caught up with Beijing. Jiangsu province has even overtaken Beijing in terms of $R \& D$ expenditure. While Figure 7.3 and Figure 7.4 inform us of the changing amount of R\&D expenditure in various regions, Figure 7.5 presents the R\&D intensity change in various regions from 1999 to 2010. During this period, China's national R\&D intensity increased by about one per cent (Figure 7.2), but with significant variation across provinces (Figure 7.5). Tianjin, Zhejiang, Shanghai, Jiangsu, Shandong realised a rapid increase in $\mathrm{R} \& \mathrm{D}$ intensity of about 1.5 per cent. In contrast, the R\&D intensity in Hainan decreased, and that in Shaanxi barely changed.

In China's 'National Medium- and Long-Term Program for Scientific and Technological Development (2006-2020)', not only is the growth of R\&D intensity emphasised, it is also proposed that business enterprises should become an increasingly important entity in conducting R\&D. How do various regions perform in this regard? To answer the question about business enterprises' R\&D performance, statistics are given for large and medium-sized enterprises in China, which are reported in the China Statistical Yearbook on Science and Technology.

Figure 7.6 illustrates the share of large- and medium-sized enterprises' intramural $\mathrm{R} \& \mathrm{D}$ expenditure in total regional $\mathrm{R} \& \mathrm{D}$ expenditure in year 1999 and year 2010 respectively, and also the change of the share from 1999 to 2010. 
Among the 31 regions, 25 regions saw their large- and medium-sized enterprises' intramural $\mathrm{R} \& \mathrm{D}$ become more important in total regional R\&D. In Hubei, Tianjin, Henan, Hunan, Inner Mongolia, the share of large- and mediumsized enterprises' intramural R\&D in total regional R\&D grew by more than 20 per cent during 1999 and 2010. In contrast, in Hainan, this share decreased significantly from 50 per cent to as low as 26 per cent; in Ningxia, Qinghai, Guizhou, Fujian and Guangdong, the respective shares began from more than 70 per cent in 1999, and yet shrank from the original high level. Interestingly, large- and medium-sized enterprises' R\&D share in Beijing is very low, at only 13 per cent in 2010, and higher only than the share in Tibet.

Figure 7.3 Intramural R\&D expenditure of 31 provincial regions in 1999 (billion RMB)

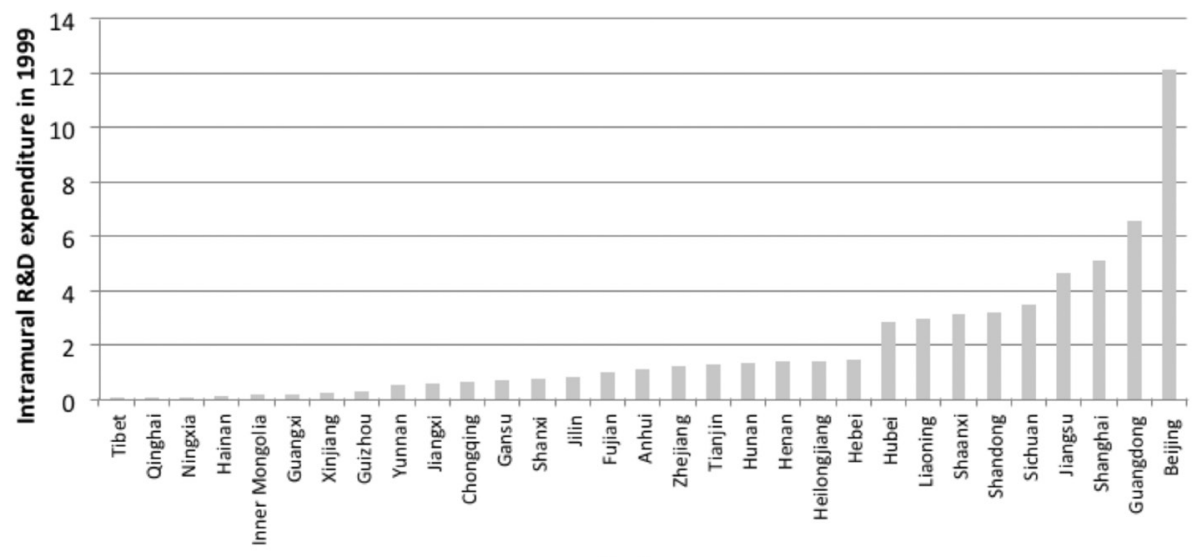

Regions

Source: China Statistical Yearbook on Science and Technology (various issues).

Figure 7.4 Intramural R\&D expenditure of 31 provincial regions in 2010 (billion RMB)

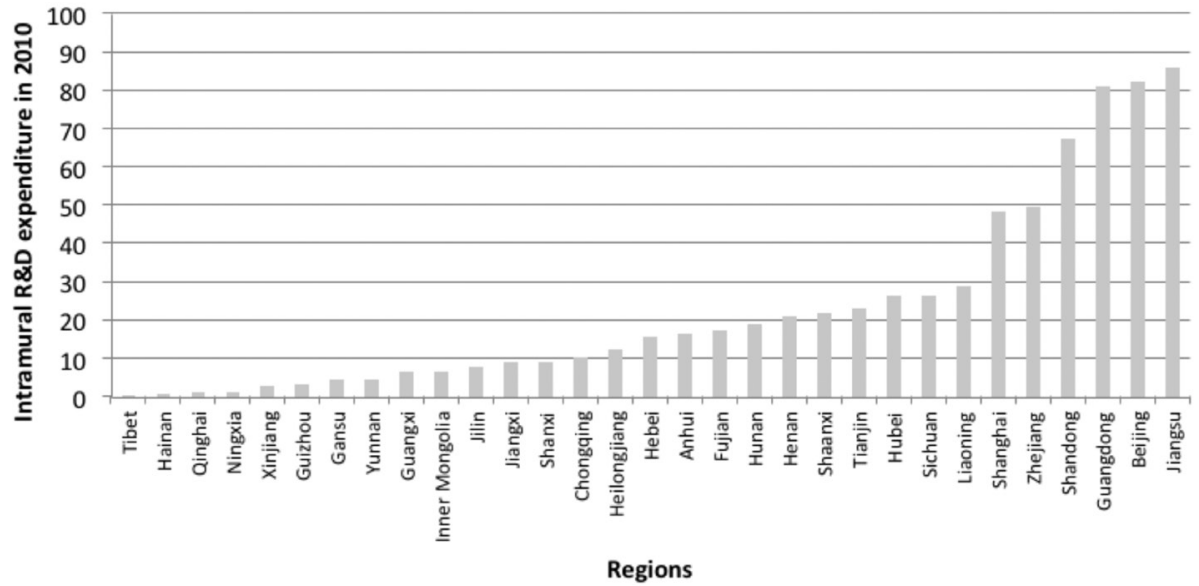


Figure 7.5 Change of intramural R\&D intensity in 31 provincial regions from 1999 to 2010

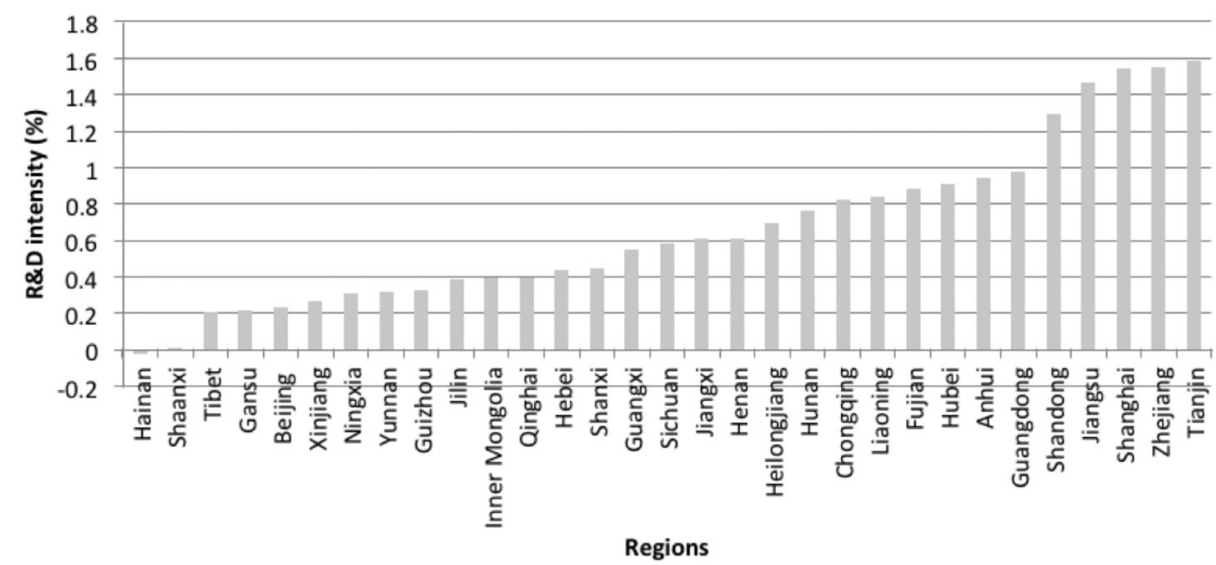

Source: China Statistical Yearbook on Science and Technology $(2000,2011)$.

Figure 7.6 Share of large and medium-sized enterprise R\&D expenditure in regional R\&D expenditure in 1999 to 2010 and changes of this share from 1999 to 2010

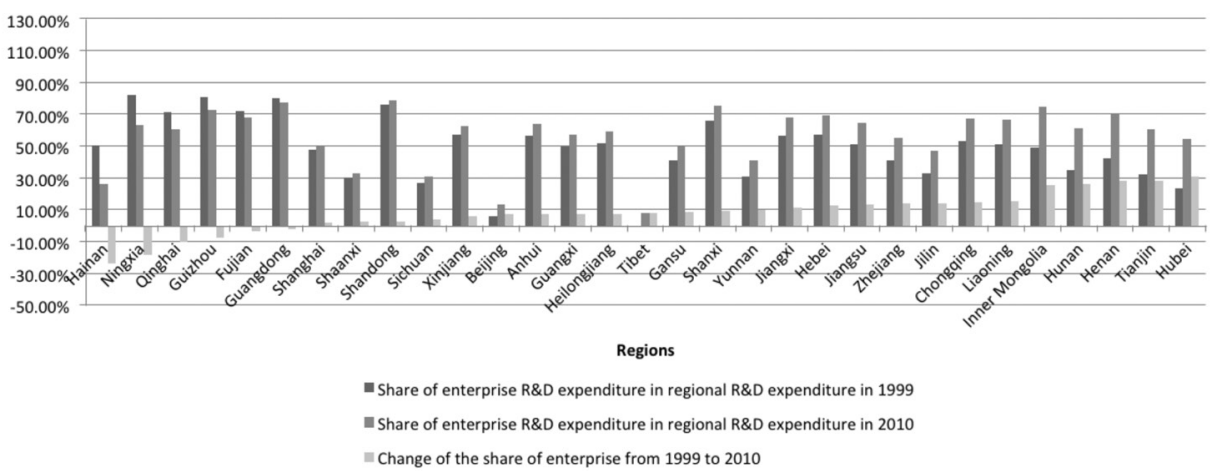

Source: China Statistical Yearbook on Science and Technology $(2000,2011)$.

In order to simultaneously stimulate the growth of regional $R \& D$ intensity and promote the importance of enterprise $R \& D$, it is fundamental that business enterprises allocate a larger share of resources towards $R \& D$ activities. Figure 7.7 represents the changes to the share of the R\&D intensity of large- and medium-sized enterprises from 1999 to 2012. The focus of this chapter is on the determinants of R\&D intensity of large- and medium-sized enterprises in China using a firm-level dataset. Researchers have already investigated various factors that may induce Chinese firms to carry out R\&D activities. This literature has not, however, provided a rigorous study of the impact on R\&D activities 
of the institutional quality of the economic environment in which the firms are located. Hence, this chapter examines whether institutional quality plays a critical role in enhancing the R\&D investment of Chinese firms.

Figure 7.7 Change of R\&D intensity of large and medium-sized enterprise (the share of R\&D expenditure in gross output) from 1999 to 2010

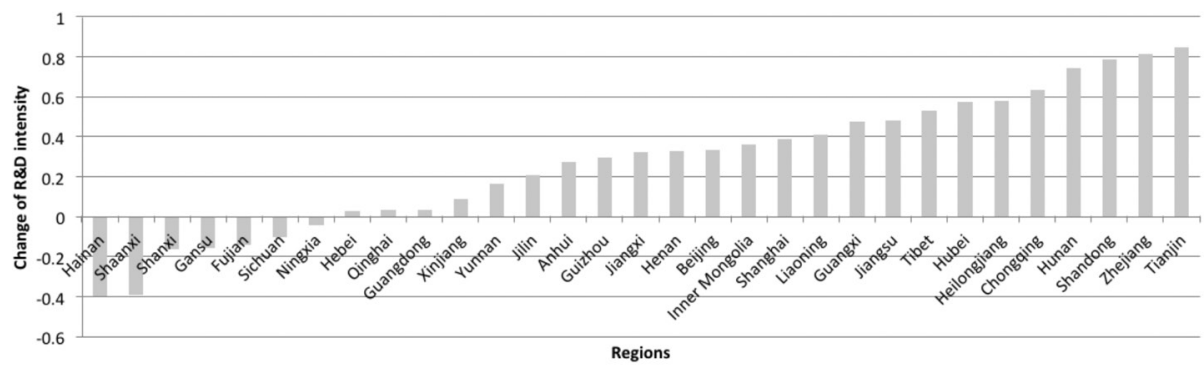

\section{Institutional Quality and Firm Research and Development Activities}

In the existing literature, several channels through which institutional quality could impact on a firm's innovation activities have been identified. Firstly, in terms of external financing, some studies show that sound legal systems and efficient financial infrastructures can facilitate the access of firms to external finance and, thus, their ability to fund investment projects (La Porta et al. 1997, Demirguc-Kunt and Maksimovic 1999, Beck et al. 2006). Secondly, in terms of internal financing, Cull and Xu (2005) find that Chinese firms exposed to a greater risk of expropriation by government have a lower reinvestment rate. Lin and Wong (2012) also provide evidence that the provision of good-quality institutions and services by government is positively associated with a firm's investment and sales growth.

Thirdly, the characteristics of innovation activities as a form of investment make them particularly sensitive to institutional quality. Jorde and Teece (1990) argue that 'Innovation ... involves uncertainty, risk taking, probing and reprobing, experimenting, and testing. It is an activity in which "dry holes" and "blind alleys" are the rule, not the exception'. Other analysts also regard risks and uncertainties as defining characteristics of innovation, since technological development is full of unforeseeable contingencies; and they emphasise the 
importance of formal laws and regulation introduced by the state to help reduce the risk and uncertainty that is faced by firms engaging in innovation (Kaasa, Kaldaru and Parts 2007).

In terms of the specific institutions that matter for innovation activities, Eicher and García-Peñalosa (2008) suggest that the key institution that determines sustained growth in R\&D-based or innovation-driven growth models is the strength of intellectual property rights. In the Romer model (1990), firms engage in $R \& D$ in order to invent new varieties of intermediate goods and obtain their patent rights. When the patent is enforced, the innovation is produced by the inventor under monopolistic conditions and the inventor enjoys monopolistic profit from the innovation output; if the patent is not enforced, the commodity can be imitated and produced by firms on a competitive fringe and, in this case, the innovator receives no profits.

While the Romer model applies to countries at the world technology frontier that rely on innovation for economic growth, there is also literature that pays attention to how an economy moves from a pure imitation regime to an equilibrium with private R\&D. Eicher and García-Peñalosa (2008) show that those countries with initial institutions above a threshold, converge to the highgrowth/strong-institutions equilibrium with private $R \& D$, and those starting below the threshold will move to the no-growth/ no-IPR protection equilibrium. Moving from the no-growth to the high-growth equilibrium with private $R \& D$ is shown to require the adoption of sufficiently strong institutions that overcome the institutional threshold defined by the low-growth equilibrium.

\section{Other Determinants of Firm-Level R\&D Intensity}

It is recognised in the literature that government subsidies play a role in firms' innovation activities. For example, it is maintained by some that the use of public funding to foster private research and development (R\&D) activities is common in many countries. Statistics from Eurostat (2009) have been used to illustrate that the public share in R\&D activities from the mid 1990s to the mid 2000s was about 35 per cent in the EU27, 30 per cent in the United States and 18.5 per cent in Japan (Zúñiga-Vincente et al. 2012). And a sizable amount of these public R\&D funds is used to subsidise $R \& D$ activities undertaken by private enterprises. Hence, the share of subsidy in industrial sales is a potential determinant of Chinese firms' innovation activities as well.

While this study examines whether Chinese firms' $R \& D$ investment is associated with government subsidies, assessing the economic impact of government subsidies for firms' R\&D investment thoroughly, however, requires 
the following two questions to be considered. First, will R\&D activities that are supported via government subsidy be economically rational and efficient? Will a firm's R\&D activities, if funded by government subsidy, bring about market value? Public policies should be aimed at supporting only those private $\mathrm{R} \& \mathrm{D}$ projects that are socially desirable and which would not otherwise be undertaken. The major justification for the public support of R\&D is that market failures, such as the incomplete appropriability of R\&D returns and the problems of information and incomplete markets, would otherwise hamper firms from reaching the socially optimal level of R\&D. Nevertheless, identifying the target projects to which public effort should be devoted is not a simple task. Second, what is the relationship between a government subsidy for R\&D and a firm's actual R\&D expenditure? Will government subsidies act as a stimulant for R\&D or, contrarily, exert a crowding-out effect on private R\&D investment and be dissipated in higher $R \& D$ wages, instead of stimulating real private $R \& D$ spending (Lokshin and Mohnen 2012)? These two problems are critical for the role of government subsidy in promoting firm R\&D activities and will need further research to be addressed fully.

The availability of financial funds will impact on R\&D activities of firms as well. Financial constraints may be particularly restrictive for R\&D investment compared with other forms of investment. Firms with high R\&D expenditure tend to have few tangible assets that can serve as collateral for credit (Brown et al. 2009). R\&D expenditures largely go to salaries and wages for scientists and researchers, which is human capital investment that cannot be collateralised. Furthermore, due to the need to protect their proprietary information over innovation, firms may be unable or unwilling to offer sufficient information about their intended R\&D programs to potential funding providers (Maskus, Neumann and Seidel 2012).

Basic alternatives for innovation financing include internal finance (out of profit) and external finance (credit-based or equity-financed systems) (Unger and Zagler 2003). Prior work on investment financing at the firm level has demonstrated that firms first resort to internal funds in order to maintain control rights over their innovations. When additional capital to fund R\&D expenditure is needed, they turn to external funds, first accessing bank credit and then equity markets (Maskus, Neumann and Seidel 2012).

In order to examine the effect of financial constraints on firms' innovation activities, the share of profit in industrial sales, total debt to total assets ratio and the share of interest payment in industrial sales are included in the regression as potential determinants of $R \& D$ activities. 
Closely related to the financial constraints problem are the issues about the size, market structure and innovation activities of firms. Joseph Schumpeter argued that large firms operating in a concentrated market are the main engines of technological progress. The seven reasons behind Schumpeter's argument include the ability of large firms to cover the fixed costs of R\&D projects, scale and scope economies in the production of innovations, the better position of larger firms to exploit unforeseen innovations, their stronger ability to spread the risks of $\mathrm{R} \& \mathrm{D}$ by undertaking many projects at one time and better access to external finance (Symeonidis 1996). As to firms with greater market powers, these firms are in a better position to finance R\&D from their own profits. They also have more incentive to innovate because they can appropriate the returns from innovation more easily. In this study, the number of employees, share of sales in the total sales of firms in the same four-digit industry and the four-digit, industry-level Herfindahl index are included in the regression as proxies for firm size, market power and market structure respectively.

There is evidence in the literature that R\&D-intensive firms have, on average, higher wages. Four possible explanations for how the positive relationship between R\&D intensity and wages should be understood include the demand for workers in particular occupations or with particular skills in firms with higher R\&D intensity; the need for more educated workers with innate ability, or other unobserved characteristics, in firms with higher R\&D intensity; quasirents generated by $\mathrm{R} \& \mathrm{D}$ intensive firms to be shared with workers with certain characteristics; and, wage premiums are related to firm size (Mishra and Smyth 2012). The size of $R \& D$-intensive firms is larger because investing in $R \& D$ is likely to involve more fixed costs. Therefore, the average wage of employees is included in the regression analysis.

The age of a firm can exert two distinct impacts on R\&D. Although Loderer and Waelchli (2009) are not focused on the relationship between age and R\&D, the effect of a firm's age is clearly explained by them. One the one hand, age allows firms to become more efficient as they discover what they are good at, and learn how to do things better over time. On the other hand, older age may also make knowledge, abilities, and skills obsolete and induce organisational decay. On balance, it is therefore unclear whether older firms experience increased prosperity, or whether they are burdened by their age, which could result in an insignificant estimate of the coefficient of the variable age in the regression analysis.

A firm's export participation may affect its R\&D activities as well. This could be because exporting requires prior R\&D innovation (Yu and Dai 2013), and innovation can help a firm maintain a competitive advantage in international markets (Porter 1990). The causality could also be reverse. It could also be because firms that export to international markets are more likely to be exposed 
to the stock of world knowledge, and enjoy larger knowledge spillovers, which in turn promotes R\&D activities. As one of the largest exporting countries in the world market, the relationship between trade participation and innovation performance is vital for China's growth prospect. This question will be fully addressed in the next chapter where firm-level production data will be merged with transaction-level trade data. In that merged dataset, it is possible to observe the trade activities of different firms, such as the number of imported intermediate and capital goods, unit value of imported goods, geographical diversification of export markets and forms of trade. The various channels through which trade activities impact on a firm's innovation performance are illustrated in the next chapter.

\section{Data}

The analysis is based on a firm-level panel dataset of the Chinese manufacturing industry for the period 2005-2007. The data were obtained from the Annual Census of Chinese Industrial Firms compiled by the National Bureau of Statistics of China (NBS). This census provides detailed firm-level financial and operational information for state-owned enterprises and all firms with annual turnover of over five million RMB. The NBS has requested all these firms to report information to the local statistical offices that report to the NBS. The NBS has the final responsibility to process the data and produce the census. This census is considered to be the most comprehensive firm-level dataset ever compiled by the NBS, accounting for about 90 per cent of total output in most industries. The NBS has endeavored to maintain consistency in data collection across time, industries and regions (Yi, Wang and Kafouros 2013). Table 7.1 and Table 7.2 provide a description of the $R \& D$ activities of the firms in the dataset from 2005 to 2007.

To measure institutional quality of provincial regions in China, I adopt the National Economic Research Institute (NERI) Index of Marketization for China's Provinces (Fan, Wang and Zhu 2011). The NERI index is an assessment system for relative progress in marketisation for China's provinces (Wang, Fan and Zhu, 2004). It assesses marketisation performance in five fields by a total of 23 basic indicators. For a certain field, a field index is calculated as the arithmetic average of a few basic indices. And the arithmetic average of the five indices constitutes the overall marketisation index. The five fields covered are government and market relations, development of the non-state enterprise sector, development of the commodity market, development of factor markets, market intermediaries, and the legal environment for the market. In this study, two measures of institutional quality are used and they are both from the NERI index system. One measure is the overall marketisation index from the NERI index system. The other measure 
is the basic index for the protection of intellectual property rights, which is one of the basic indices that compose the field index for market intermediaries and the legal environment for the market in the NERI index system. Specifically, this basic index for the protection of intellectual property rights is based on numbers of patent applications and patent grants per technical personnel in various regions.

On the one hand, intellectual property protection receives considerable attention in the discussion about incentives for a firm engaging in innovation and, on the other hand, overall institutional quality will affect the production process and a firm's ability to enjoy the fruits of R\&D investment. Therefore, these two measures of institutional quality are both examined in the regression analyses below.

Table 7.1 Number of all firms and number of firms that engaged in R\&D expenditure

\begin{tabular}{l|c|c|c}
\hline Year & $\mathbf{N}$ & Number of observations with nonzero R\&D & Percentage \\
\hline 2005 & 243994 & 26051 & 0.106769 \\
\hline 2006 & 271002 & 29804 & 0.109977 \\
\hline 2007 & 304936 & 34232 & 0.1122596 \\
\hline
\end{tabular}

Source: Annual Census of Chinese Industrial Firms compiled by the National Bureau of Statistics of China.

Table 7.2 Descriptive statistics of the sample for regression

\begin{tabular}{l|c|c|c|c}
\hline Descriptive statistics & Mean & Standard deviation & Min & Max \\
\hline Variables & 0.0018 & 0.0146 & 0 & 0.9906 \\
\hline R\&D intensity & 4.66 & 1.08 & 2.2 & 12.1 \\
\hline size & 9.2 & 9.12 & 1 & 180 \\
\hline age & 87.97 & 231.3 & -4.78 & $26,818.19$ \\
\hline k & 0.015 & 0.027 & 0.00099 & 0.92 \\
\hline herfindahl & 0.0017 & 0.0089 & 0 & 0.88 \\
\hline marketshare & 2.72 & 0.57 & -5.3 & 8.39 \\
\hline wage & 0.0102 & 8.88 & -7710.8 & 628.8 \\
\hline profitability & 0.17 & 0.34 & 0 & 1.4 \\
\hline exportintensity & 0.57 & 0.44 & -24.3 & 270.5 \\
\hline debtratio & 0.015 & 4.62 & -28 & 4130 \\
\hline interestpayment & 0.0028 & 0.036 & -0.24 & 17.24 \\
\hline subsidy & 13.22 & 10.59 & 0.02 & 41.47 \\
\hline intellectual property & & 1.58 & 0.29 & 10.92 \\
\hline protection & $26,329.84$ & $12,033.13$ & 5052 & 66,367 \\
\hline overall institutional quality & percapitaGDP & & & \\
\hline
\end{tabular}

Source: Annual Census of Chinese Industrial Firms compiled by the National Bureau of Statistics of China. 


\title{
Empirical Specification and Estimation
}

\author{
$R \&$ Dintensity $y_{i, j, k, t}=$ \\ $\beta_{0}+\beta_{1} * \operatorname{size}_{i, j, k, t}+\beta_{2} *$ age $_{i, j, k, t}+\beta_{3} *$ profitability $_{i, j, k, t}+\beta_{4} *$ \\ exportintensity $_{i, j, k, t}+\beta_{5} *$ wage $_{i, j, k, t}+\beta_{6} *$ marketshare $_{i, j, k, t}+\beta_{7} *$ \\ herfindahl $_{j, t}+\beta_{8} *$ debtratio $_{i, j, k, t}+\beta_{9} * k_{i, j, k, t}+\beta_{10} * \operatorname{subsid}_{i, j, k, t}+\beta_{11} *$ \\ interestpayment $_{i . j, l, t}+\beta_{12} *$ institutionalquality $_{k, t}+\beta_{13} *$ percapitaGD $_{k, t}+$
} $\varepsilon_{i, j, k, t}(1)$

$i$ denotes an individual firm in a certain four-digit industry, $j$ denotes a certain four-digit industry, $k$ denotes a certain province, $t$ denotes a certain year.

$R \&$ Dintensity $y_{i, j, k, t}$ is the share of a firm's R\&D expenditure in its industrial sales. This is a measure of input into the innovation process. Measures of innovative or technological activity can be classified as measures of either innovative inputs or output. Measures of output include the number of patents, the number of significant innovations, and indices of the market value of innovations. The most frequently used measures of inputs into the innovation process are $R \& D$ expenditure and personnel involved in $R \& D$ (Symeonidis 1996). There is no information about the number of patents and the personnel involved in R\&D in our dataset, and therefore R\&D intensity is adopted.

size $_{i j, k, t}$ is the natural logarithm of a firm's number of employees.

$a g e_{i, j, k, t}$ is the number of years of a firm's existence.

profitability $_{i, j, k, t}$ is the share of profit in a firm's industrial sales.

exportintensity $_{i, j, k, t}$ is the share of export value in a firm's industrial sales.

wage $_{i . j, k, t}$ is the average wage of the firm's employees; i.e. the sum of wage compensation and welfare compensation divided by the number of employees.

marketshare $_{i, j, k, t}$ is the share of a firm's industrial sales in the industrial sales of all firms in the same four-digit industry.

herfindahl $_{j, t}$ is the four-digit, industry-level Herfindahl Index. This is calculated as the sum of squared market shares of all the firms in the same four-digit industry. The range of Herfindahl Index is between 0 and 1 with 0 denoting perfect competition where each firm's market share is infinitesimally small and 1 denoting monopoly, where one firm takes up the whole market.

debtratio $_{i, j, k, t}$ is the share of a firm's total liabilities in its total assets. 
$k_{i, j, k, t}$ is the net value of a firm's fixed assets per employee.

$\operatorname{subsidy}_{i, j, k, t}$ is the share of subsidy in a firm's industrial sales.

interestpayment $_{i, j, k, t}$ is the share of interest payment in a firm's industrial sales.

institutionalquality $_{k, t}$ is the measure of institutional quality (overall or focused on the protection of intellectual property rights) of the province in which a firm is located.

percapitaGDP $P_{k, t}$ is the per capita GDP of the province in which a firm is located.

The difficulty of the estimation of Equation (1) lies in the concentration of the dependent variable $R \&$ Dintensity $_{i, j, k, t}$ on the zero value. It is known that if one uses ordinary least squares (OLS) estimation on the non-zero part of the original variable $R \&$ Dintensity $i, t$, the results could be biased due to the sample selection problem. This problem is made more complex when firms may have unobserved heterogeneity, such as the ability of the entrepreneur. The coexistence of the concentration of independent variable on the zero value and the necessity to take into account fixed effects at the firm level, requires an estimation strategy that can tackle these two problems at the same time. Previous studies on the determinants of the R\&D intensity of Chinese firms resort to the random-effects Tobit model for panel data. Although this approach pays attention to the fact that the dependent variable is left-censored at zero value, it also assumes that the, possibly omitted, firm-specific variables are not correlated with variables included in the empirical specification. This assumption is problematic if, for example, the omitted variable is the ability of the entrepreneur, which influences the R\&D intensity of the firm and is potentially correlated with other independent variables such as profitability and market share of the firm. Therefore, this study adopts an estimation strategy (Kyriazidou 1997). This estimation strategy solves the sample selection problem and the omitted variables problem due to unobserved firm heterogeneity at the same time.

\section{Empirical Results}

Table 7.2 presents the descriptive statistics of the sample for the regression. Table 7.3 and Table 7.4 report the regression results. Table 7.3 examines how intellectual property rights protection influences the R\&D intensity of firms, and Table 7.4 illustrates the effect of overall institutional quality. It can be seen that the results based on these two different measures of institutional quality are qualitatively similar. All other things being equal, a firm with a larger size is more likely to do R\&D; a firm that pays higher wages, enjoys higher profitability and has higher export intensity is more likely to do R\&D; a firm with a higher 
debt burden is less likely to do R\&D; a firm where received subsidy is of a larger proportion in the industrial sales is more likely to do R\&D; lastly, when the protection of intellectual property rights (or overall institutional quality) is stronger in the province where a firm is located, the firms is more likely to do R\&D.

Table 7.3 Regression results

\begin{tabular}{l|c|c|c|c}
\hline \multirow{2}{*}{ Regressors } & \multicolumn{2}{c|}{$\begin{array}{c}\text { Likelihood of conducting } \\
\text { R\&D activities }\end{array}$} & \multicolumn{2}{c}{$\begin{array}{c}\text { R\&D intensity (share of R\&D } \\
\text { expenditure in total industrial sales) }\end{array}$} \\
\hline size & Coefficients & Standard error & Coefficients & Standard error \\
\hline age & $0.48^{* *}$ & $2.6 \mathrm{E}-02$ & $-2.3 \mathrm{E}-03$ & $1.6 \mathrm{E}-03$ \\
\hline k & -0.0034 & $3.3 \mathrm{E}-03$ & $-1.8 \mathrm{E}-05$ & $3.9 \mathrm{E}-05$ \\
\hline herfindahl & $6.2 \mathrm{E}-05$ & $7.2 \mathrm{E}-05$ & $4.1 \mathrm{E}-06$ & $6.4 \mathrm{E}-06$ \\
\hline marketshare & -0.27 & 0.71 & $0.057^{* * *}$ & $2.0 \mathrm{E}-02$ \\
\hline wage & 0.16 & 2.1 & $-0.073^{* * *}$ & $2.6 \mathrm{E}-02$ \\
\hline profitability & $0.38^{* *}$ & $2.1 \mathrm{E}-02$ & $6.5 \mathrm{E}-04$ & $1.3 \mathrm{E}-03$ \\
\hline exportintensity & $0.055^{*}$ & $2.6 \mathrm{E}-02$ & -0.010 & $5.6 \mathrm{E}-03$ \\
\hline debtratio & $0.29 * * *$ & $6.4 \mathrm{E}-02$ & $-3.0 \mathrm{E}-03$ & $3.2 \mathrm{E}-03$ \\
\hline interestpayment & $-0.15 * * *$ & $4.7 \mathrm{E}-02$ & $-3.5 \mathrm{E}-03$ & $2.2 \mathrm{E}-03$ \\
\hline subsidy & 0.22 & 0.15 & $0.080 * * *$ & $3.0 \mathrm{E}-02$ \\
\hline intellectual property & $0.022^{* * *}$ & $4.3 \mathrm{E}-03$ & $-7.9 \mathrm{E}-05$ & $5.2 \mathrm{E}-02$ \\
\hline protection & $0.56^{*}$ & 0.26 & $4.6 \mathrm{E}-07$ & $2.0 \mathrm{E}-04$ \\
\hline percapitaGDP & $-7.70 \mathrm{E}-07$ & $8.5 \mathrm{E}-06$ & $6.1 \mathrm{E}-04$ & $8.7 \mathrm{E}-04$ \\
\hline year2006 & 0.075 & $2.5 \mathrm{E}-02$ & $-1.6 \mathrm{E}-03$ & $1.7 \mathrm{E}-03$ \\
\hline year2007 & 0.15 & $4.9 \mathrm{E}-02$ & & \\
\hline
\end{tabular}

Note: ${ }^{* * *},{ }^{* *},{ }^{*}$ indicate that the level of significance is $1 \%, 5 \%$ and $10 \%$, respectively.

Source: Author's own estimations.

The influences of these variables on the R\&D intensity of a firm that indeed conducts $R \& D$ activities are as follows. If the four-digit industry to which a firm belongs becomes less competitive, the more R\&D intensive a firm becomes. The higher the market share of a firm in the four-digit industry, the less R\&D intensive the firm becomes. The larger the share of interest payment in the industrial sales of a firm, the more R\&D intensive the firm becomes.

Comparing how the variables impact on the likelihood of doing R\&D and the R\&D intensity of firms, one can see the following two points. First, the market share of a firm, the industrial concentration of the industry to which a firm belongs and the share of interest payment in the industrial sales of a firm exert influence on the R\&D intensity of a firm that conducts $R \& D$ activities, but not on the decision whether to do R\&D. Secondly, the size of a firm, wage rate, profitability, export intensity, debt burden of a firm, received subsidy and 
intellectual property rights protection positively influence the likelihood to do R\&D, but do not significantly impact on the R\&D intensity of a firm that has already decided to do R\&D.

Table 7.4 Regression results

\begin{tabular}{l|c|c|c|c}
\hline & \multicolumn{2}{|c|}{$\begin{array}{c}\text { Likelihood of conducting } \\
\text { R\&D activities }\end{array}$} & \multicolumn{2}{c}{$\begin{array}{c}\text { R\&D intensity (share of R\&D } \\
\text { expenditure in total industrial sales) }\end{array}$} \\
\hline Regressors & Coefficients & Standard error & Coefficients & Standard error \\
\hline size & $0.48^{* *}$ & $2.62 \mathrm{E}-02$ & $-1.2 \mathrm{E}-03$ & $1.3 \mathrm{E}-03$ \\
\hline age & -0.0034 & $3.21 \mathrm{E}-03$ & $-2.4 \mathrm{E}-05$ & $4.6 \mathrm{E}-05$ \\
\hline k & $6.34 \mathrm{E}-05$ & $7.23 \mathrm{E}-05$ & $-1.1 \mathrm{E}-06$ & $7.1 \mathrm{E}-06$ \\
\hline herfindahl & -0.27 & $7.08 \mathrm{E}-01$ & $0.068^{* * *}$ & $2.6 \mathrm{E}-02$ \\
\hline marketshare & 0.27 & $2.09 \mathrm{E}+00$ & $-0.10^{* * *}$ & $3.5 \mathrm{E}-02$ \\
\hline wage & $0.38^{* *}$ & $2.05 \mathrm{E}-02$ & $1.3 \mathrm{E}-03$ & $1.4 \mathrm{E}-03$ \\
\hline profitability & $0.055^{*}$ & $2.56 \mathrm{E}-02$ & $-0.015 *$ & $8.3 \mathrm{E}-03$ \\
\hline exportintensity & $0.30^{* *}$ & $6.37 \mathrm{E}-02$ & $4.7 \mathrm{E}-04$ & $2.7 \mathrm{E}-03$ \\
\hline debtratio & $-0.15^{* * *}$ & $4.64 \mathrm{E}-02$ & $-1.5 \mathrm{E}-03$ & $2.5 \mathrm{E}-03$ \\
\hline interestpayment & 0.22 & $1.55 \mathrm{E}-01$ & $0.094 * * *$ & $3.8 \mathrm{E}-02$ \\
\hline subsidy & $0.55^{* *}$ & $2.55 \mathrm{E}-01$ & 0.10 & $6.2 \mathrm{E}-02$ \\
\hline $\begin{array}{l}\text { Overall institutional } \\
\text { quality }\end{array}$ & $0.022^{* * *}$ & $5.17 \mathrm{E}-02$ & $9.3 \mathrm{E}-04$ & $1.8 \mathrm{E}-03$ \\
\hline percapitaGDP & $2.28 \mathrm{E}-05^{* * *}$ & $6.34 \mathrm{E}-06$ & $4.0 \mathrm{E}-07$ & $3.0 \mathrm{E}-07$ \\
\hline year2006 & $-0.0751^{* *}$ & $2.87 \mathrm{E}-02$ & $9.4 \mathrm{E}-04$ & $9.6 \mathrm{E}-04$ \\
\hline year2007 & $-0.093^{*}$ & $4.81 \mathrm{E}-02$ & $-1.1 \mathrm{E}-04$ & $1.7 \mathrm{E}-03$ \\
\hline
\end{tabular}

Note: ${ }^{* * *},{ }^{* *},{ }^{*}$ indicate that the level of significance is $1 \%, 5 \%$ and $10 \%$, respectively.

Source: Author's own estimations.

On the one hand, the finding that a firm of larger size and a firm with higher profitability are more likely to do R\&D, but may not be more R\&D intensive, reflects the complex relationship between firm size, firm profitability and innovation activities; on the other hand, the finding that a firm in a more concentrated industry and a firm with smaller market share are more R\&D intensive shows the links between market power and innovation activities. However, the evidence found in this study is not consistent with Schumpeter's argument, and it requires further research on the channels behind the results to provide a convincing explanation.

As to the relationship between financial constraints and innovation activities, the finding that a firm with a larger debt burden is less likely to do $\mathrm{R} \& \mathrm{D}$ supports the hypothesis that internal funds are a critical funding source for a firm's R\&D activities, and a firm with more equity will conduct more R\&D activities. When $R \& D$ intensity is considered, the significant role of the share of interest payment in the industrial sales of a firm suggests the importance of 
the availability of external funding sources, such as bank loans to fund R\&D activities. Interestingly, the share of subsidy in total industrial sales is found to increase the propensity of a firm to do R\&D. This finding suggests that the role of government in the 'science and technology take-off' of China may be important, and how government subsidy influences a firm's investment in innovation and innovation output is a question that requires further research. Also, the fact that institutional quality matters for engaging firms in R\&D activities, but not for $R \& D$ intensity once firms opt in to $R \& D$ activities, further points to the importance of other potential determinants of R\&D intensity.

Stronger intellectual property protection clearly boosts the possibility that a firm will invest in innovation. This finding suggests that China is no exception in terms of the importance of institutions that provide protection for the R\&D fruit. If the Chinese Government hopes to achieve the goal, set in the 'National Medium- and Long-Term Program for Scientific and Technological Development (2006-2020)', that firms should become the major agents of R\&D activities, one helpful strategy that the government could adopt is to build up institutions that facilitate market operations and strengthen the protection of intellectual property rights that increase the expected return to R\&D investment of firms. Interestingly, intellectual property protection does not significantly influence the R\&D intensity of a firm that has already decided to do R\&D. This empirical finding suggests that the importance of the protection of intellectual property rights probably lies mainly in inducing a phase change of firms from technological imitation to innovation. Once this phase change is completed, the continuous growth of innovative capability may rely on other determinants and dynamics.

The real per capita GDP of the province where a firm is located is included in the regression to act as a control for the influences from the stage of development. Provinces with higher real per capita GDP may enjoy better infrastructure, more human resources, or a generally more mature business environment. These factors could be conducive to a firm's R\&D activities and could also be correlated with institutional quality. Therefore, real per capita GDP is controlled in the regression. We can see from the results that real per capita GDP is not significant in explaining the likelihood of a firm to perform R\&D, and the R\&D intensity of firms that have already decided to perform R\&D. This finding further confirms the importance of institutional quality itself.

Lastly, a firm that has higher export intensity is found to be more likely to conduct $R \& D$ activities, although, for a firm that is doing $R \& D$, export intensity is not significantly associated with R\&D intensity. 


\section{Policy Implications}

As China continues to draw level with countries on the world knowledge frontier, the need has intensified for the economy to become more knowledgeintensive and innovative in order to sustain the growth momentum. While some studies argue that China has been able to grow fast despite its relatively low institutional quality (Huang 2008, Allen et al. 2005), the findings in this chapter suggest the institutional quality is critical for China's innovative performance and hence for the economy's future growth.

This study employs a firm-level panel dataset which covers the period 2005-2007 and covers all state-owned enterprises and all enterprises with annual turnover of over five million RMB. Based on an estimation strategy (Kyriazidou 1997) which takes into account the sample selection problem and the firm-level fixed effects at the same time, the study shows that higher levels of overall institutional quality and higher levels of intellectual property rights protection that exists in the province where a firm is located increase the likelihood that a firm will conduct R\&D activities, when other potential determinants of a firm's R\&D participation are controlled. The two measures of institutional quality are not, however, found to be significantly related to a firm's R\&D intensity once the firm has already decided to invest in R\&D.

These findings suggest that institutional quality at the provincial level positively affects the decision of firms to enter into R\&D activities. But, once firms start to do R\&D, the subsequent expansion of firm-level R\&D intensity depends on other factors. Therefore, improving domestic institutional quality is just the first step towards the goal of building a knowledge-intensive economy, becoming a global R\&D player and contributing to the world pool of knowledge and technology. Better understanding of other factors that influence the R\&D intensity of firms after they begin to have $R \& D$ investment is important for ensuring continuous growth of the firms' innovative capabilities. For example, trade-related factors could be very important for the R\&D intensity of firms, since there are complex relationships between trade and innovation suggested by the existing literature. Although export intensity, the only trade-related factor in this study, is found to enhance a firm's likelihood of doing R\&D, but not the R\&D intensity of the firm, more trade-related measures will need to be considered in a complete study on the effects of firm-level trade or innovation. 


\section{References}

Acemoglu, D., Johnson, S. \& Robinson, J.A., 2001, 'The Colonial Origins of Comparative Development: An Empirical Investigation,' American Economic Review, vol. 91, no. 5, pp. 1369-401.

— , 2002, 'Reversal of Fortune: Geography and Institutions in the Making of the Modern World Income Distribution', Quarterly Journal of Economics, vol. 107, pp. 1231-94.

Acemoglu, D. \& Johnson, S. 2005, 'Unbundling Institutions', Journal of Political Economy, vol. 113, pp. 949-95.

Allen, F., Qian, J. \& Qian, M., 2005, 'Law, Finance, and Economic Growth in China,' Journal of Financial Economics, vol. 77, pp. 57-116.

Beck, T. \& Demirguc-Kunt, A., 2006, 'Small and Medium-Size Enterprises: Access to Finance as Growth Constraint', Journal of Banking and Finance, vol. 30, pp. 2931-43.

Brown, J.R., Fazzari, S.M. \& Petersen, B.C., 2009, 'Financing Innovation and Growth: Cash Flow, External Equity, and the 1990s R\&D Boom', The Journal of Finance, vol. 64, pp. 151-85.

Cull, R. \& Xu, L.C., 2005, 'Institutions, Ownership, and Finance: The Determinant of Profit Reinvestment Among Chinese Firms', Journal of Financial Economics, vol. 77, pp. 117-46.

Demirguc-Kunt, A. \& Maksimovic, V., 1999, 'Institutions, Financial Markets, and Firm Debt Maturity', Journal of Financial Economics, vol. 54, pp. 295336.

Eicher, T. \& García-Peñalosa, C., 2008, 'Endogenous Strength of Intellectual Property Rights: Implications for Economic Development and Growth', European Economic Review, vol. 52, no. 2, pp. 237-58.

Eurostat, 2009, 'Research and Development Expenditure, by Sectors of Performance', European Commission.

Fan, G., Wang, X. \& Zhu, H., 2011, NERI INDEX of Marketization of China's Provinces 2011 Report (in Chinese).

Fisher-Vanden, K. \& Ho, M.S., 2007, 'How do Market Reforms Affect China's Responsiveness to Environmental Policy?' Journal of Development Economics, vol. 82, no. 1, pp. 200-33. 
Gao, J. \& Jefferson, G., 2007, 'Science and Technology Take-off in China: Sources of Rising R\&D Intensity', Asia Pacific Business Review, vol. 13, no. 3, pp. 357-71.

Hall, R.E. \& Jones, C.I., 1999, 'Why Do Some Countries Produce So Much More Output per Worker than Others?' Quarterly Journal of Economics, vol. 114, pp. 83-116.

Huang, Y., 2008, Capitalism with Chinese Characteristics, Cambridge University Press.

Hutschenreiter G. \& Zhang, G., 2007, 'China's Quest for Innovation-driven Growth: The Policy Dimension', Journal of Industrial Competition and Trade, vol. 7, no. 3-4, pp. 245-54.

Jones, C.I. \& Romer, P.M., 2010, 'The New Kaldor Facts: Ideas, Institutions, Population, and Human Capital', American Economic Journal: Macroeconomics, American Economic Association, January, vol. 2, no. 1, pp. 224-45.

Jorde, T.M. \& Teece, D.J., 1990, 'Innovation and Cooperation: Implications for Competition and Antitrust', Journal of Economic Perspectives, vol. 4, no. 3, pp. 75-96.

Kaasa, A., Kaldaru, H. \& Parts, E., 2007, 'Social Capital and Institutional Quality as Factors of Innovation: Evidence from Europe', Working Paper Series of the University of Tartu.

Kyriazidou, E., 1997, 'Estimation of a Panel Data Sample Selection Model', Econometrica, vol. 65, pp. 1335-64.

La Porta, R., Lopez-de-Silanes, F., Shleifer, A. \& Vishny, R., 1997, 'Legal Determinants of External Finance', Journal of Finance, vol. 52, pp. 1131-50.

Lin, J.Y., 2011, 'China and the Global Economy,' China Economic Journal, vol. 4, no. 1, pp. 1-14.

Lin, C. \& Wong, S.M., 2012, 'Government Intervention and Firm Investment: Evidence From International Micro-data', Journal of International Money and Finance, vol. 32, pp. 637-53.

Lokshin, B. \& Mohnen, P., 2012, 'How Effective are Level-Based R\&D Tax Credits? Evidence From The Netherlands', Applied Economics, vol. 44, no.12, pp. 1527-38.

Loderer, C. \& Waelchli, U., 2009, 'Firm Age and Performance', University of Bern, Working Paper. 
Maskus, K.E., Neumann, R. \& Seidel, T., 2012, ‘How National and International Financial Development Affect Industrial R\&D', European Economic Review, vol. 56, no. 1, pp. 72-83.

Mishra, V. \& Smyth, R., 2012, 'Technological Change and Wages in China: Evidence from Matched Employer-Employee Data', Monash Economics Working Papers 28-12, Monash University, Department of Economics.

Porter, M.E., 1990, The Competitive Advantage of Nations, Free Press, MacMillan, New York.

Romer, P., 1990, 'Endogenous Technological Change,' Journal of Political Economy, vol. 98, no. 5.

Serger, S.S. \& Breidne, M., 2007, 'China's Fifteen-year Plan for Science and Technology: An Assessment', Asia Policy, no. 4, pp. 135-64.

Song, Z., Storesletten, K. \& Zilibotti, F., 2011, 'Growing Like China', American Economic Review, vol. 101, no. 1, pp. 196-233.

Sun, Y. \& Du, D., 2010, 'Determinants of Industrial Innovation in China: Evidence from its Recent Economic Census', Technovation, vol. 30, no. 9-10, pp. 540-50.

Symeonidis, G., 1996, 'Innovation, Firm Size and Market Structure: Schumpeterian Hypothesis and Some New Themes,' Economics Department Working Paper No. 161, London School of Economics.

Unger, B. \& Zagler, M., 2003, 'Institutional and Organizational Determinants of Product Innovations', Innovation, vol. 16, no. 3, pp. 293-310.

Wang, X., Fan, G. \& Zhu, H., 2004, 'Marketization in China: Progress and Prospects', in R. Garnaut \& L. Song (eds), China: Is Rapid Growth Sustainable?, Asia Pacific Press, Canberra, pp. 118-36.

Wu, Y., 2010, 'Innovation and Economic Growth in China', Discussion Paper 10.10, The University of Western Australia.

Yi, J., Wang, C. \& Kafouros, M., 2012, 'The effects of innovation capabilities on exporting: do institutional forces matter?' International Business Review, vol. 22, issue 2, pp. 392-406.

Yu, M. \& Dai, M. 2013, 'Firm R\&D, Absorptive Capacity, and Learning by Exporting: Firm-Level Evidence from China', The World Economy. 
China: A New Model for Growth and Development

Zúñiga-Vicente, J., Alonso-Borrego, C., Forcadell, F. \& Galan, J., 2012, 'Assessing the Effect of Public Subsidies on firm R\&D Investment: A Survey', Journal of Economic Surveys. 


\section{China's Agricultural Development:

\author{
Achievements and Challenges
}

Li Zhou

\section{Introduction}

The development of the agricultural sector plays an important role in the Chinese economic transformation during the reform period (1978-2012). First, the rural reform centring on the household production responsibility system has increased agricultural output and productivity, lifting millions of people out of absolute poverty since the late 1970s. Second, increased productivity in the agricultural sector, coupled with institutional reform allowing the mobility of rural labour force, has led to unprecedented and large-scale rural-urban migration, permitting China to enjoy the effects of a tremendous 'resource shift' to enhance its economic growth. ${ }^{1}$ Third, in the past 30 years, the seemingly unlimited supplies of labour flowing from the rural to the urban sector have contributed positively to China's industrialisation process. Finally, development of the agricultural sector, in terms of rising outputs and productivity, helps China to confront the food security challenges arising from meeting the food demand of one-fifth of the world population using only seven per cent of the world's arable land.

The agricultural sector, however, faces some important challenges with respect to reform and management of the land system, economy of scale in agricultural production, technological development in agriculture, fertility of farmland, the rural social protection system, and rural community management. These challenges indicate that further development of the agricultural sector is crucial for China in implementing the new growth strategy. This chapter reviews the major achievements in China's agricultural development to date, and discusses the key challenges now facing the sector. The chapter points out how China can confront these challenges by deepening the agricultural reform, including reform of the land system; enhancing technological progress in agricultural production; providing the necessary social support and protection for farmers as part of the government's effort to address China's rural and

1 The effect of the 'resource shift' is defined as the efficiency gains resulting from moving resources (labour) from low (rural) to high (urban) productivity areas of the economy. 
urban income inequality; and, changing the consumption patterns of certain agricultural products in order to improve people's health and reduce the waste of agricultural resources.

\section{Achievements in Agricultural Development}

\section{Steady Growth of Agricultural Outputs Resulting from Reform and Policy Change}

Agricultural production over the period from 1978 to 2012 demonstrated a pattern of stable growth, much due to the impact of economic reform in rural areas and changes in government policies towards agricultural production and farmers' wellbeing. For example, from 1978 to 2012, China's grain production nearly doubled and its milk production increased by 41.1 times. More recently, from 2000 to 2012, milk production increased 3.5 times, while vegetable oil production increased by 17.64 per cent. The difference in the growth rates during the two periods has obviously narrowed, but the outputs of all the major agricultural products continue to increase (Table 8.1 and Figure 8.1).

An important criterion that can be used to measure progress in agricultural development is output per capita, which is increasing. Grain output per capita was 435.4 kilograms $(\mathrm{kg})$ in 2012, substantially higher than the $116.4 \mathrm{~kg}$ and $69.3 \mathrm{~kg}$ observed in 1978 and 2000, respectively. Pork, beef and lamb per capita production in 2012 was also higher than the $45.5 \mathrm{~kg}$ and $17.0 \mathrm{~kg}$ observed in 1978 and 2000. The aquatic products per capita in 2012 were higher than the $38.7 \mathrm{~kg}$ and $14.2 \mathrm{~kg}$ observed in 1978 and 2000. The milk per capita in 2012 is higher than the levels of $27.7 \mathrm{~kg}$ and $21.1 \mathrm{~kg}$ observed in 1978 and 2000 . The oils per capita in 2012 are higher than the observed levels of $20.2 \mathrm{~kg}$ and $2.3 \mathrm{~kg}$ in 1978 and 2000. The cotton per capita in 2012 is higher than the levels of $2.8 \mathrm{~kg}$ and $1.6 \mathrm{~kg}$ in 1978 and 2000 (Table 8.2). 


\begin{tabular}{|c|c|c|c|c|c|c|c|c|c|c|c|c|c|c|c|c|}
\hline 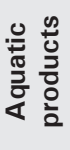 & $\begin{array}{l}0 \\
\dot{1} \\
\llcorner \\
0 \\
\dot{+}\end{array}$ & 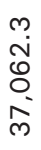 & 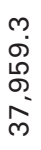 & $\begin{array}{l}0 \\
\infty \\
+ \\
\dot{+} \\
\text { ம) } \\
\text { ले }\end{array}$ & 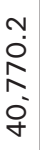 & 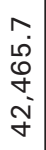 & $\begin{array}{l}0 \\
\infty \\
\infty \\
\sigma \\
\leftarrow \\
\dot{+}\end{array}$ & \begin{tabular}{l}
0 \\
0 \\
$\oplus$ \\
$\infty$ \\
$\infty$ \\
\multirow{+}{+}{}
\end{tabular} & 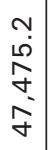 & $\begin{array}{l}- \\
\dot{\varphi} \\
\stackrel{2}{\sigma} \\
\infty \\
\dot{+}\end{array}$ & $\begin{array}{l}0 \\
\dot{\sigma} \\
0 \\
\check{\sigma} \\
\check{L}\end{array}$ & $\begin{array}{l}0 \\
\dot{0} \\
\text { N} \\
\text { mं } \\
\dot{0}\end{array}$ & $\begin{array}{l}\check{\sim} \\
\text { లె } \\
0 \\
0 \\
\llcorner\end{array}$ & $\begin{array}{l}0 \\
\stackrel{0}{ } \\
\stackrel{0}{0} \\
0 \\
\text { के }\end{array}$ & 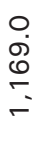 & $\begin{array}{l}+ \\
\text { ه } \\
\end{array}$ \\
\hline 옹 & 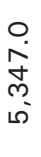 & $\begin{array}{l}\check{\sigma} \\
\stackrel{N}{ } \\
\infty \\
\bar{v}\end{array}$ & $\begin{array}{l}\stackrel{0}{-} \\
\stackrel{0}{0} \\
\stackrel{2}{N}\end{array}$ & 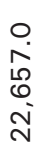 & $\begin{array}{l}\hat{O} \\
m \\
m \\
m \\
\tilde{v}\end{array}$ & $\begin{array}{l}\stackrel{+}{0} \\
\stackrel{0}{N} \\
\stackrel{N}{N}\end{array}$ & 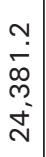 & 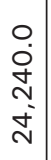 & $\begin{array}{l}\infty \\
\infty \\
\infty \\
\infty \\
\sim \\
\sim \\
\sim\end{array}$ & 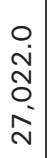 & $\begin{array}{l}\stackrel{j}{\dot{J}} \\
\stackrel{+}{+} \\
\stackrel{N}{N}\end{array}$ & 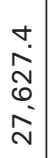 & $\begin{array}{l}\stackrel{v}{\dot{J}} \\
\frac{1}{\mp} \\
\stackrel{\infty}{N}\end{array}$ & $\begin{array}{l}\circ \\
\stackrel{0}{0} \\
\frac{0}{0} \\
\stackrel{\infty}{\circ}\end{array}$ & 亡. & $\frac{\check{m}}{\check{m}}$ \\
\hline 羙 & $\begin{array}{l}\text { ○ } \\
\ddot{m} \\
\infty \\
\infty\end{array}$ & \begin{tabular}{l}
$m$ \\
\multirow{N}{*}{} \\
$\stackrel{\infty}{\infty}$ \\
$\infty$
\end{tabular} & 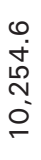 & 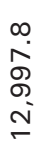 & 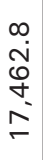 & $\begin{array}{l}\check{0} \\
\stackrel{0}{ } \\
\circlearrowright \\
\stackrel{1}{N}\end{array}$ & 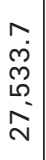 & $\begin{array}{l}\check{\dot{d}} \\
\text { m. } \\
\check{\sigma} \\
\bar{m}\end{array}$ & 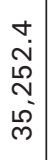 & $\begin{array}{l}N \\
\infty \\
10 \\
10 \\
10 \\
\infty\end{array}$ & 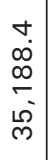 & 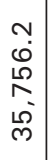 & $\begin{array}{l}0 \\
\infty \\
\infty \\
0 \\
0 \\
0 \\
\infty\end{array}$ & 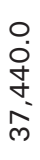 & 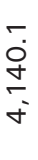 & 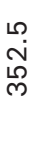 \\
\hline 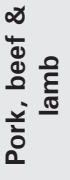 & $\begin{array}{l}\circ \\
\text { ले } \\
\llcorner \\
0 \\
\infty\end{array}$ & 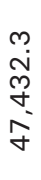 & \begin{tabular}{l}
$\tau$ \\
$\check{\sim}$ \\
m \\
$\infty$ \\
\multirow{\sigma}{*}{}
\end{tabular} & 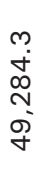 & 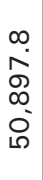 & 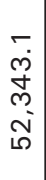 & 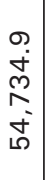 & $\begin{array}{l}0 \\
\dot{g} \\
\circ \\
\sigma \\
\dot{\sigma} \\
\llcorner\end{array}$ & 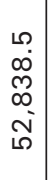 & $\begin{array}{l}0 \\
0 \\
+ \\
\leftarrow \\
\vdots \\
0\end{array}$ & 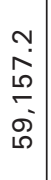 & $\begin{array}{l}\stackrel{\rho}{-} \\
\stackrel{m}{\tilde{N}} \\
\bar{\sigma}\end{array}$ & $\begin{array}{l}\stackrel{n}{0} \\
\hat{m} \\
o \\
\dot{0}\end{array}$ & $\begin{array}{l}\circ \\
\circ \\
\infty \\
\infty \\
\text { ஸे } \\
\text { ஸे }\end{array}$ & $\begin{array}{l}\circ \\
\text { 우 } \\
\stackrel{\circ}{\wedge}\end{array}$ & $\begin{array}{l}0 \\
0 \\
0\end{array}$ \\
\hline $\begin{array}{l}\text { त्ञ } \\
\stackrel{\Phi}{\Sigma}\end{array}$ & $\begin{array}{l}0 \\
\stackrel{0}{0} \\
\stackrel{0}{ } \\
\stackrel{2}{-} \\
\stackrel{-}{-}\end{array}$ & 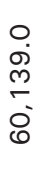 & $\begin{array}{l}+ \\
\infty \\
0 \\
0 \\
0 \\
\dot{\sigma}\end{array}$ & 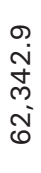 & 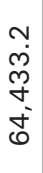 & $\begin{array}{l}\Upsilon \\
\infty \\
\infty \\
0 \\
0 \\
0\end{array}$ & $\begin{array}{l}\hat{\infty} \\
\infty \\
\infty \\
m \\
\stackrel{0}{0}\end{array}$ & $\begin{array}{l}+ \\
\circ \\
\circ \\
\infty \\
\circ \\
\circ\end{array}$ & $\begin{array}{l}N \\
\text { L } \\
0 \\
\infty \\
0 \\
0\end{array}$ & 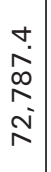 & 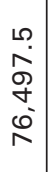 & $\begin{array}{l}m \\
\infty \\
1 \\
\stackrel{n}{n} \\
\infty \\
N\end{array}$ & 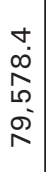 & $\begin{array}{l}0 \\
0 \\
+ \\
\infty \\
\infty \\
\infty\end{array}$ & $\begin{array}{l}\text { N. } \\
\text { ભn } \\
\text { m) }\end{array}$ & $\begin{array}{l}\dot{\nabla} \\
\dot{m}\end{array}$ \\
\hline$\frac{\infty}{\overline{0}}$ & $\begin{array}{l}\stackrel{0}{\infty} \\
\frac{\infty}{N} \\
\leftarrow\end{array}$ & $\begin{array}{l}m \\
\infty \\
+ \\
\stackrel{+}{+} \\
\stackrel{2}{ } \\
\stackrel{2}{ }\end{array}$ & 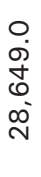 & 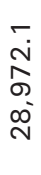 & $\begin{array}{l}\stackrel{0}{0} \\
\stackrel{0}{\mp} \\
\stackrel{\infty}{\sim}\end{array}$ & 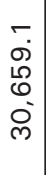 & 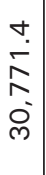 & $\begin{array}{l}\check{M} \\
\text { Oे } \\
+ \\
\dot{v}\end{array}$ & 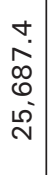 & 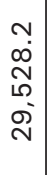 & 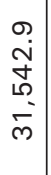 & $\begin{array}{l}m \\
\dot{0} \\
m \\
\tilde{m} \\
m\end{array}$ & $\begin{array}{l}0 \\
\hat{n} \\
0 \\
0 \\
m \\
m\end{array}$ & 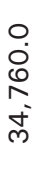 & $\begin{array}{l}N \\
\oplus \\
\oplus \\
\qquad\end{array}$ & $\begin{array}{l}0 \\
\end{array}$ \\
\hline ○े & $\begin{array}{l}\stackrel{0}{0} \\
\frac{0}{N}\end{array}$ & $\begin{array}{l}n \\
\frac{n}{\dot{\sigma}} \\
\dot{j}\end{array}$ & 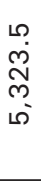 & $\begin{array}{l}\text { ஸे } \\
\frac{\sigma}{+}\end{array}$ & 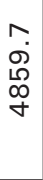 & 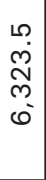 & $\begin{array}{l}\frac{N}{\dot{J}} \\
\stackrel{5}{\sigma}\end{array}$ & 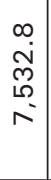 & 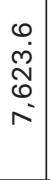 & $\begin{array}{l}\sigma \\
\dot{\sigma} \\
\dot{+} \\
\end{array}$ & $\begin{array}{l}\infty \\
0 \\
0 \\
0 \\
0\end{array}$ & 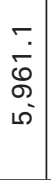 & $\begin{array}{l}0 \\
\infty \\
\infty \\
19 \\
0\end{array}$ & 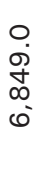 & $\frac{\dot{\sigma}}{\stackrel{\sigma}{v}}$ & $\begin{array}{l}0 \\
0 \\
0\end{array}$ \\
\hline 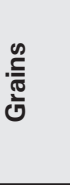 & 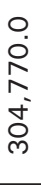 & 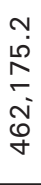 & 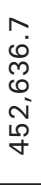 & 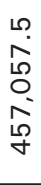 & 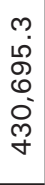 & 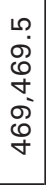 & 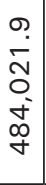 & 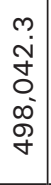 & 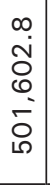 & 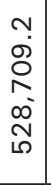 & 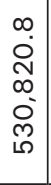 & 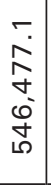 & 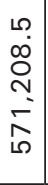 & 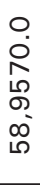 & $\begin{array}{l}\text { சे } \\
\text { ஸ் }\end{array}$ & $\stackrel{0}{N}$ \\
\hline ঠ্ঠ & $\stackrel{\infty}{\stackrel{\infty}{\sigma}}$ & 응 & ঠ্ণী & $\begin{array}{l}\text { ○े } \\
\text { ঠे }\end{array}$ & 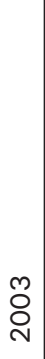 & 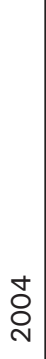 & $\begin{array}{l}\text { L } \\
\text { 유 }\end{array}$ & $\begin{array}{l}0 \\
\text { ঠे } \\
\text { ঠ }\end{array}$ & 오 & $\begin{array}{l}\infty \\
\text { ঠ } \\
\text { ঠ }\end{array}$ & $\begin{array}{l}\text { ̊ } \\
\text { ঠे }\end{array}$ & $\stackrel{\circ}{\circ}$ & $\overline{\mathrm{N}}$ & $\frac{N}{\stackrel{N}{N}}$ & 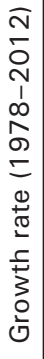 & 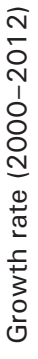 \\
\hline
\end{tabular}


China: A New Model for Growth and Development

Figure 8.1 Outputs of major agricultural products during 2000-2012

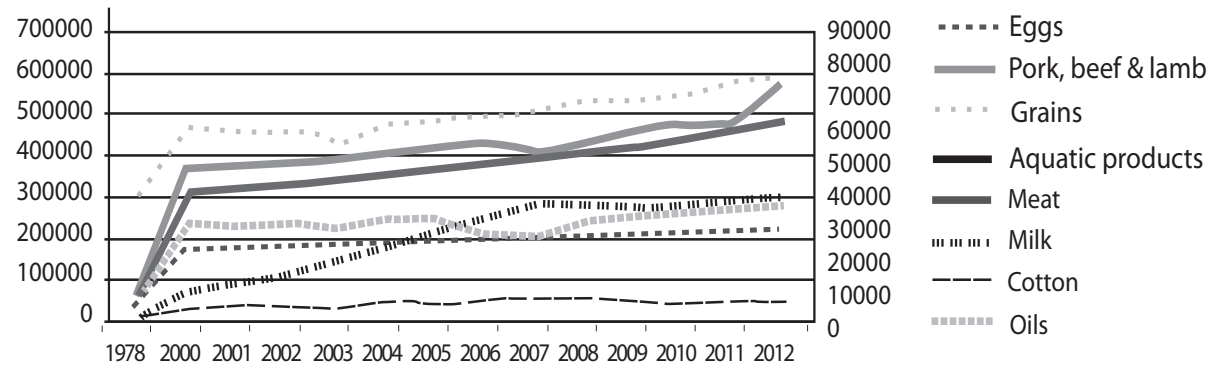

Source: Data for 1978-2011 is from China Statistical Yearbook 2012, data in 2012 is from Statistical Communiqué of the People's Republic of China 2012.

Table 8.2 Key agricultural output per capita since $1978(\mathrm{~kg})$

\begin{tabular}{l|c|c|c|c|c|c}
\hline Year & Grains & Cotton & Oils & Pork, beef \& lamb & Aquatic products & Milk \\
\hline 1978 & 319.0 & 2.3 & 5.5 & 9.1 & 4.9 & \\
\hline 2000 & 366.1 & 3.5 & 23.4 & 37.6 & 29.4 & 6.6 \\
\hline 2001 & 355.9 & 4.2 & 22.5 & 38.0 & 29.9 & 8.1 \\
\hline 2002 & 357.0 & 3.8 & 22.6 & 38.5 & 30.9 & 10.2 \\
\hline 2003 & 334.3 & 3.8 & 21.8 & 39.5 & 31.6 & 13.6 \\
\hline 2004 & 362.2 & 4.9 & 23.7 & 40.4 & 32.8 & 17.4 \\
\hline 2005 & 371.3 & 4.4 & 23.6 & 42.0 & 33.9 & 21.1 \\
\hline 2006 & 379.9 & 5.7 & 20.1 & 42.7 & 35.0 & 24.4 \\
\hline 2007 & 380.6 & 5.8 & 19.5 & 40.1 & 36.0 & 26.7 \\
\hline 2008 & 399.1 & 5.7 & 22.3 & 42.4 & 37.0 & 26.8 \\
\hline 2009 & 398.7 & 4.8 & 23.7 & 44.4 & 38.4 & 26.4 \\
\hline 2010 & 408.7 & 4.5 & 24.2 & 45.8 & 40.2 & 26.7 \\
\hline 2011 & 425.2 & 4.9 & 24.6 & 45.4 & 41.7 & 27.2 \\
\hline 2012 & 435.4 & 5.1 & 25.7 & 54.6 & 43.6 & 27.7 \\
\hline Increment & 116.4 & 2.8 & 20.2 & 45.5 & 38.7 & 27.7 \\
\hline $1978-2012)$ & & & & & & 21.1 \\
\hline Increment & 69.3 & 1.6 & 2.3 & 17.0 & & \\
\hline
\end{tabular}

Source: Data for 1978-2011 is from China Statistical Yearbook 2012, data for 2012 is from Statistical Communiqué of the People's Republic of China 2012.

\section{Conditions of Agricultural Production have Improved}

During the period 1978-2012, the agricultural sector witnessed increases in the level of integrated mechanisation, which rose by almost two times from 18.8 per cent to 56 per cent. The level rose by 10.2 percentage points during 
1978-2000 and 27 percentage points during 2000-2012. As shown in Figure 8.2 and Table 8.3, the level has risen more quickly since 2000. This rising level of integrated mechanisation has become an important factor underlying the steady growth of agricultural production.

Table 8.3 Changes in the level of integrated mechanisation (\%)

\begin{tabular}{c|c|c|c|c|c|c|c|c|c}
\hline Year & $\%$ & Year & $\%$ & Year & $\%$ & Year & $\%$ & Year & $\%$ \\
\hline 1978 & 18.8 & 1993 & 23.5 & 1998 & 27.0 & 2003 & 32.0 & 2008 & 45.0 \\
\hline 1985 & 20.0 & 1994 & 24.2 & 1999 & 27.7 & 2004 & 33.5 & 2009 & 48.8 \\
\hline 1990 & 20.7 & 1995 & 24.9 & 2000 & 29.0 & 2005 & 35.9 & 2010 & 50.0 \\
\hline 1991 & 22.1 & 1996 & 25.6 & 2001 & 30.0 & 2006 & 38.0 & 2011 & 52.3 \\
\hline 1992 & 22.8 & 1997 & 26.3 & 2002 & 31.0 & 2007 & 42.5 & 2012 & 57.0 \\
\hline
\end{tabular}

Source: Data for 1978-2011 is from China Agricultural Yearbook 1979, 1986, 1991-2012; and data for 2012 is from a speech given by Taolin Zhang, Vice Minister of Ministry of Agriculture (MOA) at the national working conference on agricultural machinery purchase subsidy in Hangzhou on February 26, 2013.

Figure 8.2 Changes in the level of integrated mechanisation (\%)

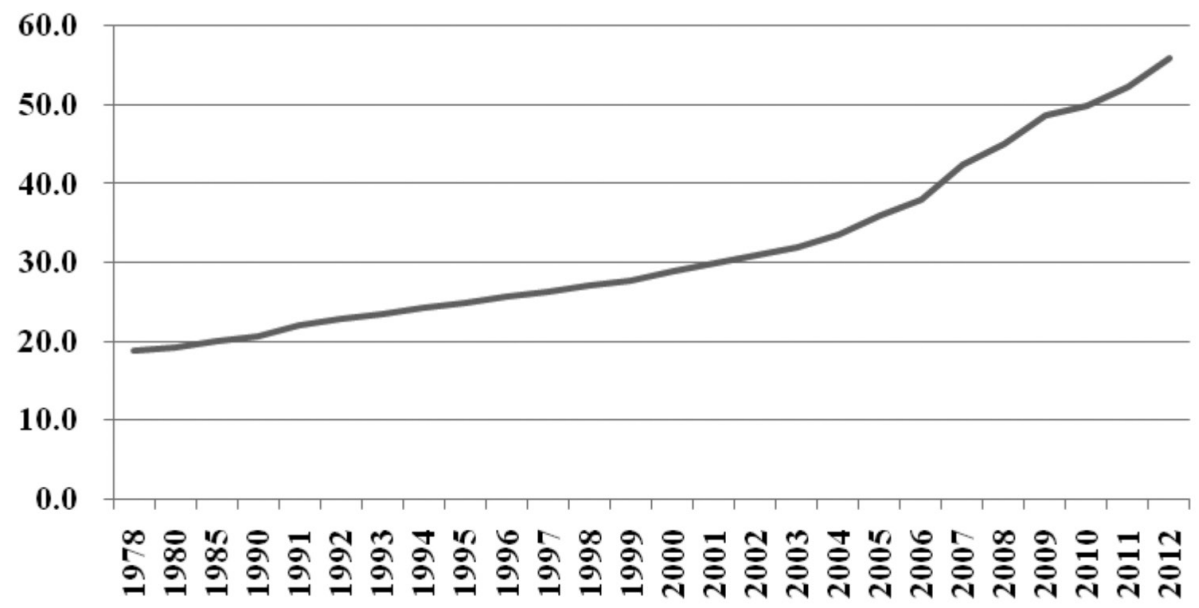

Source: Data for 1978-2011 is from China Agricultural Yearbook 1979, 1986, 1991-2012; and data for 2012 is from the Ministry of Agriculture.

Over the same period, the agricultural sector also witnessed a continuous expansion of effective irrigation areas. Table 8.4 shows the effective irrigation areas during the past decades, from which one can see that the area has expanded by over one-third from 45 million hectares (ha) in 1978 to more than 60 million in 2011 . 
China: A New Model for Growth and Development

Table 8.4 Effective irrigation areas since 1978 (1,000 ha)

\begin{tabular}{c|c|c|c|c|c|c|c}
\hline Year & $\begin{array}{c}\text { Effective } \\
\text { irrigation areas }\end{array}$ & Year & $\begin{array}{c}\text { Effective } \\
\text { irrigation areas }\end{array}$ & Year & $\begin{array}{c}\text { Effective } \\
\text { irrigation areas }\end{array}$ & Year & $\begin{array}{c}\text { Effective } \\
\text { irrigation areas }\end{array}$ \\
\hline 1978 & $44,965.0$ & 1994 & $48,759.1$ & 2000 & $53,820.3$ & 2006 & $55,750.5$ \\
\hline 1985 & $44,035.9$ & 1995 & $49,281.2$ & 2001 & $54,249.4$ & 2007 & $56,518.3$ \\
\hline 1990 & $47,403.1$ & 1996 & $50,381.4$ & 2002 & $54,354.9$ & 2008 & $58,471.7$ \\
\hline 1991 & $47,822.1$ & 1997 & $51,238.5$ & 2003 & $54,014.2$ & 2009 & $59,261.4$ \\
\hline 1992 & $48,590.1$ & 1998 & $52,295.6$ & 2004 & $54,478.4$ & 2010 & $60,347.7$ \\
\hline 1993 & $48,727.9$ & 1999 & $53,158.4$ & 2005 & $55,029.3$ & 2011 & $61,681.6$ \\
\hline
\end{tabular}

Source: China Statistical Yearbook 2012

Fertilisation based on soil testing started to be used in 2005. Since then, the project has been implemented in all the agricultural counties (including state-owned farms). By 2012, the technology was being used on over 87 million ha, benefiting over two-thirds of the rural households in the country (Figure 8.3). A sampling survey at the household level shows that the technology could increase the production of wheat, rice and corn by 3.7 per cent, 3.8 per cent, and 5.9 per cent per ha, respectively; increase the sale income of grains, and vegetables and fruits by 450 yuan/ha and 1,500 yuan/ha, respectively. By 2011, fertilisation based on soil testing saved over seven million tons of fertiliser, by which the agricultural sector has saved the equivalent of 18.2 million tons of coal and reduced carbon dioxide emissions by 47.3 million tons.

Figure 8.3 Areas fertilising based on the soil tested (million ha)

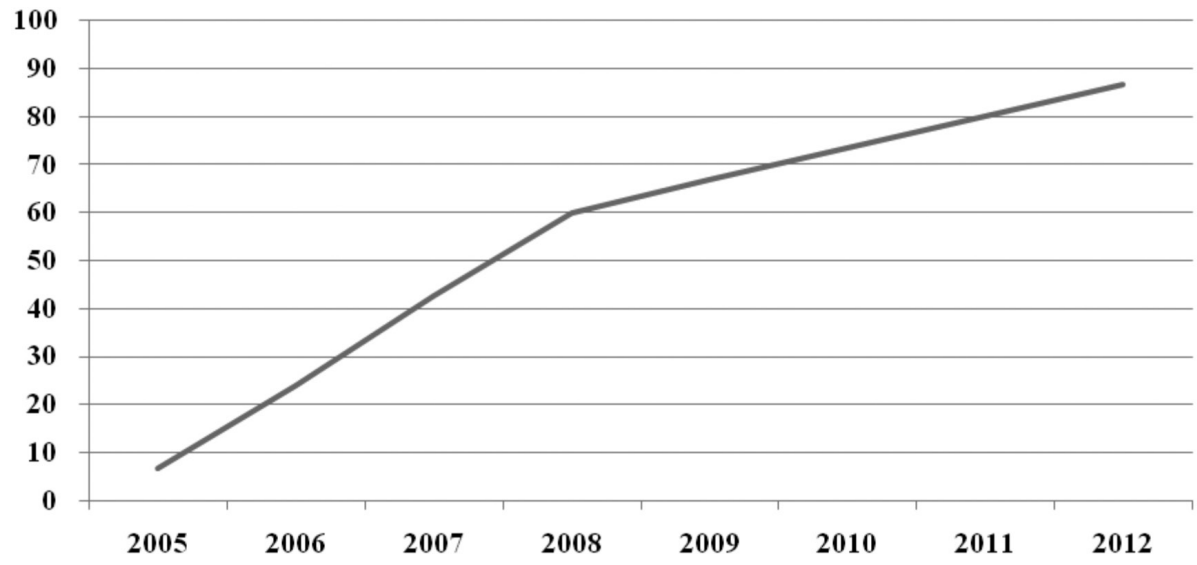

Note: The areas in 2005 and 2006 are estimated based on the data in 2007.

Source: Ministry of Agriculture.

One can see from Table 8.5, because of the improvement in fertilising technologies, that the share of nitrogen in the total fertiliser used declined from 73.6 per cent in 1980 to 41.8 per cent in 2011 , while the share of compound fertiliser (which improves the utilisation rate of nitrogen fertiliser) rose from 2.1 per cent to 33.2 per cent during the same period. 


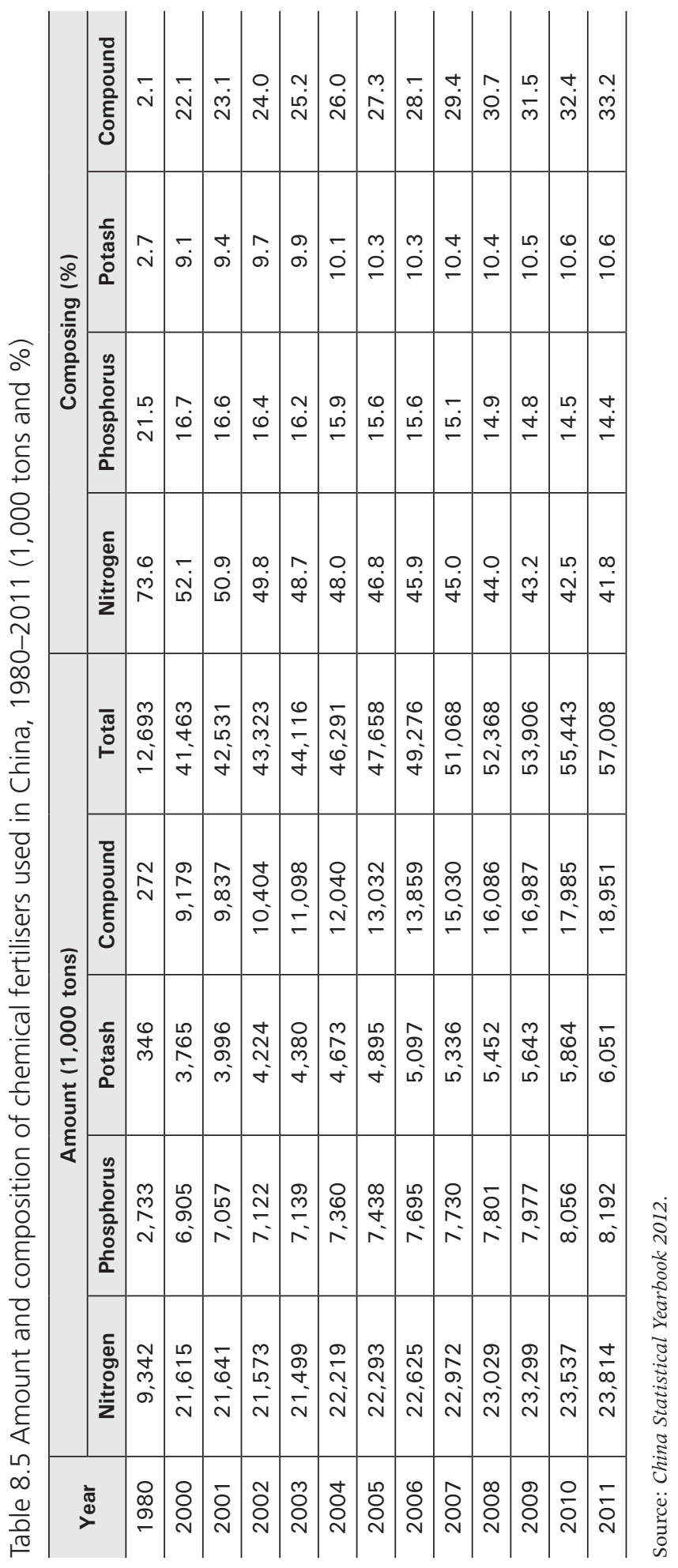


As shown in Figure 8.4, plastic-covered areas more than doubled over this period, from less than 6 million ha in 1993 to over 16 million ha in 2010. Also, the coverage of improved varieties of grains, cotton and oils expanded from 90 per cent in 2005 to 96 per cent in 2012.

Figure 8.4 Expansion of plastic-covered areas during 1993-2010 (1,000 ha)

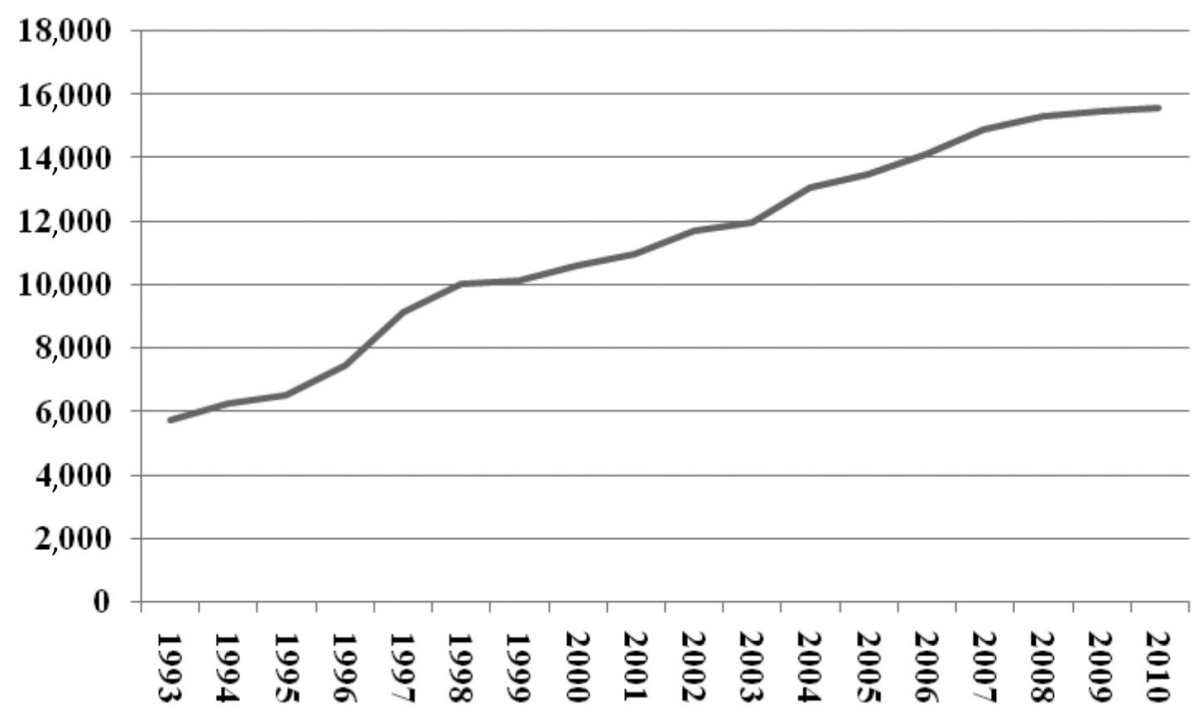

Source: Ministry of Agriculture.

The agricultural sector has also demonstrated a tendency to increase regional concentration in the production of major agricultural products. As shown in Table 8.6, the share of grain production in the 13 major provinces (regions) rose from 69.21 per cent during 1949-1959 to 75.15 during 2000-1009 and further to 77.78 per cent during 2010-2012, increased by 5.94 and 8.57 percentage points, respectively. Zones have been created for the production of soybeans and corn in the north-east, nuts and wheat in the Huang-Huai-Hai region, oilseeds in the Yangtze watershed, and cotton in the Yellow River watershed and the northwest. In addition, pork produced in the 13 major provinces accounts for over 75 per cent of the country's total production and the milk produced in the seven major provinces accounts for over 60 per cent of the country's total production. 
Table 8.6 Share of grains produced in the 13 major provinces in the total amount of the country (\%)

\begin{tabular}{l|r|r|r|r|r|r|r}
\hline Province & $\begin{array}{c}1949- \\
1959\end{array}$ & $\begin{array}{c}1960- \\
1969\end{array}$ & $\begin{array}{c}1970- \\
1979\end{array}$ & $\begin{array}{c}1980- \\
1989\end{array}$ & $\begin{array}{c}1990- \\
1999\end{array}$ & $\begin{array}{c}2000- \\
\mathbf{2 0 0 9}\end{array}$ & $\begin{array}{c}\text { 2010- } \\
\mathbf{2 0 1 2}\end{array}$ \\
\hline Hebei & 4.79 & 4.92 & 5.21 & 4.91 & 5.40 & 5.50 & 5.47 \\
\hline $\begin{array}{l}\text { Inner } \\
\text { Mongolia }\end{array}$ & 1.99 & 2.09 & 1.70 & 1.52 & 2.57 & 3.33 & 4.12 \\
\hline Liaoning & 3.48 & 3.26 & 3.76 & 3.25 & 3.28 & 3.35 & 3.42 \\
\hline Jilin & 3.21 & 3.01 & 3.12 & 3.47 & 4.41 & 4.94 & 5.45 \\
\hline Heilongjiang & 4.51 & 4.25 & 4.53 & 4.10 & 5.72 & 5.99 & 9.52 \\
\hline Jiangsu & 6.57 & 6.95 & 7.15 & 8.02 & 7.01 & 6.21 & 5.78 \\
\hline Anhui & 5.05 & 4.67 & 5.35 & 5.56 & 5.25 & 5.67 & 5.54 \\
\hline Jiangxi & 3.41 & 4.03 & 3.81 & 3.87 & 3.49 & 3.62 & 4.07 \\
\hline Shandong & 7.21 & 6.50 & 6.90 & 7.66 & 8.44 & 8.04 & 7.73 \\
\hline Henan & 6.61 & 5.82 & 6.42 & 7.02 & 7.54 & 9.55 & 9.68 \\
\hline Hubei & 5.21 & 5.63 & 5.47 & 5.54 & 5.18 & 4.51 & 4.16 \\
\hline Hunan & 5.85 & 5.94 & 6.30 & 6.59 & 5.70 & 5.62 & 5.12 \\
\hline Sichuan & 11.32 & 10.21 & 9.26 & 10.12 & 9.32 & 8.82 & 7.72 \\
\hline Total & 69.21 & 67.28 & 68.98 & 71.63 & 73.31 & 75.15 & 77.78 \\
\hline
\end{tabular}

Source: Data for 1949-1999 is from Comprehensive Statistical Data and Materials on 50 Years of New China; data for 2000-2011 is from China Agricultural Yearbook 2001-2012; and, data for 2012 is from National Statistics Bureau, Grain Production Communiqué, http://www.gov.cn/zwgk/2012-11/30/content_2279385.htm

\section{Agricultural Total Factor Productivity (TFP) is Rising}

Current research shows that the annual growth rate of China's TFP in the agricultural sector rose by around one percentage point during 19852010. According to information released by the Ministry of Agriculture, the contribution of technological progress to China's agricultural growth is 54.5 per cent in 2012 (Table 8.7). During 1985-2010, the annual growth rate of China's TFP was 3.8 per cent on average, of which the annual growth rate of agricultural technological progress is 5.1 per cent, while the annual growth rate of agricultural technical efficiency is -1.2 per cent. Obviously, the technological progress promotes the growth of China's TFP, while the decline in the technical efficiency partly offsets the effects of technological progress in enhancing productivity.

Productivity growth in China's agriculture is further estimated by dividing the whole period into four sub-periods (1985-1989, 1990-1995, 1996-2003, and 2004-2010) and by dividing the whole country into different regions (the major 
and non-major agricultural production regions and the eastern, central and western regions), and the results are the same. China's TFP growth in the agricultural sector during this period, therefore, is mainly technology induced.

Table 8.7 China's agricultural TFP growth rate and its composition (1985-2010)

\begin{tabular}{c|c|c|c|c|c|c|c}
\hline Year & $\begin{array}{c}\text { Technical } \\
\text { efficiency }\end{array}$ & $\begin{array}{c}\text { Technology } \\
\text { progress }\end{array}$ & TFP & Year & $\begin{array}{c}\text { Technical } \\
\text { efficiency }\end{array}$ & $\begin{array}{c}\text { Technology } \\
\text { progress }\end{array}$ & TFP \\
\hline $1986 / 1985$ & 0.964 & 1.086 & 1.048 & $2001 / 2000$ & 0.986 & 1.027 & 1.012 \\
\hline $1987 / 1986$ & 0.997 & 1.000 & 0.996 & $2002 / 2001$ & 1.006 & 0.990 & 0.996 \\
\hline $1988 / 1987$ & 0.978 & 1.077 & 1.053 & $2003 / 2002$ & 0.976 & 1.092 & 1.066 \\
\hline $1989 / 1988$ & 1.008 & 1.039 & 1.047 & $2004 / 2003$ & 0.997 & 1.125 & 1.122 \\
\hline $1990 / 1989$ & 1.007 & 1.025 & 1.033 & $2005 / 2004$ & 0.970 & 1.055 & 1.023 \\
\hline $1991 / 1990$ & 0.972 & 1.014 & 0.986 & $2006 / 2005$ & 1.208 & 1.050 & 1.269 \\
\hline $1992 / 1991$ & 0.939 & 1.052 & 0.987 & $2007 / 2006$ & 0.808 & 1.074 & 0.868 \\
\hline $1993 / 1992$ & 0.988 & 1.165 & 1.150 & $2008 / 2007$ & 0.997 & 1.103 & 1.100 \\
\hline $1994 / 1993$ & 0.979 & 1.120 & 1.097 & $2009 / 2008$ & 1.021 & 1.030 & 1.052 \\
\hline $1995 / 1994$ & 1.047 & 1.096 & 1.147 & $2010 / 2009$ & 0.992 & 1.028 & 1.020 \\
\hline $1996 / 1995$ & 0.989 & 1.061 & 1.049 & $1989 / 1985$ & 0.983 & 1.058 & 1.036 \\
\hline $1997 / 1996$ & 0.954 & 1.030 & 0.982 & $1995 / 1990$ & 0.988 & 1.077 & 1.064 \\
\hline $1998 / 1997$ & 0.992 & 0.952 & 0.944 & $2003 / 1996$ & 0.987 & 1.015 & 1.001 \\
\hline $1999 / 1998$ & 1.025 & 0.970 & 0.994 & $2004 / 2010$ & 0.993 & 1.066 & 1.059 \\
\hline $2000 / 1999$ & 0.966 & 1.008 & 0.973 & $2010 / 1985$ & 0.988 & 1.051 & 1.038 \\
\hline
\end{tabular}

Note: The national index is the geometric mean of the provincial indexes.

Source: China Statistical Yearbook 1986-2011; Li and Zhang (forthcoming).

The question is, then, whether the agricultural sector has room for further improving technical efficiency, rather than continuously relying on the expansion of economies of scale. As shown in Table 8.8, technical efficiency in China's grain production is 0.795 , which shows that significant room remains for further improvement. On the other hand, the economies of scale is already 0.957, and room for further improvement is not substantial. Increasing total land areas may, however, help with increasing farmers' income. There are almost no remarkable economies of scale in the production of wheat, rice and corn (Xu et al. 2011). Expanding the land scale would have a significant effect on the reduction of production costs. Each additional mu (1/15 ha) in the scale expansion could reduce the cost by two to ten per cent. That means that the scale expansion would notably raise the farmers' income (Xu et al. 2011). 


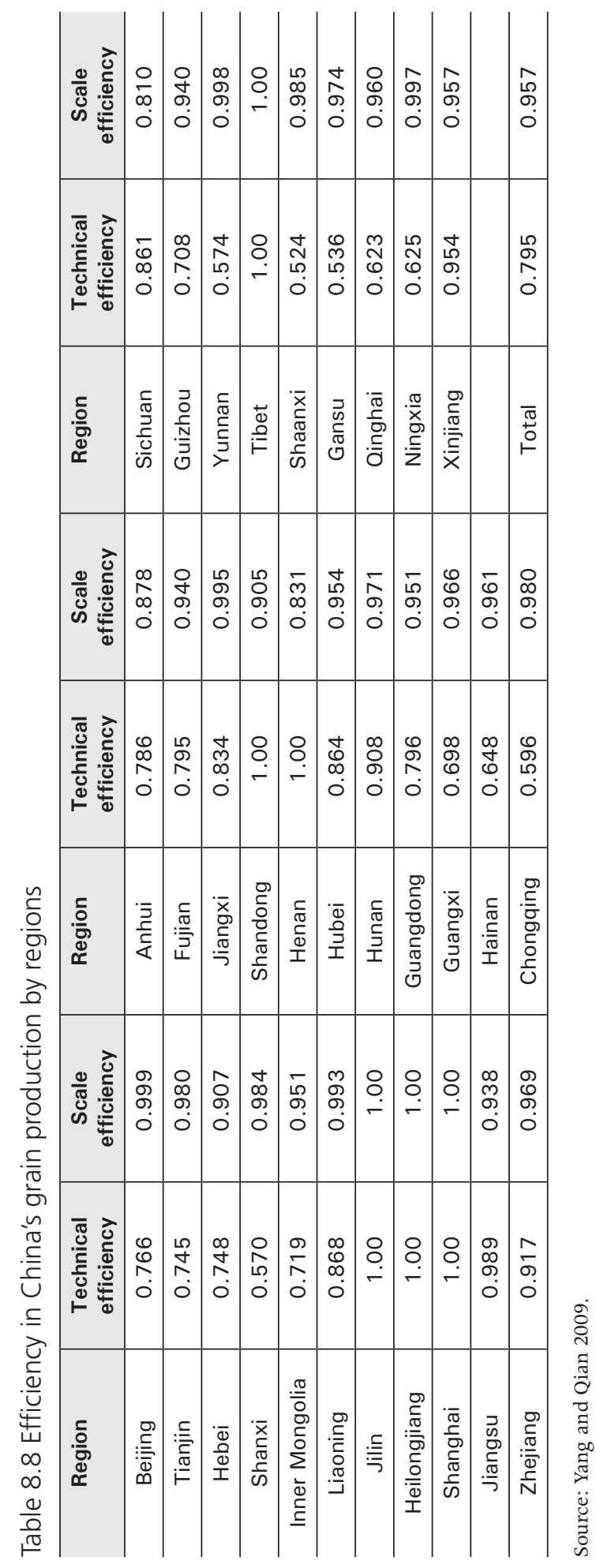




\section{Farmers' Contributions to Growth of Agricultural Production}

Under the planned economic system, famers are required to live in rural areas, be engaged in agricultural production, and participate in collective production. Agricultural productivities are low under that system because of the absence of incentives for farmers to work hard. The key to rural reform is to empower farmers through institutional and policy changes. During the early stage of reform, farmers were granted the right to make decisions on their own production. This had tremendous incentive effects and farmers quickly solved the problem of agricultural shortages. During the mid 1980s, farmers were empowered with the right to be engaged in non-agricultural industries. This allowed farmers to engage in substantial off-farm opportunities, and they created the miracle of township and village enterprises (TVEs), which occupy half of the country's industry. Since the 1990s, farmers have been empowered with the right to be employed in the urban areas; this has led to large-scale rural-urban migration, with farmers soon becoming the major force in China's working class. For the next period of development, farmers should be empowered with the right to be integrated into urban life, and to participate in managing urban affairs.

Table 8.9 shows that the number of farmers employed in non-agricultural sectors more than quadrupled from 59.6 million in 1985 to 262.61 million in 2012. Table 8.10 illustrates that, of the total farmers employed outside agriculture, almost half leave the land individually, while the other half are those who are employed in the local areas or with their families in other areas. These statistics underline social problems arising from rural-urban migration, as many migrant workers have moved to the cities on their own, leaving their families in rural homes.

With the expansion of employment opportunities, the contribution of farmers to China's national economy has extended from agricultural to non-agricultural sectors and from rural to urban areas. As shown in Table 8.11, from 2008 to 2012, the share of GDP created by farmers employed outside agriculture in the country's GDP rose from 32.1 per cent to 38.6 per cent, 6.5 percentage points increase in four years. The farmers' contribution to GDP would be bigger if one takes into account the income earned by selling cheap farmland to the government, which is then sold on to business at much higher prices. 


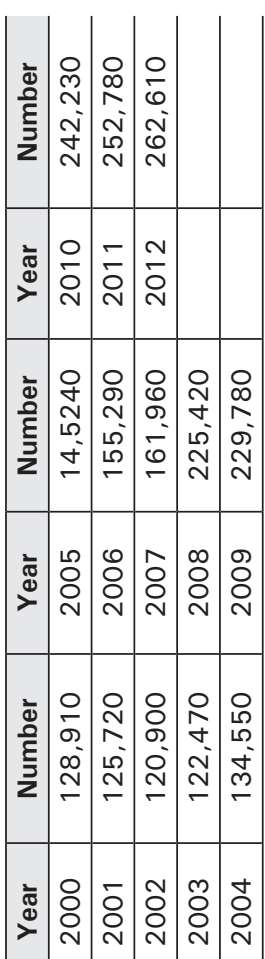

む)

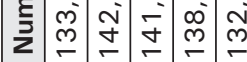

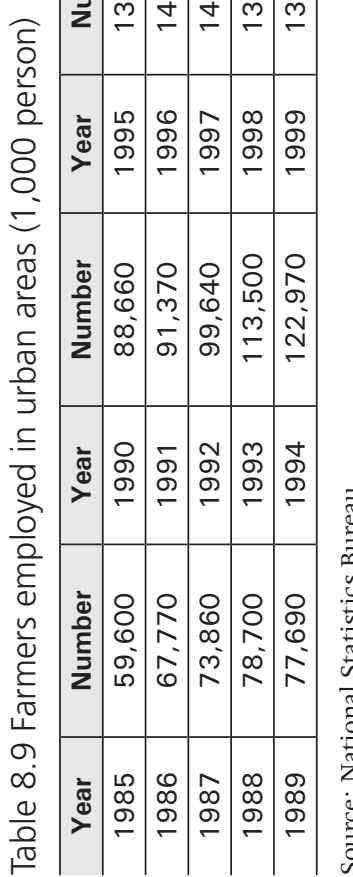

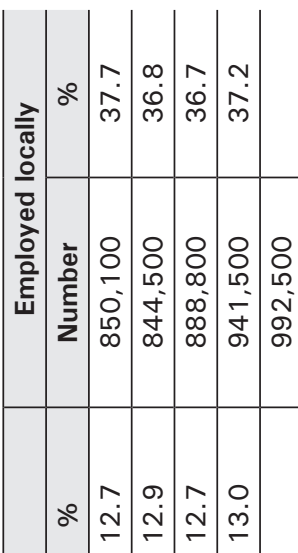

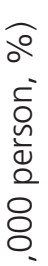
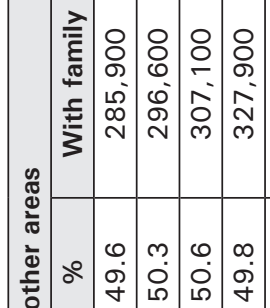

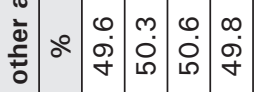

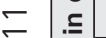

๖

$\infty$

궁

옹

$\stackrel{\oplus}{\rightleftharpoons}$

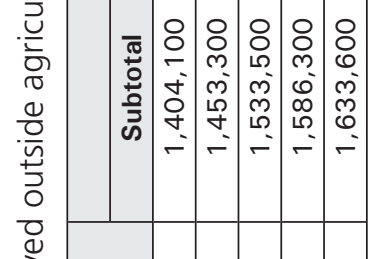

$\frac{0}{\frac{1}{0}}$

응

हैँ

竞

$\stackrel{0}{\circ}$

$\infty$
$\frac{0}{0}$
$\frac{0}{\sigma}$

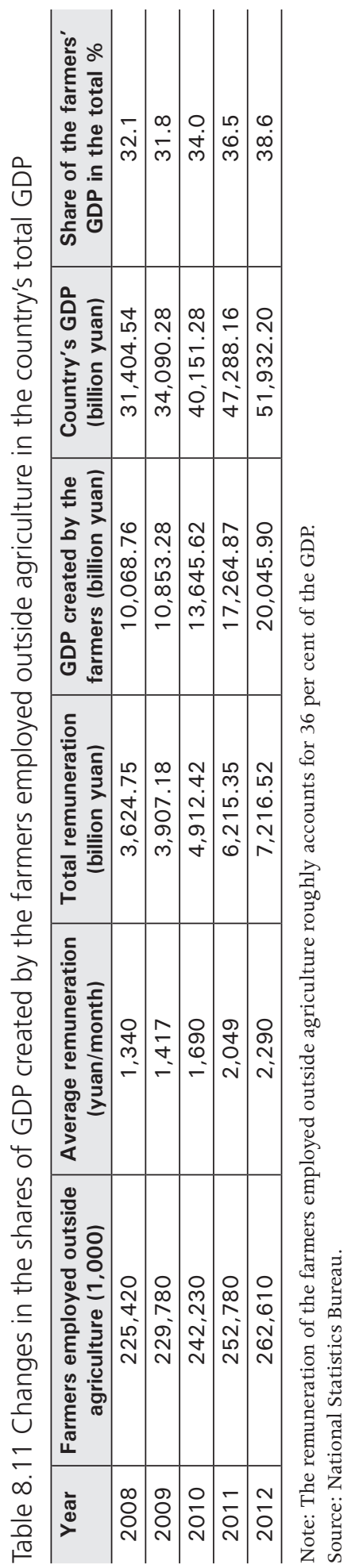




\section{Farmers' Income is Rapidly Increasing}

From 1978 to 2012, farmers' per capita income increased from 133.6 yuan to 7,917 yuan, a 10.77 times increase at constant prices. During the same period, urban residents' per capita disposable income rose from 343.4 yuan to 24,565 yuan, a 10.46 times increase at constant prices. This means that farmers' and urban residents' incomes are growing at basically the same rates over the entire reform period. Judged by this statistic, it may not be accurate to argue that the income difference between rural and urban residents has expanded, even though the absolute levels of per capita income between rural and urban residents are different. In recent years, the growth rate of rural incomes has been faster than that of urban incomes. There are a number of factors which have lead to a more rapid increase in farmers' incomes.

First, distortions in agricultural prices have been eliminated through reform and price liberalisation, which enables farmers to work harder to benefit more from market prices. Agricultural taxes were abolished in 2005. At the same time, government agricultural subsidies are increasing. These changes have substantially increased farmers' incomes and contributed to narrowing the difference between urban and rural incomes.

Second, the income of farmers employed in non-agricultural sectors is underestimated. Farmers usually regard the money that they take back home as their income, but ignore the money that they have spent in the urban locations in which they are employed. In total there are 160 million Chinese farmers employed outside their hometown. If one of them spends 2,000 yuan a month in their place of employment, then the living costs for those 160 million farmers is 320 billion yuan per month. This money can be converted to an average per capita income of 300 yuan for all the farmers in China, but this amount is not currently included in calculating the total income of farmers.

Third, calculations of the income of urban residents includes government subsidies for housing and medical treatment, and this inflates the urban income. As a result, estimates based on provincial-level data show that the ratio of urban to rural nominal income goes down (Table 8.12 and Figure 8.5). Because of this, increasingly, farmers prefer to maintain their administrative status as rural, rather urban, residents. This change in attitude on the part of farmers reflects the narrowing of the difference between rural and urban incomes, and that working conditions in rural areas continue to improve due to the policy changes towards the sector. 
Table 8.12 Comparison of the incomes of farmers and urban residents since 1978

\begin{tabular}{|c|c|c|c|c|c|}
\hline \multirow[t]{2}{*}{ Year } & \multicolumn{2}{|c|}{$\begin{array}{l}\text { Farmers' net income } \\
\text { (per capita) }\end{array}$} & \multicolumn{2}{|c|}{$\begin{array}{c}\text { Urban residents' disposable } \\
\text { income (per capita) }\end{array}$} & \multirow[t]{2}{*}{ Income ratio } \\
\hline & $\begin{array}{c}\text { Amount } \\
\text { (yuan) }\end{array}$ & $\begin{array}{c}\text { Index } \\
(1978=100)\end{array}$ & $\begin{array}{c}\text { Amount } \\
\text { (yuan) }\end{array}$ & $\begin{array}{c}\text { Index } \\
(1978=100)\end{array}$ & \\
\hline 1978 & 133.6 & 100.0 & 343.4 & 100.0 & 2.6 \\
\hline 1980 & 191.3 & 139.0 & 477.6 & 127.0 & 2.5 \\
\hline 1985 & 397.6 & 268.9 & 739.1 & 160.4 & 1.9 \\
\hline 1990 & 686.3 & 311.2 & $1,510.2$ & 198.1 & 2.2 \\
\hline 1991 & 708.6 & 317.4 & $1,700.6$ & 212.4 & 2.4 \\
\hline 1992 & 784.0 & 336.2 & $2,026.6$ & 232.9 & 2.6 \\
\hline 1993 & 921.6 & 346.9 & $2,577.4$ & 255.1 & 2.8 \\
\hline 1994 & 1221.0 & 364.3 & $3,496.2$ & 276.8 & 2.9 \\
\hline 1995 & 1577.7 & 383.6 & $4,283.0$ & 290.3 & 2.7 \\
\hline 1996 & 1926.1 & 418.1 & $4,838.9$ & 301.6 & 2.5 \\
\hline 1997 & 2090.1 & 437.3 & $5,160.3$ & 311.9 & 2.5 \\
\hline 1998 & 2162.0 & 456.1 & $5,425.1$ & 329.9 & 2.5 \\
\hline 1999 & 2210.3 & 473.5 & $5,854.0$ & 360.6 & 2.6 \\
\hline 2000 & 2253.4 & 483.4 & $6,280.0$ & 383.7 & 2.8 \\
\hline 2001 & 2366.4 & 503.7 & $6,859.6$ & 416.3 & 2.9 \\
\hline 2002 & $2,475.6$ & 527.9 & $7,702.8$ & 472.1 & 3.1 \\
\hline 2003 & $2,622.2$ & 550.6 & $8,472.2$ & 514.6 & 3.2 \\
\hline 2004 & $2,936.4$ & 588.0 & $9,421.6$ & 554.2 & 3.2 \\
\hline 2005 & $3,254.9$ & 624.5 & $10,493.0$ & 607.4 & 3.2 \\
\hline 2006 & $3,587.0$ & 670.7 & $11,760.0$ & 670.7 & 3.3 \\
\hline 2007 & $4,140.4$ & 734.4 & $13,786.0$ & 752.5 & 3.3 \\
\hline 2008 & $4,760.6$ & 793.2 & $15,781.0$ & 815.7 & 3.3 \\
\hline 2009 & $5,153.2$ & 860.6 & $17,175.0$ & 895.4 & 3.3 \\
\hline 2010 & $5,919.0$ & 954.4 & $19,109.0$ & 965.2 & 3.2 \\
\hline 2011 & $6,977.0$ & $1,063.2$ & $21,810.0$ & $1,046.3$ & 3.1 \\
\hline 2012 & $7,917.0$ & $1,177.0$ & $24,565.0$ & $1,145.7$ & 3.1 \\
\hline
\end{tabular}

Source: Data for 1978-2011 is from China Statistical Yearbook 2012, and data for 2012 is from Statistical Communiqué of the People's Republic of China 2012. 
Figure 8.5 A fitting curve of the ratio of urban to rural per capita incomes using provincial-level data during 1978-2010

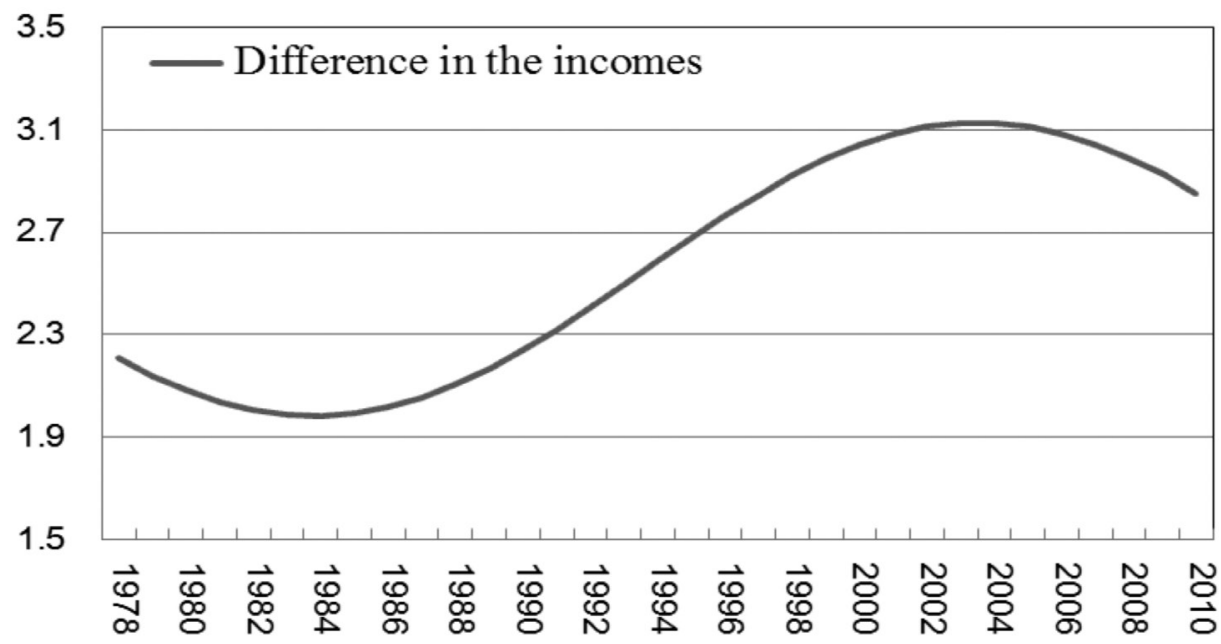

Source: Data for 1978-1999 is from Comprehensive Statistical Data and Materials on 50 Years of New China, and data for 2000-2010 is from China Agruculture Yearbook 2001-2011.

\section{Farmers' Welfare is Improving}

Besides rapid increases in income, farmers' welfare is also improving. First, development of the economies of the central and western regions and the counties has created more opportunities for farmers to be employed in their local areas. This might not raise farmers' incomes to the same level that can be earned in the cities, but the quality of life of the farmer and the extended family is significantly improved by remaining in the local area. Changes in government policies in favour of the agricultural sector have accordingly improved the welfare of farmers.

Second, the outsourcing of agricultural production is now substituting for the work of farmers' families. Contracting out farm work to others increases the family's production expenditures, but reduces the family's labour intensity on farm and household work, thereby improving their welfare and quality of life.

Third, the market-oriented services that are increasingly available to farmers are substituting for housework. This substitution obviously raises the family's spending on food and other consumption items, and inhibits the decline of the Engel coefficient, as one would normally see with rising income. As a result, however, families have more leisure time and consequently experience a remarkable improvement in their welfare. 


\section{Major Achievements in the Rural Development}

For the past decade, 2002-2012, with the improvement of China's agricultural policies, there have been notable achievements in rural development, especially in terms of farmers' income, agricultural production, the environment and social change.

\section{From Collecting Agricultural Surplus to Supporting Agricultural Development}

Before tax and fee policy reform in 2005, village committees and local governments collected 150-160 billion yuan per year from famers in agricultural, livestock, special agricultural product taxes, and 'three retained fees', 'five overall planned fees', and unwanted pooling of funds. ${ }^{2}$ Agricultural taxes accounted for around one-third of the total taxes collected by the government.

Since 2004, the central and provincial governments issued a series of policies, including the provision of direct subsidies for grain production, improved varieties of agricultural products, purchases of large-scale farm machinery, and agricultural production inputs. As shown in Table 8.13, only the direct subsidies for grain production have remained stable since 2007, while the others have increased to the significant benefit of farmers.

Table 8.13 The central government's subsidies to agriculture (billion yuan)

\begin{tabular}{c|c|c|c|c|c}
\hline Year & Total & $\begin{array}{c}\text { Subsidies for } \\
\text { the input }\end{array}$ & $\begin{array}{c}\text { Direct subsidies for } \\
\text { grain production }\end{array}$ & $\begin{array}{c}\text { Subsidies } \\
\text { for improved } \\
\text { varieties }\end{array}$ & $\begin{array}{c}\text { Subsidies for } \\
\text { farm machinery }\end{array}$ \\
\hline 2003 & 13.00 & - & - & - & - \\
\hline 2004 & 14.52 & - & 11.60 & 2.85 & 0.07 \\
\hline 2005 & 17.37 & - & 13.20 & 3.87 & 0.30 \\
\hline 2006 & 30.95 & 12.00 & 14.20 & 4.15 & 0.60 \\
\hline 2007 & 51.36 & 27.60 & 15.10 & 6.66 & 2.00 \\
\hline 2008 & 103.04 & 71.60 & 15.10 & 12.34 & 4.00 \\
\hline 2009 & 127.45 & 79.50 & 15.10 & 19.85 & 13.00 \\
\hline 2010 & 122.59 & 70.59 & 15.10 & 20.40 & 16.50 \\
\hline 2011 & 140.6 & 86.00 & 15.10 & 22.00 & 17.50 \\
\hline 2012 & 166.4 & 107.80 & 15.10 & 22.00 & 21.50 \\
\hline
\end{tabular}

Source: Ministry of Finance.

2 The Chinese Government started reforming agricultural and rural tax and fee policies in 2003 and the reform task was basically completed by the end of 2004, leading to the abolition of agricultural tax in 2005. 


\section{From General Support to Key Specific Support by the Governments}

From the start of the reform process, the central government's policies were general and applied consistently across the country. Later, in order to promote the formation of agricultural production zones, some key support policies were implemented. For instance, since 2005 a policy has been implemented to reward the governments of counties for meeting grain-production targets (Table 8.14). Since 2007 the policy has been expanded to include a target for the sale of hogs outside the county (1.5 billion yuan per year) and, since 2008, a target of 2.5 billion yuan per year has been set for the production of oils. Guided by industrial policies, agricultural production is concentrating on these favoured areas, and the zoning production of the key agricultural products is more and more obvious.

Table 8.14 The central government's special funds for rewarding the governments of counties where a certain amount of grains are produced

\begin{tabular}{l|c|c|c|c|c|c|c}
\hline Year & 2005 & 2006 & 2007 & 2008 & 2009 & 2010 & 2011 \\
\hline Funds (billion yuan) & 5.5 & 8.5 & 12.5 & 14.0 & 17.5 & 21.0 & 22.5 \\
\hline
\end{tabular}

Source: Ministry of Finance.

\section{From Promoting Production to Protecting the Environment}

In the past decade, the Chinese Government began to pay more attention to ecological protection and addressing environmental concerns, issuing policies to protect forest, grassland and wetland systems.

In order to eliminate the negative impacts of deforestation on the environment, in 1998 the Chinese Government implemented a natural forest protection project. The project was implemented in the upper Yangtze River, the middle and upper Yellow River, the north-eastern regions and Inner Mongolia, and other state-owned natural forest areas. The project will be implemented in different phases, the first of which was divided into two stages. The first stage, from 2000-2005, had the major tasks of stopping deforestation of natural forests, constructing ecological forests, and redeploying individuals who lost jobs because of the policy. The second stage ran from 2006 to 2010 and the major tasks were to protect the natural forests, recover vegetation, and promote sustainable development. The total investment in the project is 96.2 billion yuan and it has resulted in the protection of 56 million ha of natural forests, the establishment of 15.27 million ha of afforestation, and an increase in forest stocks of 460 million cubic metres. 
In 2011, the project entered into the second phase with a planned investment of 244 billion yuan. The main goals are to, by 2020, increase the ecological forests by 7.7 million ha and other forests by 5.2 million ha, forest stocks by 1.1 billion cubic meters, and carbon sequestration by 416 million tons. The project also aims to increase biodiversity significantly, and to maintain social stability in forest areas.

The project of converting cropland to forestland started in 1999. In all China's ecological construction projects, this one has received the greatest investment and covers the most extensive areas. The investment for the first phase is 224.5 billion yuan and involves planting trees on croplands and barren areas and closing the hillsides to facilitate the growth of forests. Forest areas have been increased by 24.27 million ha and forest coverage has risen by over two percentage points on average. In 2007, when the government policy of subsidising grains and living costs expired, the government added 206.6 billion yuan to subsidise the farming households that are involved in implementing the project. The total investment is 431.1 billion yuan during the two phases of project implementation.

In addition, China also implemented projects involving forest shelterbelts, dust-storm source control around Beijing, wildlife conservation, natural reserves, and fast-growing and high-yield timber forests. Promoted by these projects, China's forest area has increased by 60.4 per cent from 121.86 million ha to 195.45 million ha, the stumpage volume has increased by 56.5 per cent from 9.53 billion $\mathrm{m}^{3}$ to 14.91 billion $\mathrm{m}^{3}$, and the forest-coverage ratio rose from 12.70 per cent to 20.36 per cent over the period 2000-2010.

Table 8.15 shows the results of the six major forest projects. One can see that carbon sequestration increased by 338.22 million ton per year, of which 175 million tons is produced by the new forests, accounting for over 50 per cent of the total carbon sequestration.

China has also amended development strategies for pastoral areas and changed the focus from agricultural production to preservation of grasslands and animals. The goal is to increase agricultural efficiency and preserve the natural environment by limiting grazing areas and fencing grasslands. This policy shift has helped China to complete the transformation from focusing purely on economic growth to focusing on ecological systems and economic development. By so doing, China has given a higher priority to the environment. 
Table 8.15 Area and carbon sequestration of the six major forest projects during 2000-2010

\begin{tabular}{l|c|c|c|c}
\hline \multirow{2}{*}{ Project } & \multicolumn{2}{|c|}{ Total forest } & \multicolumn{2}{c}{ New forest } \\
\cline { 2 - 5 } & $\begin{array}{c}\text { Area } \\
\left(1,000 \mathbf{~ k m}^{2}\right)\end{array}$ & $\begin{array}{c}\text { Carbon } \\
\text { sequestration rising } \\
\text { by year (million t) }\end{array}$ & $\begin{array}{c}\text { Area } \\
\left(1,000 \mathbf{~ k m}^{2}\right)\end{array}$ & $\begin{array}{c}\text { Carbon } \\
\text { sequestration rising } \\
\text { by year (million t) }\end{array}$ \\
\hline $\begin{array}{l}\text { Converting } \\
\text { cropland to } \\
\text { forestland }\end{array}$ & 319.8 & 73.46 & 273.0 & 71.08 \\
\hline $\begin{array}{l}\text { Dust storm } \\
\text { source control } \\
\text { around Beijing }\end{array}$ & 49.4 & 11.13 & 31.7 & 7.13 \\
\hline $\begin{array}{l}\text { Natural forest } \\
\text { protection }\end{array}$ & 388.8 & 94.99 & 83.9 & 18.99 \\
\hline $\begin{array}{l}\text { Forest } \\
\text { shelterbelts }\end{array}$ & 344.0 & 95.46 & 142.7 & 37.60 \\
\hline $\begin{array}{l}\text { Fast-growing } \\
\text { and high-yield } \\
\text { timber }\end{array}$ & 133.3 & 40.20 & 133.3 & 40.20 \\
\hline Natural reserve & 9.74 & 22.98 & 66.46 & 175.00 \\
\hline Total & 133.27 & 338.22 & & \\
\hline
\end{tabular}

Source: State Forestry Administration.

During 2003-2010, the total investment in the protection of grasslands was 14.3 billion yuan, of which 10 billion yuan was subsidised by the central government and 4.3 billion yuan was matched by local governments. The policy subsidises ranchers with a seasonal payment of $82.5 \mathrm{~kg} /$ ha per year of grains (around 74.25 yuan/ha per year) for nine months, and $20.625 \mathrm{~kg} / \mathrm{ha}$ per year of grains (around 18.56 yuan/ha per year) for three months. The ranchers are subsidised with a payment of 247.5 yuan/ha for fencing. The subsidy period runs for five years.

In order to intensify conservation of grasslands, China also aims to change the style of animal husbandry, to promote the ranchers' continuous increase in income, and to maintain the country's ecological safety. Since 2011, the central government has allocated 13.6 billion yuan/year to subsidise and reward grassland conservation in Inner Mongolia, Xinjiang, Tibet, Qinghai, Sichuan, Gansu, Ningxia, and Yunnan. The activities and reward standards are:

1. A 90 yuan/ha subsidy to ranchers for stopping grazing in heavily degraded grassland areas.

2. Ranchers who graze within an established grazing capacity are rewarded with a payment of 22.5 yuan/ha. 
3. Ranchers who produce on the 6 million ha artificial grassland within the eight provinces are subsidised with a payment of 150 yuan/ha for their use of improved varieties of livestock and grass. The two-million rancher households in the eight provinces are subsidised with a total payment of 500 yuan/household for their production inputs.

In total, the area in which grazing is forbidden now covers 29.3 million ha. According to results provided by the Ministry of Agriculture, the coverage, height and production of grass in the project area has increased 29 per cent, 64 per cent, and 78 per cent than those in the non-project areas, respectively.

During the 1950s-1970s, a large number of lakes in China were converted to farmland, as a result of concerns about grain shortages. Since the mid 1980s, China reached food self-sufficiency and the government started to implement a policy of converting cropland back to lakes, which altered China's 1,000-year history of converting lakes to farmland.

The Plan of National Wetland Conservation (2002-2030) proposes that over 90 per cent of natural lakes would be effectively conserved and protected by 2030, enhancing wetland systems and reaching the target of sustainable use of wetland resources.

\section{From Economic to Social Development}

With the increasing strength of the national economy, China has strengthened the implementation of the free and compulsory education system, and cooperative medical care in rural areas. The government has also tried to realise equalisation in financing infrastructure supply, providing minimum living security, and a social pension system in rural areas.

The free and compulsory education system started to be implemented in 2006. The system includes that, during the compulsory education period, all rural students' tuition and fees are waived, students from poor families are provided with textbooks and the living expenses of boarders from poor families are subsidised. Public funds for rural primary and secondary schools have increased and funds for the maintenance and reconstruction of rural primary and secondary schools, and teachers' salaries, are guaranteed.

This system was implemented in parts of the western and central regions in 2006 and extended to the whole country in 2007. Government payments for the 'two exemptions and one subsidy' reduced the over-230 billion yuan being spent by rural families on education, cutting 250 yuan/year in education costs and 390 yuan/year of expenses for families with a student at a primary and secondary school. 
At present, the net enrollment rate in China's primary schools is 99.5 per cent; the gross enrollment rate in the secondary schools is 98.5 per cent, 13 and 20 percentage points higher than the world average level, respectively, and close to the levels in the developed countries.

Since 2003, a new type of cooperative medical care has been promoted. By the end of 2011 the program covered 832 million rural residents in 2,637 counties, accounting for 97.5 per cent of the rural population. The total fund raised for the program reached 204.76 billion yuan in 2011, with the per capita level reaching 246.2 yuan. The total payments were 171.02 billion yuan, with the total beneficiaries numbering 1.315 billion person-time. Of the beneficiaries, hospital treatments were provided for 700 million person-time; general outpatients numbered 1.167 billion person-time, effectively reducing the economic burden on farmers for medical treatments.

By 2012, the participation rate in cooperative medical care has risen to 98.1 per cent. In the beginning, the standard payment was 30 yuan per capita, of which the government subsidised 20 yuan, while the participants paid 10 yuan. In 2012, the payment rose to 300 yuan per capita, of which the government subsidised 250 yuan.

As for the provision of the rural infrastructure, a key focus is the provision of safe drinking water. There are two objectives in this plan. The first, which was achieved in 2000 , related to quantitative security whereby rural residents always have ready access to drinking water. The second objective is to achieve qualitative security. In 2000, there were 379 million rural residents without access to safe drinking water. During the tenth five-year plan period, conditions were improved for 67 million rural residents. During the 11th five-year plan period, another 213 million rural residents could access safe drinking water. It is anticipated that the second objective will be achieved in 2013.

Rural infrastructure extends to electricity supply, for which there are three objectives. The first objective, which was achieved in 1997, was the provision of electricity to all counties, almost all the townships and villages, and 95 per cent of the country's rural households. The second objective, achieved by the end of the 11th five-year plan period, was to improve the reliability of electricity supply in rural areas and lower the cost of electricity for rural consumers. The third objective is that rural residents experience parity with urban residents for supply and cost of electricity. This will be achieved by updating the rural electricity grids, which is anticipated to take place during the 12th five-year plan period. 
The objective of rural road construction has been regularly updated. The first objective, which was achieved by the end of the 20th century, involved the provision of roads suitable for motor vehicles. The second objective, basically achieved during the 11th five-year plan period, is that all towns and villages would have all-weather road access. The present objective is about the integration of urban and rural road networks.

The government has also focused on the provision and improvement of rural communication infrastructure by the construction of television, telephone, and internet infrastructure.

In 1996 China started implementing pilot projects to address minimum living security in a couple of provinces and cities. In 2007, the project extended to all the country's rural areas (Table 8.16). The procedure involves a farmer submitting an application to a village committee, which considers the candidates' financial conditions. The application from approved candidates is sent to the township government for verification and the result is sent to the county bureau of civil affairs, which approves or rejects the application. In order to guarantee fairness and transparency, all levels of assessment are responsible for publicising the results of their deliberations.

During 2006-2010, the country started providing the social pension system to rural aged people aged over 60. By 2011, in the pilot project areas, around 326 million rural aged residents participated in the project, of which 85.25 million received the pension. The implementation of the rural social pension system reflects two fundamental changes: one is a shift from relying on farmers' posterity and land to their family income; and the other is a shift from aged people relying on their families to depending on the society.

Overall, the government's expenditure on agriculture and rural development is rapidly increasing over time. Figure 8.6 shows the increasing trend of the central government's total expenditure on agriculture, farmers and rural areas. One can see that, since 2002, expenditure has been continuously rising. The amount increased from 190.5 billion yuan in 2003 to 1,238.7 billion yuan in 2012, a rise from 13.7 per cent to 22.1 per cent of China's total expenditure. 
China: A New Model for Growth and Development

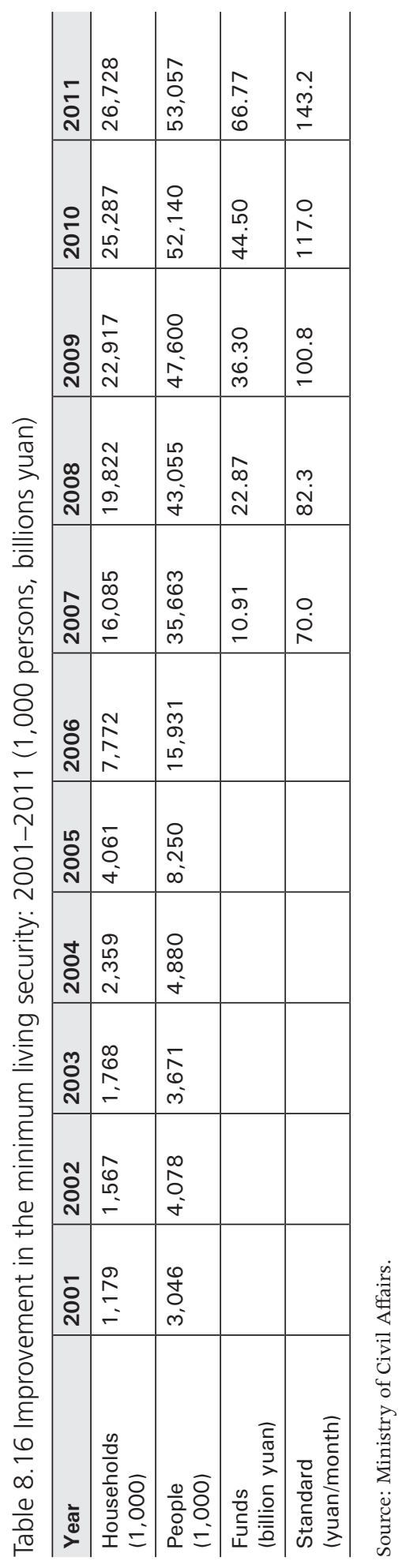


Figure 8.6 Central government's expenditure on agriculture, farmers, and rural areas: 2002-2012 (billion yuan)

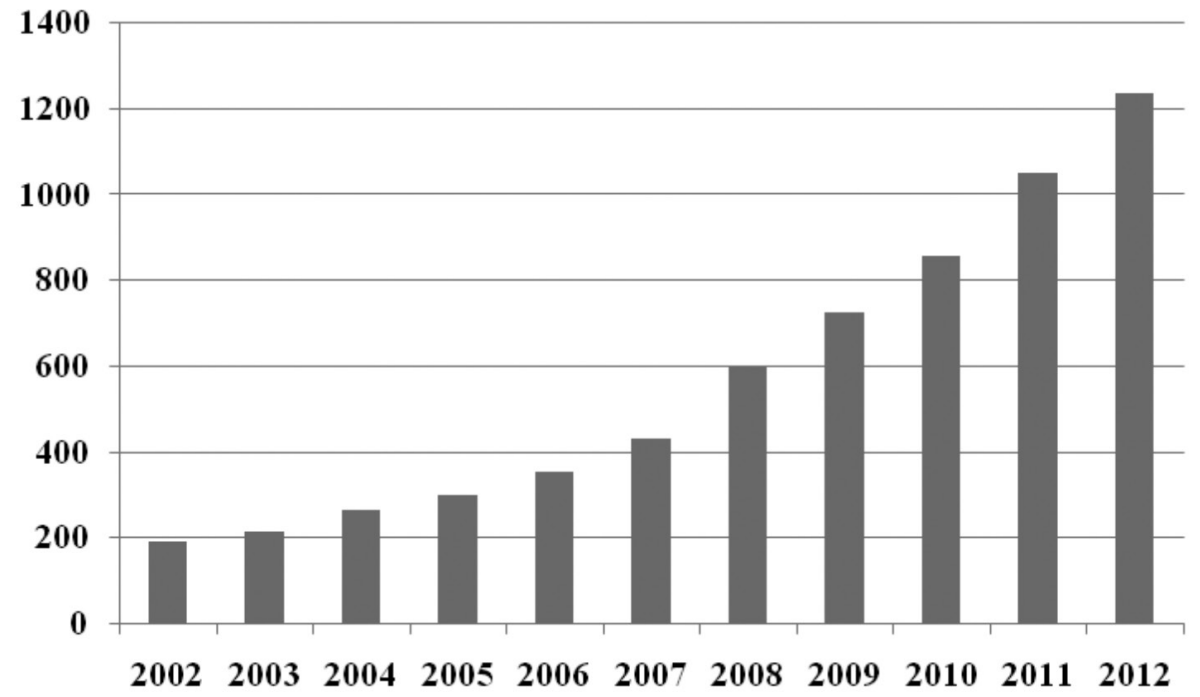

Source: Ministry of Civil Affairs.

\section{New Challenges Faced by the Rural Sector}

Despite these tremendous achievements in rural sector development, the agricultural and rural sector in China faces important challenges. Confronting these challenges will determine the way by which the agricultural sector will further develop and, more importantly, how agricultural development will contribute to China's future economic growth and social development and stability. These challenges are outlined below.

\section{Coping with the Decline in Agricultural Competitiveness}

In recent years, China's net imports of agricultural products has increased. Locally grown soybean, a land-intensive product, is largely substituted by foreign supplies. Corn imports are also increasing, as are imports of rice and cotton, which are labour-intensive. There are three reasons for the decline in the competitiveness of China's agriculture. The first is the rising cost of agricultural labour. In reality, young adults are employed outside agriculture or local areas, and those left to undertake rural labour are the elderly, women and children. 
The rural population is also made up of landlords, who contract out their lands to professional farmers. Most of the mechanical ploughing, sowing and harvesting is conducted by professional farmers who provide outsourcing services. ${ }^{3}$

Table 8.17 shows that the production of rice, wheat and corn in China only needed 177.8, 121.5, and 149.6 working days per ha in 2004, respectively. The amount of labour for producing these three crops declined to 117.3, 84.6 and 110.0 working days per ha in 2010, respectively. During the same period, labour costs rose from 2,571.6, 1,677.6, and 2,107.4 yuan per ha to 3,998.7, 2,682.5, and 3,526.5 yuan per ha. The cost of land also continues to increase. With the expansion in the scale of land transfer, particularly because the demand for land transfer is greater than the supply, land transfer costs have risen to 900012000 yuan/ha. The costs of other production inputs have also risen over time. As these three factors may persist, it will be a challenge for China to manage the decline in its agricultural competitiveness.

Table 8.17 Labour and labour costs in the production of rice, wheat and corn per ha

\begin{tabular}{l|c|c|c|c|c|c}
\hline \multirow{2}{*}{} & \multicolumn{3}{|c|}{ Labour (days) } & \multicolumn{3}{c}{ Cost of labour (yuan/mu) } \\
\cline { 2 - 7 } & $\mathbf{2 0 0 4}$ & $\mathbf{2 0 1 0}$ & Decline (\%) & $\mathbf{2 0 0 4}$ & $\mathbf{2 0 1 0}$ & Increase (\%) \\
\hline Average & 149.6 & 104.0 & 30.5 & $2,118.9$ & $3,402.6$ & 60.6 \\
\hline Rice & 177.8 & 117.3 & 34.0 & $2,571.6$ & $3,998.7$ & 55.5 \\
\hline Wheat & 121.5 & 84.6 & 30.4 & $1,677.6$ & $2,682.5$ & 59.9 \\
\hline Corn & 149.6 & 110.0 & 26.5 & $2,107.4$ & $3,526.5$ & 67.3 \\
\hline
\end{tabular}

Source: Materials of Agricultural Costs and Returns, China Agricultural Production Cost and Benefit data Collection 2005, and 2011.

\section{Reducing Farming Intensity}

China's agriculture is moving from a traditional to a modern system. Traditionally, agriculture pursued maximum productivity, and additional inputs stop at the point where the marginal product is zero. Modern agriculture pursues maximum profit, and additional inputs stop at the point where they equal marginal revenue. Comparing modern with traditional agriculture, marginal inputs tend to be higher than marginal outputs. For this reason, the decline in farming intensity is typical of modern agriculture and is observable in China in the decision of farmers to change from double to single cropping on two-quarters of the agricultural land.

3 Rural households make the logical decision to encourage their young adult members to seek employment outside agriculture; at present, land holdings are too small for farmers to be fully employed. Productivity levels under a reformed agricultural system need to be determined over time and, that being the case, outsourcing arrangements can help farmers to be fully employed, which is a win-win system. 
Changing from double to single cropping has three advantages. First, the farmer's income increases, resulting from higher prices caused by reduced output. In 2006, the net profit of double-cropping rice was 3,813.7 yuan/ha, while the net profit of single-cropping rice was 4,504.5 yuan/ha. Second, single cropping saves inputs, such as irrigation, fertiliser and pesticides. Third, one season fallow is conducive to maintaining the fertility of the land. Clearly, the disadvantage in single cropping is the decline in the total output on a unit of farmland, but the extent of decline in the total output is less than the extent of decline in the seeded area. During 1998-2006, in two-quarters of the agricultural area, the area of double-cropping rice decreased by 13 per cent, while the total output of rice decreased by only 5.4 per cent. Considering the fact that less seeds are needed in single cropping, there is an impact on the volume of grain available for consumption. It is unlikely that there will be a reversal of the current trend in agricultural production intensities.

The fertility of land is limited both physically and ecologically. The intensity of farming and multiple cropping indexes is not, therefore, a case of more being better. At the early stage of reform, some places even practiced triple cropping, which was a response to profit incentives. In the future, the traditional concept that planting should be practiced in any crop growing season must be abandoned. The traditional thinking that while a fallow season maintains soil fertility but leaves the land uncultivated for no income, must be changed. When food is relatively scarce, the country could subsidise farmers to produce grains by double cropping; when food is relatively abundant, the choice to single crop must be respected.

\section{Promoting the Economy of Scale in Production}

The promotion of scale operations in agricultural production by transferring rights to farmland between farmers and/or between farmers and enterprises should be an important part of agricultural transformation, and also a key measure to enhance the competitiveness of China's agriculture and the economies of scale. Farmers, however, pay some attention to the economies of scale, but also are concerned about the risk involved in sharing the benefits derived from increased economies of scale. That is the major reason why a lot of economies of scale have not developed. In addition, the obstacles faced by farmers in migrating to cities and non-agricultural industries have not been completely eliminated; the social security system has not been fully established. These are the factors that currently restrict land transfer. The challenge is to ensure that farmers do not risk losing their land rights, that they are provided with a stable source of income should they choose to be employed in non-agricultural sectors, 
and that social security can be regarded as an adequate substitute for land security. Before this happens, it is not realistic to expect farmers to recognise the advantages of increasing scale operation in production.

As mentioned earlier, for grain production, the major benefits of land scale operation are reducing the costs and increasing the income, but the role of raising grain production to increase farmers' income is limited. In reality, most land transfer is related to land that is not used for grain production. The operation scale must be considered in the context of particular locations, including their economic, social and institutional conditions, instead of taking the agricultural operation scale in other countries or regions as a benchmark for China. ${ }^{4}$

Besides the scale operation, there are other measures that could increase agricultural efficiency:

- actively guiding famers to cooperate in the purchase of production factors, land consolidation, construction and maintenance of agricultural infrastructure

- adopting advanced agronomic measures

- establishing and improving agricultural equipment and outsourcing services

- optimising industrial patterns and updating industrial structures.

The difficulties in implementing these measures are smaller than those related to the issue of land transfer practices. These measures should, therefore, be the first choices for the government to adopt in order to increase agricultural productivity.

\section{Promoting Cooperation between Farmers}

In theory, at least, there are many advantages in farmers working in cooperation. In reality, however, there are many obstacles to hamper such cooperation. First, rural so-called elites will use government policies to generate personal benefits, but they are unwilling to help other farmers. This is the major reason why it is difficult for farmers to cooperate with each other. Second, outsourcing of services could meet the farmers' demand for mechanical ploughing, sowing, and harvesting. This is a form of cooperation on which a farmer can rely that is based on a market mechanism. Third, agricultural enterprises are based on enterprises + households, and this structure has the effect of making farmers' cooperatives redundant. The challenge is to coordinate cooperative arrangements for the benefit of famers.

4 In general, agricultural scale is larger in immigrant societies, such the United States, Australia, Canada, Brazil, Argentina, and north-eastern China and Xinjiang, and smaller in non-immigrant societies. 


\section{Strengthening the Management of Food Consumption}

In 2012, China's production of grain, meat, and aquatic products were $435 \mathrm{~kg}$ per capita, $54.6 \mathrm{~kg}$ per capita, and $43.6 \mathrm{~kg}$ per capita, which is higher than the world average (332.7 kg per capita, $42.1 \mathrm{~kg}$ per capita, and $22.1 \mathrm{~kg}$ per capita) by 30.7 per cent, 29.7 per cent, and 97.3 per cent, respectively. China's production of vegetables and fruits per capita is also higher than the world average level. Nevertheless, because management of production is not well developed, there is significant waste and excessive consumption, which leads to waste of agricultural resources. The challenge is to how effectively solve these problems and ensure the sustainable development of China's agriculture.

The measures that need to be taken include improvement of equipment for and conditions of grain storage (to reduce loss), establishing standards for grain processing, and raising awareness of the relationship between both diet and health, and agriculture and environmental degradation.

\section{Protection of Farmers' Land Rights following Urbanisation}

In the early phase of urbanisation in China, new cities and towns were mainly built on farmland. Fearful of losing too much farmland, the central government has been strengthening the management of farmland, and construction of the urban areas has been focusing more on transformation of old cities and towns. The space in established urban areas is limited, and the costs of transformation are high; thus, construction of urban areas has been moving towards consolidation of construction (non-farm) land in rural areas. There are key policy implications related to the further development of urban areas on rural land so as to accommodate more migrants.

First, the construction of urban areas on consolidated rural land should be undertaken in stages. According to our survey, however, some local government officials in a number of local areas have been eager to complete consolidation in rural areas within their appointed terms to boost their performance and achievements. Second, it is advantageous that consolidation relates to demand; thus, urbanisation is a result of, rather than a prerequisite for, development. For this reason, farmers should be encouraged to move to non-agricultural sectors and/or urban areas, and the government should establish a social security system for rural residents to increase their employment opportunities in non-agricultural sectors. Only under these circumstances will social security be seen as a fair substitute for land security. By so doing, farmers' interests will be guaranteed rather passively lost without full compensation. It is a challenge for China to find appropriate ways to solve problems arising from further urbanisation. 


\section{Establishing New Systems of Community Management for Social Stability}

To strengthen the rural community management system, organisations supporting farmers should be strengthened. The major tasks of rural community management include: to strengthen the cohesion of rural communities, promote the development of rural communities, and mediate conflicts in order to maintain the stability of rural communities. It is also important to build channels of communication between farmers and different levels of government, so that the needs and interests of the rural sector can be addressed democratically. In order to promote the democratic management of rural communities, the government must accept the supervision of farmers' organisations, and there must be systems to facilitate participation and influence from the rural sector. The first step is to improve the system of 'one project one discussion' that dominates public affairs and public finances at the village level, and improve the method of providing rewards and subsidies to farmers in order to promote public welfare at the village level. The participation of farmers (or their organisations) in public affairs will change the way that government functions in local communities and will have a direct effect on improving farmers' welfare. The challenge for governments is to transform current management techniques by empowering farmers' collective actions.

\section{Conclusion}

In short, the issues relating to farmers, agriculture, and rural areas are the weak links on the chain of China's economic development. It is crucial to resolve these issues in order to promote the development of the national economy. Rural China is undergoing rapid economic and social changes, which have impacted on the ways in which farmers, traditional communities and governments operate. To confront these challenges, it is important for government policies to complement market mechanisms in facilitating the ongoing process of urbanisation, and creating more employment opportunities for both migrant workers and farmers, while maintaining rural social stability at time of rapid social change. It is also important for the government to adopt measures that conform to or respect farmers' own choices through developing a more democratic local governance system. 


\section{References}

Department of Comprehensive Statistics of the National Bureau of Statistics, 1999, Comprehensive Statistical Data and Materials on 50 Years of New China, China Statistics Press, Beijing.

Department of Price, National Development and Reform Commission, 2011, China Agricultural Production Cost and Benefit Data Collection, China Statistics Press, Beijing.

Li, Zhou, 2012, 'Scientific and Technological Progress and Agricultural Development in China', in Jianguo Huang (ed.), Huxiang Agricultural Forum, 2012, Hunan Normal University Press, Changsha, pp.16-20.

Li, Zhou, \& Zhang, Haipeng, (forthcoming), 'Productivity Growth in China Agriculture during 1985-2010', Journal of Integrative Agriculture.

Ministry of Agriculture, 1979, 1986, 1991-2012, China Agriculture Yearbook, China Agriculture Press, Beijing.

National Bureau of Statistics of China, 1986-2012, China Statistical Yearbook, China Statistical Press.

- 2012, Statistical Communiqué of the People's Republic of China for 2012, available at http://www.stats.gov.cn/english/newsandcomingevents/ t20130222_402874607.htm

Yang, Tianrong, \& Lu, Qian, 2009, 'Efficiency Analysis Based on Regional Specialized Production of Grain in China', Journal of Southwest Agricultural University (Social Sciences Edition), vol. 7, pp. 29-33.

$\mathrm{Xu}$, Qing, Yin, Rong, \& Liang, Zhanghui, 2011 'Economies of Scale, Returns to Scale and the Problem of Optimum-scale Farm Management: An Empirical Study Based on Grain Production in China', Economic Research Journal, vol. 3, pp. 59-71.

Zhang, Jun, Qin, Zhihao, Li, Wenjuan, You, Fei, Zhang, Wenbo, Zhang, Wei, \& Cheng, Min, 2011, 'Change of Grain Production and its Spatial Distribution in China during the 1949-2009 Periods', Chinese Agricultural Science Bulletin, vol. 27, no. 24, pp. 13-20. 



\section{Rural-Urban Migration: Trend and Policy Implications (2008-2012)}

Xin Meng

Over the past 20 years China has experienced unprecedented economic growth. During this period rural to urban migration has increased from 39 million in 1996 to 159 million in 2011 (NBS 2012). Migrants have contributed significantly to China's economic miracle. It is foreseeable that rural-urban migration in China will continue to grow, together with China's economic maturity in the next decades to come. A systematic record of the migration movement has, however, been lacking. As an exception, over the past five years the Rural-Urban Migration in China (RUMiC) project has been monitoring the changes in the rural-urban migration process. This chapter intends to present the dynamic progress of rural-urban migration in terms of migrant demographic composition, labour market outcomes and their access to social welfare.

The RUMiC survey was initiated in early 2008 and has since received five waves of data. The survey is conducted in 15 cities located in nine provinces. These cities include major exporting regions such as Guangzhou, Shenzhen, Dongguan, Shanghai, Wuxi, Nanjiang, Hangzhao, and Ningbo; as well as major cities in interior regions: Chengdu, Chongqing, Wuhan, Hefei, Bangbu, Zhengzhou and Luoyang. Between 2008 and 2010, two companion surveys of rural and urban households were also conducted. The rural survey was conducted in the rural areas of the provinces where the 15 cities are located, while the urban household survey was conducted in the same 15 cities as the migrant survey, plus four additional cities. The rural and urban surveys both used the National Bureau of Statistics Annual Household Survey sample. A comparison between the migrant survey and these two samples allows us to identify the distinctive features of migrants. ${ }^{1}$ After 2010, due to lack of funding, the rural and urban household surveys were discontinued, but the city migrant survey has been continued.

RUMiC is designed to be a longitudinal survey, which follows migrants over time. In 2008 a random sample of 5,000 migrant households was selected from the 15 cities. The attrition rate in the 2009 wave was extremely high ( 63 per cent), however, due to the nature of the sample: frequent mobility and the effects of the global financial crisis, which reduced China's exports by 20 per cent

1 For detailed information on RUMiCI, see http://rse.anu.edu.au/rumici/ or Gong et. al. (2008). 
and, as a result of which, many migrants returned home. The attrition rate has been reduced gradually since 2009 from 63 per cent to 35 per cent in 2012 . To maintain the original sample size, each year we re-sample a number of new households. Thus, apart from 2008, in subsequent years the RUMiC city migrant survey has two sub-samples: one traces part of the previous year sample (labeled old sample) and one draws a new random sample (labeled as new sample). The new sample gives a representative picture of migrants in general, while the old sample presents a dynamic picture of migrant life and work.

\section{Demographic Structure of Rural-Urban Migrants and China's Future Labour Supply}

Understanding the demographic structure of rural-urban migrants is an essential part of understanding China's unskilled labour supply. Because of the introduction of the One Child policy in 1979, and the fact that the policy has been strictly enforced in urban areas but less so in rural areas, China's future labour supply depends primarily on the rural hukou population. This can be seen clearly from the population pyramid in Figure 9.1. ${ }^{2}$

Figure 9.1 clearly indicates that China's urban hukou population is shrinking. The urban 'pyramid' is a diamond shape. The rural hukou population has also reduced, but the absolute numbers are far larger than the urban population. Furthermore, the reduction in rural population is related to the famine that occurred during 1959-1961, which generates the zigzags in the pyramid, indicating future birth cohorts may increase again. Thus, the future city labour supply depends predominantly on the rural hukou population.

2 The same graph was presented using the 2000 Population Census data in Meng (2012). 
Figure 9.1 Population pyramid by hukou status

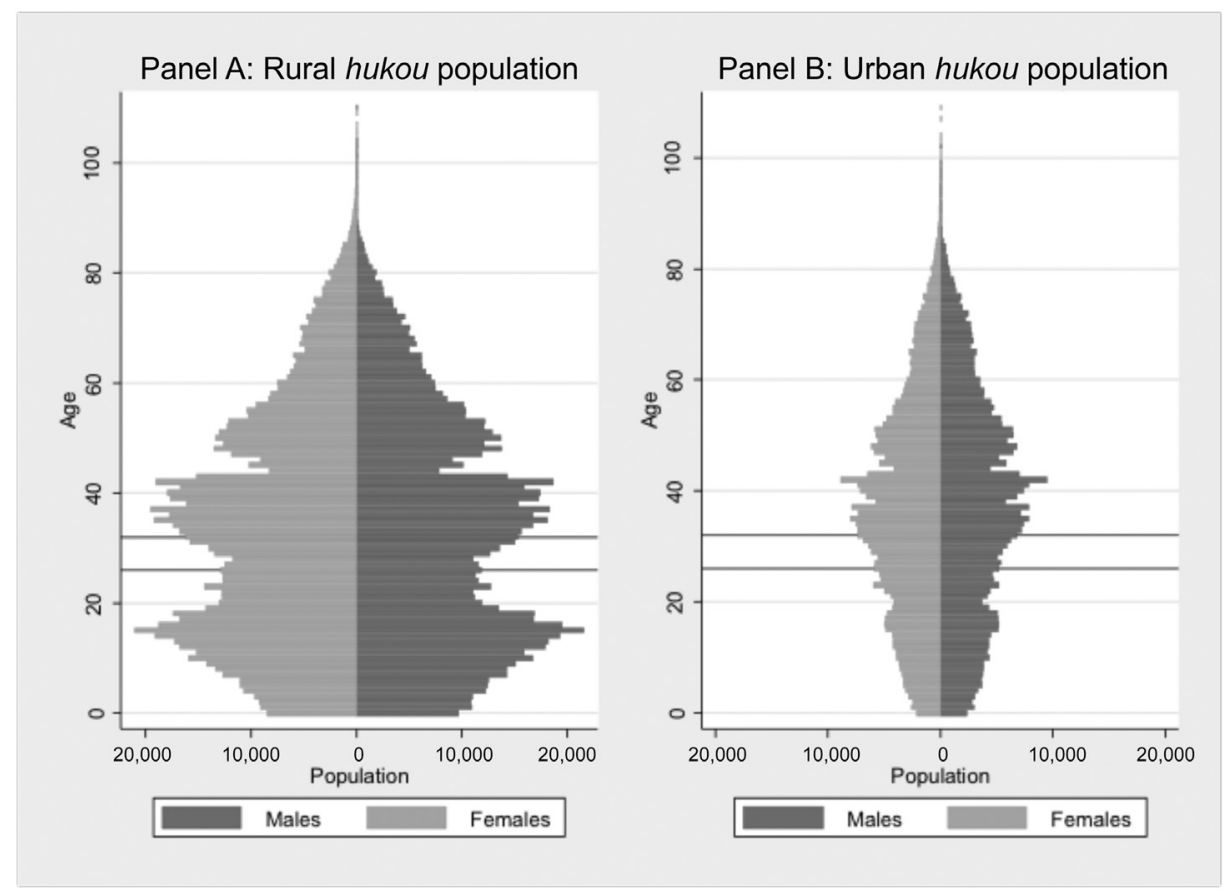

Source: China 1\% Population Survey, 2005.

The above figures, however, do not distinguish the extent to which some rural hukou population are already working in cities. To establish the size of the potential future additional labour supply to cities, it is necessary to understand the demographic structure of the current urban labour supply, including urban hukou population and rural-urban migrants in cities. This calculation must also include the size of the potential source of future supply: the current rural hukou labour force that has not yet migrated.

To do so, we use RUMiC 2008 samples of Rural Household, Urban Household, and City Migrant surveys. Note that 'migrants' in the city migrant survey are defined as individuals with rural household registration (hukou), but who are currently living and working in one of the 15 cities included in the survey. The Rural Household survey also records the migration experience of any rural household members in previous years. In that survey 'migrants' are defined by the responses to the following three questions: a. Last year how many months did the person live out of his/her own village/township? (if less than one month, record as one month); b. If the person lived outside his/her own village for three or more months last year, where did he/she live? (1) rural areas within own county; (2) rural areas outside own county in own province; (3) rural areas in other provinces; (4) county town; (5) other city in own province; (6) city in 
another province; (7) other (please explain); c. If the person lived outside his/ her own village for three or more months, what was the purpose? (1) going to school; (2) joined army; (3) work; (4) visit relatives or friends; (5) other (please explain). We thus define a 'migrant' as a rural household member who spent three or more months working (Question C, answer (3)) in an urban area outside his/her own county of residence (Question B, answers (5)-(7)).

Figure 9.2 examines the age and gender distribution of migrant and nonmigrant labour force (individuals aged 16 to 65 and are employed or unemployed) in urban and rural areas. The left figure in Panel A takes all urban hukou labour force as 1 and examines the share of each age and gender group in the total urban hukou labour force. Similarly, the right figure of Panel A takes the sample of migrant labour force in our 15 city sample as 1 and examines the age-gender distribution of the migrant labour force. Panel B takes the labour force in the rural survey (including non-migrants and migrants) as 1 and examines the age-gender as well as migrants-non-migrant distribution of the rural hukou labour force.

The figures in Panel A of Figure 9.2 suggest that majority of migrant workers in cities are aged between 16 and 30, and there are more males than females. Relative to the urban hukou labour force, it is clear that migrant workers are much younger than their urban counterparts.

The two figures in Panel B of Figure 9.2 indicate that migrants still account for a small portion of the total rural hukou labour force: 21 per cent in 2008 and 22 per cent in 2010. By including those who migrated to their own counties, this proportion increases to 24.3 per cent; by relaxing the restrictions on the length of migration last year from three or more months for work purposes to everybody who ever migrated for any length of time and any reason, the ratio increases to 29.2 per cent. Thus, no matter how we define 'migrant', it still only accounts for a small proportion of rural hukou labour force.

The figures show, however, that more than half of the young rural hukou workers (aged 16 to 30) have migrated to cities outside of their home county (the basic story stands if cities within the home county are included) and this is especially so for men rather than women. Nevertheless, the majority of the rural labour force between 16 and 64 years has not migrated, and this is true in 2010. 
Figure 9.2 Age and gender distribution of labour force by hukou and migration status

\section{Panel A: Age-gender share of labour force within each sample}

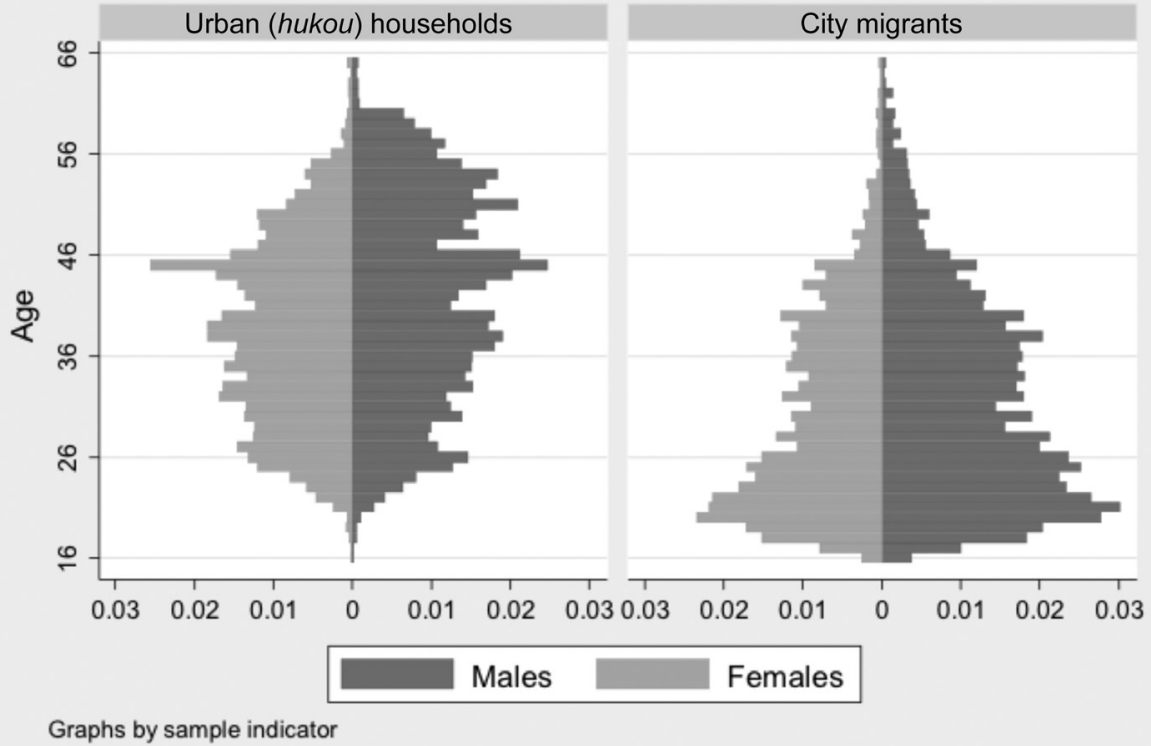

Graphs by sample indicator

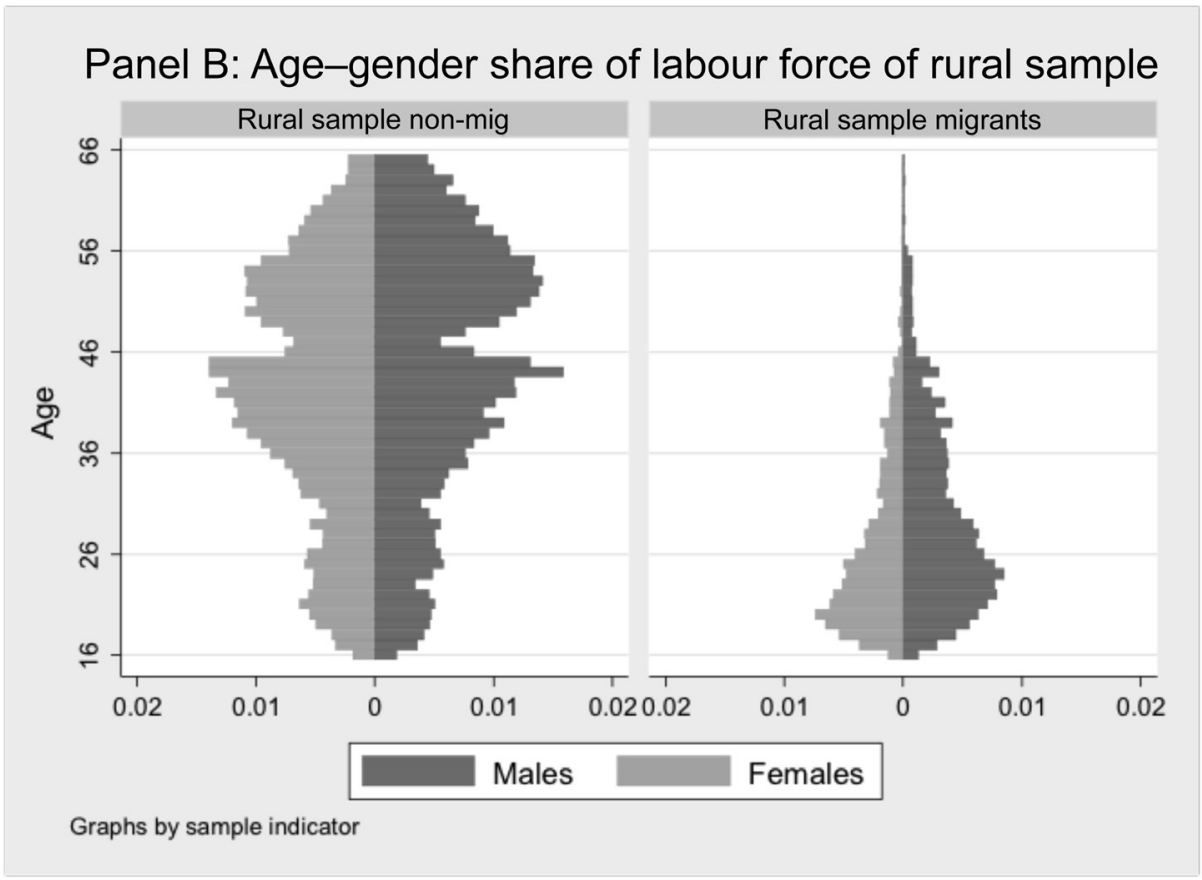

Source: RUMiC 2008 samples of Rural Household, Urban Household, and City Migrant surveys. 
It is important to note that many of the non-migrant workers at the time of the survey are in fact return migrants. For example, of the total rural workers who have ever migrated in 2010, 34 per cent had returned home at the time of the survey. Figure 9.3 present the age and gender distribution of the rural hukou labour force for migrants, return migrants and non-migrants separately. The figure clearly indicates that a significant proportion of rural labour force, of all ages, return home. This has an important implication for the urban labour supply, which is discussed later in the chapter.

Figure 9.3 Age and gender distribution of rural hukou labour force, 2010
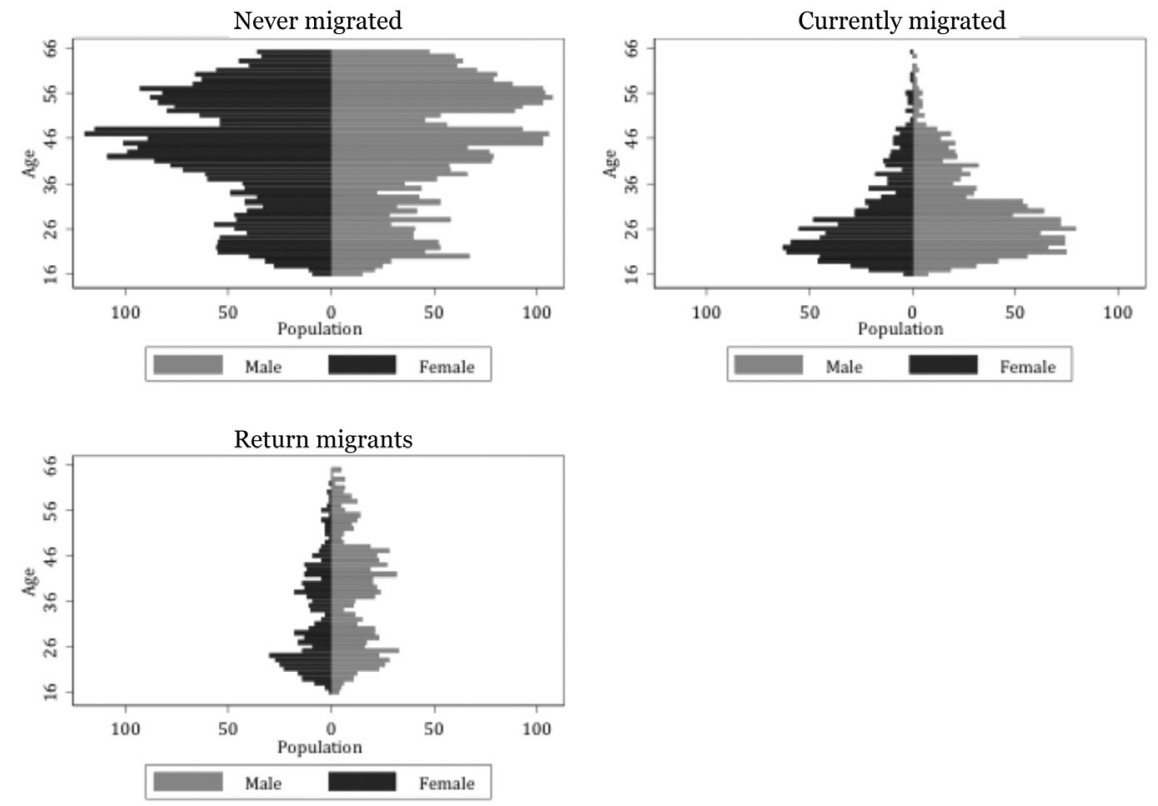

Source: RUMiC 2008 samples of Rural Household, Urban Household, and City Migrant surveys.

The averages show that, in general, migrants are more likely to be male and are relatively younger than their counterparts who still live in rural villages and those with urban hukou. Panel A of Table 9.1 indicates that urban hukou labour force is on average around 40 years of age and 55 per cent of them are male workers. On average, the rural hukou non-migrated labour force is 43 years of age and 52 per cent of them are males. In contrast, migrants in cities are, on average, ten years younger (31 years of age) and 60 per cent are men.

The next question is whether the age-gender distribution of the migrant workforce in cities has changed over the past five years. Table 9.1 columns 1 and 2 in both Panels $B$ and $C$ present the average age and proportion of male 
migrant labour force for the full sample and the new sample, respectively. The data for the full sample, which include individuals who are being tracked over the years, indicate that there is less than a one year increase in age in each subsequent years and the proportion of male workers has reduced slightly. The full sample, however, may provide misleading information regarding age changes as the age of the individuals examined annually will increase each year. When we examine the age change for the new sample, though, the increase in the mean age becomes very small. Over the five years the average age of migrants increased from 31.2 to 32.9 years, an average of 0.34 year increase annually. The most significant change seems to have occurred between 2011 and 2012 .

Table 9.1 Summary statistics of different samples

\begin{tabular}{|c|c|c|c|c|c|}
\hline & \multicolumn{4}{|c|}{ Panel C: Rural, urban, and migrant sample: 2008 survey } & \multirow[t]{2}{*}{ No. of obs. } \\
\hline & Age (1) & Males (2) & $\begin{array}{l}\text { Year since first } \\
\text { migration (3) }\end{array}$ & Schooling (4) & \\
\hline Urban hukou & 40.24 & 0.55 & & 10.28 & 7,813 \\
\hline Migrant in cities & 31.18 & 0.60 & & 8.83 & 6,749 \\
\hline \multirow[t]{3}{*}{ Rural hukou non-mig } & 42.96 & 0.52 & & 6.89 & 15,352 \\
\hline & \multicolumn{4}{|c|}{ Panel B: Migrant full sample } & \multirow[t]{2}{*}{ No. of obs. } \\
\hline & Age & Males & $\begin{array}{l}\text { Year since first } \\
\text { migration }\end{array}$ & Schooling & \\
\hline 2008 & 31.18 & 0.60 & 7.81 & 8.99 & 6,749 \\
\hline 2009 & 32.19 & 0.58 & 8.59 & 9.05 & 7,399 \\
\hline 2010 & 32.50 & 0.58 & 8.54 & 9.15 & 7,155 \\
\hline 2011 & 33.12 & 0.56 & 9.60 & 9.01 & 7,793 \\
\hline \multirow[t]{3}{*}{2012} & 34.32 & 0.56 & 10.55 & 8.96 & 8,068 \\
\hline & \multicolumn{4}{|c|}{ Panel C: Migrant new sample } & \multirow[t]{2}{*}{ No. of obs. } \\
\hline & Age & Males & $\begin{array}{l}\text { Year since first } \\
\text { migration }\end{array}$ & Schooling & \\
\hline 2008 & 31.18 & 0.60 & 7.81 & 8.99 & 6,749 \\
\hline 2009 & 31.57 & 0.59 & 7.96 & 9.12 & 4,594 \\
\hline 2010 & 31.20 & 0.58 & 6.67 & 9.30 & 3,308 \\
\hline 2011 & 31.78 & 0.56 & 8.09 & 8.97 & 3,083 \\
\hline 2012 & 32.88 & 0.57 & 8.95 & 9.02 & 2,647 \\
\hline
\end{tabular}

Source: Calculated based on Rural, urban, and migrant sample: 2008 survey. 
Figure 9.4 The change in age and gender distribution of migrant labour force: 2008 vs 2012

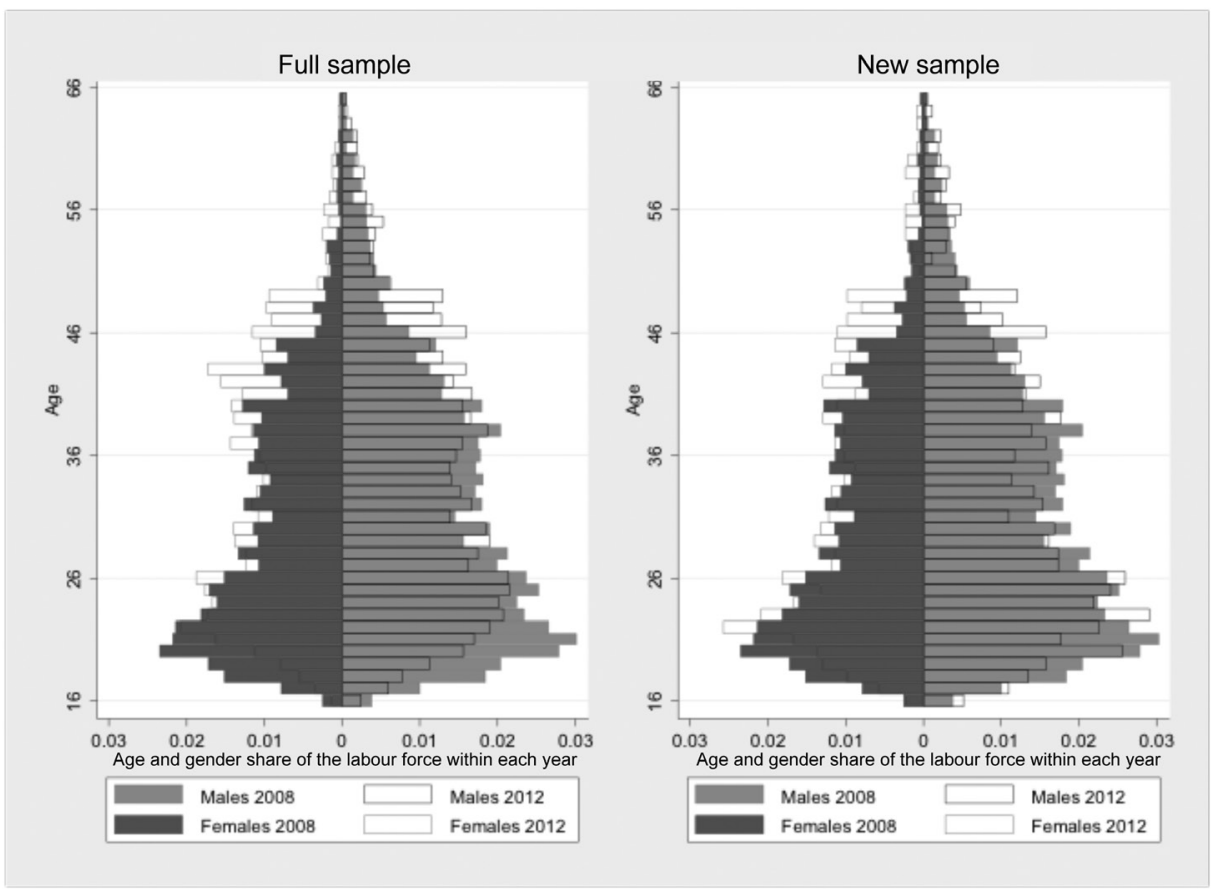

Source: RUMiC 2008 samples of Rural Household, Urban Household, and City Migrant surveys.

Figure 9.4 presents the age-gender distribution of the migrant labour force for the years 2008 and 2012. The new sample panel shows that, over the past five years, the proportion of migrant workers over 40 years old has increased, while the proportion of under 20 years old has declined. This is particularly true for the female labour force. This may suggest an interesting trend: perhaps the young generation of rural hukou population are more likely to go to school now than five years ago, and those who are aged 40 and over are now more likely to move to the city. Labour force pyramids alone, however, will not provide the answer to these questions.

To examine this issue, we turn to data for those who are new arrivals. In the RUMiC migrant survey, we ask each migrant worker the year in which they first migrated. Using this information we can identify individuals who migrated in the period 2006-2010, ${ }^{3}$ and examine whether the change in aggregate age structure is due to the change in age structure of the migrant inflow or not. Table 9.2 presents the results. It shows that since 2006, the proportion of newly

3 The number of migrants who migrated in 2011 and 2012 is small ( $<200$ observations for each year). To avoid the problem of lack of representative, we do not include data from these years. 
arrived migrant workers who are aged between 16 and 25 years has increased year by year, from 57 per cent in 2006 to 78 per cent in 2010, whereas the proportion of those aged 36 and above has reduced year by year. This trend does not coincide with the picture observed from the cross-section comparison presented in Table 9.1 and Figure 9.4. One possible explanation for this inconsistency is that migrant workers are staying in the city longer than before. Thus, those we observed in cities are gradually getting older.

Table 9.2 Proportion of each age group among the new arrivals by year

\begin{tabular}{l|c|c|c|c|c}
\hline & $\mathbf{2 0 0 6}$ & $\mathbf{2 0 0 7}$ & $\mathbf{2 0 0 8}$ & $\mathbf{2 0 0 9}$ & $\mathbf{2 0 1 0}$ \\
\hline Aged 16-25 & 56.54 & 63.14 & 66.64 & 68.91 & 77.53 \\
\hline Aged 26-35 & 21.4 & 15.32 & 13.64 & 14.39 & 8.49 \\
\hline Aged 36-45 & 13.9 & 13.55 & 9.97 & 9.76 & 7.31 \\
\hline Aged 45-55 & 6.02 & 5.02 & 6.8 & 5.86 & 4.93 \\
\hline Aged 55-65 & 2.14 & 2.96 & 2.95 & 1.08 & 1.74 \\
\hline Total & 100.00 & 100.00 & 100.00 & 100.00 & 100.00 \\
\hline
\end{tabular}

Source: RUMiC 2008 samples of Rural Household, Urban Household, and City Migrant surveys.

\section{Employment and Wages}

Migrants' employment and wages are affected mainly by market conditions. Given that they have no, or very limited, access to minimum living allowances and unemployment benefits, migrants who lose their jobs normally go back to their rural home. Thus, the measured unemployment rate for migrants in cities is very low. In the five years of our survey, the unemployment rate for migrant workers has never exceeded 1.8 per cent. This, however, does not mean that migrants do not lose jobs, but is simply an artifact of data collection and migrant geographic mobility. Had we able to track down all the migrants surveyed, we would have observed a larger proportion who returned home or changed cities due to unemployment. In this subsection we focus mainly on hours worked and wages.

\section{Hours Worked}

Migrants have very limited work protection and they do not see a future in settling down in cities due to the various institutional restrictions that they face there. Thus, they come to cities and work as hard as they can to make money and then go home. As a result, while in cities, they work extremely long hours. In 2008, for example, the average number of hours worked by migrant wage-salary workers was 60 hours per week, while the number for urban hukou workers was 43 hours, a difference of 17 hours. Figure 9.5 presents the weekly 
working hours distribution for the two groups. It shows that while the majority of urban workers worked 40 hours a week, more than half of the migrants worked above 50 hours weekly.

Figure 9.5 Weekly hours worked for urban and migrant wage-salary workers, 2008

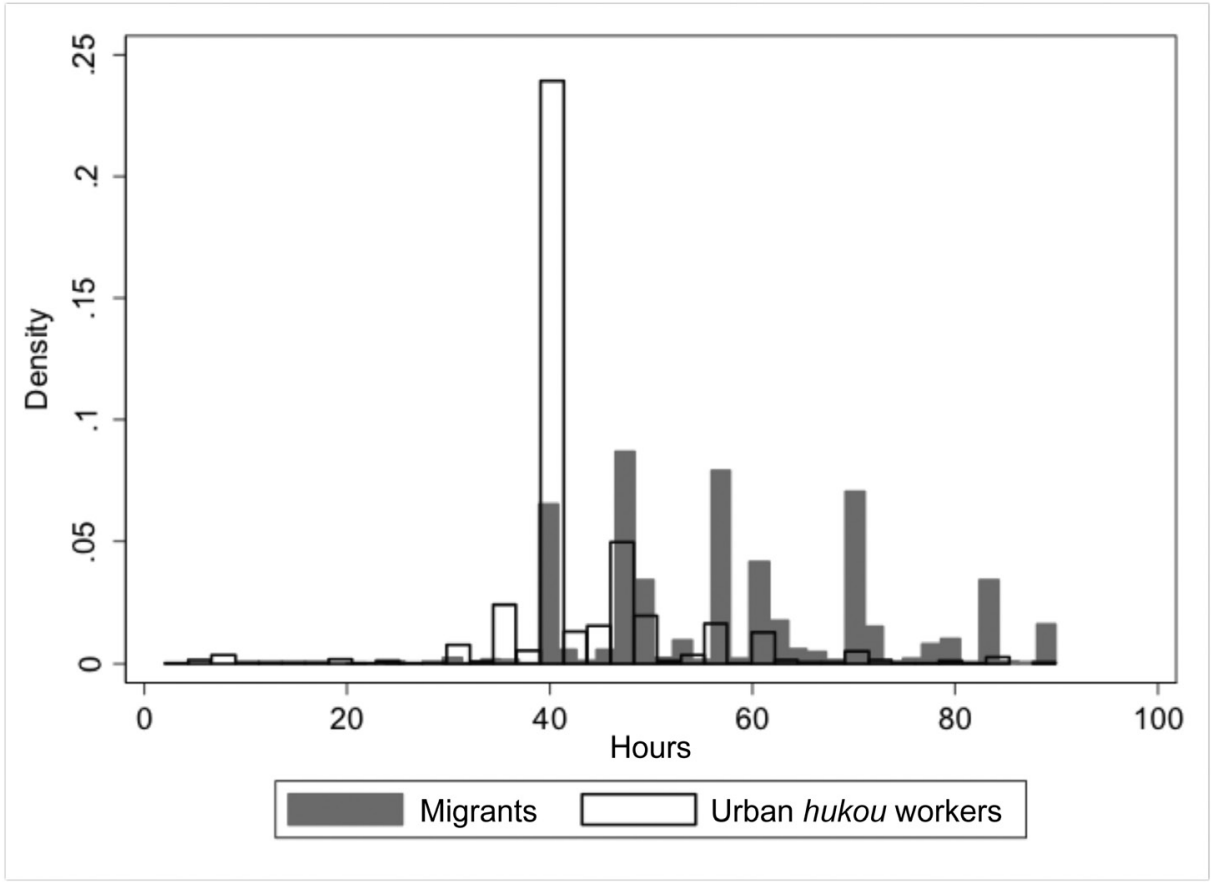

Source: Calculated based on Rural, urban, and migrant sample: 2008 survey.

Studies have found that working long hours is bad for mental health. Our data certainly indicates such a correlation (Figure 9.6, also Frijters, Johnston and Meng 2011). In particular, migrants who worked over 50 hours clearly have a higher incident of mental health problems. This, in the long run, may have significant implications not only for the human capital of China's most important workforce, but also for China's future healthcare costs.

The good news is that there seems to be a slight reduction in hours worked. In 2008 the average wage and salary workers worked 60 hours per week. Since then, this total has reduced slightly and, in 2012, the average was 58 hours. The reduction, though, has been very slow. 
Figure 9.6 Relationship between hours worked and mental health problems

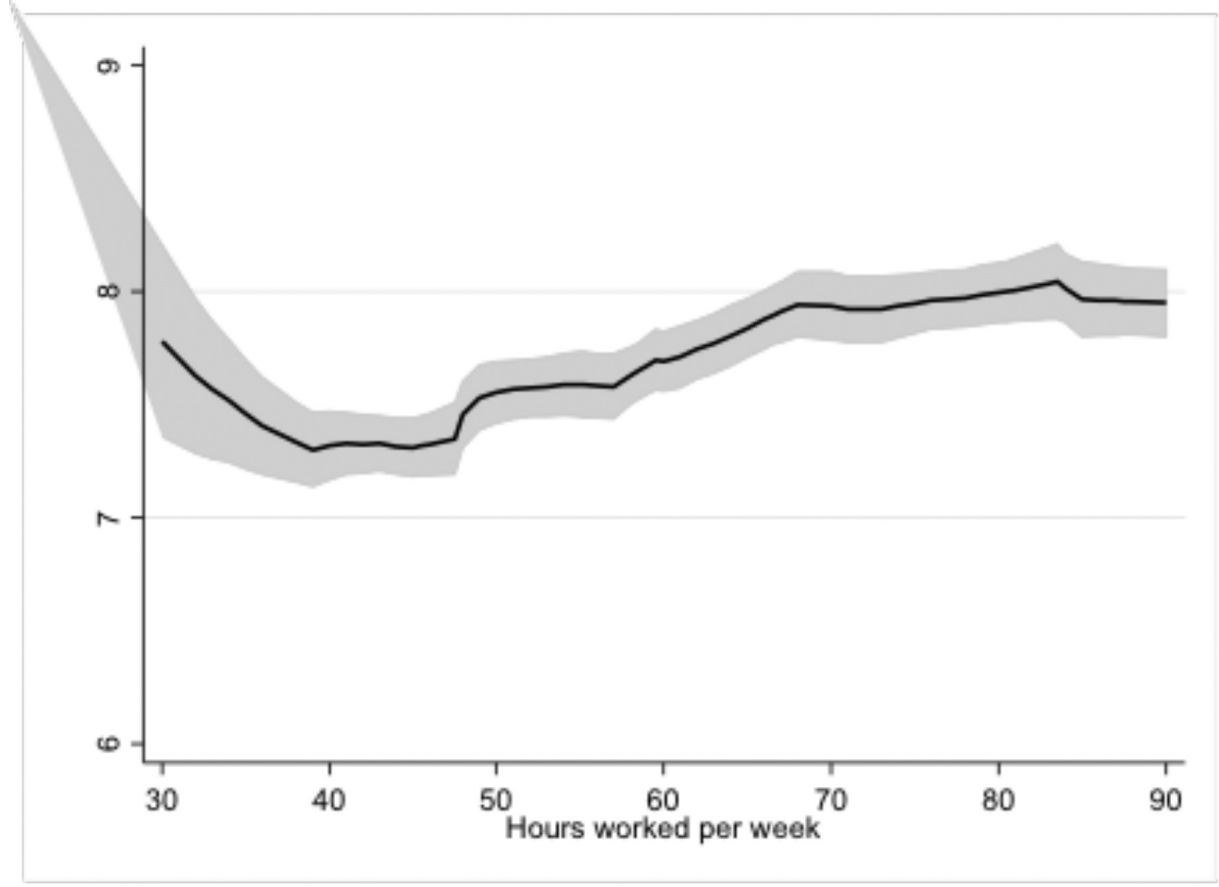

Source: Calculated based on Rural, urban, and migrant sample: 2008 survey.

\section{Wages}

Over the past five years, wages of migrant workers have increased significantly. This may reflect, to some extent, the tightening of the unskilled labour market, and it may also be a result of government policy.

The increase in monthly and hourly earnings for wage-salary earners between 2008 and 2012 is 12 and 14 per cent per annum, respectively. In particular, between 2010 and 2011, the real hourly earnings increased by 23 per cent. During the same period, minimum wages also increased dramatically. For example, between 2010 and 2011, the average minimum wage in the 15 sampled cities increased by close to 19 per cent. For cities located in Pearl River Delta and Yangzi River Delta, the average increase is around 20 per cent (data for minimum wages in the 15 cities are from various city government web pages). This may indicate that many local governments are using minimum wages to influence the industrial structure. In recent years, cities in the more developed regions have been talking about the importance of moving up the value-added chain and trying to reduce labour intensive industry. Perhaps, instead of directly picking industry winners, they are trying to use minimum 
wage as a policy device to achieve the objective of pushing the low profit industries out of the cities. This, however, requires more in-depth research to confirm.

It is interesting to note, though, that wage growth of such significant magnitudes seems to have stopped in 2012. The real hourly wage growth between 2011 and 2012 is only 3.7 per cent (see Figure 9.7).

Figure 9.7 Monthly and hourly real wages, 2008-2012

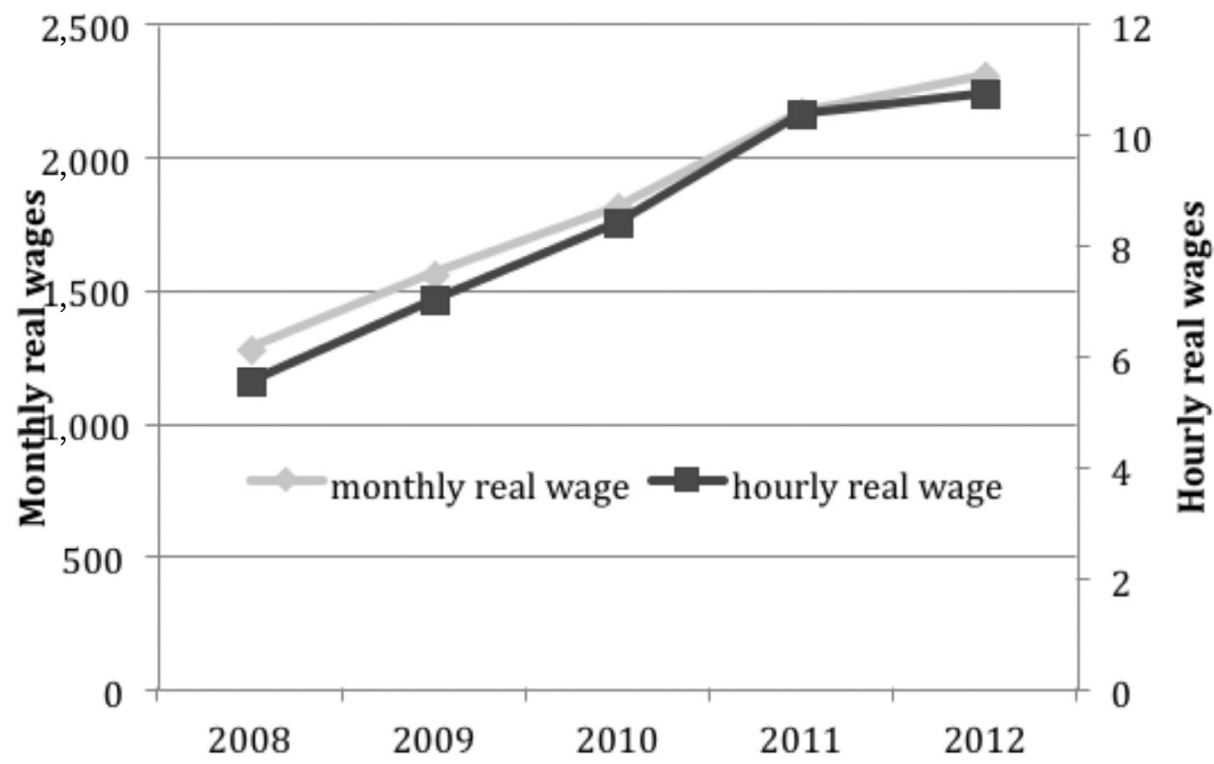

Source: RUMiC 2008 samples of Rural Household, Urban Household, and City Migrant surveys.

The above mentioned wage-growth data do not take into account that for each additional year migrant workers work in the city, they accumulate more work experience and, hence, become more skilled and earn more. The issue may be handled by estimating an earnings regression to control for individual human capital and other wage-related characteristics and include the year dummy to examine the wage changes arising mainly to the change in market price for the same quality workers. To do this, earnings data can be used in two different ways. In addition to the monthly earnings of current employment, the RUMiC survey also asks migrants to report the year when they first migrated and the earnings they received in the first month of the first job. This variable increases the time period under review and it directly teases out the wage increase due to the accumulation of work experience. The earliest year of migration is restricted to 2000 and the real first month earnings equation is estimated by controlling for age, education, city of employment and a gender dummy variable. The result of the estimated two different earnings equations for wage-salary earners is reported in Table 9.3. 
Table 9.3 Results from earnings regressions

\begin{tabular}{|c|c|c|c|}
\hline VARIABLES & $\begin{array}{l}\text { Log real monthly } \\
\text { earnings }\end{array}$ & $\begin{array}{l}\text { Log real hourly } \\
\text { earnings }\end{array}$ & $\begin{array}{l}\text { Log real monthly } \\
\text { earnings for } 1 \mathrm{st} \\
\text { month of } 1 \text { st job }\end{array}$ \\
\hline \multirow[t]{2}{*}{ Age } & $0.033 * * *$ & $0.047 * * *$ & $0.021 * * *$ \\
\hline & {$[0.002]$} & {$[0.002]$} & [0.004] \\
\hline \multirow[t]{2}{*}{ Age squared } & $-0.001 * * *$ & $-0.001 * * *$ & $-0.000 * * *$ \\
\hline & {$[0.000]$} & {$[0.000]$} & {$[0.000]$} \\
\hline \multirow[t]{2}{*}{ Years of schooling } & $0.024 * * *$ & $0.040 * * *$ & $0.028 * * *$ \\
\hline & {$[0.001]$} & {$[0.001]$} & {$[0.003]$} \\
\hline \multirow[t]{2}{*}{ Dummy for males } & $0.195 * * *$ & $0.162 * * *$ & $0.054 * * *$ \\
\hline & {$[0.005]$} & {$[0.007]$} & {$[0.011]$} \\
\hline \multirow[t]{2}{*}{ Years since first migration } & $0.019 * * *$ & $0.014 * * *$ & \\
\hline & {$[0.001]$} & {$[0.002]$} & \\
\hline \multirow[t]{2}{*}{ Years since first migration2 } & $-0.000 * * *$ & $-0.000 * * *$ & \\
\hline & {$[0.000]$} & {$[0.000]$} & \\
\hline \multirow[t]{2}{*}{2001} & & & $0.055 * *$ \\
\hline & & & {$[0.025]$} \\
\hline \multirow[t]{2}{*}{2002} & & & $0.076 * * *$ \\
\hline & & & {$[0.024]$} \\
\hline \multirow[t]{2}{*}{2003} & & & $0.116 * * *$ \\
\hline & & & {$[0.023]$} \\
\hline \multirow[t]{2}{*}{2004} & & & $0.142 * * *$ \\
\hline & & & [0.023] \\
\hline \multirow[t]{2}{*}{2005} & & & $0.228 * * *$ \\
\hline & & & {$[0.023]$} \\
\hline \multirow[t]{2}{*}{2006} & & & $0.319 * * *$ \\
\hline & & & {$[0.024]$} \\
\hline \multirow[t]{2}{*}{2007} & & & $0.304 * * *$ \\
\hline & & & {$[0.024]$} \\
\hline \multirow[t]{2}{*}{2008} & & & $0.450 * * *$ \\
\hline & & & {$[0.027]$} \\
\hline \multirow[t]{2}{*}{2009} & $0.196 * * *$ & $0.223^{* * *}$ & $0.569 * * *$ \\
\hline & [0.008] & {$[0.010]$} & {$[0.031]$} \\
\hline \multirow[t]{2}{*}{2010} & $0.329 * * *$ & $0.362 * * *$ & $0.639 * * *$ \\
\hline & {$[0.008]$} & [0.010] & {$[0.037]$} \\
\hline \multirow[t]{2}{*}{2011} & $0.523^{* * *}$ & $0.564 * * *$ & $0.868 * * *$ \\
\hline & {$[0.008]$} & {$[0.010]$} & {$[0.050]$} \\
\hline \multirow[t]{2}{*}{2012} & $0.569 * * *$ & $0.611 * * *$ & $0.885 * * *$ \\
\hline & {$[0.008]$} & {$[0.010]$} & {$[0.068]$} \\
\hline City dummy variables & Yes & Yes & Yes \\
\hline \multirow[t]{2}{*}{ Constant } & $6.224 * * *$ & $0.459 * * *$ & $5.787 * * *$ \\
\hline & {$[0.031]$} & {$[0.039]$} & {$[0.078]$} \\
\hline Observations & 23,522 & 23,449 & 12,864 \\
\hline R-squared & 0.394 & 0.341 & 0.167 \\
\hline
\end{tabular}

Source: Author's own estimations. 
The resulting average annual increase over five years (2008-2012), using the current monthly earnings data as the dependent variable, is 9.7 per cent per annum, but the for 20011-2012 is much lower, at 4.6 per cent. Using the first month of first pay data, the annual average increase over the 13 year period is five per cent per annum. If we only examine the period of 2008-2012, the annual change is 7.5 per cent. Figure 9.8 presents the year-to-year wage change in the first month of the first job, and the data confirm that the period after 2008 has had a high wage growth, but, between 2011 and 2012, the growth rate has dropped to 1.7 per cent. It is important to note, however, even in 2010 (the last year for urban household survey data), migrant wage-salary workers were only making 52 per cent of the hourly earnings of the urban wage-salary workers.

Figure 9.8 Annual change in real wages for the first month of the first job

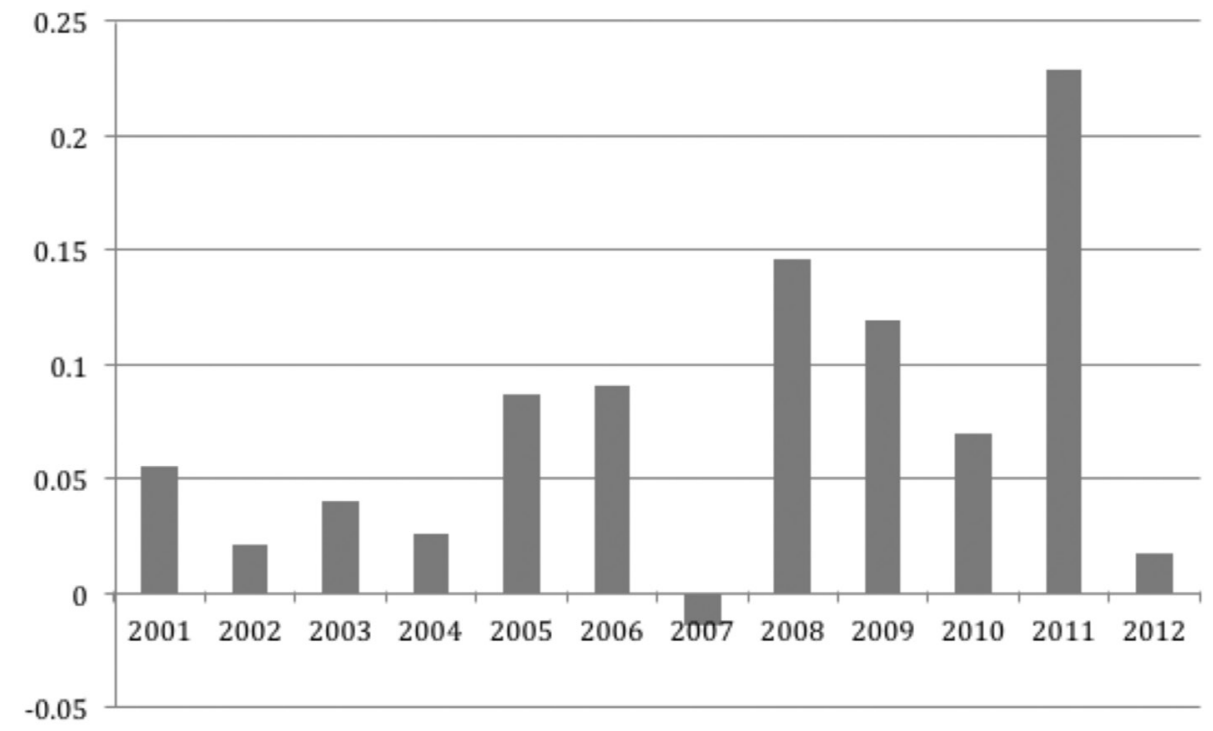

Source: Calculated based on RUMiC 2008 samples of Rural Household, Urban Household, and City Migrant surveys.

The substantial reduction in real wage growth may be an indication of the slowdown of the Chinese economy.

\section{Social Welfare Access}

Inability to access social welfare is one of the most important remaining deterrences for migrants to stay in cities. Due to the lack of social insurance for health, pension, work injury, and unemployment, migrants cannot sever their connections with rural villages. Whenever they are sick, injured at work, 
unemployed, or become old, it is necessary for them to return to their rural hometown. This, to a large extent, reduces the duration of migration, which, in turn, puts significant strain on the migrant labour supply. Thus, improving migrant social welfare access not only benefit migrants themselves, it is an important measures to lift the pressure on the migrant labour supply.

During the past five years, some improvements have been made on this front (Figure 9.9). For example, the proportion of migrant workers with unemployment insurance increased from 11 per cent in 2008 to 21 per cent in 2012. Similarly, those with health, pension, and work injury insurance increased from 13, 18 and 17 per cent in 2008 to 27, 31 and 23 per cent in 2012, respectively. The large majority of migrant workers, however, still work in cities without any financial or health protection. In addition, in recent years, the proportion of migrant workers with some type of contract seems to have reduced sharply. There was significant improvement in this regard during the period 2008 to 2010, but, since then, the proportion has dropped from 66 per cent in 2010 to 59 per cent in 2012. This trend can be observed in both total sample and new sample.

Figure 9.9 Migrant social welfare access: 2008-2012

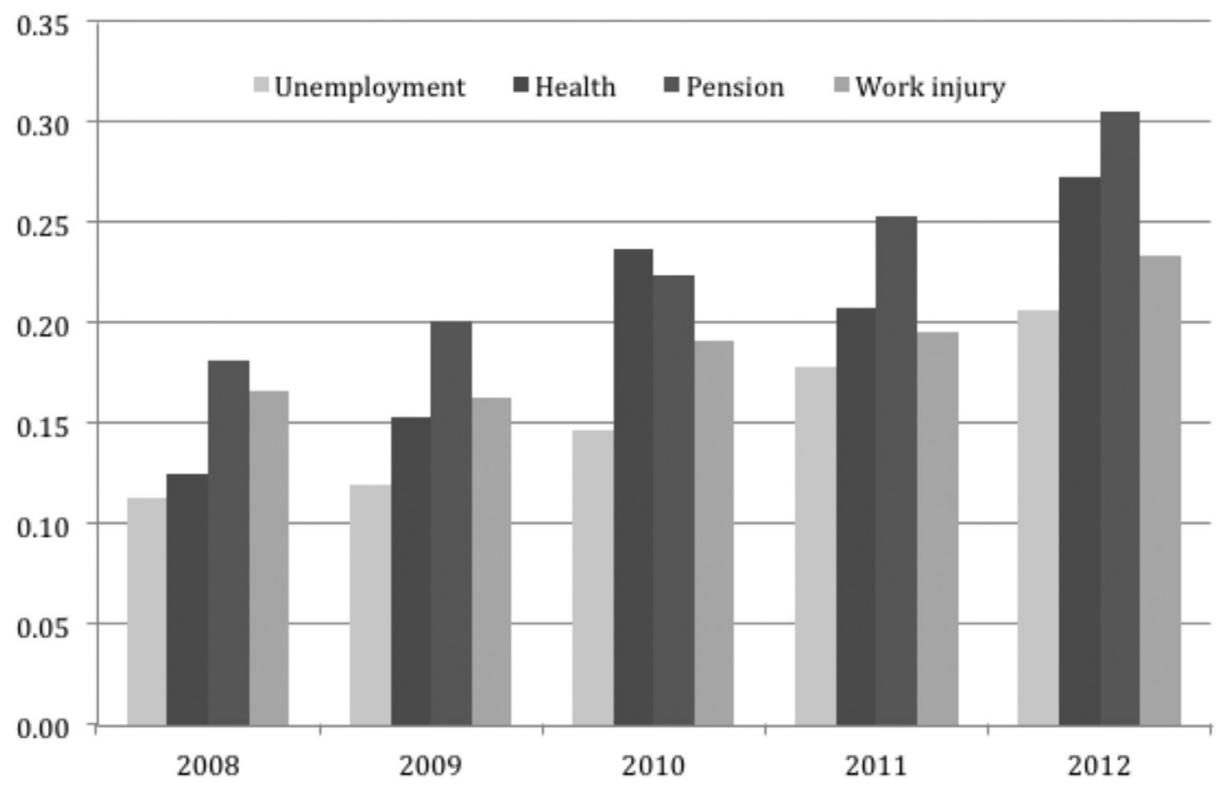

Source: Calculated based on RUMiC 2008 samples of Rural Household, Urban Household, and City Migrant surveys. 


\section{Duration of Migration and its Impact on Migrant Labour Supply}

Part of the reason for the recent significant increase in migrant wages is the tightening of the migrant labour market. This, to a large extent, is related to the issue of duration of migration. The lack of access to social welfare significantly reduces migration duration. If migrants stayed in cities for a longer period, migrant labour supply would increase by the same amount.

In a normal case scenario, a healthy worker starts working in their late teens or early 20s, and retires in their late 50s to early 60s. Thus, a normal working life is around 35 to 40 years. Due to restrictions on migration, however, migrants on average currently only work in cities for eight-nine years.

Column 3 of Table 9.1 shows the average number of years since our sample migrants first came to the cities (see column 3 of Table 9.1). This measure may overstate the duration of migration, as it does not take into account whether migrants have returned to their rural hometown for a substantial period since they first migrated to cities, which happens very often. It does, however, give a rough indication of the trend. The more reliable measure is from the new sample, as the total sample includes people who have been tracked over time, and their 'year since first migration' is supposed to increase over time. The new sample data indicate that the average years since first migration has increased from 7.8 years in 2008 to almost nine years in 2012. Imagine, if cities are becoming more welcoming to migrant families and the average duration of migration increases from nine years to 18 years, this will be equivalent to double the current supply of migrant workers. If this happens, any foreseeable tightening of the migrant labour market should disappear.

\section{Human Capital Accumulation}

In addition to the gain in increase in labour supply, the increasing duration of migration is extremely beneficial for human capital accumulation and, hence, for productivity gains. Using the regression results reported in column 1 on Table 9.3, a city work experience - earnings profile is plotted (Figure 9.10). The figure shows that for each additional year migrants work in cities, their earnings increase by two per cent, controlling for other characteristics. This indicates that through learning-by-doing and on-the-job training, migrants are accumulating significant productivity improvements. Such gains peaks in the 24 th year since migrants first migrated to cities. Only after that year does the productivity gain begin to wear out. In every wave of our survey, however, less than three per cent of the migrants have stayed in cities for 24 or more years. That the current 
average duration of migration is approximately nine years, which is far from the maximum return the economy can receive from its labour force, suggests a significant waste of human capital.

Figure 9.10 Rate of return to city work experience

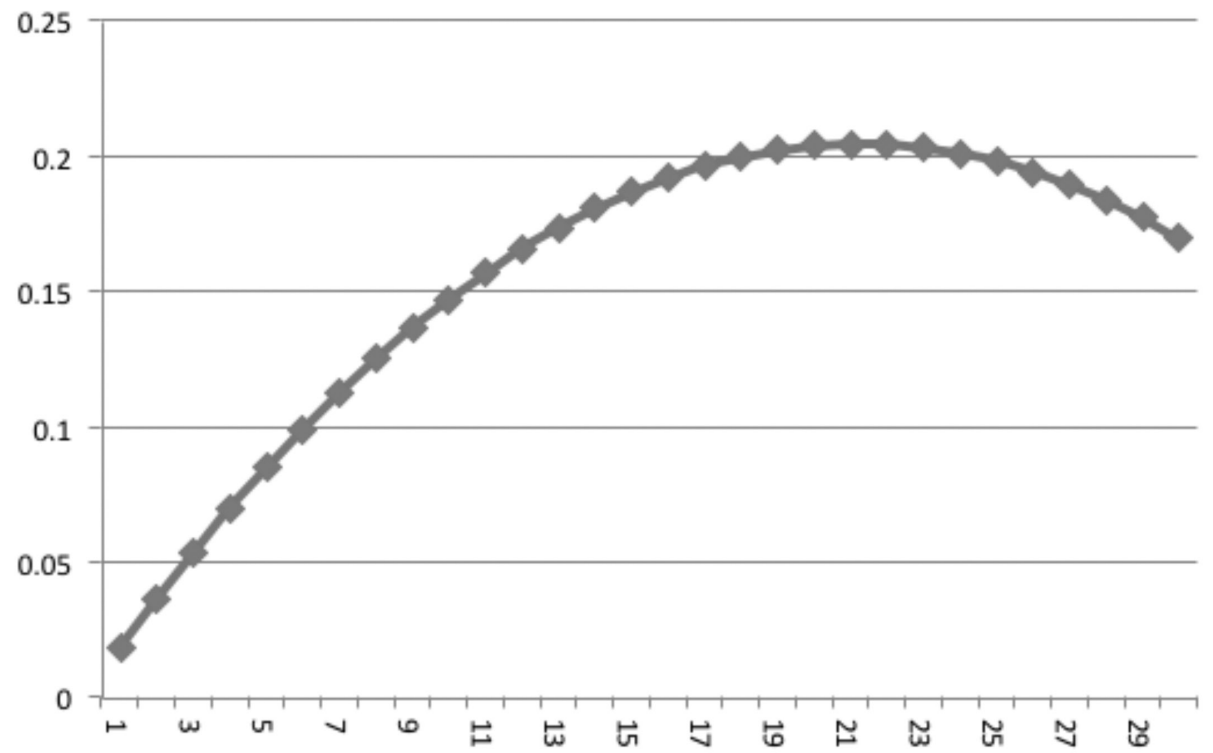

Source: Calculated based on RUMiC 2008 samples of Rural Household, Urban Household, and City Migrant surveys.

The other side of the human capital accumulation is related to formal schooling. Migrants on average have 8.8 years of schooling, which is two years more than the rural hukou non-migrated workforce, which has only 6.9 years. Migrants, however, are less educated than their urban hukou counterparts who, on average, have 10.3 years of schooling (see column 4 in Panel C of Table 9.1).

Over the past five years, the average education level of migrants has not changed significantly. Column 4 in Panel B of Table 9.1 indicates that the average education level of migrants only increased very slightly from nine years to 9.02 years.

Table 9.3 also shows that rate of return to education for migrant workers is low. The highest estimate is obtained when estimating an hourly earnings equation in which a four per cent return is observed for each additional year of schooling. This rate of return has not changed substantially over the past five years. Using urban household survey data, it is found that the rate of return to years of schooling is 7.2 per cent, more than 80 per cent higher than returns to years of schooling for migrants. The significant difference in rate of return 
to education may be the result of a lower quality of education obtained from the rural areas. It could also be related to the fact that migrants are denied better paid jobs, in other words, a result of labour market discrimination.

The low rate of return to education, in turn, may deter rural children from obtaining a higher level of education.

The issue of the large disparity between the quantity and quality of education between rural and urban areas is a considerable concern for China's future labour supply. As noted earlier, in the next few decades, the main labour supply in Chinese cities will come from the rural hukou population. If rural education does not improve, the quality of Chinese future labour supply will drag down economic growth.

\section{Conclusions}

Using RUMiC survey data 2008-2012 and the 2005 one per cent Population Survey data, this chapter presents important features of the rural-urban migration during this period. These features have long-lasting policy implications for China's future labour market development.

In the next few decades, the main addition to the labour force of Chinese cities will come from the rural hukou population. Less than 30 per cent of the rural labour force has migrated to cities to work. Hence, there is still large proportion of them who could potentially migrate. Whether they will do so, however, depends largely on government migration policy. Currently, the lack of social welfare for rural migrants has deterred many people from migrating to cities, or remaining there for long periods. On average, migrants stay in cities for eight-nine years. If this duration can be doubled, migrant labour supply in cities could be doubled. In addition, we find, based on the current rate of return to migrant city work experience, that migrant productivity improvement reaches a peak at the 24th year. The current average duration of migration, however, is far from the productivity peak, indicating a significant productivity loss due to the short duration of migration. Once again, duration of migration to a large extent depends on migration policy.

As a result of the restrictions on migration, the shortage of migrants in cities is apparent when the economy is doing well. For example, between 2010 and 2011, there was a 23 per cent increase in the monthly earnings for migrant wage-salary workers. During the same period, however, minimum wages also increased by 20 per cent. It is possible that the sharp increase in wages in this period is partially due to government policy, and wage increases seem to have 
come to an end in 2012. Between 2011 and 2012, raw monthly earnings growth was only 3.7 per cent, down from 23 per cent in the previous year, suggesting perhaps an economic downturn.

Some long-term and unintended consequences of migration, due mainly to institutional restrictions, are also observable. Because of these restrictions, migrants do not have long-term expectations and they regard themselves as temporary workers in cities. The objective is to earn as much money as they can over a short period and then build a life for themselves when they return to their rural hometown. Thus, while in cities, they work extremely long hours, which also indicates the lack of work protection for migrant workers. The long work hours are identified as related to migrant mental health problems.

\section{References}

Frijters, P., Johnston, D. \& Meng, X., 2009, 'The Mental Health Cost of Long Working Hours: The Case of Rural Chinese Migrants; , unpublished manuscript, Australian National University.

Gong, Xiadong, Kong, Sherry Tao, Li, Shi \& Meng, Xin, 2008, 'Rural-Urban Migrants: A Driving Force for Growth', in Ligang Song and Wing Thye Woo (eds), China's Dilemma, ANU E Press and Asia Pacific Press, Canberra.

National Bureau of Statistics (NBS), 2012, China Yearbook of Household Survey, China Statistics Press. 



\section{Reforming China's Public Finances for Long-term Growth}

Christine Wong

\section{Introduction}

In a modern state, the government performs three main functions: resource allocation-including the provision of public goods such as national defence, internal order and a legal system; the redistribution of income-including the provision of social protection and safety nets; and macroeconomic stabilisation. To finance these functions, the government raises revenues, and its ability to do so fluctuates with the size of the economy and its rate of growth. Since the global financial crisis in 2008, the general public has gained a greater appreciation of how important public finances are to a nations' well-being, affecting both its economic growth prospects and the welfare of citizens.

In the course of its transition from a planned to a market economy, China has had to rebuild the existing system of public finances, since the previous one was embedded in the central planning institutions and wholly unsuitable for a mixed economy. When administrative prices and monopoly state ownership of industry - two pillars of central planning - were gradually dismantled in the 1980s, government revenues went into a freefall, bottoming out in 1996 at just 11 per cent of GDP - one-third of their former size. This fiscal decline was reversed only after the Tax Sharing System reform of 1994 brought in a new tax system and created a national tax administration (Wong and Bird 2008).

In addition to the creation of a new revenue mechanism, rebuilding public finances required the reform of budget institutions. In China's centrally planned economies, the budget was mostly a bookkeeping function subordinated to the physical planning of inputs and outputs, and the Ministry of Finance (MOF) had a low status among central government agencies. With the end of economic planning, the budget became increasingly the government's primary tool for allocating resources, and major reforms were needed to build a system of budget management to support this new role. This process has proved trickier-and far from complete, because it required the elevation of the role of the MOF in managing public resources.

In this chapter I examine the current state of China's public finances and discuss the reforms necessary to improve their capacity for supporting the long-term growth of the economy. The focus of this chapter will be on the 
macroeconomic stabilisation role of the budget. Along the way I will note the prominent role played by local governments in making macroeconomic control more difficult, but reform of the intergovernmental fiscal system has been discussed elsewhere and will not be the main focus in this chapter. ${ }^{1}$

In the next section I will briefly review the reforms that have been implemented to date. In the following two sections I will focus on two critical areas where reforms have conspicuously failed - the persistence of extra-budgetary resources and fragmented control of the budget, and the government's inability to curb the tendency toward excessive public investment. Both are important parts of public financial management, and they have remained stubbornly resistant to the reach of reform. In the final section, I discuss the macroeconomic challenges faced by the new Xi Jinping - Li Keqiang administration, and propose some urgent fixes that will be required for the public finance system.

\section{Incremental Reform of the Fiscal System}

Since embarking on its transition in 1978, China has come a long way toward building a new fiscal system to support the growth and operation of an increasingly decentralised, complex market economy. The list of reforms is impressive, and covers virtually all aspects of the fiscal system.

\section{Tax System Reform²}

Since restoring fiscal health was of the utmost urgency, tax reform came first. As noted earlier, a new system of taxes has been put in place since 1994, centred around the value-added tax, a business tax, a corporate income tax, a personal income tax, and several taxes on property, land transactions, and land use. These are broad-based taxes with uniform rates of levy that have facilitated tax administration and the monitoring of tax capacity across regions. The system still has significant room for improvement. Currently, revenues are overly dependent on productive activities rather than income, which distorts resource allocation as localities compete to attract industry and businesses; and the heavy dependence on turnover taxes and small share of income taxes means the tax structure lacks progressivity, to name just two examples. Overall, though, the tax system is highly income-elastic, and has produced buoyant revenues that have grown at roughly 1.5 times the rate of GDP growth over the past decade.

1 See, for example, Wong 2009, 2010 and 2013.

2 A more detailed discussion can be found in Wong and Bird (2008), and World Bank (2002). 


\section{Public Financial Management Reform ${ }^{3}$}

With revenues recovering, the government began in the late 1990s to turn to financial management reform. Since then, a broad package has been introduced that includes reforms in budget preparation, budget classification, treasury management, government procurement, and the installation of new fiscal information systems. Until then, the budgeting process had changed little from the planned economy. A World Bank team found in 1997 that the budgeting process was passive and incremental, provided inadequate time for preparation, had little focus on strategic priorities, and was unable to shift expenditures to emerging needs or to adequately track how public funds were spent, or even how many people the government employed (World Bank 2000). As the budget gained importance as the key instrument for resource allocation and macroeconomic management, reforms were urgently needed to improve the effectiveness of the budget as a policy instrument for managing public expenditures.

Since 1999, the MOF has introduced new procedures for budget preparation and approval, and strengthened budget reporting to the National People's Congress (NPC). To adjust to the new budget procedures, the MOF underwent a radical restructuring in 1999 so as to streamline budgeting work (Wong 2005). The centrepiece of reform in budget preparation was the introduction of departmental budgets that clearly identify all resources and expenditures for each government department, the first step toward building a system whereby spending units could be held accountable for the public monies that they receive.

A treasury single account was created to manage the government's cash receipts and payments. Before this reform, expenditure monitoring was one of the weakest links in the budget process, and the MOF had no information on when and how money was spent. Although much effort was spent on ex ante allocation, actual expenditures could not be monitored, and diversion and other abuses could be exposed only by audits, which took place only occasionally. With the general ledger of budget appropriations linked to the treasury single account, the government could, at least in principle, track the government's fiscal position in real time.

To support treasury reform and improved budgeting, the MOF began work on a new government financial management information system. A new budget classification system was rolled out in 2006 to improve the tracking of expenditure by functional categories. Standardised procedures for government

3 For more details of public financial reform, see Wong $(2005,2012)$ and World Bank $(2000)$. 
procurement were introduced to improve cost efficiencies and reduce the scope for corruption, adopting many of the procedures of international organisations for tendering large-scale purchases of equipment and services.

With these reforms, China has over the past decade put in place the basic infrastructure for a modern system of budget management. Great strides have also been made in budget transparency and reporting to the NPC. The annual reports to the NPC are providing far more detail than in the past; starting from just a few pages in the 1990s, the report for 2012 and draft budget for 2013 included 23 supplementary tables and 12 figures, which provide many details on revenues and expenditures as well as central transfers. At the last count, 91 central government departments had put their budgets on the web for public scrutiny by 2012, including the MOF's, whose departmental budget was 32 pages in length. This year it has grown to 38 pages. ${ }^{4}$

\section{Intergovernmental and Tax Sharing Reform}

China's fiscal system is among the most decentralised in the world in terms of budgetary expenditures. The central government itself spends less than a quarter of the national budget, and this share has fallen from more than 50 per cent at the outset of transition to 17 per cent in 2011. This decentralisation was driven mainly by the changing composition of budget expenditures. With the government withdrawing from directly funding economic activities during the course of market transition, expenditures became more weighted toward public services. This has shifted expenditures toward local governments since nearly all public services, including some of the costliest, including basic education, health care, social security, and infrastructure, are assigned to local governments, often at the grassroots level. Counties and districts, for example, the fourth tier of government, account for a majority of the total national expenditures on education and health (Wong 1991, 2009; World Bank 2002).

Given the important role of local governments, getting the intergovernmental fiscal system 'right' should have been a priority focus of fiscal reform, but this area received little attention through the 1990s. Indeed, since the 1994 reform was aimed principally at stemming fiscal decline and especially the erosion of central government control over resources, it imposed a reform that recentralised revenues and gave the central government control over roughly half the budget. With expenditure assignments unchanged, local governments were left with a huge fiscal gap. With the central government unwilling or unable to provide financial assistance, they faced severe fiscal difficulties that resulted in pervasive

4 These can be downloaded at http://www.mof.gov.cn/zhengwuxinxi/caizhengshuju/201304/ t20130416_825081.html 
shortfalls and large regional disparities in public services (Wong 2007). By the late 1990s, many local governments were in arrears in pension payments, and wage arrears for teachers and civil servants were common. The rural sector bore the brunt of these deprivations, since they are at the lowest levels of the administrative structure and last in line to fight for resources (Fock and Wong 2008).

From the turn of the century, and especially over the past few years, the central government has made strenuous efforts to gradually address these funding problems. Under the government's 'three rurals' policy ${ }^{5}$ - a signature program of the $\mathrm{Hu}$ Jintao and Wen Jiabao administration, fiscal resources have poured into rural services. Many new programs were introduced with central government subsidies, including the rural fee reform that abolished all fees and agricultural taxes, the 'new education funding guarantee mechanism' that ensured school fees would be eliminated and funding standards improved in rural compulsory education, the new rural cooperative medical schemes that now provide health insurance coverage to virtually all farmers, and income support for farmers under the rural dibao program. (Wong 2010). With these programs 'tilting' the balance, the share of the county and township governments has risen from 28 per cent to 40 per cent of total national budgetary expenditures since 1998.

A salient feature of the policies of the $\mathrm{Hu}-\mathrm{Wen}$ administration is that they were implemented largely within the existing framework of intergovernmental assignment of revenues and expenditures, and relied heavily on the use of transfers. While the beneficial effects of increased funding for public and especially rural services are clearly visible, so are many of the distortions and inefficiencies common to the use of transfers. Moreover, the heavy use of transfers imposes an administrative burden on the central bureaucracy that seems mismatched to its small size, and the government's capacity to monitor and evaluate the use of central transfers is conspicuously lacking (Wong 2010, 2012).

In the longer term, it is likely that reforms will be considered to the expenditure assignments to improve efficiency and equity. Over the past decade, three reforms were implemented to adjust the intergovernmental fiscal system, all of them at the sub-provincial levels: the province-managing-counties reform, the county-as-key link reform, and the counties-managing-township-finances. Implementation of the county-as-key link reform began around 2002 and moved the responsibilities for providing education, health care and other key services upward from the township to the county level. Contemporaneously, the counties-managing-township-finances moved the accounting and disbursement

5 The 'three rurals' are 'agriculture, rural villages and farmers'. For earlier papers on the three-rurals policies, see Fock and Wong (2008), Lin and Wong (2012). 
functions of township finances upward to counties. They were followed by the province-managing-counties reform, which removed the municipality as an intermediate level of management to allow a direct pass-through of fiscal resources and authorities from the province to the counties. Officially, these reforms are said to be aimed at enhancing the counties' fiscal capacity and improving financial management at the grassroots levels of government (Xie 2011). In practical terms they were equally important for facilitating the flow of central transfers by reducing the number of administrative layers from five to three.

\section{Extra-Budgetary Revenues and the Fragmentation of Budget Control}

In the budget report presented to the NPC in March in 2013, then finance minister Xie Xuren reported on three 'budgets' that include four types of fiscal revenues: the 'public finance budget' comprising tax revenues and nontax revenues, the 'government funds budget', and the newly created 'revenues from state capital operations' comprising remitted profits from large stateowned enterprises (SOE). He also announced that, starting from the 2013 budget, MOF will also report on the 'social insurance funds budget'. In the draft budget presented for 2013, he reported, for the first time, the sum of social insurance contributions and fiscal subsidies as 'social insurance fund revenues' (MOF 2013).

Table 10.1 Composition of fiscal revenues in the comprehensive budget, 2012

\begin{tabular}{l|c|c}
\hline & Billions $\mathbf{q}$ & Shares \\
\hline Public finance budget & 11,721 & $64.2 \%$ \\
\hline Tax revenues & 10,060 & $55.1 \%$ \\
\hline Non-tax revenues & 1,661 & $9.1 \%$ \\
\hline Government funds & 4,136 & $22.6 \%$ \\
\hline Land revenues & 2,889 & $15.8 \%$ \\
\hline Other government funds & 1,248 & $6.8 \%$ \\
\hline Revenues from state capital operations & 157.3 & $0.9 \%$ \\
\hline Social insurance funds (contributions only) & 2,255 & $12.30 \%$ \\
\hline Total & 18,270 & \\
\hline
\end{tabular}

Source: 2013 Budget Report to the NPC, 5 March.

Table 10.1 presents the revenues for each of these fiscal resources, including contributions to the social insurance fund (SIF), in what I term the 'comprehensive budget' for 2012. Because of the size of land revenues, I 
have listed them separately from government funds. It can be seen that tax revenues of $¥ 10.1$ trillion were equal to 55 per cent, or just over half of the total $¥ 18.3$ trillion in the comprehensive budget. The other components include:

\section{From Extra-Budgetary to Non-Tax Revenues}

The rise of extra-budgetary funds (EBF) can be dated to the retreat of the budget in the 1980s and 1990s, when support for public services fell across the board. Public service providers, including primary and middle schools, received, on average, only one-half of their operating revenues from the budget, and had to find the rest through fees and 'other incomes' ${ }^{6}$ Even local police departments typically received only budgetary support for salaries, and had to buy their uniforms, batons and other equipment from revenues collected through fines and penalties (Bai 2004). To keep services going, local governments and public agencies were encouraged to find supplementary sources of revenue (Wong 2009). With incentives that allowed the collecting agencies to use a part of the receipts for bonuses and topping-up salaries, they obliged by levying fees, user charges, fines and penalties (World Bank 2005, Wong 2009). Fees and other levies proliferated; by the late 1990s revenue from these sources totaled eight to ten per cent of GDP, and they were reportedly financing half or more of local government expenditures (Fan 1998, and Wong 1998, 2001).

Since 1998, the government has taken a number of measures to reverse this trend. The strategy was to clamp down on unauthorised fees and levies, bring administrative fees collected by government departments and agencies into the budget as much as possible, improve monitoring of revenues and expenditures of the major items of the reported EBF, and to gradually convert them to taxes.

The efforts have achieved some measure of success. Many fees have been abolished and replaced by budgetary support-including, most famously, all rural levies under the Rural Fee Reform campaign that was implemented during 2001-2003. Administrative fees continued to grow, but are now incorporated into budget accounting, though not unified budgeting. Reclassifying and removing some of the biggest sources of EBF (see below) also helped the government whittle down what is reported in the formal category of EBF. Finally, in 2010, the MOF renamed them 'non-tax revenues' (NTR), ending the existence of 'extra-budgetary funds' as an official category. In 2012 NTR were $¥ 1.66$ trillion, equal to 3.2 per cent of GDP.

6 For details of how public service providers were funded, see World Bank (2005). 


\section{Government Funds}

The category of 'Government Funds' (GF) was created in 1996 from reclassifying 13 of the largest items from EBF as government funds, including the road maintenance fee, the vehicle purchase fee, the railroad construction fund, electric power fund, the Three Gorges Dam fund, and airport management fees and construction fund, which together accounted for more than one-fourth of the EBF in 1997. The intent was to improve the reporting of fund receipts, as a first step toward converting some of the items into taxes and extending budgetary control over them. While this has happened with some - the road maintenance fee and the vehicle purchase fee, for example, government funds have grown steadily, with the addition of some large and rapidly growing sources of revenue. In 2010, it comprised more than 50 funds, with revenues of $¥ 3.7$ trillion $(9.2$ per cent of GDP), compared to $¥ 7.3$ trillion in tax revenues. ${ }^{7}$ The biggest funds are 'user fees on newly developed (urban) land', 'railroad construction fund', 'water conservancy construction fund', and 'local education surcharge.' These are essentially quasi-taxes; they are authorised by administrative agencies, and do not require approval by the NPC. In other words, they are but a new name for the EBF of old.

\section{Land Transfer Revenues}

Aside from charging user fees and imposing quasi-taxes, monetising state assets was another avenue for supplementing the budget, and land is the principal asset of local governments. ${ }^{8}$ In addition to existing city land, local governments earn revenues from the conversion of farmland into non-agricultural use- a profitable activity over which local governments have a constitutional monopoly, and where the law fixes the procurement price of farmland at a low level so that the bulk of the rising values of urban land accrues to local governments. ${ }^{9}$

Local governments began to tap this rich source of revenue in the early 1990s (Wong 1997, Guan and Peng 2011). With accelerated urbanisation boosting land values, it has grown to be a key source of revenue for municipal governments: in 2011 revenues reached $¥ 3.11$ trillion nationwide, but fell back to $¥ 2.89$ trillion in 2012. In 2007 the government designated land revenues as GF, and required them to be remitted to the treasury and budget management.

7 MOF final accounts for the 2010 budget, July 2011, accessed 18 February 2012, http://yss.mof.gov. cn/2010juesuan/201107/t20110720_578448.html

8 The 1982 constitution specifies that urban land is owned by the state while rural land is owned by the collectives.

9 See Cao et al. (2008) and Tao et al. (2010). 


\section{Revenues from State Capital Operations}

This category is at present a misnomer as it comprises only the remitted profits of the 117 giant state-owned companies (enterprise groups) controlled by the central government and reporting to the State-owned Assets Supervision and Administration Commission (SASAC), an agency created in 2003 under the State Council. At present the remittances are a fraction of the total profits of these companies, in 2012 they were just $¥ 97.1$ billion, compared to combined revenues of $¥ 26.06$ trillion, equivalent to half of China’s gross domestic product. ${ }^{10}$ It is likely that this budget component will grow in the future, as the new Finance Minister has vowed to extract a greater share of SOE profits for government coffers.

\section{Social Insurance Funds}

The SIF was created in 1996, with the introduction of insurance schemes for urban employees that provide coverage for pensions, work injury, unemployment, maternity and health. ${ }^{11}$ City-level pooling of pension obligations had begun in the 1980s - shifting from the system where enterprises had borne the pension costs of their retirees. The change was formalised in 1991, when the State Council introduced universal pooling of pension burdens and placed them at the city level-be they provincial, prefectural or county-level cities. ${ }^{12}$ Through the 1990s, the system was adjusted in several steps, creating the framework that exists today.

Under the new system, each city is responsible for collecting the employer and employee contributions to each scheme and managing the fiduciary responsibilities for the SIF. Although the framework is based on regulations issued by the central government, many details of the schemes are left to the discretion of the provincial and municipal governments (Hussain 2007). To minimise fiscal risks, cities were permitted to set contribution rates and benefit levels to balance receipts and payouts, though, in recent years, there have been some efforts to harmonise contribution and benefit levels across pension pools.

Even though cities are the budget unit for social security, the SIFs are managed by the Ministry of Human Resources and Social Security (MOHRSS) and its subnational counterparts outside the budget. ${ }^{13}$ With urbanisation,

10 http://blogs.ft.com/beyond-brics/2013/03/27/chinas-new-captain-of-industry/?utm_ source $=$ Sinocism + Newsletter\&utm_campaign $=$ ela48e008c-Sinocism03_28_13\&utm_medium $=$ email

11 For the creation of the SIF and its component schemes see, for example, Hussain (2007), Wang (2005), and Watson (2009).

12 State Council decision on the reform of the pension insurance system for urban enterprise employees, June 1991.

13 The 'social security and employment assistance' expenditure item in the budget comprises expenditures on social welfare, disaster relief and fiscal subsidies to the SIF to cover shortfalls, while the main expenditures on social security are made under the SIF. 
an ageing population, and with recent policies that have significantly expanded social insurance provisions, the SIF has grown rapidly. Coverage has grown from the initial pension scheme for SOE workers and an unemployment insurance program to include a pension program for residents who have never held a formal sector job, as well as a basic medical, work injury and maternity insurance programs. Contributions to the SIF have grown to 5.4 per cent in 2011.

\section{Fragmentation of Control}

Although these various types of fiscal (extra-budgetary in the broad sense) revenues have been in existence since the 1990s, or even earlier, they will be presented to the NPC together, in a single report, for the first time in 2014. Indeed, a salient feature of these extra-budgetary revenues is that information is scattered in different channels. Under China's decentralised statistical system, for example, information on the SIF are reported by the MOHRSS, separately from fiscal data. Until recently there was little public information about the aggregate size of land transfer revenues because they accrue almost entirely to local governments, and the central government has struggled to gain access. ${ }^{14}$ Moreover, until 2001, land transfers were mostly made by administrative allocation and negotiation, and the real value of the transactions was largely hidden. The Ministry of Land Resources has published national and provincial data back to 2001. The data were incomplete, however - an audit conducted by the National Audit Office (NAO) of 11 municipalities including Beijing, Tianjin, Chongqing and Guangzhou found that during 2004-2006, land transfer revenues were under-reported by 71 per cent. ${ }^{15}$ With their designation as a government fund in 2007, reporting seems to have improved. The same NAO audit found that for 2007-2008, the 11 municipalities under-reported land transfer revenues by a much reduced 20 per cent.

The fragmented reporting is symptomatic of the fragmentation of control. Among the components, only tax revenues are fully under unified budget management by the MOF and its subnational counterparts. Even for NTR and GF, which are reported to the budget and partially remitted to the treasury, their 'ownership' and hence allocation rights remain with the collecting agency. Land revenues belong to local-mostly municipal-governments, and are allocated outside of the budget. As noted earlier, SIF are managed separately in the local SIF pools, also outside the budget. In other words, the pool of revenues allocated through the budgeting process, guided by the government's strategic

14 The difficulty of gaining information was made more so because, until recent years, the central government was continually asserting its right to share the revenue.

15 See Fu (2010). 
priorities, includes only tax revenues and to some extent the nontax revenues. Virtually everything else is earmarked for specific purposes and allocated by different agencies and local governments. Most importantly, the MOF (and its subnational counterparts) lacks the authority to impose aggregate discipline over the comprehensive budget.

Figure 10.1 shows the trend for the comprehensive budget based on all known fiscal resources excluding borrowing. (One caveat to keep in mind is that these data are somewhat soft - they are collected by different agencies using definitions that are not always consistent, and are often subject to revision and adjustment.) Nationwide, the comprehensive budget has grown rapidly, from 30.1 per cent of GDP in 2006 to a peak of 36.2 per cent in 2010 before retreating to 35.1 per cent. This upward drift can be attributed to decentralised forces in the economy - each component grew (or shrank) according to its internal objectives and the economic environment it faced. Most of the growth came from land, a notoriously volatile revenue source. The public finance budget (tax revenues plus NTR) also grew steadily through these six years, from 18.9 per cent to 22.6 per cent, as has the SIF through steadily growing coverage and participation. The rapid growth of the overall envelope-by nearly one per cent of gross domestic product per year, should be alarming to policy makers.

Figure 10.1 China's comprehensive budget: 2006-2012 (\%)

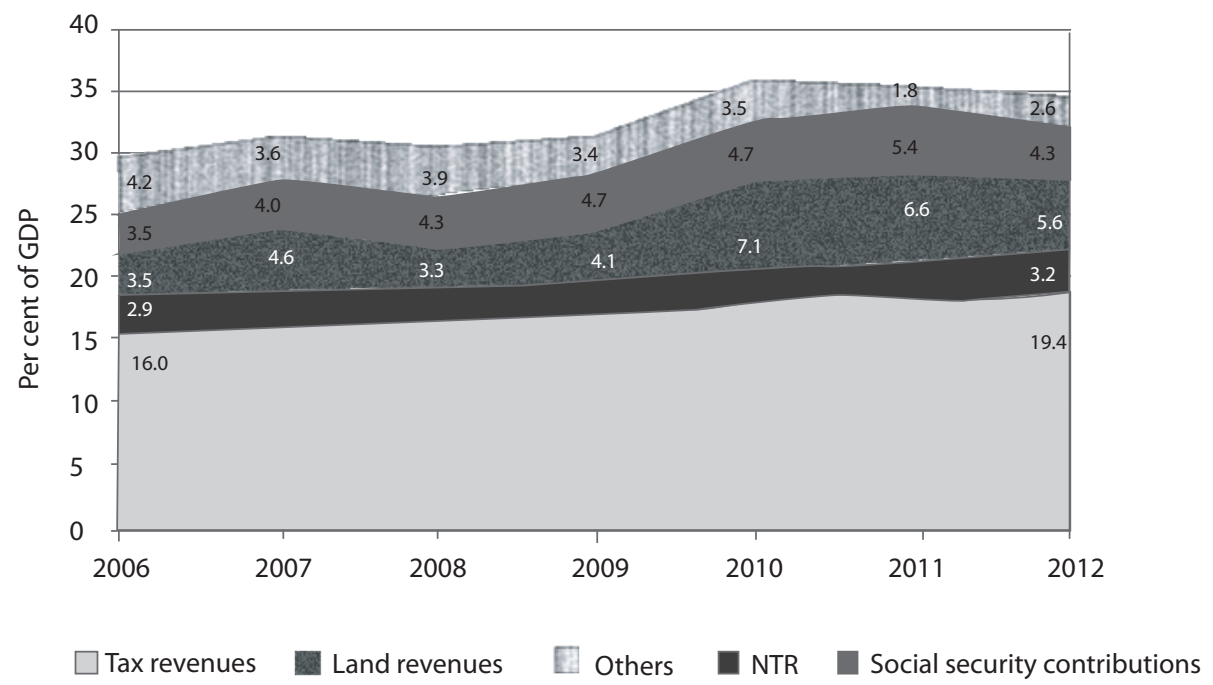

Source: Author calculations based on data from MOF final accounts, Chinese Statistical Yearbook (various years), and China Land and Resources Communique (various years). 'Others' includes government funds other than land, and state capital revenues. 


\section{Public Investment Management}

Among the most important changes in the role of government through the transition are those affecting investment, where reform has seen the government curtail its role and attempt to shift from directing the overall pattern of investment to ensuring adequate support to economic growth and public services. Negotiating the reduction in the scope of government has proved tricky, and progress in reforming the system of public investment management has been uneven.

On the upside, China's record in investing in public infrastructure has been outstanding. From having less than 10,000 kilometres of expressways a decade ago, the country now has more than 65,100 kilometres, second only to the United States in total length. During 2006-2010 alone, the road system was expanded by 639,000 kilometres, including 33,000 kilometres of expressways. China has also expanded the railway system by 16,000 kilometres over the same period. The country has some of the world's biggest and most modern airports, and has invested heavily in container port facilities. Chinese cities are remarkably well-served by urban facilities and services given the rapid rate of urbanisation over the past three decades, where some 500 million people have moved into cities (Wong 2013). In 2010, China was ranked 27th among 155 countries in the World Bank Logistics Performance Index (LPI) - a measure of how efficiently a country gets its goods into the global trading system. With an overall LPI score of 3.49, China is within striking distance of the average of 3.55 for High Income Countries, well ahead of its peer group of middle income countries. On the financing side, though, reforms have been problematic.

Under market reforms, the financing of public investment has changed dramatically (Wong 2011a). By far the most important was the rapid withdrawal of budgetary inputs to investment that was driven by fiscal decline. Except for a small spike under the fiscal stimulus programs in the late 1990s and again in 2008-2010, the share of budgetary inputs has been below 5 per cent of total investment since 1993 (Table 10.2). ${ }^{16}$ 'Self-raised' funds have always been large, and now finance more than three-quarters of total. Their composition is amorphous, however, and ill-defined. 
Table 10.2 Sources of finance for fixed investment: 1982-2010 (\%)

\begin{tabular}{l|r|r|r|r|r|r|r}
\hline & 1982 & 1993 & 1995 & $\mathbf{2 0 0 0}$ & $\mathbf{2 0 0 3}$ & $\mathbf{2 0 0 7}$ & $\mathbf{2 0 1 0}$ \\
\hline Budget & 22.7 & 3.7 & 3.5 & 6.8 & 4.8 & 3.9 & 4.7 \\
\hline Domestic credit & 14.3 & 23.5 & 21.7 & 23.6 & 23.0 & 15.3 & 15.2 \\
\hline Foreign & 4.9 & 7.3 & 13.1 & 5.8 & 4.5 & 3.4 & 1.6 \\
\hline Self-raised and other & 58.1 & 65.5 & 61.7 & 63.8 & 67.6 & 77.4 & 78.5 \\
\hline
\end{tabular}

Note: Self-raised funds are own receipts of enterprises or institutions. 'Other' includes capital from bond issue by enterprises or banks, levies, own capital and donations.

Source: National Bureau of Statistics, New China 55 Years Statistical Compendium, and National Bureau of Statistics, Chinese Statistical Yearbook.

The second important change was that investment became decentralised. Figure 10.2 shows the local governments' share of budgetary investment rising in line with their share of budgetary expenditures. ${ }^{17}$ An additional aspect of the decentralisation of investment responsibilities is that, just as higher level governments were offloading them to local governments, fiscally constrained local governments often devolved the responsibilities to public institutions such as schools and hospitals, and likewise encouraged them to find their own resources.

Figure 10.2 Local governments' share of budgetary expenditures and investment (\%)

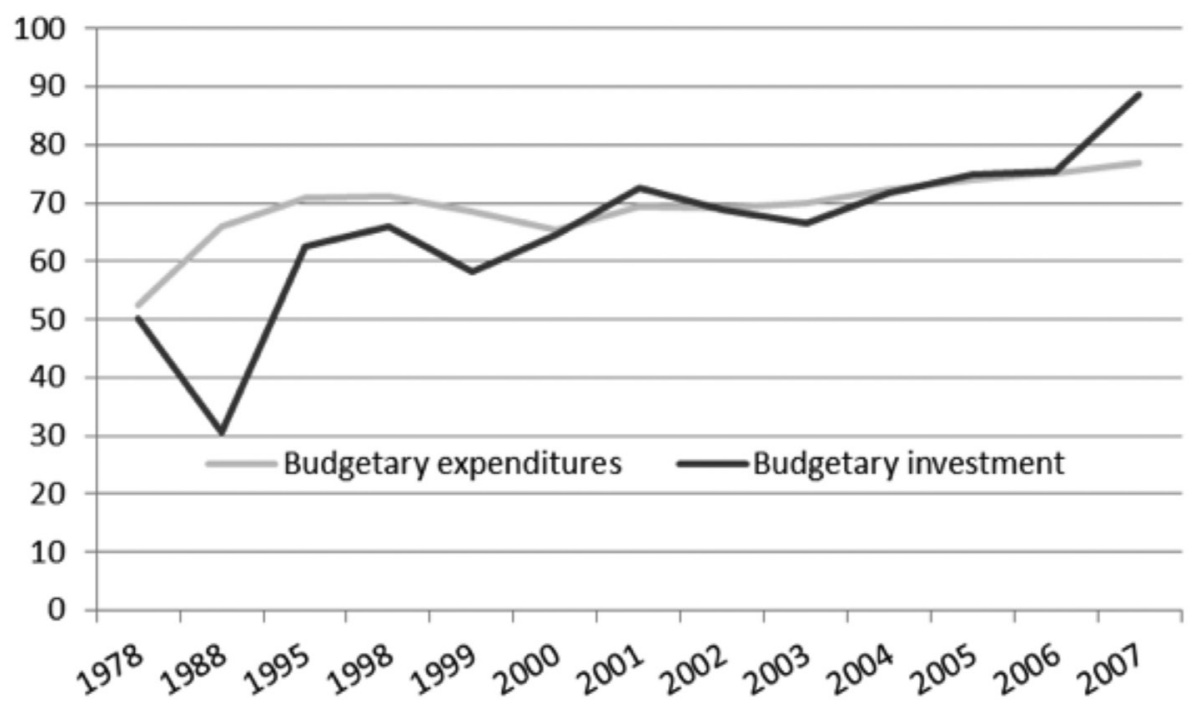

Sources: Chinese Statistical Yearbook 2011, and MOF data.

17 In 2007 the MOF changed budget classification systems, and stopped reporting capital spending separately from recurrent expenditures. 
Along with financing, the authorities for investment decisions were also progressively devolved. Under the planned economy, investment projects went through a formal process of preparation that included feasibility studies, technical reviews and appraisals before approval. Project approval authority was vested with the State Planning Commission (now renamed the National Development and Reform Commission, NDRC) and its subnational counterparts, the DRCs. This was a key part of the macro-coordination function performed by the NDRC, since project approval was a precondition for application for land, raw materials, and funding including bank loans. Through the transition, project approval was progressively decentralised to lower level governments. The decisive reform came in 2004, when the government limited the requirement for administrative approval to only projects financed by public funds and mega projects with investments exceeding a specified threshold or in strategic sectors. ${ }^{18}$ Given the diversified funding of public investments and a lack of clear definition on what constituted 'public funds', this decision was widely interpreted by local governments to mean that only projects funded by the budget were required to go through the approval framework. The vast majority of public investment was considered exempted from 2004 onward, and the gatekeeper function of the NDRC and DRCs has been severely eroded. Anecdotal information collected in fieldwork conducted in several provinces during 2008-2010 indicates that, even in localities where administrative approval procedures were retained, the exercise was largely pro forma, since approval was always granted if funding was assured. ${ }^{19}$

With market reforms unleashing rapid economic growth and accelerating urbanisation, local governments have faced tremendous pressure for investment in public infrastructure. They have managed to achieve and maintain high levels of investment, despite inadequate fiscal resources, partly by making extensive use of extra-budgetary resources. Many of the EBFs, and later, the GFs, were created to help provide funding for investment in infrastructure, such as the airport maintenance and construction fee, the railroad construction fund, and the Three Gorges Dam fund. In addition, local governments came to rely heavily on land revenues, which are mostly earmarked for investment in urban development. My estimates are that land transfer revenues comprised almost one-third of the comprehensive budget revenues of prefectural level cities, on average, in 2010 (Wong 2013).

Equally, or perhaps even more important, were the special financial vehicles. To work around the prohibition on direct borrowing, starting in the 1980s local governments - mostly at the municipal and provincial levels - turned to the

18 State Council document on Reform of Investment Institutions (2004). See Wong (2011a)

19 See Mikesell et al. (2011) for practices in Guangdong. I conducted fieldwork in Shandong, Jiangsu and Zhejiang. 
creation of corporate entities to undertake the task of raising funds to finance public investment. They were initially created as financially independent, single-purpose entities, often for the purpose of taking on loans from international financial institutions. Being financially independent restricted their undertakings to those with the capacity for debt servicing and repayment, and these corporations were prevalent in the construction and operation of toll roads, power companies, water companies and utilities.

Shanghai created the first broad-based investment corporation in 1992 to undertake investment in urban infrastructure, the General Corporation of Shanghai Municipal Property, and gave it the mission to coordinate and provide for the construction of facilities such as water supply, sewerage, roads and utility hook-ups. To finance these tasks, the corporation was assigned earmarked revenues from the municipal budget and authorised to borrow from banks and issue corporate bonds. Its creation made possible a quantum leap in the financing available for investments in infrastructure to support urban renewal and expansion in Shanghai. This model was widely emulated. By the turn of the century, most cities had established local investment corporations (LICs) - sometimes called urban development investment corporations (UDICs), and they came to play a key role in financing urbanisation in China (Wong 2013).

As they became more accepted, the separation of LICs from local public finances was relaxed, and local governments began to guarantee bank loans for LICs. Typically, the LICs raise and bundle together bank loans and other financing, using municipal assets including budgetary and extra-budget revenues as equity and collateral. Increasingly, with urbanisation bringing rising land values, land became the principal asset backing LICs, and many municipalities have pledged future receipts from land revenues as collateral for bank loans. ${ }^{20}$

The extent to which the growth and development of LICs occurred 'below the radar' of central authorities was revealed only in 2010-2011. Because LICs were local experiments that lacked formal endorsement by the central government, they operated in the interstices of China's mixed economic system. They were never assigned a supervisory agency, and were not required to file regular reporting of their activities. During 2008-2010, asked to finance three-quarters of the 4 trillion $¥$ stimulus program, local governments were invited to set up financial platforms from which to borrow. The response was overwhelming: LICs proliferated and grabbed large portions of investment funding and bank credit. Central authorities finally took notice, and found that no agency had systematic

20 The 2011 survey of LICs conducted by the NAO found that future land revenues were pledged as collateral for bank loans in 309 prefectures and 1131 counties, equal to 93 per cent and 56 per cent of the those administrative units, respectively (NAO 2011, p.11). 
information on LICs - not the China Banking Regulatory Commission, the People's Bank, the MOF, the Ministry of Construction, or the NDRC (Wong 2011b)! ${ }^{21}$ Even after a massive nationwide audit in 2011 with 41,000 auditors led by the $\mathrm{NAO}$, the picture remains clouded by the lack of consensus on what an LIC is, how much of their investments are 'public infrastructure', and what portion of their debts should be assigned to local government responsibilities. ${ }^{22}$ Given the prominent role played by local governments and LICs in financing public investment, this is a clear indication that the government has lost aggregate control over public investment.

In borrowing to finance infrastructure, China is following common practice in other parts of the world, and borrowing to finance capital spending is considered good public policy when it matches the economic life of expenditure to its financing. By stretching out the payment period to match the long stream of benefits from infrastructure such as bridges, subways or schools, this financing method adheres to the user-pay principal and promotes greater efficiency and intergenerational fairness. Where China differs is in the unsupervised nature of the borrowing, not only by national authorities, but apparently at the local level as well. In a trenchant critique, researchers in the NDRC Investment Research Institute described the current system of local investment finance as operating under 'the three nos': with no guiding framework, no limit, and no accountability. ${ }^{23}$

In fact, the critique can be applied more generally to public investment over the past decade, where there is no overall framework that defines the scope of public investment. Municipalities often lack an investment plan that includes consideration of total debt levels. LICs often do not compile an assets and liabilities account, and they are so closely linked to local governments that it is difficult to separate out and define their responsibilities. In China's immature financial system, banks are ill-equipped to provide the discipline expected from capital markets, especially when local government finances are so complex and non-transparent. In any case, after more than 20 years of hyper-growth, there was a widespread belief that land values will always rise, and government can make good on guarantees.

21 LICs grabbed nearly one-third of all new loans issued in 2009, and in the first quarter of 2010 they accounted for 40 per cent of all new bank loans (Investors Bulletin, 2010; Wei, 2010).

22 According to Zhang and Batson (2011), estimates diverged significantly across agencies:

\begin{tabular}{|l|r|r|}
\hline Agency & Number of LICs & LIC debt (RMB trn) \\
\hline People's Bank of China & $>10,000$ & $<14.4$ \\
\hline China Banking Regulatory Commission & 9828 & 9.1 \\
\hline National Audit Office & 6576 & 5 \\
\hline
\end{tabular}

23 Wang et al. (2010). 
Today it is not possible to fully identify and account for total public investment in China and its configuration. Clearly, in the absence of an effective system of monitoring and evaluation, the unsupervised borrowing by local governments and public institutions created a soft budget constraint that encouraged excessive borrowing and investment, and wasteful and inefficient use of both land and capital.

\section{Macroeconomic Challenges and Next Steps in Public Financial Reform}

Over the past three decades, China has harnessed a process of gradual, incremental reform to achieve spectacular economic growth and development. Through this transition, the public finance system - albeit with many problems, appears to be doing its main job in providing support for government functions. By focusing on the fragmentation of budget control and the decentralised and extremely problematic management of public investment, I have traced the roots of the government's current macroeconomic problems to weaknesses in the fiscal system.

To support sustainable, long-term growth of the Chinese economy, the government must regain control over macroeconomic management. The technical part of the work would start with curbing local government borrowing and investment, a process already begun in 2010, when administrative controls were placed on bank lending to LICs. ${ }^{24}$ While the immediate, short-term task is to clarify the size of local government debt and devise a plan for its resolution, reforms must aim to change the incentives for decentralised investment and borrowing, to avoid reverting to what Yu Yongding has called the Groundhog Day cycle that has characterised Chinese economic growth over the past two decades. ${ }^{25}$

This process could start with putting in place a framework for managing subnational borrowing. Having seen that the prohibition on local government borrowing served only to push it underground and out of the purview of national authorities, the reform should explicitly endorse local government borrowing

24 This began in June 2010, when the State Council issued a circular on enhancing the management over subnational government financial platforms (Guo Fa [2010] no. 19).

$25 \mathrm{Yu}$ describes a pattern where 'high investment supported by expansionary policy drives growth; inflation follows after lag; policy is tightened; growth drops away, but inflation is still high; more tightening; inflation falls at last, but growth falls away more than desired at the same time; policy is shifted from tight to expansionary; again, led by investment, growth rebounds,' and the whole cycle starts again (2013). 
for the purpose of financing long-term infrastructure. In most countries, local governments are permitted borrow for capital spending, but this process has to be carefully managed to minimise fiscal and financial risks.

To manage the potential fiscal risks, in 2011 the MOF introduced a monitoring and regulatory framework that requires local governments to report on their debt. This merely continued a decade-long effort by the MOF to build a national monitoring system for local debt, and is likely to prove no more effective than past efforts unless it is bolstered by support from additional measures, such as annual audits and legal requirements for local governments to make regular public disclosure of key fiscal data including their direct and contingent liabilities (including LICs), loan servicing, as well as their borrowing plans.

The government also needs to regain control over aggregate fiscal discipline by assigning the oversight authority and responsibility over the comprehensive budget with all of the components to a single institution: most suitably the MOF. The high degree of reliance on extra-budgetary revenues in China is unusual but not unique. For example, the public finance system of Singapore consists of four 'pillars': the budget itself, the Central Provident Fund, the government investment agencies, and various special funds that are not consolidated into the budget. The budget process, however, is indisputably managed by the MOF, and is characterised by close inter-ministerial cooperation and the use of constitutional fiscal rules (Blondal 2006).

For these reforms to 'stick', they require political support from leaders to adjust the distribution of authorities across central institutions so as to elevate the MOF and put it firmly in charge of all fiscal resources. Support should also be given to enhance the capacity of the NPC to play its supervisory role over the budget - and hence the MOF - that is assigned by the constitution. The NPC should also be asked to empower the NAO to expand its auditing over budget implementation - as it has done several times since the mid 1990s (Wong 2012), to include the comprehensive budget as well as public debt management. 


\section{References}

Bai, Nansheng, 2004, 'A Police Story', paper presented at the Conference on Rural Change in China, Peking University, 5-6 July.

Blondal, Jon, 2006, 'Budgeting in Singapore', OECD Journal on Budgeting, vol. 6 , no. 1, pp. $45-86$.

Cao, Guangzhong, Feng, Changchun and Tao, Ran, 2008, 'Local "Land Finance" in China's Urban Expansion: Challenges and Solutions', China \& World Economy, vol. 16, no. 2, pp. 19-30.

Fan, Gang, 1998, 'Market-oriented Economic Reform and the Growth of OffBudget Local Public Finance', in Donald Brean (ed.), Taxation in Modern China, Routledge Press, New York.

Fock, Achim, and Wong, Christine, 2008, 'Financing Rural Development for a Harmonious Society in China: Recent Reforms in Public Finance and Their Prospects', World Bank Policy Research Working Paper No. 4693, August, http://econ.worldbank.org/docsearch

Fu, Weigang, 2010, 'Why is There so much Chaos on the Use of Land Transfer Revenues?', Dongfang Morning Post, 25 April.

Guan, Qingyou and Peng, Mei, 2011, 'Land Finance: the Opiate', unpublished paper.

Hussain, Athar, 2007, 'Social Security in Transition', in Vivienne Shue and Christine Wong (eds), Paying for Progress in China: Public Finance, Human Welfare and Changing Patterns of Inequality, Routledge, London.

Investors Bulletin, 2010, 'A Tight Hoop Should be Put on Local Government Financing Platforms', 6 June, viewed 20 May 2011, http://finance.ifeng.com/ news/special/dfzwwj/20100606/2282325.shtml

Lin, Wanlong and Wong, Christine, 2012, ‘Are Beijing's Equalization Policies Reaching the Poor? An Analysis of Direct Subsidies under the "Three Rurals" (Sannong)', China Journal, no. 67, January.

Mikesell, John L., Ma, Jun, Tat-kei Ho, Alfred, and Niu, Meili, 2011, 'Financing Local Public Infrastructure: Guangdong Province', in Joyce Yanyuan Man and Yu-Hung Hong (eds), China's Local Public Finance in Transition, Lincoln Institute of Land Policy, Cambridge, MA.

Ministry of Finance, 2013, Budget Report to the National People's Congress, 5 March.

National Audit Office, 2011, Local Government Debt Audit Results, no. 35, 27 June. 
National Bureau of Statistics, 2009, New China 55 Years Statistical Compendium, Beijing.

Tao, Ran, Su, Fubing, Liu, Mingxing, and Cao, Guangzhong, 2010, 'Land Leasing and Local Public Finance in China's Regional Development: Evidence from Prefecture-level Cities', Urban Studies, vol. 47, pp. 2217-36.

Wang, Dewen, 2005, 'China's Urban and Rural Old Age Security System: Challenges and Options', Chinese Academy of Social Sciences, Working Paper Series No. 53, viewed 21 March 2012, http://iple.cass.cn/file/dw17.pdf

Wang, Yuanjing, Gao, Zhenhua and He, Yinzi, 2010, 'The Challenge of Local Government Fund-Raising and Rebuilding the Model-Taking Urban Construction as an Example', Jingji lilun yu jingji guanli (economic theory and economic management) (in Chinese), no. 4, pp. 53-60.

Watson, Andrew, 2009, 'Social Security for China's Migrant Workers-Providing for Old Age', Journal of Current Chinese Affairs, vol. 38, no. 4, pp. 85-115.

Wei, Jianing, 2010, 'The Causes and Fixes of Risks from Local Government Financial Platforms', mimeographed (in Chinese).

Wong, Christine, 1991, 'Central-Local Relations in an Era of Fiscal Decline: The Paradox of Fiscal Decentralization in Post-Mao China', The China Quarterly, no. 128, December, pp. 691-715.

- (ed.), 1997, Financing Local Government in the People's Republic of China, Oxford University Press, Hong Kong.

, 1998, 'Fiscal Dualism in China: Gradualist Reform and the Growth of OffBudget Finance', in Donald Brean (ed.), Taxation in Modern China, Routledge Press, New York.

_ , 2001, 'Converting Fees into Taxes: Reform of Extra-Budgetary Funds and Intergovernmental Fiscal Relations in China', in Richard Bird, Robert Ebel and Christine Wallich (eds), Decentralization of the Socialist State: Intergovernmental Finance in Transition Economies, The World Bank; Chinese edition: Central Translation Press, Beijing.

— 2005, 'Public Sector Budgeting Issues in China' in OECD, Governance in China, OECD Publishing, Paris.

, 2007, 'Can the Retreat from Equality Be Reversed? An Assessment of Redistributive Fiscal Policies from Deng Xiaoping to Wen Jiabao', in Vivienne Shue and Christine Wong (eds), Paying for Progress in China: Public Finance, Human Welfare and Changing Patterns of Inequality, Routledge, London. 
- 2009, 'Rebuilding Government for the 21st Century: Can China Incrementally Reform the Public Sector?', China Quarterly, no. 200, December.

- 2010, 'Fiscal Reform: Paying for the Harmonious Society', China Economic Quarterly, vol. 14, no. 2, pp. 22-7.

—, 2011a, 'Can Humpty Dumpty Be Put Together Again? A Review of Public Investment Management in China', in World Bank, Investing to Invest: Strengthening Public Investment Management and Global Lessons, Washington, DC.

- 2011b, 'The Fiscal Stimulus Program and Problems of Macroeconomic Management in China', OECD Journal on Budgeting, vol. 2011/3.

- 2012, 'Toward Building Performance-Oriented Management in China: the Critical Role of M\&E and the Long Road Ahead', World Bank Independent Evaluation Group, ECD Working Paper Series No. 27, September http:// siteresources.worldbank.org/EXTEVACAPDEV/Resources/wp_27_china_ me.pdf

- 2013, 'Paying for Urbanization: Challenges for China's Municipal Finance in the 21st Century', in R. Bahl, J. Linn and D. Wetzel (eds), Metropolitan Government Finances in Developing Countries, Lincoln Institute for Land Policy, Cambridge, MA.

Wong, Christine, and Bird, Richard, 2008, 'China's Fiscal System: A Work in Progress', in Loren Brandt and Thomas Rawski (eds), China's Great Transformation: Origins, Mechanism and Consequences of the Post-Reform Economic Boom, Cambridge University Press, New York.

World Bank, 2000, China: Managing Public Expenditures for Better Results, Report No. 20342-CHA, Washington DC.

- 2002, China: National Development and Sub-national Finance, a Review of Provincial Expenditures, Report No. 22951-CHA, April, Washington DC.

- 2005, China: Deepening Public Service Unit Reform to Improve Service Delivery, Washington, DC.

Xie, Xuren, 2011, China's Public Finance Management, October, Chinese Fiscal Economics Press, Beijing.

Yu, Yongding, 2013, 'China's Groundhog Day Growth Pattern', East Asia Forum, 10 February.

Zhang, Janet, and Batson, Andrew, 2011, DragonWeek: 04 July, GaveKalDragonomics. 



\section{Changing Business Environment in China:}

\section{A Regional Context and Policy Implications}

Xiaolu Wang, Jingwen Yu and Fan Gang ${ }^{1}$

\section{Introduction}

China's business environment is constantly changing in response to developments in markets, external conditions and government policies that have resulted from China's move towards a market-oriented economy. Improving the business environment is a key policy objective, as changes in that environment affect the behaviour and operations of firms, especially those private firms that are subject to policy and institutional constraints. A much improved business environment in terms of the market and legal environment, fair competition, access to finance, supply of human resources, taxation and infrastructure development will, therefore, not only facilitate business activities, but also, in an important way, nurture much needed entrepreneurship in China. It remains an important task for different levels of government, through their policy changes, to improve the business environment. This chapter reports changes and regional differentials in the business environment in China's provinces in recent years, and discusses some of the policy implications. The study is based on four enterprise surveys that were conducted in 2006, 2008, 2010 and 2012 respectively; each survey covers more than 4,000 enterprises located in 29 provinces (including several ethnic autonomy regions and administrative municipalities at the provincial level).

Classification of the total 4,020 sample enterprises in the 2012 survey, according to their ownership is as follows: 418 state-owned enterprises (SOEs) (including shareholding companies with controlling shares that are held by the state), which account for 10.4 per cent of the total samples; 3,082 private enterprises, stock companies and limited liability companies without controlling shares held by the state (76.7 per cent), 257 foreign-funded enterprises and enterprises with funds from Hong Kong, Macao and Taiwan (6.4 per cent); and, 263 collective-owned enterprises, shareholding cooperatives, and other nonstate enterprises (6.5 per cent).

1 This chapter results from the Business Environment Project that is run by the National Economic Research Institute and the Entrepreneur Survey System, and is a continuation of our earlier reports (Wang, Fan, and Liu 2008; Wang, Fan, and Li 2012). Our surveys were supported by many enterprises, government and non-government organisations as well as individuals. We thank all those who, in many different ways, contributed to this study. 
Sample enterprises, classified according to scales, are as follows: 365 large enterprises (9.1 per cent), 1,415 medium enterprises (35.2 per cent), 2,035 small enterprises (50.6 per cent), 190 micro enterprises (4.7 per cent), and 15 unclassified enterprises (0.4 per cent).

Enterprises classified by sectors include: 2,808 manufacturing (69.8 per cent), 350 agriculture, mining, power generation, gas, water supply (8.7 per cent), 516 transport, storage and post, information transmission, computer services and software, wholesale and retail trade, hotels and catering services (12.8 per cent), and 346 other services ( 8.7 per cent).

Compared with statistical data (see, The State Council Office and National Statistical Bureau 2009 and National Statistical Bureau 2012), the sample distribution in terms of ownership type and scale of enterprise is balanced and generally consistent with the nationwide distribution, only micro enterprises are much fewer, the proportion of manufacturing enterprises is higher, and service enterprises are lower, but this is not problematic in reviewing the business environment in different provinces/regions.

The sample enterprises are located in 29 out of a total of 31 provinces in mainland China. Tibet and Qinghai are excluded in this study, due to insufficient samples. Hong Kong, Macao and Taiwan are also excluded.

On the basis of the surveys, we constructed a Business Environment Index for China's Provinces (BEIFCP). The index assesses the business environment that exists in eight areas: government administration, legal environment, tax and non-tax burdens, financial services, supply of human resources, infrastructure conditions, market intermediaries and technical/export services, and ethical business environment. We evaluate the business environment using a score of 1-5, with 5 indicating 'very good', 3 indicating 'average', and 1 indicating 'poor'. Thus, an index above 3 is a positive score, and below 3 is a negative score.

In the first section of this chapter, we report the general situation, changes, and rankings of Chinese provinces in terms of the business environment, measured by BEIFCP. The second section reports on China's business environment divided into eight areas. The third section analyses differentials of BEIFCP for both SOEs and private enterprises, differently scaled enterprises, enterprises in different sectors, and in different regions, including the east, north-east, centre, and west. The detailed structure of the BEIFCP, and the method of calculation, is explained in the Appendix. 


\section{General Situation and Provincial Ranking in BEIFCP}

\section{The Changing Business Environment in China}

Indicated by our surveys, there was a general improvement in China's business environment over the period 2006-2012 period (Figure 11.1). The overall score of BEIFCP, as a provincial average, was 3.05 in 2012, which increased by 0.17 from 2.88 in 2006. The score deteriorated in the 2009-2010 period, however, and improvement in the 2011-2012 period did not fully offset that deterioration. Significantly, the score of 3.05 in 2012 is only slightly above the neutral score of 3 , and this should not be regarded with great optimism.

Figure 11.1 Changes in the overall BEIFCP: 2006-2012

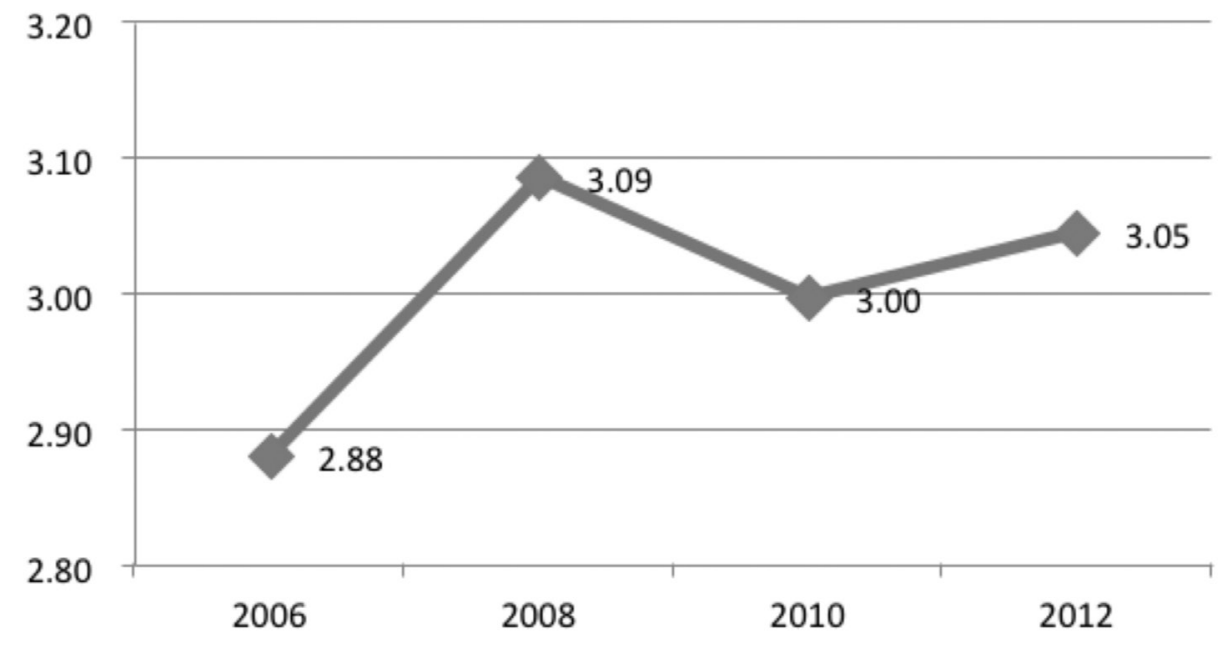

Source: Plotted using the data from the survey.

In the 2011-2012 period, the overall index increased in 19 provinces, and decreased in ten provinces. This indicates a general improvement in the business environment during these two years, although the trend is not persuasive. On the contrary, as is explained below, it decreased in 27 out of the total 29 provinces during the 2009-2010 period.

Loose monetary policy, including government policy on bank credit, and expansionary fiscal policy, which developed in response to the global financial crisis (GFC) are at least partially responsible for deterioration of the business environment during the 2009-2010 period. Total bank credit increased dramatically, by 32 per cent in 2009, and then by 20 per cent in 2010 . Credit is used predominantly for large government investment projects and has the 
effect of crowding out market forces. Medium- and long-term loans increased by 86 per cent in these two years, whereas short-term loans increased only by 33 per cent, of which, those extended to firms increased only by 17.6 per cent (People's Bank of China, http://www.pbc.gov.cn).

This had a contradictory effect on some enterprises, especially those small private enterprises that were affected by increasing input costs. In these two years, nominal GDP increased by 27.9 per cent, and the nominal wage rate increased by 26.4 per cent. This resulted in an adverse situation, particularly for small enterprises, as the banking sector in China is dominated by a few large, state-owned, commercial banks, which favour large enterprises over smaller ones in extending credit and providing bank loans. In this period, the area index for 'financial services' decreased from 2.90 to 2.82 .

The situation improved in 2011 and 2012 when the number of short-term loans increased and medium- and long-term loans decreased. The financial service index indicates that the cost of obtaining loans from formal banks remained the same, but firms were obliged to pay less in extra charges besides the formal interest. In addition, over this two-year period, it was easier to access external finance from informal channels.

The indexes indicate that both government administration and the legal environment for business deteriorated during the 2009-2010 period, as the scores of the two area indexes dropped by 0.04 and 0.14 , respectively. This was also related to the government's expansionary macro policy, which saw expansionary investments and credits strengthen the role of government in resource allocation, and weaken the role of the market in allocating resources.

During the 2011-2012 period, scores of the two area indexes, government administration and the legal environment, increased by 0.05 and 0.11 , respectively, showing some improvement in these areas.

In terms of infrastructure conditions and the supply of human capital, the scores decreased in 2009-2010, and increased in 2011-2012. This is related to large-scale investment in the first period, which caused a heavy increase in the demand for railway transport and power generation, as well as an increasing demand for labour. As an indicator to measure the strength of the economy, in 2010, the nationwide demand for electricity reached its highest peak since 2004, and fell moderately in the second period.

This analysis does not deny the need for, and rationality of, the expansionary macroeconomic policy that was applied during the GFC. When China's export industry was hit by the crisis, the expansionary policy got the economy moving at a relatively high speed. In retrospect, however, some lessons may be drawn in terms of the extent, measure and implementation of the macro policies. It is 
possible that the expansionary fiscal policy adopted in that period over-relied on government investments, and did not manage to sufficiently utilise measures that could mitigate the negative effect of this on the market, such as tax reductions for medium-sized enterprises (SMEs), public expenditure on education and social security, and protection of the environment. The government-led credit expansion was extensively bound to government investment projects. This had the effect of squeezing out normal business demand for credit and, therefore, had a negative affect on the non-state sector.

In addition, when the government became powerful in resource allocation, it compromised its transparency, discipline, and public monitoring, which led to increased abuse of power, corruption, and misallocation of resources, and thus badly damaged the business environment.

\section{Provincial Ranking and Scores of BEIFCP}

Based on the four enterprise surveys, provincial ranking of the overall index in 2006, 2008, 2010 and 2012 is provided in Table 11.1. The province with the best business environment is ranked at the top.

Table 11.1 Provincial ranking by business environment (2006-2012)

\begin{tabular}{|c|c|c|c|c|}
\hline Rank/Year & 2006 & 2008 & 2010 & 2012 \\
\hline 1 & Shanghai & Shanghai & Shanghai & Tianjin \\
\hline 2 & Zhejiang & Jiangsu & Jiangsu & Shanghai \\
\hline 3 & Jiangsu & Zhejiang & Tianjin & Beijing \\
\hline 4 & Tianjin & Beijing & Zhejiang & Zhejiang \\
\hline 5 & Shandong & Tianjin & Beijing & Jiangsu \\
\hline 6 & Guangdong & Fujian & Anhui & Chongqing \\
\hline 7 & Fujian & Anhui & Henan & Heilongjiang \\
\hline 8 & Beijing & Liaoning & Guangdong & Jilin \\
\hline 9 & Liaoning & Shandong & Fujian & Guangxi \\
\hline 10 & Anhui & Guangdong & Shandong & Shandong \\
\hline 11 & Hebei & Hebei & Chongqing & Guangdong \\
\hline 12 & Sichuan & Jilin & Liaoning & Fujian \\
\hline 13 & Jilin & Heilongjiang & Sichuan & Liaoning \\
\hline 14 & Henan & Henan & Hubei & Henan \\
\hline 15 & Heilongjiang & Guangxi & Yunnan & Sichuan \\
\hline 16 & Xinjiang & Sichuan & Jiangxi & Anhui \\
\hline 17 & Inner Mongolia & Chongqing & Shanxi & Inner Mongolia \\
\hline 18 & Yunnan & Hubei & Hebei & Hainan \\
\hline 19 & Hubei & Inner Mongolia & Jilin & Hubei \\
\hline 20 & Chongqing & Ningxia & Heilongjiang & Shaanxi \\
\hline 21 & Shanxi & Shaanxi & Hunan & Guizhou \\
\hline 22 & Hainan & Guizhou & Inner Mongolia & Hunan \\
\hline 23 & Qinghai & Jiangxi & Hainan & Ningxia \\
\hline
\end{tabular}


China: A New Model for Growth and Development

\begin{tabular}{c|c|c|c|c}
\hline Rank/Year & $\mathbf{2 0 0 6}$ & $\mathbf{2 0 0 8}$ & $\mathbf{2 0 1 0}$ & $\mathbf{2 0 1 2}$ \\
\hline 24 & Guangxi & Yunnan & Gansu & Hebei \\
\hline 25 & Jiangxi & Gansu & Guangxi & Jiangxi \\
\hline 26 & Shaanxi & Xinjiang & Ningxia & Shanxi \\
\hline 27 & Guizhou & Hunan & Shaanxi & Yunnan \\
\hline 28 & Hunan & Hainan & Guizhou & Gansu \\
\hline 29 & Ningxia & Oinghai & Xinjiang & Xinjiang \\
\hline 30 & Gansu & Shanxi & & \\
\hline
\end{tabular}

Source: Ranked using the data from the survey.

As shown in Table 11.1, Tianjin, Shanghai, Beijing, Zhejiang and Jiangsu were ranked in the top five provinces in 2008, 2010 and 2012, according to the overall BEIFCP. Their relative ranks did, however, change. Shanghai was number one in 2006, 2008 and 2010, but was replaced by Tianjin in 2012. Zhejiang and Jiangsu both dropped in rank. After 2006, Shandong dropped out of the top five and was replaced by Beijing.

Table 11.1 shows that provinces with a higher ranking are mainly situated in the east, and they have greater economic development. Their positions are relatively stable, with limited change over the years. There does not, however, exist a linear correlation between the business environment and the level of economic development. For instance, both Guangdong and Fujian have a much higher GDP per capita than Chongqing and Heilongjiang, but they are ranked significantly lower than the latter (11th and 12th versus 6th and 7th).

Low-ranking provinces are mainly those from the western and central regions, with relatively lower economic achievement. Their ranking is, however, unstable, with large fluctuations over years. In 2012, the last five provinces, according to the overall BEIFCP ranking, are Jiangxi, Shanxi, Yunnan, Gansu and Xinjiang, but only one of them (Gansu) was in the bottom five in 2006. The other four with the lowest ranks (26th- 29th) in 2006 were Shaanxi, Guizhou, Hunan and Ningxia, but they jumped to 20th-24th in 2012.

It is important to acknowledge that the dramatic change in the rank of some provinces does not necessarily mean dramatic changes in their business environment. Because index scores for some provinces are quite close, their rankings are sensitive to small changes of scores. Improvement in one province that is slightly more or less than others may result in a change in rank, which affects a number of provinces.

In fact, changes in business environment at the provincial level are reflected more accurately by provincial scores rather than ranking. Figure 11.2 illustrates ranking and the overall scores for all the 29 provinces in 2006, 2008, 2010 and 2012 (30 provinces in earlier years) respectively. Their overall scores can be seen more clearly in Table 11.2. 
Figure 11.2 Overall scores and ranking of provinces (2006-2012)

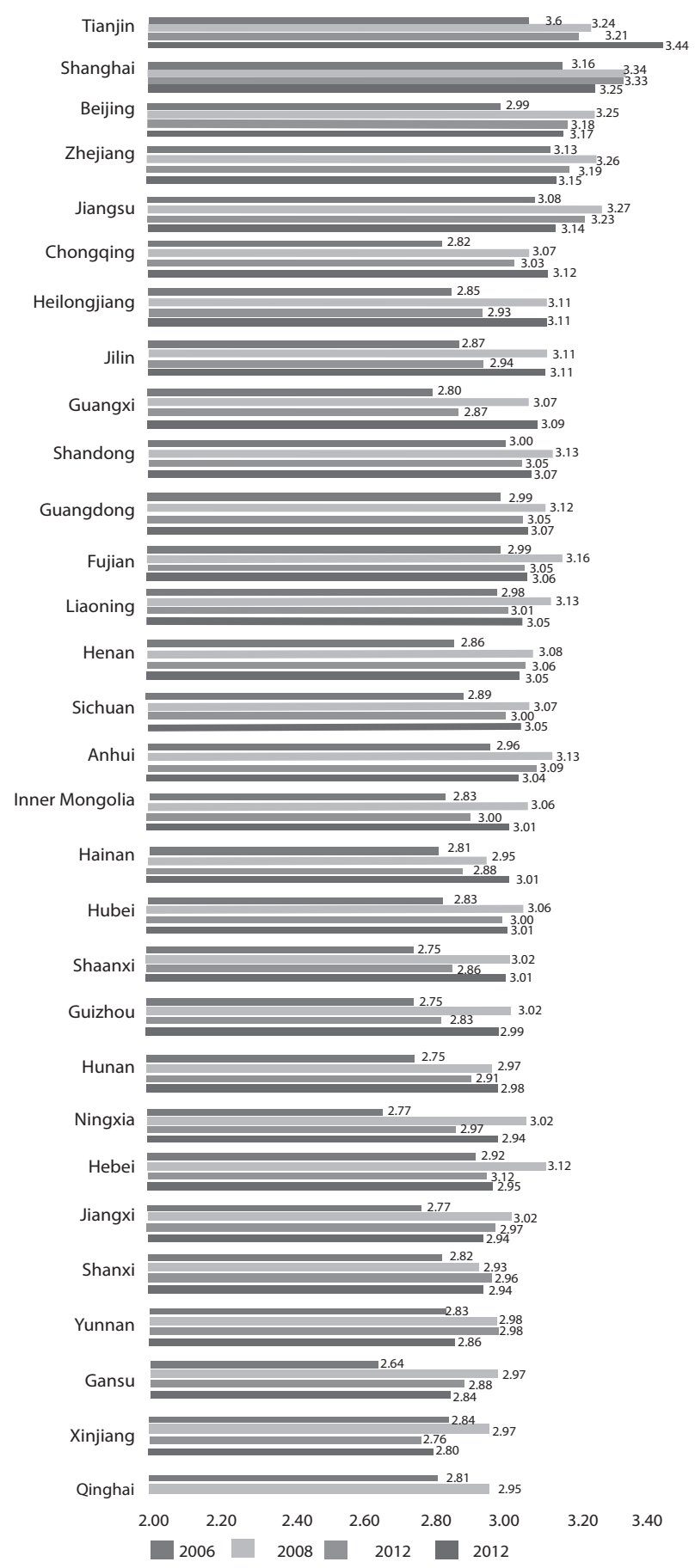

Note: Provincial ranking is according to their 2012 scores. Bars for each province are arranged from high to low in the order of years 2006, 2008, 2010 and 2012. Qinghai is placed at the low end in the figure because of missing values in 2010 and 2012, which does not mean lowest ranking.

Source: Using the data from the survey. 
As shown in Table 11.2, the 2012 scores of all the provinces, except Xinjiang, are higher than their 2006 scores, indicating improvement in the business environment of most of the provinces, although the scores of many of them are still lower than their score from 2008. Data in the table also indicates that some central and western provinces, which originally ranked low, improved more than most higher-ranking east coast provinces; thus, a general trend of convergence in the business environment, although not strong, may be observed.

Table 11.2 Overall scores and changes in ranking by provinces (2006-2012)

\begin{tabular}{|c|c|c|c|c|c|c|c|}
\hline & 2006 & 2008 & 2010 & 2012 & \begin{tabular}{|c|} 
Changes \\
$(2006-2008)$
\end{tabular} & $\begin{array}{c}\text { Changes } \\
(2008-2010)\end{array}$ & $\begin{array}{c}\text { Changes } \\
(2010-2012)\end{array}$ \\
\hline Beijing & 2.99 & 3.25 & 3.18 & 3.17 & 0.27 & -0.08 & -0.01 \\
\hline Tianjin & 3.06 & 3.24 & 3.21 & 3.44 & 0.18 & -0.03 & 0.23 \\
\hline Hebei & 2.92 & 3.12 & 2.95 & 2.97 & 0.20 & -0.17 & 0.02 \\
\hline Shanxi & 2.82 & 2.93 & 2.96 & 2.94 & 0.11 & 0.03 & -0.03 \\
\hline $\begin{array}{l}\text { Inner } \\
\text { Mongolia }\end{array}$ & 2.83 & 3.06 & 2.91 & 3.01 & 0.23 & -0.15 & 0.11 \\
\hline Liaoning & 2.98 & 3.13 & 3.01 & 3.05 & 0.15 & -0.11 & 0.04 \\
\hline Jilin & 2.87 & 3.11 & 2.94 & 3.11 & 0.25 & -0.17 & 0.17 \\
\hline Heilongjiang & 2.85 & 3.11 & 2.93 & 3.11 & 0.26 & -0.18 & 0.18 \\
\hline Shanhai & 3.16 & 3.34 & 3.33 & 3.25 & 0.18 & -0.01 & -0.08 \\
\hline Jiangsu & 3.08 & 3.27 & 3.23 & 3.14 & 0.19 & -0.04 & -0.08 \\
\hline Zhejiang & 3.13 & 3.26 & 3.19 & 3.15 & 0.13 & -0.07 & -0.04 \\
\hline Anhui & 2.96 & 3.13 & 3.09 & 3.04 & 0.17 & -0.04 & -0.05 \\
\hline Fujian & 2.99 & 3.16 & 3.05 & 3.06 & 0.17 & -0.11 & 0.01 \\
\hline Jiangxi & 2.77 & 3.02 & 2.97 & 2.94 & 0.24 & -0.04 & -0.04 \\
\hline Shandong & 3.00 & 3.13 & 3.05 & 3.07 & 0.13 & -0.08 & 0.03 \\
\hline Henan & 2.86 & 3.08 & 3.06 & 3.05 & 0.22 & -0.02 & -0.01 \\
\hline Hubei & 2.83 & 3.06 & 3.00 & 3.01 & 0.23 & -0.06 & 0.01 \\
\hline Hunan & 2.75 & 2.97 & 2.91 & 2.98 & 0.22 & -0.06 & 0.08 \\
\hline Guangdong & 2.99 & 3.12 & 3.05 & 3.07 & 0.13 & -0.07 & 0.01 \\
\hline Guangxi & 2.80 & 3.07 & 2.87 & 3.09 & 0.27 & -0.20 & 0.22 \\
\hline Hainan & 2.81 & 2.95 & 2.88 & 3.01 & 0.14 & -0.07 & 0.13 \\
\hline Chongq. & 2.82 & 3.07 & 3.03 & 3.12 & 0.24 & -0.04 & 0.09 \\
\hline Sichuan & 2.89 & 3.07 & 3.00 & 3.05 & 0.18 & -0.07 & 0.04 \\
\hline Guizhou & 2.75 & 3.02 & 2.83 & 2.99 & 0.27 & -0.19 & 0.16 \\
\hline Yunnan & 2.83 & 2.98 & 2.98 & 2.86 & 0.15 & 0.00 & -0.12 \\
\hline Shaanxi & 2.75 & 3.02 & 2.86 & 3.01 & 0.27 & -0.17 & 0.15 \\
\hline Gansu & 2.64 & 2.97 & 2.88 & 2.84 & 0.33 & -0.09 & -0.04 \\
\hline Ningxia & 2.66 & 3.06 & 2.86 & 2.98 & 0.40 & -0.19 & 0.12 \\
\hline Qinghai & 2.81 & 2.95 & & & 0.14 & & \\
\hline Xinjiang & 2.84 & 2.97 & 2.76 & 2.80 & 0.13 & -0.21 & 0.04 \\
\hline Average & 2.88 & 3.09 & 3.00 & 3.05 & 0.21 & -0.09 & 0.05 \\
\hline
\end{tabular}

Note: The overall scores in the table are valued between one and five. Greater scores indicate better business environment. Numbers in the last three columns are changes in the scores between 2008 and 2006, 2010 and 2008, and 2012 and 2010, respectively. Positive value indicates improvement, and vice versa.

Source: Calculated using the data from the survey. 


\section{The Changing Business Environment in Eight Areas}

\section{Major Obstacles in Business Environment}

In the 2012 survey, information was collected from enterprise owners or general managers about their views on the major obstacles that they encountered in their business environment. They were asked to indicate, from 28 external factors, the major obstacles for their business.

A total of 3,285 firm owners or general managers responded to the question regarding the major obstacles to their business. Their selection was grouped into seven areas, which correspond to the seven area indexes, i.e., government administration, legal environment for business, tax and non-tax burdens, financial services, supply of human resources, market intermediaries and technical services, and ethical business environment. Infrastructure conditions were not included, but this is not problematic because it has the highest score among the eight area indexes.

Perceptions of the primary obstacle to the conduct of business were as follows:

A. Government administration. A total of 33.7 per cent of the respondents treat factors in this area as the primary obstacle. Of them, most complaints concentrated on the aspect of 'openness, fairness, and equity' of policies and government administration. These problems include non-transparency of policies and government administration, unfair enforcement of regulations, and unequal treatment for different enterprises. There are also problems with the 'inefficiency of government administration', 'unnecessary government intervention' and 'cleanness of government officials'.

B. Tax and non-tax burden. Of the total effective samples, 30.3 per cent of those interviewed treat factors in this area as the primary obstacle. Most complaints relate to the tax burden, which possibly arises from efforts by local taxation bureaus to fulfill tax targets set by higher-level governments, and this may result in firms being over-taxed. Abuse of power by taxation officials may also be a problem.

C. Shortage of human resources. A total of 16.1 per cent of firms see this as the primary obstacle to their business. Respondents ranked the shortage of technicians as the most significant issue, followed by shortages of skilled workers and managers. 
D. Financial services. This is treated as the primary obstacle by 14.3 per cent of the firms, with most complaining of difficulties in obtaining bank loans; but high interest, extra charges and the difficulties of obtaining informal sector finance were also noted.

E. Legal environment. This problem is regarded as a primary obstacle by 3.7 per cent of the firms.

Table 11.3 ranks the distribution of complaints from the 2008 and 2012 surveys for comparison. According to the 2008 survey, the primary obstacle was access to financial services (which accounts for 35 per cent of the sample firms, this ratio is reduced to 14.3 per cent). The second was government administration (29.3 per cent), and the third, shortage of human resources (21.3 per cent). This survey did not include the tax and non-tax burden, but included infrastructure conditions. In 2012, the first, second, third and fourth rankings became government administration, tax and non-tax burden, shortage of human resources, and financial services.

This result indicates the necessity of government-sector reform, especially in terms of transparency, policy equity, self-discipline, and public monitoring in order to further improve the business environment. Tax policy, the supply of human resources and financial services are also key areas in the improvement of the business environment.

Table 11.3 Major obstacles to businesses by the sample firms: 2008 and 2012

\begin{tabular}{|c|c|c|c|c|}
\hline & 2008 & Rank & 2012 & Rank \\
\hline Government administration & $29.3 \%$ & 2 & $33.7 \%$ & 1 \\
\hline Openness,fairness, equity & $11.4 \%$ & & $20.9 \%$ & \\
\hline Government efficiency & $7.3 \%$ & & $5.6 \%$ & \\
\hline Government over-intervention & $6.8 \%$ & & $5.8 \%$ & \\
\hline Government official cleanness & $3.7 \%$ & & $1.4 \%$ & \\
\hline Tax and non-tax burden & & & $30.3 \%$ & 2 \\
\hline Tax burden & & & $29.9 \%$ & \\
\hline Non-tax collection & $0.6 \%$ & & $0.4 \%$ & \\
\hline Shortage in human resources & $21.3 \%$ & 3 & $16.1 \%$ & 3 \\
\hline Technicians & $6.2 \%$ & & $8.6 \%$ & \\
\hline Managers & $6.7 \%$ & & $2.5 \%$ & \\
\hline Skilled workers & $8.3 \%$ & & $5.1 \%$ & \\
\hline Financial services & $35.0 \%$ & 1 & $14.3 \%$ & 4 \\
\hline Formal financial services & $34.1 \%$ & & $13.2 \%$ & \\
\hline Informal sector finance & $0.9 \%$ & & $1.1 \%$ & \\
\hline Legal environment & $6.0 \%$ & 4 & $3.7 \%$ & 5 \\
\hline Enforcing law: fairness\& efficiency & $1.7 \%$ & & $0.9 \%$ & \\
\hline Legal right protection & $4.3 \%$ & & $2.8 \%$ & \\
\hline
\end{tabular}




\begin{tabular}{l|c|c|c|c}
\hline & $\mathbf{2 0 0 8}$ & Rank & $\mathbf{2 0 1 2}$ & Rank \\
\hline Infrastructure conditions & $\mathbf{3 . 3} \%$ & $\mathbf{5}$ & & \\
\hline Ethical business environment & $\mathbf{3 . 1 \%}$ & $\mathbf{6}$ & $\mathbf{1 . 5 \%}$ & $\mathbf{6}$ \\
\hline Market intermediary \& services & $\mathbf{1 . 4 \%}$ & $\mathbf{7}$ & $\mathbf{0 . 4 \%}$ & $\mathbf{7}$ \\
\hline Market intermediaries & $0.4 \%$ & & $0.4 \%$ & \\
\hline Technical \& export services & $1.0 \%$ & & $0.1 \%$ & \\
\hline & $\mathbf{1 0 0 . 0 \%}$ & & $100.0 \%$ & \\
\hline
\end{tabular}

Source: Calculated using the data from the survey.

\section{Business Environment in Eight Areas}

Figure 11.3 shows an improvement in the business environment over eight area indexes areas from 2006 to 2012 (data is collated in Table 11.4). Area rankings from low to high, according to the average scores are: supply of human resources, tax and non-tax burdens, market intermediaries and technical/ export services, financial services, ethical business environment for business, government administration, legal environment for business, and infrastructure conditions.

These areas all showed some improvement from 2006 to 2012, except infrastructure conditions. Three of the scores remain, however, in a negative interval in 2012.

Figure 11.3 Eight areas of business environment: an improvement (2006-2012)

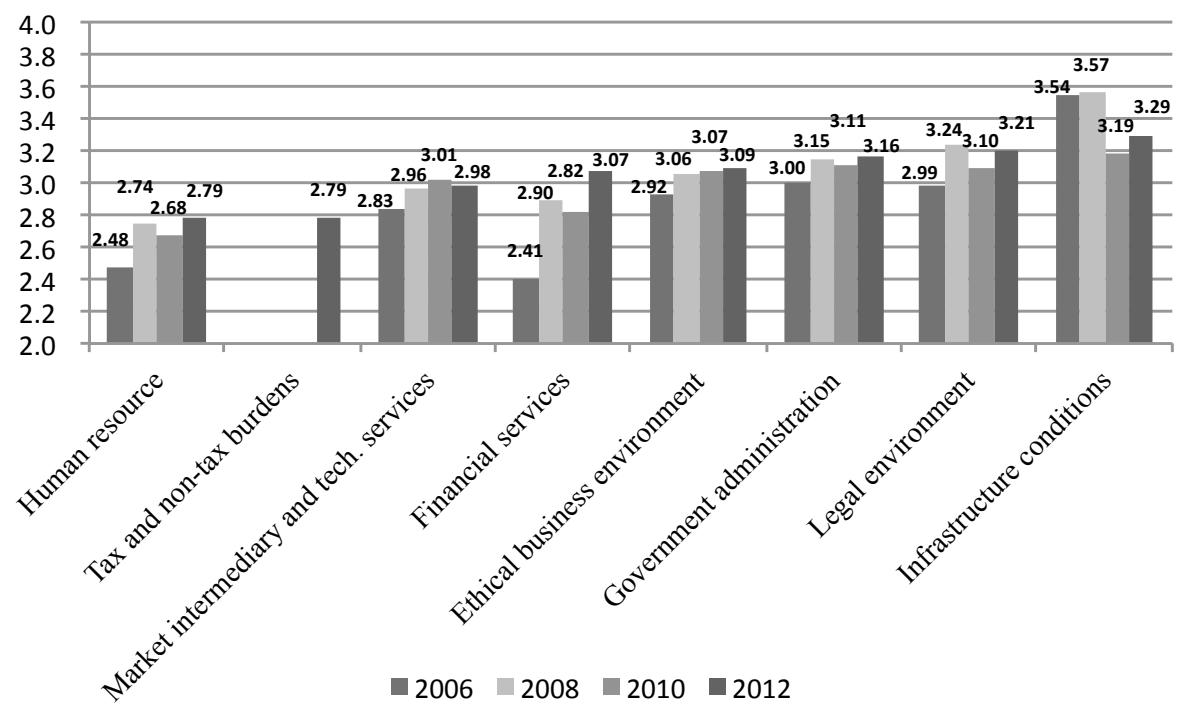

Source: Calculated using the data from the survey. 
Table 11.4 indicates that financial services made the biggest improvement during this period. The supply of human resources also improved, but still in a negative interval. Infrastructure condition is the only area since 2006 in which the score dropped.

Table 11.4 Eight areas of business environment: changes in scores

\begin{tabular}{|c|c|c|c|c|c|}
\hline & 2006 & 2008 & 2010 & 2012 & $2006-2012$ changes \\
\hline Human resource & 2.48 & 2.74 & 2.68 & 2.79 & 0.31 \\
\hline Tax and non-tax burdens & & & & 2.79 & \\
\hline $\begin{array}{l}\text { Market intermediary and } \\
\text { technicalservices }\end{array}$ & 2.83 & 2.96 & 3.01 & 2.98 & 0.15 \\
\hline Financial services & 2.41 & 2.90 & 2.82 & 3.07 & 0.66 \\
\hline Ethical business environment & 2.92 & 3.06 & 3.07 & 3.09 & 0.17 \\
\hline Government administration & 3.00 & 3.15 & 3.11 & 3.16 & 0.16 \\
\hline Legal environment & 2.99 & 3.24 & 3.10 & 3.21 & 0.22 \\
\hline Infrastructure conditions & 3.54 & 3.57 & 3.19 & 3.29 & -0.25 \\
\hline Overall & 2.88 & 3.09 & 3.00 & 3.05 & 0.17 \\
\hline
\end{tabular}

Source: Calculated using the data from the surveys.

One may notice the difference between indexing of the business environment here and the assessment of obstacles to business provided in last section. A major difference relates to government administration. In last section, it is assessed as the primary obstacle to business, although the score of this area index in Table 11.4 is not so disappointing, as it is above the neutral value of three. Its ranking among the eight area indexes is also not very low. The puzzle is that both categories of information come from the same sample enterprises.

The difference is partially due to the outcomes from different emphases in assessment. The obstacle assessment focuses on the seriousness of problems, whereas the scores of indexes mainly reflect the extent of influences by factors.

Moreover, because of many influencing factors, the area index of government administration consists of four sub-indexes and more basic indexes. The average of a few basic indexes constitutes a sub-index, and the average of the four subindexes forms the area index. Because each basic index only concerns a particular factor in the area, the probability that a firm will encounter problems relating to a single factor is usually low, whereas other firms, without experiencing this kind of problem, may give an average, or even above average, assessment for the relevant factor. This can result, to some extent, in a converging assessment towards the average. ${ }^{2}$ The situation is different in the obstacle assessment. Because problems relating to each factor may act as a major obstacle to a firm, it

2 The same thing may occur when lower-level indexes are averaged for a sub-index or area index. This is to be a shortcoming of subjective assessment method in indexing. We have not yet found a solution for 
is necessary to calculate the rate at which each obstacle occurs so as to assess its impact in the same area, instead of taking the average. The sum of these rates in the area, 33.7 per cent, becomes a considerably high proportion.

This suggests that the obstacle assessment on government administration provides more direct information and has higher creditability, whereas indexing for this area may provide a more or less over-evaluation. In spite of this shortcoming, the indexing method provides a useful and indispensable means of measuring the differences in the business environment among regions/ provinces, between different categories of enterprises, and over time.

\section{Environment Differentials by Type of Enterprises}

\section{Business Environment for SOEs and Non-State Enterprises}

In this section we compare business environment for SOEs (including shareholding companies with controlling shares that are owned by the state) and nonstate enterprises (NSEs) (including mainly private enterprises, stock companies and limited liability companies that are not controlled by the state, and all other non-state enterprises).

Of the total 418 SOEs in our 2012 survey, large, medium, and small enterprises account for 30.7, 43.6, and 24.0 per cent, respectively. Micro enterprises account for only 1.7 per cent.

Of the total 3,602 NSEs, only 6.6 per cent are large enterprises, medium and small enterprises account for 34.4 and 53.9 per cent, respectively. Micro enterprises account for 5.1 per cent. Obviously, there are more large and medium enterprises in SOEs, and more small and micro enterprises in NSEs. This reflects the differentials in firm size between the two categories, but the proportion of micro enterprises in NSE samples is much less than in reality.

In 2012, the average score of overall index for SOEs is 3.13, greater than the average of NSEs (3.08) by 0.05 . The difference is significant at the five per cent level $(t=2.25)$. This indicates a better business environment for SOEs than NSEs. This is abnormal since, when both SOEs and NSEs are operating in the same competitive market, their business environment should be equal. The unequal environment suggests that SOEs may enjoy favourable treatment by the government.

Table 11.5 reports the overall index, area indexes and sub-indexes for both SOEs and NSEs, and the statistical significance of their differences. All differences that are significant at five per cent or higher are scaled out in bold. The environment scores in six out of the eight areas are greater for SOEs 
than NSEs. Two of them are significant, and more are significant at the subindex level. For instance, 'openness, fairness, and equity' has a positive and significant difference (indicating SOEs experience more fairness than NSEs), but 'unnecessary intervention' has a negative difference (SOEs encounter more intervention than NSEs). The differences in two sub-indexes cancel out each other, so that the difference in area index becomes insignificant.

This reveals that there are discriminatory treatments that favour SOEs against NSEs, which, in general, has a negative effect on NSEs. It is, therefore, necessary to adjust relevant government policies to standardise the treatment of SOEs and NSEs.

Table 11.5 Differences in business environment between SOEs and NSEs

\begin{tabular}{|c|c|c|c|c|c|}
\hline & SOE & NSE & Difference & t-statistics & P-value \\
\hline Government administration & 3.20 & 3.25 & -0.05 & -1.44 & 0.15 \\
\hline Openness, fairness, equity & 3.09 & 3.00 & 0.09 & 2.53 & 0.01 \\
\hline Government efficiency & 2.88 & 2.96 & -0.08 & -1.62 & 0.11 \\
\hline Non-necessary intervention & 3.34 & 3.57 & -0.23 & -5.48 & 0.00 \\
\hline Government cleanness & 3.51 & 3.47 & 0.04 & 0.64 & 0.52 \\
\hline Legal environment & 3.27 & 3.24 & 0.03 & 0.90 & 0.34 \\
\hline Fairness \& efficiency & 3.04 & 3.01 & 0.03 & 0.64 & 0.52 \\
\hline Legal right protection & 3.50 & 3.46 & 0.04 & 1.22 & 0.22 \\
\hline Tax and non-tax burden & 2.88 & 2.75 & 0.13 & 3.29 & 0.00 \\
\hline Tax burden & 3.59 & 3.43 & 0.16 & 2.90 & 0.00 \\
\hline Non-tax collection & 2.17 & 2.07 & 0.10 & 2.47 & 0.01 \\
\hline Financial services & 3.15 & 3.10 & 0.05 & 0.74 & 0.33 \\
\hline Formal financial services & 3.26 & 3.04 & 0.22 & 5.52 & 0.00 \\
\hline Informal sector finance & 3.03 & 3.17 & -0.14 & -2.45 & 0.01 \\
\hline Shortage in human resource & 2.98 & 2.77 & 0.21 & 4.46 & 0.00 \\
\hline Technicians & 2.94 & 2.71 & 0.23 & 4.49 & 0.00 \\
\hline Managers & 3.05 & 2.78 & 0.27 & 4.99 & 0.00 \\
\hline Skilled workers & 2.94 & 2.82 & 0.12 & 2.42 & 0.02 \\
\hline Infrastructure conditions & 3.32 & 3.33 & -0.01 & -0.27 & 0.79 \\
\hline Power supply & 3.95 & 3.89 & 0.06 & 1.29 & 0.20 \\
\hline Railway service & 3.11 & 3.15 & -0.04 & -0.88 & 0.38 \\
\hline Other infrastructure & 2.91 & 2.96 & -0.05 & -1.13 & 0.26 \\
\hline Market intermediaries \& service & 3.06 & 3.02 & 0.04 & 1.09 & 0.28 \\
\hline Market intermediaries & 3.12 & 3.04 & 0.08 & 2.11 & 0.04 \\
\hline Technical \& export service & 3.01 & 3.00 & 0.01 & 0.16 & 0.88 \\
\hline Ethical business environment & 3.18 & 3.16 & 0.02 & 0.63 & 0.53 \\
\hline Overall & 3.13 & 3.08 & 0.05 & 2.25 & 0.03 \\
\hline
\end{tabular}

Source: Calculated using the data from the surveys. 


\section{Business Environment for Enterprises of Different Scales}

This section investigates the business environment for large, medium, small and micro enterprises. In 2012, scores of the overall index were 3.20 for large enterprises, 3.09 for medium enterprises, 3.07 for small enterprises, and 2.98 for micro enterprises. These differences are statistically significant; obviously, the smaller the enterprise scale is, the less-favoured business environment it enjoys.

In Table 11.6, the overall index, area indexes and sub-indexes for enterprises of different scales are reported. Differences in significance at five per cent or higher are scaled out in bold. The t-ratios are listed in the second part of the table. Differences in five areas, out of a total of eight, are statistically significant at least between two categories of enterprises. The remaining three areas all have differences where some sub-indexes are statistically significant.

Table 11.6 Difference in business environment between enterprise scales

\begin{tabular}{|c|c|c|c|c|c|c|c|}
\hline & \multicolumn{4}{|c|}{ Score } & \multicolumn{3}{|c|}{ Difference } \\
\hline & Large & Medium & Small & Micro & L-M & $\mathbf{M}-\mathbf{S}$ & S-I \\
\hline Government administration & 3.25 & 3.24 & 3.26 & 3.15 & 0.01 & -0.02 & 0.11 \\
\hline Openness, fairness, equity & 3.14 & 3.04 & 2.98 & 2.84 & 0.10 & 0.06 & 0.14 \\
\hline Government efficiency & 2.92 & 2.92 & 2.99 & 2.91 & 0.00 & -0.07 & 0.08 \\
\hline Non-necessary intervention & 3.42 & 3.51 & 3.59 & 3.48 & -0.10 & -0.08 & 0.11 \\
\hline Government cleanness & 3.54 & 3.48 & 3.47 & 3.36 & 0.05 & 0.02 & 0.11 \\
\hline Legal environment & 3.34 & 3.27 & 3.21 & 3.13 & 0.07 & 0.06 & 0.08 \\
\hline Fairness \& efficiency & 3.11 & 3.04 & 2.98 & 2.89 & 0.06 & 0.06 & 0.09 \\
\hline Legal right protection & 3.58 & 3.50 & 3.43 & 3.37 & 0.08 & 0.06 & 0.07 \\
\hline Tax and non-tax burden & 2.85 & 2.77 & 2.75 & 2.81 & 0.08 & 0.02 & -0.06 \\
\hline Tax burden & 3.59 & 3.45 & 3.42 & 3.45 & 0.14 & 0.03 & -0.03 \\
\hline Non-tax collection & 2.10 & 2.08 & 2.07 & 2.17 & 0.02 & 0.00 & -0.09 \\
\hline Financial services & 3.29 & 3.14 & 3.08 & 2.85 & 0.15 & 0.06 & 0.23 \\
\hline Formal financial services & 3.39 & 3.11 & 2.99 & 2.77 & 0.28 & 0.12 & 0.22 \\
\hline Informal sector finance & 3.20 & 3.16 & 3.16 & 2.94 & 0.03 & 0.01 & 0.22 \\
\hline Shortage in human resource & 2.95 & 2.76 & 2.78 & 2.77 & 0.19 & -0.02 & 0.01 \\
\hline Technicians & 2.89 & 2.70 & 2.72 & 2.68 & 0.19 & -0.02 & 0.04 \\
\hline Managers & 3.01 & 2.78 & 2.79 & 2.77 & 0.22 & -0.01 & 0.02 \\
\hline Skilled workers & 2.94 & 2.79 & 2.82 & 2.87 & 0.15 & -0.03 & -0.05 \\
\hline Infrastructure conditions & 3.36 & 3.33 & 3.33 & 3.29 & 0.03 & 0.01 & 0.04 \\
\hline Power supply & 4.00 & 3.90 & 3.89 & 3.87 & 0.10 & 0.01 & 0.01 \\
\hline Railway service & 3.15 & 3.16 & 3.14 & 3.04 & -0.01 & 0.01 & 0.10 \\
\hline Other infrastructure & 2.94 & 2.95 & 2.95 & 2.95 & -0.01 & -0.01 & 0.01 \\
\hline Market intermediaries \& service & 3.20 & 3.05 & 2.99 & 2.86 & 0.15 & 0.06 & 0.13 \\
\hline Market intermediaries & 3.23 & 3.08 & 3.01 & 2.87 & 0.16 & 0.06 & 0.15 \\
\hline Technical \& export services & 3.16 & 3.03 & 2.97 & 2.86 & 0.13 & 0.06 & 0.11 \\
\hline Ethical business environment & 3.33 & 3.17 & 3.13 & 3.01 & 0.16 & 0.04 & 0.12 \\
\hline Overall & 3.20 & 3.09 & 3.07 & 2.98 & 0.11 & 0.02 & 0.09 \\
\hline
\end{tabular}


China: A New Model for Growth and Development

Table 11.6 Difference in business environment between enterprise scales (continued)

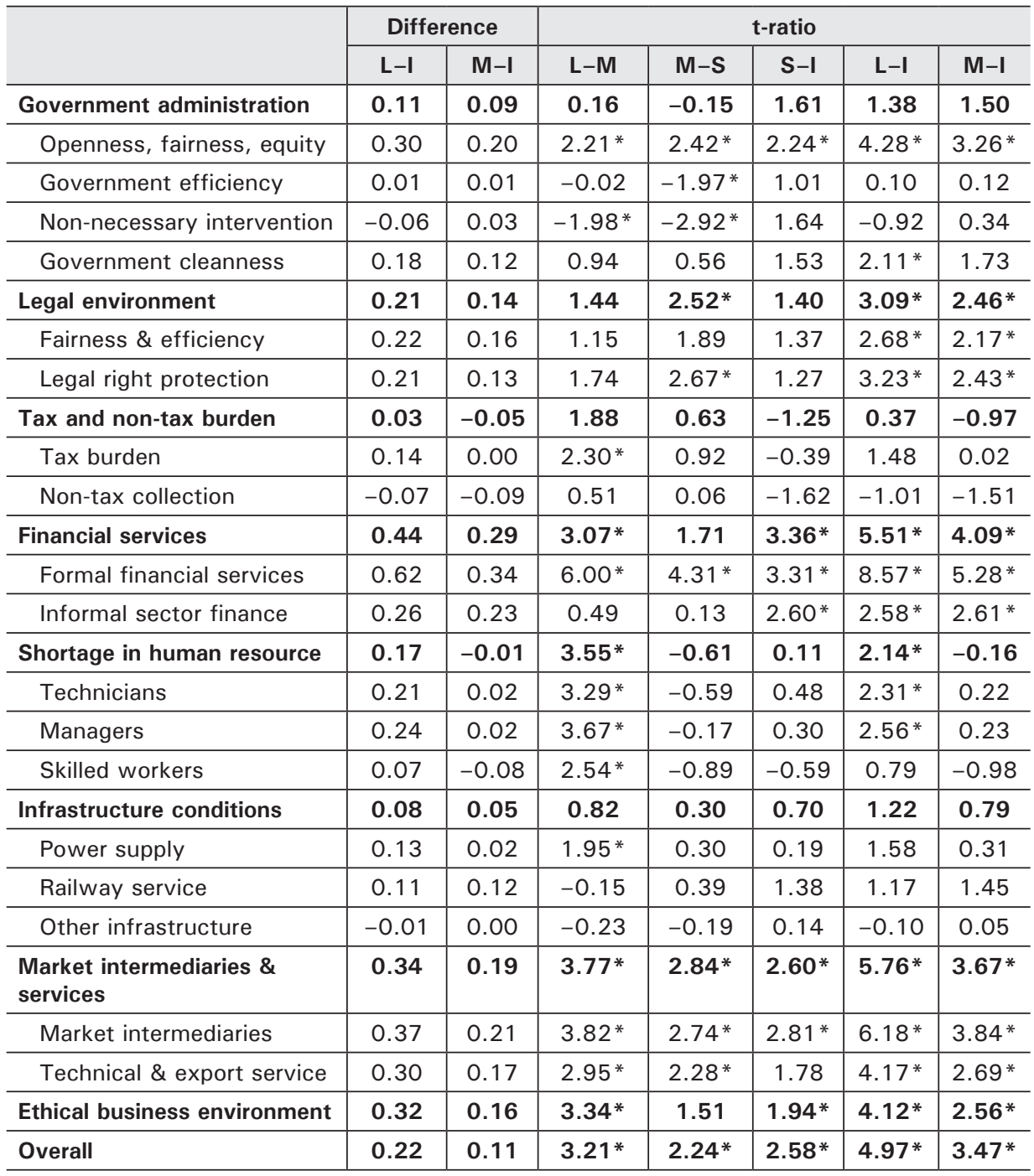

Note: t-ratio with * are significant at five per cent or higher levels. L, M, S and I in the table stands for large, medium, small and micro enterprises, respectively.

Source: Calculated using the data from the surveys.

Figures 11.4 and 11.5 illustrate differences between enterprise scales in legal environment and financial services, respectively. They show clear differences among different enterprises by size. 
Figure 11.4 Legal Environment Index for enterprise scales

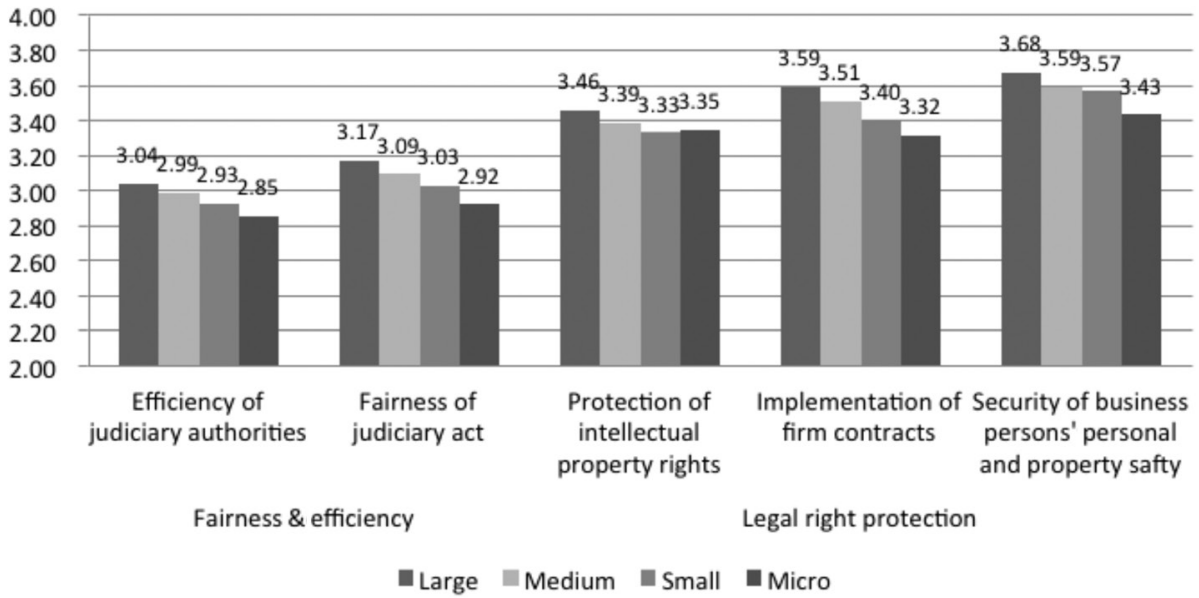

Source: Calculated using the data from the survey.

Figure 11.5 Financial Services Index for enterprise scales

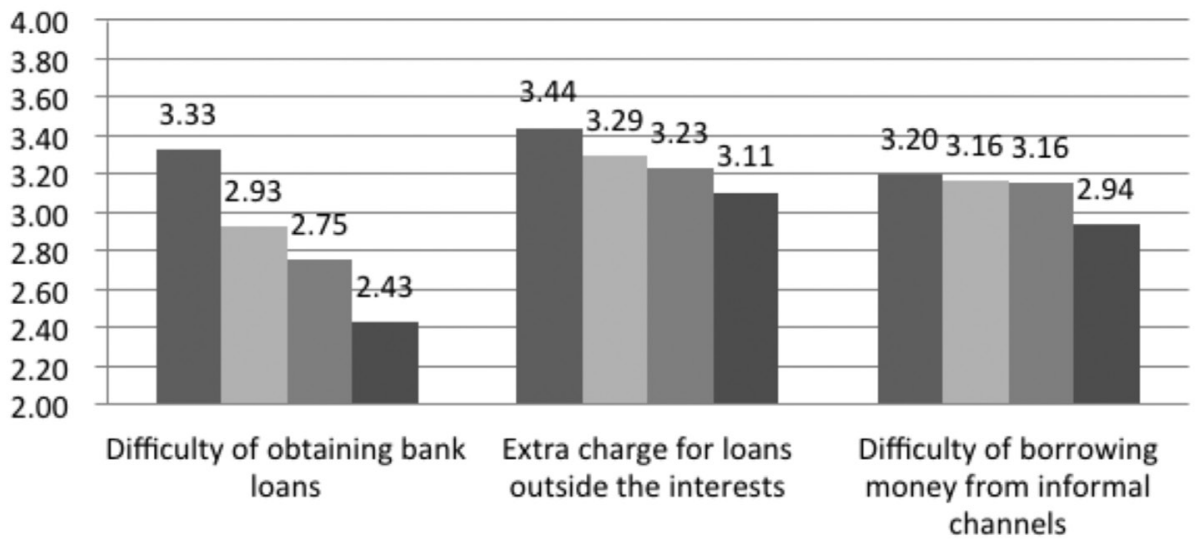

Formal financial services

Informal sector finance

\section{- Large Medium $\quad$ Small Micro}

Source: Calculated using the data from the surveys.

The evidence provided in this section clearly indicates that larger enterprises enjoy favoured treatment by the government, which leaves small and micro enterprises to face discriminatory conditions. It is a priority to improve the business environment for small and micro enterprises by standardising treatment by government and implementing laws and regulations fairly.

In addition, some supportive policies may be needed; for example, promoting the development of guilds or chambers of commerce and other market intermediaries, to help small and micro enterprises in their business operations, 
and improving vocational education and training programs so as to increase the numbers of technicians, managers and skilled workers that are needed by small and micro enterprises.

\section{Business Environment in Different Sectors}

In this section, the business environment in 18 different industrial sectors is examined. The 2012 survey covers enterprises in 19 sectors. Only a few enterprises are engaged in 'public management and social organisations', which are excluded in the following study.

From comparing business environment indexes in the 18 sectors, there is evidence of significant differentiation between them. They are grouped into three categories according to their overall environment scores and the eight area scores:

- The first group includes those sectors with overall scores falling below the average. This includes mining, construction, finance, real estate, education, and health, social security and social welfare. These sectors are found to have the following characteristics: dependence on natural resources that are not allocated via market, or monopolistic to certain extent (high concentration ratio), or having dual features of providing both public goods and private goods.

- The second group includes those sectors with scores or indexes around the average. They are agriculture, manufacturing, transport, wholesale and retail sales, hotels and catering services, leasing and business services, and services to households and other services. These sectors are generally subject to relatively high market competition.

- The third group includes those sectors with index scores mostly above the average. They are information transmission, computer services and software; management of water conservancy, environment and public facilities; culture, sports and entertainment; scientific research, technical services and geologic prospecting; and production and supply of electricity, gas and water. Among them, only the electricity sector (including gas and water) is a monopoly, whereas the rest can be classified as newly developed services sectors. They have developed faster because of either technical innovation and progress, or a growth in consumption.

Table 11.7 shows the overall index and area indexes of these sectors. The electricity sector is reclassified into the first group according to the nature of its production. 

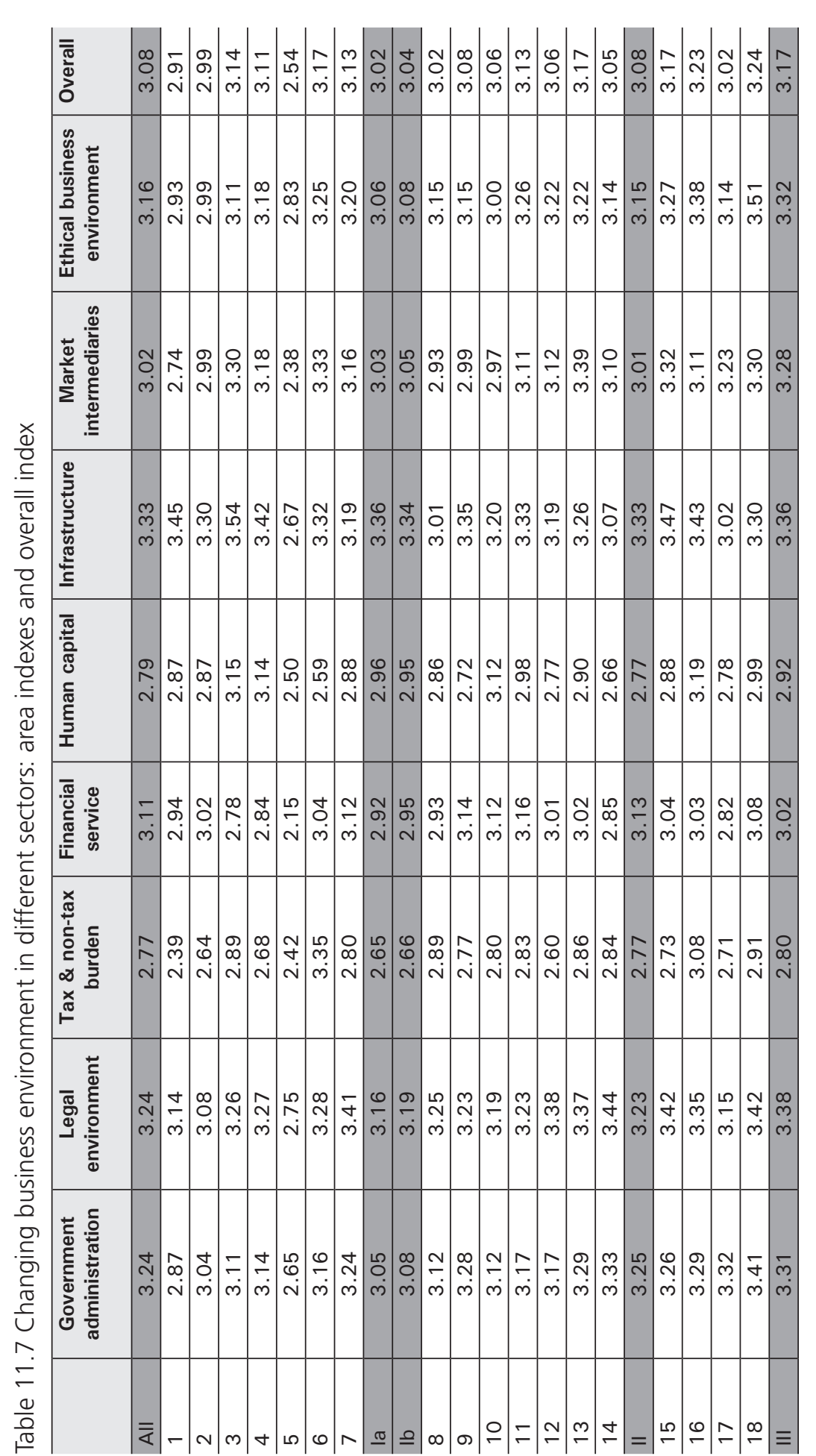

$\therefore \dot{\square}$

is

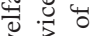

उ

.

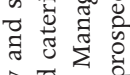

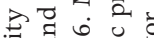

势

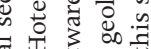

తa

엉

ड这范

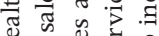

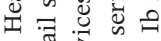

เ

ปี :

ฮै

ว

1. ब

in $\frac{1}{3}$ 员.

نे 3 .

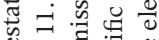

记

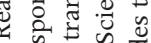

+

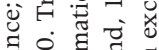

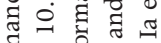

的结苛

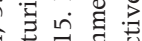

.

氖

范势

ช $\sigma$ ठี ठี

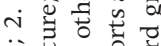

के

灵它

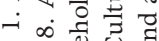

$\ddot{4}$

焉范苍芯

ड़ 뭉 :

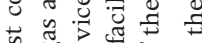

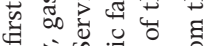

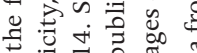

घ

उ

क

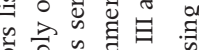

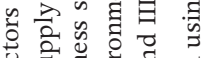

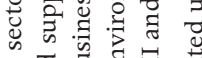

$\infty$ 司娄

๘ छ

政

$\ddot{\sim})$ o 
Five out of eight area indexes in the first group of sectors reported in Table 11.7 have significantly lower scores than the average, and the second group. They are government administration, legal environment for business, tax and non-tax burdens, financial services, and ethical business environment. Two area indexes are similar; that is, infrastructure conditions, and market intermediaries and technical services. Only one area index, supply of human resources, has a higher score than both the average and the second group. This may suggest that job seekers prefer this group of sectors over others, possibly because of the better pay and welfare that is offered in this group of sectors.

Table 11.8 shows differences in the environment scores of the three groups and their statistical significance. Regressions show that both negative and positive differences between the first and second groups in six areas are statistically significant at one per cent or five per cent respectively. Although the difference in one area index is positive and significant, that of the overall index is negative, consistent with the five areas, and significant at the ten per cent level.

Table 11.8 also indicates that the overall index, and seven out of eight area indexes of the second group, are lower than the third group, and statistically significant.

Sectors in the first group each have some characteristics which are different from others:

1. Dealing with natural resources. This includes mining and real estate (construction also relates to real estate). Mineral resources and land are allocated by government at different administrative levels, or, at least, not entirely allocated in competitive markets, therefore, they have some features of a monopoly.

2. Monopoly or oligopoly. The financial sector, for instance, has a high concentration ratio, as the market is dominated by a few large, commercial banks. Financial institutions are also subject to government regulations on interest rates, and interventions on loan extensions. There are entry barriers that act especially against small, private financial institutions. This has weakened the mechanism of market competition.

3. Dual producer. The education and health care sectors both provide public and private goods. Public institutions in these sectors normally have policy advantages as compared with private institutions, as they shoulder the responsibility for providing public services. They may also have disadvantages, as these sectors are subject to various kinds of government regulations. For example, the salary levels of doctors in public hospitals are restricted by government regulations, and are significantly lower than those in private hospitals, although they may have a better chance to obtain commissions from prescribing drugs to patients. In addition, due to information asymmetry between producers and consumers in these sectors, these sectors easily form a sellers' market, thus they have some similarities with monopolistic or oligopolistic sectors. 


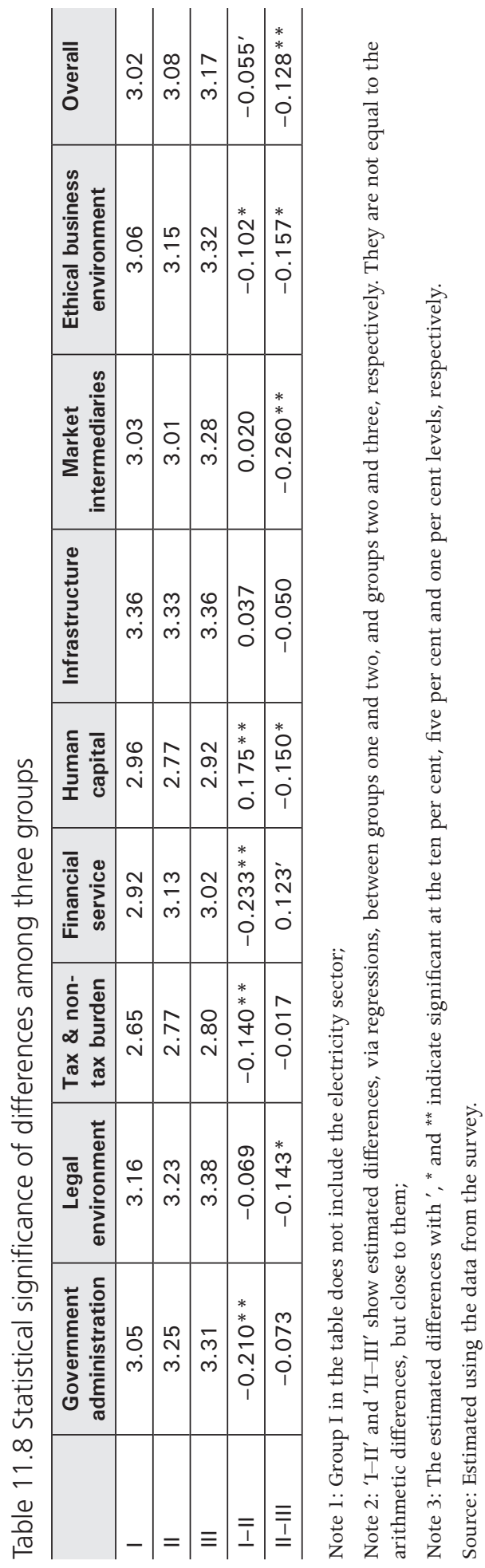


Although these sectors have different characteristics from each other, their common feature is that their market competition is naturally or administratively restricted. This has a negative effect on the business environment and the seriousness of this effect will depend on the extent to which government administration, particularly government transparency, policy openness, fairness and effectiveness as well as the legal framework apply, in those sectors.

Among those sectors with a certain level of monopoly or oligopoly, the electricity sector is an exceptional case. It has a high level of market concentration, and has higher scores in business environment indexes. This is related to the following situation: firms in a monopolistic or oligopolistic sector are divided into two situations, some have monopolistic status and therefore have advantages over others; other firms, usually smaller ones, do not have this status and are, therefore, in a situation of disadvantage in market competition. Normally the latter accounts for the largest proportion of firm, even in a monopolised sector. If, however, those firms with the status of a monopoly account for a large proportion in the sector, this may better explain why this sector has high scores in business environment. To separate out the sample firms in the electricity sector, we find that they have another distinctive feature. The proportion of SOEs in this sector is much higher than others, they account for 66 per cent of the total, whereas in the other sectors the highest ratio is only 37 per cent. As we have seen, the business environment assessments of SOEs are significantly higher than others, and this may explain why the difference exists between the electricity sector and others.

Table 11.9 shows that the first group of sectors have a higher proportion of large and medium enterprises than the second and third groups, and also a higher proportion of SOEs, whereas the electricity sector has even higher proportions than the first group, particularly in terms of the proportion of SOEs.

This shows that the higher scores in the electricity sector may be read negatively, especially if this occurred because the sector enjoys monopoly status or is treated favourably by the government.

Table 11.9 Scales and ownership types of the sample enterprises by sector groups

\begin{tabular}{l|c|c|c|c|c|c|c|c}
\hline & Large & Medium & Small & Micro & Sum & SOEs & NSEs & Sum \\
\hline All & $9.1 \%$ & $35.3 \%$ & $50.8 \%$ & $4.8 \%$ & $100 \%$ & $10.4 \%$ & $89.6 \%$ & $100 \%$ \\
\hline Group I & $11.9 \%$ & $39.8 \%$ & $43.9 \%$ & $4.4 \%$ & $100 \%$ & $15.0 \%$ & $85.0 \%$ & $100 \%$ \\
\hline Electricity & $18.9 \%$ & $45.3 \%$ & $32.1 \%$ & $3.8 \%$ & $100 \%$ & $66.0 \%$ & $34.0 \%$ & $100 \%$ \\
\hline Group II & $8.6 \%$ & $35.2 \%$ & $52.0 \%$ & $4.3 \%$ & $100 \%$ & $8.9 \%$ & $91.1 \%$ & $100 \%$ \\
\hline Group III & $10.5 \%$ & $25.0 \%$ & $47.4 \%$ & $17.1 \%$ & $100 \%$ & $13.2 \%$ & $86.8 \%$ & $100 \%$ \\
\hline
\end{tabular}

Note: Group I in the table does not include the electricity sector.

Source: Calculated using the data from the survey. 
The results in Tables 11.7 and 11.8 also indicate that the third group of sectors has higher scores for the business environment than the second group. This is different from the situation of the electricity sector, as we do not see significant monopoly in the newly developed services sectors. Higher scores in the third group may be due to the following reason: product differentials that are often brought by technical progress or brand effects, may bring producers the status of a monopoly, and extra profits in certain periods; however, this kind of activity normally does not exclude market competition. Market competition can still work to push forward technical innovation and productivity growth. In addition, policy promotion in the areas of information technology, environment protection and $\mathrm{R} \& \mathrm{D}$, may play positive roles.

The findings in this section show that sectors with sufficient market competition have better business environments than those monopolised sectors in general, showing the positive role of the market in allocating resources. Different kinds of monopolies have negative impacts on the business environment, however, this has different causes in different sectors. Therefore, countermeasures should accordingly be different, depending on the specific situation in a particular sector.

In those sectors that have high entry barriers and a high degree of government intervention, such as the financial sector, policy adjustment is required to limit those barriers and to promote the competitiveness of smaller private firms.

In sectors dealing with mineral and land resources, particularly petroleum, the priority is to improve the regulatory and legal framework to make the process of allocation of resources more transparent, competitive and fair, so that irregular operations and rent-seeking behaviours can be prevented or eliminated. Moreover, taxation systems that target the gains from natural resources and profits from monopolies should be improved to guarantee a balanced and fair income distribution.

In education, health care and other sectors producing both public and private goods, a double-track system with respect to both the market forces and government intervention should be well maintained to ensure that public services are effective, equitable and efficient. 


\section{Business Environment in Four Regions}

The 29 provinces may be grouped into four regions, namely east, northeast, centre and west, to examine regional similarities and differences in the business environment. ${ }^{3}$ Provinces in each region have some common features in terms of their level of economic development, and cultural traditions. Table 11.10 provides both the overall index and area indexes in different years for the four regions. It is clear that the business environment in the east is better than in the north-east and centre, and that in the latter two is better than in the west.

In 2006, the scores of the overall index for the east, north-east, centre and west are 3.01, 2.90, 2.83 and 2.78, respectively. In 2012 improvement was evident in all four regions, which increased to 3.13, 3.09, 2.99 and 2.97. The north-east and west regions performed slightly better (both increased 0.19) than the centre (0.16) and east (only 0.12), and this reveals a tendency of convergence, although weak, among regions.

In terms of area indexes, all the areas, except infrastructure conditions, improved in all the four regions during the 2006-2012 period (tax and nontax burden is excluded as it was added in 2012). Regional ranking of the area indexes is basically consistent with that of the overall index. The east had the highest ranking in most area indexes, except in the supply of human capital and infrastructure conditions across some years. The west still has the lowest scores in most area indexes, but surpassed the centre in legal environment and ethical business environment.

Table 11.10 shows that regional rankings are similar in most areas of the business environment. The relative patterns of scores in the four regions are also similar; in 2012, they all have the lowest scores for the supply of human resources, and the highest scores for infrastructure conditions. Compared with that in 2006, only financial services improved significantly faster than other area indexes, and all the rest of the area indexes achieved similar rankings in the four regions. These indicate that different regions in China face similar problems in their business environments, although their relative achievements with respect to improving their business environments differ.

3 There are ten provinces in the east region: Beijing, Tianjin, Hebei, Shanghai, Jiangsu, Zhejiang, Fujian, Shandong, Guangdong and Hainan. Only three provinces are in the north-east: Liaoning, Jilin and Heilongjiang. Six provinces are in the centre region: Shanxi, Anhui, Jiangxi, Henan, Hubei and Hunan. The west region consists of 12 provinces: Inner Mongolia, Guangxi, Chongqing, Sichuan, Guizhou, Yunnan, Shaanxi, Gansu, Ningxia, Xinjiang, Qinghai and Tibet. In this study, Qinghai and Tibet are excluded due to insufficient sample firms. 


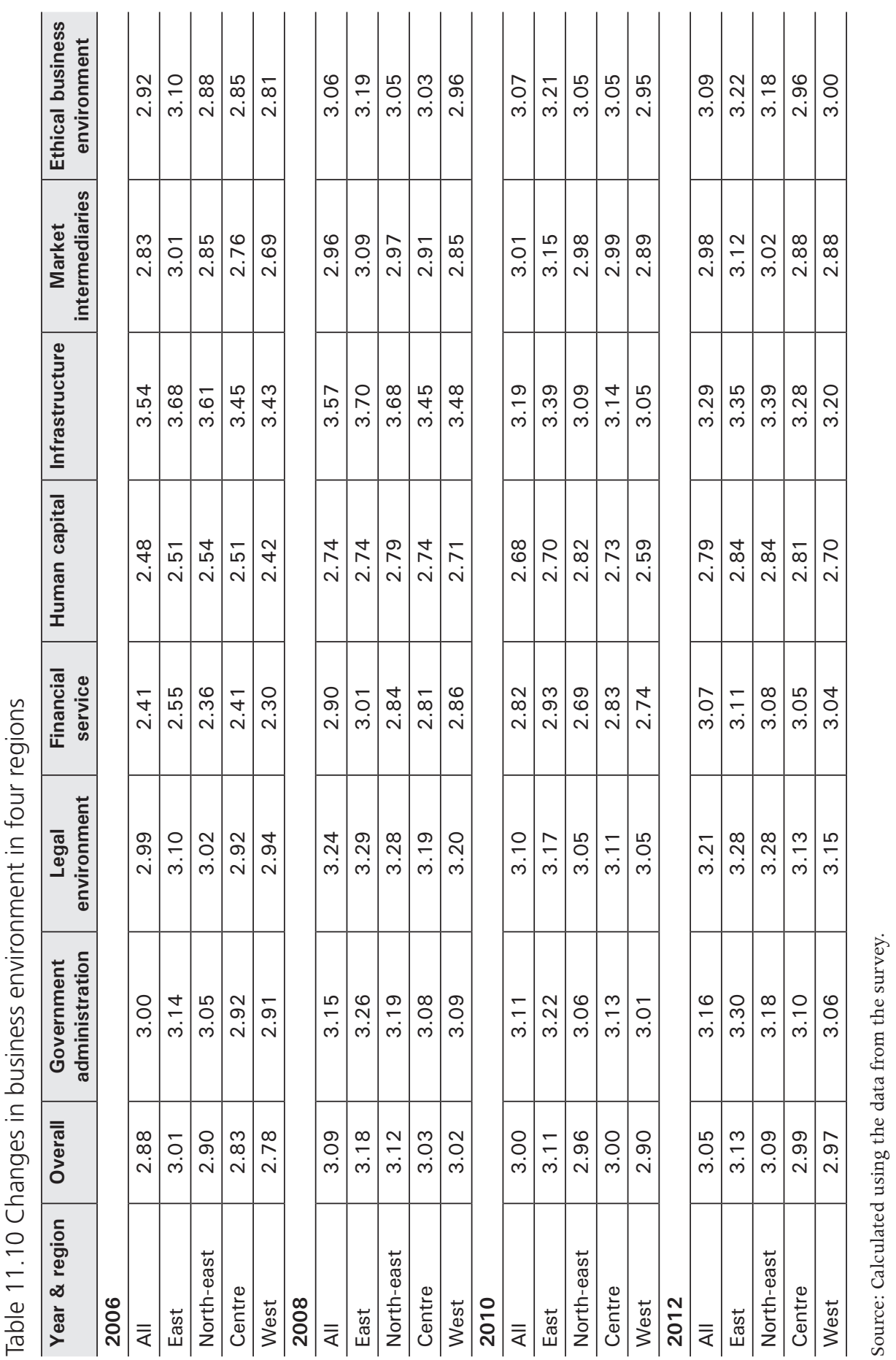




\section{Conclusions}

Based on the four enterprise surveys conducted in 2006, 2008, 2010 and 2012, this chapter reports changes and regional differentials in the business environments of China's provinces in recent years, and discusses some of the policy implications. On the basis of the surveys, we constructed the BEIFCP, which is used to assess changes in eight areas of the business environment.

The results show, first, a general improvement in the business environment of China during the 2006-2012 period. We also identified, however, some of the developments that could negatively affect that environment. For example, the expansionary fiscal policy adopted by the government in response to the GFC over the sample period had the effect of squeezing out normal business demand for credit and, therefore, affected the non-state sector negatively. An alternative approach could be to adopt those measures that could mitigate the negative effects on the market mechanism, such as tax reduction for SMEs, public expenditure on education and social security, and protection of the environment.

Secondly, the top-ranking provinces in terms of business environment continue to be those in the eastern regions, even though the relative rankings change somewhat over the period. The survey data also show that there is a trend of convergence in the business environment across different provinces and this highlights the need, especially for those provinces in the central and western regions, to do more in improving their business environment.

Thirdly, most of the complaints that were expressed by surveyed firms concentrated on the aspect of 'openness, fairness, and equity' of policies and government administration. The problems experienced with this aspect of administration include the non-transparency of policies and government administration, unfair enforcement of regulations, and unequal treatment for different enterprises. Other issues with this area arise from 'inefficiency of government administration', 'non-necessary government intervention' and 'cleanness of government officials'. This result indicates the necessity of government sector reform, especially in terms of transparency, policy equity, self-discipline of the government, and public monitoring in order to further improve the business environment.

Fourthly, sectors with sufficient market competition are found to have a better business environment than those monopolised sectors in general, which illustrates the positive role played by the market in allocating resources. The results also show that there are some kinds of discriminatory practices that distinguish between SOEs and NSEs, which, in general, have a negative effect on the operation and performance of NSEs. It is necessary to adjust 
relevant government policies to ensure both kinds of enterprises experience equal treatment. It is also a priority for the government to improve the business environment for small and micro enterprises, to standardise practices and apply fair implementation of the laws and regulations governing business activities in China.

\section{Appendix: The Structure and Calculation Method of the Index}

The BEIFCP consists of an overall index, eight area indexes, 19 sub-indexes and a total of 28 basic indexes. The overall index, area indexes and sub-indexes are available at the provincial, regional and national levels, and also for different types of enterprises and different sectors.

All the original data are from the surveys with enterprise owners or general managers who were asked to assess different aspects of the local business environment.

For developing the basic indexes, the percentage of each assessment in effective samples at the provincial level was used to derive weighted average scores. The average scores of a few basic indexes form a sub-index, and the average of a few sub-indexes constitute an area index. The overall index is an average of eight area indexes.

There are different methods for calculating an index system, including expert assessment, principal component analysis, and arithmetic averages. The expert assessment method relies on a group of experts who assess the weight of each indicator according to their relative importance, and then derive the weighted average for indexes. The principal component analysis method utilises correlations among variables to reduce the number of variables. In empirical studies it usually chooses the first-principal component that is based on certain hypotheses. Unlike the arithmetic average method, these two methods evaluate variables of different weights in different ways.

The following considerations led us to adopt the arithmetic average method in this study:

- The expert assessment method frequently exhibits arbitrary qualities, as evidenced by the same variables being given different weights by different expert groups, or the same expert group gives different weights to similar indicators on different occasions. This reduces the credibility of this method.

- The method of principal component analysis relies on hypotheses, which may not be sufficiently rational. Moreover, in time series analysis, the 
weights of variables generated by the principal component analysis method change over time and, thus, the calculation lacks comparability over years. The arithmetic average method does not have this shortcoming.

- Some international studies, and our own research experiences (e.g., Fan, Wang and Zhu 2011), indicate that when the number of variables is sufficiently large, both principal component analysis and arithmetic average method produce similar results, which show that they have a relationship of substitution.

Based on these considerations we believe that the arithmetic average method is a reasonable choice for this study.

In Table 11.A1, we provide the entire structure of the BEIFCP, including all the area indexes, sub-indexes and basic indexes.

Table 11.A1 The structure of the BEIFCP

\begin{tabular}{|c|c|}
\hline Name of index & $\begin{array}{l}\text { Category ot } \\
\text { the index }\end{array}$ \\
\hline 1. Government administration & Area index \\
\hline 1.1 Openness, fairness, and equity & Sub-index \\
\hline 1.1.1 Transparency of policies and regulations & Basic index \\
\hline $\begin{array}{l}\text { 1.1.2 Fairness of regulation enforcement by administrative } \\
\text { bodies }\end{array}$ & Basic index \\
\hline 1.1.3 Equal treatment of different enterprises & Basic index \\
\hline 1.2 Government efficiency & Sub-index \\
\hline 1.2.1 Convenience of obtaining administrative admissions & Basic index \\
\hline 1.3 Unnecessary government intervention & Sub-index \\
\hline 1.3.1 Over-intervention by the local government & Basic index \\
\hline $\begin{array}{l}\text { 1.3.2 Proportion of time spent by firm managers dealing with } \\
\text { government officials }\end{array}$ & Basic index \\
\hline 1.3.3 If entering a market is over restricted & Basic index \\
\hline 1.4 Government cleanness & Sub-index \\
\hline 1.4.1 Cleanness of government officials & Basic index \\
\hline 1.4.2 Informal payment of the form to gov. officials & Basic index \\
\hline 2. Legal environment for business & Area index \\
\hline 2.1 Fairness and efficiency in enforcement of laws & Sub-index \\
\hline 2.1.1 Efficiency of judiciary authorities & Basic index \\
\hline 2.1.2 Fairness of judiciary act & Basic index \\
\hline 2.2 Protection of the legal rights of business people & Sub-index \\
\hline 2.2.1 Implementation of firm contracts & Basic index \\
\hline 2.2.2 Security of the personal property of business people & Basic index \\
\hline 2.2.3 Protection of intellectual property rights & Basic index \\
\hline 3. Tax and non-tax burden of firms & Area index \\
\hline
\end{tabular}




\begin{tabular}{|c|c|}
\hline Name of index & $\begin{array}{l}\text { Category of } \\
\text { the index }\end{array}$ \\
\hline 3.1 Tax burden of firms & Sub-index \\
\hline 3.1.1 Tax burden of firms & Basic index \\
\hline 3.2 Fees, collections and charges outside state regulation & Sub-index \\
\hline 3.1.2 Proportion of fees, collections and charges to total sales & Basic index \\
\hline 4. Financial services & Area index \\
\hline 4.1 Formal financial services & Sub-index \\
\hline 4.1.1 Difficulty of obtaining bank loans & Basic index \\
\hline 4.1.2 Extra charge for loans outside the interest & Basic index \\
\hline 4.2 Informal finance & Sub-index \\
\hline 4.2.1 Difficulty of borrowing money from informal channels & Basic index \\
\hline 5. Human resource supply & Area index \\
\hline 5.1 Technicians & Sub-index \\
\hline 5.1.1 Difficulty of finding technicians locally & Basic index \\
\hline 5.2 Managers & Sub-index \\
\hline 5.2.1 Difficult of finding managers locally & Basic index \\
\hline 5.3 Skilled workers & Sub-index \\
\hline 5.3.1 Difficulty of finding skilled workers locally & Basic index \\
\hline 6. Infrastructure conditions & Area index \\
\hline 6.1 Power supply & Sub-index \\
\hline 6.1.1 Power supply & Basic index \\
\hline 6.2 Rail transport & Sub-index \\
\hline 6.2.1 Rail transport & Basic index \\
\hline 6.3 Other infrastructure & Sub-index \\
\hline 6.3.2 Other infrastructure & Basic index \\
\hline 7. Market intermediaries and technical and export services & Area index \\
\hline 7.1 Market intermediaries & Sub-index \\
\hline 7.1.1 Local services of lawyers and accountants & Basic index \\
\hline $\begin{array}{l}\text { 7.1.2 Development of local guilds and their helpfulness to } \\
\text { business }\end{array}$ & Basic index \\
\hline 7.2 Technical and export services & Sub-index \\
\hline 7.2.1 Local conditions of technical and export services & Basic index \\
\hline 8. Ethical business environment & Area index \\
\hline 8.1 Local ethical business environment & Sub-index \\
\hline 8.1.1 Local ethical business environment & Basic index \\
\hline
\end{tabular}

Source: Authors' summary. 


\section{References}

Fan Gang, Wang Xiaolu, and Zhu Hengpeng, 2011, NERI Index of Marketization of China's Provinces: 2011 Report, Economic Sciences Press.

National Statistical Bureau, 2012, China Statistical Yearbook 2012, China Statistics Press.

State Council Office for the Second National Economic Census and National Statistical Bureau, 2009, 'The Second National Economic Census Bulletin', the National Statistical Bureau website.

Transparency International, 2011, '2010 Corruption Perceptions Index', http://www.transparency.org/policy_research/surveys_indices/cpi/2010.

Wang Xiaolu, Fan Gang, and Liu Peng, 2008, 'Business Environment for China's Entrepreneurs 2007', in Li Lan (ed.), China's Macro Environment for Enterprises: Entrepreneurs vs Economists, Machinery Industry Press.

Wang Xiaolu, Fan Gang, and Li Feiyue, 2012, Business Environment Index: 2011 Report, China CITIC Press.

World Bank, 2004, World Development Report 2005: A Better Investment Climate for Everyone.

World Bank, 2006, Governance, Investment Climate, and Harmonious Society: Competitiveness Enhancement for 120 Cities in China.

World Bank, 2011, 'Doing Business 2011: Making a Difference for Entrepreneurs', http://www.doingbusiness.org/reports/global-reports/doing-business-2011. 


\section{Will Chinese Industry Ever Be 'Green'?}

Shiyi Chen and Jane Golley

\section{Introduction}

In January 2013, as air pollution reached record levels in much of eastern China, Chinese multimillionaire Chen Guangbiao sold cans of air on the street in smog-ridden Beijing to send a simple message: 'I want to tell mayors, county chiefs and heads of big companies: don't just chase GDP growth, don't chase the biggest profits at the expense of our children and grandchildren and the cost of sacrificing our ecological environment'. ${ }^{1}$ As a temporary response to the 'hazardous' air quality in Beijing, with particulate matter readings reaching over 40 times those considered safe by the World Health Organisation, the municipal government temporarily shut down more than 100 heavily polluting factories and ordered 30 per cent of government vehicles off the roads. ${ }^{2}$ It is clear (pardon the pun), however, that these emergency measures are not longterm solutions, with the transition towards a new model of economic growth now widely considered to be an imperative, not an option.

This imperative is reflected in the World Bank's report China 2030, which states that: 'It is clear that however global carbon budgets may be allocated via national actions and international negotiations over the next twenty years, there will never be enough carbon emission space for China to copy the past industrialisation model of developed countries' (2012: 235). One of the six key characteristics of the report's proposal for a 'New Development Strategy for 2030' is the concept of green development, 'a pattern of development that decouples growth from heavy dependence on resource use, emissions and environmental damage, and promotes growth through the creation of new green products, technologies, investments, and changes in consumption and conservation behaviour' (2012: 233).

Given the dominance of industry in generating China's aggregate carbon dioxide emissions (at 86 per cent of the country's 8.2 billion tons in 2010), a sustainable pattern of industrial growth will be a critical component of the transition towards a green, low-carbon economy. Traditionally, a rising share of total-factor productivity (TFP) in output growth has been taken as a signal of

1 'Chinese Millionaire Fights Pollution with Thin Air', 30 January 2013, Reuters, available at http://www.reuters.com/article/2013/01/30/us-china-pollution-cans-idUSBRE90T0LM20130130

2 'Beijing Shuts Factories, Removes Cars, but Pollution Stays High', Reuters, available at http://www.reuters.com/article/2013/01/29/us-china-pollution-idUSBRE90SOAJ20130129 
the transformation towards a 'sustainable' development model based on quality rather than quantity; that is, on intensive rather than extensive growth (Solow 1957; Krugman 1994; Young 1995). There have been many studies assessing the contribution of TFP to China's economic growth since 1978, with ongoing debates about whether and when its development model has made this transformation. ${ }^{3}$ Most of these studies use Solow residuals or regressions based on Cobb-Douglas (CD) or translog production functions to estimate productivity, while some use parametric stochastic frontier production functions and others utilise data envelopment analysis (DEA). In much of the existing literature, however, measures of productivity have been calculated using data that only includes the traditional inputs of capital and labour, neglecting both the energy inputs required for economic growth and their environmental impacts. ${ }^{4}$ Even if these measures were to reveal a rising and, at some point, dominant share of TFP in output growth, this neglect surely raises questions about the true sustainability of the evolving growth model.

There is a range of alternative measures for evaluating a country's development performance, which take these issues into account; for example, by incorporating energy as an intermediate input in the production process (as in the KLEM model of Jorgenson et al. 1987), or by treating emissions as an unpaid and unobservable input in the production function (Mohtadi 1996). In our view, however, none of these measures accurately accounts for the negative externalities associated with emissions generated in the production process. In contrast, the directional distance function (DDF), (Chung et al. 1997), incorporates an emissions variable as an undesirable output directly into the production function, which enables an explicit evaluation of the negative impact of emissions growth on a country's production frontier using DEA analysis. This results in a measure of TFP growth known variously as actual, total, environment-sensitive, or green TFP (henceforth GTFP), which can be separated into efficiency and technical change components.

There have been wide applications of this approach outside China, ${ }^{5}$ but only a few on China to date. For example, one analysis (Hu et al. 2008) uses DDF to rerank the technical change and efficiency of Chinese provinces once energy and emissions are taken into account, and shows different rankings compared to the more traditional measures (e.g. Zheng and Hu 2005). A 2010 study (Wang et al.) estimates Chinese regional-level TFP and finds that changes in GTFP and TFP deviate from each other, with GTFP suffering mainly from the over-emission

3 See Wu (1995, 2008); Woo (1998); Young (2003); Bosworth and Collins (2008); and, Jefferson et al. $(2000,2008)$ for a sample of a large list. Chen et al. 2011 provide a recent survey of this literature.

4 One exception is Chen (2009), who includes both energy and carbon dioxide emissions as input factors in China's growth accounting to estimate the productivity growth of 38 Chinese industrial sectors for the period 1980-2006.

5 For examples, see Hailu and Veeman 2000; Jeon and Sickles 2004; and 2006. 
of sulphur dioxide and chemical oxygen demand. Another study ( $\mathrm{Tu} 2008$ ) estimates only China's regional environmental efficiency, but not productivity, while this chapter does both below. Furthermore, none of these studies conduct their analysis at this chapter's high level of industrial disaggregation.

This chapter uses DEA and the DDF to estimate the changing patterns of GTFP growth of 38 industrial sectors during the period 1980-2010 to assess whether Chinese industry is on the path towards a sustainable form of low-carbon growth or not. Unfortunately, as will become clear below, it seems to have lost its way.

\section{Method and Data}

DEA is a nonparametric linear programming method for estimating a production frontier with multiple inputs and outputs. A comparison with the best-practice frontier enables the identification of each inefficient decisionmaking unit (DMU) and its relative efficiency value, as revealed by its distance from the frontier. ${ }^{6}$ There are numerous different specifications of emissions ${ }^{7}$ within the DEA framework, which rely on different distance functions to calculate productivity indexes that can then be separated into efficiency and technical change components. Below, three alternative specifications are considered: one in which emissions are ignored altogether (Model 1); one in which they are treated as a desirable output (or good), using the Shephard distance function (Model 2); and one that treats emissions as an undesirable output (or bad) using the directional distance function (Model 3).

We use a panel dataset of 38, two-digit industrial sectors between 1980 and 2010, classified according to the 2002 version of the National Standard of Industrial Classification (GB/T4754) and developed by Chen (2011). Each sector is classified as a DMU, which produces a desirable output (measured as industrial value added (IVA) at 1990 prices) and an undesirable output (carbon dioxide emissions) using three inputs, capital, labour and energy. The capital stock cannot be obtained directly and is estimated using the perpetual inventory approach, depreciated at constant 1990 prices of investment in fixed assets. The labour input is annual average employed workers and the energy input is total energy consumption, measured in tons of coal equivalent (TCE). Total energy is sourced from coal, petroleum, natural gas and electricity, each of which has a different emission factor. The quantity of emissions (measured in tons) for each sector is calculated by multiplying the quantity of each energy source by its emission factor and summing across all sources.

6 See the pioneering work of Farrell 1957 and Charnes et al. 1978.

7 We focus on carbon dioxide emissions in this chapter, although the approach can readily be applied to other emissions as well. For ease of reference, we use 'emissions' to refer to carbon dioxide emissions for the remainder of the chapter. 
Figure 12.1 illustrates the DEA method for models 2 and 3 (but not Model 1, since it does not measure emissions). Technology is represented by the output set $P(\mathbf{x})$ to which the output vector of point $(\mathbf{y}, \mathbf{b})$ belongs, where $\mathbf{y}$ is the good (IVA) and $\mathbf{b}$ is the bad (emissions). Linear programming is used to calculate the value of the distance function for each DMU (i.e., sector) at a fixed point in time. In the case of Model 3, the directional distance function (DDF) increases IVA and simultaneously reduces emissions for a given level of inputs, by scaling from point $\mathrm{A}$ in the direction along $\mathrm{AB}$, represented by the direction vector $\mathbf{g}=(\mathbf{y},-\mathbf{b})$. In contrast, the more commonly used Shephard distance function (SDF) used in Model 2 radially scales the original vector from point A proportionally to point $\mathrm{C}$ to describe the simultaneous increase in both IVA and emissions. The key difference between the two models relates to their assumptions about the disposability of bads. In particular, the assumption of strong or free disposability of bads in SDF implies that disposing of them costs nothing, whereas the weak disposability assumption of bads in DDF implies that the disposal of bads is costly (i.e., requiring the diversion of inputs to achieve this end, or non-zero mitigation costs). The latter seems a far better representation of reality, which is why Model 3 is our preferred model.

Figure 12.1 The directional and Shephard distance functions

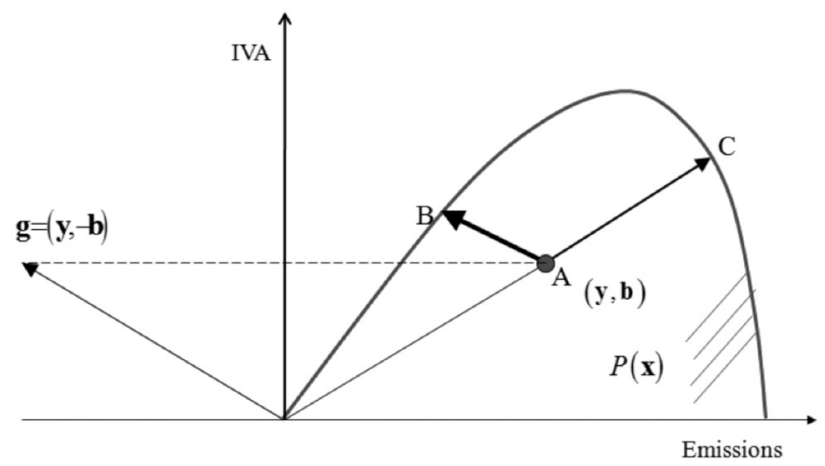

Source: Authors' schema.

In models 1 and 2, TFP is estimated by computing the Malmquist productivity index whereas, in Model 3, GTFP is estimated by calculating the Malmquist-Luenberger productivity index, which explicitly credits an increase in good outputs and a proportional reduction of bad outputs. Both productivity indexes (PI) can be decomposed into an efficiency index (EI) and a technical change index (TI). If there have been no changes in either inputs or outputs between two points in time, then $\mathrm{PI}=1$, while an improvement (deterioration) in productivity is signaled by $\mathrm{PI}>1$ ( $\mathrm{PI}<1)$. EI measures the change in output efficiency between two periods, reflecting the movement of each DMU either towards $(\mathrm{EI}>1)$ or away from $(\mathrm{EI}<1)$ the frontier. TI measures the shift in the production frontier between two time periods. If technical change enables higher production of goods and lower production of bads (i.e., a shift of the production 
frontier towards the north-west), then TI $>1$; whereas $\mathrm{TI}<1$ implies a shift of the frontier in the direction of fewer goods and more bads. All of these indices can be converted to average annual growth rates to provide a more familiar indication of the performance of Chinese industry over time in terms of productivity, efficiency and technical change. Positive (negative) growth rates in all cases correspond to indexes greater (less) than one.

Figure 12.2 China's aggregate industrial energy and emissions, 1980-2010

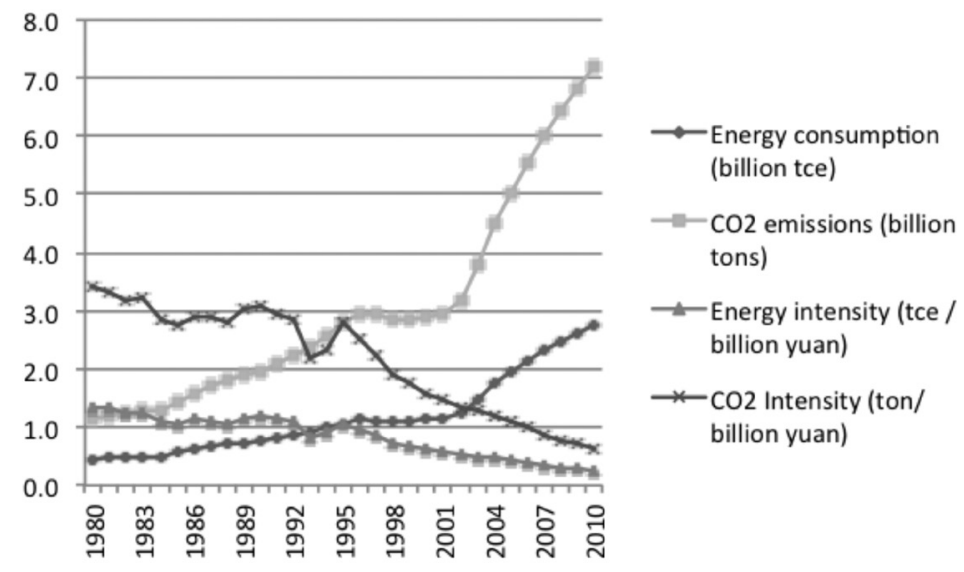

Source: Industrial dataset described in the text and authors' calculations.

Before presenting these estimates, Figure 12.2 illustrates the aggregate trends in levels of energy consumption and emissions, along with their intensities (with aggregate IVA in the denominator), as revealed by our dataset. This combination of trends reflects the rapid growth of industrial output, which has resulted in a dramatic rise in emissions in the last decade, despite the steady reduction in intensity over time.

Table 12.1 presents the IVA, emissions and emission intensities of each industrial sector in 2010 and the growth rates of IVA and emissions for the period 1980-2010. Not surprisingly, there is substantial heterogeneity across sectors. The largest emitter of carbon dioxide in 2010 is the electric- and heat-power sector, generating over three billion tons. Another five heavy-industrial sectors emitted over 400 million tons each - petroleum, coking and nuclear fuel processing (listed in the table as petrol processing); ferrous metal smelting and pressing; non-metal manufactures; coal mining; and chemicals - compared with 'just' 900,000 tons for the lowest emitting sector, cultural, sports and educational articles. Of course, high emissions do not necessarily imply high emission intensity, as they may, instead, be due to high levels of output. The overlap is significant, however, with the top five emission-intensive sectors being petroleum, coking, and nuclear fuel processing; electric and heat power; coal mining; petroleum and natural gas extraction; and gas production and supply. 
China: A New Model for Growth and Development

Table 12.1 Levels and growth of key variables by sector

\begin{tabular}{|c|c|c|c|c|c|}
\hline \multirow[t]{2}{*}{ Sector } & \multicolumn{3}{|c|}{ Levels (2010) } & \multicolumn{2}{|c|}{ Growth $(1980-2010, \%)$} \\
\hline & IVA & Emissions & $\begin{array}{l}\text { Emission } \\
\text { intensity }\end{array}$ & IVA & Emissions \\
\hline Total industry & 11,333 & $7,188.6$ & 634 & 12.6 & 6.4 \\
\hline Coal mining & 152 & 438.5 & 2,881 & 8.7 & 5.5 \\
\hline Petrol. extraction & 26 & 71.0 & 2,766 & 2.0 & 4.0 \\
\hline Ferrous metal mining & 59 & 3.0 & 51 & 14.7 & 3.4 \\
\hline Non-F. metal mining & 50 & 1.8 & 37 & 10.1 & -0.2 \\
\hline Non-metal mining & 63 & 14.5 & 231 & 7.3 & 5.5 \\
\hline Logging & 7 & 1.3 & 181 & 1.1 & -2.5 \\
\hline Food processing & 331 & 33.8 & 102 & 13.2 & 3.8 \\
\hline Food manu. & 162 & 20.7 & 128 & 13.9 & 2.7 \\
\hline Beverages & 221 & 15.7 & 71 & 13.3 & 3.1 \\
\hline Tobacco & 260 & 1.8 & 7 & 12.1 & 1.6 \\
\hline Textiles & 450 & 46.4 & 103 & 9.1 & 1.7 \\
\hline Apparel & 212 & 4.2 & 20 & 14.3 & 6.5 \\
\hline Leather & 106 & 1.7 & 16 & 13.3 & 0.2 \\
\hline Wood processing & 177 & 8.9 & 50 & 16.6 & 3.2 \\
\hline Furniture & 79 & 0.6 & 8 & 13.6 & -0.1 \\
\hline Paper & 172 & 82.2 & 479 & 12.2 & 5.9 \\
\hline Printing & 89 & 0.9 & 10 & 11.2 & -1.6 \\
\hline Cultural articles & 59 & 0.4 & 7 & 13.5 & 1.0 \\
\hline Fuel processing & 44 & $1,688.7$ & 38,181 & 2.6 & 6.7 \\
\hline Chemicals & 628 & 416.4 & 663 & 11.3 & 4.1 \\
\hline Medicine & 370 & 14.0 & 38 & 16.5 & 3.6 \\
\hline Fibers & 85 & 14.3 & 168 & 13.9 & 1.8 \\
\hline Rubber & 108 & 9.1 & 84 & 10.9 & 2.0 \\
\hline Plastic & 260 & 8.7 & 33 & 15.4 & 6.2 \\
\hline Nonmetal manu. & 550 & 492.6 & 895 & 11.1 & 6.2 \\
\hline Ferrous smelt/press & 437 & 576.4 & 1,319 & 10.6 & 5.3 \\
\hline Non-F. smelt/press & 248 & 58.3 & 235 & 12.8 & 6.8 \\
\hline Metal products & 327 & 7.1 & 22 & 12.2 & 1.4 \\
\hline General machines & 641 & 9.6 & 15 & 12.6 & -1.7 \\
\hline Special machines & 404 & 12.9 & 32 & 12.2 & 0.6 \\
\hline Transport equip. & 1,018 & 19.7 & 19 & 17.9 & 1.2 \\
\hline Electrical equip. & 865 & 12.4 & 14 & 15.9 & 3.4 \\
\hline Electronic equip. & 2,014 & 4.4 & 2 & 24.3 & 1.5 \\
\hline Measuring inst. & 166 & 0.6 & 3 & 14.0 & -1.0 \\
\hline Electric \& heat power & 301 & $3,059.7$ & 10,152 & 9.9 & 8.6 \\
\hline Gas & 18 & 27.2 & 1,517 & 11.4 & 3.3 \\
\hline Water & 7 & 0.5 & 63 & 6.7 & 4.1 \\
\hline Others & 164 & 8.7 & 53 & 12.5 & -1.0 \\
\hline
\end{tabular}

Note: IVA - billions of yuan, emissions - millions of tons, intensity - tons/million yuan.

Source: Industrial dataset described in text and authors' calculations.

One piece of good news here is that none of the top five sectors in terms of emissions levels or intensities are in the top ten fastest growing, or the top ten largest sectors in terms of IVA. Another is that in only two of the 38 sectors 
(petroleum processing and petroleum and natural gas extraction) did the growth of emissions exceed that of IVA over the period, suggesting that the downward trend in emission intensity shown in Figure 12.1 has been industry wide, not sector specific. Emissions growth, however, was only negative in a handful of sectors, providing an early indication that GTFP is likely to be higher, not lower, than the more traditional TFP estimates. More generally, the data summarised in Figure 12.2 and Table 12.1 highlight the magnitude of the challenges facing China as it attempts to decouple the rapid growth of industrial production from that of energy use and emissions.

\section{China's Industrial GTFP Growth, 1980-2010}

The average annual growth rates of Chinese industry's productivity, efficiency and technical change between 1980 and 2010, weighted by the IVA share for each sector and averaged geometrically over the sample period for each of the three models specified above, are reported in Table 12.2 .

Table 12.2 Growth of productivity, efficiency and technical change in Chinese Industry, 1980-2010

\begin{tabular}{l|c|c|c}
\hline & $\begin{array}{c}\text { Model 1 } \\
\text { (Ignore emissions) }\end{array}$ & $\begin{array}{c}\text { Model 2 } \\
\text { (Emissions as good) }\end{array}$ & $\begin{array}{c}\text { Model 3 } \\
\text { (Emissions as bad) }\end{array}$ \\
\hline Productivity & $5.5^{* *}$ & $4.4^{* *}$ & 1.8 \\
\hline Efficiency & $0.9^{* *}$ & $0.8^{*}$ & -0.1 \\
\hline Technical change & 4.7 & $3.7^{*}$ & 2.0 \\
\hline
\end{tabular}

Note: Null hypothesis of the $t$ test is that the estimated productivity, technical progress and efficiency of models 1 and 2 are identical to those estimated by model $3 .{ }^{* * *},{ }^{* *},{ }^{*}$ indicate that the level of significance is $1 \%, 5 \%$ and $10 \%$, respectively.

Source: Industrial dataset described in text and authors' calculations.

According to Model 1, the growth of TFP, efficiency, and technical change were 5.5 per cent, 4.7 per cent and 0.9 per cent, respectively. Productivity is lower when emissions are included as a good in Model 2, and this reduction is almost entirely due to lower technical change, indicating that the inclusion of emissions impacts mainly on the location of the production frontier, rather than on the movement of individual sectors towards or away from the frontier over time.

Based on our preferred model, Model 3, the average annual growth rates of GTFP, technical change and efficiency between 1980 and 2010 were 1.8 per cent, two per cent and -0.1 per cent, respectively. Like TFP, this indicates that improvements in China's GTFP have resulted from technical change rather than efficiency improvements, which is consistent with findings based on traditional measures (e.g., Wu 1995 and Zheng et al. 2003). Indeed, at this aggregate industry level, there appears to have been a backwards step in terms of latter (indicated by $\mathrm{EI}<1$, or the negative growth rate seen in Table 12.2). The GTFP 
growth estimated by Model 3 is less than the estimates of models 1 and 2, and all the measures surveyed by Chen et al. (2011), apart from the 1.8 per cent estimate by Wing Thye Woo (1998). The estimates of efficiency and technical change contained in Model 3 are also smaller than those of models 1 and 2, although the difference between the technical change estimates of models 1 and 3 is not statistically significant (see note under Table 12.2).

Figure 12.3 illustrates the change in aggregate industrial GTFP growth and its components over time. Through the 1980s, GTFP growth remained low, and was even negative at times, before experiencing a long and steady increase through the 1990s to peak at 4.2 per cent in 2002 , followed by a continuous decline since then to reach just half a per cent in 2010. As the figure illustrates, the rise and fall of China's GTFP has been driven by the rise and fall in technical change, while efficiency has fluctuated at low levels throughout the period of analysis.

Figure 12.3 Growth rates of GTFP, efficiency and technical change

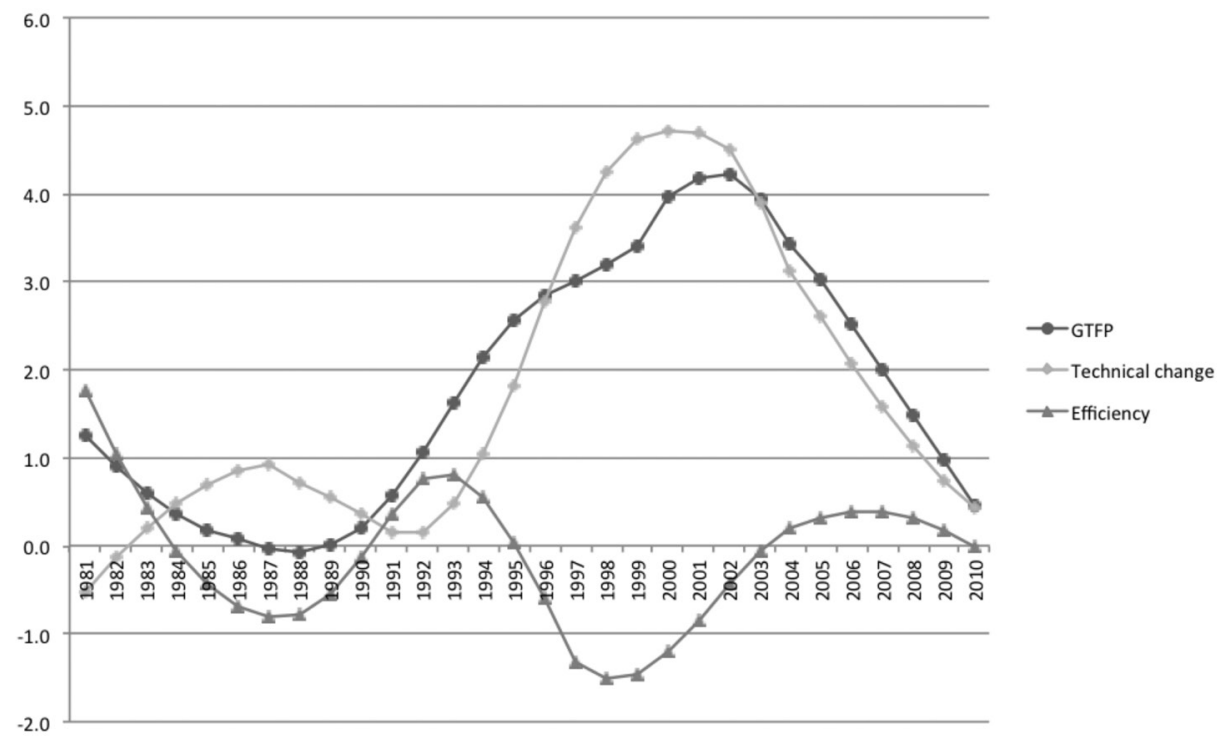

Source: Industrial dataset described in the text and authors' calculations.

Table 12.3 takes a closer look at the aggregate-level productivity results for the entire period and for three distinct sub-periods. Following Chen et al. (2011), and because of the varying patterns of energy consumption and emissions, the reform period is classified into three sub-periods: 'slow and steady' (1980-1995), stagnant (1996-2002), and rapid growth (2003-2010). For each period we report the average annual rate of growth of IVA, emissions, capital, labour, energy and productivity (TFP or GTFP) from each of the three models, averaged over the 38 sectors. Over the entire period, and for each sub-period, capital and energy are the dominant contributors to growth in terms of inputs. During the period 
1996-2002, energy consumption and emissions grew by their lowest annual rate (hence 'stagnant') while labour growth was negative. These figures contrast starkly with the rapid growth of energy and emissions in the most recent period, at over ten per cent each.

Table 12.3 Average annual growth rates of outputs, inputs and productivity (\%)

\begin{tabular}{|c|c|c|c|c|c|c|c|c|}
\hline \multirow{2}{*}{ Period } & \multirow{2}{*}{ IVA } & \multirow{2}{*}{ Emissions } & \multirow{2}{*}{ Capital } & \multirow{2}{*}{ Labour } & \multirow{2}{*}{ Energy } & \multicolumn{3}{|c|}{ Productivity } \\
\hline & & & & & & Model 1 & Model 2 & Model 3 \\
\hline $1980-1995$ & 8.5 & 5.9 & 9.8 & 3.7 & 5.7 & $\begin{array}{c}1.4 \\
(17 \%)\end{array}$ & $\begin{array}{c}1.2 \\
(14 \%)\end{array}$ & $\begin{array}{c}0.9 \\
(10 \%)\end{array}$ \\
\hline $1996-2002$ & 12.6 & 2.8 & 5.8 & -2.9 & 3.0 & $\begin{array}{c}10.1 \\
(80 \%)\end{array}$ & $\begin{array}{c}6.4 \\
(51 \%)\end{array}$ & $\begin{array}{c}3.9 \\
(31 \%)\end{array}$ \\
\hline $2003-2010$ & 21.1 & 10.2 & 11.0 & 4.6 & 10.1 & $\begin{array}{c}10.6 \\
(50 \%)\end{array}$ & $\begin{array}{c}8.5 \\
(40 \%)\end{array}$ & $\begin{array}{c}2.1 \\
(10 \%)\end{array}$ \\
\hline $1980-2010$ & 12.6 & 6.4 & 9.3 & 2.6 & 6.3 & $\begin{array}{c}5.5 \\
(44 \%)\end{array}$ & $\begin{array}{c}4.4 \\
(35 \%)\end{array}$ & $\begin{array}{c}1.8 \\
(14 \%)\end{array}$ \\
\hline
\end{tabular}

Note: For each period, the numbers in brackets report the contribution share of each productivity estimate to IVA growth, equal to 100 minus the share of all inputs.

Source: Industrial dataset described in the text and authors' calculations.

The first key message from Table 12.3 is that, by accounting for the negative impact of energy-related emissions in Model 3, productivity estimates in all subperiods are below the traditional estimates. Similar to the findings in Table 12.2, for each period the estimates of productivity growth for models 1 and 2 are greater than the corresponding estimates for Model 3, with the only exception being Model 2 in the first sub-period.

The figures in brackets in Table 12.3 indicate the percentage contribution of TFP (for models 1 and 2) and GTFP (for Model 3) to the growth of IVA, revealing the second key message of Table 12.3. According to the traditional estimate of Model 1, TFP accounted for 80 per cent of output growth between 1996 and 2002, and one half of it between 2003 and 2005, supporting claims that growth has been predominantly intensive, rather than extensive since the mid 1990s. When emissions are included in Model 3, however, GTFP accounted for only 32 per cent of IVA growth in the second period, falling to 10 per cent in the third. Furthermore, the productivity contribution estimated by all three models decreased between the second and third periods.

The first two columns of Table 12.4 present the average annual growth rates of TFP, and GTFP and its components for each sector between 1980 and 2010. The combination of growth rates of IVA and emissions for each sector shown in the final two columns of Table 12.1 are useful for understanding the differences between the TFP and GTFP results reported in Table 12.4. Each sector's productivity growth depends on both the change in that sector's input-output combination between two points in time, and the shape of the production frontier near that combination at the initial point in time. As long as frontier production of the good increases when output of the bad increases 
(as we would typically expect), the relative values of TFP and GTFP depend not only on the growth in emissions between the two points in time, but also on this growth relative to that of output (Jeon and Sickles 2004). The standard and most intuitive case is where GTFP growth rates are less than TFP growth rates because emissions growth is positive: simply put, emissions growth is penalised in the 'green' estimate. This was the case in coal mining, ferrous metal mining, and another 27 sectors, and in aggregate in Table 12.3. The other intuitive case, in which GTFP growth is higher than TFP growth because emissions growth is negative, occurred in just two sectors, logging and 'others'.

In another five sectors (non-ferrous metal mining, furniture, printing, general machines and measuring instruments), even though emissions growth is negative, GTFP is still lower than TFP because the fall in emissions growth is small relative to the increase in IVA growth (for example, -0.1 per cent versus 13.6 per cent respectively for furniture). Finally, there is one perverse result, the petroleum extraction sector, in which emissions growth exceeds IVA growth and yet GTFP is greater than TFP ( 0.1 per cent compared with -1.3 per cent). As one study explains (Jeon and Sickles 2004), this might happen because of limited data in the neighbourhood of this sector (which is likely, given its high ranking in terms of emission intensity) and because the production frontier in that neighbourhood does not necessarily expand in the direction of more IVA, even with an increase in emissions.

Table 12.4 also presents the growth rates of efficiency and technical change for each sector between 1980 and 2010. As for the aggregate results illustrated in Figure 12.3, technical change is the dominant source of GTFP growth in virtually all sectors, peaking at an average annual rate of 6.3 per cent in the electronics sector, and recording positive values in all but one sector (petroleum, coking and nuclear fuel processing). In contrast, efficiency recorded negative growth in 28 sectors and was greater than one per cent in just two sectors (electronics and electric and heat power).

In amongst the pessimistic news is the slightly consoling fact that GTFP growth was positive in all but three sectors over the first three decades of reform. But, does this signal the transformation of industry towards a sustainable, lowcarbon, intensive model of growth? The answer is an emphatic no. The final three columns of Table 12.4 show the contribution of GTFP to output growth in each sector for the three time periods. Between the first two periods, this contribution increased in 28 of the 38 sectors, and in the second period GTFP accounted for more than half of IVA growth in five sectors, and for more than 20 per cent in another 12 sectors. Between the second two periods, however, the contribution of GTFP fell in 34 of the 38 sectors and, in the third period, it only exceeded a half in one sector (tobacco) and was greater than 20 per cent in just another three. This, combined with the other evidence presented in this section, signals a setback in the low-carbon transformation of Chinese industry in recent years. 
Table 12.4 TFP, GTFP, Efficiency and technical change across sectors and time

\begin{tabular}{|c|c|c|c|c|c|c|c|}
\hline \multirow[b]{2}{*}{ Sector } & \multicolumn{4}{|c|}{$\begin{array}{l}\text { Av. annual growth } \\
(1980-2010, \%)\end{array}$} & \multicolumn{3}{|c|}{$\begin{array}{l}\text { Share of GTFP in IVA growth } \\
\qquad(\%)\end{array}$} \\
\hline & TFP & GTFP & Effic. & Tech & $1980-95$ & $1996-2002$ & 2003-10 \\
\hline Coal mining & 2.7 & 0.0 & -0.1 & 0.1 & 0.2 & 0.6 & -0.0 \\
\hline Petrol. extraction & -1.3 & 0.1 & -0.7 & 0.8 & 15.5 & -1.4 & 0.2 \\
\hline Ferrous metal mining & 4.1 & 0.7 & -0.2 & 0.9 & 7.4 & 7.5 & 1.7 \\
\hline Non-F. metal mining & 3.7 & 0.8 & -0.4 & 1.1 & 5.8 & 24.8 & 4.2 \\
\hline Non-metal mining & 1.5 & -0.1 & -1.0 & 0.9 & -4.2 & -4.4 & 0.6 \\
\hline Logging & -0.4 & 0.1 & -0.6 & 0.7 & -4.6 & 19.8 & -9.0 \\
\hline Food processing & 1.7 & 0.3 & -0.2 & 0.5 & 2.1 & 3.6 & 1.5 \\
\hline Food manu. & 3.2 & 0.3 & -0.1 & 0.4 & 2.2 & 4.2 & 0.9 \\
\hline Beverages & 1.4 & 0.5 & -0.2 & 0.8 & 3.7 & 12.7 & 1.9 \\
\hline Tobacco & 5.6 & 2.6 & -0.0 & 2.6 & -12.4 & 44.3 & 68.7 \\
\hline Textiles & 0.3 & 0.3 & -0.4 & 0.7 & 5.0 & 7.1 & 1.1 \\
\hline Apparel & 5.9 & 1.7 & -1.5 & 3.3 & 13.4 & 24.4 & 5.3 \\
\hline Leather & 6.6 & 2.1 & -0.2 & 2.3 & 16.8 & 31.0 & 8.2 \\
\hline Wood processing & 5.5 & 1.0 & -0.1 & 1.1 & 7.1 & 15.9 & 1.9 \\
\hline Furniture & 7.1 & 2.6 & -0.1 & 2.7 & 19.0 & 30.7 & 15.2 \\
\hline Paper & 2.2 & 0.1 & -0.1 & 0.2 & 1.0 & 1.3 & 0.2 \\
\hline Printing & 9.1 & 2.7 & -0.3 & 3.0 & 32.0 & 27.0 & 15.3 \\
\hline Cultural articles & 8.4 & 3.7 & -0.6 & 4.3 & 23.6 & 53.3 & 20.9 \\
\hline Fuel processing & -0.6 & -2.4 & -1.5 & -0.9 & 315.5 & 56.1 & -42.3 \\
\hline Chemicals & 3.3 & 0.1 & -0.1 & 0.1 & 0.9 & 0.6 & 0.2 \\
\hline Medicine & 4.2 & 2.5 & 0.0 & 2.5 & 4.8 & 34.8 & 14.6 \\
\hline Fibers & 8.9 & 0.4 & -0.0 & 0.4 & 1.6 & 4.4 & 3.9 \\
\hline Rubber & 1.0 & 0.4 & -0.3 & 0.7 & 4.7 & 6.9 & 1.4 \\
\hline Plastic & 7.1 & 1.4 & -0.7 & 2.1 & 7.4 & 29.8 & 1.2 \\
\hline Nonmetal manu. & 2.6 & 0.0 & -0.1 & 0.1 & 0.1 & 1.1 & 0.2 \\
\hline Ferrous smelt/press & 3.1 & 0.0 & -0.1 & 0.1 & 0.7 & 0.4 & -0.4 \\
\hline Non-F. smelt/press & 3.4 & 0.1 & -0.3 & 0.4 & 0.1 & 1.5 & 0.4 \\
\hline Metal products & 6.6 & 1.4 & -0.5 & 1.9 & 13.2 & 24.9 & 5.2 \\
\hline General machines & 9.1 & 1.7 & 0.0 & 1.7 & 16.7 & 25.3 & 7.6 \\
\hline Special machines & 8.1 & 1.0 & -0.2 & 1.2 & 14.2 & 13.4 & 3.2 \\
\hline Transport equip. & 9.7 & 1.5 & 0.1 & 1.4 & 10.6 & 8.6 & 6.3 \\
\hline Electrical equip. & 9.4 & 3.3 & -0.2 & 3.5 & 20.8 & 36.2 & 12.2 \\
\hline Electronic equip. & 19.3 & 8.4 & 1.9 & 6.3 & 30.7 & 54.8 & 21.9 \\
\hline Measuring inst. & 11.2 & 5.4 & 0.2 & 5.2 & 25.3 & 64.4 & 39.0 \\
\hline Electric \& heat power & 7.5 & 1.5 & 1.3 & 0.2 & 29.5 & 43.6 & -10.0 \\
\hline Gas & 5.5 & -0.0 & -0.0 & 0.0 & 0.5 & 0.0 & 0.1 \\
\hline Water & 1.1 & -0.1 & -2.2 & 2.1 & -1.9 & 50.4 & 3.3 \\
\hline Others & 2.4 & 2.5 & 0.1 & 2.4 & 6.9 & 109.3 & 15.2 \\
\hline
\end{tabular}

Source: Industrial dataset described in text and authors' calculations. 


\section{Policy Implications}

It is worth noting that the average annual growth of aggregate industrial output (measured by IVA) was 12.6 per cent between 1996 and 2002, a period in which the vast majority of sectors recorded their lowest output growth but also enjoyed their highest rate of GTFP growth. In contrast, aggregate output grew at a whopping 21.2 per cent in 2003-2010, with virtually all sectors recording their highest output growth in this period but also reduced rates of GTFP growth. Do these results imply that low-carbon growth can only be achieved by slower economic growth or, conversely, that rapid economic growth can only be achieved by incurring high, and increasingly intolerable, environmental costs?

According to the World Bank (2012: 233), the answer is no: The world's development process is at a crossroad. Given the unsustainability of current economic growth both in China and the world, a new approach is needed. The concept of green development is such an approach. Green development can become a potentially transformative process for the economy, society, the environment, and the role of government. It is an opportunity: an open door.

The report outlines the mix of market incentives, regulations, public investments, industrial policy and institutional developments that China plans to use in order to seize the opportunity to 'go green', including ways to 'encourage new investments in a range of low-pollution, energy- and resource-efficient industries that would lead to greener development, spur investments in related upstream and downstream industries and services and build international competitive advantage in a global sunrise industry' (World Bank 2012: xvi).

Within this new growth strategy, emerging green industries, including clean energy markets (solar-, wind-, and hydro-power), biotechnology, highend manufactures and clean-energy vehicles, will be supported by new incentives for innovation and research that are intended to make China a world leader in key green technologies and products. Almost 40 per cent of China's RMB4,000 billion (US $\$ 584$ billion) fiscal stimulus package, which was launched in November 2008, was allocated to green themes, while Chinese investment in renewable energy became the world's largest in 2009, reaching more than US\$20 billion (Robins et al. 2009). These are just two examples of steps that could result in the significant expansion not only of China's own production frontier, but of the global frontier as well, enabling technical progress to become a strong driver of productivity growth and putting China's industrial GTFP back on track in the years ahead. The Chinese leadership's ongoing commitment to green, low-carbon development, as evidenced by the adoption of these and numerous other energy-saving and emission-abating policies and regulations in recent years, will be absolutely critical for turning this potential into reality. 
The 'green transformation' of traditional sectors is another crucial component of the green growth strategy, with the focus on energy-efficient investments that will yield high economic returns. For example, the report cites the fact that, although Chinese cement makers have reduced their energy intensity by 30 per cent between 1998 and 2009, they are still 30 per cent less efficient than global best practice, while China's iron and steel industry could potentially save more than 100 million tons of coal per year. In combination, these two industries could save an average of US\$9.9 billion per year between 2008 and 2030 by using the best energy-saving technologies currently available, with even greater savings given future possible energy price trajectories and technological advances. In other words, there is potential for efficiency gains that will move individual sectors towards both China's and the global production frontier, raising their GTFP in the process.

\section{Conclusions}

Any effort to account for the environmental costs of economic growth comes with practical challenges, including how to weight carbon dioxide (and other) emissions in the absence of prices and/or reliable estimates of the costs of the damage they inflict. The directional distance function (DDF) uses the Malmquist-Luenberger productivity index to overcome this problem by penalising emissions growth in proportion to rewarding output growth, with the underlying presumption being that 'consumers have preferences for reducing bad outputs regardless of the actual damage resulting from those outputs' (Färe et al. 2001: 382). This may appear to some as an extreme way of assessing a country's economic - or industrial - growth performance. But then, desperate times call for desperate measures, and the image of Chen Guangbiao selling canned air to masked customers in Beijing is a powerful symbol of the desperate extent of China's environmental problems.

This chapter uses DEA analysis and the DDF to estimate 'green' TFP and its components for 38 Chinese industrial sectors between 1980 and 2010, focusing on the damage caused by high and rising carbon dioxide emissions. The results reveal that China's industrial GTFP growth estimated in this way is significantly lower than productivity estimates that do not account for the negative impact of carbon dioxide emissions generated in the production process. Throughout the sample period, both in aggregate and for the majority of sectors, GTFP growth has been predominantly shaped by technical change, which increased steadily from the mid 1990s to the early 2000s, but which has declined continuously since then, in contrast with fluctuating but generally low rates of efficiency growth. GTFP growth was positive in the majority of sectors and in aggregate, both over the entire period and in each sub-period. The most worrying sign, 
however, was that between 2003 and 2010 GTFP growth was not only low (and well below the 50 per cent level that is often taken to signal the transition to 'sustainable' growth), but also lower than it was in the preceding decade. This trend is not in the direction that the Chinese leadership, or anyone else, is hoping for. GTFP and its components offer a useful tool for assessing whether China is progressing towards its goal of becoming a green, low-carbon economy. With the most recent evidence indicating that Chinese industry seems to have lost its way on what remains a long road ahead, some may wonder whether it will ever be green? It is far from guaranteed, but there is definitely hope.

\section{Acknowledgments}

Shiyi Chen acknowledges the support from National Natural Science Foundation (71173048), National Social Science Foundation (12AZD047), Ministry of Education (11JJD790007), Shanghai Leading Talent Project and Fudan Zhuo-Shi Talent Plan.

\section{References}

Bosworth, B., \& Collins, S.M., 2008, 'Accounting for Growth: Comparing China and India', Journal of Economic Perspectives, vol. 22, no. 1, pp. 45-66.

Charnes, A., Cooper, W., \& Rhodes, E., 1978, 'Measuring the Efficiency of Decision-Making Units', European Journal of Operational Research, vol. 2, pp. 429-44.

Chen, K., Wang, H., Zheng, Y., Jefferson, G.H. \& Rawski, T.G., 1988, 'Productivity Change in Chinese Industry: 1953-1985', Journal of Comparative Economics, vol. 12, no. 4, pp. 570-91.

Chen, S., 2009. 'Engine or Drag: Can High Energy Consumption and CO2 Emission Drive the Sustainable Development of Chinese Industry?', Frontier of Economics in China, vol. 4, no. 4, pp. 548-71.

_ 2011, 'Estimates of Sub-industrial Statistical Data in China (1980-2008)', China Economic Quarterly (Jing-Ji-Xue Ji-Kan), vol. 10, no. 3, pp. 735-76.

Chen, S., Jefferson, G.H. \& Zhang, J., 2011, 'Structural Change, Productivity Growth and Industrial Transformation in China', China Economic Review, vol. 22, no. 1, pp. 133-50. 
Chung, Y.H., Färe, R. \& Grosskopf, S., 1997, 'Productivity and Undesirable Outputs: A Directional Distance Function Approach', Journal of Environmental Management, vol. 51, pp. 229-40.

Färe, R., Grosskopf, S. \& Pasurka, Jr. C.A., 2001, 'Accounting for Air Pollution Emissions in Measures of State Manufacturing Productivity Growth', Journal of Regional Science, vol. 41, no. 3, pp. 381-409.

Farrell, M., 1957, 'The Measurement of Productive Efficiency', Journal of the Royal Statistical Society, Series A (General), vol. 120, no. 3, pp. 253-81.

Hailu, A. \& Veeman, T.S., 2000, 'Environmentally Sensitive Productivity Analysis of the Canadian Pulp and Paper Industry, 1959-1994', Journal of Environmental Economics and Management, vol. 40, pp. 251-74.

Hu, A., Zheng, J., Gao, Y., Zhang, N. \& Xu, H., 2008, ‘Provincial Technology Efficiency Ranking with Environment Factors (1999-2005)', China Economic Quarterly (Jing-Ji-Xue Ji-Kan), vol. 7, no. 3, pp. 933-60.

Jefferson, G.H., Rawski, T.G., Wang, L. \& Zheng, Y., 2000, 'Ownership, Productivity Change, and Financial Performance in Chinese Industry', Journal of Comparative Economics, vol. 28, no. 4, pp. 786-813.

Jefferson, G.H., Rawski, T.G. \& Zhang, Y., 2008, 'Productivity Growth and Convergence across China's Industrial Economy', Journal of Chinese Economic and Business Studies, vol. 6, no. 2, pp. 121-40.

Jeon, B.M. \& Sickles, R.C., 2004, 'The Role of Environmental Factors in Growth Accounting', Journal of Applied Econometrics, vol. 19, no. 5, pp. 567-91.

Jorgenson, D.W., Gollop, F. \& Fraumeni, B., 1987, Productivity and U.S. Economic Growth, Harvard University Press, Cambridge, MA.

Krugman, P., 1994, 'The Myth of Asia's Miracle', Foreign Affairs, vol. 73, no. 6, pp. 62-78.

Kumar, S., 2006, 'Environmentally Sensitive Productivity Growth: A Global Analysis using Malmquist-Luenberger Index', Ecological Economics, vol. 56, no. 2, pp. 280-93.

Mohtadi, H., 1996, 'Environment, Growth and Optimal Policy Design', Journal of Public Economics, vol. 63, pp. 119-40.

Robins, N., Clover, R. \& Singh, C., 2009, 'A Climate for Recovery: The Colour of Stimulus goes Green', HSBC Global Research, 25 February, pp. 1-45. 
Solow, R.M., 1957, 'Technical Change and the Aggregate Production Function', Review of Economics and Statistics, vol. 39, pp. 312-20.

Tu, Z., 2008, 'The Coordination of Industrial Growth with Environment and Resource', Economic Research Journal (Jing-Ji Yan-Jiu), vol. 2, pp. 93-105.

Wang, B., Wu, Y. \& Yan, P., 2010, 'Environmental Efficiency and Environmental Total Factor Productivity Growth in China's Regional Economies', Economic Research Journal (Jing-Ji Yan-Jiu), vol. 5, pp. 95-109.

Woo, W.T., 1998, 'Chinese TFP: The Role from Labor Reallocation in Agricultural Sector', Economic Research Journal (Jing-Ji Yan-Jiu), vol. 3, pp. 31-39.

World Bank, 2012, China 2030: Building a Modern, Harmonious and Creative High-Income Society, International Bank for Reconstruction and Development, Washington D.C., http://www.worldbank.org/content/dam/Worldbank/ document/China-2030-complete.pdf

Wu, Y., 1995, 'Productivity Growth, Technological Progress, and Technical Efficiency Change in China: A Three-Sector Analysis', Journal of Comparative Economics, vol. 21, no. 2, pp. 207-29.

— 2008, 'The Role of Productivity in China's Growth: New Estimates', China Economic Quarterly (Jing-Ji-Xue Ji-Kan), vol. 7, no. 3, pp. 827-42.

Young, A., 1995, 'The Tyranny of Numbers: Confronting the Statistical Realities of the East Asian Growth Experience', Quarterly Journal of Economics, vol. 110, pp. 641-80.

— 2003, 'Gold into Base Metals: Productivity Growth in the People's Republic of China during the Reform Period', Journal of Political Economy, vol. 111, no. 1, pp. 1220-61.

Zheng, J. \& Hu, A., 2005, 'An Empirical Analysis of Provincial Productivity in China (1979-2001)', China Economic Quarterly (Jing-Ji-Xue Ji-Kan), vol. 4, no. 2, pp. 263-96.

Zheng, J., Liu, X. \& Bigsten, A., 2003, 'Efficiency, Technical Progress, and Best Practice in Chinese State Enterprises (1980-1994)', Journal of Comparative Economics, pp. 134-52. 


\section{Can China Achieve Green Growth?}

Yongsheng Zhang

\section{Introduction}

In 1978, after over 100 years of decline, China embarked on a journey to restore its status as the world's largest economy. From the early 1500s until the early 1800s, China's economy was the world's largest. By 1820, it accounted for one-third of the world's gross domestic product (GDP). The next two centuries, however, were tumultuous for China. The country experienced catastrophic decline between 1820 and 1950 and then, starting in 1978, it experienced meteoric rise (Maddison 2001). After reform and opening up in 1978, China started to catch-up with the western world with an average of 10 per cent annual growth rate over the past three decades. It now takes the second place in the world, with its per capita GDP increasing from US\$154 in 1978 to US\$6,060 in 2012. It is widely expected that around 2020, China's economy will overtake that of the United States and regain its first place in the globe if the economic boom continues, or even if it slows down a little. As such, China is likely to become a high-income society with per capita earning reaching the average level of the OECD by 2030 (WB/DRC 2013: 3).

Nonetheless, China faces unprecedented challenges resulting from its unsustainable traditional growth model, which is characterised by high resource consumption and severe environmental degradation. To successfully accomplish its modernisation, China must achieve the following two significant transformations. First, China must rebalance its development between economic and social undertakings, internal and external demands, urban and rural areas, as well as different regions. In this regard, China can draw on best practices from developed countries. Second, China has to take a green growth path that represents the future trend. The first transition, to a large extent, is an internal issue for China, while the second transition is a common issue shared by all nations of the world. China needs to make the two above transitions at the same time, as it is no longer feasible for China to achieve its modernisation target by simply continuing along the pathways previously taken by industrialised countries. China should jump over the current unsustainable development mode and instead directly modernise its economy in a green way, in order to be a frontrunner in international competition as it joins the high-income nations club. 
Green growth could play a significant role in China's modernisation. The barriers for China to achieve green growth do not stem from investment or technology, but instead from its distorted market system. China has unique advantages to achieve green growth and leapfrog to modernisation in a green way, but it also has many institutional obstacles to overcome. This chapter aims to identify the opportunities, advantages, barriers to, as well as the path for China to accomplish green growth. The second section introduces new thinking on how to understand green growth; the third section focuses on opportunities for green growth in China; the fourth section analyses the advantages and disadvantages of green growth in China; and, the fifth section elaborates upon the unfinished reforms aimed at achieving green growth in China.

\section{New Thinking on Green Growth}

\section{Understanding Green Growth in a New Way}

It's vital to understand green growth in a new way. Green growth is an unprecedented new development pattern which decouples growth from a heavy dependence on use of material resources, carbon emissions, and environmental damage, in order to promote growth through the creation of new green products markets, technologies, and investments, as well as changes in consumption and conservation behaviour. It is based on three key concepts. The first, that economic growth may be decoupled from rising greenhouse gas emissions and environmental degradation. Secondly, that the process of 'going green' can itself be a source of growth and, thirdly, that 'going green' is part of a virtuous circle which is mutually reinforcing with growth. Green growth is the means by which green development is achieved (WB/DRC 2013: 217). Green growth represents enormous opportunities and is the inevitable trend that China must follow. That said, the opportunities behind green growth are not evident to everyone. To comprehend the opportunities, a new thinking is needed.

First, it is difficult to understand the opportunities behind green growth in conventional industrialised thinking. Traditional industrialisation, which began with the Industrial Revolution, has been based on material resources input, and has been coupled with high carbon emissions, high-energy consumption and environmental damage. Consequently, 'going green' seems to contradict economic growth in nature and is bound to be a burden of growth. Some think green growth is merely an issue related to the need for energy efficiency improvement, renewable energy utilisation or cutting-edge technology development. This type of understanding of green growth is too narrow to fully recognise the opportunities behind it. 
Second, it is hard to understand green growth when using the analytical framework of marginal analysis focusing on optimising resource allocation in a given economic structure. Under a given economic structure, emission reduction is largely dependent on cutting resource input, and it seems to inevitably result in decreased output. In fact, 'going green' refers to changes that occur when an economic organisation jumps to a more competitive structure of division of labour, which is likely to accelerate economic development. According to Adam Smith (1776) and Allyn Young (1928), evolution of division of labour is the spring of economic growth. The insight was revived by Xiaokai Yang (2001) with inframarginal analysis, which is particularly powerful for investigating green growth driven by changes to economic structures.

A typical example may explain how the two misunderstandings above stop us from understanding green growth properly. A popular argument questioning green growth is that there does not exist sufficient evidence proving the feasibility of green growth. In this case, government is not convinced to take serious action in promoting green growth before sufficient evidence emerges. Nonetheless, the problem is that green growth is a self-fulfilling process, and the evidence and actions are interdependent. If the government does not take serious action on reducing emissions and protecting the environment, it is very hard for green growth evidence to become apparent. And this is the biggest dilemma for green growth. If the government and public take muscular action with confidence, then resources will be allocated in the green direction and the economy would jump from a non-green structure to a green structure, yielding green growth. Otherwise, economic development will never jump to the new model and instead it will lock on to the traditional non-green path. Nevertheless, the analytical framework of conventional marginal analysis fails to predict the inframarginal changes arising from the structure of division of labour.

It is difficult to fully understand the essence of green growth and see the opportunities behind it if green growth is understood in a traditional sense. Green growth perhaps represents the most profound and comprehensive transformation since the Industrial Revolution, and could bring about changes in all aspects of society including production, living, consumption, organisation and business models.

\section{New Context for Green Growth}

Aside from the new thinking, green growth can't be sufficiently understood unless it is put into the larger picture of new revolutions including the rapid development of information and communication technology (ICT), big data, new materials (like nano technology), or high-speed railway. In essence, the core of all the changes is the unprecedented improvement of transaction efficiency. 
As Smith (1776) pointed out, the spring of economic growth is the division of labour that is determined by the extent of the market, while the latter is determined by transaction efficiency. As Coase (1937) notes, the key to determine economic organisational structure is transaction efficiency. Specifically, the dramatic improvement of transaction efficiency is reflected as follows:

- Changes of information flow: Information dissemination is growing exponentially in terms of speed and content with the fast development of ICT, big data, and cloud data.

- Changes of people flow: People move much more conveniently and faster than ever before with the progress of high-speed railway, highways, aviation and the increased popularity of private cars.

- Changes of logistics: Transportation speed of goods is significantly boosted with quick and convenient logistics systems.

Consequently, the dramatic enhancement of transaction efficiency results in two outcomes, First, it gives birth to many new business, Second, it brings about many new business models or economic organisations. The function of entrepreneurs is to maximise profits through efficiently organising division of labour by using product market or factor market. With higher transaction efficiency, the room for businessmen to organise division of labour is largely expanded and a higher level of division of labour can be developed, which represents economic growth potential (Yang 2001).

In practical terms, the world is witnessing enormous changes that differ from those of traditional industrial society. The changes are not only to the context in which green growth develops, but the changes are themselves green growth.

First, the definition of resources is changing. Old resources may become valueless while some resources, previously seen as useless, may become valuable. For example, individual information is not valuable if it is scattered, but, once connected by ITC and big data, it forms part of an invaluable resource and, as a result, varieties of new business models appear (see examples such as Twitter and Facebook). Natural environment is another example. Due to underdevelopment, the ecological environment in poor regions is conserved and it now becomes a vital resource and can be translated into wealth. It's the same case for fossil fuel, which became more valuable during the Industrial Revolution.

Second, the business model is shifting. The function of entrepreneurs is to find the most efficient way to organise division of labour in the market. As the dramatic increase of transaction efficiency driven by the development of ICT, big data, high-speed railway, transportation systems and logistics systems, the 
room for them to organise division of labour is dramatically increasing as well. Under the same resource scarcity, a more efficient structure of division of labour means higher productivity.

Third, consumption patterns are also changing. As smart phones and internet become common, people's demands for goods and services are changing significantly. For instance, internet-based requirements for new, nonmaterial services are dramatically increasing. The change of consumption means a decrease in the scarcity of natural resources.

Fourth, the production model is shifting and the so-called third industrial revolution is emerging. In the future, manufacturing is likely to turn from a centralised and massive production model into a distributed and individual model. It is not impossible for countries with poor manufacturing capacities to leapfrog to the era of digital manufacturing. And traditional agriculture promises to be a profitable business. When it comes to services, changes are also significant. For example, the internet-based revolution in educational models, such as Courser or Khan Academy, enables everyone to access to the best educational resources in the world. Thanks to the non-competitive nature of educational resources, the cost does not increase with the rise in the number of users. This internet-based educational model provides opportunities for building the knowledge-based economy, which is conducive to improvement in the environment.

The changes elaborated above are just part of the comprehensive changes that are happening. A striking feature of the changes is that they all have the effect of decreasing scarcity of resources and emitting less pollution per unit of output. That means that green growth cannot be narrowly understood as the stories of new energy, or a few cutting-edge high technologies. In fact, green growth is the most profound and comprehensive transformation of development mode since the Industrial Revolution, and the potential for green growth is much bigger than many thought. Nonetheless, the opportunities of green growth can only be comprehended if its nature is properly understood.

\section{Opportunities of Green Growth in China}

Green growth is likely to not only be a new engine for economic progress, but also to improve the quality of growth in China (WB/DRC 2013).

First, 'going green' can be a new source of economic growth. In the process of green transformation, the upgrading of traditional industries and the emergence of new green industries, including green services, provide new drives for 
economic progress. Moreover, it will consume fewer resources, emit less carbon, and become more environmental friendly per unit of output. The sources fall into three categories.

\section{Green Transformation of Traditional Sectors}

Many existing techniques and management patterns will not only help in conserving energy and reducing pollution, but also increasing profit. For instance, according to estimates by McKinsey \& Company (2009), installing light-emitting diodes(LEDs) for lighting in buildings could generate US $\$ 25$ billion in annual financial savings by 2030, compared to business as usual (measured in 2009 dollars). Improving passive heating through design modifications could provide another US $\$ 6$ billion. Together, the potential for direct savings through efficiency gains in China could be as high as US\$65 billion per year by 2030, if the full technical and economic potential of these so-called 'no-regret' options can be realised (WB/DRC 2013: 224).

Though these figures are estimates only, it is certain that traditional sectors have great potential for 'going green'. Though the effects of upgrading traditional sectors are not as dramatic and revolutionary as the effects of a few cutting-edge green technologies, its potential for 'going green' is huge due to its massive scale.

\section{Expansion of Emerging Green Industries}

Green industries involve all industries with low levels of pollution and greenhouse gas emissions. In the narrow sense, it refers to industries represented by clean energy sectors, mainly solar energy, wind energy and related device manufacturing and electric vehicles. Cost reductions and technological progress in renewable energy technologies in China have exceeded expectations, mostly due to a massive scaling-up in the industry. In renewable energy, the cost of both wind energy and solar photovoltaic (PV) equipment has decreased dramatically during the past five years (Feng \& Wang 2011).

\section{Expansion of Service Sectors}

Ecosystem service has become a big industry in some countries. Instead of making money through selling wood, farmers in some economically poor regions in China now make their living by providing ecosystem services. There are also other new green services, such as carbon asset management, carbon trade, energy performance management, environment assessment, climatic-risk disclosure, and integrated solutions for urban management. Certainly, most traditional service industries are green, and China has great potential in these sectors. 
Second, green growth can improve the quality of growth in China. The benefits for improving the environment are numerous - it not only enhances people's welfare and health conditions, but also mutually reinforces economic growth. Japan's experience also shows that, even under stringent environmental policies, its economy has been expanding more rapidly without environmental policy. Moreover, preventive environmental policy is even more economically rewarding (Kobayashi 2011).

Green growth also promises to solve other problems, such as energy security, urban livability, and agricultural output augmentation. Rapid energy consumption will affect China's energy security. It's predicted that, under current energy policies, China is likely to be dependent on imports for 75 per cent of its petroleum (making it the world's largest oil importer) and 50 per cent of its natural gas requirements by 2030 (WB/DRC 2013). Traffic congestion and energy consumption can be relieved by strengthening land management for higher efficiency of use. Agricultural output can be enhanced by impeding the decrease of land fertility and water pollution.

\section{Advantages of China in Achieving Green Growth}

China has lots of advantages in promoting green growth (see WB/DRC 2013). Fundamentally, green growth relies on market forces. Nonetheless, the prerequisite for the market to function well in promoting green growth is that the government should play its role in reducing carbon emissions and forcefully protecting the environment. The determination of senior levels of government on green growth and effective decision-making mechanisms, as well as strong government execution, will, therefore, play a vital role for the country to promote green growth. In this respect, China has evident strengths. The Chinese Government has the ability to mobilise action on high priority issues and its senior leaders have already reached a consensus on the importance of green development. This commitment is also evident in the Work Program to Control Greenhouse Gas Emissions during the 12th five-year plan, in which the State Council makes clear that 'addressing climate change will accelerate economic restructuring and the reform of economic development, driving forward the opportunities of the next industrial revolution'. The following paragraphs outline an additional seven advantages that benefit China in seeking green growth. 
First, China enjoys the advantage of being a relative latecomer to industrialisation. Its relatively lower level of development gives it a room to meet its new demands by developing green productivity and infrastructures. In contrast, developed countries will have to shut down some old capacities in order to go green.

Second, a large domestic market allows China to scale-up its green sectors. As the world's second largest market, China is likely to embrace an even more rapid market expansion of green products and services over the next few years, since its domestic green market is still underdeveloped. As expected, the income of urban and rural residents will double by 2020, based on the 2010 level.

Third, China enjoys the advantages of abundant capital (including human capital) available to invest in its green sectors. Thanks to its high investment ratio, green industries are set to grow rapidly. In respect of human capital, in the 20 years to come, about 200 million Chinese students will graduate from school, providing green innovation with sufficient human resources (WB/DRC 2013).

Fourth, there is a huge potential for traditional sectors that are burdened with overall low efficiency to upgrade techniques. For example, it's promising to use coal in a clean way, given coal accounts about 70 per cent of total energy consumption in China.

Fifth, China has the potential to avoid lock-in effects of higher levels of nongreen urbanisation. Twenty years from now, China's urbanisation level will rise from 51 per cent to 65 per cent, with over 200 million farmers swarming into cities. That will bring about great potential for economic growth, and thereby green city construction will benefit from the avoidance of the lock-in effect.

Sixth, China has an abundant natural endowment of resources for clean energy including wind power, solar power, shale gas and methane, making the country less dependent on fossil fuels and freer to improve its energy security.

Lastly, with all of the above advantages, coupled with its strong manufacturing capacity as a 'world workshop', China is likely to be a major destination for commercialisation of green technologies worldwide. Green technologies can be produced, applied and sold in China no matter wherever they are invented. Green growth, therefore, not only provides opportunities for China, but also means opportunities for the rest of the world. 


\section{Unprecedented Challenges and Unfinished Structural Reforms}

\section{Unprecedented Challenges for China}

China has achieved remarkable progress in promoting green growth. At the moment, China is the world's largest renewable resources investor. Nonetheless, China has not given full play to its potential given that enormous challenges are yet to be overcome. The changes discussed in this chapter have two prominent features that act as an unprecedented challenge to China's current development model.

First, the changes challenge China's traditional government-led development model. Green growth that is based on ICT, big data and renewable resources is highly decentralised. Different from the conventional model driven by large and medium-sized companies, green growth is driven by networked small and medium enterprises (SMEs). This means the government-led model is not viable for green growth.

Second, the changes challenge the imitative model of China. As a catchingup economy, China has been copying Western economic models and is not innovatively creating its own. In the past all the models of economic organisation, industrial structure, and business models in industrial countries have been copied in China. Now, all of a sudden, green growth has become a global trend. In the case of green growth, China stands at the same frontier as the United States and Europe.

China must conduct in-depth reforms to meet the two challenges above. In essence, green growth is an institutional competition in which only those with creativity can stand out. Facing this pressing challenge, it is impossible for China to adopt a 'wait and see' strategy. Waiting for a mature green model to be developed by Western countries first in order to be copied by China is problematic.

There is no way for China to achieve modernisation with the existing unsustainable growth model (WB/DRC 2013). Furthermore, China would stay on the back foot even if it accomplished modernisation with the current model. Of course, higher prices must be paid in transferring to a green growth model from a lock-in status. China takes a long time to develop new industrial chains and business models and, in terms of green growth, early action is rewarding. For China, the window of opportunity is no longer than the next 20 years as this is the key period for China to become a high-income society. Once the window of opportunity is missed, China will have to pay a high price to in 'going green'. 


\section{Necessary Structural Reforms}

Enormous transitions are required for China to achieve green growth. The biggest barrier for China to promote green growth is not from capital or technology, but the failure in building effective market mechanisms. The following are the major reforms that need to be undertaken:

Type I reforms: transformation of government function. The biggest barrier is that the traditional pattern of governmental behaviour contradicts the inherent requirements of green growth. Green growth requires not only the development of green industries, but also that those industries be developed in a green way. Taking new energy industries as an example, China is now the largest new energy investor in the world. The so-called green industries, however, are not developed in a green way, but in a traditional high-pollution and high-emission way. Enjoying strong government support, those industries expanded too fast without sufficient innovation and risk resistance ability. Besides, domestic demand has not yet been fully developed. In the case of PV, 95 per cent of products were exported in 2012. The problem lies in the defective market economy and distorted government behaviour, which is a result of the existing GDP-oriented official performance evaluation system, and of the existing fiscal and tax system.

Type II reforms: consolidating the market economy. The most urgent reform related to green growth should be improving the pricing mechanism for resource products such as coal, electricity, gas and water to fully reflect their external hazard to the environment and health in exploitation, production and use, as well as to reflect their scarcity in the market. Meanwhile, the government should review and gradually remove the subsidies to the producer of resources and fossil fuel, and charge high royalties on natural resources (mineral products, oil, natural gas, shale gas, and coal bed methane) occupied by state-owned enterprises (SOEs). Moreover, it is also very important to break the monopoly and stimulate private investment in the resources and energy sector.

Type III reforms: tougher policies and regulations on emission reduction and environment protection. The prerequisite for green growth is that the government must control carbon emissions and forcefully protect the environment so as to reduce the social and coordination cost to the whole society, thereby allowing the market to function well. This kind of governmental action is actually a new public service and is consistent with the market economy. The government is obliged to make strict emission and environment policies. Moreover, the government should introduce flexible and effective policy implementation mechanisms, including market-based emission reduction mechanisms (e.g. emissions trading scheme, ETS). 
In terms of environmental protection, it is necessary to introduce marketoriented incentive mechanisms such as well-defined water rights that are enforced, ownership of land and forest, a water-rights market, emission-trading scheme, and land-use quota-trading markets. For example, farmers in poor areas would actively enhance the efficiency of land use if additional farmland quotas could be sold to developed regions. Another beneficial mechanism would be the improvement and expansion of Payments for Ecosystem Services (PES), especially in poor regions. The farmers would have the motivation to improve and protect the local ecological environment if they could get sufficient economic returns through providing ecosystem services.

In terms of laws and regulations, government should introduce tough standards for environmental protection, carbon emissions and energy efficiency improvement. For instance, introduction of a clean air Act; new standards for lighting and high fuel-efficiency for vehicles; new national standards for urban design and energy efficiency and emissions from transportation; and, identifiable green standards and labelling for products, services and techniques for consumers. Some outdated regulations, such as limits to the production of low-speed electric vehicles, need to be revised.

Type IV reforms: offsetting the negative impacts of green growth. In addition to the institutional factors, the resistance to green growth also comes from its inevitable negative impact on some industries, regions and groups. Businesses that have benefited from traditional growth models are likely to have originally opposed the 'going green' strategy. Since the comprehensive green strategy needs to reshuffle the power of some ministries, and some of their interest might be affected, they may oppose green strategy. In addition, though green strategy would bring prosperity in the long run, it may challenge some economic targets (e.g., industrial output targets) in the short run. To offset the negative impact of green growth, an incremental reform approach should be adopted, and some policy tools (e.g., subsidies and training programs for the affected individuals) should be put in place.

Type V reforms: fostering green industries. 'Going green' is a comprehensive and profound process. The government should employ various measures, including tax, finance, trade, standards and public investment, to foster the sources of green growth. For example, in the early stage, key green industries could be exempted from taxes for a limited period as part of the ongoing policy of structural tax cuts in China. In contrast, high-pollution, high-emission-and-resource products should be imposed with heavy taxes and gradually removed from the list of export tax rebates and limited for export. Meanwhile, the share of green products that enjoy rebates should be increased. 
Green enterprises should also be provided with preferential policies for loan, debt and financing. Also, green standards should be introduced in government procurement.

\section{Conclusion}

Green growth, as the most profound and comprehensive transformation of the development model since the Industrial Revolution, represents great opportunities, as well as formidable challenges for China. To seize the opportunities, we first need to understand what green growth really means. The opportunities of green growth cannot be seen in traditional industrialised thinking. We should understand the concept of green growth in new thinking and discuss it in the dynamic context of the new technology revolution.

China has many unique advantages in promoting green growth. At the same time, there are some major obstacles to be removed by deepening structural reform. The biggest barrier is not in the form of investment or technology, but instead in the form of institutional barriers. To seize the opportunities, the barriers should be overcome through structural reform. Moreover, the decentralised green growth model substantively challenges the traditional government-led centralised development model. For China, its strategic period of opportunities only exists in the coming 10 to 20 years. Once this opportunity period has passed, China will have to pay a much higher price for 'going green'.

\section{References}

Coase, Ronald, 1937, 'The nature of the firm', Economica, vol. 4, no. 16, pp. 386-405.

Feng F. \& Wang, J., 2011, 'Focusing on New Developments in Wind and Solar Power', Working Report 88, Development Research Center of the State Council, P.R. China.

Kobayashi, H., 2011, 'Basics of Eco-Business: Mutually Supportive Relationship between the Environment and the Economy', paper presented at the third international forum for sustainable Asia and the Pacific, Institute for Global Environmental Strategies, Yokohama, 26-27 July.

Maddison, Angus, 2001, The World Economy: A Millennial Perspective, OECD Publishing, Paris.

McKinsey \& Company, 2009, ‘China's Green Revolution: Prioritizing Technologies to Achieve Energy and Environmental Sustainability', http://www.mckinsey.com. 
Smith, Adam, 1776, An Inquiry Into the Nature and Causes of the Wealth of Nations, 1976 ed., E. Cannan, University of Chicago Press.

World Bank \& Development Research Center of the State Council, P.R. China, 2013, China 2030: Building a Modern, Harmonious, and Creative Society, Washington, DC.

Yang, Xiaokai, 2001, Economics: New Classicial Versus Neoclassical Frameworks, Blackwell Publishers Inc.

Young, Allyn, 1928, 'Increasing Returns and Economic Progress', The Economic Journal, vol. 38, pp. 527-42. 



\title{
14 China's Climate Change Mitigation in International Context:
}

\author{
Issues for Australia and China
}

\section{Ross Garnaut ${ }^{1}$}

\section{Introduction}

As the Chinese National Development and Reform Commission (NDRC) observes in its first survey of Chinese climate change policies, 'China is one of the countries most vulnerable to the adverse impact of climate change' (NDRC 2012).

It shares that reality with Australia, for which the extreme heat and bushfires of early 2013 join increasingly common extreme weather events that carry a climate change footprint.

We are two of the most vulnerable countries, but we share vulnerability with the whole of humanity. Extreme weather events have become more common and severe on all continents. Some of the manifestations of more common and severe extreme weather events - for example, as higher global food prices - have been felt everywhere.

The association of extreme weather events with climate change is complicated and confusing, because natural climate variability would anyway have introduced damaging extreme weather events from time to time. We can characterise the way that global warming has affected weather in probabilistic terms by thinking of any particular extreme outcome as being the result of the throwing of a standard dice with six faces. Natural variability would sometimes have generated a one or a six from the roll of the dice, and the average would have settled around three and a half. The early stages of global warming - the increase of a bit below one degree Celsius in average temperatures so far since

1 An earlier version of this chapter was presented as the opening address to the National Development and Reform Commission - State Information Centre Carbon Market Beijing International Workshop, Beijing, 31 January 2013. I am grateful for help from staff members of NDRC, Ian Davies for data for the paper and, Frank Jotzo, Stephen Howes and Ian Davies, for extensive comments. Remaining errors and misjudgements are my own. 
the concentrations of greenhouse gases began to build up strongly in the middle of last century - can be represented as having removed the one and replaced it with a seven. In the absence of effective global mitigation, we will replace the two by an eight, and then the three by a nine, with other replacements to follow. When the nine has replaced three, the average outcome from the throw of the dice will become six and a half. What once were one in 200-throw eventsan average of six over three throws - will have become average occurrences. We may still throw a four from time to time, but we will now sometimes see a nine, we will never again see a one and, the average outcome will be higher than the most extreme at the beginning.

This is the probabilistic sense in which climate scientists should be understood when they say that no particular extreme event can be said to be caused by global warming, but that extreme events will happen more often and the worst will be more extreme than before.

Climate change takes us into unknown territory for human civilisation.

Human civilisation emerged along the Yellow River and other great river valleys of Eurasia and North Africa over these past 12,000 years of equable temperatures, which scientists have called the Holocene. During this long period, average temperatures varied within a relatively narrow range - a range whose upper limits we are now breaching.

During the Holocene, human civilisation grew through the long accumulation of experience in governing populous states, of knowledge of many kinds, and much sharing of experience through friendly trade and deadly conquest. Sometimes the deadly conquest and trade came together: the Mongol conquerors destroyed state structures and disrupted ordinary life across much of Eurasia. They also brought the experience of the Persian state to China, and facilitated the long-distance trade that took the technological genius of Song China to Europe and provided building blocks for the industrial revolution.

Many people in many states contributed to the knowledge and institutional arrangements that lay the foundations for the emergence in Britain a quarter of a millennium ago of what we now recognise as modern economic growth.

Modern economic growth eventually delivered great bounties to people who embraced it. The bounties came with cost, disruption and pain. The cost and disruption caused hitherto successful societies like old China to be cautious and slow in embracing it. Its uneven distribution across humanity conferred great power upon its early hosts, giving rise to the phenomenon of imperialism, with its manifold iniquities. But, in the end, modern economic growth delivered higher 
living standards, more secure food and shelter, healthier and longer lives, more knowledge and experience of life for people who joined it. Modern economic growth came to be wanted by people all over the world.

Over the past quarter century humanity became aware that modern economic growth came with costs that had not been recognised in earlier times. There were incidental or external costs, which had to be managed and contained if they were not to destroy the natural conditions that nurtured the emergence of human civilisation and modern economic growth. One of these costs, the most urgent and dangerous, is human-induced climate change.

Modern economic growth draws on huge amounts of energy. The cheapest and most convenient way of securing much of the necessary energy was by burning fossil fuels. Fossil fuel combustion returned to the atmosphere some of the carbon dioxide that had once made the earth too hot for human life. The natural capture of carbon dioxide from the atmosphere through photosynthesis and its natural sequestration in the earth over hundreds of millions if not billions of years established the climatic conditions under which human civilisation emerged and prospered.

The accumulation of carbon dioxide in the atmosphere raises temperatures on earth. Humans are now creating the climate in which we must make our lives. Humanity has entered the anthropocene.

The brilliant species of which we are members has come an amazing distance in building civilisation over these last 12,000 and, especially, 250 years. The question is whether humanity can manage the external costs of its success. Can humanity manage the anthropocene?

People everywhere want the benefits of modern economic growth, built on high levels of energy use. When I discussed these matters with Deng Xiaoping over a quarter of a century ago, he said that by the middle of the twenty first century the people of China would enjoy the living standards of a middle income country, and that he hoped that they would then be satisfied. These were wise thoughts; but people in China, like people everywhere, are not easily satisfied, and want the best and the most that available technology and resources can give to them.

People everywhere want the living standards that are enjoyed by residents of the high-income economies. But if we seek to achieve those living standards by using energy in the quantities and forms that underpinned modern growth in the economies that are now developed, we will change the earth's climate in ways that are unlikely to be compatible with stable states and sustainable prosperity. 
The idea that the finite nature of fossil fuel resources would limit economic growth is an old one. It was a discussed a long time ago by some of the biggest names in economics and the other social sciences. W.S. Jevons discussed the coal-imposed limits to British growth one-and-a-half centuries ago (1865). Max Weber saw the wellsprings of capitalist economic growth running dry when 'the last ton of fossilized coal is burnt' (1905). In his classic 'Conditions of Economic Progress', which pioneered modern quantitative analysis of economic growth, Australian economist Colin Clark opined that we can calculate the likely amount of fossil fuel from the carbon that was once in the atmosphere. 'However, we must not set out to burn them up too fast, even if we do find them, at any rate not faster than the rate at which carbon dioxide can be stored by photosynthesis'. But, Clark added, economic growth itself need not be limited by the availability of fossil fuels: 'there is an abundance of solar energy falling on the earth if we know how to tap it' (1940).

Clark's view that economic growth can be sustained by shifting from fossil to renewable energy has been confirmed by contemporary economic analysis. Elaborate quantitative studies by Nicholas Stern (2007) for the world as a whole and myself (2008) for Australia showed that carbon emissions could be reduced to the low levels necessary to stabilise global temperatures at moderate costscosts that would slightly slow the growth in living standards in the early decades, and be much lower than the costs of unmitigated climate change after that.

The question of whether we can manage the anthropocene will be answered, yes or no, for humanity as a whole. It will not be yes for people living within some states and no for others. If rising temperatures and changing climate in the anthropocene corrode the physical foundations for human civilisation, there will be no pockets of respite in Hohot or Hobart, Jinan or Geelong, Beijing or Binalong, Xian or Xi Ao.

Stern called the absence of constraints on emissions of climate-changing gases the greatest market failure the world has ever known (2007). The challenge is to have all humans take into account the external effects on global climate of all of the decisions that they take in pursuit of economic growth. Collective action is required through all of humanity.

No state governs the whole of humanity to define the collective action that is required and to enforce rules that correct the market failure. Humanity can manage the anthropocene only if it can build mechanisms within which global collective action can be effective. 


\section{The Emergence of a Global Climate Change Regime}

China and Australia have been active participants in the international community's work to build a basis for international cooperation on climate change since the beginning at Rio de Janeiro, two decades ago. In 1992, there seemed to be lots of time, and the problem seemed to be overwhelmingly that of excessive emissions from the developed countries.

Those impressions guided the meeting of the United Nations Framework Convention on Climate Change (UNFCCC) in 1997 and the resulting Kyoto Protocol. By then there had been considerable progress in sharing perspectives within a uniquely ambitious and successful effort in international scientific cooperation, through the Intergovernmental Panel on Climate Change. Understandings were reached on which gases would be covered by efforts to reduce emissions, and on how they should be measured. An agreement was reached that all developed countries would accept constraints on emissions, and that there would be penalties for breaches of commitments. There would be opportunities to reduce the costs of mitigation through joint implementation among developed countries (where countries that were falling below their emissions reduction targets would be able to buy entitlements from countries that were reducing emissions more than was required by their targets). There would be opportunities for reducing the costs of mitigation in developed countries through a Clean Development Mechanism (CDM), which would certify carbon reduction 'offsets' generated in developing countries for sale to developed countries. Developing countries undertook to make efforts to reduce emissions; developed countries to contribute funding to these efforts and also to climate change adaptation in developing countries.

The Kyoto arrangements were damaged when the US Congress refused to ratify the agreement to which the US Government was a party. The Republican government under George W. Bush, elected in 2000, announced that it would not seek ratification for the agreement. The Australian Government followed the lead of the United States and continued to do so until policy was reversed in 2007. But both Australia and the United States remained parties to international discussions. Progress was made on some issues in conferences of the UNFCCC in Bali (2007), Copenhagen (2009), Cancun (2010), Durban (2011) and Doha (2012), including on a global objective of holding the human-induced increase in temperatures to two degrees Celsius.

These early efforts in collective action on climate change contained elements of success and failure. It is important to preserve the success (the scientific cooperation, the shared objective, the agreements on how to measure and later 
to account for and verify emissions, the mechanisms for international trade in entitlements and for transfers of financial resources to developing countries) while correcting the causes of failure.

Time has passed and times have changed.

We no longer have time: the concentrations of greenhouse gases are already approaching levels that are likely over time to generate two degrees increase in average temperatures. Emissions have grown more rapidly since the turn of the century than was suggested by the most widely used scenarios developed in the 1990s, largely because growth was stronger and more energy-intensive and energy more emissions-intensive than had been anticipated (Garnaut et al. 2009).

If temperature increases are going to be kept to two degrees, there must be an early and large reduction in global emissions trajectories. Global emissions must be reduced by half or more by mid century by putting them on a downward path now. Delays in turning down the trajectories will require an earlier end point for the emissions reductions and a more rapid rate of decline. The practical requirement that all parts of humanity see the distribution of the global mitigation effort as being fair points to movement towards similar per capita emissions entitlements in all countries - at levels more than 90 per cent lower than those present today in developed countries and more than 50 per cent lower than today in China.

In contrast to the world up to the Rio de Janeiro summit, emissions growth in the twenty first century was overwhelmingly concentrated in developing countries. My own calculations on 'business as usual' emissions for the Climate Change Review Update (Garnaut 2011a, 2011b) suggest that, in the absence of policy action to change established trends, developing countries would account for the whole of the increase in global emissions from 2005 to 2030; developed country emissions as a whole were expected to remain steady between 2005 and 2030. In the absence of policy action, China would account for 41 per cent of global emissions in 2030 and developing countries 70 per cent. Whatever weight were given to the requirements of historical responsibility and justice, effective global mitigation would require major and early reductions from business as usual emissions in China and other developing countries.

The Kyoto arrangements had envisaged a comprehensive 'top-down' agreement in which responsibility for constraining emissions would be allocated across countries and enforced internationally. This ideal would provide a firm basis for international trade in entitlements, to allow reductions in emissions to occur where they could be achieved at lowest cost. Such an agreement would provide each country with assurance that others were contributing their fair shares of the global effort, so that its own emissions reductions would be part 
of an effective global effort. It would provide each country with assurance that other countries' emissions-intensive industries were gaining no competitive advantage in international markets against its own as a result of differences in mitigation effort.

The international community has learned slowly and painfully that such an agreement is not within reach for the foreseeable future. This reality came within view at Copenhagen in 2009, and crystallised in Cancun in 2010. It was not possible because the major powers, first of all the United States but also China, were willing to bind themselves domestically to strong mitigation outcomes, but not to enter international agreements to the same end. It was not possible because there were no effective sanctions against breaches of commitmentsas demonstrated by Canada walking away without penalty from its Kyoto Protocol pledges.

Subsequent developments raise a question about whether a comprehensive 'top-down' agreement is even desirable. In anticipation of a legally binding agreement, governments settle into negotiating mode and seek to minimise commitments. By contrast, when considering a domestic commitment, governments are prepared to look more openly at the realistic boundaries of action and to go further in defining mitigation targets.

A different approach to setting national targets began to emerge at Copenhagen, took firm shape at Cancun and was elaborated in subsequent UNFCCC meetings in Durban and Doha.

The new approach carries some important features over from the early international discussions. The scientific cooperation remains centrally important to the collective effort. The two-degree objective, mechanisms for measurement and verification of emissions, and instruments for international trade in entitlements have been developed or strengthened. Ideas about mechanisms for transferring resources for mitigation and adaptation from developed to developing countries have been given substantive shape (although still little money). It must be said that additional steps need to be taken on verification of emissions: while a case can be made for developing country mitigation targets to be expressed in different ways from developed country targets (intensity rather than absolute reductions), there is no case for differentiation in measurement and verification.

The biggest departure from the old regime is in the setting of country targets for constraining emissions. It has been accepted that substantial developing countries will make commitments to constrain emissions, in the form of reductions in emissions intensity or 'business as usual' emissions. (Intensity targets are strongly preferred to business as usual, as they are capable 
of objective and unambiguous calculation). It is accepted, if only by default, that these and developed-country commitments to absolute reductions in emissions are voluntary and represent serious domestic undertakings and are not binding under international law. The voluntary targets are set domestically rather than within a comprehensive international agreement. The pressures to make them ambitious come from domestic politics and review and commentary from other countries - a process that is known as 'pledge and review'.

I describe the new process as 'concerted unilateral mitigation'.

It is a feature of the Kyoto arrangements carried over into the concerted unilateral mitigation regime that each country is free to use whatever instruments it chooses in meeting its targets. It is free to acquit its commitments through the purchase of international abatement to the extent that it chooses, or not at all. It is free to introduce carbon pricing in the form of an emissions trading system or a carbon tax, or not at all. Whether or not it places a price on carbon, it can choose to regulate emissions-intensive activities and subsidise low-emissions substitutes to the extent that it chooses. International comparisons of mitigation effort are made in terms of the outcomes in reductions in emissions below defined baselines, and not in terms of how the emissions reductions are achieved.

For concerted unilateral mitigation to be effective, one major gap in the international regime needs to be filled. The regime needs some framework for guiding assessments of the level of mitigation in each country that amounts to a fair share of an international effort to achieve the agreed global effort. It would be useful and probably necessary for heads of governments committed to strong global mitigation outcomes to appoint an expert group to develop such a framework for allocating the global effort among countries. Within the context of concerted unilateral mitigation, each country would be free to accept or reject guidance provided by such a framework. The framework would become a focus of international review of each country's effort, and evolve over time in response to discussion and experience.

The Durban conference of the UNFCCC in late 2011 agreed to launch 'a process to develop a protocol, another legal instrument or an agreed outcome with legal force'. The process, legal instrument or agreed outcome would be settled by 2015 in the Conference of the Parties in Paris, and come into effect in 2020. Developed and developing countries would all accept obligations, although the form of those obligations could vary across countries.

The Durban decision was sometimes interpreted as a commitment again to seek a binding, top-down agreement, although the words allow other interpretations. At least there is no suggestion that we should return to seeking comprehensive agreement on the allocation of the required global mitigation 
effort across countries. While there would be advantages in an internationally binding agreement, if it were possible to achieve one without reducing mitigation ambition, the practical barriers to a good binding agreement remain as strong as they were at Copenhagen. It is important that we do not allow the search for excellent form to distract the international community from grasping immediate prospects for excellent substance.

To conclude the discussion of the evolution of the global climate change regime, we should acknowledge that trade in emissions entitlements has struck some large practical problems. Within the European emissions trading system, the many regulatory and fiscal interventions are forcing much larger reductions in emissions than carbon pricing. These, together with slow growth in economic activity and the realisation of unexpected opportunities for low-cost abatement, have caused permit prices to fall to levels that are well below the economic cost of emissions and the value of abatement. The low prices raise questions about the effectiveness of the emissions trading system. Although controlled in quantum, use of offsets at very low prices from the CDM has pushed prices even lower. Low European and CDM prices would, if uncorrected, introduce low prices into other emissions trading systems with which Europe is linked, notably Australia from 2015. Already New Zealand's emissions trading scheme has prices close to zero through allowing unlimited access to credits from the CDM.

It is understood by economists that broadly based carbon pricing achieves more carbon emissions reduction at similar cost, or similar abatement at lower cost, than large numbers of separate regulatory and fiscal interventions. Considerable emissions reductions have been achieved in recent years in many countries through regulatory and differentiated fiscal interventions. The cost advantages of general carbon pricing become more important, however, as mitigation targets become more ambitious, and are likely to be essential to achieving the reductions in emissions that will be necessary to achieve the agreed global objective. The contemporary problems of uneconomically low prices in domestic and international trading schemes can therefore be seen as a threat to achievement of long-term global mitigation goals. A tightening of emissions reduction targets is necessary to restore prices that relate appropriately to the cost and value of abatement in a world that is meeting its emissions reduction targets.

The CDM has emerged as the most important locus for international trade in carbon units and, for a number of years, contributed substantially to incentives for investment in emissions reduction in developing countries. The NDRC has recently reported that to August 2012, Chinese certified emissions reduction under the CDM had reached 730 million tonnes per annum (NDRC 2012), a bit over half of the global total. 
As analysed in the recent report of an independent review panel, the CDM is experiencing chronic oversupply of abatement units. Prices have fallen to levels that barely cover transaction costs. With recent and prospective reforms, the CDM is a legitimate offset mechanism with a potentially valuable place in a global system of climate change mitigation (CDM Policy Dialogue 2012). The review panel concluded that a major tightening of emissions reduction targets and widening of access on the demand side would be necessary to correct the chronic oversupply. I would suggest as well a tightening of access on the abatement supply side, with only least developed countries having unconditional access. Other developing countries would have access if they accepted domestically binding emissions constraints and were living within those constraints without double counting of abatement for which CDM credits had been awarded. If this approach were adopted by the international community, international mechanisms would need to be developed (perhaps through the established arrangements for joint implementation) to monitor double counting of emissions.

\section{The Cancun Pledges}

Within the framework of concerted unilateral mitigation, all substantial economies placed pledges before the international community that they would reduce emissions below business as usual. The sum of the pledges represented a marked departure from established emissions trajectories. At the same time, they were no more than a small first step towards achieving the reductions in emissions that would be necessary to achieve agreed climate change objectives.

The United States pledge represented a large departure from earlier perspectives. President Bush told a meeting of representatives of large economies in 2007 that US emissions would continue to rise to a peak in 2025. The Cancun pledge was for emissions to fall from 2005 levels by 17 per cent by 2020, corresponding to a 16 per cent fall from 2000.

Canada pledged to match a binding commitment by the United States - a substantial undertaking unless the Canadian Government had it in mind to annul it by saying that the US pledge was not binding even if it were being met.

Some of the pledges contained conditional and unconditional elements - the latter being triggered if other countries took strong action. The European Union pledged to increase its emissions reductions from 20 to 30 per cent (both based on 1990) in the context of strong international action. 
The Australian pledge was unconditionally to reduce emissions by 5 per cent on 2000 levels by 2020, and to increase the reduction to as much as a 25 per cent in the context of strong international action. The unconditional commitment represented a sharp break in the trajectory of Australian emissions growth, influenced as it was by the developed world's most rapid growth in population and economic activity and exceptionally rapid expansion of emissions-intensive resource export industries. In 2011, the Australian Department of Climate Change and Energy Efficiency estimated that existing policy, without the new policies legislated in 2011, would see Australian emissions rise by 24 per cent.

The Chinese target was to reduce the emissions intensity of economic output by between 40 and 45 per cent between 2005 and 2020. This represented the largest departure from business as usual in terms of tonnes of emissions avoided. It could have had a galvanising effect on the Copenhagen meeting at which it was revealed to the international community. That its importance was not noticed and brought to account was a failure of diplomacy in China and many other countries.

Other developing countries made pledges amounting to major changes from business as usual trajectories, with the Brazilian and Indonesian pledges being noteworthy.

The other large developing country, India, made commitments to reductions in emissions intensity that were more modest, but were accompanied by statements that India would never allow per capita emissions to exceed those of developed countries (Planning Commission Government of India 2011). This formulation has the potential to be a powerful instrument of global mitigation in the context of strong action and rapid reduction in emissions across the developed world. It could be usefully incorporated into a global framework for assessing the reasonableness of national contributions to a global mitigation effort.

The various pledges within the context of concerted unilateral mitigation added up to a much larger departure from established emissions trajectories than the notionally binding commitments at Kyoto. The pledges, however, left global emissions on trajectories that were far too high for achievement of the two-degrees objective, unless much more ambitious additional commitments were made for the periods from 2015 and 2020.

Of course, one cannot say now what the Cancun pledges mean for the containment of global warming, as they say nothing about what happens after 2020, and do not allow for the possibility of concerted raising of ambition for what is left of the period before 2020 . 


\section{Encouraging Progress}

There is good and bad news in the story of humanity's struggle to find a basis for effective collective action on climate mitigation. The early news was never going to be all good on an issue as complex, difficult and new to the international community as this one.

The best news is of immense importance: emissions generally seem to be on paths to meet or exceed the Cancun targets. They are on track to meet or exceed the pledges even in the cases of China and the United States - the world's biggest emitters of greenhouse gases, the largest and most influential economies, and the pledges of which represent dramatic reductions in established trajectories. Moreover, the achievement of current pledges is being achieved at less cost than was anticipated by most analysts. Early and widely based progress at surprisingly low cost establishes sound foundations for a large and early increase in national mitigation ambition.

Far from reaching a peak in emissions in 2025, as Bush foreshadowed in 2007, it now seems that US emissions reached their highest level in the year in which Bush was speaking, and have been declining since then. Some have suggested that a decline in economic activity in and following the Great Crash of 2008 has dragged emissions down; the reality is that US output is now higher than in 2007.

Two recent private US studies, by Resources for the Future and the National Resource Defense Counsel, have concluded that the United States is on course to meet its emissions reduction targets despite the defeat in the Congress of President Obama's proposal for an emissions trading scheme (Scientific American 2012; National Resource Defense Counsel 2012). An emissions trading scheme would have allowed the same reduction of emissions at lower cost, but higher cost means can still achieve large reductions in emissions. The Resources for the Future studies attribute 10.5 percentage points of emissions reduction to US federal regulation of mobile and stationery energy, 2.5 per cent to state-level regulation and emissions trading schemes and 3.3 per cent to the expanded availability of cheap gas and other energy market developments. Since 2009, the US Government has invested heavily in research and development for new, low-emissions technologies, and this can be expected to be reflected in new opportunities for emissions reductions over time. Low gas prices - the result of combining tight restrictions on exports with large expansions of reserves - are becoming increasingly important over time, leading to the decommissioning of much coal-based generation capacity. 
Europe is already close to achieving its Cancun objectives for emissions reductions by 2020. Slow economic growth has subdued demand for emissionsintensive goods and services, but the extent of reduction and the low price of abatement in the emissions trading scheme suggest that emissions reductions have been achieved at lower cost than had been anticipated.

In Japan, as in Europe, economic stagnation has contributed to overperformance on emissions reduction goals, despite the setback to low emissions energy with the 2011 nuclear breakdown at Fukushima. Tokyo's introduction of emissions trading arrangements has been accompanied by especially rapid reductions in emissions, which, in turn, have generated extremely low emissions entitlement prices (Rudolph and Kawakatsu 2012).

In Australia, too, emissions growth has been well below anticipated levels over recent years, tending around zero, despite the continuation of robust expansion of population, output and emissions-intensive resource investment for export. In the electricity sector, stagnant or declining demand has intersected with increased renewable energy production forced by the renewable energy target to cause faster decarbonisation than had been suggested in the official estimates. The introduction of carbon pricing from July 2012 and the use of part of the associated revenue to support renewable energy innovation will extend the reduction in emissions. Preliminary data suggest that emissions from electricity generation in the first six months of the emissions trading scheme are over eight per cent lower than in the corresponding period of the previous year, with slowing demand growth, the renewable energy target and the emissions trading scheme contributing to reductions.

China's 12th five-year plan, 2011-2015, embodies far-reaching measures to constrain emissions within the intensity targets which the Chinese Government has communicated to the international community. In 2011, the first year of the new plan, emissions continued to grow strongly. This was discouraging for the international mitigation effort. The emissions reductions policies bit more deeply from 2012 and, together with economically driven structural change, changed the emissions trajectory in 2012, to an extent that over-performance against the pledge seems possible and strengthening of the pledges feasible in the context of increased global effort.

Within the electricity sector, accounting for over 44 per cent of China's emissions in 2010 (IEA, 2012), demand growth slowed to 5.7 per cent in 2012 after demand doubled over the previous decade. The slower growth in demand was in response to energy efficiency and structural policies as well as a moderate easing of output growth (GDP growth 7.9 per cent through the course of 2012). The energy efficiency policies and structural change are likely to keep electricity 
demand growth much lower than in the first decade of the 21 st century, and bring within reach the 3.5 per cent annual increase in primary energy consumption necessary to achieve the electricity targets of the 2011-2015 plan.

A Chinese State Council decision added detail to energy plans in early 2013 (Xinhua 2013). Annual primary energy consumption 2011-2015 would be held to 4.3 per cent per annum compared with 6.6 per cent through the preceding five years. This corresponds to about 3.5 per cent over the next three years. Annual coal consumption will be capped in 2015. Given the constraints on reducing coal consumption in steel-making and other industrial activities, this implies some decline in coal combustion for electricity generation.

Table 14.1 describes the remarkable change in the extent and composition of electric energy growth in 2012.

Table 14.1 China: power generation 2011 and 2012

\begin{tabular}{l|r|r|r}
\hline & \multicolumn{1}{|c|}{$\mathbf{2 0 1 1}$} & \multicolumn{1}{c}{$\mathbf{2 0 1 2}$} & \% increase \\
\hline Total power generation (TWh) & 4,692 & 4,959 & 5.7 \\
\hline thermal & 3,900 & 3,925 & 0.6 \\
\hline hydro & 668 & 800 & 19.7 \\
\hline nuclear & 87 & 102 & 17.2 \\
\hline wind & 74 & 100 & 35.8 \\
\hline Other & $\mathrm{n} / \mathrm{a}$ & 32 & $\mathrm{n} / \mathrm{a}$ \\
\hline
\end{tabular}

Source: NDRC/State Information Center, based on information from the National Energy Administration, January 2013.

Note: 'Other' is solar, biomass and geothermal. There was a large percentage increase in 2012 from a low base (more than 100 per cent for solar photovoltaic), but data on the composition of 'Other' are not available for 2011. Note that the components for 2011 exceed the total by a small percentage, but, at the time of writing, the author has no explanation for this anomaly.

Total electricity demand growth slowed to 5.7 per cent in 2012. While early data for 2012 contain some inconsistencies and are subject to revision, they are striking and encouraging. There seems to have been almost no growth in thermal power generation. Output of all low-emissions energy ('clean' energy in the Xinhua terminology) sources of electricity grew rapidly: hydro-electric by 19.7 per cent; nuclear by 17.2 per cent; wind by 35.8 per cent. Solar increased much more rapidly still from a low base. While hydro-electric power generation is affected by climatic conditions which were unfavourable in 2011 and favourable in 2012, it will fluctuate around a rising trend. Nuclear power generation is likely to continue to rapidly increase its share of power generation and wind and solar to do so at an even more rapid rate. 
Within thermal power generation, a number of factors led to reductions in greenhouse gas emissions per unit of electricity. A number of Chinese policies will contribute to maintaining the new momentum in reducing emissions from thermal generation that became apparent in 2012. There is still some way to go in replacing high-emissions coal generation in small, inefficient generators with ultra-supercritical plants operating at the world's efficiency frontiers: the International Energy Agency (IEA) refers to $68 \mathrm{GW}$ of small (less than $100 \mathrm{MW}$ ) and $138 \mathrm{GW}$ of medium (100-300 MW) of coal-generating capacity remaining in 2010, which is slated for replacement (IEA 2012). The replacement of inefficient small by efficient large plants reduces both coal use and emissions per unit of electricity output. The careful research of Mai (2013) shows that the small for large scheme will lead to reductions of between one and two per cent per annum in thermal coal use in the years immediately ahead.

Policy is focused on substantially increasing the natural and unconventional gas share of thermal power generation from the current low base. The State Council sees the gas share of primary energy consumption doubling to 7.5 per cent by 2020 (Xinhua 2013).

China is investing more heavily than any other country in technological development for capture and storage of carbon dioxide waste from fossil fuel combustion. Deregulation of electricity and coal prices in 2013, accompanied by removal of coal transport subsidies, are likely to contribute to easing in electricity demand and to increasing costs of supply from the coal sector. Major investment in high-voltage, long-distance transmission and in pumped hydro storage is leading to more complete utilisation of intermittent renewable energy capacity, and to expanding options for new investment in renewables. The 12th five-year plan greatly increases financial commitments to energy efficiency and for innovation in low-emissions technologies, including in the electricity sector.

The electricity supply and demand developments seem to have stopped growth in emissions from combustion of coal in electricity generation in 2012. This is a dramatic break from established trends, of historic importance in global terms. It takes us way outside the conventional wisdom on development of the Chinese energy market. The IEA had assessed that China would need to increase coal-based generation capacity from 710 GW in 2010 to 1190 GW in 2020, with total emissions rising despite continued replacement of economically and environmentally inefficient plants by ultra supercritical capacity (IEA 2012). That assessment is obsolete.

In more than three decades of work on Chinese economic growth and structural change in the reform era, I have become accustomed to Chinese and foreign observers alike underestimating the capacity of China's economy to 
respond quickly and powerfully to incentives and to opportunity. The current energy market adjustment seems to be another case of underestimation of the Chinese economy's capacity for rapid transformation in the reform era. Of course, the outcome will depend on the policy that emerges from continuing debates and political contests within China: in the Chinese political system, as in its counterparts in the West, the success of the public interest in shaping policy is qualified by pressure from vested interests.

The strengthening of policies and actions to change the trajectory of China's greenhouse gas emissions extends over all major sectors.

Industrial emissions, which are largest in steel production, are experiencing much slower growth as a result of policy-enhanced slowing in the rate of growth of heavy industry, and by innovation to reduce emissions intensity. Forced closure of inefficient plants (32 million tonnes of steel capacity alongside 8,000 MW of coal electricity generation in 2011 alone (NDRC 2012)), higher costs of electricity and other inputs, export taxes and restriction of investment in new capacity have slowed expansion in energy- and emissions-intensive activities. The goal articulated in the 12th five-year plan to reduce the energy intensity of steel production by a percentage point per annum is a realistic extrapolation of recent trends.

In transport, the heavy investment over the past decade in inter-city and intra-city rail will ease somewhat the growth of automobile traffic from what it would have been. Within the automotive sector, ambitious official targets for electrification are being strongly supported by a range of policies (NDRC, 2012). The combination of rapid expansion of public transport led by rail, automotive electrification and decarbonisation of the electricity sector are likely to add up to unexpectedly early peaking of emissions from the transport sector.

\section{China's and Australia's International Roles}

Within concerted unilateral mitigation, it is important for each country to make pledges that are recognised as a fair share in a global mitigation effort, and to deliver on those commitments.

China matters because of its importance as a source of emissions and its economic and strategic weight. China also matters because it is likely to have comparative advantage in mass production of capital goods embodying lowemissions technologies: large-scale production of photovoltaic units in China has lowered the cost of solar power generation all over the world, and similar developments are likely in other technologies. 
China has become one of the world's main sources of direct foreign investment. Direct investments in transmission by China's State Grid Corporation have greatly reduced the costs of modernising transmission systems in the Philippines, Portugal and Brazil in recent years, and is set to become important in Australia.

Both Australia and China can contribute to innovation in the low-emissions industries. Australian research institutions, notably Electrical Engineering at the University of New South Wales, have been at the forefront of applied research in solar technologies, the commercialisation of which has been concentrated in Chinese enterprises. Australia is disproportionately represented in innovation in the biological sciences with relevance to emissions reduction.

Australia and China share a strong interest in the nurturing of opportunities for international trade in emissions entitlements. Each has comparative advantage in emissions-intensive activities: China in manufacturing, Australia in tradeable energy. Large-scale exports of emissions-intensive products will tend over time to make both Australia and China relatively large sources of emissions per person. It is economically desirable for these two countries, and for the world as a whole, that they are able to maintain high levels of exports of emissions-intensive goods, and to meet part of their abatement responsibilities by buying emissions entitlements from other countries.

How can we build on these shared interests and favourable circumstances to improve the chances that humanity is able to manage the anthropocene?

First, we can share views on all aspects of the climate change challenge. These include views on industrial transformation - including China's experience in upgrading transmission grids to reduce energy losses, to connect energy resources to distant centres of demand, and to integrate intermittent electricity sources more efficiency into the major grids. They include, as well, experience with mitigation policies (Jotzo 2013), and the sharing of analytical insights.

Second, we can together take the lead in initiating an independent global analysis of what constitutes a 'fair share' of the strong global mitigation effort that will be required to meet the two-degrees objective. China and Australia can be among the countries that work together to provide an essential component of successful concerted unilateral mitigation.

Third, we can work together to strengthen the pledges that the substantial economies have made to reduce emissions, and to ensure that international trade in entitlements remains a legitimate means of meeting emissions reduction pledges. 
The third area of cooperation is especially important, as the international community faces decisions over the next two years which will determine whether the two-degrees objective remains within reach. This chapter has explained that marked strengthening of pledges for 2020, and the adoption at Paris in 2015 of strong targets for the period after 2020, are essential to achieve the two-degrees objective, to raise prices of traded entitlements to economically and environmentally rational levels, and to underwrite a continuing role for domestic and international trade in entitlements.

It is common for commentaries to focus on the failures of international cooperation on climate change. This chapter has drawn attention to some successes that could become the launching pad of a strong international effort to bring within reach the agreed objective of holding temperature increases to two degrees.

\section{Conclusions}

This chapter has drawn attention to the fact that the major economies including China, the United States, the European Union and Japan (despite the setback to nuclear energy at Fukushima) and Australia are making unexpectedly rapid early progress towards realising their pledges to the international community. Reducing emissions is proving to be less costly and disruptive than had been anticipated by expert observers.

The chapter has noted the importance of international trade in emissions entitlements in reducing the costs of mitigation for the world as a whole. One weak point in contemporary collective action on climate change is the low prices for carbon units in the European Union and other emissions trading systems, and in the CDM. The continuation of low prices would discredit international trade as well as domestic emissions trading systems. The low prices themselves reflect the unexpectedly low cost of reducing emissions.

Of course, there is no problem with low prices if they emerge from targets that are strong enough to achieve the agreed global mitigation objectives. But we are currently far from that point. Current targets fall well short of those necessary to achieve global objectives. In these circumstances, the remedy for prices that are well below the cost and value of optimal abatement is the same as the remedy for a global mitigation effort that currently falls well short of the requirements of the two-degrees objective: an early tightening of targets.

The recent rapid progress towards announced targets on emissions reductions in many countries, and the revelation that costs of reducing emissions have been unexpectedly low, together provide the foundations for an 
early tightening of announced targets in developed and developing countries alike. An international climate change system built around concerted unilateral mitigation provides a favourable context for China and Australia to play their parts in a renewed international effort to achieve the agreed objective of the international community.

\section{References}

CDM Policy Dialogue, 2012, Climate Change, Carbon Markets and the CDM: A Call To Action, Report of the High-Level Panel on the CDM Policy Dialogue, September 2012, http://www.cdmpolicydialogue.org/report

Clark, C., 1940, Conditions of Economic Progress, Macmillan, London.

Du, Juan, 2013,, 'Major Coal Firms Cut Production as Prices Fall, Stocks Rise', China Daily, 10 May.

Garnaut, R., 2008, The Garnaut Climate Change Review: Final Report, Cambridge University Press, Melbourne.

_ , 201 la, 'Garnaut Climate Change Review Update Paper 3: Global Emissions Trends', paper presented to Australian Agricultural and Resource Economic Society Annual Conference, Melbourne, http://www.garnautreview.org.au/ update-2011/update-papers/up3-global-emissions-trends.pdf

- 2011b, The Garnaut Review 2011: Australia in the Global Response to Climate Change, Cambridge University Press, Melbourne.

Garnaut, R., Jotzo, F., Howes, S. \& Sheehan, P., 2009, 'The Implications of Rapid Development for Emissions and Climate Change Mitigation', in D. Helm and C. Hepburn (eds), The Economics and Policy of Climate Change, Oxford University Press, pp. 81-106.

International Energy Agency (IEA), 2012, Policy Options for Low-Carbon Power Generation in China, http://www.iea.org/publications/insights/ name,32266,en.html

Jevons, W. S., 1865, The Coal Question: An Inquiry Concerning the Progress of the Nation, and the Probable Exhaustion of our Coal Mines, Macmillan and Co., London.

Jotzo, F., 2013 'Emissions Trading in China-Principles, and Lessons from International Practice' in Market Mechanisms for China's Carbon Emission Reductions: Economics, Modelling and International Experience, China State Information Center, National Development and Reform Commission, Beijing. 
Mai, Yinhua and Shanghao, Feng, 2013, 'Increasing China's Coal-fired Power Generation efficiency: The Impact on Carbon Intensity and the Broader Chinese Economy to 2020', paper to State Information Centre (SIC) and National Development and Reform Commission (NDRC) Workshop, Beijing.

National Development and Reform Commission (NDRC), 2012, China's Policies and Actions for Addressing Climate Change, Beijing, November, http://qhs. ndrc.gov.cn/zcfg/W020121122588539459161.pdf

National Resources Defense Council (NRDC), 2012, Closer than You Think: Latest U.S. CO2 Pollution Data and Forecasts Show Target Within Reach, July, New York, http://www.nrdc.org/globalwarming/closer-than-you-think-ib.asp

Planning Commission Government of India, 2011, Interim Report of the Expert Group on Low Carbon Strategies for Inclusive Growth, New Delhi, http:// planningcommission.nic.in/reports/genrep/Inter_Exp.pdf

Rudolph, S. \& Kawakatsu, T., 2012, 'Tokyo's Greenhouse Gas Emissions Trading Scheme: A Model for Sustainable Megacity Carbon Markets', Joint Discussion Paper Series in Economics, Universities of Aachen, Gieben, Gottingen, Kassel, Marburg, Siegen.

Scientific American, 2012, U.S. May Come Close to 2020 Greenhouse Gas Emission Target, http://www.scientificamerican.com/article.cfm?id=us-may-comeclose-to-2020-greenhouse-gas-emission-target

Stern, N., 2007, The Economics of Climate Change: The Stern Review, Cambridge University Press.

Weber, M., 1905, The Protestant Ethic and the Spirit of Capitalism, T. Parsons (trans., 1930), Dover Publications Inc, New York.

Xinhua, 2013, 'China Sets Slower Energy Consumption Targets', 25 January http://news.xinhuanet.com/english/china/2013-01/24/c_132125842.htm 


\section{China's Energy Demand Growth and the Energy Policy Trilemma}

Simon Wensley, Stephen Wilson and Jane Kuang

\section{Introduction}

China's remarkable pace of development and transformation in recent decades has been well documented, analysed and discussed. In less than 25 years, from 1985 to 2008, China's GDP per capita increased more than fourfold. The path between comparable levels of development took half a century in Japan (1916 to 1967), a century in Germany (1856 to 1958) and the United States (1840 to 1940), and 120 years in the United Kingdom (1820 to 1940) (Shell 2013).

Yet, China is only now just reaching world average levels of energy and economic development. And, outside China's coastal provinces and major cities, energy use and economic development are still well below world average levels. This naturally raises the question as to where China's development will take it in the next 20 years, and what the implications are for energy supply, the economies of China, Australia and the world, and the environment both locally and globally.

Over the past decade, the rapid redevelopment and construction of China's cities has put pressure on commodity supply chains, particularly for the metals required in the early phase of industrialisation, urbanisation and modernisation of infrastructure to build the new urban environments. Energy demand tends to develop more gradually and steadily with economic growth. Indeed, energy is a key input and driver of economic growth: the first section of this chapter explores the relationship between energy per capita and GDP per capita through both cross-sectional comparisons between countries and longitudinal trajectories over time within countries. The two decades from 1990 to 2010 saw a strong linear correlation in China between energy per capita and GDP per capita. The first section also discusses the factors that are expected to moderate the correlation in coming decades. China is also looked at beyond national averages: the energy-economy data shows the wide range across provinces - no one province in China is equal to the national average. The emerging demand picture underscores the energy challenge ahead of China as it becomes a society of increasing prosperity. 
Section two introduces the Energy Policy Trilemma: the tension between maximising security of supply, minimising cost and minimising environmental impacts including emissions. Resolving the Trilemma is the key challenge for energy policy makers everywhere. This chapter explores the Trilemma through four case studies: the 1970s oil crisis, China's cost revolution in nuclear power that is quietly unfolding today, the US unconventional oil and gas technoeconomic revolution, and the challenge for Japan in closing the 30 Gigawatt gap in the power system post-Fukushima.

The third section considers the resource challenge to meet China's growing energy demand. This includes the opportunities and challenges involved in the development and management of China's resources; the increasing role of imports to balance domestic supply in oil, gas, coal and uranium; and the evolution of the fuel mix, taking into account fuel diversity and import dependence.

The final section explores emerging technologies, many of which China is actively developing, that have the potential to open up new energy transformation, conversion and utilisation pathways between hydrocarbons and key sectors of the economy. These include coal to liquids, coal to chemicals, coal gasification, gas to liquids, compressed natural gas and liquefied natural gas for transport, and electric vehicles.

China has recently become the world's largest energy consumer, and yet it is still in the very early stages of its energy-economic and environmental development path.

\section{Energy is a Key Driver of Economic Development and Growth}

\section{China's Development Compared with other Countries}

This section presents a straightforward, but not commonly seen way of looking at historical data on demographic, economic and energy development paths. No advanced mathematical or econometric knowledge is required of the reader. The data itself, presented in visual form, is rich and informative, challenging and stimulating for experts, policy-makers and investors alike.

Figure 15.1 charts GDP per capita in constant 2005 US dollars, adjusted for purchasing power parity (PPP) versus per capita primary energy supply (in the common units tonnes of oil equivalent, toe). The bubble sizes represent population. 
Figure 15.1 Energy-economy development paths: China, the world and selected economies, 1990-2010

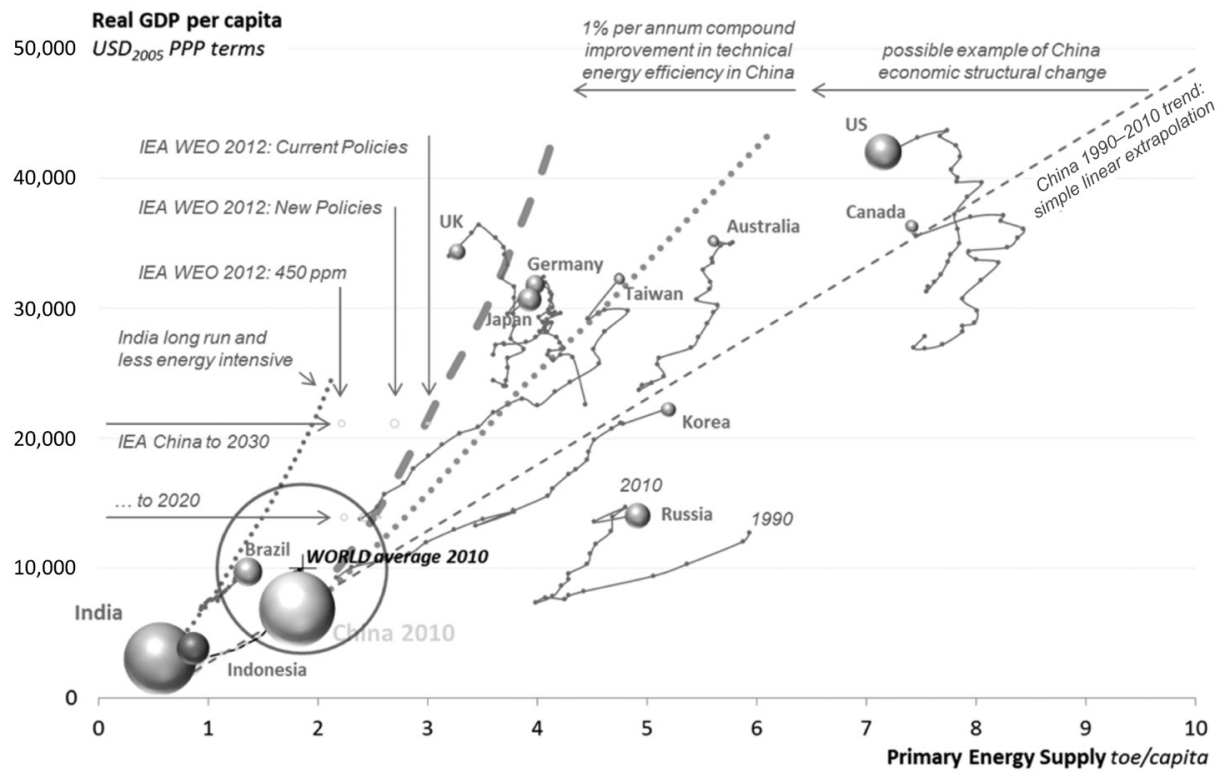

Source: IEA World Energy Outlook 2012, IMF online economic database.

Many observations can be made from the data:

- There is a large range between the industrialised economies and the world average.

- There is a range of energy intensities between economies, from the United States and Canada using seven to eight toe per capita; Australia, South Korea and Russia using between five and six; Japan, Germany and Taiwan using between four and five; and, the United Kingdom between three and four. The world average is below two toe per capita. China is at about the world average in terms of energy per capita, while its GDP is well below the world average: China's economy is more energy-intensive than the world average. Brazil's GDP per capita is just below the world average, but it is less energy intensive. India is a long way below the world average in terms of GDP per capita and primary energy, which is a long way below one toe per capita. India's economy is on a less energy intensive trajectory than China's, and has barely begun to develop. Indonesia is ahead of India and on a more energy intensive trajectory.

- The development path of South Korea has been particularly energy intensive.

- In contrast with the steady development of China's economy from 1990 to 2010, the dramatic effect of the collapse of the Soviet Union is visible in the trajectory of Russia. 
- The effect of the 2008 global financial crisis on the energy sector and economies of the United States, Canada and the United Kingdom is marked and contrasts with the limited impact on Australia: a testament to Australia's linkage with China.

- In China there has been a strong correlation between energy and GDP: 98 per cent of the growth in per capita energy requirements of the past two decades can be explained by the growth in real PPP-adjusted GDP. The relationship (not shown here) between electricity and the economy is even stronger, explaining over 99 per cent of the growth using GDP per capita as the independent variable. One could equally say that the level of energy supply or consumption almost entirely explains the level of economic activity of the past two decades. Bearing in mind that correlation is not causation, the relationship between energy and the economy is strong.

- The IEA's 'current policies scenario' implies a significant degree of structural change in China's economy combined with about one per cent per annum technical energy efficiency improvement over the next two decades. The $450 \mathrm{ppm}$ scenario allows for only a very small increase in primary energy consumption per capita in China, with sustained growth in GDP per capita.

China has undergone a remarkable story of growth and development in the past three decades, and particularly during the last 10 to 20 years. Hundreds of millions of people have been lifted out of poverty. Modern industrialisation, urbanisation and mobilisation have driven the process of development, and energy in its manifold forms has played an essential role in this process. This is clear in the data for the last 20 years.

International visitors to Beijing and Shanghai today may come away with an impression of prosperity suggesting that China is approaching the mature end of its development curve. Yet the cross-section of international comparisons in Figure 15.1, with a diverse set of major economies at widely varying stages of development shows that China as a whole is only now approaching the global average on the energy-economy development curve.

\section{Economic Structure and Energy Efficiency}

If China was to continue on the linear trajectory of the past 20 years, it would approach North American levels of energy consumption per capita by the time per capita GDP had reached the low 30,000s. This is not expected to happen, however, for several reasons. Firstly, given the size of China's population, the stress that this would place on global energy markets would be expressed in prices that would tend to moderate demand. 
Secondly, the structure of China's economy is expected to begin to evolve away from the energy-intensive, heavy industries towards higher value-adding lighter industries and the services sector and towards increased standards of living for households. This trend will, to some extent, happen naturally, and will also be encouraged by policy-makers. On average, each unit of energy consumed will be expected to generate a greater contribution to GDP. An example of a trajectory showing the effect of economic structural change is shown in Figure 15.1.

Thirdly, the technical efficiency of energy use is expected to increase, driven by improved technology and the many opportunities in a rapidly growing economy with a high proportion of new capital stock to install the latest technology. Increasing incentives for improved efficiency are provided by higher energy prices, and the encouragement of policy-makers. It is difficult to estimate the extent of actual historical technical energy efficiency improvement in an economy, but it is relatively easy to estimate the effects of future technical energy efficiency improvements. The effect of technical energy efficiency improvements of one per cent and two per cent per annum compounding are shown in Figure 15.1. In practice, two per cent is substantial. This is clear when one considers that it is equivalent to saving 20 per cent of energy across all end uses in 10 per cent of the market every year in perpetuity.

\section{There is no Average Province in China}

It is informative to go beyond the cross-section of international comparisons in Figure 15.1 and disaggregate the China data to the provincial level to see the diversity in the rates of development between the major cities and the inland provinces. This shows the degree to which provinces that might be thought economically diverse seem to cluster with respect to electricity and economic development, as well as the broad diversity of development paths across provinces. Figure 15.2 shows electricity per capita versus GDP per capita in RMB terms for each of China's provinces. 
Figure 15.2 Electricity-economy and population cross-section of China by provinces

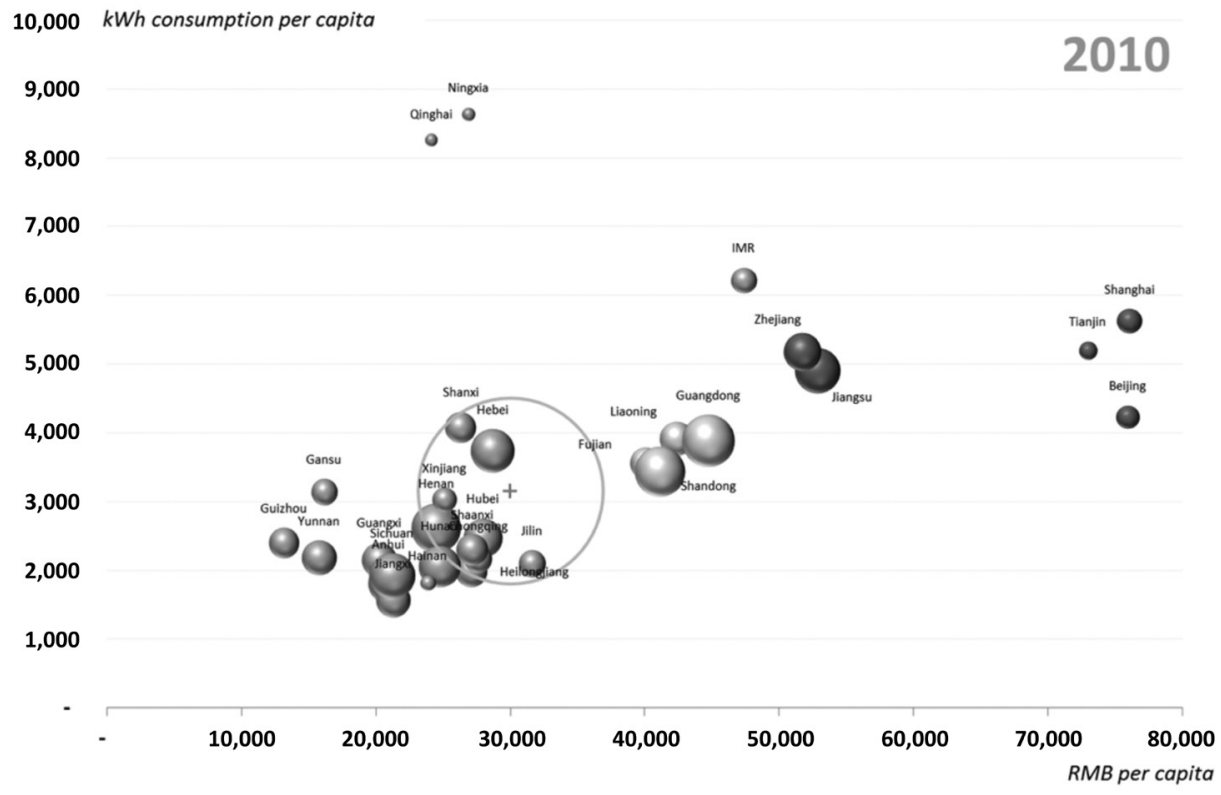

Source: National Bureau of Statistics, China Electricity Council.

Bubble sizes represent population. The enormous development between 1990 and 2010 is clear in the figure, with the national average increasing from a few thousand RMB and less than 1,000 kWh per capita in 1990 to just over $30,000 \mathrm{RMB}$ and 3,000 kWh per capita in 2010. Even more striking is the wide range of development between the provinces, from the cluster of three key cities Beijing, Tianjin and Shanghai; to Zhejiang and Jiangsu clustered together; then the four coastal provinces of Liaoning, Shandong, Fujian and Guangdong, all with very similar levels of GDP per capita and electricity use per capita. Inner Mongolia, and especially Ningxia and Qinghai are extremely electricityintensive. The income levels of the inland provinces remain below the national average, as does their electricity consumption, with the exception of the coalrich provinces, which tend to have higher per capita electricity consumption. Unlike 1990, none of the provinces is representative of the national average marked as ' + ' at the centre of the circle representing the 2010 China population. 


\section{The Policy-Makers' Challenge}

\section{Resolving the Energy Policy Trilemma}

'Policy-makers looking for simultaneous progress towards energy security, economic and environmental objectives are facing increasingly complex-and sometimes contradictory-choices' (International Energy Agency 2012: 24). This may be referred to as the Energy Policy Trilemma (Figure 15.3).

Figure 15.3 The Energy Policy Trilemma
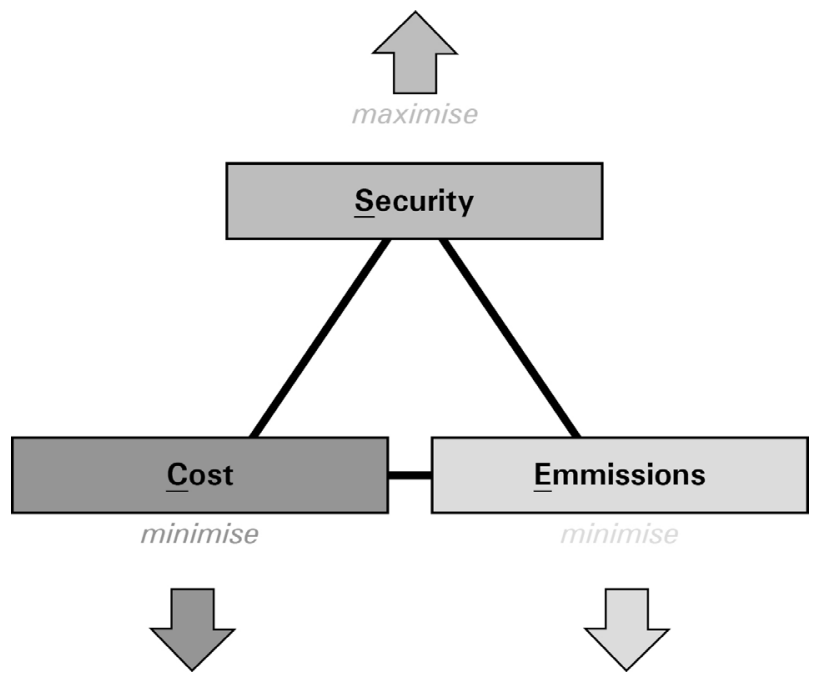

Source: Authors' own schema.

Energy prices, both for liquid fuels, electricity and natural gas, are a political concern in every country: large or small, rich or poor, free market or centrally planned. Every country has an energy policy, and policy makers in all countries are trying to achieve the same three objectives: maximising security of supply, minimising cost, and minimising environmental impacts including emissions. These three objectives are usually in tension - difficult trade-offs are normally required.

Exceptions occur after a major disruptive change. Four case studies illustrate this:

- The 1970s oil crises

- China's quiet revolution in nuclear power

- The US unconventional oil and gas revolution

- Fukushima and Japan's '30 GW problem' 


\section{Case Study 1: The 1970s Oil Crises}

The two oil crises of the 1970s - the oil embargo following the 1973 ArabIsraeli war, and the supply disruptions following the 1979 Iranian revolutionbrought large step changes in the price of oil, and its price relative to alternative fuels. Policy focus on environmental concerns was in its infancy in the 1970s. Nevertheless, in retrospect, the oil shocks can be seen as having brought the objectives of the Energy Policy Trilemma into alignment. Countries exposed to the price shocks, particularly the United States and the other industrialised economies of the OECD, responded by finding substitutes for oil where possible, particularly in power generation.

\section{Case Study 2: China's Quiet Cost Revolution in Nuclear Power}

One of the ways that OECD countries, such as the United States, France, Germany and Japan, displaced or avoided oil use in the power sector was to build nuclear power plants. In the 1950s it was famously said that nuclear power would be 'too cheap to meter'. For various reasons, particularly in the United States, the economics of nuclear power turned out to be less attractive than expected, largely due to capital cost overruns.

In recent years, China has challenged the contemporary Western conventional wisdom on the economics of nuclear power. Through the partnership between the State Nuclear Power Technology Company (SNPTC) and Toshiba Westinghouse to build the third generation Advanced Passive AP1000 reactor, and subsequently to scale up and develop the design, China is radically reducing the capital cost of building new nuclear reactors, such that nuclear power is now the lowest economic-cost generation option in China. This technological, design, manufacturing, project management and financing cost revolution brings all three elements of the Trilemma into alignment, and explains China's nuclear power policy and stated long-term goal to build $400 \mathrm{GW}$ of nuclear power capacity by 2050, which would be more than the entire global capacity today (China's Medium to Long Term Energy Strategic Plan).

\section{Case Study 3: The US Unconventional Oil and Gas Revolution}

The past five years or so have seen a techno-economic revolution in the United States from the innovative combination of two established oil and gas production technologies. Horizontal directional drilling and hydraulic fracturing have unlocked gas in low permeability shale beds and tight oil in similarly low permeability structures, enabling its commercial production. 
Prior to these developments, most observers of the industry expected that the United States would become a major importer of seaborne Liquefied Natural Gas (LNG) to meet its domestic gas demand. Spot natural gas in the United States had seen two sustained price spikes into the mid-teens in terms of dollars per million British thermal units (\$/MMBtu) in the 2000s: market conditions that are conducive to attracting LNG imports.

The recent growth in the production of shale gas was so rapid as to lead to temporary overproduction and a price crash to under $\$ 2 / \mathrm{MMBtu}$. At the time of writing, prices had recovered to over $\$ 4 / \mathrm{MMBtu}$. Widespread industry views suggest US natural gas prices will stabilise around $\$ 4$ to $\$ 6 / \mathrm{MMBtu}$. Reflecting the diametric shift in the supply-demand balance, and the large price differentials between North American and European and Asian gas prices, the nation is now publicly debating the extent to which it should export LNG. The benefits of free markets and free trade are being weighed against energy security and domestic industrial renewal and employment.

As the energy economy seeks a new equilibrium, the unconventional gas revolution has aligned the three Trilemma objectives in the short run. In the long run, the system-wide emission-reduction benefits of gas relative to coal may be offset by the deferral due to low cost gas of new nuclear and renewable energy investments.

\section{Case Study 4: Fukushima and Japan's '30 GW Problem'}

The enormous offshore earthquake and subsequent tsunami that struck the north-east coast of Japan in March 2011 caused a chain of events that resulted in the catastrophic failure of the Fukushima Daiichi nuclear power plant, a second-generation boiling water reactor plant that was first commissioned in 1971. In response, all of the reactors in Japan's nuclear fleet went off-line after their first scheduled maintenance shut down following Fukushima. The $47 \mathrm{GW}$ of capacity in Japan's pre-tsunami nuclear fleet ran at an average load capacity of about $30 \mathrm{GW}$, thereby leaving a large gap of about 30 per cent in the national power generation supply, which needed to be met initially by gas from LNG imports, and to a lesser extent by increased coal burn.

With the previous policy to increase nuclear capacity to 50 per cent of the fuel mix no longer publicly acceptable or practical, and Japan virtually 100 per cent dependent on imports for all its energy needs, the search for a new energy policy confronted a very severe version of the Trilemma. Meeting earlier $\mathrm{CO}_{2}$ emission reduction commitments had become practically impossible without large expansion of nuclear power. Japan's current account swinging to deficit due to increased energy imports, particularly of LNG, highlighted the seriousness of energy cost concerns. At the same time, Japan's traditional 
energy security concerns were exacerbated by the reduction in the most secure energy source in the mix: Japan maintains probably the longest supply duration uranium stockpiles in the world for its nuclear reactor fleet to provide maximum energy security.

\section{Resources, Domestic Supply and Imports, and the Fuel Mix}

\section{China's Resources}

Although China's discoveries of crude oil and natural gas reserves rose in recent years thanks to active and extensive exploration, the reserves are still relatively small compared to its coal resources, which underpin the country's energy security (Figure 15.4). China also has only modest uranium resources - a critical energy source to fuel its massive nuclear power plant expansion plans. According to the OECD-produced 'Red Book', estimates of recoverable resources at $166100 \mathrm{tU}$ (approximately 432M lbs U3O8) in China is only about a tenth of the level of Australia's known recoverable resources (OECD 2011). Also, China's deposits are mostly small, remotely distributed and have high estimated mining costs. The natural resource endowment has decided the fuel mix structure of China's energy supply, which is coal dominant (Figure 15.5).

Figure 15.4 China's energy resource endowment

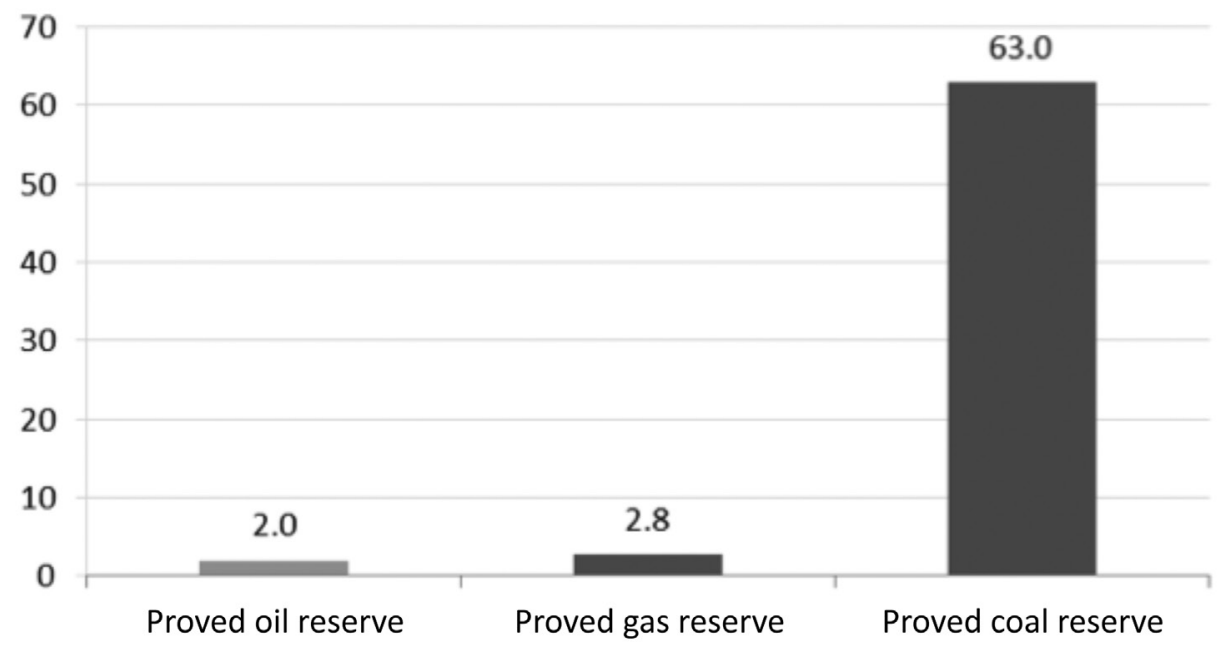

Source: BP Statistics, 2011 year-end data, Btoe. 
Figure 15.5 China's energy demand by fuel mix

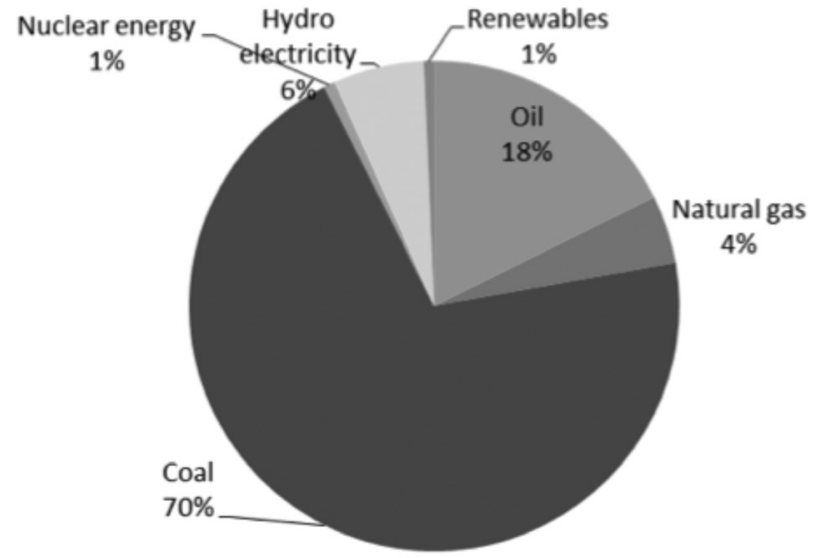

Source: China Customs Statistics, China Customs, Beijing, 2011 year-end data.

\section{Domestic Supply and Imports}

As China's energy requirements have increased, it has made the transition from a producer-consumer, with small net exports, to a major net importer in oil in 1993-1994 (Figure 15.6), in gas in 2006-2007 (Figure 15.7) and in coal in 2008-2009 (Figure 15.8). Oil import dependence is now over 60 per cent and gas import dependence over 20 per cent. Coal imports are still less than ten per cent.

Figure 15.6 China's oil consumption and import (1980-2011, million tonnes)

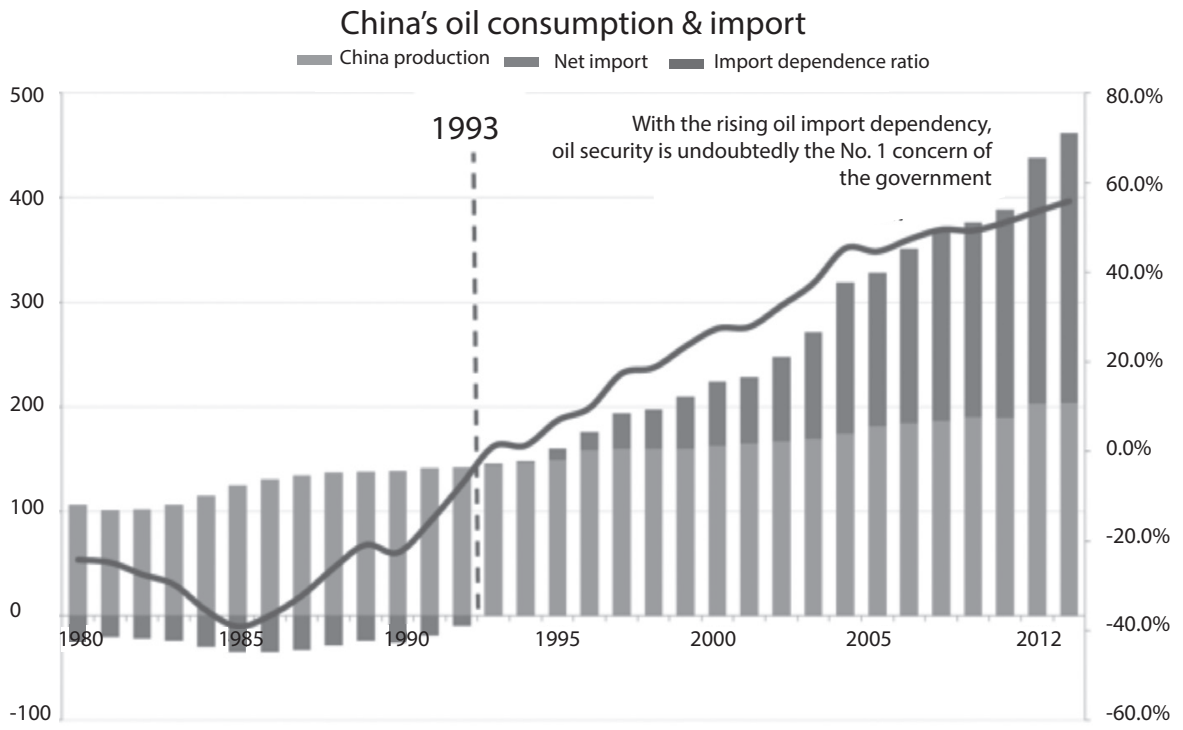

Source: China Customs Statistics, China Customs, Beijing. 
Figure 15.7 China's gas consumption and import (1980-2011, billion cubic metres)

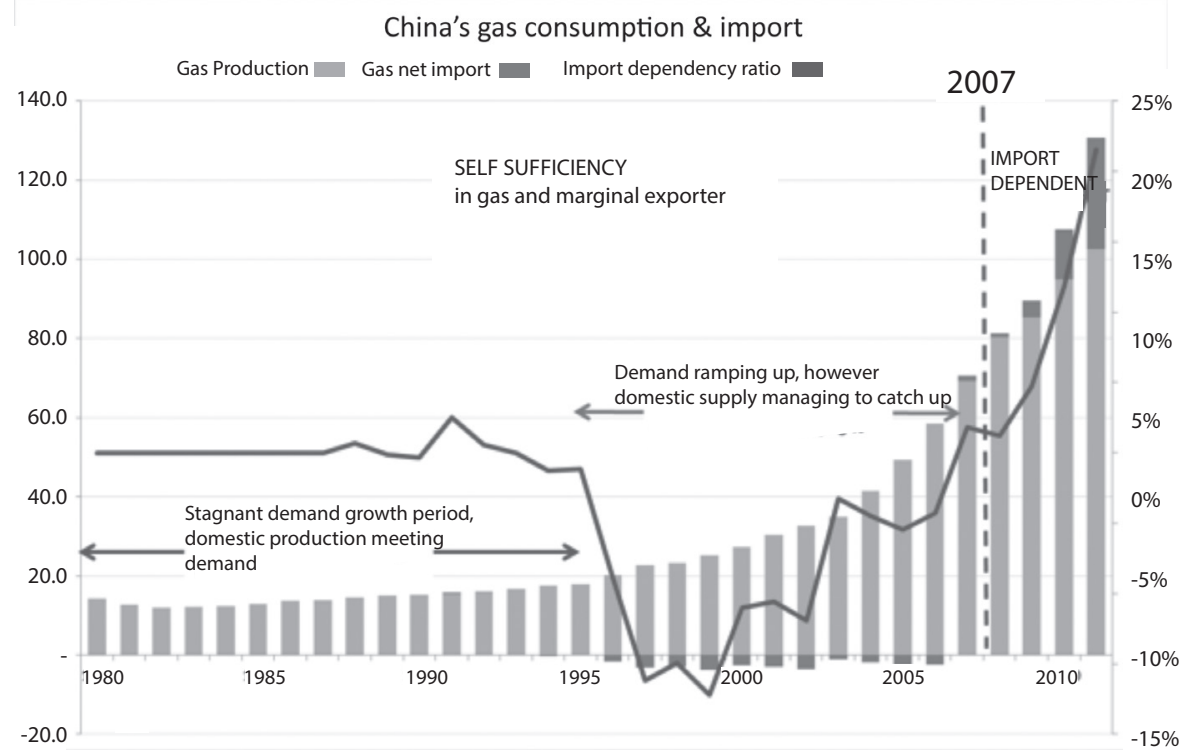

Source: China Customs Statistics, China Customs, Beijing.

Figure 15.8 China's coal consumption and import (1980-2011, million tonnes, physical)

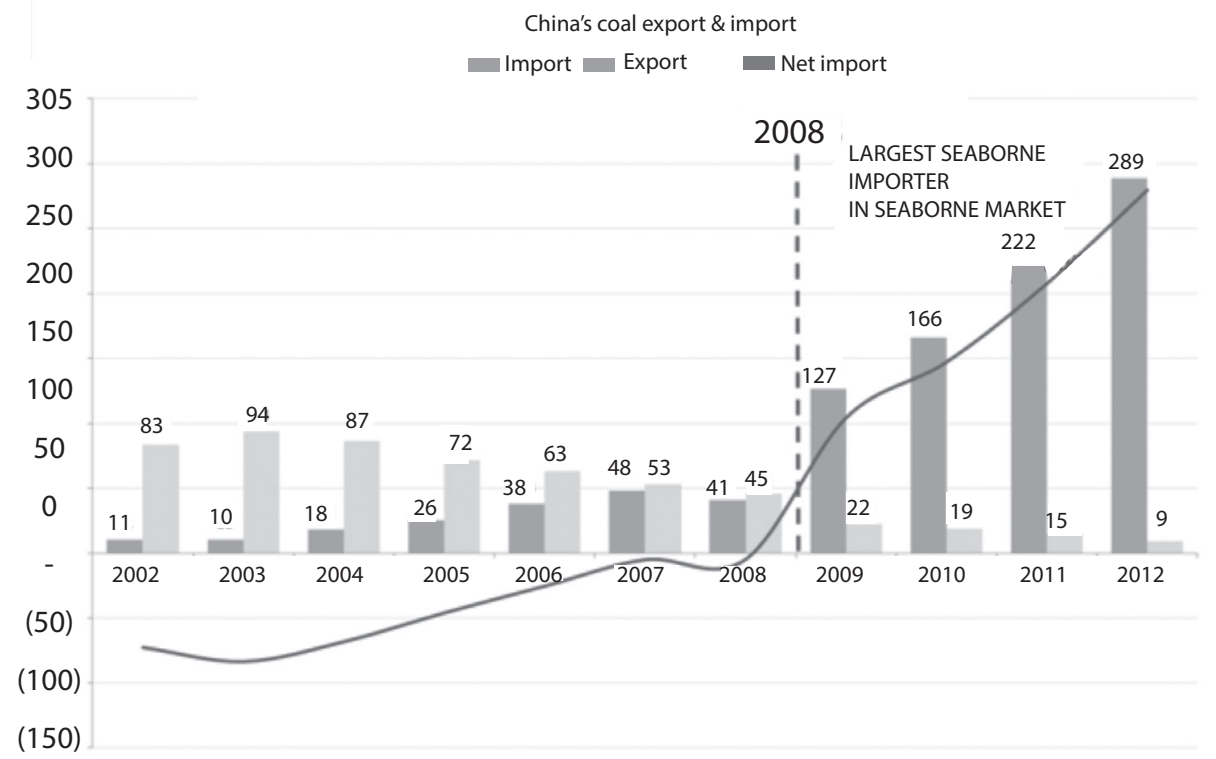

Source: China Customs Statistics, China Customs, Beijing. 
China's ability to provide its own needs is limited by the fact that its proven oil and gas reserves are small in relation to its consumption. At current production rates, the reserve to production ratio of oil is only ten years, while gas is 30 years (source: BP statistics, reserve is proven and excludes resource estimates). Consequently, China's reliance on fossil fuel imports has grown significantly in recent years - oil dependency is at 60 per cent and natural gas dependency at 20 per cent and rising.

Figure 15.9 shows a typical evolution of an emerging economy from energy producer-consumer to net energy exporter to net energy importer. Two contrasting policy choices are shown in stylised form: the pursuit of selfsufficiency at all costs for as long as possible, and stewardship of domestic resources relying on market forces to balance imports with domestic supply.

Figure 15.9 Policy choices

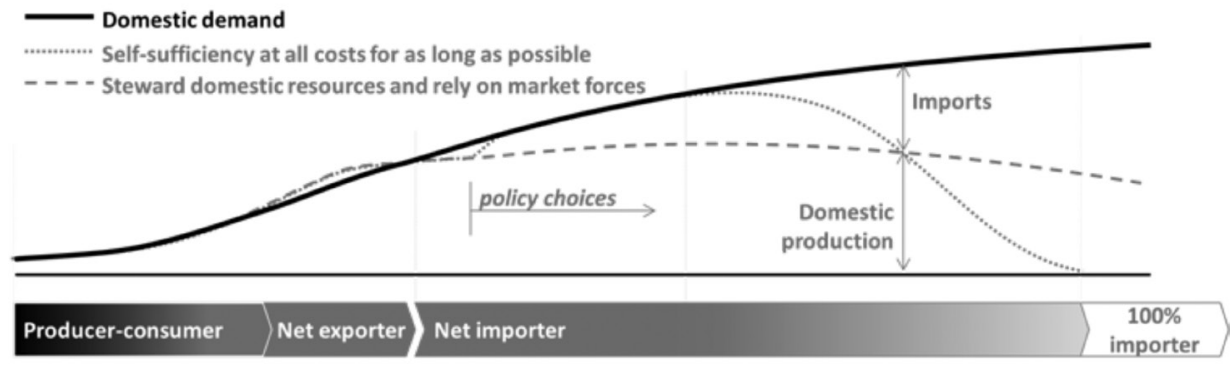

Source: Authors' own schema.

The former policy will tend to increase the marginal economic cost of supply and hence prices, while accelerating the depletion of indigenous resources. At its limit, it will bring forward the date of resource depletion and import dependence. The latter policy will tend to minimise marginal costs and hence prices, and optimise the depletion of indigenous resources.

Another policy choice (which would be lower and flatter than the stewardship curve of Figure 15.9) would be to increase imports now to conserve domestic resources for future generations. Such a policy would be expected to increase marginal costs and hence prices, and to push depletion to a later date.

A further policy (which would create a higher and more 'peaked' curve than the self-sufficiency of Figure 15.9) would be to encourage exports. The United States is currently debating whether to allow unrestricted LNG exports now, at the possible cost of higher prices and depletion of shale gas resources faster and sooner. Stewarding domestic resources and relying on market forces may result 
in net imports balancing supply and demand in some countries and at some times, or in net exports balancing supply and demand in other countries or at other times.

Evidence from current policy settings and the evolution of energy policy in China suggests an approach best described as stewarding domestic resources for the long run by increasingly relying on market forces to find the appropriate balance between domestic supply and imports.

Tax policy can be used to fine-tune such an approach, as has been done in China with, for example, a shift from duties and taxes that encouraged coal exports towards duties and taxes that discourage coal exports.

\section{Opportunities and Challenges: The 7 Ds Facing the Coal Sector}

Despite the fact that coal provides the fundamentals of China's energy security of supply, the over-reliance on this sector and massive production rates at close to 4 billion tonnes per annum has imposed increasingly greater challenges to this sector's future development.

The challenges facing China's coal sector can be summarised in seven D's: depletion of the resource base, characterised by increasing mining depths; quality deterioration; increasing geological difficulty; increasing distances from mines to markets; and, the imperative to improve safety to reduce mining deaths. The challenges of these resource fundamentals are compounded by China's changing demographics and socio-economic development, in which the labour pool has begun to shrink, and employment opportunities continue to improve with economic growth.

\section{Opportunities and Challenges: Unconventional Gas}

The shale gas revolution and production boom in the United States has given rise to hopes for China to unlock its unconventional resources and improve energy security in general. According to a consultant's estimate, published by the US Energy Information Administration, China has larger shale gas resources than the United States (Advanced Resources International, Inc. 2011). Estimates by Chinese geologists from the Ministry of Land and Resources estimate China's shale gas resources are around the same scale as the United States.

The benefits of a shale-gas boom in China would be enormous, with the potential benefits and likely environmental costs perhaps even greater than in the United States. So far, however, the sector's success is limited by the challenging geology and the monopolistic structure of China's oil and gas sector. 
While over 100,000 horizontal wells have been drilled into shales in the United States and hydraulically fractured or 'fracked', China has only about 80 drill holes to date. The sector is characterised by investors as a high risk proposition, with insufficient infrastructure in place, no third-party access to the pipelines (over 80 per cent of China's pipelines are owned and operated by China National Petroleum Company) and potentially further complicated by local environmental concerns in relation to groundwater and disruption and disturbance of the daily lives of host communities.

Analysts at the optimistic end of the range expect that large-scale, commercial production could happen in the next ten to 20 years. The International Energy Agency predicts China's unconventional gas production could rise from $10 \mathrm{Bcm}$ in 2010 to over $110 \mathrm{Bcm}$ in 2020 and $390 \mathrm{Bcm}$ by 2035 (2012). Under this scenario, total gas production rises from just under $100 \mathrm{Bcm}$ in 2010 to nearly $475 \mathrm{Bcm}$ in 2035, and unconventional gas accounts for 83 per cent of total gas production by the end of the projection period. Unconventional gas production in 2035 is predominately from shale gas ( 56 per cent). Coal bed methane (38 per cent) and tight gas (six per cent) provide smaller shares. While China would still rely on gas imports, the unconventional gas success would significantly reduce its foreign gas dependency ratio (Table 15.1).

Table 15.1 Two gas development scenarios for China

\begin{tabular}{|c|c|c|c|c|c|c|}
\hline & \multirow[b]{2}{*}{2010} & \multicolumn{2}{|c|}{$\begin{array}{l}\text { Golden Rules } \\
\text { Case }\end{array}$} & \multicolumn{2}{|c|}{$\begin{array}{c}\text { Low Unconventional } \\
\text { Case }\end{array}$} & \multirow[t]{2}{*}{ Delta* } \\
\hline & & 2020 & 2035 & 2020 & 2035 & \\
\hline Production & 97 & 246 & 473 & 139 & 194 & 279 \\
\hline Unconventional & 12 & 112 & 391 & 37 & 112 & 279 \\
\hline Unconventional share of total & $12 \%$ & $45 \%$ & $83 \%$ & $27 \%$ & $58 \%$ & $25 \%$ \\
\hline Net imports & 14 & 77 & 119 & 143 & 262 & -143 \\
\hline Imports as share of demand & $12 \%$ & $24 \%$ & $20 \%$ & $51 \%$ & $57 \%$ & $-37 \%$ \\
\hline Gas share of the energy mix & $4 \%$ & $8 \%$ & $13 \%$ & $7 \%$ & $10 \%$ & $3 \%$ \\
\hline
\end{tabular}

*Delta is the difference between the Golden Rules Case and the Low Unconventional Case.

Source: Data and projections: International Energy Agency.

\section{Diversity and Dependence}

In China, energy security of supply is already equal with or greater than cost as a policy priority. The environment has historically been a lesser concern. This is changing as incomes increase, leading to greater impacts on the environment from increased mobilisation, industrialisation and urbanisation. Reducing the emissions that contribute to local air pollution from oxides of sulphur and 
nitrogen dioxide and particulate matter is becoming an increasingly important policy priority. This is particularly evident in China's major cities and the more developed coastal provinces, where incomes are highest.

\section{Pushing the Technology Envelope}

\section{Traditional and Emerging Energy Pathways}

The degree of competition between 'the big three' hydrocarbons - oil, gas and coal-varies from country to country. Since the oil crises of the 1970s, however, oil has tended to be priced out of uses such as power generation in most oil-importing countries where new economic alternatives are available. The growth of the gas industry in the second half of the 20th century in Europe and the United States also displaced oil from the industrial sector, leaving oil as the dominant fuel in the transport sector, where it is has the greatest advantages and where it is most challenging to find attractive substitutes. Oil, gas and coal have generally found niches for which their particular characteristics are best suited. The security, cost and logistical advantages of coal are most evident in the power sector. Gas is the premium fuel for the residential, commercial and industrial sectors. The degree of inter-fuel competition varies somewhat from country to country and region to region. The left hand panel of Figure 15.10 illustrates this.

Figure 15.10 Hydrocarbon energy conversion and utilisation pathways
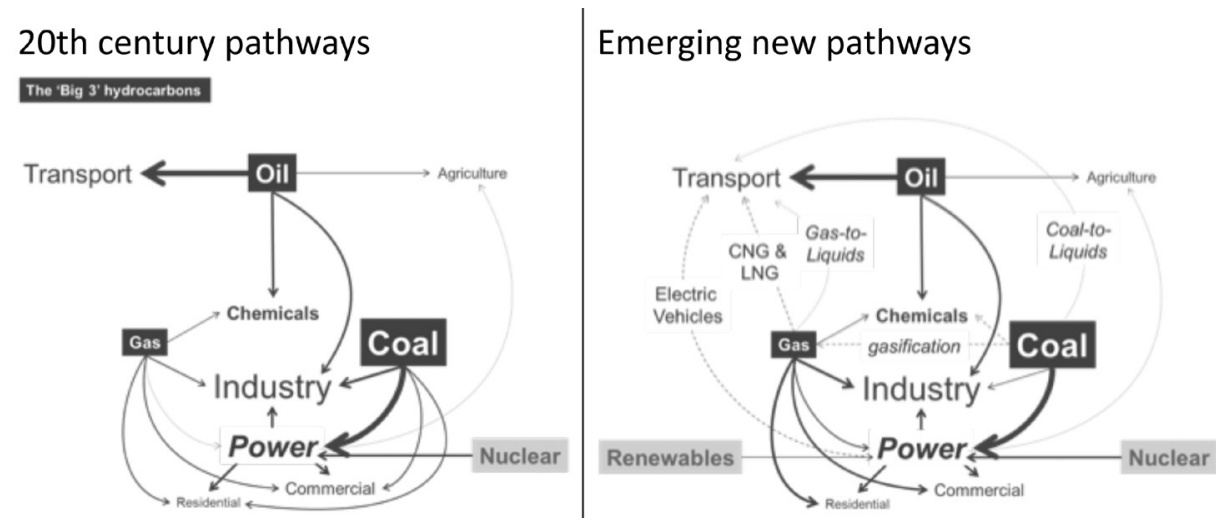

Source: Authors' own schema.

Technology, led by China in particular, is opening up the prospect for emerging new pathways to transform hydrocarbons. As the right hand panel of Figure 15.10 illustrates, this would increase the potential variety of applications for each fuel and hence the extent of possible substitutability. Coal combustion 
in the residential and commercial sectors is expected to be replaced by gas where possible and, subject to availability and price, gas use will increase in the industrial sector.

\section{Oil and Gas: Alternatives to Imported Crude Oil-Easing the Pinch Point for Energy Security}

The right hand panel of Figure 15.10 shows four emerging new fuel-technology pathways for transport: natural gas vehicles (NGVs) using compressed natural gas (CNG) or liquefied natural gas (LNG); coal-to-liquids (CtL) technologies; gasto-liquids (GtL) technologies and electric vehicles (EVs).

Gas use in vehicles via CNG and LNG technologies has begun, including for heavy-haul vehicles in China, and is expected to be encouraged by policy settings, and potentially by relative prices, although the oil-to-gas price differential in China is not expected to be as wide as it has been in the United States in recent years.

China is working on CtL technologies and pilot plants. GtL technologies are less likely to be applied in China (compared with the Middle East, for example), as China's oil and gas companies do not have a surplus of gas to monetise. Many CtL technologies, however, use coal gasification as the first step in the process of producing liquid fuels.

Small electric vehicles for urban use, notably scooters, are already common in China and domestic companies such as BYD are manufacturing electric vehicles.

\section{Coal: Pressures to Reduce Coal Use; Pressures and Opportunities to Increase Coal Use}

China is facing a number of internal and external pressures to reduce coal use. These include the economic pressures of rising costs, the social need to further reduce the rate of coal-mining deaths, the need to reduce the impacts of mining on land and communities, and local and international environmental concerns. At the same time the energy required for economic growth brings pressures from the demand side to increase coal use. Profitable opportunities for Chinese companies to develop and mine coal reserves, along with profitable import opportunities also bring supply-side pressure to increase coal use. From the policy level, the importance of reducing pressure on the oil market may increase upward pressure on coal. 
Displacing imported oil to increase energy security of supply is a key focus of the emerging new hydrocarbon pathways in China. Alternatives for coal, including increased use of gas in small-scale applications where emissions are difficult to control and monitor, and to enforce regulatory standards, enable coal to be released for transformation to relieve the pressure on oil demand. In addition to CtL, coal can be gasified and the gas used directly. There are over 100 coal-to-chemicals (CtC) projects in various stages of proposal, planning, development and operation in China.

China's nuclear build program, the largest in the world, will complement efforts to relieve the pressure on oil demand. Developing the balance of China's hydro potential, as well as from intermittent renewable energy forms will also contribute to the same goal.

China's efforts to push the technology envelope are best understood within the framework of the Energy Policy Trilemma, and particularly in terms of concerns about oil security of supply. There is a risk of rapid growth in China's oil demand driven by personal and commercial transportation activity rising with incomes and economic growth, which will put enormous stress on the global oil-supply system. This could be expressed in high prices, even in the absence of supply shocks similar to those of the 1970s (for example a conflictrelated closure of the Straits of Hormuz).

\section{Conclusion}

China has undergone an enormous economic transformation in the past two decades and is now approaching world average levels of per capita income and energy consumption. Energy is a key driver of economic development, particularly in China's case, where relatively energy-intensive industries have played a key role. Rapid economic transformation has been primarily driven by the coastal provinces and the major cities. Looking beyond national averages into province-level data shows that energy demand and economic development still have a long way to go in China. Structural change in the economy towards a greater weighting of less energy-intensive secondary industries and higher value-added services are expected to moderate the strong linear relationship of the past two decades between energy requirements and GDP. Improvements in technical energy efficiency will further help moderate the rate of energy demand growth.

In absolute terms, China is abundant in energy resources. Relative to the scale of demand arising from the scale of its population and its rapid economic development, however, it will increasingly be fundamentally energy short. 
China was historically energy self-sufficient, and even able to export a small proportion of its energy production. Exports of oil stopped in 1993, gas in 2006 and coal in 2008. Security of supply is already the highest policy priority, which is felt most acutely in oil. The trade-offs between the three corners of the Energy Policy Trilemma are steadily becoming more acute in China. As China's energy import dependence deepens from oil to gas, security of supply is expected to increase rather than decrease in importance. The challenges for policy makers will increase as the economic pressures on coal production grow, caused by the 7Ds' of resource depletion and demographic change. The increasing imperative to reduce the environmental impacts of energy use on China's local air quality, water resources and soils emphasise the challenge.

China's energy mix is changing, driven by the cost revolution in third generation nuclear reactor technology, the push to increase the role of the gas sector and encouragement of renewable energy technology. In parallel, technology offers the prospect of increased flexibility by transforming coal to oil, chemicals or gas and by new applications for gas and for electricity in the transport sector.

Energy imports, including gas, coal and uranium from stable regional trading partners, such as Australia, have a key role to play in balancing production of China's own resources with its large and rapidly growing energy needs. Continuation of the reforms that have enhanced the scope for price signals to indicate opportunities for energy imports will help to facilitate this process to the mutual benefit of China's people and her regional trade partners.

\section{References}

Advanced Resources International, Inc., 2011, World Shale Gas Resources: An Initial Assessment of 14 Regions Outside the United States, US Energy Information Administration, Washington DC, April.

China Engineering Institute, 2011, China Medium and Long Term Energy Strategic Plan 2030 and 2050, Beijing.

International Energy Agency, 2012, World Energy Outlook 2012, OECD, Paris.

International Energy Agency, 2012, World Energy Outlook 2012 Special Report: Golden Rules for a Golden Age of Gas, OECD, Paris, 29 May.

OECD, Uranium 2011: Resources, Production and Demand, Paris.

Shell, 2013, New Lens Scenarios: A Shift in Perspective for a World in Transition, http://www.shelldialogues.com/event/new-lens-scenarios-shift-perspectiveworld-transition 



\section{Financial Constraints on Chinese Outward Direct Investment by the Private Sector ${ }^{1}$}

Bijun Wang, Miaojie Yu and Yiping Huang

\section{Introduction}

China's outward direct investment(ODI) has become a worldwide phenomenon in recent years, having increased from $\$ 2.85$ billion in 2003 to $\$ 74.65$ billion in 2011 in flow terms, and jumped from $\$ 29.9$ billion to $\$ 424.8$ billion in stock terms during the same period. China, following the United States, Japan, United Kingdom, France and Hong Kong, was in 2011 the sixth-largest ODI investor in the world, and the largest in developing countries.

State-owned enterprises (SOEs) are currently the major players in Chinese ODI, albeit their relative importance is declining (Wang and Huang 2012a). Wholly state-owned unincorporated enterprises devoured 66 per cent of total investments in 2010. Meanwhile, SOEs under central government contributed nearly 80 per cent of Chinese total overseas investments.

Should private enterprises, especially small and medium-sized enterprises (SMEs) pursue ODI? Such a question obviously should be left to the investors themselves. But international experience and existing literature seems to argue that even those primarily domestically oriented SMEs must operate internationally in order to improve their competitiveness and maintain viability (Etemad 1999, 2004). There is also evidence that entry into foreign markets, regardless of how this happens, could significantly promote, improve and increase the development, performance and profitabilty of firms, thus contributing to domestic wealth (Daniels and Bracker 1989). Besides, ODI compared with exports is found to generate the highest profit level and maximise control of critical knowledge (Lu and Beamish 2001; Tang and Yu 1990).

1 The study is supported by the Key Research Base of Humanities and Social Sciences, Ministry of Education of the People's Republic of China (Project No. 11JJD790027). 
Then, why is it that SOEs currently dominate Chinese ODI? It has been proposed that this is the result of the growth of a Chinese-style ODI (Huang and Wang 2011), which forms part of an evolutionary path from Chinese-style ODI, to Japanese-style ODI and finally US-style ODI (Wang and Huang 2012b). That SOEs dominate current Chinese ODI partly reflects the focus of Chinese ODI being to strengthen domestic production, rather than moving factories overseas, to improve the competitiveness of investing firms, rather than exploit existing, firm-specific advantages. But domestic financial repression also makes the dominance of SOEs possible. The direct result is that private sector SMEs, especially, face severe financial constraints. The direct, firm-level evidence on the effect of financial constraints on ODI has, however, been limited. The application to China is almost zero.

This chapter fills this void by providing a detailed analysis of the role that financial constraint plays in restricting firms' ODI activity. Using detailed, firmlevel data of Zhejiang Province between 2006 and 2008, three main findings become clear: first, firms with less financial constraint (more liquidity, or with foreign ownership) are more likely to enter the foreign market, pursuing ODI; second, higher productivity can mitigate some of the negative impact of financial constraints for exporters, but can not compensate for the financial constraint that is faced by ODI firms.

This evidence indicates that financial constraint hinders Chinese private enterprises pursuing ODI, and their higher productivity does not mitigate that negative impact. These results are verified by sensitivity analysis. Other variables that might affect ODI activities are controlled, including firm productivity, size, age, profitability, capital intensity, firm export experience, cyclical effects and industry-specific effects. The empirical approach adopted here addresses some concerns about reverse causality by using lagged variables, and reducing observations to ODI for the first time.

The chapter implies that if financial constraint is still in existence, those more viable, more productive and more competitive private enterprises are likely to be shut out of opportunities for ODI. As a result, the quality and return of Chinese ODI, and the image and reputation of overseas Chinese enterprises, will become a concern. Section 2 of this chapter reviews existing literature on firm heterogeneity and internationalised activities. Section 3 is a data description, which is followed by variable construction. Section 4 employs a multinomial logit model to assess the impact of financial constraint on a firm's decision to become the domestic, exporter, or ODI player. Section 5 presents the impact of financial constraint on the amount of ODI made; and, Section 6 provides some concluding remarks. 


\section{Literature Review}

Firms generally have three channels to serve foreign customers: through export, through foreign subsidiaries, or through licensed foreign partners. Comprehensive considerations influence a firm's choice of using a single or mixed channels. S. Lael Brainard (1997) offers a characterisation of, and empirical support for, the proximity-concentration trade-off in the face of a firm's ODI/ export decision. That is, firms invest abroad rather than export when the gains from proximity to local market outweigh the cost advantages to concentration (economies of scale).

Firms are heterogeneous; even facing the same industry costs and the same investment opportunity, they may still make different choices about market entry. Paul Krugman (1980) produced one of the early studies incorporating firm heterogeneity into a trade model. As an extension, Marc Melitz (2003) develops a dynamic industry model based on heterogeneous firms and shows that exposure to trade will induce only the more productive firms to enter the export market, some less productive firms continue to produce only for the domestic market, and the least productive firms will be forced to exit the market. Stephen Yeaple (2005) shows similar findings based on a general equilibrium trade model in which homogeneous firms choose competing technologies and workers of heterogeneous skill.

With the growth of multinational sales outpacing trade expansion, literature increasingly focuses the impact of firm heterogeneity on the choice between exports and ODI. The most important one is Elhanan Helpman, Melitz and Yeaple (2004) (henceforth HMY). HMY develop a simple, multicountry model based on multiple sectors of monopolistically competitive firms. The heterogeneity of firms arises from productivity differences. They find that cross-sectoral differences in firm heterogeneity predict the composition of trade and investment: the least productive firms serve only the domestic market, the relatively more productive firms export, and the most productive firms engage in ODI. They also prove the argument by using US exports and affiliate sales data that cover 52 manufacturing sectors and 38 countries.

Several other studies try to test HMY's argument. Going beyond tests for differences in mean productivity, that are typically found in the literature, Sourafel Girma, Richard Kneller and Mauro Pisu (2005) apply KolmogrovSmirnov stochastic dominance to UK-owned multinational corporations. Their finding is quite consistent with HMY's: the productivity distribution of multinational firms dominates that of export firms, which in turn dominates that of non-exporters. 
HMY's model assumes that all ODI is horizontally motivated and happening among economies with similar factor price and market size. Keith Head and John Ries (2003) extend the model to vertical ODI by introducing heterogeneous labour costs in different countries, which involve fragmentation of production across countries. They show the productivity ordering predicted by HMY can be reversed if the foreign country is the low-cost production site. That is, the low productivity firms may also engage in ODI in low-cost foreign countries, and more productive firms may stay at home and supply foreign markets through exports. But, as David Greenaway and Kneller (2007) point out, since the data sample in Head and Ries (2003) only consists of 1070 large, publicly listed Japanese firms, their result could be an exception to the general pattern.

Productivity is not, however, the sole determinant of firms' internationalisation behaviours. Many productive firms only serve the domestic market, while many less productive firms engage in export or ODI (Bernard et al. 2003; Mayer and Ottaviano 2007). Figure 16.1 displays the distribution of the log of productivity (approximate total factor productivity and Labour productivity) for Chinese ODI firms and Non_ODI firms. As shown, firms engaging in ODI are generally more productive than those that do not. Nevertheless, the two distributions overlap. That is, many productive firms do not invest abroad. Conversely, many unproductive firms make ODI decisions. Analysts have found similar patterns in the United States, Belgium and Japan (Bernard et al. 2003; Mayer and Ottaviano 2007; and, Todo 2011).

Credit constraints influence whether the firm can finance the initial costs of export and ODI. Using cross-country data, Kalina Manova (2008) finds that equity market liberalisation increases exports more in credit-constrained sectors than in other sectors. There is also growing micro-evidence that credit market imperfections severely restrict the export capacity of firms. Using detailed customs data from China, Manova, Wei Shang-Jin and Zhang Zhiwei (2011) have identified the negative impact of credit constraints on export performance. More specifically, they find that financial frictions limit exporters' product scope, number of trade partners, and volume of cross-border flows within each product-destination market. Robert Feenstra, Li Zhiyuan and Yu Miaojie (2011) developed a theoretical setting where banks do not observe firms' productivities, and induced a tighter credit constraint on exporters than on purely domestic firms, even in the exporters' home market. Their empirical application to Chinese firms strongly supports the theoretical results, and they find a sizable impact of the financial crisis in reducing exports. Similar results are reported in Mirabelle Muuls (2008), Nicolas Berman and Jérôme Héricourt (2008) and Raoul Minetti and Susan Chun Zhu (2010). 
Figure 16.1 Distribution of productivity across Chinese firms

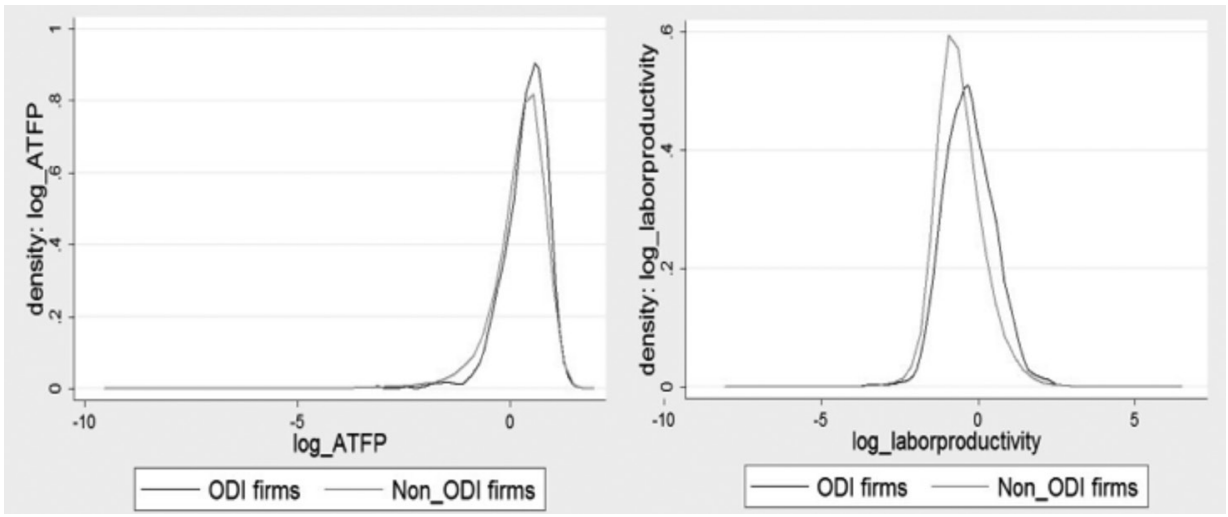

Source: Wang 2011.

To address the endogeneity of financial constraints to firms' international trade decisions, Mary Amiti and David Weinstein (2009) have employed exogenous shocks to firms' access to external finance, and found that Japanese banks transmitted financial shocks to exporters during the crises in the 1990s. In addition to export decisions, Yasuyuki Todo (2011) also finds credit constraints have a negative effect on firms' ODI decisions.

Credit constraints are particularly severe in SMEs and have a greater impact on their investment behaviours (Berger and Udell 1998; Hall 1992). Compared with large enterprises, SMEs usually have higher failure rates, more pronounced problems of agency and asymmetric information (Bruderl et al. 1992). As a result, some policy schemes, like direct loans, interest subsidies and loan guarantees, have been set up to alleviate the credit constraint of SMEs (Cressy 1996, 2002). Nevertheless, there has been limited study in the existing literature that explores the financial constraints SMEs face when pursuing ODI, although quite a number of studies have found that SMEs frequently face a shortage of capital to finance their exports (Bilkey \& Tesar 1977; Crick 2004; Hook \& Czinkota 1988). A survey by the European Commission suggested that SMEs, engaging in ODI, might confront a shortage of capital (European Commission 2003a). Wouter de Maeseneire and Tine Claeys (2012) found the home bias of financiers, and the capital gearing method used by banks to evaluate small firms' foreign projects, give rise to financial constraints for Belgian SMEs' ODI projects.

The majority of studies on firms' heterogeneity and decisions with regard to internationalisation are based on experiences in developed countries and/ or are limited to analysis of export behaviour (for example, Bernard et al. 2003; Greenaway \& Kneller 2004; Girma, Kneller \& Pisu 2005). The inclusion of ODI 
into reviews of internationalisation decision-making starts with HMY (2004), but mostly are still drawn from high income economies, such as the United States (Helpman et al. 2004), and Japan (Head \& Ries 2003; Tomiura 2007; Todo 2011).

This line of research following developing economies' experience is limited. One exception uses Slovenian manufacturing data, and finds roughly a 20 per cent average productivity advantage of exporting and ODI firms over those that serve only domestic markets (Damijan et al. 2007). But, according to the same study, in Slovenia, due to transition-specific features related to inherited foreign investments of large inefficient firms, there is no statistically significant productivity advantage of ODI firms over exporting firms.

Another exception is Tian and Yu (2011). To our knowledge, theirs is the only firm-level empirical investigation on the relationship between Chinese manufacturing firms' productivity and their ODI decision-making. They find firms with high total factor productivity (TFP) are more likely to engage in ODI, and the higher TFP the firm has, the more the ODI is. But Tian and Yu (2012) do not explore why firms with similar TFP will make different decisions with regard to ODI.

This chapter makes two distinct contributions to the literature. First, this study applies to Chinese ODI with firm level information. The research on Chinese ODI lags behind China's influential role in global ODI scene. MOFCOM (Ministry of Commerce, China) data is currently the most widely used official data, but analysis based on such data should be accepted with caution because it is aggregate data, and information is missed during the process of aggregation. This study uncovers a real picture of Chinese manufacturing firms' ODI with a valid, representative, authoritative and comprehensive micro foundation. Secondly, this study provides evidence on the effects of financial constraints on private SMEs' ODI. This study not only describes the productivity characteristics of firms that only serve domestic markets, and firms entering foreign markets through export and/or through ODI. It also goes a step further in uncovering the impact of financial constraints, in particular, on private enterprises and SMEs, and on firms' internationalisation behaviour. These factors reflect the institutional features in transitional economies, such as a repressive financial system and a controlled capital account. This study provides micro-evidence of the urgency in deepening domestic reform and restructure. It also provides reference to other emerging and developing economies. 


\section{Data and Measures}

\section{The Dataset}

To uncover true pattern of Chinese ODI in manufacturing, this study is based on a comprehensive and authoritative firm-level data from 2006 to 2008 in Zhejiang Province. ${ }^{2}$

ODI from Zhejiang Province is widely representative of China's local investing firms' behaviour. From 2003 to 2009, although 82.57 per cent of Chinese non-financial ODI flow is produced by enterprises under the central governments, 92.24 per cent of Chinese ODI firms are local. Among those local firms, 66.5 per cent on average from 2005 to 2009 are contributed by Zhejiang, Jiangsu, Shandong, Guangdong, Shanghai and Heilongjiang provinces. The largest amount of ODI investors is from Zhejiang Province, accounting 22.44 per cent of the total.

ODI from Zhejiang Province is also widely representative of the behaviour of China's private investing firms. Of these investors, 70 per cent are from Zhejiang and Fujian provinces. The decisions of private firms are reflected in market forces, and they are less influenced by political and administrative elements. Thus, it is useful to compare this evidence with international experience and the existing literature.

Firm-level ODI data is merged with firm-level production data, which is compiled by China's National Bureau of Statistics in an annual survey of manufacturing enterprises. Table 16.1 reveals the ODI pattern and, thereupon, three aspects are evident.

First, the majority of ODI investors went to developed economies, but there is larger-scale investment in developing countries. The economy that attracts most Chinese firms is the United States, followed by Hong Kong, United Arab Emirates, Germany and Vietnam; four of these five are high-income economies. In fact, 66.82 per cent of Chinese ODI investors concentrated their efforts on developed economies. Investment scale in developed economies is not, however, as large as in developing countries. Of this, 33.18 per cent of investors occupied 58.44 per cent of the investment in developing countries. Vietnam has the largest share of this investment, while Cambodia is also an important host country.

Second, most of Chinese ODI institutions are in the form of trading or trade-related companies, and very few enterprises set up their production facilities abroad. Of Chinese firms, 82.89 per cent conducted ODI either through

2 This data is owned by the Foreign Trade and Economic Cooperation Bureau of Zhejiang Province. 
establishing economic and trade offices, or by establishing a trading company. Only 9.23 per cent of Chinese ODI firms were involved in production activity, while 5.51 per cent produced for the processing trade. Nevertheless, because of the higher cost of setting up production facilities, in comparison with establishing trading offices, 63.93 per cent of Chinese ODI was used for funding production.

Third, among the top five Chinese ODI industries, the largest group of investors was from the machinery manufacturing industry, but investment in textiles accounted for a larger share in ODI value. As shown in Table 16.1, 16.82 per cent of investors were from the textile industry and they contributed to 40.49 per cent of the investment amount. Meanwhile, investors from machinery manufacturing industries were also important ODI players, but their investment scale was smaller.

\section{Variable Definition}

To measure the severity of financial constraints, the literature in corporate finance has suggested several possibilities, including investment-cash flow sensitivities (Fazzari et al. 1988), the Kaplan and Zingales (KZ) index of constraints (Lamont et al. 2001), the Whited and Wu (WW) index of constraints (Whited and Wu 2006), the size-age (SA) index of constraints (Hadlock and Pierce 2010), and various sorting criteria based on firm characteristics. There is considerable debate with regard to the relative merits of each approach. But the variables consistently predict that a firm's financial constraint status, after controlling for size and age, are a firm's leverage and cash flow (Hadlock and Pierce 2010). That is, larger, older firms with lower leverage and more cash flow usually face less financial constraints. But, because of the endogenous nature of this variable, it is necessary to use caution when assessing leverage as an indicator for financial constraint.

Therefore, after controlling the size and age of the firm, we consider two measures of firm-level financial constraint. The first is liquidity, defined as the share of current assets in total assets. Given other factors, the lower liquidity, the larger the financial constraint. 


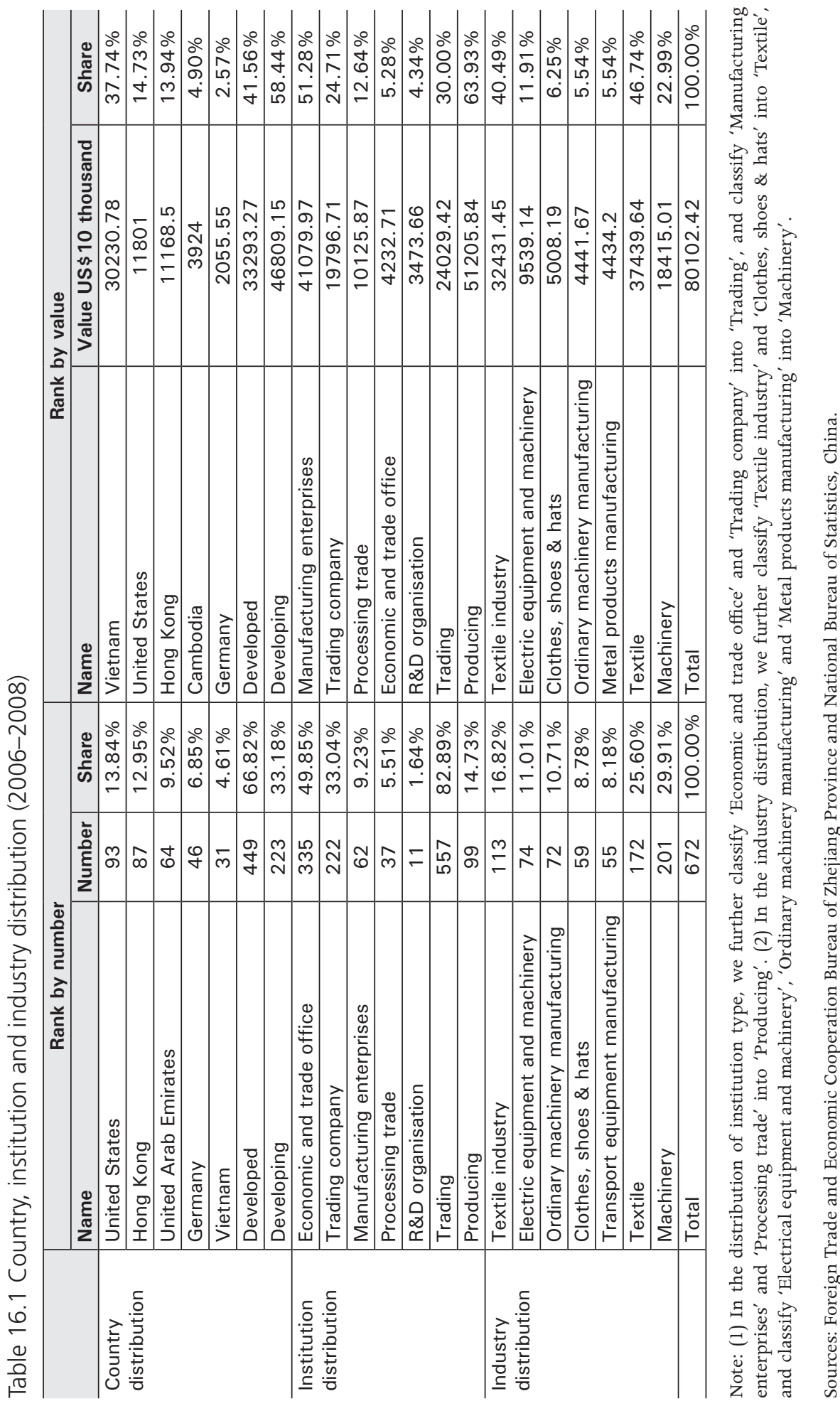


The second measure is the dummy variable for foreign invested enterprises (FIE). Various researches have found that FIE are less financially constrained since they have additional funding sources from their parent company. For instance, research has found that the affiliates of US multinational corporations use less external financing in countries with underdeveloped financial markets, but have greater borrowing from the parent company so as to overcome imperfections in external capital markets. Similar evidence is also found in China (Desai et al. 2004). Analysis using detailed customs data from China, has shown that foreignowned affiliates and joint ventures have better export performance than private domestic firms, and that this advantage is systematically greater in sectors at higher levels of financial vulnerability (Manova et al. 2011). The effect of FIE on ODI could also, however, proxy for foreign market experience, which does not necessary reflect the financial constraint considerations. To address this concern, the export experience is controlled in the model specification of this analysis.

Productivity is measured as the output per worker, after controlling for capital intensity. There are two reasons for the adoption of labour productivity rather than TFP (based on Olley and Pakes 1996) as a productivity measure. First, labour productivity is the most widely used way to measure productivity in literature (for example, Helpman, Melitz and Yeaple 2004), making our results comparable to existing studies. And second, accounting data does not necessarily correspond well to the underlying economic variables in theoretical production functions (Head and Ries 2003), and the principle shortcoming of productivity estimates cannot be greatly reduced by more complex econometric methods that appear to make strong identifying assumptions (Syverson 2004).

Table 16.2 reports the definition for other control variables and their descriptive statistics.

Table 16.2 Variable definition and summary statistics

\begin{tabular}{l|l|r|r|r|r}
\hline Variable & Definition & Mean & \multicolumn{1}{c|}{ Std. Dev. } & \multicolumn{1}{c}{ Min } & \multicolumn{1}{c}{ Max } \\
\hline Liquidity & Current assets/ total assets & 0.71 & 0.18 & 0 & 1 \\
\hline FIE & $\begin{array}{l}1 \text { if it is foreign invested firms; } \\
\text { O otherwise }\end{array}$ & 0.20 & 0.40 & 0 & 1 \\
\hline Productivity & Log of output per worker & -0.60 & 0.77 & -8.01 & 6.44 \\
\hline Size & Log of labour & 4.38 & 0.98 & 0 & 10.39 \\
\hline Inventory & Inventory/total sales & 0.13 & 0.18 & 0 & 11.17 \\
\hline Age & Years since firms established & 8.19 & 5.68 & 1 & 133 \\
\hline Profitability & Return on assets & 0.12 & 15.57 & -9.23 & 5325 \\
\hline Capital intensity & Capital/labour & 0.74 & 3.79 & 0.00 & 776.85 \\
\hline Export share & Export/total output & 0.27 & 0.39 & 0 & 4.50 \\
\hline
\end{tabular}

Source: Calculated based on the firm survey data provided by Foreign Trade and Economic Cooperation 


\section{Higher Financial Constraint, Lower Propensity of Investing Abroad?}

We employ a multiple choice logit model to dissect how financial constraints impact three decisions on foreign market entry: ODI (may or may not export), purely export, and domestic oriented. In addition to financial constraints, we also control other variables that might play a role in a firms' decision, including productivity, size, inventory ratio, firm age, profitability and capital intensity, as well as year dummy to capture cyclical effects and industry dummy to capture industry-specific effects.

Accordingly, we obtain the following multinomial logit model for estimation:

$\operatorname{Pr}\left[y_{i t}=j\right]=\frac{\exp \left(\alpha+\beta_{1 j} F C_{i t}+\beta_{2 j} \operatorname{Pr} o d_{i t}+\beta_{3 j} \text { Size }_{i t}+\beta_{4 j} \text { Inven }_{i t}+\beta_{5 j} \operatorname{Pr}_{i t}+\beta_{6 j} \text { Capitalten }_{i t}+Y d+I d\right)}{\sum_{k=D, E, F} \exp \left(\alpha+\beta_{1 k} F C_{i t}+\beta_{2 k} \operatorname{Pr} o d_{i t}+\beta_{3 k} \text { Size }_{i t}+\beta_{4 k} \text { Inven }_{i t}+\beta_{5 k} \operatorname{Pr} f_{i t}+\beta_{6 k} \text { Capitalten }_{i t}+Y d+I d\right)}$

$\mathrm{j}$ is the nature of the firm, which is either ODI firms (F), exporters (E), or domestic firms (D).Yd is year dummy, and Id is industry dummy. The description for other variables and their mean, standard deviation, minimum and maximum is shown in Table 16.2.

\section{Basic Results}

Table 16.3 provides the results for estimating equation (1) for the full sample. For both measures, financial constraint plays a significant and influential role in Chinese firms' export and ODI decision. Firms with less financial constraint (more liquidity, or with foreign ownership) are more likely to enter foreign markets, pursuing ODI. This finding suggests that financial constraints reduce the probability that a firm will engage in export and ODI, as this it is difficult to finance the initial costs of entry into a foreign market. Todo (2011) also finds such a negative effect in Japan, but there it is not significant. It can be implied that the financing constraint is a more serious and repressive factor in China than in Japan.

Besides this, firms with higher productivity are more likely to conduct ODI and export. This is consistent with Melitz (2003) and HMY (2004). In addition to productivity, firm size also positively affects the probability of engaging in both export and ODI. And the magnitude of such positive influence is much larger by firm size than by productivity. For instance, firm size compared with productivity has roughly three times larger positive effects on firms' probability of ODI. That the impact of productivity is smaller in magnitude has been found by other analysts (Bernard et al. 2003; Greenaway and Kneller 2004). The coefficient of profitability is also negative and generally significant. For Chinese firms it means that the higher their profitability, the lower the probability that they will 
enter foreign markets. This behaviour may be partly because of the higher risk involved in internationalisation. When firms earn a reasonable profit at home, they may be reluctant to take such risk. This behaviour also reflects why some Chinese firms lack a global perspective.

Table 16.3 Results for multinomial logit model: full sample

\begin{tabular}{|c|c|c|c|c|}
\hline & \multicolumn{2}{|c|}{ Liquidity } & \multicolumn{2}{|c|}{ FIE } \\
\hline & Export & ODI & Export & ODI \\
\hline \multirow[t]{2}{*}{ Financial constraint } & $0.185 * * *$ & $1.254 * * *$ & $1.208 * * *$ & $0.966 * * *$ \\
\hline & $(0.036)$ & $(0.292)$ & $(0.019)$ & $(0.113)$ \\
\hline \multirow[t]{2}{*}{ Productivity } & $0.0442 * * *$ & $0.512 * * *$ & 0.0165 & $0.512 * * *$ \\
\hline & $(0.009)$ & $(0.060)$ & $(0.010)$ & $(0.072)$ \\
\hline \multirow[t]{2}{*}{ Size } & $0.833^{* * *}$ & $1.509 * * *$ & $0.736 * * *$ & $1.414 * * *$ \\
\hline & $(0.007)$ & $(0.039)$ & $(0.008)$ & $(0.046)$ \\
\hline \multirow[t]{2}{*}{ Inventory } & $0.257 * * *$ & 0.17 & $0.0995 * *$ & 0.259 \\
\hline & $(0.035)$ & $(0.253)$ & $(0.040)$ & $(0.261)$ \\
\hline \multirow[t]{2}{*}{ Age } & $-0.0121 * * *$ & $-0.0231 * * *$ & 0.000884 & -0.00919 \\
\hline & $(0.001)$ & $(0.007)$ & $(0.001)$ & $(0.009)$ \\
\hline \multirow[t]{2}{*}{ Profitability } & $-0.617 * * *$ & $-1.024 * * *$ & $-0.586 * * *$ & $-0.923 * * *$ \\
\hline & $(0.068)$ & (0.275) & $(0.073)$ & $(0.317)$ \\
\hline \multirow[t]{2}{*}{ Capitalintensity } & $0.0129 * * *$ & $0.0157 * * *$ & -0.00576 & -0.00288 \\
\hline & $(0.003)$ & $(0.006)$ & $(0.004)$ & $(0.028)$ \\
\hline Year-specific fixed effects & Yes & Yes & Yes & Yes \\
\hline Industry-specific fixed effects & Yes & Yes & Yes & Yes \\
\hline Observations & \multicolumn{2}{|c|}{134,051} & \multicolumn{2}{|c|}{115,969} \\
\hline Pseudo R2 & \multicolumn{2}{|c|}{0.152} & \multicolumn{2}{|c|}{0.1826} \\
\hline
\end{tabular}

Note: Standard errors in parentheses; ${ }^{* * *} \mathrm{p}<0.01,{ }^{* *} \mathrm{p}<0.05,{ }^{*} \mathrm{p}<0.1$.

Source: Authors' own estimations.

\section{Mitigating Effects of Productivity?}

This section considers if there are mitigating effects of productivity on financial constraint. That is, if higher productivity could to some extent compensate for financial constraints when firms make foreign market entry decisions. The following equation therefore includes the interaction terms of financial constraint and productivity in the multinomial logit model (2):

$\operatorname{Pr}\left[y_{i t}=j\right]=\frac{\exp \left(\alpha+\beta_{1 j} F C_{i t}+\beta_{2 j} F C_{i t} * \operatorname{Prod}_{i t}+\beta_{3 j} \operatorname{Pr}_{i t}+d_{i t} \beta_{4 j} \text { Size }_{i t}+\beta_{5 j} \text { Inven }_{i t}+\beta_{6 j} \operatorname{Prof}_{i t}+\beta_{7 j} \text { Capitalten }_{i t}+Y d+I d\right)}{\sum_{k=D, E, F} \exp \left(\alpha+\beta_{1 k} F C_{i t}+\beta_{2 k} F C_{i t}{ }^{*} \operatorname{Pr} o d_{i t}+\beta_{3 k} \operatorname{Pr} o d_{i t}+\beta_{4 k} \text { Size }_{i t}+\beta_{5 k} \text { Inven }_{i t}+\beta_{6 k} \operatorname{Pr}_{i t}+\beta_{7 k} \text { Capitalten }_{i t}+Y d+I d\right)}$ 
Table 16.4 Results for multinomial logit model: consider the mitigating effects of productivity

\begin{tabular}{|c|c|c|c|c|}
\hline & \multicolumn{2}{|c|}{ Liquidity } & \multicolumn{2}{|c|}{ FIE } \\
\hline & Export & ODI & Export & ODI \\
\hline \multirow[t]{2}{*}{ Financial constraint } & $0.135 * * *$ & $1.272 * * *$ & $1.148 * * *$ & $0.852 * * *$ \\
\hline & $(0.046)$ & $(0.321)$ & $(0.022)$ & $(0.123)$ \\
\hline \multirow{2}{*}{$\begin{array}{l}\text { Financial } \\
\text { constraint * productivity }\end{array}$} & $-0.0784^{*}$ & 0.0723 & $-0.108 * * *$ & $-0.263 * *$ \\
\hline & $(0.045)$ & $(0.325)$ & $(0.021)$ & $(0.125)$ \\
\hline \multirow[t]{2}{*}{ Productivity } & $0.101 * * *$ & $0.456^{*}$ & $0.0421 * * *$ & $0.602 * * *$ \\
\hline & $(0.034)$ & $(0.254)$ & $(0.012)$ & $(0.086)$ \\
\hline \multirow[t]{2}{*}{ Size } & $0.833 * * *$ & $1.508 * * *$ & $0.738 * * *$ & $1.414 * * *$ \\
\hline & $(0.007)$ & $(0.039)$ & $(0.008)$ & $(0.046)$ \\
\hline \multirow[t]{2}{*}{ Inventory } & $0.257 * * *$ & 0.168 & $0.0976 * *$ & 0.249 \\
\hline & $(0.035)$ & $(0.253)$ & $(0.040)$ & $(0.258)$ \\
\hline \multirow[t]{2}{*}{ Age } & $-0.0121 * * *$ & $-0.0231 * * *$ & 0.000866 & -0.00934 \\
\hline & $(0.001)$ & $(0.007)$ & $(0.001)$ & $(0.009)$ \\
\hline \multirow[t]{2}{*}{ Profitability } & $-0.621 * * *$ & $-1.025 * * *$ & $-0.565 * * *$ & $-0.885 * * *$ \\
\hline & $(0.068)$ & $(0.275)$ & $(0.073)$ & (0.329) \\
\hline \multirow[t]{2}{*}{ Capitalintensity } & $0.0126 * * *$ & $0.0153 * *$ & -0.00306 & 0.00298 \\
\hline & $(0.003)$ & $(0.006)$ & $(0.003)$ & (0.019) \\
\hline Year-specific fixed effects & Yes & Yes & Yes & Yes \\
\hline Industry-specific fixed effects & Yes & Yes & Yes & Yes \\
\hline Observations & \multicolumn{2}{|c|}{134051} & \multicolumn{2}{|c|}{115969} \\
\hline Pseudo R2 & \multicolumn{2}{|c|}{0.152} & \multicolumn{2}{|c|}{0.1828} \\
\hline
\end{tabular}

Note: (1) Standard errors in parentheses; ${ }^{* * *} \mathrm{p}<0.01,{ }^{* *} \mathrm{p}<0.05,{ }^{*} \mathrm{p}<0.1$;

(2) Year-specific fixed effects and Industry-specific fixed effects are controlled.

Source: Authors' own estimations.

As seen in Table 16.4, the mitigating effects of productivity indeed exist in export decisions, but are not generally valid for ODI decisions. After controlling for financial constraints and productivity, there is still a significantly negative impact of their interaction terms on export decision. The results of interaction terms on ODI decisions are mixed, however: liquidity measure for financial constraint does not have a significant impact, while the FIE measure predicts a significantly negative sign. It suggests that higher productivity can mitigate some of the negative impact of financial constraint for exporters. But financial constraint is so serious for ODI firms that higher productivity could not compensate for its presence. 


\section{Dealing with Potential Endogeneity}

One challenge for studies that try to establish a causal effect of financial constraint on firms' foreign market entry decisions is that the measures of financial constraints may be endogenous. For example, a 2007 study found that the financial health of UK firms improves after they begin exporting, despite the fact that at the time of entry into the export market, future exporters do not demonstrate as financially healthier than firms focusing only the domestic market (Greenaway et al. 2007).

To deal with potential endogeneity in the specification here, one-period lag variable for financial constraint is included in the multinomial logit regression. Here, FIE variable is time-invariant. In addition to the fact of financial constraint, it could also proxy for the foreign market experience. The export share is, therefore, incorporated with one-period lag in the robustness check to control for the possible foreign market experience. Results are reported in Table 16.5. As seen, after including the liquidity variable with one-period lag and control export share variable with one-period lag, financial constraint is still negatively impacting the ODI decision, as well as the export decision. Firms with less financial constraint (more liquidity, or with foreign ownership) are more likely to enter foreign markets, pursuing ODI. Also, productivity and size have a significantly positive effect, while profitability is a negatively influential factor.

Table 16.5 Results for multinomial logit model: one-period lag

\begin{tabular}{|c|c|c|c|c|c|}
\hline & \multicolumn{2}{|c|}{ Liquidity } & & \multicolumn{2}{|c|}{ FIE } \\
\hline & Export & ODI & & Export & ODI \\
\hline \multirow{4}{*}{$\begin{array}{l}\text { Financial } \\
\text { constraint with } \\
\text { one-period Lag }\end{array}$} & $0.163 * *$ & $1.468 * *$ & \multirow{2}{*}{$\begin{array}{l}\text { Financial } \\
\text { constraint }\end{array}$} & $0.774 * * *$ & $0.571 * * *$ \\
\hline & \multirow[t]{3}{*}{$(0.074)$} & \multirow[t]{3}{*}{$(0.617)$} & & $(0.033)$ & $(0.148)$ \\
\hline & & & & $6.527 * * *$ & $6.343 * * *$ \\
\hline & & & lag & $(0.062)$ & $(0.190)$ \\
\hline \multirow[t]{2}{*}{ Productivity } & 0.0157 & $0.455 * * *$ & \multirow[t]{2}{*}{ Productivity } & $0.170 * * *$ & $0.679 * * *$ \\
\hline & $(0.019)$ & $(0.132)$ & & $(0.018)$ & $(0.098)$ \\
\hline \multirow[t]{2}{*}{ Size } & $0.805 * * *$ & $1.644 * * *$ & \multirow[t]{2}{*}{ Size } & $0.708 * * *$ & $1.396 * * *$ \\
\hline & $(0.015)$ & $(0.082)$ & & $(0.015)$ & $(0.061)$ \\
\hline \multirow[t]{2}{*}{ Inventory } & $0.239 * * *$ & 0.0511 & \multirow[t]{2}{*}{ Inventory } & $0.371 * * *$ & $0.624 * *$ \\
\hline & $(0.063)$ & $(0.561)$ & & $(0.065)$ & $(0.263)$ \\
\hline \multirow[t]{2}{*}{ Age } & $-0.0171 * * *$ & -0.00729 & \multirow[t]{2}{*}{ Age } & $-0.00602 * * *$ & -0.0106 \\
\hline & $(0.002)$ & (0.013) & & $(0.002)$ & $(0.012)$ \\
\hline \multirow[t]{2}{*}{ Profitability } & $-0.644 * * *$ & -0.504 & \multirow[t]{2}{*}{ Profitability } & $-0.462 * * *$ & $-0.809 * *$ \\
\hline & $(0.134)$ & $(0.805)$ & & $(0.129)$ & $(0.393)$ \\
\hline
\end{tabular}




\begin{tabular}{|c|c|c|c|c|c|}
\hline & \multicolumn{2}{|c|}{ Liquidity } & & \multicolumn{2}{|c|}{ FIE } \\
\hline & Export & ODI & & Export & ODI \\
\hline \multirow[t]{2}{*}{ Capitalintensity } & $0.0173 * * *$ & $0.0224 *$ & \multirow[t]{2}{*}{ Capitalintensity } & 0.00213 & -0.0114 \\
\hline & $(0.006)$ & $(0.012)$ & & $(0.005)$ & $(0.044)$ \\
\hline Observations & \multicolumn{2}{|c|}{78713} & Observations & \multicolumn{2}{|c|}{68353} \\
\hline Pseudo R2 & \multicolumn{2}{|c|}{0.1502} & Pseudo R2 & \multicolumn{2}{|c|}{0.5209} \\
\hline
\end{tabular}

Note: (1) Standard errors in parentheses; ${ }^{* * *} \mathrm{p}<0.01,{ }^{* *} \mathrm{p}<0.05,{ }^{*} \mathrm{p}<0.1$;

(2) Year-specific fixed effects and Industry-specific fixed effects are controlled.

Source: Authors' own estimations.

To deal with potential endogeneity in this specification, the sample is reduced to firms pursuing ODI for the first time in the period 2006-2008. The results of re-estimating equation (1) are presented in Table 16.6. As reported, even for firms pursing ODI for the first time, financial constraint is still a significant negative factor that firms with less financial constraint are more likely to conduct ODI. Still, productivity and size play a contributing role in foreign market entry, while profitability is negatively related with the probability of ODI and exports.

Table 16.6 Results for multinomial logit model: first-time ODI

\begin{tabular}{|c|c|c|c|c|}
\hline & \multicolumn{2}{|c|}{ Liquidity } & \multicolumn{2}{|c|}{ FIE } \\
\hline & Export & ODI & Export & ODI \\
\hline \multirow[t]{2}{*}{ Financial constraint } & $0.185 * * *$ & $1.170 * * *$ & $1.260 * * *$ & $1.099 * * *$ \\
\hline & $(0.036)$ & (0.319) & (0.019) & $(0.123)$ \\
\hline \multirow[t]{2}{*}{ Productivity } & $0.0445 * * *$ & $0.425 * * *$ & $0.216 * * *$ & $0.726 * * *$ \\
\hline & (0.009) & $(0.067)$ & $(0.012)$ & $(0.116)$ \\
\hline \multirow[t]{2}{*}{ Size } & $0.834 * * *$ & $1.518 * * *$ & $0.755 * * *$ & $1.486 * * *$ \\
\hline & $(0.007)$ & $(0.043)$ & $(0.008)$ & $(0.051)$ \\
\hline \multirow[t]{2}{*}{ Inventory } & $0.257 * * *$ & 0.0385 & $0.355 * * *$ & $0.523 *$ \\
\hline & $(0.035)$ & $(0.312)$ & $(0.045)$ & (0.293) \\
\hline \multirow[t]{2}{*}{ Age } & $-0.0121 * * *$ & $-0.0192 * * *$ & 0.000943 & -0.00293 \\
\hline & $(0.001)$ & $(0.007)$ & $(0.001)$ & $(0.010)$ \\
\hline \multirow[t]{2}{*}{ Profitability } & $-0.618 * * *$ & $-0.984 * * *$ & $-0.883 * * *$ & -0.728 \\
\hline & $(0.068)$ & $(0.352)$ & $(0.073)$ & (0.573) \\
\hline \multirow[t]{2}{*}{ Capitalintensity } & $0.0128 * * *$ & $0.0155^{*}$ & -0.00311 & 0.00934 \\
\hline & $(0.003)$ & $(0.009)$ & $(0.003)$ & $(0.007)$ \\
\hline Observations & \multicolumn{2}{|c|}{133961} & \multicolumn{2}{|c|}{115103} \\
\hline Pseudo R2 & \multicolumn{2}{|c|}{0.1521} & \multicolumn{2}{|c|}{0.1831} \\
\hline
\end{tabular}

Note: (1) Standard errors in parentheses; ${ }^{* * *} \mathrm{p}<0.01,{ }^{* *} \mathrm{p}<0.05,{ }^{*} \mathrm{p}<0.1$;

(2) Year-specific fixed effects and Industry-specific fixed effects are controlled.

Source: Authors' own estimations. 


\section{Concluding Remarks}

This chapter provides firm-level evidence on the harmful consequences of financial constraint on firms' capability to pursue ODI. It shows that financial constraint severely restricts the probability of a firm entering the ODI market. This finding is robust after controlling for possible endogeneity.

Consistent with existing literature, this chapter also finds firm productivity plays a significant contributing role in a firm's ODI activities, in the decision to engage in ODI, and how much to invest. But it is clear that such contributing role does not mitigate the negative impact of financial constraint for ODI, albeit it could relieve some financial constraint for exporters. That is, even if a firm improves its productivity significantly, if the financial crunch remains, the firm may be unable to pursue ODI.

This chapter has strong policy implications. Financial constraint for SMEs is a worldwide problem, but it is even more serious in China, which is characterised by financial repression and controlled capital account. The Chinese Government has attached great importance to outward direct investment and also provides a fiscal subsidy for ODI players. But this cannot compensate for the financial constraint Chinese private SMEs face when they decide whether or not pursue ODI, and how much to invest. As a result, the more viable, more productive and more competitive enterprises are likely to be shut out, which is detrimental to capital efficiency and the transformation of growth mode.

\section{References}

Amiti, M. \& Weinstein, D., 2009, 'Exports and Financial Shocks.' Columbia University mimeo.

Berger, A. \& Udell, G., 1998, 'The Economics of Small Business Finance: The Roles of Private Equity and Debt Markets in the Financial Growth Cycle', Journal of Banking and Finance, vol. 22, no. 6, pp. 613-73.

Berman, N. \& Héricourt, J., 2008, 'Financial Factors and the Margins of Trade: Evidence from Cross-Country Firm-Level Data', CES Working Paper 2008.50.

Bernard Andrew B., Eaton, Jonathan, Jensen, J. Bradford \& Kortum, Samuel, 2003, 'Plants and Productivity in International Trade', American Economic Review, vol. 93, no.4, pp. 1268-90.

Bilkey, W. \& Tesar, G., 1977, 'The Export Behavior of Smaller-sized Wisconsin Manufacturing Firms', Journal of International Business Studies, vol. 8, no. 1, pp. 93-98. 
Brainard, S. Lael, 1997, 'An Empirical Assessment of the Proximity-Concentration Trade-Off Between Multinational Sales and Trade', American Economic Review, vol. 87, no. 4, pp. 520-44.

Bruderl, J., Preisendorfer, P. \& Ziegler, R., 1992, 'Survival Chances of Newly Founded Business Organizations', American Sociological Review, vol. 57, pp. $227-41$.

Cressy, R., 1996, 'Pre-Entrepreneurial Income, Cash-Flow Growth and Survival of Startup Businesses: Model and Tests on UK Data', Small Business Economics, vol. 8, no. 1, pp. 49-58.

— , 2002, 'Funding Gaps: A Symposium', The Economic Journal, vol. 112, pp. 1-16.

Crick, D., 2004, 'UK SMEs' Decision to Discontinue Exporting: An Exploratory Investigation into Practices Within the Clothing Industry', Journal of Business Venturing, vol. 19, pp. 561-87.

Desai, M., Foley, F. \& Hines, J., 2004, 'A Multinational Perspective on Capital Structure Choice and Internal Capital Markets', Journal of Finance, vol. 59, pp. 2451-88.

Damijan, Jože P., Polanec, Sašo, \& Prašnikar, Janez, 2007, 'Outward FDI and Productivity: Micro-Evidence from Slovenia', The World Economy, vol. 30, no. 1, pp. 135-55.

Daniels, J. \& Bracker, J., 1989, ‘Profit Performance: Do Foreign Operations make a Difference? Management International Review, vol. 29, no. 1, pp. 46-56.

De Maeseneire, Wouter, \& Claeys, Tine, 2012, 'SMEs, Foreign Direct Investment and Financial Constraints: The Case of Belgium', International Business Review, vol. 21, pp. 408-24.

Etemad, H., 1999, 'Globalization and Small and Medium-sized Enterprises: Search for Potent Strategies', Journal of Global Focus, vol. 11, no. 3, pp. 85-105.

- 2004, 'Internationalization of Small and Medium-sized Enterprises: A Grounded Theoretical Framework and an Overview', Canadian Journal of Administrative Sciences, vol. 21, no. 1, pp. 1-21.

European Commission, 2003, Observatory of European SMEs. Internationalisation of SMEs, Luxembourg, European Commission.

Fazzari, S.M., Hubbard, R.G., \& Petersen, B.P., 1988, 'Financing Constraints and Investment'. Brookings Papers on Economic Activity, vol. 1, pp. 141-95. 
Feenstra, Robert C., Zhiyuan, Li, \& Miaojie, Yu, 2011, 'Exports and Credit Constraints Under Incomplete Information: Theory and Evidence from China', NBER Working Paper No. 16940.

Girma, Sourafel, Kneller, Richard, \& Pisu, Mauro, 2005, 'Exports Versus FDI: An Empirical Test', Review of World Economics, vol. 141, no. 2, pp. 193-218.

Greenaway, David \& Kneller, Richard, 2004, 'Exporting and Productivity in the United Kingdom', Oxford Review of Economic Policy, vol. 20, no. 3, pp. 358-71.

, 2007, 'Firm Heterogeneity, Exporting and Foreign Direct Investment', Economic Journal, vol. 117, no. 517, pp. 134-161.

Greenaway, D., Guariglia, A. \& Kneller, R., 2007, 'Financial Factors and Exporting Decisions', Journal of International Economics, vol. 73, no. 2, pp. 377-95.

Hadlock Charles J. \& Pierce, Joshua R., 2010, 'New Evidence on Measuring Financial Constraints: Moving Beyond the KZ Index', The Review of Financial Studies, vol. 23, no. 5, pp. 1909-40.

Hall, B., 1992, 'Investment and R\&D at the Firm Level: Does the Source of Financing Matter?' National Bureau of Economic Research Working paper, pp. 92-194.

Head, Keith, \& Ries, John, 2003, 'Heterogeneity and the FDI Versus Exports Decision of Japanese Manufacturers', Journal of the Japanese and International Economies, vol. 17, no. 4, pp. 448-67.

Helpman, Elhanan, Melitz, Marc J. \& Yeaple, Stephen R., 2004, 'Export Versus FDI with Heterogeneous Firms', American Economic Review, vol. 94, no.1, pp. 300-16.

Hook, R. \& Czinkota, M., 1988, 'Export Activities and Prospects of Hawaiian Firms', International Marketing Review, Winter, pp. 51-57.

Huang, Yiping \& Wang, Bijun, 2011, 'Chinese Outward Direct Investment: Is There a China Model?', China \&World Economy, vol. 19, no. 4, pp. 1-21.

Krugman, Paul, 1980, 'Scale Economies, Product Differentiation, and the Pattern of Trade', American Economic Review, vol. 70, no. 5, pp. 950-59.

Lamont, O., Polk, C. \& Saa-Requejo, J, 2001, 'Financial Constraints and Stock Returns', Review of Financial Studies, vol. 14, pp. 529-54.

Lu, J. \& Beamish, P., 2001, 'The Internationalization and Performance of SMEs', Strategic Management Journal, vol. 22, pp. 565-86. 
Manova, Kalina, 2008, 'Credit Constraints, Equity Market Liberalizations and International Trade,' Journal of International Economics, vol. 76, no. 1, pp. 33-47.

Manova, Kalina, Wei, Shang-Jin \& Zhiwei, Zhang, 2011, 'Firm Exports and Multinational Activity under Credit Constraints,' NBER Working Paper Series, W16905.

Mayer, Thierry and Ottaviano, Gianmarco I.P., 2007, 'The Happy Few: The Internationalisation of European Firms, New Facts Based on Firm-level Evidence', Intereconomic, vol. 43, no. 3, pp. 135-48.

Melitz, Marc J., 2003, 'The Impact of Trade on Intra-industry Reallocations and Aggregate Industry Productivity', Econometrica, vol. 71, no. 6, pp. 1695-725.

Minetti, R. \& Zhu, S.C., 2011, 'Credit Constraints and Firm Export: Microeconomic Evidence from Italy', Journal of International Economics, vol. 83 no. 2, pp. 109-25.

Muuls, Mirabelle, 2008, 'Exporters and Credit Constraints: A Firm-level Approach,' National Bank of Belgium Working Paper Research No. 139, Brussels.

Olley, Steven and Pakes, Ariel, 1996, 'The Dynamics of Productivity in the Telecommunications Equipment Industry,' Econometrica, vol. 64 no. 6, pp. 1263-97.

Syverson, Chad, 2004, 'Market Structure and Productivity: A Concrete Example', Journal of Political Economy, vol. 112, no. 6, pp. 1181-222.

Tang, M. \& Yu, C.-J., 1990, 'Foreign Market Entry: Production-Related Strategies', Management Science, vol. 36, no. 4, pp. 476-89.

Todo, Yasuyuki, 2011, 'Quantitative Evaluation of the Determinants of Export and FDI: Firm-level Evidence from Japan', The World Economy, vol. 34, no. 3, pp. 355-81.

Tomiura, Eiichi, 2007, 'Foreign Outsourcing, Exporting, and FDI: A Productivity Comparison at the Firm Level', Journal of International Economics, vol. 72, no. 1, pp. 113-27.

Wang, Bijun, 2011, 'Why China is Under-investing in Manufacturing ODI: Firm Heterogeneity and Institutional Reform', paper presented at The Association for Chinese Economic Studies Australia (ACESA) 2011 annual conference, 'China's Growth and The World Economy', UWA Business School, Perth, Australia, 7-8 July. 
Wang, Bijun \& Yiping, Huang, 2012a, 'Industry and Ownership Structure of Chinese Overseas Direct Investment,' paper presented at roundtable and public forum, 'China's Global Investment', at the Crawford School of Public Policy, Australian National University, Canberra, Australia, 4-5 September.

- 2012b, 'Investing Overseas without Moving Factories Abroad: The Case of Chinese Outward Direct Investment', Asian Development Review.

Wei, Tian \& Yu, Miaojie, 2012, 'Outward Foreign Direct Investment and Productivity: Firm-Level Evidence from China', China Economic Quarterly (jing ji xue ji kan), vol.11, no. 2.

Whited, T. \& Wu, G., 2006, 'Financial Constraints Risk', Review of Financial Studies, vol. 19, pp. 531-59.

Yeaple, Stephen Ross, 2005, 'A Simple Model of Firm Heterogeneity, International Trade, and Wages', Journal of International Economics, vol. 65, no. 1, pp. 1-20. 


\title{
17 Determinants of Chinese Exports in Information and Communication Technology (ICT) Products:
}

\author{
A Firm-Level Analysis
}

\section{Kunwang Li and Bingzhan Shi}

\section{Introduction}

As information and communication technology (ICT) products are becoming more common in society, the development and diffusion of ICT, because of its high-tech content, has been widely seen as a major contributor to the growth of productivity, and economic growth more generally. First, ICT is known as a key tool for enhancing innovation, and promoting technological progress, resulting in the growth of total factor productivity (TFP) in the ICT sector itself. Second, firms tend to be engaged in large-scale investment in ICT in capital formation to improve productivity. The two factors together constitute the direct contributions made by ICT to productivity growth (Jorgenson et al. 2008). Trade can play an important role in fostering development of the ICT sector. Studies suggest that strong export performance in ICT products yields higher economic growth rates and improvement in productivity (Greenaway et al. 1999, Rodrik 2006, Hausmann et al. 2007). For this reason, an increasing number of countries have introduced polices and allocated more resources to encourage exports from the ICT sector.

China is now the largest producer of ICT goods in the world. In 2007, of the world total, China produced 48 per cent of phone handset, 46 per cent of personal computers, 42 per cent of colour TVs, 65 per cent of monitors, 58 per cent of program-controlled switchboards, and 57 per cent of digital cameras. Based on China's Annual Survey of Industrial Firms (1998-2007), we calculate that the share of the ICT sector in manufacturing value-added products increased from 6.3 per cent to 9.1 per cent over the period 1998-2007, but the ICT sector contributes 15.6 per cent on average to manufacturing productivity growth in the same period. The trade data shows that the development of Chinese ICT goods relies heavily on export markets. During the period 1998-2007, export of ICT goods accounts for about 40 per cent of the sector's total sales. 
The purpose of this chapter is to examine the determinants of China's exports of ICT goods in two dimensions: export quantity and quality. Our main finding is that China's ICT export growth is mainly achieved by producing a high quantity of low quality. Furthermore, the volume and pattern of China's ICT exports are largely determined by foreign direct investment (FDI), processing trade and government supporting policies. While processing trade mainly accounts for the high quantity and low quality of China's ICT exports, FDI and government policy may help to upgrade the export quality, but decrease export quantity. The challenge for China is, therefore, to upgrade its ICT export quality while maintaining its ICT export volume through a combination of different policies.

The chapter is organised as follows: In Section 2, we describe the pattern of growth of Chinese ICT exports; Section 3 present the econometric model and introduces data used in the analysis; and, Section 4, presents and discusses the estimation results.

\section{Stylised Facts about China's ICT Exports}

China's export has expanded at the pace of almost 14.5 per cent per annum from 1995 to 2010, while the world's growth rate is only 7.2 per cent over the same period. As a result, China's share in total world exports rose from four per cent to 11.8 per cent over the same period. China has, in the past, held a large share of the world market for traditional, labour-intensive industries, such as textiles, shoes and clothes, and is now rapidly enlarging its share in high technology industries, such as ICT products. Figure 17.1 shows the shares of ICT exports in the world total exports of these products by those main producers: 
Figure 17.1 Share of world's ICT exports of the main producers

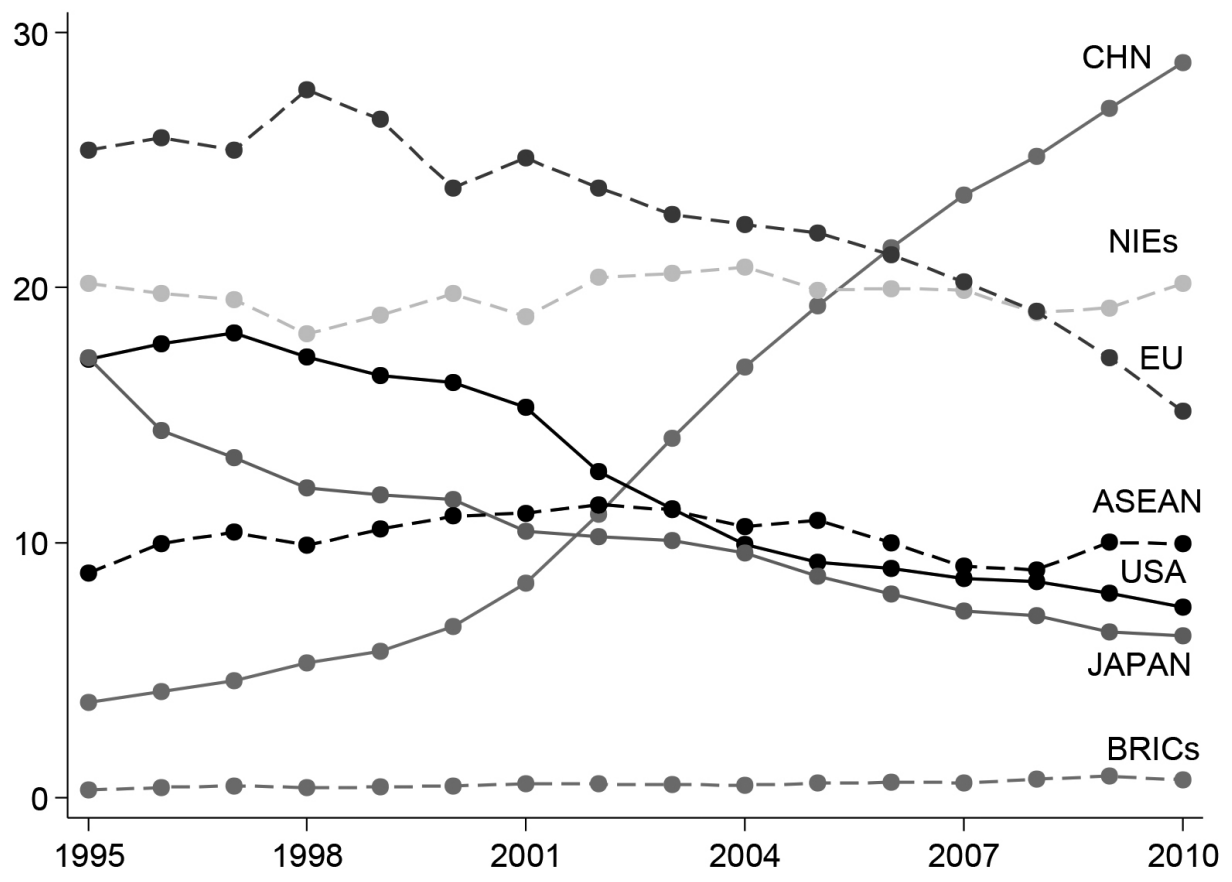

Note: NIEs: Hong Kong, Singapore, South Korea, Taiwan; ASEAN: Thailand, Indonesia, the Philippines, Malaysia; EU: the EU15; BRICS: Brazil, Russia, India, China, South Africa.

Source: CEPII BACI Database, authors' calculation.

China's share of the world's ICT exports has risen fast, from only three per cent in 1995 to 30.1 per cent in 2010. In contrast, the share of all other major producers decreased over this period. The relative changes demonstrate that China has been gaining increasing competitiveness in producing and exporting ICT products in the world markets. China's ICT export is already exceptionally high (Rodrik 2006). In illustrating a cross-country relationship between sophistication of exports and the per capita income, Dani Rodrik finds that 'China is an outlier in terms of the overall sophistication of its exports: its export bundle is that of a country with an income-per-capita level three times larger than China's'. Peter Schott (2008) arrived at a similar conclusion. We examine this conclusion from the perspective of the changing market share of China's ICT products. Figure 17.2 illustrates a cross-country relationship between export structure and per capita income, where export structure is measured by the ratio of ICT products in the country's total export: 
China: A New Model for Growth and Development

Figure 17.2 Per capita income and export structure

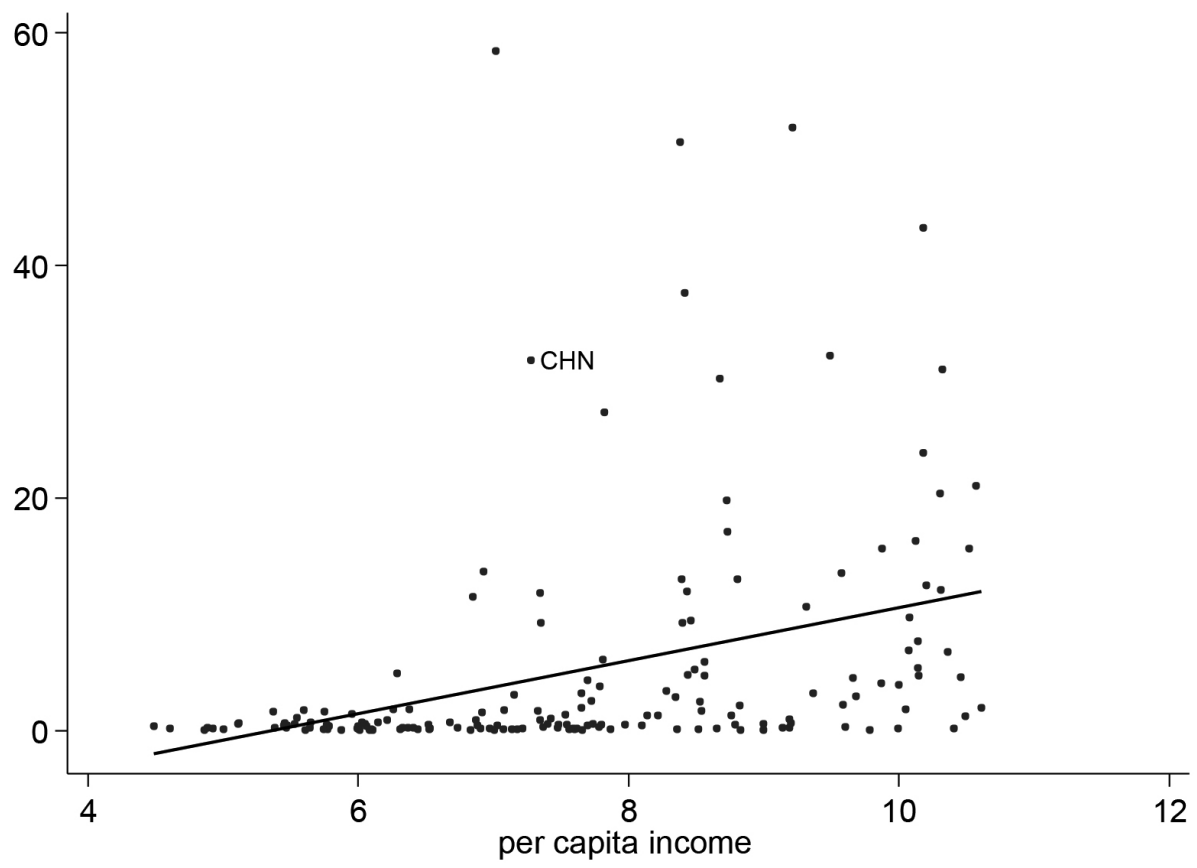

Source: CEPII BACI Database and WDI, authors' calculation.

China's ICT export ratio of its total exports is also an outlier as compared with its per capita income level, which verifies Rodrik's (2006) and Schott's (2008) conclusion.

China's ICT exports are, however, dominated by foreign firms, including wholly foreign owed firms (WFOF) and joint ventures (JV). These firms are largely responsible for the ever-growing share of China's ICT exports and they played a dominant role in increasing China's ICT exports during 2000-2006. Figure 17.3 illustrates this role: 
Figure 17.3 Breakdown of China's ICT exports by category of firms

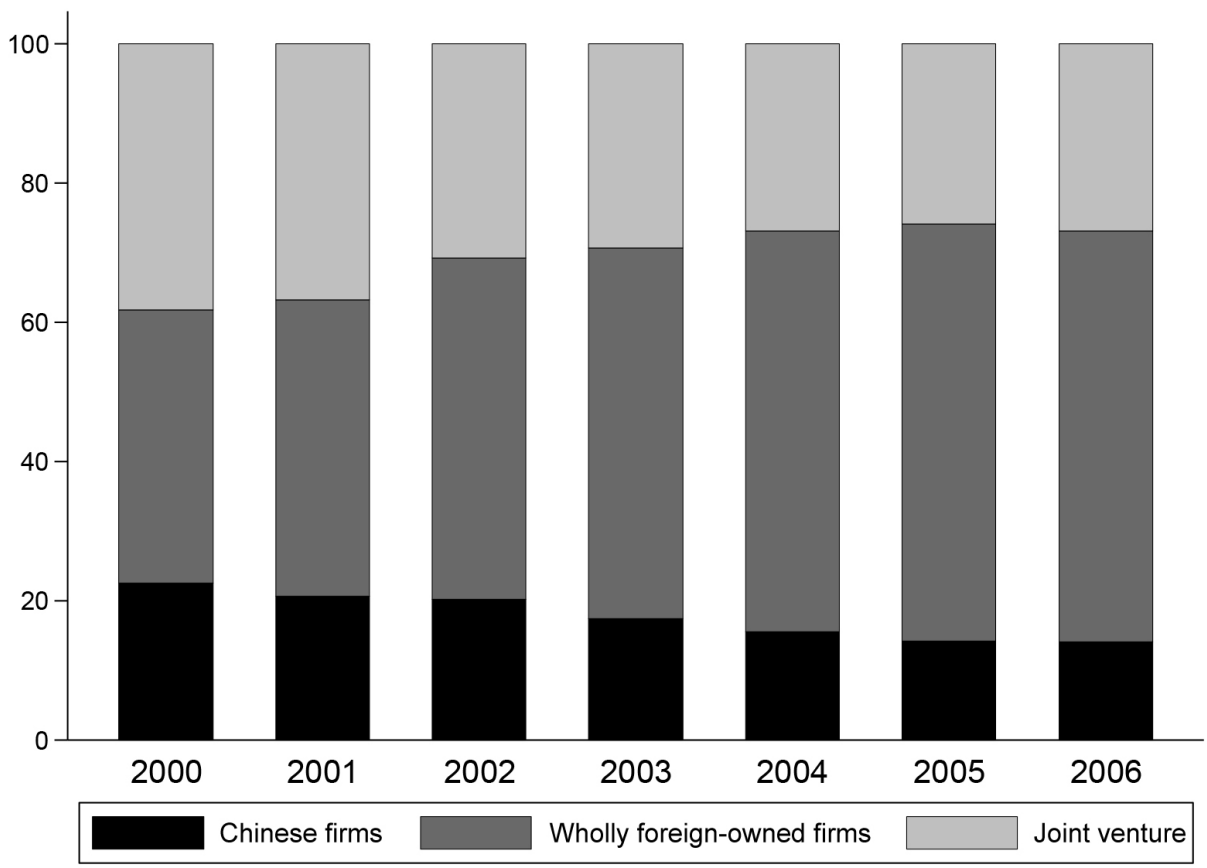

Source: Chinese Customs Trade Statistics (CCTS), 2000-2007, authors' calculations.

It is clear that foreign affiliates are at the core of China's ICT exports. They accounted for 77.4 per cent of China's ICT exports in 2000, and increased to 85.9 per cent in 2006. The increasing role of foreign affiliates in China's ICT exports was entirely due to WFOF, which accounted for more than half of China's ICT export since 2003. Chinese domestic firms are clearly losing ground in ICT exports, and are responsible for less than 20 per cent of China's ICT exports.

Also, China's ICT exports have been driven by the reorganisation of production in Asia. China is used as an export base by firms located in advanced Asian economies, which, instead of exporting finished goods to the US and European markets, now export intermediate goods to their affiliates in China. China's exports have skyrocketed and have displaced Japan's and NIEs' exports at an accelerated pace. This triangular trade pattern can be seen from the extensive role played by China's processing trade. Table 17.1 shows the processing, ordinary and other custom regime shares in China's ICT exports. 
China: A New Model for Growth and Development

Table 17.1 Breakdown of China's ICT exports by custom regime (\%)

\begin{tabular}{l|r|r|r|r|r|r|r}
\hline & $\mathbf{2 0 0 0}$ & $\mathbf{2 0 0 1}$ & $\mathbf{2 0 0 2}$ & $\mathbf{2 0 0 3}$ & $\mathbf{2 0 0 4}$ & $\mathbf{2 0 0 5}$ & $\mathbf{2 0 0 6}$ \\
\hline Processing & 90.4 & 91.0 & 90.7 & 89.2 & 87.9 & 87.2 & 83.7 \\
\hline Ordinary & 7.5 & 6.9 & 7.4 & 8.2 & 8.7 & 9.4 & 12.6 \\
\hline Other & 2.1 & 2.1 & 1.9 & 2.6 & 3.5 & 3.4 & 3.7 \\
\hline
\end{tabular}

Source: Chinese Customs Trade Statistics (CCTS), 2000-2007, authors' own calculations.

China's ICT exports are heavily concentrated in processing trade, which accounts for 90 per cent of China's ICT exports. Thus, China's ICT exports are largely due to the international segmentation of production processes. China imports parts and components of ICT products, which are incorporated in processed exports. China's ICT exports, therefore, can be explained by their high import content. In fact, it has been shown that the share of domestic content of China's manufactured exports was about 50 per cent, and relatively sophisticated products, such as electronic devices, have low domestically produced contents (about 30 per cent or less) (Koopman et al. 2012).

Furthermore, Chinese authorities have been actively promoting the level of technology in China's export structure through tax and other policy incentives. A particular manifestation of these incentives is the proliferation of special economic zones (SEZs), economic and technological development zones, hightech industrial zones, export processing zones and free trade zones around the world. In order to analyse policy effects on ICT exports, Table 17.2 reports the export ratio of different policy zones:

Table 17.2 The ratio of different policy zones in China's ICT export (\%)

\begin{tabular}{l|r|r|r|r|r|r|r}
\hline Policy zone & $\mathbf{2 0 0 0}$ & $\mathbf{2 0 0 1}$ & $\mathbf{2 0 0 2}$ & $\mathbf{2 0 0 3}$ & $\mathbf{2 0 0 4}$ & $\mathbf{2 0 0 5}$ & $\mathbf{2 0 0 6}$ \\
\hline 1 & 11.0 & 10.6 & 9.2 & 8.5 & 6.8 & 6.5 & 6.4 \\
\hline 2 & 11.3 & 13.1 & 13.0 & 14.2 & 17.6 & 20.7 & 19.8 \\
\hline 3 & 6.3 & 7.1 & 7.7 & 8.9 & 9.5 & 10.2 & 8.9 \\
\hline 4 & 7.2 & 7.1 & 8.1 & 7.6 & 8.0 & 6.7 & 6.4 \\
\hline 5 & 0.0 & 0.7 & 2.4 & 3.5 & 4.0 & 5.6 & 4.7 \\
\hline 6 & 64.2 & 61.4 & 59.7 & 57.3 & 54.1 & 50.2 & 53.8 \\
\hline
\end{tabular}

Note: Policy zone 1 stands for special economic zones. Zones 2 to 5 stand for economic and technological development zones, high-tech industrial zone, export processing zones and free trade zones respectively, 6 stands for others. The policy zone accounts for nearly half of China's ICT exports. Government policies, therefore, do effect China's export structure.

Source: Chinese Customs Trade Statistics (CCTS), 2000-2007, authors' calculations.

The above analysis shows that the extent of China's ICT exports is overestimated if we do not consider the role played by foreign affiliates through international segmentation of production processes. Government policy also plays an important role in enhancing China's exports. There is, however, another 
important difference between China's ICT exports and those of developed countries. As Schott (2004) points out, current international trade specialises within product rather than across product. Although China is responsible for nearly one-third of world ICT exports, the quality of China's ICT exports have been lower than those exported by developed countries. Following David Hummels and Peter Klenow (2005), we disaggregate the share of China's ICT exports in the world market into three margins: extensive margin, quantity and quality. Table 17.3 reports the main decomposing results:

Table 17.3 The extensive margin, quantity and quality in China's ICT export ratio

\begin{tabular}{l|l|c|c|c}
\hline Year & Ratio & Extensive margin & Quantity & Quality \\
\hline 1995 & 0.030 & 0.786 & 0.071 & 0.544 \\
\hline 1996 & 0.035 & 0.818 & 0.085 & 0.498 \\
\hline 1997 & 0.037 & 0.827 & 0.088 & 0.508 \\
\hline 1998 & 0.043 & 0.827 & 0.100 & 0.514 \\
\hline 1999 & 0.046 & 0.842 & 0.109 & 0.505 \\
\hline 2000 & 0.056 & 0.841 & 0.111 & 0.603 \\
\hline 2001 & 0.072 & 0.848 & 0.123 & 0.685 \\
\hline 2002 & 0.104 & 0.848 & 0.159 & 0.775 \\
\hline 2003 & 0.135 & 0.848 & 0.234 & 0.679 \\
\hline 2004 & 0.161 & 0.853 & 0.271 & 0.696 \\
\hline 2005 & 0.193 & 0.918 & 0.232 & 0.906 \\
\hline 2006 & 0.216 & 0.920 & 0.241 & 0.973 \\
\hline 2007 & 0.243 & 0.925 & 0.285 & 0.923 \\
\hline 2008 & 0.261 & 0.911 & 0.300 & 0.954 \\
\hline 2009 & 0.282 & 0.896 & 0.330 & 0.951 \\
\hline 2010 & 0.301 & 0.894 & 0.373 & 0.903 \\
\hline Growth rate (\%) & 229.3 & 12.9 & 165.7 & 50.7 \\
\hline
\end{tabular}

Source: CEPII BACI Database, authors' calculation.

For the quality index, the number is smaller than one, which means that China's ICT export quality is lower than the world average level. From the dynamic view, the growth rate of the ratio is 229.3 per cent, with an extensive margin growth rate of 12.9 per cent; a quantity growth rate of 165.7 per cent and a quality growth rate of 50.7 per cent. The results, therefore, show that China's ICT export growth is mainly driven by increases in quantity, which accounts for 72.3 per cent of China's ICT export growth, with the contribution made by quality accounting for only 22.1 per cent of China's ICT export growth. 
To summarise the above analysis, China's ICT export value is increasing, which is driven by the growth in quantity. The quality of these exports, however, is lower than the world average.

\section{Empirical Strategy and Data}

The modelling approach adopted here explains not only the fast growth of the ratio and quantity, but also the low growth rate of quality. Export value, quantity and quality form the dependent variables in the model estimation. We consider several categories of determinants (Xu \& Lu 2009, Wang \& Wei 2008), including the use of processing trade; the development of central and local government policy to promote these sectors; the role of foreign affiliates; and, the characteristics of the trading partners, such as their levels of GDP and physical distance from China. Formally, the econometric specification is given by the following equations:

$\operatorname{lnx}_{i j k t}=\alpha+\beta_{1} f d i_{i t}+\beta_{2}$ process $_{i j k t}+\beta_{3}$ policy $_{i j k t}+\beta_{4} \ln g d p_{j t}+\beta_{5} \ln d i s t_{j t}+\lambda_{k}+\lambda_{t}+\varepsilon_{i j k t}$

where $\ln x_{i j k t}$ is the $\log$ of firm $i$ 's export index to country $j$ in product $k$ at year $t$. We define the index of export by using three different dimensions, they are value, quantity and quality, with quality measured by the unit value. $f d i_{i t}$ is a dummy, if firm $i$ in year $t$ is a wholly foreign owned firm or joint venture, it is 1 ; if firm $i$ in year $t$ is a Chinese firm, then it is 0 . process $s_{i j k t}$ is also a dummy, indicating whether the trade involved is processing trade according to the customs regime. policy $y_{i j k t}$ is a dummy variable to show whether the firms have received some of kinds of policy promotion provided by the governments. $\ln g d p_{j t}$ is the log of the gross domestic product of the importing country $j$ in year $t, \ln$ dist $_{j t}$ is the distance between country $j$ and China. $\lambda_{k}, \lambda_{t}$ are product and year fixed effects. $\varepsilon_{i j k t}$ is the error term as normally defined.

In order to check the robustness of the regression results, we define the indexes of $f d i$, process and policy in a more detailed way. We can further classify $f d i$ into two subgroups, wfof and $j v$, where $w f o f$ standing for the wholly foreign owned firms and jv representing joint ventures. For the index process, we also have two detailed indexes, process 1 and process 2 , where process 1 means 'processing and assembling' and process 2 means 'process with imported materials'. For the index of policy, we have five different policy zones, policyl being 'special economy zone', policy2 being 'economic and technological development zones', policy3 being 'high-technology industrial zone', policy4 being 'export processing zones', policy5 being 'free trade zone'. So we have the following equation for robustness check: 


$$
\begin{aligned}
& \operatorname{lnx}_{i j k t}=\alpha+\beta_{11} w f o f_{i t}+\beta_{12} j v_{i t}+\sum_{l=1}^{2} \beta_{2 l} \text { process }_{l, i j k t}+\sum_{m=1}^{5} \beta_{3 m} \text { policy }_{m, i j k t} \\
& +\beta_{4} \ln g d p_{j t}+\beta_{5} \ln d i s t_{j t}+\lambda_{k}+\lambda_{t}+\varepsilon_{i j k t}
\end{aligned}
$$

It is argued that foreign firms have certain inherent disadvantages as compared with indigenous firms, such as communication costs, language and cultural barriers, and limited familiarity with local environments. Foreign firms, therefore, must possess certain advantages over local firms in order to compete in the host country market. One of the advantages that foreign firms have in investing in the host country is possessing more advanced technology, which local firms do not have. Furthermore, the literature on FDI also suggests that ownership structure is a key determinant of the level of technology chosen by foreign firms while investing. According to the ownership-locationinternalisation paradigm, WFOF have the advantage of internalising superior technologies or knowhow within the firm, and JV rely more on the relationship with local partners to be more competitive in local markets. So, foreign firms should consider the trade-off between securing a better position in the market and allowing local partners to share with them the technologies and profits. The foreign investors with more advanced technologies will therefore prefer WFOFs to JVs. To summarise, we expect that the FDI will not only increase China's ICT export volume, but also upgrade the quality of China's ICT exports, and this effect is more apparent for WFOFs.

As we have discussed, processing trade plays a dominant role in China's ICT exports. As Lee Branstetter and Nicholas Lardy (2006) point out, China is able to export huge quantities of ICT products only because it imports most of the value-added parts and components embodied in the exports. Estimates of the share of foreign content in China's high-technology product export are up to 80 per cent (Koopman et al. 2012). We expect, therefore, that processing trade will increase both China's ICT export value and quantity.

Policy is an important factor in determining a country's involvement in the international splitting up of the value-added chain, which further upgrades countries' technology and promotes ICT exports. China has followed a dualtrack trade policy, by imposing customs tariffs to protect domestic industries, while offering tariff exemptions on imported inputs for export production. These policies help increase China's ICT exports. Apart from these policies, Chinese authorities have also used other policy instruments to promote exports. A particular manifestation of these incentives is the proliferation of special policy zones, including special economic, economic and technological development, high-technology industrial, export processing and free trade zones. We expect, 
therefore, that government policy through various kinds of instruments will increase China's ICT exports, and some policy may also be conducive to upgrading China's ICT quality.

Finally, the characteristics of the importing country may also affect China's ICT exports at the firm level. As in the traditional gravity model, larger GDP and shorter distances should lead to larger export value and quantity. The quality of firm's exports should increase with distance (Hummels and Skiba 2004). We expect, therefore, that the importing countries' GDP positively correlates with ICT's export value and quantity, and their distance positively correlates with quality and negatively correlates with quantity and value. Before reporting the regression results, Table 17.4 provides the variable descriptions and summary statistics.

Table 17.4 Variable descriptions and summary statistics

\begin{tabular}{l|l|r|r|c}
\hline Variable & Description & Observation & Mean & $\begin{array}{c}\text { Standard } \\
\text { deviation }\end{array}$ \\
\hline Inv & Log of export value & 973,742 & 9.22 & 2.65 \\
\hline Inp & Log of export quality & 973,742 & 1.75 & 2.63 \\
\hline Inq & Log of export quantity & 973,742 & 7.47 & 3.39 \\
\hline fdi & Dummy for foreign firm & 973,742 & 0.41 & 0.49 \\
\hline process & Dummy for processing trade & 973,742 & 0.31 & 0.46 \\
\hline policy & Dummy for policy zone & 973,742 & 0.25 & 0.43 \\
\hline wfof & Dummy for wholly foreign-owned firm & 973,742 & 0.28 & 0.45 \\
\hline jv & Dummy for joint venture & 973,742 & 0.13 & 0.34 \\
\hline process1 & Dummy for processing and assembling & 973,742 & 0.23 & 0.42 \\
\hline process2 & Dummy for processing with imported & 973,742 & 0.08 & 0.27 \\
\hline policy1 & Dummy for special economic zone & 973,742 & 0.09 & 0.29 \\
\hline policy2 & Dummy for economic and technological & 973,742 & 0.07 & 0.25 \\
\hline policy3 & Dummy for high-technology zone & 973,742 & 0.04 & 0.20 \\
\hline policy4 & Dummy for export processing zone & 973,742 & 0.05 & 0.21 \\
\hline policy5 & Dummy for free trade zone & 973,742 & 0.01 & 0.09 \\
\hline Ingdp & Log of importer's GDP & 973,329 & 20.07 & 1.53 \\
\hline & Log of distance between China and & 963,358 & 8.49 & 0.77 \\
\hline & importer & & & \\
\hline & Deve & & & \\
\hline
\end{tabular}

Source: Authors' definitions and descriptions. 


\section{Estimation Results}

\section{Value Regressions}

Table 17.5 reports the estimation results from the basic regressions on value. The estimated coefficients on $f d i$ are both positive and statistically significant in regressions 5.1 and 5.4; the estimated coefficients on process are both positive and statistically significant in regressions 5.2 and 5.4; the estimated coefficients on policy are both positive and statistically significant in regressions 5.3 and 5.4. These results show that foreign firms, processing trade and government policy all have positive and statistically significant effects on upgrading China's ICT exports. The estimated coefficients on $\operatorname{lng} d p$ are all positive and statistically significant in the regressions 5.1 5.4, and the estimated coefficients on lndist are all negative and statistically significant in the regressions 5.1 5.4. All the regression results support the theoretical analysis and predictions reviewed in the previous section.

A further observation finds that the estimated coefficient on $f d i$ becomes much smaller in regression 5.4 than in regression 5.1, when we take into account the effects of processing trade. Similarly, the estimated coefficient on policy becomes much larger in regression 5.4 than in regression 5.2, when we take account of the effects of processing trade. The estimated coefficients on process, however, are nearly the same in regressions 5.2 and 5.4. These results imply that processing trade is the most important and robust factor that promotes China's ICT export. Foreign firms can promote China's ICT exports, and the effect of this will decrease when taking account of the role of processing trade. This means that foreign firms promote China's ICT exports mainly through processing trade. Following the same logic, the effects of policy on promoting China's ICT are underestimated by ignoring the influence of processing trade in determining China's ICT exports. 
China: A New Model for Growth and Development

Table 17.5 Basic estimation results for dependent variable Inv

\begin{tabular}{|c|c|c|c|c|}
\hline & $(5.1)$ & $(5.2)$ & $(5.3)$ & $(5.4)$ \\
\hline \multirow[t]{2}{*}{ Fdi } & $0.801 * * *$ & & & $0.132 * * *$ \\
\hline & $(146.862)$ & & & $(21.710)$ \\
\hline \multirow[t]{2}{*}{ process } & & $1.617 * * *$ & & $1.555 * * *$ \\
\hline & & $(280.992)$ & & $(238.022)$ \\
\hline \multirow[t]{2}{*}{ policy } & & & $0.030 * * *$ & $0.077 * * *$ \\
\hline & & & $(4.944)$ & $(13.112)$ \\
\hline \multirow[t]{2}{*}{$\operatorname{lng} d p$} & $0.194 * * *$ & $0.181 * * *$ & $0.226 * * *$ & $0.176 * * *$ \\
\hline & $(114.645)$ & (110.409) & $(133.018)$ & $(107.064)$ \\
\hline \multirow[t]{2}{*}{ Indist } & $-0.169 * * *$ & $-0.174 * * *$ & $-0.197 * * *$ & $-0.170 * * *$ \\
\hline & $(-49.629)$ & $(-52.717)$ & $(-57.390)$ & $(-51.507)$ \\
\hline Year fixed effects & yes & yes & yes & yes \\
\hline Product fixed effects & yes & yes & yes & yes \\
\hline$N$ & 963,358 & 963,358 & 963,358 & 963,358 \\
\hline$R 2$ & 0.127 & 0.175 & 0.107 & 0.176 \\
\hline
\end{tabular}

Note: The dependent variable is log value. Absolute values of t statistics are in parentheses. ${ }^{*}$ significant at $10 \% ;{ }^{* *}$ significant at $5 \% ;{ }^{* * *}$ significant at $1 \%$.

Source: Authors' estimations.

Table 17.6 reports the robustness of the regression results for value regression. In regressions 6.1 and 6.4, we break fdi into $w f o f$ and $j v$. The estimated coefficients on $j v$ are both positive and statistically significant, but it becomes smaller in regression 6.4, which implies that the $j v$ firms' effect on China's ICT export is mainly through processing trade. So the results on $j v$ confirms our discussion in Table 17.5. In regression 6.1, the estimated coefficient on wfof is positive and statistically significant, but in regression 6.4 it becomes statistically indifferent from zero, which also confirms and strengthens the analysis based on the results in Table 17.5. In fact, 92.4 per cent of WFOF's ICT exports are finished by processing trade.

In regressions 6.2 and 6.4, we distinguish two kinds of processing trade, where process 1 means the processing and assembling and process 2 means processing with imported materials. The coefficients on the two variables are all positive and statistically significant, having nearly the same magnitudes in regressions 6.2 and 6.4. We conclude, therefore, that processing trade has the most robust effects on China's ICT export, whichever kind of processing trade it is. 
Table 17.6 Robustness check for dependent variable Inv

\begin{tabular}{|c|c|c|c|c|}
\hline & (6.1) & (6.2) & (6.3) & (6.4) \\
\hline \multirow[t]{2}{*}{ wfof } & $0.815 * * *$ & & & 0.011 \\
\hline & (132.415) & & & $(1.419)$ \\
\hline \multirow[t]{2}{*}{ jv } & $0.773 * * *$ & & & $0.272 * * *$ \\
\hline & $(96.981)$ & & & $(32.092)$ \\
\hline \multirow[t]{2}{*}{ process 1} & & $1.638 * * *$ & & $1.618 * * *$ \\
\hline & & $(260.092)$ & & $(203.003)$ \\
\hline \multirow[t]{2}{*}{ process 2} & & $1.556 * * *$ & & $1.592 * * *$ \\
\hline & & $(160.883)$ & & (163.369) \\
\hline \multirow[t]{2}{*}{ policy 1} & & & $-0.221 * * *$ & -0.008 \\
\hline & & & $(-24.474)$ & $(-0.907)$ \\
\hline \multirow[t]{2}{*}{ policy2 } & & & $0.222 * * *$ & $0.232 * * *$ \\
\hline & & & $(20.904)$ & $(22.593)$ \\
\hline \multirow[t]{2}{*}{ policy3 } & & & $0.387 * * *$ & $0.168 * * *$ \\
\hline & & & (29.833) & $(13.217)$ \\
\hline \multirow[t]{2}{*}{ policy4 } & & & $-0.064 * * *$ & $0.130 * * *$ \\
\hline & & & $(-5.136)$ & $(10.510)$ \\
\hline \multirow[t]{2}{*}{ policy5 } & & & $0.165^{* * *}$ & $-0.773 * * *$ \\
\hline & & & $(5.507)$ & $(-26.561)$ \\
\hline \multirow[t]{2}{*}{ Ingdp } & $0.194 * * *$ & $0.181 * * *$ & $0.224 * * *$ & $0.177 * * *$ \\
\hline & $(114.556)$ & $(110.402)$ & $(131.914)$ & $(107.210)$ \\
\hline \multirow[t]{2}{*}{ Indist } & $-0.169 * * *$ & $-0.174 * * *$ & $-0.201 * * *$ & $-0.174 * * *$ \\
\hline & $(-49.504)$ & $(-52.756)$ & $(-58.407)$ & $(-52.730)$ \\
\hline Year fixed effects & yes & yes & yes & yes \\
\hline Product fixed effects & yes & yes & yes & yes \\
\hline$N$ & 963,358 & 963,358 & 963,358 & 963,358 \\
\hline$R 2$ & 0.127 & 0.175 & 0.109 & 0.177 \\
\hline
\end{tabular}

Note: The dependent variable is log value. Absolute values of $\mathrm{t}$ statistics are in parentheses. * significant at $10 \% ;{ }^{* *}$ significant at $5 \% ;{ }^{* * *}$ significant at $1 \%$.

Source: Authors' estimations.

In regressions 6.3 and 6.4, we break policy into five different policy zones, as defined in Table 17.4. We find that only the estimated coefficients on Policy 2 and Policy 3 are positive and statistically significant. Policy 2 is the economic and technological development zones and Policy 3 is high-technology industrial zones. Both zones are aimed at attracting FDIs with more advanced technologies, thereby upgrading the production and trade structures for firms operating in these zones. Policy 1 is the special economic zone, the aim of which is more complex and not only confined to technology upgrading. Policy 4 is the export processing zone, the effect of which may be embodied in the variable of processing trade. Policy 5 is the free trade zone, the aim of which is to enlarge trade volume using whatever technology levels that the trading products may contain. 
To summarise the discussion for value regression, we found that processing trade is the most robust and important force in promoting China's ICT exports. Only joint ventures and some kinds of special policy zones have robust and positive effects on China's ICT export.

\section{Quantity Regressions}

Table 17.7 reports the estimation results of the basic regressions for the quantity. The estimated coefficient on $f d i$ in 7.1 is positive and statistically significant but turns negative and also statistically significant in 7.4, when we consider the processing trade effects. The estimated coefficients on policy are both negative and statistically significant in regressions 7.3 and 7.4. The estimated coefficients on process are both positive and statistically significant in regressions 7.2 and 7.4. So we can conclude that foreign firms and government policy tend to decrease the ICT export quantity, while processing trade tends to increase the ICT export quantity.

The estimated coefficients on lngdp are all positive and statistically significant in regressions 7.1-7.4. The estimated coefficients on lndist are all negative and statistically significant in regressions 7.1-7.4. These results are similar to the results in the regressions for the value.

Table 17.7 Basic estimation results for dependent variable Inq

\begin{tabular}{|c|c|c|c|c|}
\hline & (7.1) & $(7.2)$ & (7.3) & (7.4) \\
\hline \multirow[t]{2}{*}{ fdi } & $0.032 * * *$ & & & $-0.647 * * *$ \\
\hline & $(5.052)$ & & & $(-93.225)$ \\
\hline \multirow[t]{2}{*}{ process } & & $1.444 * * *$ & & $1.747 * * *$ \\
\hline & & (217.915) & & $(234.177)$ \\
\hline \multirow[t]{2}{*}{ policy } & & & $-0.634 * * *$ & $-0.453 * * *$ \\
\hline & & & $(-93.502)$ & $(-67.361)$ \\
\hline \multirow[t]{2}{*}{$\operatorname{lng} d p$} & $0.166 * * *$ & $0.127 * * *$ & $0.176 * * *$ & $0.151 * * *$ \\
\hline & $(85.566)$ & $(67.171)$ & (91.809) & $(80.064)$ \\
\hline \multirow[t]{2}{*}{ Indist } & $-0.316 * * *$ & $-0.296 * * *$ & $-0.317 * * *$ & $-0.315 * * *$ \\
\hline & $(-80.922)$ & $(-77.889)$ & $(-81.851)$ & $(-83.453)$ \\
\hline Year fixed effects & yes & yes & yes & yes \\
\hline Product fixed effects & yes & yes & yes & yes \\
\hline$N$ & 963,358 & 963,358 & 963,358 & 963,358 \\
\hline$R 2$ & 0.298 & 0.331 & 0.304 & 0.342 \\
\hline
\end{tabular}

Note: The dependent variable is log quantity. Absolute values of $\mathrm{t}$ statistics are in parentheses. * significant at $10 \% ;{ }^{* *}$ significant at $5 \% ;{ }^{* * *}$ significant at $1 \%$.

Source: Authors' estimations. 
Table 17.8 Robustness check for dependent variable Inq

\begin{tabular}{|c|c|c|c|c|}
\hline & (8.1) & (8.2) & (8.3) & (8.4) \\
\hline \multirow[t]{2}{*}{ wfof } & $0.055^{* * *}$ & & & $-0.664 * * *$ \\
\hline & $(7.806)$ & & & $(-75.468)$ \\
\hline \multirow[t]{2}{*}{ jv } & $-0.016 *$ & & & $-0.429 * * *$ \\
\hline & $(-1.784)$ & & & $(-44.374)$ \\
\hline \multirow[t]{2}{*}{ process 1} & & $1.296 * * *$ & & $1.781 * * *$ \\
\hline & & (179.078) & & (195.875) \\
\hline \multirow[t]{2}{*}{ process 2} & & $1.894 * * *$ & & $1.830 * * *$ \\
\hline & & (170.329) & & (164.605) \\
\hline \multirow[t]{2}{*}{ policy 1} & & & $-0.294 * * *$ & $-0.115 * * *$ \\
\hline & & & $(-28.854)$ & $(-11.525)$ \\
\hline \multirow[t]{2}{*}{ policy2 } & & & $-0.678 * * *$ & $-0.548 * * *$ \\
\hline & & & $(-56.584)$ & $(-46.775)$ \\
\hline \multirow[t]{2}{*}{ policy3 } & & & $-0.802 * * *$ & $-0.762 * * *$ \\
\hline & & & $(-54.722)$ & $(-52.634)$ \\
\hline \multirow[t]{2}{*}{ policy 4} & & & $-1.065 * * *$ & $-0.569 * * *$ \\
\hline & & & $(-75.980)$ & $(-40.295)$ \\
\hline \multirow[t]{2}{*}{ policy5 } & & & $-1.036 * * *$ & $-1.709 * * *$ \\
\hline & & & $(-30.709)$ & $(-51.495)$ \\
\hline \multirow[t]{2}{*}{ Ingdp } & $0.166 * * *$ & $0.127 * * *$ & $0.177 * * *$ & $0.150 * * *$ \\
\hline & (85.445) & (67.329) & $(92.544)$ & (79.876) \\
\hline \multirow[t]{2}{*}{ Indist } & $-0.315 * * *$ & $-0.295 * * *$ & $-0.319 * * *$ & $-0.313^{* * *}$ \\
\hline & $(-80.735)$ & $(-77.748)$ & $(-82.330)$ & $(-83.023)$ \\
\hline Year fixed effects & yes & yes & yes & yes \\
\hline Product fixed effects & yes & yes & yes & yes \\
\hline$N$ & 963,358 & 963,358 & 963,358 & 963,358 \\
\hline$R 2$ & 0.298 & 0.332 & 0.306 & 0.344 \\
\hline
\end{tabular}

Note: The dependent variable is log quantity. Absolute values of $t$ statistics are in parentheses. ${ }^{*}$ significant at $10 \% ;{ }^{* *}$ significant at $5 \% ;{ }^{* * *}$ significant at $1 \%$.

Source: Authors' estimations.

Table 17.8 provides the robustness check results for estimating quantity regressions. Based on these results, we can conclude that both WFOFs and JVs have negative effects on export quantity, when taking into account processing trade. Both processing and assembling, with imported materials, have positive effects on export quantity. All the five types of policy zones have negative effects on export quantity.

To summarise the results reported in tables 17.7 and 17.8, we found that processing trade can promote ICT export quantity, but FDI and government policy lead to smaller export quantity. We found, however, that policy can promote export value, which requires further analysis of the quality regressions. 


\section{Quality Regressions}

Table 17.9 reports the basic estimation results for quality regression. The estimated coefficients on $f d i$ are positive and statistically significant in 9.1 and 9.4, and are nearly the same in magnitudes. The estimated coefficients on policy are positive and statistically significant in 9.1 and 9.4, and are also the same in magnitude. Foreign firms and government policy, therefore, tend to upgrade the quality of China's ICT exports, and this finding is robust, even taking into account processing trade.

The estimated coefficient on process, however, is not robust. It is positive and statistically significant in 9.2, but it turns negative and statistically significant in 9.4, when taking into account $f d i$ and the role of government policy. So, processing trade may degrade the quality of China's ICT exports, but it promotes value and quantity of China's ICT export as found in the previous regression on quantities.

The estimated coefficients on $\operatorname{lng} d p$ are positive and statistically significant in regressions 9.1-9.4. The larger the gross domestic product level is, the more demands for ICT product, the more fierce competition firms face. Only those firms, therefore, who can produce high quality products can export to these markets. The estimated coefficient on Indist are positive and statistically significant in regressions 9.1-9.4, so the longer the distance, the higher the quality (Hummels and Skiba 2004).

Table 17.9 Basic estimation results for dependent variable Inp

\begin{tabular}{|c|c|c|c|c|}
\hline & (9.1) & $(9.2)$ & (9.3) & (9.4) \\
\hline \multirow[t]{2}{*}{$f d i$} & $0.770 * * *$ & & & $0.779 * * *$ \\
\hline & (193.688) & & & (172.535) \\
\hline \multirow[t]{2}{*}{ process } & & $0.174 * * *$ & & $-0.192 * * *$ \\
\hline & & (39.580) & & $(-39.520)$ \\
\hline \multirow[t]{2}{*}{ policy } & & & $0.664 * * *$ & $0.530 * * *$ \\
\hline & & & (152.210) & $(121.200)$ \\
\hline \multirow[t]{2}{*}{$\operatorname{lng} d p$} & $0.028 * * *$ & $0.054 * * *$ & $0.050 * * *$ & $0.026 * * *$ \\
\hline & (22.778) & $(43.383)$ & $(40.567)$ & (21.069) \\
\hline \multirow[t]{2}{*}{ Indist } & $0.147 * * *$ & $0.122 * * *$ & $0.120 * * *$ & $0.145 * * *$ \\
\hline & $(59.180)$ & $(48.383)$ & $(48.181)$ & $(58.938)$ \\
\hline Year fixed effects & yes & yes & yes & yes \\
\hline Product fixed effects & yes & yes & yes & yes \\
\hline$N$ & 963,358 & 963,358 & 963,358 & 963,358 \\
\hline$R 2$ & 0.530 & 0.512 & 0.523 & 0.538 \\
\hline
\end{tabular}

Notes: The dependent variable is log quality. Absolute values of $t$ statistics are in parentheses. ${ }^{*}$ significant at $10 \% ;{ }^{* *}$ significant at $5 \% ;{ }^{* * *}$ significant at $1 \%$. 
Table 17.10 provides the robustness check results for quality regressions. We can conclude that both WFOFs and JVs have positive effects on export quality. Both processing and assembling, and processing with imported materials have negative effects on export quantity. The five types of policy zones have positive effects on export quantity. The larger the GDP level, the further the distance it is, the higher the level of export quality. All these results are supportive of the basic regression results reported in Table 17.9.

Table 17.10 Robustness check for dependent variable Inp

\begin{tabular}{|c|c|c|c|c|}
\hline & $(10.1)$ & $(10.2)$ & (10.3) & $(10.4)$ \\
\hline \multirow[t]{2}{*}{ wfof } & $0.760 * * *$ & & & $0.675 * * *$ \\
\hline & (169.519) & & & $(118.179)$ \\
\hline \multirow[t]{2}{*}{$j v$} & $0.789 * * *$ & & & $0.701 * * *$ \\
\hline & $(135.958)$ & & & $(111.700)$ \\
\hline \multirow[t]{2}{*}{ process 1} & & $0.342 * * *$ & & $-0.163 * * *$ \\
\hline & & $(71.382)$ & & $(-27.604)$ \\
\hline \multirow[t]{2}{*}{ process 2} & & $-0.338 * * *$ & & $-0.238 * * *$ \\
\hline & & $(-45.897)$ & & $(-32.956)$ \\
\hline \multirow[t]{2}{*}{ policy 1} & & & $0.073 * * *$ & $0.107 * * *$ \\
\hline & & & $(11.204)$ & $(16.530)$ \\
\hline \multirow[t]{2}{*}{ policy 2} & & & $0.900 * * *$ & $0.780 * * *$ \\
\hline & & & (117.594) & $(102.571)$ \\
\hline \multirow[t]{2}{*}{ policy3 } & & & $1.189 * * *$ & $0.929 * * *$ \\
\hline & & & (127.069) & (98.934) \\
\hline \multirow[t]{2}{*}{ policy4 } & & & $1.001 * * *$ & $0.699 * * *$ \\
\hline & & & (111.818) & $(76.271)$ \\
\hline \multirow[t]{2}{*}{ policy5 } & & & $1.201 * * *$ & $0.936 * * *$ \\
\hline & & & $(55.718)$ & $(43.460)$ \\
\hline \multirow[t]{2}{*}{$\operatorname{lngdp}$} & $0.028 * * *$ & $0.054 * * *$ & $0.047 * * *$ & $0.027 * * *$ \\
\hline & $(22.849)$ & $(43.431)$ & $(38.200)$ & $(21.732)$ \\
\hline \multirow[t]{2}{*}{ Indist } & $0.146 * * *$ & $0.121 * * *$ & $0.118 * * *$ & $0.139 * * *$ \\
\hline & $(59.056)$ & (48.154) & $(47.826)$ & $(56.691)$ \\
\hline Year fixed effects & yes & yes & yes & yes \\
\hline Product fixed effects & yes & yes & yes & yes \\
\hline$N$ & 963,358 & 963,358 & 963,358 & 963,358 \\
\hline$R 2$ & 0.530 & 0.516 & 0.531 & 0.542 \\
\hline
\end{tabular}

Notes: The dependent variable is log quality. Absolute values of t statistics are in parentheses. * significant at $10 \% ;{ }^{* *}$ significant at $5 \% ;{ }^{* * *}$ significant at $1 \%$.

Source: Authors' estimations. 
We can summarise the regression results reported in Tables 17.5 to 17.10 as follows. FDI, processing trade and government policy are important key determinants of China's ICT export pattern. FDI can upgrade export quality, but decrease export quantity and value. Processing trade promotes export value through lower quality and larger quantity. Government policy increases value and quality, but decreases export value. These results suggest that, in order to further increase the export quantities of ICT products and, at the same time, to increase the export qualities of these products, China may consider applying different policy instruments for addressing different objectives. For example, if export quality is a concern, the government should do more in attracting FDI with more advanced technologies, and in further developing high-tech zones.

\section{Conclusion}

In this chapter we focus on the quantity and quality of China's ICT exports and its determinants to find out the key characteristics associated with China's ICT exports. We arrived at the following conclusions: China's ICT export is mainly driven by high quantity and low quality production; and, FDI, processing trade and government policies are the main determinants for China's ICT export growth. FDI, processing trade and government policies, however, have a different impact on quantity and quality. Processing trade increases quantity but decreases quality, while FDI and government policy have the opposite impact. How to upgrade quality and increase quantity simultaneously, therefore, is a challenge for Chinese central and local governments in their efforts to restructure the export sectors and move production towards producing high value-added and high quality products, while increasing the level of employment.

In this sense, the pattern of high quantity and low quality production and export will have an important influence on China' future growth. As quantity contributes significantly to China's ICT exports, it means China should continue to employ a large labour force to produce the export quantity; the quantitydriven export growth pattern, therefore, is good for employment. Considering that China is still relatively abundant in labour supplies, the quantity-driven growth pattern is consistent with China's comparative advantage and quantity, therefore, remains a policy option for the time being. Quantity-driven growth patterns, however, consume more natural resources and tend to lead to more pollution and damage to the environment, which is harmful to sustainable economic growth. As product quality is important for maintaining export competitiveness, and leads to more endogenously determined economic growth, how to upgrade the export quality is important for China's sustainable export and economic growth. Importantly, China is undergoing a fundamental change in its demographic structure leading to the slow growth of its labour force, 
apart from ageing, with rising wage levels (Cai 2013). This will add further pressure for the Chinese Government to optimise its economic structure and move towards producing more high-quality products. As a result, one would expect that China's export sector will be transformed from the quantity-driven to an extensively margin-driven and quality-driven one. This transformation is consistent with the new growth strategy adopted by the Chinese Government in confronting the new challenges for future growth.

\section{References}

Branstetter, L. \& Lardy, N., 2006, 'China's Embrace of Globalization', NBER Working Paper, No. 12373.

Cai, Fang, 2013, 'Can China Avert the Middle Income Trap?', working paper, Chinese Academy of Social Sciences, Beijing.

Feenstra, Robert C., 1994, 'New product varieties and the measurement of international prices', American Economic Review, vol. 84. no. 1, pp. 157-77.

General Administration of Customs of China, Chinese Customs Trade Statistics (CCTS), 2000-2007.

Greenaway, D., Morgan, C.W. \& Wright, P.W., 1999, 'Export Composition, Exports and Growth', Journal of International Trade and Economic Development, vol. 8, pp. 41-52.

Hausmann, R., Hwang, J. \& Rodrik, D., 2007, 'What you Export Matters', Journal of Economic Growth, vol. 12, no. 1, pp. 1-25.

Hummels, D. \& Klenow, P.J., 2005, 'The Variety and Quality of a Nation's Exports', American Economic Review, vol. 95, pp. 704-19.

Hummels, D. \& Skiba, A., 2004, 'Shipping the Good Apples Out? An Empirical Confirmation of the Alchian-Allen Conjecture', Journal of Political Economy, vol. 112, no. 6, pp. 1384-402.

Jorgenson, D.W., Ho, M.S. \& Stiroh, K.J., 2008, 'A Retrospective Look at the U.S. Productivity Growth Resurgence', Journal of Economic Perspectives, vol. 22, no. 1, pp. 3-24.

Koopman, R., Wang, Zhi \& Wei, Shang-Jin, 2012, ‘Estimating Domestic Content in Exports When Processing Trade is Pervasive', Journal of Development Economics, vol. 99, pp. 178-89. 
National Bureau of Statistics of China, China's Annual Survey of Industrial Firms (CASIF), 1998-2007.

Onlier, S. \& Sichel, D., 2000, 'The Resurgence of Growth in the Late 1990s: Is Information Technology the Story', Journal of Economic Perspective, vol. 14, no. 4, pp. 3-22.

Rodrik, D., 2006, 'What is So Special about China's Export', China \& World Economy, vol. 14, no. 5, pp. 1-19.

Schott, P., 2004, 'Across-Product versus Within-Product Specialization in International Trade', Quarterly Journal of Economics, vol. 119, no. 2, pp. 647-78.

Simon, J.P., 2011, 'The ICT Landscape in BRICS Countries: Brazil, India and China', European Commission Joint Research Centre Institute for Prospective Technological Studies.

UNCTAD, 2011, 'Measuring the Impacts of Information and Communication Technology for Development', Current Studies on Science, Technology and Innovation, No. 3.

Wang, Z. \& Wei, S.J., 2008, 'What Accounts for the Rising Sophistication of China's Exports?', NBER Working Paper, No. 13771.

Xu, B. \& Lu, J.Y., 2009, 'Foreign Direct Investment, Processing Trade and the Sophistication of China's Export', China Economic Review, vol. 20, pp. 425-39.

\section{Appendix: The Disaggregating Procedure for Table 17.3}

We follow the method of Hummels and Klenow (2005) to decompose trade ratio to get Table 17.3.

Considering China and world's ITC export, supposing the exporting product sets are $\Omega_{C}$ and $\Omega_{W}$, and the overlapped exporting products set is $\Omega$, that is $\Omega=\Omega_{C} \cap \Omega_{W}$, then the ratio of export between China and world can be expressed as equation (1)

$$
R=\frac{\sum_{i \in \Omega_{C}} v_{i C}}{\sum_{i \in \Omega_{W}} v_{i W}}=\left(\frac{\sum_{i \in \Omega_{C}} v_{i C}}{\sum_{i \in \Omega} v_{i C}} / \frac{\sum_{i \in \Omega_{W}} v_{i W}}{\sum_{i \in \Omega} v_{i W}}\right) \times \frac{\sum_{i \in \Omega} v_{i C}}{\sum_{i \in \Omega} v_{i W}}
$$


Similar to Feenstra (1994), Hummels and Klenow (2005), $\sum_{i \in \Omega} v_{i C} / \sum_{i \in \Omega} v_{i W}$ means extensive margin; if the kinds of product in China's export is more than the world's, than the extensive margin is bigger than 1, therefore, it expresses the meaning of product variety of China's export. $\sum_{i \in \Omega}^{\frac{\sum_{i \in \Omega} v_{i C}}{\sum_{i W}}}$ margin. $v$ stands for export value. It can be furthered decomposed into price and quantity, as equation (A2):

$$
\frac{\sum_{i \in \Omega} v_{i C}}{\sum_{i \in \Omega} v_{i W}}=\frac{\sum_{i \in \Omega} p_{i C} q_{i C}}{\sum_{i \in \Omega} p_{i W} q_{i W}}=\prod_{i}\left(\frac{p_{i C}}{p_{i W}}\right)^{w_{i}} \prod_{i}\left(\frac{q_{i C}}{q_{i W}}\right)^{w_{i}}
$$

$$
\text { The ratio } w_{i}=\frac{\frac{s_{i C}-s_{i W}}{\ln s_{i C}-\ln s_{i W}}}{\sum_{i}\left(\frac{s_{i C}-s_{i W}}{\ln s_{i C}-\ln s_{i W}}\right)}, s_{i} \text { stands for value share, } s_{i}=\frac{p_{i} q_{i}}{\sum_{i \in \Omega} p_{i} q_{i}}
$$

At last we can decompose the export ratio of China's ITC export into three margins, as equation (A3):

$$
R=\frac{\sum_{i \in \Omega c} v_{i c}}{\sum_{i \in \Omega_{W}} v_{i W}}=E X \times P \times Q=\left(\frac{\sum_{i \in \Omega c} v_{i c}}{\sum_{i \in \Omega} v_{i c}} / \frac{\sum_{i \in \Omega_{W}} v_{i W}}{\sum_{i \in \Omega} v_{i W}}\right) \times \prod_{i}\left(\frac{p_{i c}}{p_{i t}}\right)^{w_{i}} \times \prod_{i}\left(\frac{q_{i c}}{q_{i t}}\right)^{w_{i}}
$$

EX is extensive margin, which measures the variety of export. $\mathrm{P}$ is relative price of China's exports to the world average, which stands for the quality index. $\mathrm{Q}$ is the quantity ratio of China's exports to the whole world, which provides the relative quantity of China's ICT export. 



\section{Index}

Africa 110, 282

Anhui Province 155, 157, 225, 227, 228, 244

Annual Census of Chinese Industrial Firms 135

Asia 22, 76, 77, 79, 109, 121, 309, 345

Asian economies 3, 44, 76, 77, 79, 103, $113,116,120,345$ savings glut $9,97,113,120$

Asian Development Bank 38

Asian Financial Crisis 3

Association of Southeast Asian Nations (ASEAN) 82

Australia 78, 109, 111, 113, 116, 174, 301, 303, 304, 310, 319 climate change 281, 284, 285-86, 289, 291, 293, 296-99

Beijing 51, 165, 166, 208, 251, 263, 284, 304, 306

Beijing Province 128, 129, 157, 225, 226, 227, 228, 244

Brazil

GDP 303

business environment 11-12, 141, 221-49 census, national 56-57, 64, 65 changing 223-24 enterprises, types of 233-43 provincial 225-28 regional $244-45$

business environment index for China's provinces (BEICP) 222, 223, 225, 226, $246,247,248$

Bush, George W. 285, 290, 292

Canada 174, 287, 290, 303, 304

China Banking Regulatory Commission 214

China Development Research Foundation (CDRF) 57

China Investment Corporation (CIC) 98, 108-09

China National Petroleum Company 315
Chinese

agricultural development 147, 150

challenges 171-76

fertilisation 152-53, 173, 273

fertility 147,173

output 148, 273

policy 148, 163-71

production 148, 150, 152, 154, 158

total factor productivity (TFP)

155-156

economy

consumption share $35,36,41,42$,

43, 45, 46-47, 51

current account surplus 4, 7, 36, 39, $83,84,97,99,101,102,107,118$ debt 9, 97, 98, 105, 108, 110, 116, $118,119,120-21$

provincial debt 9, 11, 25, 105, $120,214,215-16$

factor markets 7, 8, 36-37, 43, 44, $45,49,51,84,85,92,93,135,270$, 324

GDP 7, 15, 17, 25, 27, 35, 36, 39, 42, $43,45,46,48,50,76,77,79,82,85$, $86,88,89,90,91,93,101,102,104$, $105,106,107,109,111,128,136$, $138,139,140,141,158,159,199$, 205, 206, 209, 226, 267, 276, 301, $302,303,304,305,306,318,348$, $350,351,352,353,354,355,356$, 357-58 slowing 36-38 global performance 97, 110-13, 116-18 growth of 30-31, 32, 35, 36-38, 41-42, 55-71, 100-01, 106, 127, 200, 224, 251, 293, 301, 304, 305 innovation 125-27 investment share 51, 79 new model of economic growth $1-6,17-18,35-36,39-43$ 'new normal' 7, 35, 36, 39, 43-50, 51

policy 51-52, 142 
potential growth rate $56-59,63$,

$66-67,68,69$

public finances 199-216

public investment management

210-15

reform 200-04, 215-16

revenue $204-08$

purchasing power parity $76,77,78$,

$80,81,302,304$

quantitative easing (QE) 9, 97, 98,

114-21

rebalancing 36, 39-42, 44, 45, 47,

49, 51, 98-99, 107

saving $1,2,3,8-9,35,45,55-57$,

60-61, 83, 89, 97-98, 100, 101, 102,

$106-08,110,111,112-13,118-21$,

272

corporate 104-05

government 105-06, 111

household 103-04, 108, 111

reserves $108-10$

education $28,32,50,67,90,100,125$,

$134,238,240,243,271$

access to $83,89,90,167,271$

investment in 5, 47, 52, 89, 202, 203,

206, 225, 246

migrant 49, 90, 190, 195-96

reform 2, 5, 32

rural 6, 28, 167, 196

urban 28, 195, 196

government 9, 12, 16, 45, 57, 70, 105,

$106,118,120,125,141,164,273,293$,

336,359

bonds 98, 114, 118, 213

construction permits 19-21,

corruption within 4, 6, 18-24, 49,

51, 202, 225

rent seeking 20, 21-22, 24, 83,

$85,88,91,92,243$

Ministry of Agriculture 155, 167

Ministry of Construction 214

Ministry of Finance (MOF) 11, 14, 199, 201, 202, 204, 205, 208, 209, 214,216
Ministry of Human Resources and

Social Security (MOHRSS) 207, 208

Ministry of Land and Resources

208, 314

labour 5, 7-8, 10, 16, 26, 27, 28, 29, 31, $32,35,36,38,43-44,45,46,47-48$, 50-51, 55-59, 60, 61-71, 83, 84, 85, 88, $89,90,100,126,147,162,171-72,179$, 180-86, 189, 193, 194-96, 224, 252, 253, 258-59, 269-71, 314, 324, 330, 342,358

labour force participation $7,56,58$, 63-67

labour force participation rate

(LFPR) 56, 58, 59, 63, 64-65, 66, 67

local government revenue 24-26

non-state enterprise (NSE) 12, 233-34,

242, 246

population 10, 21, 27, 28, 29, 50,

55-58, 60, 66, 70, 103, 125, 196, 302,

304, 306, 318

ageing 28, 66, 208

demographic dividend 29, 55

demographic change 56, 61, 88, 100,

$101,179,180-81,302,314,319,358$

growth 58-64

rural 25, 26, 168, 172, 180-81, 186,

196

urban $26,28,30,75,79,180-81$

working age $4,7,38,46,55,56,56$,

$57,59,62-64,66,70$

state-owned enterprise (SOE) 3, 12, 23 , $31,44,48,49,52,70,90,92,100,101$, 104, 105, 107, 108, 135, 142, 152, 204, 207, 208, 221, 222, 224, 233-34, 242,

246, 276, 315, 321-22

Chongqing Province 157, 179, 208, 225 ,

226, 227, 228, 244

climate change $273,281-86,289,290$,

292, 297-99

pollution 4, 16, 19, 65, 85, 251, 262,

271, 272, 273, 276, 277, 315, 358

coal 15, 152, 253, 263, 274, 276, 284, 292, 295, 296, 302, 306, 309, 310, 311, 312,

$314-15,316-18,319$ 
coal bed methane 276, 315

consumption 294, 295, 312, 317

mining 255, 256, 260, 261, 317

pricing 86

tons of coal equivalent (TCE) 253

Communist party 1, 2, 4, 23, 24, 25

discretionary power 20-21, 23

role in the economy 22

construction $31,49,165,169,174,175$,

206, 212, 213, 214, 238, 239, 240, 274,

301,322

Cultural Revolution 2, 23

data envelopment analysis (DEA) 252,

253, 254, 263

directional distance function (DDF)

252-53, 254, 263

emissions 14, 252-53, 276, 277, 285, 286, 287, 289, 292, 293, 294, 295, 296, 297,

298, 302, 307, 318

carbon 12, 13-14, 152, 251, 253,

254-57, 258-60, 262, 263, 268, 273,

$276,277,284$

intensity targets 14, 79, 255, 256, 257, 262, 269, 273, 276, 284, 285, 286,

287-88, 289, 290-91, 292-93, 296, 297,

298, 309, 315-16

trading 14, 85, 277, 288, 289, 292, 293,

297, 298

vehicle 86

employment 3, 38, 50, 57, 58, 59, 61, 63, $64,66,68,83,84,93,121,158,182$,

$309,314,358$

agricultural 26, 38, 64, 158, 160, 162,

$171,173,175,176$

manufacturing 27

migrant 25, 50, 62, 89-90, 158, 159,

$160,176,187,190,192-93$

unemployment 38, 50, 56, 59, 62-63, $68,89,99,116,182,187,192-93,207$,

208

urban 10, 26-27, 61-62, 158, 159, 207

energy

clean 262, 272, 274, 276, 284, 294

biomass 294

geothermal 294 hydro 262, 294, 295, 318

solar 262, 272, 274, 284, 294, 296,

297

wind 262, 272, 274, 294

consumption 2, 13-14, 15, 79, 86, 91, 252, 253, 255, 257-59, 262, 268, 272, 273, 274, 283, 286, 294, 295, 296, 301, $302,303,304,305,309,311,313,317$, 318,319

efficiency 5, 85-86, 263, 268, 272, 277, 293-94, 295, 304, 305, 318

import dependence 15, 319

inputs 252, 253, 301

market 295-96, 297, 304, 309, 313

oil 15, 44, 273, 276, 311, 313, 314, 316,

317-19

crisis (1970s) 14, 302, 307-08, 309,

310,316

policy 15, 273, 195, 302, 307, 308, 309, 314,319

policy trilemma 14-15, 301, 302,

307-10, 318-19

pricing $8,14,44,45,48,83,84,85,86$, $94,118,305,307$

resources $310-318$

security 13, 273, 274, 307, 309, 310,

314, 315, 317-18

supply 15, 85, 118, 297, 301, 302, 304, $310,315,318,319$

Europe 9, 77, 108, 110, 113, 114, 120, 125, $275,282,289,293,309,316,325,345$

European Union 97, 98, 110, 290, 298

farming 2, 10, 152, 158, 172

diminishing population 26, 158, 274

farm workers 28, 38, 83

income 156, 160-62, 163, 172, 174, 203

intensity 172, 173

resumption of land 24-25, 173-74, 175,

206

social support 147-48, 168-69, 176,

203

welfare 162, 176

five-year plan 63, 85

10th 168

11th 168, 169 
12 th $5,7,14,57,63,66,168,273,293$, 295, 296

13th 7, 57, 63, 66

foreign government bonds 108, 112, 114, $118,119,120$

France 78, 308, 321

Fujian Province 129, 157, 225, 226, 227, 228, 244, 306, 327,

Gansu Province 157, 166, 226, 227, 228, 244

gas

consumption 311,312

fracturing (fracking) 308, 315

natural 15, 118, 222, 238, 239, 253, 255,

256, 257, 261, 273, 276, 292, 295, 302,

$307,308,309,310,311,313,314,315$,

$316-19$

supply $15,255,313$

shale $274,276,313,314,315$

General Corporation of Shanghai

Municipal Property 213

Germany 78, 301, 303, 308, 327, 329

Gini coefficient 7, 40-41

global economy 9, 98, 101, 118

Global Financial Crisis 3, 4, 12, 35, 37, 60, 97, 103-07, 110, 112, 113, 117, 179-80, $199,223,224,246,304,324$

global financial markets 97, 110 greenhouse gas emissions 4, 13, 14, 268, 272, 273, 282, 286, 292, 295, 296

greenhouse gas policy 14

Guangdong Province 90, 128, 129, 157, 212, 225, 226, 227, 228, 244, 306, 327

Guizhou Province 129, 157, 225, 226, 227, 228, 244

Hainan Province 157, 225, 226, 227, 228 , 244

Hebei Province 128, 129, 155, 157, 225, $226,227,228,244$

Heilongjiang Province 155, 157, 225, 226, 227, 228, 244, 327,

Henan Province 129, 155, 157, 225, 227, 228, 244

Hong Kong 19, 22, 78, 79, 221, 222, 321, $327,329,343$

Independent Commission against
Hubei Province 129, 155, 157, 225, 227, 228, 244

Hunan Province 129, 155, 157, 225, 226, $227,228,244$

income $3-4,6,7,8,17,19,26,32,35,36$, $41,44-45,46-47,48,50,51,67,75-76$, $77,83,84,88,90,91,92-93,100$, 102-03, 125, 199, 210, 243, 267, 275, $283,306,315,316,318,343-44$ agricultural and rural 2, 4, 10, 27, 28, 39-40, 152, 156, 158, 160-63, 166, 169, 173-74, 203, 274

foreign factor income 102 income safety net 6, 199 middle-income trap 7, 36, 48, 50, 51, 100

net factor income 107, 111

purchasing power $4,27,76,302$

urban 10, 29-30, 39-40, 147-48,

$160-62,274$

$\operatorname{tax} 200$

India

GDP 303

Indonesia 76, 291, 303, 343

industrial value added (IVA) 253, 254, 255, 256-57, 258, 259, 260, 261, 262

industrialisation 8, 46, 75-94, 147, 251, $268,274,301,304,315$

economic impact 91-93

'green' growth 12-13, 251-64, 267-78

history 76-82

policy 82-91, 262-63, 276-78

information and communications

technology, exports 341-58

infrastructure $8,17,30,31,37,51,52,79$, 91, 94, 131, 141, 167, 202, 210, 212, 213, 214, 216, 221, 222, 224, 229, 230, 231, 232, 234, 235, 236, 239, 240, 241, 244, $245,249,274,315$

housing 17, 30, 31

rural 168-69, 174

transport 17, 37

urban 5, 91, 213, 301

Inner Mongolia 129, 155, 157, 164, 166, $225,227,228,244,306$

intellectual property 9, 49, 50, 126, 132, $136,138-40,141,142,248$ 
International Energy Agency 295, 304, 315

investment, private sector 321-36

Japan

energy 293, 298, 309-10

Fukushima 293, 298, 309

GDP 79

nuclear energy, 309-10

saving 9, 113, 120

uranium 310

Jiangsu Province 128, 157, 212, 225, 226 , 227, 228, 244, 306, 327

Jiangxi Province 155, 157, 225, 226, 228, 244

Jilin Province 155, 157, 225, 227, 228, 244

Korea 30

Liaoning Province 155, 157, 225, 227, 228 , 244, 306

logistics 91, 270

World Bank Logistics Performance Index (LPI) 210

local investment corporation (LIC) 213-15, 216

Macao 221, 222

manufacturing 17, 27, 39, 47, 49, 63, 70, 90, 99, 100, 101, 126, 135, 222, 238, 255, 262, 271, 272, 274, 297, 308, 317, $323,326,327,328,329,341$

export oriented 17, 35, 90, 91, 100, 126, 346

Mexico 77, 78, 79, 82

New Zealand 289

Nanjiang 179

National Audit Office (NAO) 208, 213, 214,216

National Bureau of Statistics (NBS) 40, 41, 47, 62, 135, 179, 327

National Development and Reform Commission (NDRC) 18, 212, 214, 281

National Economic Research Institute (NERI) 135, 136

National People's Congress (NPC) 11, 202, 204, 206, 208, 216

Netherlands, the 77, 78
Ningxia Province 129, 157, 166, 225, 226 , 227, 228, 244, 306

North American Free Trade Agreement (NAFTA) 82

nuclear

fuel processing 255, 260

power 14-15, 255, 294, 302, 307,

308-09, 310, 318

reactors 308, 319

Obama, Barak 39, 292

OECD 26, 91, 267, 308, 310

outward direct investment (ODI) 15, 321-22-36

Pakistan 19

Papua New Guinea 19

Pearl River Delta 189

Peking University 38

People's Bank of China (PBC) 39, 87, 108, 119, 214

petroleum 86, 113, 118, 243, 253, 255, 257, 260, 273

Philippines 76, 297, 343

Portugal 297

productivity, growth in 30-32

Qinghai Province 129, 157, 166, 222, 225, 226, 227, 228, 244, 306

Qualified Domestic Institutional Investor (QDII) 86

Qualified Foreign Institutional Investor (QFII) 86-87

research and development (R\&D) 6, 9-10, $18,32,50,125-42,243,292,329$

R\&D intensity 127-28, 130-31, 132-34, $136,137,138-42$

rural-urban migration $8,10,18,25$,

26-28, 30, 49, 63, 67-68, 69-70, 75, 83,

$90,147,158,173,175,179-97$

education 195-96

hukuo

population 10, 180-87, 195, 196

system $8,18,26,27,67-68,83,90$, 94

mental health 11, 188-89, 197 
migrant labour 2, 10-11, 27, 38, 49, 50, $52,61,62,63,67-68,69-70,75,83,85$, 89-90, 158, 175, 176, 181, 182, 184-86, 187-93, 194, 196

wages 45, 55, 88, 187, 189-92, 194, 196

Russia 303, 343

Shaanxi Province 128, 157, 225, 226, 227, 228, 244

Shandong Province 128, 155, 157, 212, 225, 226, 227, 228, 244, 306, 327

Shanghai 179, 213, 304, 306

Shanghai Province 128, 157, 179, 225 , 226, 227, 244, 327

Shanxi Province 157, 225, 226, 227, 228, 244,

Sichuan Province 155, 157, 166, 225, 227, 228, 244

Singapore 19, 22, 71, 78, 79, 216, 343

Slovenia 326

social insurance 192, 204, 208

social insurance fund (SIF) 204, 207-09

social safety net $25,30,83,199$

social welfare $6,10,18,28,47,179$,

192-93, 194, 196, 238

State Council 12, 75, 88, 90, 92, 125, 207, 212, 215, 273, 294, 295

State-owned Assets Supervision and

Administration Commission (SASAC)

207

Development Research Centre 12

sterilisation bonds 108

South Africa 343

South Korea 32, 46-7, 78, 79, 82, 90, 127, 303

State Grid Corporation 297

State Nuclear Power Technology Company (SNPTC) 308

State-owned Assets and Administration Commisstion (SASAC) 207

Taiwan 27, 46-7, 78, 79, 221, 222, 303, 343

taxation 229

carbon tax 14,288

corporate 36, 44, 200, 221, 222, 225,

$229,230,231,232,234,235,236,239$,

240, 241, 243, 244, 246, 248, 277 customs 19

export 296, 314, 346

household 36, 44

income 19, 200

land 26, 200

reform 90, 92, 105, 160, 163, 199, 200-

$02,203,230,243,246,276,277,314$

revenue 105, 204-05, 206, 208-09

resource taxes $14,85,86,314$

system reform 201

Three Gorges Dam fund 206, 212

Tianjin Province 128, 129, 157, 208, 225 , 226, 227, 228, 244, 306

Tibet 129, 157, 166, 222, 244

Toshiba Westinghouse 308

total factor productivity (TFP) 7-8, 12, $30,56,57,58-59,63-64,68-70,71$, 155-56, 251-52, 254, 257, 258, 259-61, $324,326,330,341$

green TFP (GTFP) 12, 253, 254, 257-58, 259-61, 262, 263-64

Turkey 77, 78, 79

United Arab Emirates 327, 329

United Kingdom 78, 301, 303, 304, 321

United Nations Framework Convention on Climate Change 4, 14, 285

Bali 285

Cancun 285, 287, 290-91, 292, 293

Copenhagen 4, 285, 287, 289, 291

Durban 285, 287, 288

Doha 285, 287

Kyoto Protocol 285, 286, 287, 288, 291

Rio de Janeiro 285, 286

United States 4, 8, 9, 28, 30, 70, 78, 91, $91,97,98,98,108,109,110,112,113$,

$114,114,116-17,118,119,120,125$.

127, 132, 174, 210, 267, 275, 285, 287,

290, 292, 298, 301, 303, 304, 308-09,

313-15, 316, 317, 321, 324, 326, 327, 329

debt 110, 116

energy 15, 98, 118, 120, 292

oil \& gas 15, 302, 307, 308-09, 316

University of New South Wales 297

uranium 15, 302, 310, 319

urban development investment

corporation (UDIC) 213 
urbanisation 26-30

World Bank 12, 19, 37, 48, 91, 201, 251, 262

Logistics Performance Index 91, 210 World Health Organisation 251

world financial crisis, 1997-1998 17

Yangzi River Delta 189

Xinjiang Province 157, 166, 174, 225, 226, 228, 244

Yi Gang 39, 87

Yunnan Province 157, 166, 225, 226, 227, 228, 244

Zambia 19

Zhejiang Province 15, 128, 157, 212, 225 , $226,227,228,244,306,322,327,327$ 
